\title{
A National Risk Assessment for Selected Hazardous Materials in Transportation
}

Decision and Information Sciences Division

Argonne National Laboratory

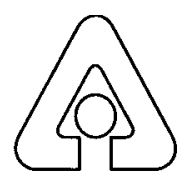

Operated by The University of Chicago, under Contract W-31-109-Eng-38, for the United States Department of Energy 


\section{Argonne National Laboratory}

Argonne National Laboratory, with facilities in the states of Illinois and Idaho, is owned by the United States Government and operated by The University of Chicago under the provisions of a contract with the Department of Energy.

This technical report is a product of Argonne's Decision and Information Sciences Division (DIS). For information on the division's scientific and engineering activities, contact:

Director, Decision and Information Sciences Division

Argonne National Laboratory

Argonne, Illinois 60439-4832

Telephone (630) 252-5464

http://www.dis.anl.gov

Publishing support services were provided by Argonne's Information and Publishing Division (for more information, see IPD's home page: http://www.ipd.anl.gov/).

\section{Disclaimer}

This report was prepared as an account of work sponsored by an agency of the United States Government. Neither the United States Government nor any agency thereof, nor The University of Chicago, nor any of their employees or officers, makes any warranty, express or implied, or assumes any legal liability or responsibility for the accuracy, completeness, or usefulness of any information, apparatus, product, or process disclosed, or represents that its use would not infringe privately owned rights. Reference herein to any specific commercial product, process, or service by trade name, trademark, manufacturer, or otherwise does not necessarily constitute or imply its endorsement, recommendation, or favoring by the United States Government or any agency thereof. The views and opinions of document authors expressed herein do not necessarily state or reflect those of the United States Government or any agency thereof, Argonne National Laboratory, or The University of Chicago. 
ANL/DIS-01-1

\section{A National Risk Assessment for Selected Hazardous Materials in Transportation}

by D.F. Brown, W.E. Dunn, ${ }^{*}$ and A.J. Policastro

Decision and Information Sclences Division

Argonne National Laboratory, 9700 South Cass Avenue, Argonne, Illinois 60439

December 2000

Work sponsored by the U.S. Department of Transportation, Research and Special Programs Administration, Office of Hazardous Materials Technology

\footnotetext{
* Dunn is affiliated with the University of Illinois, Urbana-Champaign.
} 
This report is printed on recycled paper. 


\section{Contents}

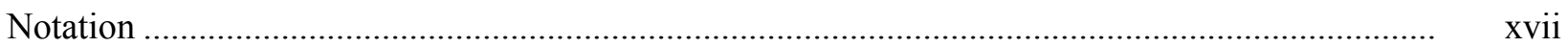

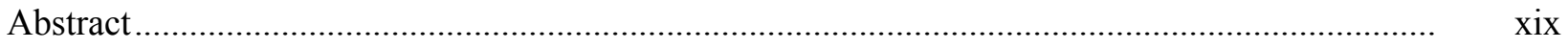

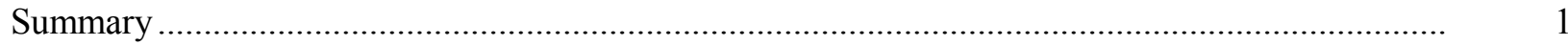

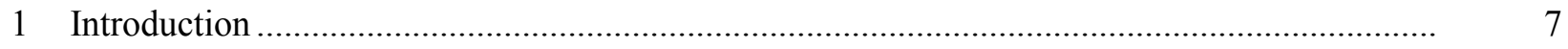

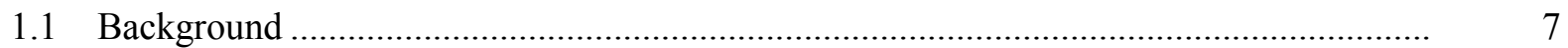

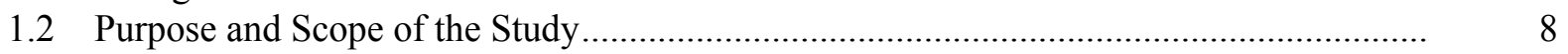

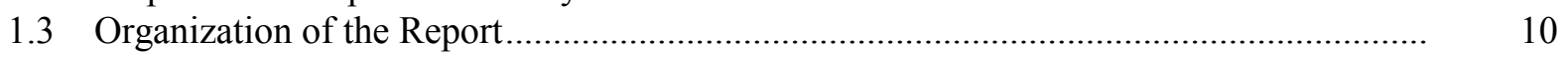

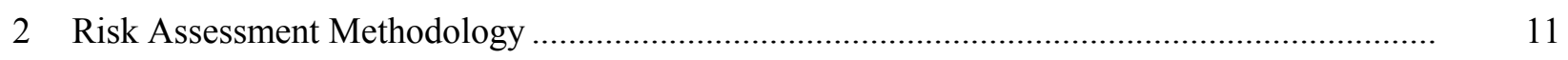

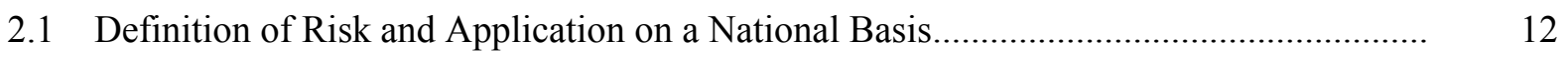

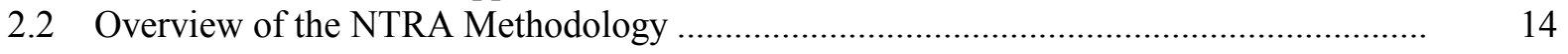

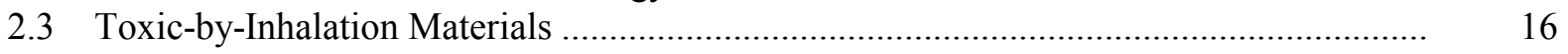

2.3.1 TIH Chemicals Selected for Detailed Analysis ..................................................... 16

2.3.2 CASRAM Risk Assessment Model ........................................................................ 19

2.3.3 Accident Rates and Release Probabilities ............................................................... 27

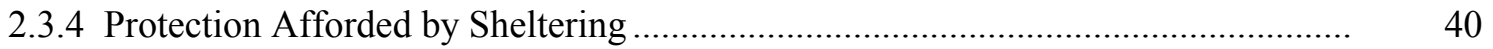

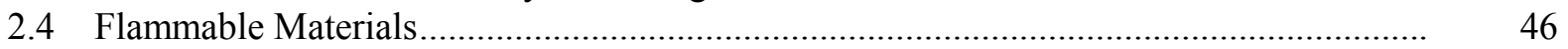

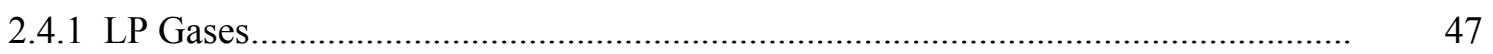

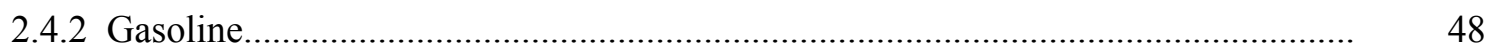

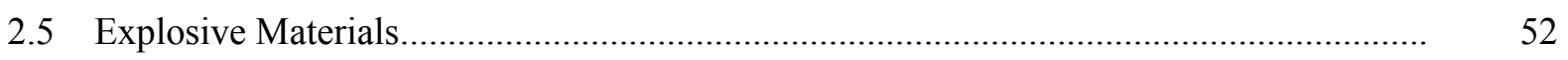

2.5.1 Event Probabilities and Consequence Analysis ................................................. 53

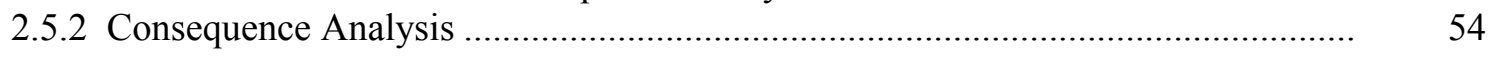

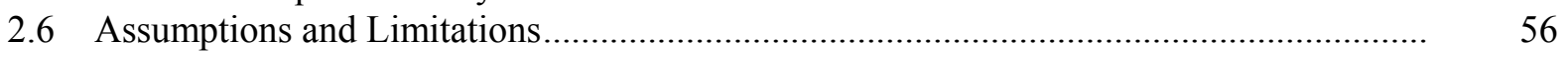

3 Review and Analysis of HMIS Incident Records ............................................................. 59

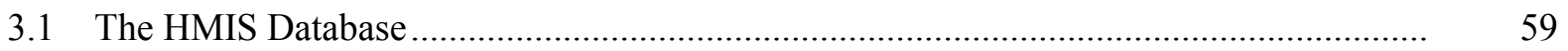

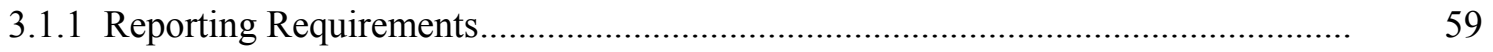

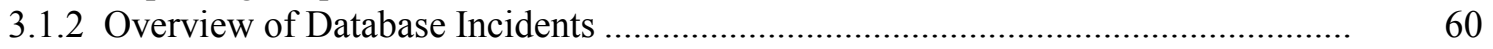

3.1.3 Highway and Rail Incident Counts by Transportation Phase ............................... 62

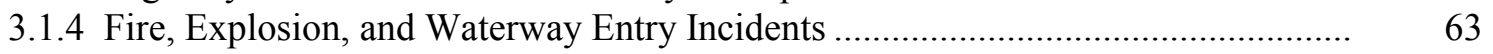

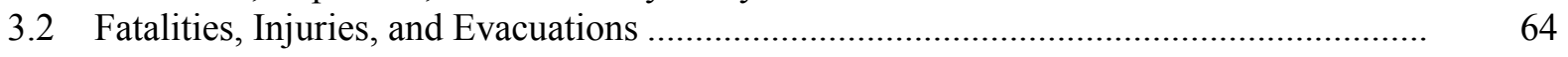

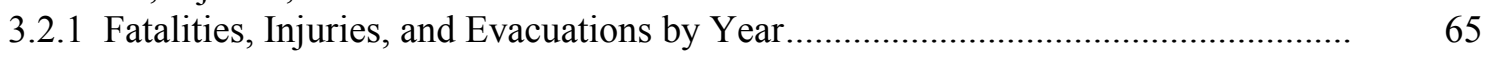

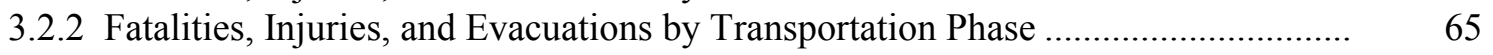

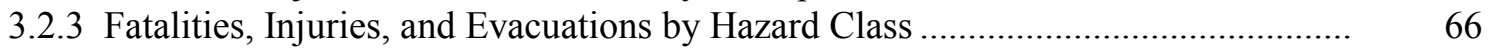

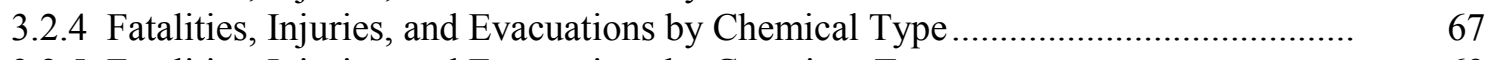

3.2.5 Fatalities, Injuries, and Evacuations by Container Type ....................................... 69 


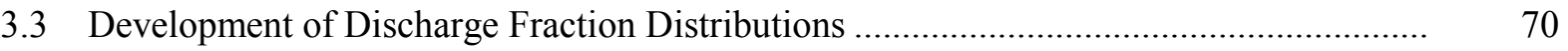

3.3.1 Overview of Available Container Information ....................................................... 70

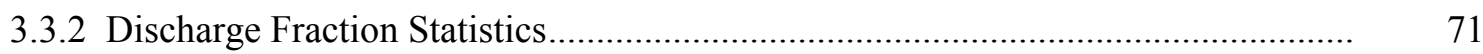

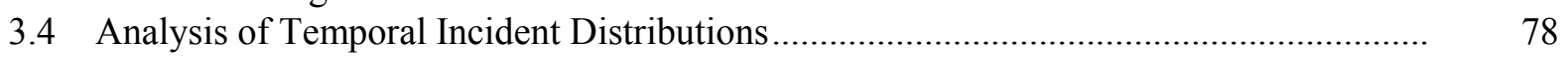

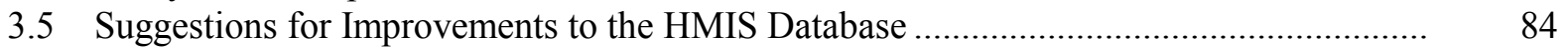

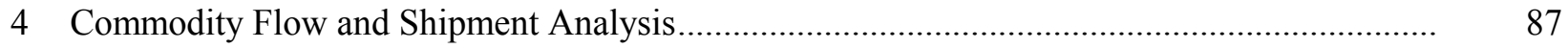

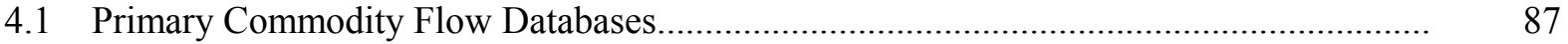

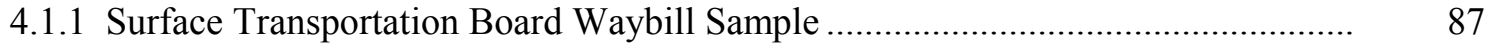

4.1.2 Commodity Transportation Survey and Commodity Flow Surveys ........................ 89

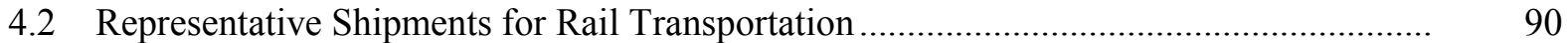

4.2.1 Analysis of Origin and Destination Data from Waybill Samples .......................... 90

4.2.2 Formulation of Representative Rail Shipments ....................................................... 92

4.2.3 Calculation of Rail Routes by Using INTERLINE 5.0 ........................................... 95

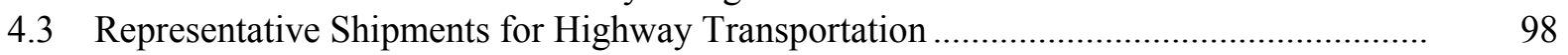

4.3.1 Analysis of Origin and Destination Data from the 1977 CTS ................................ 99

4.3.2 Formulation of Representative Highway Shipments …........................................ 100

4.3.3 Calculation of Highway Routes by Using HIGHWAY 3.3 .................................. 114

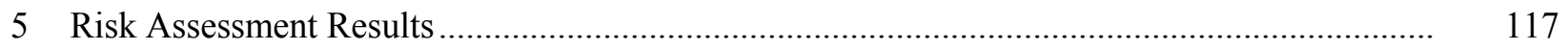

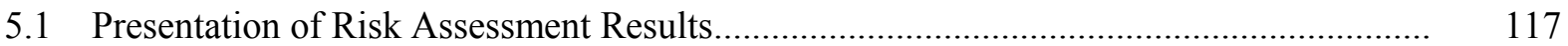

5.1.1 Risk Assessment Averaging Time .................................................................... 117

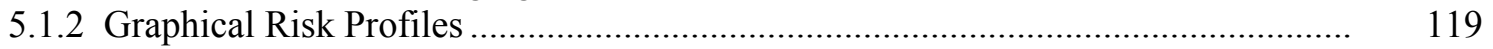

5.1.3 Consequence Levels and Risk Measures .................................................................. 121

5.1.4 Treatment of Mitigating Effects That Reduce TIH-Related Risk ......................... 122

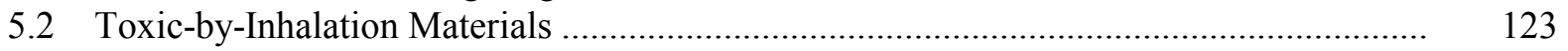

5.2.1 Accident-Related Highway Releases ........................................................... 124

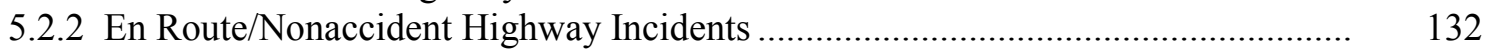

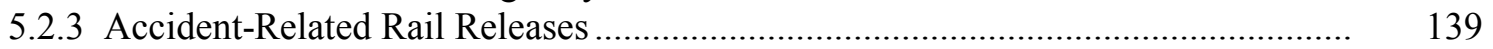

5.2.4 En Route/Nonaccident Rail Incidents .................................................................. 139

5.2.5 Risk Distributions with Respect to Incident Type ................................................ 148

5.2.6 Risk Distributions with Respect to Chemical and Total TIH Risk .......................... 148

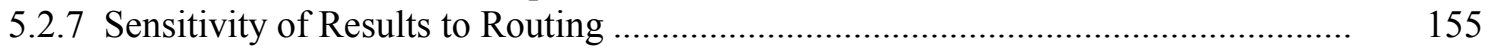

5.2.8 Reduction of Risk Resulting from 1990 Regulatory Changes .................................. 159

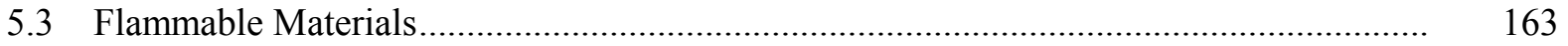

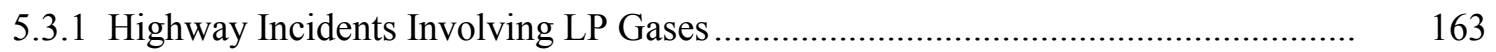

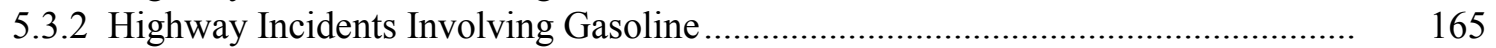

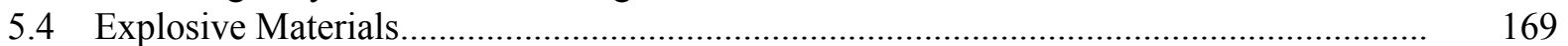

5.5 Comparison of Risk from Transportation of TIH Materials, Flammable

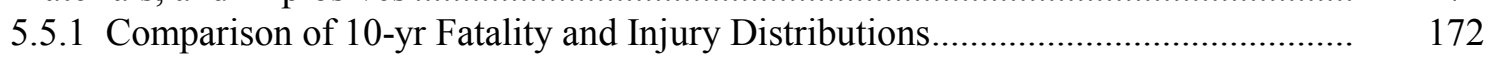

5.5.2 Comparison of Total Annual and Normalized Injury and Fatality Risk................. 176

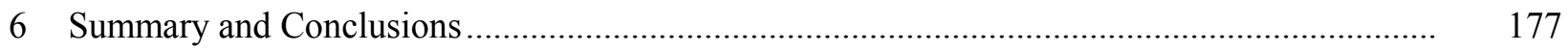

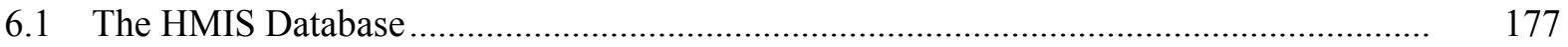




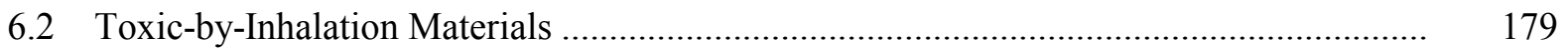

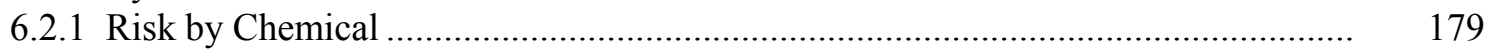

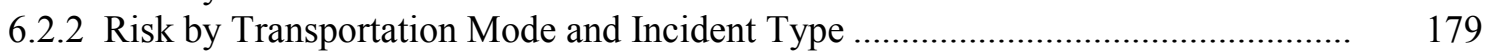

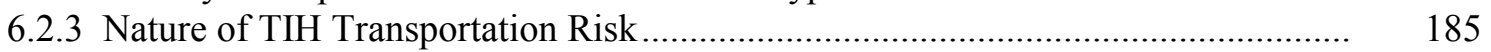

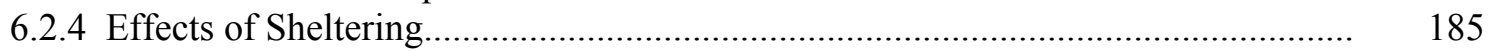

6.2.5 Effects of the 1990 Regulatory Changes for TIH Liquids ..................................... 186

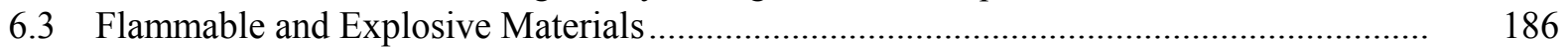

6.3.1 Risk for Highway Transportation of Flammable Materials ................................... 186

6.3.2 Risk for Highway Transportation of Explosive Materials ...................................... 187

6.3.3 Nature of Transportation Risk for Flammables and Explosives ............................. 188

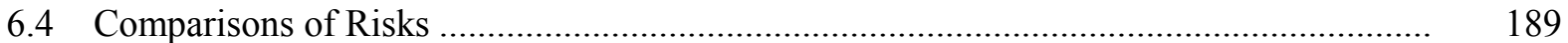

6.4.1 TIH Materials, Flammable Materials, and Explosives ........................................... 189

6.4.2 Comparison with Other Transportation-Related Risks .......................................... 190

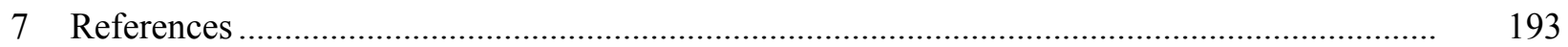

\section{Appendixes}

Appendix A: Technical Basis for Consequence Assessments..................................................... 199

Appendix B: Top 150 Hazardous Materials Transported by Rail, 1986-1995 _............................ 229

Appendix C: HMIS Incident Counts by Container Type....................................................... 235

Appendix D: HMIS Fatalities, Injuries, and Evacuations by Container Type ….......................... 237

Appendix E: HMIS Fatality and Major Injury Incidents ............................................................. 239

\section{Figures}

S.1 Distribution of Total TIH Fatality and Injury Risk ….................................................... 5

S.2 Fatalities and Injuries Normalized by Commodity Flow ...............................................

2.1 General Risk Assessment Methodology Applied to Individual Hazardous

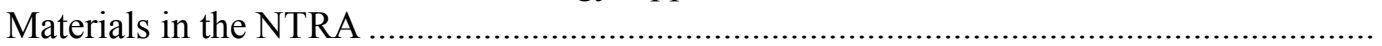

2.2 Flowchart for the CASRAM Methodology for Consequence Analysis as Applied to

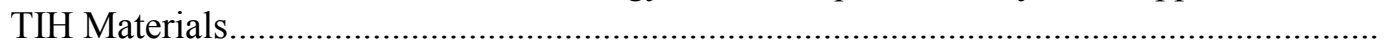

2.3 Three Source Types for Inhalation Risk: (a) Ordinary Liquids, (b) Compressed Gases, and (c) Liquefied Gases 


\section{Figures (Cont.)}

2.4 Locations of the 64 National Weather Service Stations Used for the NTRA

National Meteorological Database

2.5 Effects of Sheltering for Outdoor and Indoor Release Scenarios

for a Large Release of Liquefied Gas....

2.6 Effect of Sheltering for Outdoor and Indoor Release Scenarios

for a Large Release of a Liquid

2.7 Flowchart for the CASRAM Methodology for Consequence Analysis

as Applied to LP Gas Transportation

2.8 Flowchart for the CASRAM Methodology for Consequence Analysis

as Applied to Explosives Transportation.

3.1 Incidents Reported in the HMIS Database, 1985-1995

3.2 Discharge Fraction Cumulative Probability for Bulk Nonpressure and Low-Pressure Containers as Derived from the HMIS Database for (a) Accident-Related Releases,

(b) En Route/Nonaccident Releases, and (c) Loading/Unloading Releases

3.3 Discharge Fraction Cumulative Probability for Bulk Pressurized Containers as Derived from the HMIS Database for (a) Accident-Related Releases,

(b) En Route/Nonaccident Releases, and (c) Loading/Unloading Releases.

3.4 Discharge Fraction Cumulative Probability for Package Freight Containers as Derived from the HMIS Database for (a) Accident-Related Releases,

(b) En Route/Nonaccident Releases, and (c) Loading/Unloading Releases.

3.5 Hourly Distribution of Highway-Transportation-Related Hazardous Material Releases Occurring during (a) Vehicle Accidents, (b) En Route/Nonaccident Incidents, and (c) Loading/Unloading Incidents.

3.6 Monthly Distribution of Highway-Transportation-Related Hazardous Material Releases Occurring during (a) Vehicle Accidents, (b) En Route/Nonaccident Incidents, and (c) Loading/Unloading Incidents....

3.7 Hourly Distribution of Rail-Transportation-Related Hazardous Material Releases Occurring during (a) Train Derailments, (b) En Route/Nonaccident Incidents, and (c) Loading/Unloading Incidents.

3.8 Monthly Distribution of Rail-Transportation-Related Hazardous Material Releases Occurring during (a) Train Derailments, (b) En Route/Nonaccident Incidents, and (c) Loading/Unloading Incidents.

5.1 Cumulative Probability Curves Characteristic of Transportation-Related Risk 


\section{Figures (Cont.)}

5.2 Probability of ERPG-2 Exposure for Accident-Related Highway

Releases over a 10-yr Period for the Six NTRA TIH Chemicals

5.3 Probability of Fatal Exposure Resulting from Accident-Related Highway

Releases over a 10-yr Period for the Six NTRA TIH Chemicals

5.4 Probability of ERPG-2 Exposure for En Route/Nonaccident Highway

Releases over a 10-yr Period for the Six NTRA TIH Chemicals

5.5 Probability of Fatal Exposure Resulting from En Route/Nonaccident Highway

Releases over a 10-yr Period for the Six NTRA TIH Chemicals

5.6 Probability of ERPG-2 Exposure Resulting from Accident-Related Rail

Releases over a 10-yr Period for the Six NTRA TIH Chemicals

5.7 Probability of Fatal Exposure Resulting from Accident-Related Rail

Releases over a 10-yr Period for the Six NTRA TIH Chemicals

5.8 Probability of ERPG-2 Exposure Resulting from En Route/Nonaccident Rail

Releases over a 10-yr Period for the Six NTRA TIH Chemicals

5.9 Probability of Fatal Exposure Resulting from En Route/Nonaccident Rail

Releases over a 10-yr Period for the Six NTRA TIH Chemicals

5.10 Probability of Population Exposure to ERPG-2 Concentrations Resulting from Accident-Related and En Route/Nonaccident Releases for Highway and Rail Transportation over a 10-yr Period for the Six NTRA TIH Chemicals

5.11 Probability of Fatal Exposure Resulting from Accident-Related and En Route/ Nonaccident Releases for Highway and Rail Transportation over a 10-yr Period for the Six NTRA TIH Chemicals.

5.12 Annual Risk Denoted by ERPG-2 Exposures as a Function of the Number of Routes Used in the Risk Assessment

5.13 Annual Risk Denoted by ERPG-2 Exposures to Ammonia and Chlorine as a Function of the Number of Routes Used in the Risk Assessment.

5.14 Probability of Injuries and Fatalities Resulting from Highway Transportation of LP Gases over a 10-yr Period

5.15 Probability of Injuries and Fatalities Resulting from Highway Transportation of Gasoline over a 10-yr Period.

5.16 Probability of Injuries and Fatalities Resulting from Transportation of Explosives over a 10-yr Period. 


\section{Figures (Cont.)}

5.17 Comparison of Injury Probability Resulting from Transportation of TIH

Materials, LP Gas, Gasoline, and Explosives over a 10-yr Period

5.18 Comparison of Fatality Probability Resulting from Transportation of TIH

Materials, LP Gas, Gasoline, and Explosives over a 10-yr Period

6.1 Distribution of Total TIH Fatality and Injury Risk by Chemical

6.2 Distribution of Total TIH Fatality and Injury Risk by Transportation Mode

and Release Type

6.3 Normalized Risk of (a) Fatalities and (b) Injuries per Million Ton-Miles

Associated with Highway and Rail Transportation for the Six

NTRA TIH Chemicals

6.4 Distribution of Total TIH Fatality and Injury Risk between Bulk Freight and

Package Freight for Highway Transportation for the Six NTRA TIH Chemicals

6.5 Normalized Risk of (a) Fatalities and (b) Injuries per Million Ton-Miles

Associated with Bulk and Package Freight Highway Transportation for the Six

NTRA TIH Chemicals

6.6 Annual Fatalities and Injuries as Estimated in the NTRA

6.7 Fatalities and Injuries Normalized by Commodity Flow as Estimated

in the NTRA

A.1 Increase in Hazard Zone Size with Decreasing Threshold Concentration

for Stable, Neutral, and Unstable Meteorological Conditions

A.2 Geometry for Calculating Radiative Effects from Fireballs

A.3 Human Health Impacts from Thermal Radiation

A.4 Scaled Pressure as a Function of Scaled Distance for Pentolite.

\section{Tables}

S.1 Comparisons of Risks Calculated in This Study with Other Transportation-Related Risks in the United States

2.1 Summary of Incidents Involving TIH Materials as Catalogued in the HMIS

Database from 1985 to 1995 .... 


\section{Tables (Cont.)}

2.2 Truck Accident Rates for California, Illinois, and Michigan ......................................... 28

2.3 Accident Rates for Single- and Double-Combination Trucks for Interstates, State Highways, and Local Streets

2.4 Accident Rates for Interstate and Noninterstate Truck Transportation Used in the NTRA

2.5 Distribution of FHWA Accidents Involving Hazardous Materials by Cargo Type, 1984-1985

2.6 Release Probability Analysis for Liquefied Gases

2.7 Release Probability Analysis for Bulk Liquids

2.8 Release Probabilities for Various Bulk and Package Freight Containers Used in Highway Transportation.....

2.9 Release Probabilities for Bulk Highway Transportation of the Six NTRA TIH Chemicals and LP Gas

2.10 Release Probabilities for Package Freight Highway Transportation of the Six NTRA TIH Chemicals

2.11 Commodity Flow Estimates and Derailment-Related Release Numbers for Four Commodities Used to Estimate Release Probabilities for Nonpressurized and Pressurized Railcars, 1986-1995

2.12 Railcar Types and Release Probabilities Used for Rail Transportation of the Six NTRA TIH Chemicals

2.13 Relative Number of En Route/Nonaccident Releases Compared with Accident-Related Releases for Various Container Types

2.14 Outdoor Air Exchange Rates for Various Building Types

2.15 Average Reduction in Casualties in Transportation-Related Incidents for Three Building Ventilation Rates ....

2.16 Relationship of Relative Hazard Category to Release Type and Threshold Concentration.

2.17 Ignition Probabilities for Small, Medium, and Large Highway LP Gas Releases

2.18 Incident Frequencies and Distribution Parameters for Modeled Fatality and Injury Consequence Distributions for Highway Transportation of Gasoline. 


\section{Tables (Cont.)}

2.19 Comparison of Predicted and Observed Fatality and Injury Distributions

for Gasoline Transportation on a Per-Incident Basis.

2.20 Probabilistic Data Used in Estimating the Detonation Frequency for Explosives

in the NTRA .

3.1 Yearly and Total Numbers of Incidents Recorded in the HMIS Database

for Various Transportation Modes

3.2 Incident Counts Recorded in the HMIS Database for Accident, En Route/Nonaccident, and Loading/Unloading Releases for Highway and Rail

Transportation, 1990-1995.

3.3 Number of Fire, Explosion, and Water Immersion Incidents Recorded

in the HMIS Database for Highway Transportation, 1990-1995

3.4 Number of Fire, Explosion, and Water Immersion Incidents Recorded in the HMIS Database for Rail Transportation, 1990-1995.

3.5 Number of Fatalities, Major Injuries, Minor Injuries, and Persons Evacuated as Reported in the HMIS Database for Rail and Highway Incidents, 1985-1995

3.6 Percentage of Fatalities, Major Injuries, Minor Injuries, and Persons Evacuated for Rail and Highway Incidents Occurring in Accidents, En Route/Nonaccident Events, and Loading/Unloading Events as Determined from the HMIS Database, 1990-1995

3.7 Number of Fatalities, Major Injuries, Minor Injuries, and Persons Evacuated as Reported in the HMIS Database by Hazard Class of the Material, 1985-1995

3.8 Top Three Hazard Classes in Terms of Fatalities, Major Injuries, Minor Injuries, and Persons Evacuated as Determined from the HMIS Database, 1985-1995.

3.9 Top 10 Materials Responsible for Fatalities as Determined from the HMIS Database, 1985-1995

3.10 Top 10 Materials Responsible for Major Injuries as Determined from the HMIS Database, 1985-1995

3.11 Top 10 Materials Responsible for Minor Injuries as Determined from the HMIS Database, 1985-1995

3.12 Top 10 Materials Responsible for Persons Evacuated as Determined from the HMIS Database, 1985-1995 


\section{Tables (Cont.)}

3.13 Top 10 Container Types Involved with Fatalities and Major Injuries as Determined from the HMIS Database, 1985-1995

3.14 Suggested Correction Factors for Use with En Route/Nonaccident and Loading/Unloading Incidents Involving Shipments of One or Two Containers

4.1 Sampling Strata in the MRI Format.

4.2 Top 10 FIPS Code Pairs for Origin and Destination for Chlorine in the STB Waybill Sample, 1986-1995.

4.3 Thirty Representative Rail Routes Used to Model Risk due to Rail Transportation of Anhydrous Ammonia.

4.4 Thirty Representative Rail Routes Used to Model Risk due to Rail

Transportation of Chlorine

4.5 Twenty-six Representative Rail Routes Used to Model Risk due to Rail

Transportation of Sulfur Dioxide

4.6 Twenty Representative Rail Routes Used to Model Risk due to Rail

Transportation of Hydrogen Fluoride.

4.7 Seventeen Representative Rail Routes Used to Model Risk due to Rail

Transportation of Fuming Sulfuric Acid

4.8 Sixteen Representative Rail Routes Used to Model Risk due to Rail

Transportation of Fuming Nitric Acid

4.9 Percentage of Single-Car Lading Weights Occurring in Six Weight Ranges

for the NTRA TIH Chemicals

4.10 Summary of Routing Information Used for Rail TIH Shipments.

4.11 Example of a Rail Route Generated by INTERLINE 5.0 as Postprocessed

to Provide Latitude and Longitude for Each Node.

4.12 Twenty-two Representative Highway Shipments Used to Model Risk due to Highway Transportation of Ammonia Determined by Using the 1977 CTS and the HMIS Database.

4.13 Twenty Representative Highway Shipments Used to Model Risk due to Highway Transportation of Chlorine Determined by Using the 1977 CTS and the HMIS Database. 


\section{Tables (Cont.)}

4.14 Fifteen Representative Highway Shipments Used to Model Risk

due to Highway Transportation of Sulfur Dioxide Determined by Using

the 1977 CTS and the HMIS Database.

4.15 Twelve Representative Highway Shipments Used to Model Risk

due to Highway Transportation of Anhydrous Hydrogen Fluoride Determined

by Using the Data Provided by EPA and the HMIS Database

4.16 Seventeen Representative Highway Shipments Used to Model Risk due to Highway Transportation of Fuming Sulfuric Acid Determined by Using the 1977 CTS and the HMIS Database ....

4.17 Seventeen Representative Highway Shipments Used to Model Risk due to Highway Transportation of Fuming Nitric Acid Determined by Using the 1977 CTS and the HMIS Database

4.18 Thirty-three Representative Highway Shipments Used to Model Risk due to Highway Transportation of LP Gases Determined by Using the 1977 CTS and the HMIS Database.

4.19 Twenty-eight Representative Highway Shipments Used to Model Risk due to Highway Transportation of Explosives Determined by Using the 1977 CTS and the 1993 CTS

4.20 Commodity Flow Data in Tons and Ton-Miles for Industrial Inorganic and Organic Chemicals from the 1977 CTS and the 1993 CFS with Scaling Factors Derived from the Data

4.21 Commodity Flow Data in Tons and Ton-Miles for Anhydrous Ammonia from the 1977 CTS with Estimated Values for 1993 Calculated by Using the Scaling Factors in Table 4.20 .....

4.22 Commodity Flow Data in Tons and Ton-Miles for Chlorine from the 1977 CTS with Estimated Values for 1993 Calculated by Using the Scaling Factors in Table 4.20

4.23 Commodity Flow Data for Sulfur Dioxide in Tons Shipped...

4.24 Commodity Flow Data in Tons and Ton-Miles for Sulfuric Acid

from the 1977 CTS with Estimated Values for 1993

4.25 Commodity Flow Data in Tons and Ton-Miles for Nitric Acid

from the 1977 CTS with Estimated Values for 1993

4.26 Commodity Flow Data in Tons and Ton-Miles for Products of Petroleum Refining from the 1977 CTS and 1993 CFS with the Scaling Factors Derived from the Data. 


\section{Tables (Cont.)}

4.27 Commodity Flow Data in Tons and Ton-Miles for LP Gas, Gasoline, and Fuel Oil from the 1977 CTS with Estimated Values for 1993 Calculated by Using the Scaling Factors in Table 4.26

4.28 Commodity Flow Data in Tons and Ton-Miles for Miscellaneous Chemical Products from the 1977 CTS and 1993 CFS with the Scaling Factors Derived from the Data.

4.29 Commodity Flow Data in Tons and Ton-Miles for Explosives from the 1977 CTS with Estimated Values for 1993 by Using the Scaling Factors in Table 4.28

4.30 Summary of the 1993 Commodity Flow Data for Explosives.

4.31 Highway Route Generated by HIGHWAY 3.3 as Postprocessed to Provide Latitude and Longitude

5.1 Hypothetical Distribution of Incidents and Consequences.

5.2 Cumulative Probability for Incidents Shown in Table 5.1 for 1-, 5-, and 10-yr Averaging Times.

5.3 Effect of Averaging Time on Cumulative Probability.

5.4 Reduction Factors for Relating ERPG-2 Exposures to Injuries and Fatal Exposures to Fatalities

5.5 Probability of Population Exposure to Airborne Concentrations Exceeding ERPG-2 Thresholds Resulting from Accident-Related Highway Releases over a 10-yr Period for the Six NTRA TIH Chemicals ....

5.6 Risk Measures and Annual Population Exposure Statistics for ERPG-2 Exposures Resulting from Accident-Related Highway Releases for the Six NTRA TIH Chemicals

5.7 Probability of Population Exposure to Airborne Concentrations Exceeding Fatal Thresholds Resulting from Accident-Related Highway Releases over a 10-yr Period for the Six NTRA TIH Chemicals....

5.8 Risk Measures and Annual Population Exposure Statistics for Fatal Exposures Resulting from Accident-Related Highway Releases for the Six NTRA TIH Chemicals

5.9 Probability of Population Exposure to Airborne Concentrations Exceeding ERPG-2 Thresholds Resulting from En Route/Nonaccident Highway Releases over a 10-yr Period for the Six NTRA TIH Chemicals... 


\section{Tables (Cont.)}

5.10 Risk Measures and Annual Population Exposure Statistics for ERPG-2 Exposures

Resulting from En Route/Nonaccident Highway Releases for the Six NTRA

TIH Chemicals

5.11 Probability of Population Exposure to Airborne Concentrations Exceeding

Fatal Thresholds Resulting from En Route/Nonaccident Highway Releases

over a 10-yr Period for the Six NTRA TIH Chemicals

5.12 Risk Measures and Annual Population Exposure Statistics for Fatal Exposures

Resulting from En Route/Nonaccident Highway Releases for the Six NTRA

TIH Chemicals

5.13 Probability of Population Exposure to Airborne Concentrations Exceeding

ERPG-2 Thresholds Resulting from Accident-Related Rail Releases

over a 10-yr Period for the Six NTRA TIH Chemicals

5.14 Probability of Population Exposure to Airborne Concentrations Exceeding

Fatal Thresholds Resulting from Accident-Related Rail Releases

over a 10-yr Period for the Six NTRA TIH Chemicals .....

5.15 Probability of Population Exposure to Airborne Concentrations Exceeding ERPG-2 Thresholds Resulting from En Route/Nonaccident Rail Releases over a 10 -yr Period for the Six NTRA TIH Chemicals

5.16 Probability of Population Exposure to Airborne Concentrations Exceeding

Fatal Thresholds Resulting from En Route/Nonaccident Rail Releases

over a 10-yr Period for the Six NTRA TIH Chemicals

5.17 Average ERPG-2 Exposure Statistics for Four NTRA Incident Types

for 10- and 1-yr Periods

5.18 Average Fatal Exposure Statistics for Four NTRA Incident Types

for 10- and 1-yr Periods

5.19 Probability of Population Exposure to Airborne Concentrations Exceeding ERPG-2

Thresholds Resulting from Accident-Related and En Route/Nonaccident Releases

for Highway and Rail over a 10-yr Period for the Six NTRA TIH Chemicals

5.20 Probability of Population Exposure to Airborne Concentrations Exceeding Fatal Thresholds Resulting from Accident-Related and En Route/Nonaccident Releases for Highway and Rail over a 10-yr Period for the Six NTRA TIH Chemicals

5.21 Probability of ERPG-2 Exposure Resulting from All Highway and Rail TIH Transportation over a 10-yr Period 


\section{Tables (Cont.)}

5.22 Probability of Fatal Exposure Resulting from All Highway and Rail

TIH Transportation over a 10-yr Period

5.23 Geographical Distribution of Highway Incidents from the HMIS Database, $1985-1995$.

5.24 Percentage of Miles in Generic Routing by Population Density

5.25 Sensitivity of NTRA Results as Measured by Average Annual ERPG-2 Exposures from Highway Accident-Related Releases

5.26 Reduction of Annual Risk Associated with Highway Accident-Related Releases for Fuming Sulfuric Acid and Fuming Nitric Acid as a Result of 1990 Regulatory Changes for MC 312 Cargo Tanks

5.27 Reduction of Annual Risk Associated with Derailment-Related Releases for Fuming

Sulfuric Acid and Fuming Nitric Acid as a Result of 1990 Regulatory Changes

5.28 Probability of Injuries Resulting from Highway Transportation of LP Gas over a 10 -yr Period

5.29 Probability of Fatalities Resulting from Highway Transportation of LP Gas over a 10-yr Period

5.30 Probability of Injuries Resulting from Highway Transportation of Gasoline over a 10 -yr Period

5.31 Probability of Fatalities Resulting from Highway Transportation of Gasoline over a 10-yr Period

5.32 Probability of Injuries Resulting from Highway Transportation of Explosives over a 10 -yr Period

5.33 Probability of Fatalities Resulting from Highway Transportation of Explosives over a 10 -yr Period

5.34 Median and Average Injuries and Fatalities Resulting from Transportation of TIH Materials, LP Gas, Gasoline, and Explosives over a 10-yr Period.

5.35 Total Annual Risk and Normalized Risk Resulting from Transportation of TIH Materials, LP Gas, Gasoline, and Explosives

6.1 Comparisons of Risks Calculated in This Study with Other Transportation-Related Risks in the United States.

A.1 Injury Threshold Concentrations for the Six NTRA TIH Chemicals 
$\Delta$

Tables (Cont.)

A.2 Lethality Threshold Concentrations for the Six NTRA TIH Chemicals ........................... 211

A.3 Expected Damage and Injury for Various Levels of Blast Overpressure.......................... 225

A.4 Injury and Lethality Thresholds for Blast Overpressure Used in the NTRA ..................... 226

B.1 Top 150 Most Heavily Shipped Hazardous Materials by Rail, 1986-1995, Determined from the AAR Waybill Sample. 


\section{Notation}

The following is a list of the acronyms, initialisms, and abbreviations (including units of measure) used in this document.

\section{Acronyms, Initialisms, and Abbreviations}

$\begin{array}{ll}\text { AAR } & \text { Association of American Railroads } \\ \text { AIHA } & \text { American Industrial Hygiene Association } \\ \text { ANFO } & \text { ammonium nitrate fuel oil mixture } \\ \text { APH } & \text { air exchanges per hour } \\ \text { BEA } & \text { Bureau of Economic Activity } \\ \text { CASRAM } & \text { Chemical Accident Statistical Risk Assessment Model } \\ \text { CFR } & \text { Code of Federal Regulations } \\ \text { CFS } & \text { Commodity Flow Survey } \\ \text { CTS } & \text { Commodity Transportation Survey } \\ \text { CWIC } & \text { cross-wind-integrated concentration } \\ \text { DOE } & \text { U.S. Department of Energy } \\ \text { DOT } & \text { U.S. Department of Transportation } \\ \text { EPA } & \text { U.S. Environmental Protection Agency } \\ \text { ERPG } & \text { Emergency Response Planning Guideline (AIHA, Level 2) } \\ \text { FHWA } & \text { Federal Highway Administration } \\ \text { FIPS } & \text { Federal Information Processing Center } \\ \text { HF } & \text { hydrogen fluoride } \\ \text { HMIS } & \text { Hazardous Materials Information System } \\ \text { ICC } & \text { Interstate Commerce Commission } \\ \text { LC } 50 & \text { lethal concentration to 50\% of the exposed population; } \\ & \text { median lethal concentration } \\ \text { LP } & \text { liquefied petroleum } \\ \text { MRI } & \text { machine-readable input } \\ \text { NO } & \text { nitrogen oxide(s) } \\ \text { n.o.s. } & \text { not otherwise specified } \\ \text { NTRA } & \text { National Transportation Risk Assessment } \\ \text { O/D } & \text { origin/destination } \\ \text { ORNL } & \text { Oak Ridge National Laboratory } \\ \text { OSHA } & \text { Occupational Safety and Health Administration } \\ \text { PEL } & \text { permissible exposure limit } \\ \text { RPI } & \text { Railroad Progress Institute } \\ \text { RSPA } & \text { Research and Special Programs Administration } \\ \text { SEBMET } & \text { Surface Energy Budget METeorological (model) } \\ \text { SO } & \text { sulfur dioxide } \\ \text { SO } & \text { sulfur trioxide } \\ \text { STB } & \text { Surface Transportation Board } \\ & \end{array}$


STCC Standard Transportation Commodity Code

TIH toxic by inhalation

TNT trinitrotoluene

UN United Nations

\section{Units of Measure}

$\begin{array}{ll}{ }^{\circ} \mathrm{C} & \text { degree(s) Celsius } \\ \mathrm{d} & \text { day(s) } \\ \mathrm{deg} & \text { degree(s) } \\ { }^{\circ} \mathrm{F} & \text { degree(s) Fahrenheit } \\ \mathrm{ft} & \text { foot (feet) } \\ \mathrm{g} & \text { gram(s) } \\ \text { gal } & \text { gallon(s) } \\ \mathrm{h} & \text { hour(s) } \\ \mathrm{K} & \text { degree(s) Kelvin } \\ \mathrm{kg} & \text { kilogram(s) } \\ \mathrm{m} & \text { meter(s) } \\ \mathrm{m}^{2} & \text { square meter(s) } \\ \mathrm{m}^{3} & \text { cubic meter(s) } \\ \mathrm{mi} & \text { mile(s) } \\ \mathrm{min} & \text { minute(s) } \\ \mathrm{mm} & \text { millimeter(s) } \\ \mathrm{MTM} & \text { million ton-mile(s) } \\ \text { ppm } & \text { part(s) per million } \\ \mathrm{s} & \text { second(s) } \\ \mathrm{yr} & \text { year(s) }\end{array}$




\section{Abstract}

This report details a quantitative risk assessment conducted for transportation of selected hazardous materials on a national basis. These materials include six toxic-byinhalation (TIH) chemicals, which account for more than $90 \%$ of the total $\mathrm{TIH}$ transportation-related risk; liquefied petroleum gas; gasoline; and explosives. For TIH materials, both highway and rail transportation are considered, and two classes of incidents are examined - those that occur (1) during a traffic accident or a train derailment and (2) while en route from the origin to the destination, but not during an accident or derailment. For the other materials evaluated in the study, only accidentrelated incidents for highway transportation are considered because transportationrelated risk for these materials is dominated by highway incidents.

The report describes the hazardous materials and consequence levels evaluated; the risk assessment methodology; the databases used to determine hazardous materials commodity flow and incident rates; and results of the study, including quantitative risk distributions and risk measures for the materials evaluated. The results suggest that, compared with other types of transportation risks encountered by the public, overall societal risks due to hazardous materials transportation remain relatively low. However, the potential exists for very serious accidents involving large numbers of injuries and fatalities, especially for TIH materials, although the probability of such events is low. This study also reveals areas of substantially higher risk relative to hazardous materials transportation risk as a whole. 
$\Delta$ 


\section{Summary}

\section{Background}

Every year, more than 40,000 Americans die and several hundred thousand are injured in transportation-related incidents, mainly from motor vehicle accidents. A small number of these fatalities and injuries result from the unintentional release of hazardous materials during transport. For example, during each of the past 15 years, approximately 10 people died as a result of fires that occurred in gasoline-truck accidents, with truck drivers accounting for approximately 7 of the 10 deaths. Given that a typical American family uses approximately a tanker-truckful of gasoline every 5 to 10 years, trucks must transport very large quantities of gasoline around the country to meet demand - about 10 to 20 million shipments a year. As a result, there are many opportunities for accidents, and the available statistics provide relatively reliable data concerning the fatality and injury risks of accidents and fires associated with transporting gasoline.

For most hazardous materials, however, estimating the fatality and injury risks associated with their transportation is more difficult. Approximately 100,000 shipments of chlorine occur each year, which means that far fewer opportunities for accidents exist and that the few accidents that have occurred do not provide reliable data for estimating future risks. For example, since 1985, only one fatality and a handful of injuries have occurred as the result of accidents involving the transportation of chlorine in the United States. In addition, unlike gasoline-truck fires, which typically affect only the people involved in the accident, releases of toxic chemicals can kill and injure people located relatively far from the accident. Thus, these types of accidents often have the potential to cause large numbers of deaths and injuries, and as a result, often lead to large-scale evacuations. Similar issues arise for hazardous substances that are explosive.

While review of the statistics alone might suggest that accidents associated with the transportation of hazardous materials should not be a major concern, these accidents can have enormous impacts when they occur. As a result, the failure to identify and evaluate opportunities to reduce the risks from these types of relatively rare accidents could ultimately lead to thousands of fatalities, injuries, and evacuations. Fortunately, risk assessment tools now combine experience with engineering analysis and a thorough understanding of the various factors affecting risk to support a comprehensive and integrated approach to risk management. While these tools are not perfect, they do enable numerical estimation of the risks from transportation of diverse classes of hazardous materials on a national scale. This report presents a study that is a first step in that direction - a national risk assessment for transportation of selected hazardous materials. 


\section{Purpose and Scope}

The purpose of this National Transportation Risk Assessment (NTRA) study is to quantitatively characterize the risks associated with the transportation of selected hazardous materials on a national basis. At the center of this study is a detailed risk assessment of the transportation of six toxic-by-inhalation (TIH) materials that represent acute inhalation hazards, liquefied petroleum (LP) gas, gasoline, and explosives. The TIH materials include chlorine, ammonia, sulfur dioxide, hydrogen fluoride, fuming sulfuric acid, and fuming nitric acid, and collectively represent at least $90 \%$ of transportation risk from all $\mathrm{TIH}$ materials. The report evaluates the risks of these substances for both truck and rail transportation and for both accident situations and nonaccident releases that occur due to container or valve failures while the material is en route. For LP gas, gasoline, and explosives, the report addresses only accident-related incidents for highway transportation because highway incidents dominate the transportation-related risk for these materials.

The objectives of the NTRA study are to (1) characterize the relative risks of transporting the selected hazardous materials by evaluating the potential health impacts (defined as fatalities and injuries) for the public (including workers) from accidental releases and (2) to evaluate the probability that certain consequences might occur in a specified period. For TIH materials, the report estimates acute health impacts from inhalation of toxic vapors, whereas for flammable materials and explosives, the report estimates health impacts due to thermal radiation from flash fires or fireballs and blast effects from explosions.

This study does not address the risks associated with non-TIH, nonflammable chemicals, such as regular sulfuric acid, sodium hydroxide, radioactive materials, or infectious substances. Also, the study does not evaluate risks associated with the transportation of hazardous materials by aircraft, waterborne vessels, or pipelines. Finally, while this study focuses on identifying and quantifying transportation risk, future studies are needed to apply these results to risk management efforts.

\section{Methodology}

This study reports risk estimates for gasoline on the basis of reliable historical fatality and injury data from the U.S. Department of Transportation (DOT) Hazardous Materials Information System (HMIS) database. For other hazardous substances, the historical data in the HMIS database did not provide sufficient information for direct estimation of risks. As a result, a risk assessment model was developed that relies extensively on a more general array of hazardous-material-transportation-related statistical data taken primarily from the HMIS database, including temporal incident rates, discharge fractions, and ignition probabilities for flammable and explosive materials. It also relies on commodity flow and routing information obtained from national commodity flow surveys and rail waybill data available at the time of the study. Other resources used include (1) a detailed consequence assessment model, which provides emission rates and atmospheric dispersion estimates for TIH material releases, as well as thermal radiation 
and blast overpressure from flammable materials and explosives incidents; (2) routing models, which provide routes and population density distributions for both highway and rail shipments; and (3) National Weather Service meteorological observations for 64 U.S. cities, which provide necessary weather and climate data for emission rate and dispersion analyses.

The risk assessment model uses probabilistic sampling of input variables to calculate long-term averages of the resulting risks. The model analyzes available commodity flow data and shipment information to determine the primary shipping corridors, shipment sizes, and overall shipment volume. Existing DOT regulations for transporting hazardous substances form the basis for determining the specifications of tank cars, cargo tanks, and package freight containers in transport. The model relies on separating the total national commodity flow for each material into a large number of representative shipments to capture the variations of accident probability, population density, and meteorology that characterize the transportation risk for that material. For each representative shipment, the model assesses the probabilities of fatalities and injuries for a specified period of operation, and it then combines the results of individual shipments to estimate the transportation risk profile for each material considered.

\section{Results}

This study affirms that compared to the other types of transportation risks encountered by the public (provided at the top of Table S.1) the overall societal risks due to hazardous materials transportation (provided at the bottom of Table S.1) remain relatively low. However, the potential exists for very serious accidents involving large numbers of fatalities and injuries, especially for TIH materials, although the probability of such events is very low. In addition, this study reveals areas of substantially higher risk relative to hazardous materials transportation risk as a whole.

The results suggest that approximately 18 fatalities and 122 injuries will occur on average each year from the combined unintentional releases resulting from highway and rail transportation of TIH materials and from highway transportation of LP gas, gasoline, and explosives. Because of the very large amounts of gasoline transported, the average projected annual fatalities due to gasoline transportation substantially exceed those from transportation of TIH materials, LP gas, and explosives. For TIH materials, the fact that rare accidents can produce very large consequences greatly increases the average fatality and injury estimates over what has been observed in the recent past. As a result, the number of fatalities and injuries in most years falls below the average annual values, with a very small percentage of years having a large number of fatalities and injuries as a result of a very unlikely, but very large, incident. The influence of low-probability events also affects the fatality and injury estimates of LP gas and explosives, but much less than it affects the risk estimates for TIH materials. Low-probability events have little influence on gasoline transportation risk. 
Table S.1 Comparisons of Risks Calculated in This Study with Other Transportation-Related Risks in the United States

\begin{tabular}{|c|c|c|c|c|}
\hline \multirow[b]{2}{*}{ Risk Type } & \multicolumn{2}{|c|}{ 10-yr Period } & \multicolumn{2}{|c|}{ Annual } \\
\hline & Fatalities & Injuries & Fatalities & Injuries \\
\hline \multicolumn{5}{|l|}{ Risks primarily due to trauma } \\
\hline Motor vehicles, including large trucks ${ }^{a}$ & 416,160 & $22,500,000$ & 41,616 & $2,250,000$ \\
\hline Large trucks ${ }^{b}$ & 50,877 & $1,327,000$ & 5087 & 132,700 \\
\hline Large trucks carrying HAZMATC & 2,500 & 66,000 & 250 & 6,600 \\
\hline Rail accidents (grade crossing) ${ }^{d}$ & 5,439 & 16,905 & 544 & 1,691 \\
\hline Rail accidents (nongrade crossing) ${ }^{d}$ & 5,860 & 163,377 & 586 & 16,338 \\
\hline \multicolumn{5}{|l|}{ Risks due to hazardous materials releases only } \\
\hline Gasoline transportation ${ }^{\mathrm{e}}$ & 108 & 205 & 11 & 21 \\
\hline Highway LP gas transportation ${ }^{f}$ & 42 & 154 & 4.2 & 15 \\
\hline Explosives transportation ${ }^{\dagger}$ & 4.9 & 14 & 0.49 & 1.4 \\
\hline TIH highway accidents $^{f}$ & 3.8 & 149 & 0.38 & 15 \\
\hline TIH highway en route/nonaccidents ${ }^{\dagger}$ & 0.70 & 36 & 0.07 & 3.6 \\
\hline TIH rail derailments ${ }^{f}$ & 16 & 559 & 1.6 & 56 \\
\hline TIH rail en route/nonaccidents ${ }^{f}$ & 2.0 & 103 & 0.20 & 10 \\
\hline Total TIH materials transportation ${ }^{\dagger}$ & 23 & 846 & 2.3 & 85 \\
\hline Total highway risk for HAZMAT releases ${ }^{g}$ & 160 & 558 & 16 & 56 \\
\hline Total rail risk for TIH material releases & 18 & 662 & 1.8 & 66 \\
\hline Total risk for HAZMAT releases considered in study $\mathrm{g}$ & 178 & 1,219 & 18 & 122 \\
\hline
\end{tabular}

a 1994-1998, Injury Facts, National Safety Council, Itasca, III. (1996-1999).

b 1989-1998, MCSAFE Newsletter, Federal Motor Carrier Safety Administration (May 2000); available at http://www.fmcsa.dot.gov/factsfigs/Mcsafe51.htm.

c Taken as $5 \%$ of all large truck injuries and fatalities following Harwood, D.W., and E.R. Russell, Present Practices of Highway Transportation of Hazardous Materials, FHWA/RD-89/013, U.S. Department of Transportation, Federal Highway Administration, Washington, D.C. (1990).

d 1989-1998, Injury Facts, National Safety Council, Itasca, III. (1999).

e Estimated from the HMIS on the basis of the statistical analysis developed in this report. A factor of 1.5 was applied to estimate total intrastate plus interstate fatalities and injuries and to account for under-reporting.

$f$ As estimated in the risk assessment phase of this study.

g TIH materials, gasoline, LP gas, and explosives.

On the basis of the risks from TIH materials, the results suggest that chlorine and ammonia account for $70 \%$ to $80 \%$ of the total TIH transportation risk (Figure S.1). Rail transportation accidents account for about $70 \%$ of the TIH transportation risk, even though such incidents are infrequent. However, highway transportation leads to greater risks per ton-mile (normalized risk) than rail transportation for the six TIH materials considered. (Representing the risk in this manner ignores the current usage of different transportation modes and total volume of materials shipped.) Toxic-by-inhalation materials exceed all other materials considered in this study in terms of total injury risk 


\section{Total Fatality Risk}

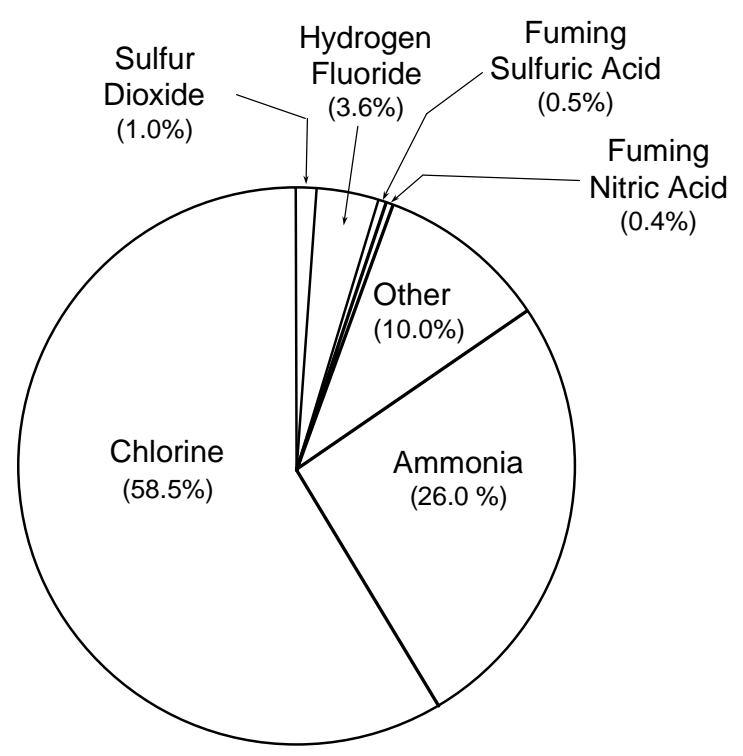

\section{Total Injury Risk}

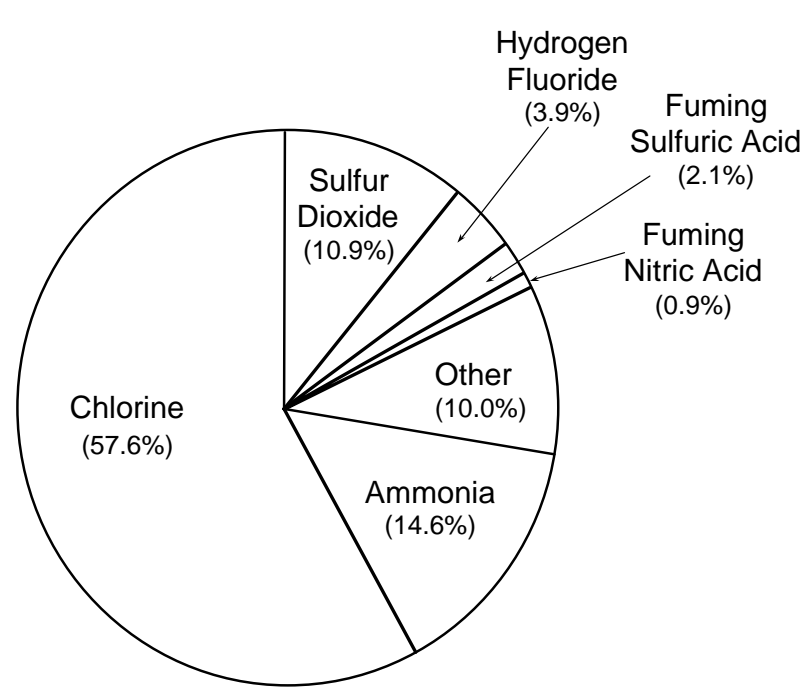

Figure S.1 Distribution of Total TIH Fatality and Injury Risk

due to the potential for accidents that affect large areas with chemical concentrations exceeding injury limits.

Considering fatality risks on a per-ton-mile basis, the risks from LP gas substantially exceed the risks for gasoline, TIH, and explosives (Figure S.2). Considering injury risks per ton-mile, TIH materials and LP gas carry a similar level of risk, with gasoline and explosives carrying substantially lower per-ton-mile injury risks.

\section{Limitations}

While the risk assessment methods used in this study are state of the art, imprecision of certain input data leads to limitations of the results. Specifically, uncertainty about the commodity flow and routing data for some individual materials, the degree of underreporting in the HMIS database, and the failure rates of package freight containers and certain bulk containers required the use of assumptions that might not fully represent actual practice. Given the inherent uncertainties in the statistical data and consequence models used in the study, the absolute values of the risk assessment results are less significant than the relative values, and small differences in values (a factor of 3 or less) may not prove to be statistically significant as more accurate models, assumptions, or data become available. Nevertheless, the quantitative results have a significant value in addressing not only the types of incidents that lead to the greatest risk but also the level of risk incurred from hazardous materials transportation. Despite these limitations, the methodology developed in this study can be a useful tool in assessing the impacts of specific risk management decisions (routes, modes, packaging) and in characterizing the expected benefits of particular regulatory options. 

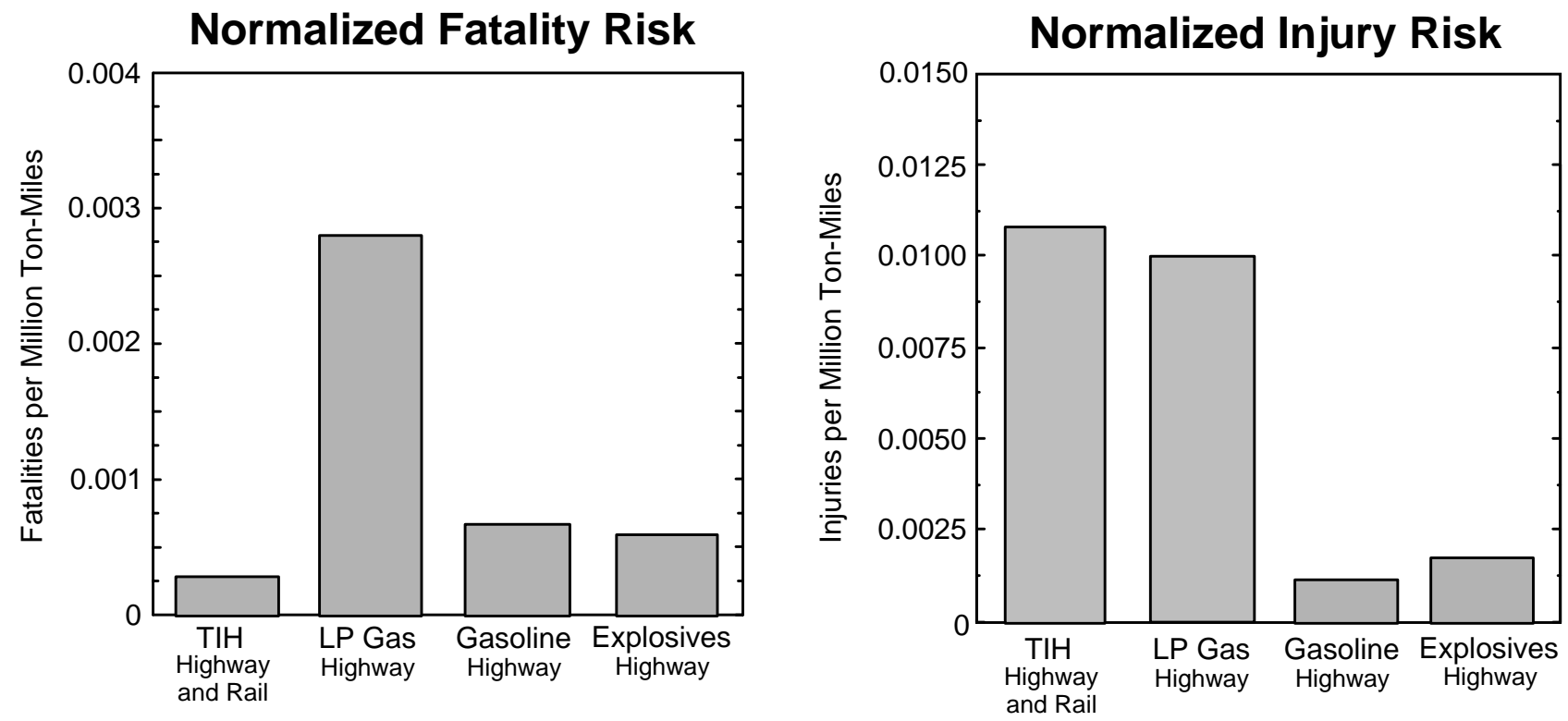

Figure S.2 Fatalities and Injuries Normalized by Commodity Flow 


\section{Section 1 Introduction}

\subsection{Background}

Many conveniences taken for granted in modern civilization depend in part on hazardous materials. These materials must be transported from producers to end users, which creates opportunities for accidents (e.g., traffic accidents, train derailments, equipment failures) that could release hazardous chemicals into the environment. To manage and minimize the risks associated with the transportation of hazardous materials, the U.S. Department of Transportation (DOT) maintains and enforces a rigorous set of regulations. The process of developing and modifying these regulations has been guided by experience and by examination of the hazards associated with particular chemicals or classes of chemicals. As part of this effort, DOT's Research and Special Programs Administration (RSPA) has sponsored considerable research to quantify and better understand the nature of such risks to provide a more accurate appraisal than can be ascertained from historical data alone.

Historical data provide valuable clues to the risks of transporting hazardous materials. They do not, however, necessarily reflect the actual distribution of risk among various hazardous materials because the risks associated with certain materials are largely driven by rarely occurring catastrophic events. For example, historical data for the past 20 years show that fatalities are more likely to result from events associated with the transportation of gasoline and other flammable materials than from other transportationrelated incidents. 1 Risk from flammable materials (e.g., gasoline) is driven by frequently occurring accidents that involve low numbers of injuries and fatalities. These types of accidents are called high-probability/low-consequence fevents. Because the historical record contains information on many gasoline incidents and because the maximum potential impacts from an incident involving gasoline are limited (relative to some toxic materials), these historical data provide an accurate measure of risk.

Transporting toxic-by-inhalation (TIH) materials poses significantly different risks than are associated with transporting gasoline. Risks associated with TIH materials are strongly influenced by rarely occurring catastrophic accidents, such as the rupture of a rail car that contains chlorine near a populated area in adverse atmospheric conditions. Such accidents are called low-probability/high-consequence events. Because of the

1 While a significant portion of injuries are due to the transportation of flammable materials, most injuries are caused by corrosive materials, many of which are toxic by inhalation, and by poisonous materials.

2 In describing probability and consequences, the terms low and high are used in a relative sense. For example, low-consequence incidents on average affect fewer people than do high-consequence incidents. Similarly, low-probability incidents occur less often on average than do high-probability incidents, although neither may be high probability in an absolute sense. 
strong influence of low-probability events on the overall risk profile and because too few accidents have occurred to support statistical characterization, experience does not provide an adequate basis for defining TIH transportation risks. The fact that the number of deaths and injuries for any given year or for any given decade is small does not necessarily mean that the risk is small. Rather, it may reflect the good fortune that no large toxic releases have occurred near populated areas. As a result, the number of injuries or fatalities in a given time period can differ substantially from an average based on the distribution of possible accidents that accounts for low-probability/highconsequence events (i.e., the long-term average).

The character of the risk associated with transporting materials, such as liquefied flammable gases, falls between that of TIH materials and gasoline. In general, incidents that involve liquefied petroleum (LP) gas occur less frequently but are more severe than incidents that involve gasoline. However, worst-case LP gas incidents are not nearly as severe as worst-case TIH incidents, so the influence of such events does not dramatically affect their overall risk profile. In terms of consequences per incident, explosives and LP gas are similar; however, the low commodity flow for explosives leads to very few incidents. This situation makes the assessment of risk directly from the historical record more problematic, thus requiring a more sophisticated approach.

\subsection{Purpose and Scope of the Study}

To compare the risks that result from transporting various hazardous materials, the nature of the risk for each commodity must be evaluated and understood. To assist in this effort, we conducted a National Transportation Risk Assessment (NTRA) to define the risks associated with rail and highway transportation of hazardous materials in the United States and to outline the nature of that risk. At the center of this study is a detailed risk assessment for the national transportation of (1) six TIH chemicals, (2) LP gas, (3) gasoline, and (4) explosives. The results of the risk assessment for these chemicals, together with historical data, provide an excellent basis for comparison of the transportation risks associated with various hazardous material classes, container types, and transportation modes.

This report does not address all hazardous materials in all transportation modes; rather, it focuses primarily on those materials and transportation modes that pose the greatest transportation-related risks to the general public. In addition, a broad selection of materials is included to help answer some important questions concerning the relative degree of risk between different classes of hazardous materials. A brief discussion of the materials and transportation modes selected for this study is presented below.

The NTRA study considered highway and rail transportation of six TIH materials and highway transportation of LP gas, gasoline, and explosives. The TIH materials chlorine, ammonia, sulfur dioxide $\left(\mathrm{SO}_{2}\right)$, hydrogen fluoride $(\mathrm{HF})$, fuming sulfuric acid, and fuming nitric acid - account for more than $90 \%$ of the risks for all TIH-related transportation incidents, as inferred from fatality and injury records in the Hazardous Materials Information System (HMIS). Not specifically modeled in this study are injury 
and fatality risks associated with non-TIH, nonflammable chemicals (e.g., regular sulfuric acid, sodium hydroxide, hydrogen peroxide). An analysis of the historical data showed that non-TIH, nonflammable materials account for many injuries (both major and minor), but for very few fatalities. Most injuries associated with those materials are caused when workers accidentally come into contact with chemicals because of container breakage, hose and valve failures, or other mishaps during loading or unloading operations, or from incidental contact with material that spills during transit (primarily affecting drivers and railroad personnel). While spills of such materials pose a hazard to the general public, the injury and fatality risk associated with TIH materials poses a far greater hazard to this population group.

The NTRA study focused on LP gas because it is by far the most frequently shipped liquefied flammable gas. Only highway transportation of LP gas is considered, although rail transportation accounts for more than $60 \%$ of the total LP gas commodity flow and poses some significant risks. Twenty years of historical data clearly show that highway transportation accounted for a substantial majority of injuries and fatalities associated with the transportation of LP gas. Prior to 1980, rail accidents that involved LP gas caused many more injuries and fatalities than did highway transportation of the gas because numerous incidents occurred as a result of car punctures in derailments or switchyard activities. Redesigned tank cars (introduced in the early 1980s) equipped with shelf couplers and head shields dramatically reduced the rail transportation risk from pre-1980 levels.

Gasoline was selected for the analysis because historically it has been responsible for more transportation-related fatalities than any other hazardous material. Transportation of gasoline also serves as a convenient baseline for comparison of the risks associated with other materials. Only highway transportation of gasoline was considered because it dominates gasoline commodity flow.

Finally, highway transportation of explosives was included in the analysis so that risks due to the transportation of this rarely shipped commodity could be compared with those of other materials on a relative basis. Again, only highway transportation was considered because it is the primary means for the overall commodity flow for explosives.

For TIH materials, analyses were conducted for two classes of releases:

- Accident-related releases that occur during a traffic accident or a train derailment and

- En route/nonaccident releases that occur while en route from the point of origin to the destination, but not during an accident or derailment.

Releases that occur during loading and unloading are catalogued and discussed in the analysis of HMIS data in Section 3 but are not considered in the risk assessment phase of the study because they are more closely associated with fixed-site risk than with 
transportation risk and because insufficient statistical data exist for characterizing such releases. Loading and unloading incidents could pose serious hazards, although overall they pose substantially less risk than the accident-related and en route/nonaccident incidents considered in the NTRA study.

En route/nonaccident releases comprise a small portion of the overall risk profile for LP gas, gasoline, and explosives, and therefore were not considered in this study. In addition, the risks associated with transportation by aircraft, waterborne vessels, or pipelines were not considered. Risks due to radioactive materials and infectious substances also were not examined.

\subsection{Organization of the Report}

Section 2 outlines the NTRA methodology. Careful attention is given to the risk assessment portion of the study where injury and fatality distributions for particular chemicals and material classes are developed. Section 3 provides a detailed review and analysis of the HMIS database. The specific statistical data used in the NTRA are developed in this section. Recommendations for ways to improve the database are also provided. Section 4 discusses the commodity flow analysis for the hazardous materials considered in this report. For the six TIH chemicals, LP gas, and explosives, the transportation of each material nationwide is reduced to a limited number of representative highway and rail shipments that capture the overall distributions of geography, population density, shipment containers, and shipment sizes for each material. Section 5 presents and discusses the fatality and injury distributions developed in this study for the six TIH chemicals, LP gas, and explosives. The fatality and injury distributions for gasoline as calculated from historical data are also presented and discussed, and the risks of transporting TIH materials, flammable materials, and explosives are compared. Finally, Section 6 highlights the major observations and conclusions of this study. Technical discussions of the models used in the study are presented in Appendix A. Appendixes B-E present supporting materials for the NTRA, including discussions of the top 150 hazardous materials shipped by rail; HMIS incident counts and fatality, injury, and evacuation data by container type; and fatality and major incidents from the HMIS database. 


\section{Section 2 \\ Risk Assessment Methodology}

The purpose of this study is to determine and characterize the risks associated with the transportation of specific hazardous materials in the United States. For this analysis, hazardous materials are categorized into three distinct classes: (1) TIH materials, (2) flammable materials, and (3) explosives. Toxic-by-inhalation materials, which are both toxic and volatile, quickly evaporate and therefore pose significant inhalation hazards. Hazards from flammable material releases arise from two potential consequences: (1) burning of the material in a liquid pool fire, a vapor cloud fire, or a fireball resulting from a vapor cloud explosion, and (2) explosion due to ignition of a confined vapor cloud or a boiling liquid expanding vapor explosion. The principal hazard associated with burning of the material is thermal radiation, whereas hazards associated with an explosion of the material are blast overpressure (i.e., pressure disturbances due to the blast wave) and flying debris. Fatality and injury statistics for both flammable liquids and flammable liquefied gases, including LP gas, suggest that hazards due to thermal radiation are much greater than those due to an explosive force. Similarly, the hazards for explosive materials include both thermal and explosive effects, although hazards due to explosive force typically equal or exceed those due to thermal radiation.

Historical data from the HMIS database demonstrate that risk from flammable liquids occurs primarily as a result of fatalities and injuries associated with the transportation of gasoline (Section 3). The nature of such risk leads to several fatalities and tens of injuries every year. While a gasoline accident could potentially involve 50-100 fatalities, risk from the transportation of gasoline is clearly driven by frequent accidents that involve only a few fatalities. This type of risk is called high-probability/low-consequence risk. Because of this aspect of gasoline transportation risk and because many incidents have occurred, the historical record provides an excellent representation of the national risk profile.

Toxic-by-inhalation transportation risk differs significantly from that of gasoline. Although numerous transportation incidents involving TIH chemicals have occurred, TIH transportation risk is largely driven by catastrophic accidents that have a low probability of occurrence. Because of the low-probability/high-consequence nature of TIH risk, the true nature of TIH transportation risk cannot be estimated from the historical record alone because the statistical sample of accidents that drives the risk within the historical record is very low to nonexistent. Therefore, we conducted a detailed analysis of risk associated with TIH chemical transportation in the United States, as discussed in detail in this section.

In the intermediate range between the high-probability/low-consequence flammable liquid risk and the low-probability/high-consequence TIH risk is the risk associated with the transportation of liquefied flammable gases and explosives. Incidents that involve these materials have the potential for substantially greater consequences than those 
involving flammable liquids; however, such consequences are substantially less than those for many TIH materials. For example, a worst-case accident involving a gasoline tank truck could result in about 50 fatalities, whereas a similar incident involving an LP gas tank truck or an explosives shipment could result in more than 250 fatalities. On the other hand, a worst-case incident involving a chlorine tank truck could result in a few thousand fatalities. Fortunately, the frequency of these catastrophic events decreases substantially from perhaps 1 in 25 years for gasoline to 1 in 1,000 years for LP gas to 1 in 100,000 years for chlorine. To investigate these issues further, we extended the TIH analysis to include the transportation of both LP gas and explosives via highways. To provide comparative information for gasoline, we have constructed injury and fatality distributions resulting from the transportation of gasoline by using a statistical approach that directly uses historical fatality and injury data.

This section discusses in detail the overall approach undertaken in the NTRA as applied to TIH materials, liquefied flammable gases, gasoline, and explosives. Section 2.1 defines risk and discusses the concept of national risk. Section 2.2 provides an overview of the risk assessment process, including the conceptualization of the problem and the use of available data. Section 2.3 outlines the analysis of TIH chemicals used in this study. This section also introduces and describes the CASRAM (Chemical Accident Statistical Risk Assessment Model) quantitative risk assessment model developed by the University of Illinois and Argonne National Laboratory for transportation and illustrates the use of the model in the NTRA. Sections 2.4 and 2.5 describe the analysis of flammable materials and explosive materials, respectively. Section 2.6 lists assumptions and limitations of the NTRA analysis.

\subsection{Definition of Risk and Application on a National Basis}

The risk associated with a given activity is governed by two independent components: (1) the various hazards associated with that activity and (2) their respective probabilities of occurrence. In the transportation of hazardous materials, the hazard could be a measure of consequence severity should a release occur.

To elucidate various terms associated with the risk assessment process, as well as to illustrate how the risk analysis process is applied on a national scale, we consider the risk associated with the transportation of chlorine, a TIH material. Bne measure of the transportation risk (or how the risk is quantified) of chlorine, for example, could be the total number of people exposed to a set threshold concentration of chlorine. Another measure could be fatalities that result from inhalation. To illustrate the application of this idea, we considered the risk associated with a hypothetical shipment of chlorine. We assumed (1) that the potential consequences that could result from a chlorine release from this shipment are the exposure of 1, 100, or 10,000 people to the concentration threshold defined by the Emergency Response Planning Guideline - Level 2 (ERPG-2) and (2) that the probability that these exposures will occur is 1 in 100, 1 in 1,000, and

3 In this report, only the risk associated with inhalation effects will be considered for TIH chemicals. 
1 in 10,000, respectively, per shipment. A convenient, often used risk measure is the average number of persons exposed. For this case, this average risk is easily calculated by summing the consequences $(N)$ and multiplying by their respective probability of occurrence $(P)$ :

$$
\text { Risk }=\sum_{i=1}^{3} N_{i} P\left(N_{i}\right)=1(1 / 100)+100(1 / 1,000)+10,000(1 / 10,000)=1.11 .
$$

Therefore, the average risk of this shipment, denoted as persons exposed, is 1.11. Although average exposure is a convenient way to express the risk, this example illustrates another important consideration; namely, risk can be driven by low probability/high-consequence events, especially for $\mathrm{TIH}$ transportation. In this example, the probability of exposing 10,000 persons is very small compared with the probabilities associated with the lower-consequence events. However, more than $90 \%$ of the total risk is attributed to the high-consequence (i.e., 10,000 exposed persons) event. Although this example is purely hypothetical, the results of the NTRA TIH risk assessment reflect this aspect of TIH transportation risk.

Of course, analyzing risks from a single transportation shipment is significantly more complicated than the example given above because the factors that influence the risk, such as release amount, accident probability, meteorology (which strongly affects release rate into the atmosphere and dispersion downwind), and population density, vary both temporally and geographically along a shipment route. As such, these parameters are actually continuous distributions. Therefore, the risk is also a distribution. Deterministic analyses that attempt to fix various input parameters to average values and derive an average risk value are fundamentally flawed because they ignore the true range of possible consequences. For cases where risk is strongly affected by low-probability/highconsequence events (e.g., for TIH transportation), such techniques can easily lead to erroneous conclusions.

The quantitative risk assessment used in the NTRA and outlined in the remainder of this section is explicitly designed to model the millions of possible release scenarios and consequences that could occur as a result of transporting hazardous materials. This capability allows the distribution of risk, as well as the probability of high-consequence events, to be determined in a realistic manner. While the average risk calculated in the example is clearly useful for comparing various transportation alternatives, it is the distribution of risk that is often of greater interest. Furthermore, without a statistical approach that takes into account the entire range of possible accident scenarios, the average risk of various transportation scenarios cannot be determined accurately.

In the NTRA, the analysis for a single shipment is extended to calculate transportation risk as a result of all shipments of chlorine in the United States for a given time period. The calculation of risk is essentially the same, except that the transportation of chlorine is modeled along its major commodity flow corridors. The resulting risk distribution, therefore, characterizes risk for all chlorine shipments in the United States 
for that time period. In this process, consideration of each actual chlorine shipment in the United States is not possible because commodity flow information is not available at that detail, and the computational requirements for such an analysis are prohibitive. Therefore, the national transportation of chlorine is modeled by approximately 50 hypothetical shipments that represent transportation along the primary highway and rail transportation corridors for chlorine determined from a detailed commodity flow study. By analyzing the risk of these representative chlorine shipments and scaling the results to account for the total national commodity flow (by varying the frequency of shipment), we can estimate the national risk profile for chlorine transportation.

\subsection{Overview of the NTRA Methodology}

This section provides an overview of the general quantitative risk assessment methodology used to develop the national risk profiles for TIH chemicals, LP gas, and explosives. The NTRA methodology is illustrated schematically in Figure 2.1. For each hazardous material, available commodity flow data and shipment information are analyzed to determine the primary shipping corridors, shipment sizes, and overall shipment volumes for the material. Commodity flow information for highway transportation is taken from the 1977 Commodity Transportation Survey (CTS) (U.S. Department of Commerce [DOC] 1981) and the 1993 Commodity Flow Survey (CFS) (DOC 1996), together with publicly available industry information. Commodity flow estimates for rail transportation are developed from Association of American Railroads (AAR) waybill records from 1986 to 1995. Because of the less regulated nature of highway transportation, the large number of companies involved in transportation, and the lack of available data, commodity flow estimates for highway transportation contain substantial uncertainty for many materials (Section 2.6). On the other hand, commodity flow data for rail transportation are very well characterized because railroad waybills are subject to mandatory reporting, and the collected data are available to the public.

Commodity flow and shipment information are combined to provide a set of representative highway and rail shipments for each of the hazardous materials considered in this study. The exact number of shipments modeled for each chemical and transportation mode depends on the amount of information available and varies between 10 and 33. The shipment attributes defined in this process are origin, destination, amount of material shipped, container type, and frequency of shipment. The frequency of shipment is assigned so that the overall national commodity flow of a particular material is represented by the shipments considered for that material to the best degree possible with the available information. The shipment frequencies are weighted so that the risk is correctly distributed among the principal commodity flow corridors for the material. The HIGHWAY 3.3 and INTERLINE 5.0 routing models are used to determine the shipping routes and the population density distributions along the route from the origin/destination $(\mathrm{O} / \mathrm{D})$ pairs. For highway transportation, the routes are assigned by using applicable hazardous material routing constraints together with a minimum travel time criterion. For rail transportation, origin and termination railroads are chosen so that the pass-through 


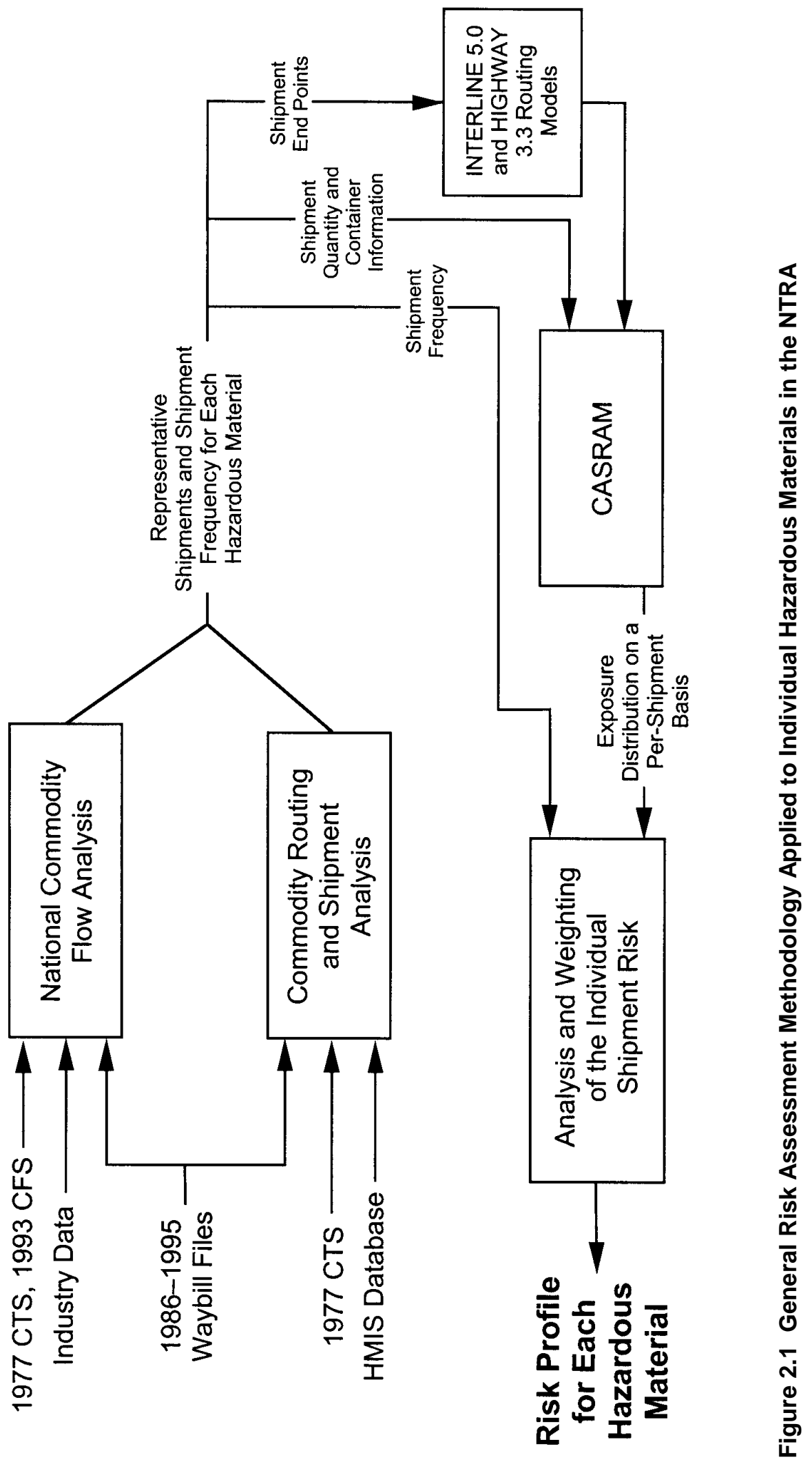


states in the route match those that occur most frequently on the waybills for which that route is characterized (Section 4.2.3). In this manner, actual rail shipment routes are approximated with a greater level of detail.

The next step is to apply the CASRAM risk assessment model to estimate the statistical distribution of the following:

- Persons exposed to both the ERPG-2 and LC50 (Lethal Concentration for 50\% of the population concentrations as a result of transportation-related TIH releases),

- Persons injured or killed due to thermal radiation exposure from LP gas releases, and

- Persons injured or killed due to thermal and blast effects from explosives detonations.

The NTRA considers two categories of releases: (1) releases that occur as a result of traffic accidents and train derailments and (2) releases that occur while en route from the origin to the destination, but not due to accidents or derailments (for TIH materials only). The latter category includes releases that occur, for example, as a result of cargo shifts, valve failures, and corrosion-induced container failure. As discussed in Section 3, the second category of releases is considerably more common; however, release amounts for incidents that involve accidents and derailments are considerably higher than those that involve the first category of releases. Thus, the overall risk due to releases in accidents and derailments is substantially greater than those that involve en route accidents.

As described in greater detail in Section 2.3.2, CASRAM simulates accidents along a prescribed route. CASRAM uses statistical distributions of accident scenario attributes (i.e., time, location, release amount, local population density) together with meteorological, chemical property, and chemical toxicology databases to develop statistical distributions for exposure, injury, or fatality probability. The statistical information for the various shipment routes is then combined by taking the shipment frequency to determine the distributions of exposed population for the transportation of the particular hazardous material during a 10-yr period. Details of this methodology as applied to each class of hazardous materials are discussed in the remainder of this section and in Appendix A.

\subsection{Toxic-by-Inhalation Materials}

\subsubsection{TIH Chemicals Selected for Detailed Analysis}

For detailed analysis in this study, we selected the TIH materials most often involved in hazardous materials incidents as well as those with the highest shipping volumes. To a considerable degree, these two criteria are related because the number of incidents is directly proportional to the total commodity flow when other factors remain constant. Table 2.1 provides a summary of incidents that involved TIH materials as catalogued in the HMIS database for 1985 to 1995 . Chemicals are identified by both proper name and United Nations (UN) number. Statistics are given for both highway and rail 


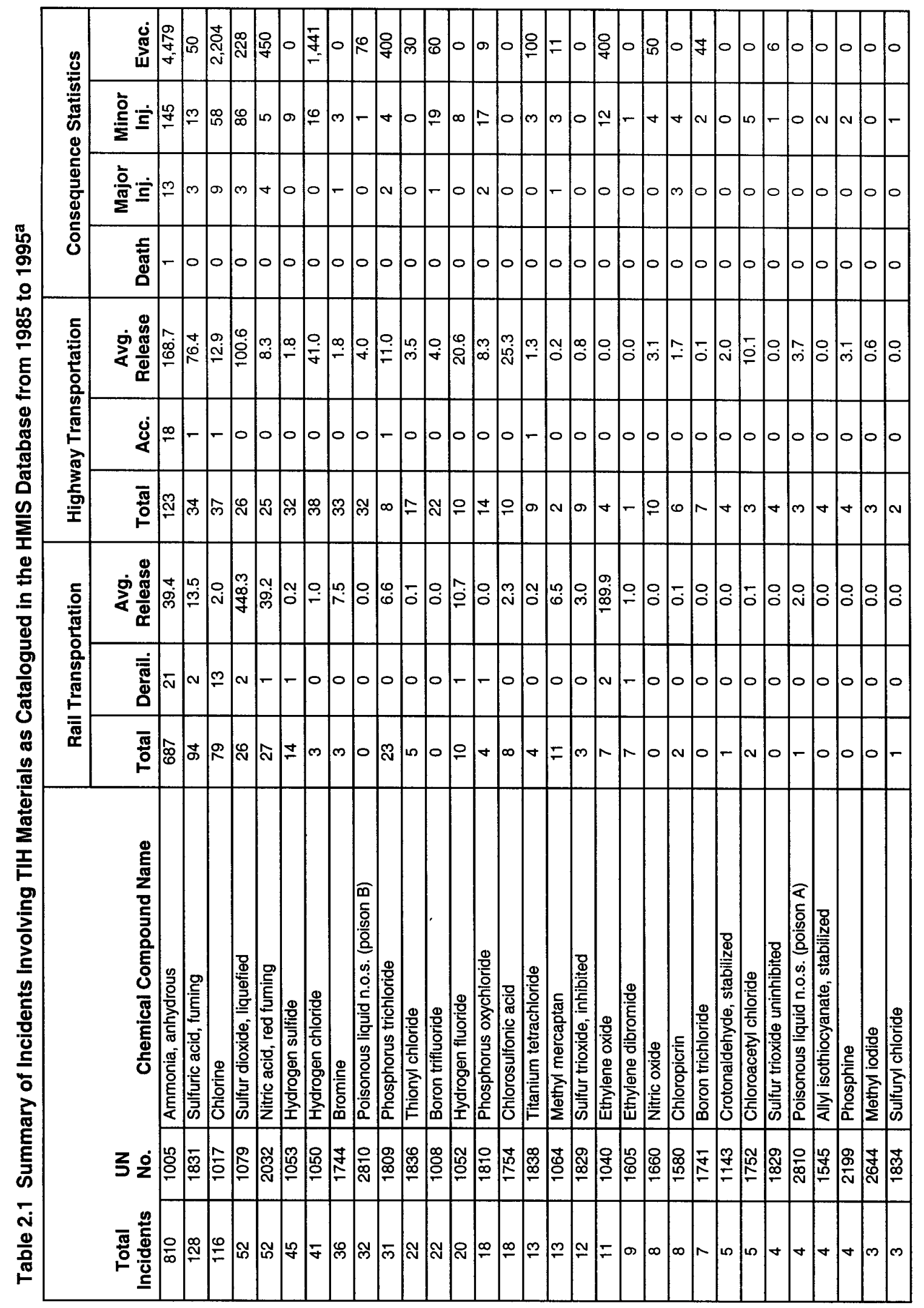




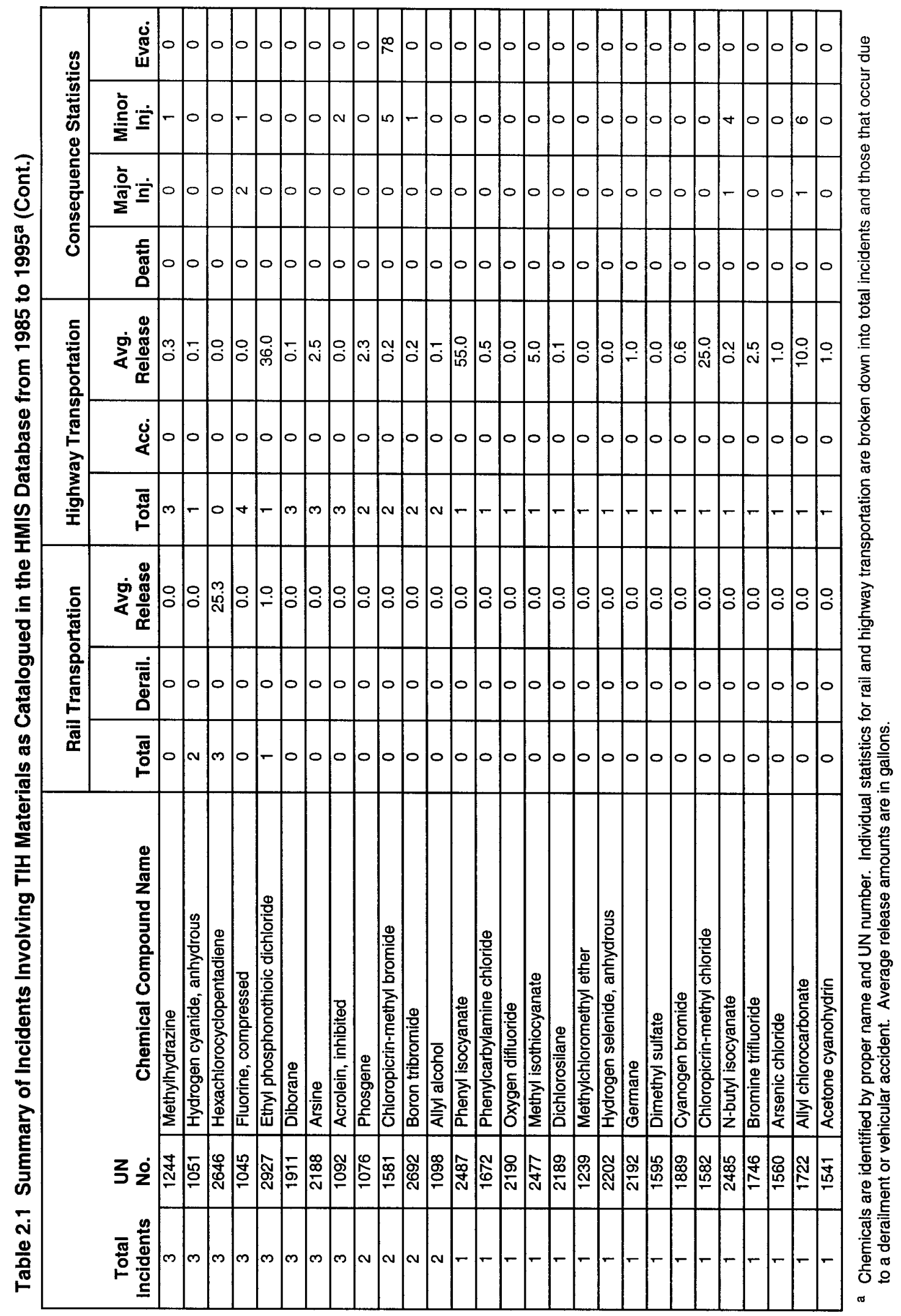


transportation and include the total number of incidents resulting from vehicular accidents or derailments, along with the average release amount. Fatality, injury, and evacuation statistics for highway and rail are also listed.

On the basis of statistics shown in Table 2.1, several interesting observations can be made. First, although more than 175 TIH chemicals are transported within the United States, only about 60 have been involved in transportation incidents from 1985 to 1995. Furthermore, the top five TIH materials in terms of HMIS incident reports (anhydrous ammonia, fuming sulfuric acid, chlorine, $\mathrm{SO}_{2}$, and fuming nitric acid) account for about $75 \%$ of the total number of TIH incident reports considered in this study $(1,158$ of 1,563). The fatality and injury statistics show 1 fatality, 46 major injuries, 428 minor injuries, and 8,675 persons evacuated. The top five TIH chemicals in terms of incident frequency were responsible for the single fatality, $71 \%$ of injuries, and $85 \%$ of persons evacuated due to all incidents that involved TIH materials. For all fatalities, injuries, and evacuations listed in the HMIS database, TIH materials are responsible for $1 \%$ of fatalities, $12 \%$ of major injuries, $11 \%$ of minor injuries, and $9 \%$ of persons evacuated.

These top five chemicals also dominate the national commodity flow for TIH materials transported by both highway and rail. Two other materials, ethylene oxide and $\mathrm{HF}$, also appear in the top five TIH materials transported by rail (Appendix B). In particular, HF is substantially more toxic than ethylene oxide and is of considerable interest to the scientific and regulatory community (e.g., U.S. Environmental Protection Agency [EPA] 1993). On the basis of the above factors, HF was included in addition to the top five TIH materials in terms of HMIS incident reports. These six materials comprise the pool of TIH materials for which detailed risk assessments were completed.

\subsubsection{CASRAM Risk Assessment Model}

CASRAM is a statistical, chemical accident, risk assessment model that predicts distributions of hazard zones (i.e., areas in which a threshold chemical concentration is exceeded) resulting from hazardous material shipment or storage. The model uses various shipment or storage attributes along with an extensive meteorological database to statistically model hazardous material release rates and downwind dispersion. Together with health criteria (i.e., toxicological threshold concentrations) for the applicable hazardous materials, distributions of hazard zones are generated stochastically through Monte Carlo sampling of accident scenario parameters. CASRAM is specifically designed for the statistical analysis of hazardous material release problems. This feature, in particular, separates CASRAM from other hazardous material release models, such as SCIPUFF (Defense Threat Reduction Agency 1999), ALOHA (EPA 1999), and HGSystems (Post 1994). Rather than specifying a deterministic measure of risk, CASRAM determines the distribution of possible outcomes, thus allowing the probability of a particular consequence to be identified within the limits of the statistical data used. 
The assessment of risk from airborne hazardous materials can be naturally divided into three components:

- Characterization of the release rate into the atmosphere for the materials involved,

- Estimation of dispersion downwind of the release location, and

- Translation of atmospheric concentrations of the materials involved into specific health effects.

This section briefly reviews the physics of hazardous material releases, highlighting important issues associated with each phase of the analysis. Various analytical procedures used within CASRAM are also described without delving into technical aspects of the numerous physical submodels within CASRAM. Appendix A provides a technical discussion of the physical submodels within CASRAM. Additional details are available in Brown (1997), Brown and Dunn (1998), and Brown et al. (2000).

\subsubsection{Overview of Model Philosophy}

For the NTRA, CASRAM was used to analyze approximately 40 to 60 representative shipments for each hazardous material. For each shipment, the amount of material and the shipment end points were specified in the NTRA commodity flow analysis. Specific routes and corresponding population-density data were generated by using standard routing models. For highway transportation, the HIGHWAY 3.3 model was employed, whereas for rail transportation, the INTERLINE 5.0 model was used (Johnson et al. 1993a,b, respectively).

Although CASRAM is structured differently to optimize execution time, the flowchart shown in Figure 2.2 conveniently illustrates the procedure for analyzing the risk for a TIH chemical shipment due to accidents and derailments. The model begins by reading the shipment and route information and initializing model variables. The first route segment is then considered. A random number is selected to assess whether an accident occurs based on the local accident probabilities as dictated by segment length, road type, and population density. In the likely event that an accident does not occur, the next segment is considered. This process continues until either (1) the shipment is completed or (2) an accident occurs. When completed successfully, the shipment is reinitiated from the origin, and the process continues. Because of the low probability that an accident will occur, the shipments considered in the NTRA typically require hundreds or thousands of trips before an accident might occur. 


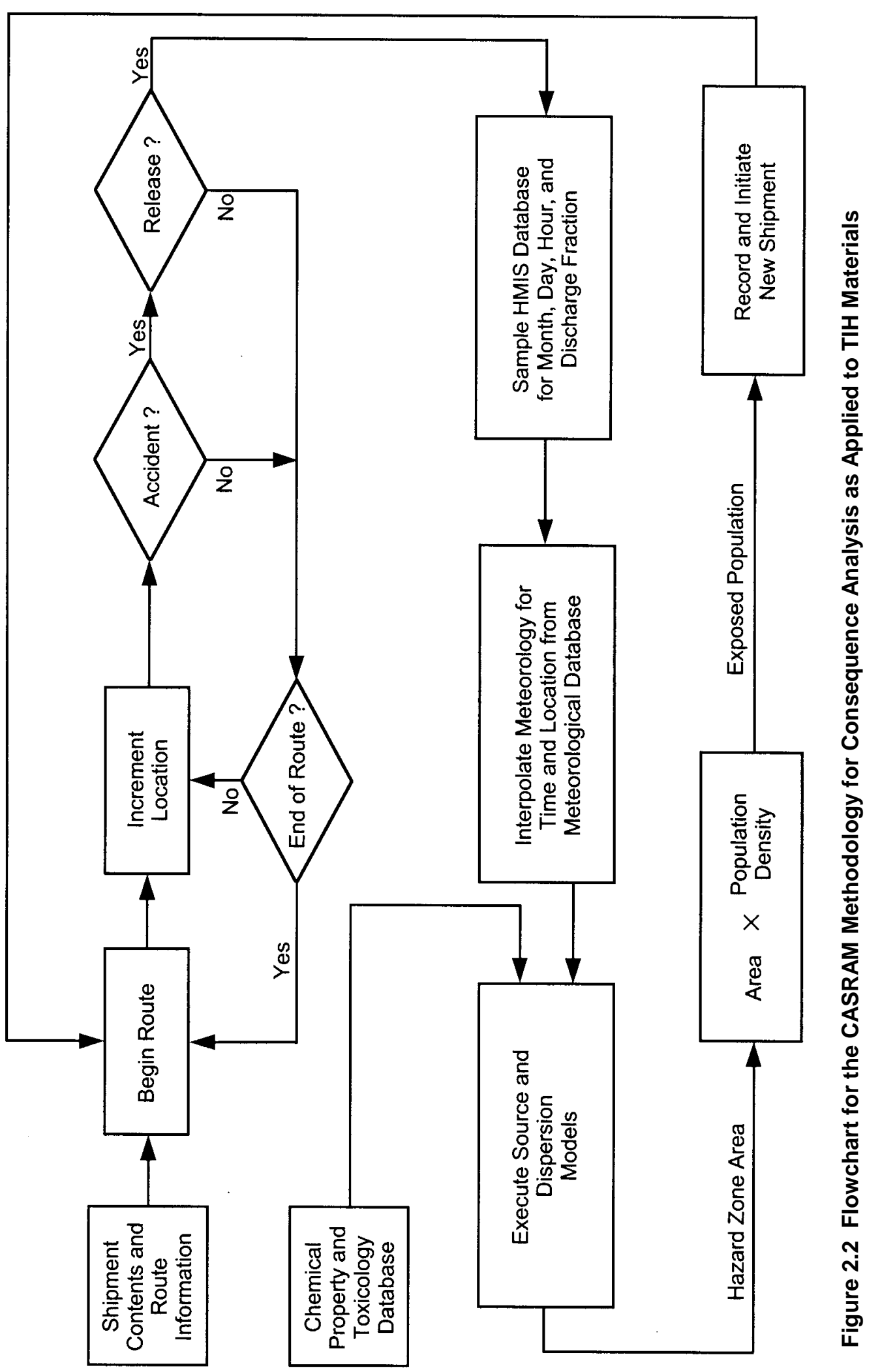


If an accident occurs, another random number is selected and compared with the probability of a release. These release probabilities are given as a function of freight and container type. If a release does not occur, the segment-by-segment analysis procedure continues until another accident occurs. If, however, a release occurs, emission rate and dispersion models determine the size of the hazard zone. By taking the size of the hazard zone and using local population density information, we can determine the number of people exposed to a threshold concentration of the hazardous material (i.e., the health criteria).

For each accident, the month, day, and hour of the release are selected randomly on the basis of the temporal distributions of accidents in the HMIS database (Section 3.3). The time of the release and its location allow the selection of appropriate meteorological data from a preprocessed meteorological database. On the basis of the container type involved and the transportation phase of the release (i.e., releases during accidents, while en route but not during an accident, or while loading or unloading), the discharge fraction is estimated by sampling the appropriate discharge fraction distribution from the HMIS database (Section 3.2). For releases from rail cars, the hole size that regulates the release rate into the atmosphere is also selected by sampling hole-size distributions based on the analysis of Raj and Turner (1993).

The emission rate model then uses the release amount, local meteorological data, and chemical property data to calculate average emission rates for 15, 30, and $60 \mathrm{~min}$. These rates are then used in the dispersion model to determine the hazard zone area. The hazard zone area is multiplied by the local population density to determine the number of exposed persons. For releases where the hazard zone extends several miles, the population exposed is calculated by using several different population densities along the hazard zone path rather than a single value at the accident site. In addition, for large releases in which the plume travel time extends over an hour, temporal variations in meteorological parameters are incorporated into the dispersion analysis.

For each representative shipment, this process continues until 10,000-50,000 releases have been modeled. Each release provides an individual estimate of ERPG-2 exposures or fatal exposures. For hazardous materials shipments typical of those considered in this study, the 10,000-50,000 modeled releases represent a statistical sample that corresponds to more than 1 billion actual shipments of the material considered. As discussed in Section 2.2, the national transportation of each hazardous material considered in detail in this report is modeled by using 40-60 representative shipments, which are independently modeled with CASRAM. By considering the annual shipment frequency of the representative shipments, it is possible to determine that the statistical analysis developed in this study represents a 10 million-100 million-yr sample of accident scenarios and consequences for the materials considered.

Extensions of the CASRAM methodology, which include LP gas releases and explosive detonations, are outlined in Sections 2.4 and 2.5, respectively. 


\subsubsection{Estimation of Release Rate}

Materials are shipped as solids, ordinary liquids, compressed gases, or liquefied gases. To a large degree, the release rate of the material depends on the shipment state. Because of their low volatility, solids typically exhibit very low release rates. Unless the vapor of the solid is extremely toxic, inhalation risks posed by solid materials are low relative to hazardous materials in other shipment states. Consequently, solids are usually not considered sources of significant inhalation risk. ĐThe remaining shipment or storage states are illustrated in Figure 2.3 and are discussed below.

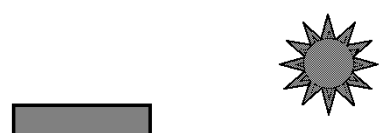

Liquid

$\uparrow \uparrow \uparrow \uparrow$ ${ }^{1}$ (a)

Pool Evaporation

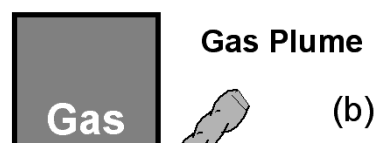

(b)

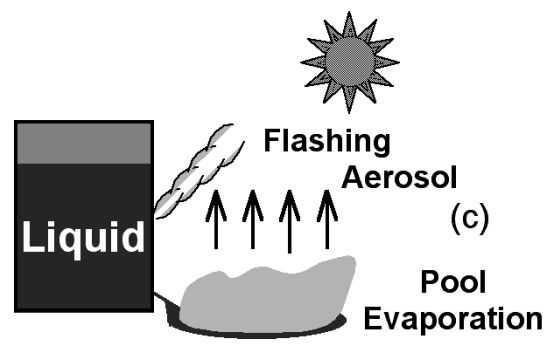

(c)

Figure 2.3 Three Source Types for Inhalation Risk: (a) Ordinary Liquids, (b) Compressed Gases, and (c) Liquefied Gases

Liquid materials are emitted to the atmosphere through pool evaporation (Figure 2.3a). The pool evaporation rate depends on many factors. For volatile liquids, the governing factors in determining the release rate in approximate order of importance include (1) vapor pressure of the liquid, (2) available energy, (3) wind speed, and (4) atmospheric stability. In the case of low-volatility liquids (i.e., those characterized by low vapor pressure), meteorology replaces available energy in relative importance. Highly volatile liquids can evaporate very quickly (within minutes), cooling the pool in excess of $30^{\circ} \mathrm{C}$ below the ambient temperature. In such cases, the evaporating material can actually freeze, thereby reducing the evaporating rate.

Compressed gases are released in a so-called "blowdown" process (Figure 2.3b). The blowdown process usually empties the container rapidly and, in severe accidents, can result in a near instantaneous release. All else being equal, release rates for compressed gases are many times higher than those for ordinary liquids. The exceptions to this rule are valve leaks and minor cracks, for which release rates can be very small. Valve failures are the most common release mechanism for en route/nonaccident releases.

The most catastrophic form of release involves liquefied gases (Figure 2.3c). This form of release is divided into two phases. In the initial phase, the flashing and entrainment phase, a fraction of the material (usually $0 \%-30 \%$ of the total) is

4 Exceptions to this general rule include solids that emit a toxic gas upon exposure to water. Release of these materials in water can present significant inhalation hazards. 
instantaneously vaporized upon exiting the vessel because the pressure is suddenly reduced. Because the material expands rapidly, much of the remaining liquid that exits the vessel is broken into tiny drops, forming an aerosol. The vapor typically entrains substantial quantities of this aerosol with the larger droplets quickly settling to the ground or "raining out." This aerosol usually evaporates quickly when exposed to air, cooling the vapor/air mixture to the point where the density of the mixture can become considerably heavier than air. In the second phase, the liquid that remains on the ground or surrounding surfaces is released through evaporation. Because the vapor pressures for such materials are generally well above atmospheric pressure, the evaporation phase is usually short, especially in comparison with the pool evaporation phase for materials that are liquids at atmospheric pressure. Because large quantities of material are typically involved, liquefied gas releases yield the largest release rates in comparison to liquid and compressed gas releases.

The emission rate model of CASRAM determines hazardous material release rates for the spill and/or vaporization scenarios previously described. Pool evaporation within CASRAM is determined by using a time-dependent, energy-budget model that carefully accounts for the key air-pool-ground energy fluxes that govern the evaporation rate. Heat transfer to and from the pool is treated via explicit consideration of solar radiation, air convection, ground conduction, and evaporative heat loss from the pool. The necessary transfer coefficients for evaporation are provided by a chemical property database and a preprocessed meteorological database. Compressed gas releases are treated by using semi-empirical blowdown relationships based on compressible flow theory. Liquefied gas releases are treated by first calculating the flash fraction of the exiting material and then determining the fraction of the remaining liquid that is entrained into the flashed vapor. This entrainment fraction is calculated by using empirical relationships based on the discharge kinetic energy of the two-phase mixture. Released material that (1) does not flash to vapor and (2) is not entrained in the vapor cloud is assumed to deposit on the ground. Release of this deposited material is modeled as a pool evaporation problem.

To help characterize release scenarios and estimate release rates, the source model in CASRAM accesses a database of the key physical properties for more than 200 chemical compounds. The current version of CASRAM contains statistical empirically based discharge fractions that depend on container type and size and on transportation phase. These discharge fractions were developed by using data contained in the HMIS (Section 3.2). In addition, several other parameters, such as pool depth, are treated by using statistical information rather than deterministic quantities.

\subsubsection{Atmospheric Dispersion Modeling}

In the atmospheric dispersion modeling phase of the problem, the hazardous material release rate and the prevailing meteorology are used to estimate chemical concentrations at various downwind distances. For passive dispersion (i.e., that in which buoyancy of the plume is insignificant), downwind concentrations are linearly related to (1) the release rate for a continuous release or (2) the release amount for an instantaneous release. The dispersion of the material depends a great deal on the meteorology. 
Generally, dispersion is very good during a day with no cloud cover (i.e., maximum surface heating) and is very poor during a night with clear skies and light winds. Given the same release rate, the ground-level material concentrations from a surface release can vary by three orders of magnitude between these two extremes. For moderate-to-high wind speeds and/or overcast conditions, atmospheric dispersion falls between these two limiting cases.

Estimating dispersion is a two-step process. Step 1 involves characterizing the meteorology from the available surface observations, and Step 2 involves estimating transportation and dispersion from the applicable meteorological parameters. Step 1 is often accomplished with a meteorological preprocessor, which is a series of algorithms that takes raw meteorological data (e.g., wind speed, temperature, cloud cover) and site information (e.g., roughness length) and calculates parameters necessary for estimating dispersion. These parameters are either in the form of stability classes or fundamental turbulence measures of the atmospheric boundary layer (e.g., friction velocity, surface heat flux, inversion height).

For transportation risk assessment studies, CASRAM uses a preprocessed meteorological database that includes hourly meteorological parameters for 64 cities in the United States from 1985 to 1989 (Figure 2.4). This database was generated with SEBMET (Surface Energy Budget METeorological model; Brown 1997; Brown and Dunn 1998). SEBMET is a meteorological preprocessor that uses routinely available meteorological data, together with site characteristics, to estimate surface-sensible and latent heating of the atmosphere, friction velocity, and mixing height. SEBMET is based on a detailed model of the energy budget at the surface of the Earth, along with an integral model that predicts the growth of the daytime convective boundary layer.

In CASRAM, the dispersion calculation is broken into two components: vertical turbulent dispersion and horizontal turbulent dispersion. Vertical turbulent dispersion is treated with a Lagrangian-integral model parameterized in terms of mean plume height, average advection velocity, and a dimensionless travel time (Brown 1997). These parameters are expressed as integral equations in terms of plume travel time and atmospheric boundary layer parameters. Continuous releases are treated as plumes, and instantaneous releases are treated as puffs. Horizontal turbulent dispersion is represented with Gaussian relationships parameterized in terms of the Lagrangian time scale and lateral wind direction fluctuations. Continuous release calculations are "straight line" because CASRAM currently does not consider terrain effects.

\subsubsection{Assessment of Health Effects}

The third aspect of assessing the inhalation consequences of accidental hazardous material releases is defining the health end point, which is typically represented by a threshold concentration referred to as a health criterion. For most substances, established health criteria values are based on a critical review of the animal study data. Several sets of published health criteria can be classified into two groups: occupational health and emergency response. Occupational health values comprise a majority of health criteria 
$\Delta$

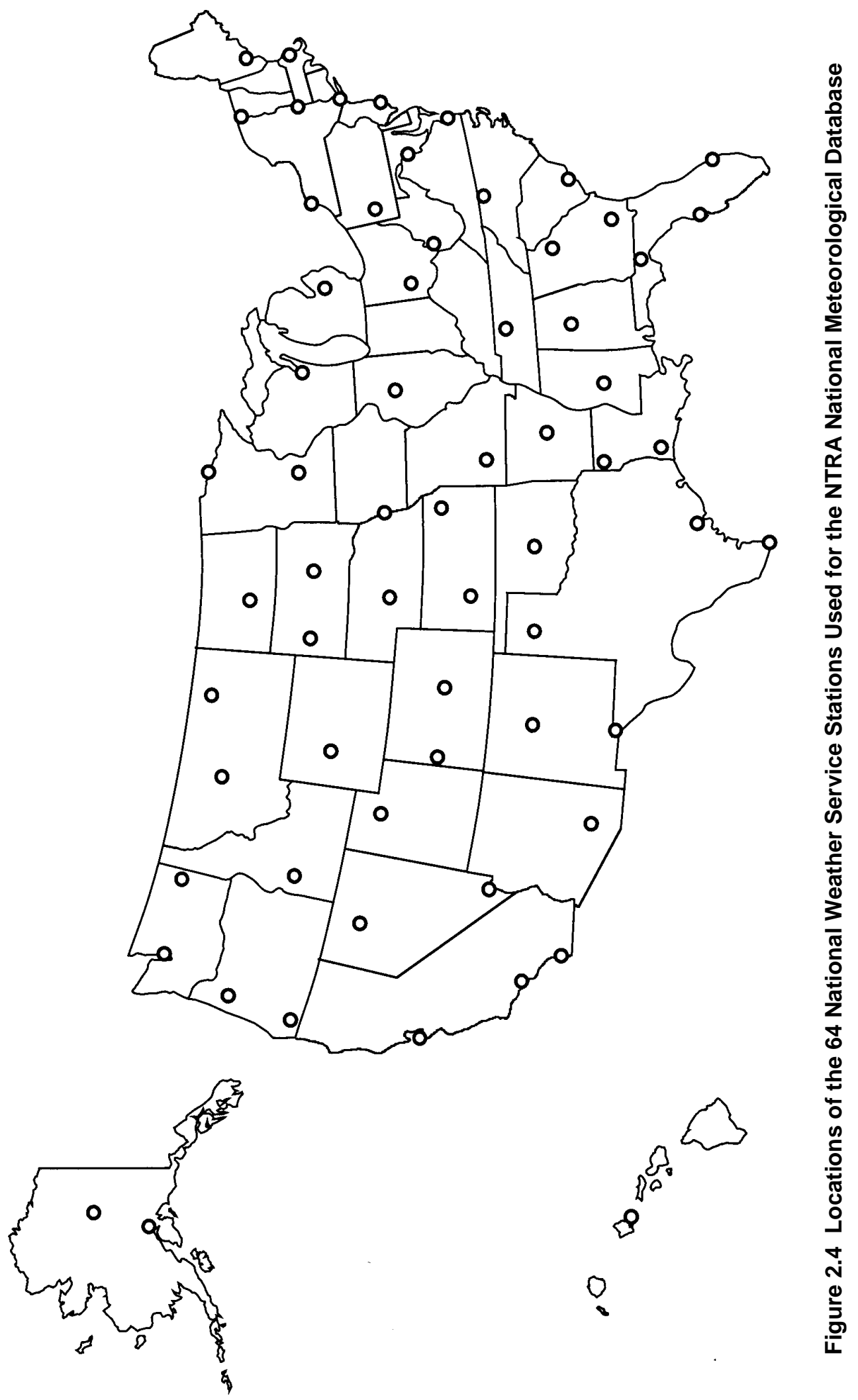

26 
data and are typically specified for exposure times ranging from 1 to $8 \mathrm{~h}$. Because of their long exposure times and applicability for chronic exposure, they are not generally used for assessing consequences due to accidental hazardous materials releases unless no other health information is available for the chemical in question.

Emergency response values are for acute exposures of $1 \mathrm{~h}$ or less. For emergency response applications, the American Industrial Hygiene Association (AIHA) ERPG health criteria are widely considered to be the best values available. ERPG values are specified for 1-h exposures. Each hazardous material included is associated with three ERPG values: (1) ERPG-1, which denotes the maximum airborne concentration at which only mild, transient health effects or clearly objectionable odor are observed;

(2) ERPG-2, which denotes the maximum airborne concentration at which most persons could be exposed without developing irreversible or other serious health effects or symptoms that could impair their ability to take protective action; and (3) ERPG-3, which denotes the maximum airborne concentration at which most persons could be exposed without developing potentially life-threatening effects. Currently, ERPG values are available for about 100 chemicals, but values for new chemicals are being added every year. For hazardous materials that do not have ERPG values, protective action values can be approximated by using alternate health criteria, such as the $\mathrm{LC}_{50}$.

Although CASRAM does not include specific models for selecting health criteria (i.e., it is a user-specified parameter), it does allow for specification of multiple health criteria for each hazardous material corresponding to different averaging times and for the treatment of multiple chemical exposures. As a preprocessor to CASRAM, Dunn et al. (1996) have developed a standard hierarchy for selecting health criteria to use for emergency response, including relationships to adjust published health criteria for different averaging times.

Two health end points are identified in the NTRA. The first denotes potential injuries. The health criteria used for this end point is the ERPG-2, which is the same as that used for Protective Action Distances in the Emergency Response Guidebook (DOT et al. 1999). The second health end point is associated with life-threatening injury. Here, the $\mathrm{LC}_{50}$ health criteria are used. To estimate total fatalities, the total population exposed to the $\mathrm{LC}_{50}$ concentration is scaled by a factor of 1.1 to account for persons inside the $\mathrm{LC}_{50}$ hazard zone who are not fatally injured and for persons outside the $\mathrm{LC}_{50}$ hazard zone who are fatally injured. Health criteria for each of these health end points are described in Appendix A.

\subsubsection{Accident Rates and Release Probabilities}

The specification of accident rates and release probabilities has been the subject of extensive efforts in the risk assessment community. Unfortunately, the identification and specification of these events can lead to substantial bias and uncertainty in risk assessment results if not performed carefully. For the NTRA, we reviewed previous studies to assess the current knowledge for specifying accident rates and release probabilities. After finding inconsistencies among several published studies, we 
developed an alternative approach to the problem on the basis of an analysis of national commodity flow information and hazardous material release data. This approach largely eliminated the large bias errors in accident and release probabilities that have often resulted from combining different (and sometimes incompatible) data sources. The analysis of highway and rail accident and release probabilities is presented in the following sections.

\subsubsection{Highway Transportation}

2.3.3.1.1 Accident Rates. Accident rates are determined by analyzing historical data. Detailed analyses of several publicly available databases by many workers has made it possible to specify accident probabilities on a per-mile basis as a function of road type, truck type, and population density. One of the most detailed analyses of such data was conducted by Harwood and Russell (1990). On the basis of computerized data files from three states - California, Illinois, and Michigan, Harwood and Russell calculated the accident probabilities by using the number of reported accidents and the total number of truck-miles and then segregated the results by highway class. The results of their analysis, which is the accident rate per million truck-miles traveled, are provided in Table 2.2.

Table 2.2 Truck Accident Rates for California, Illinois, and Michigan ${ }^{a}$

\begin{tabular}{|cccccc|}
\hline Area & Highway Class & California & Illinois & Michigan & Average \\
\hline Rural & Two-lane & 1.73 & 3.13 & 2.22 & 2.19 \\
Rural & Multilane undivided & 5.44 & 2.13 & 9.50 & 4.49 \\
Rural & Multilane divided & 1.23 & 4.80 & 5.66 & 2.15 \\
Rural & Freeway & 0.53 & 0.46 & 1.18 & 0.64 \\
Urwan & Two-lane & 4.23 & 11.10 & 10.93 & 8.66 \\
Urban & Multilane undivided & 13.02 & 17.05 & 10.37 & 13.92 \\
Urban & Multilane divided & 3.50 & 14.80 & 10.60 & 7.47 \\
Urban & One-way street & 6.60 & 26.36 & 8.08 & 9.70 \\
Urban & Freeway & 1.59 & 5.82 & 2.80 & 2.18 \\
\hline
\end{tabular}

a Accidents per million truck-miles; average weighted by total truck-miles.

Source: Harwood and Russell (1990).

In a review of available accident data, Rhyne (1994) noted that the accident rates of Harwood and Russell generally agreed with the results of Smith and Wilmot (1982) and Graf and Archuleta (1985). However, accident rates from other studies differed considerably. For instance, in a study of accident rates for single- and doublecombination trucks, Jovinas et al. (1989) obtained accident rates a factor of $\sim 2$ to 3 higher than those of Harwood and Russell for interstate and state highways (Table 2.3). Saricks and Kvitek (1994), on the other hand, calculated significantly lower accident rates than those of Harwood and Russell through a detailed analysis of (1) the 50-T Master File of Accidents of Motor Carriers of Property compiled by the Office of Motor 
Table 2.3 Accident Rates for Single- and Double-Combination Trucks for Interstates, State Highways, and Local Streets ${ }^{a}$

\begin{tabular}{|lcc|}
\hline \multicolumn{1}{c}{ Road Type } & Single & Double \\
\hline Interstate & 3.8 & 3.5 \\
State highway & 28.5 & 18.8 \\
Local street & 15.7 & 10.0 \\
\hline
\end{tabular}

a Accidents per million truck-miles. Source: Jovinas et al. (1989).
Carriers to provide accident frequency data, and (2) a variety of Federal Highway Administration (FHWA) commodity flow information to estimate total vehicle-miles.

Although different accident rates can be calculated from the same database because analytical procedures differ, the primary source of differences in reported accident rates is the reporting threshold. For instance, the reporting threshold for accidents analyzed by Harwood and Russell was between $\$ 200$ and $\$ 500$, depending on the state. The reporting threshold

for accidents analyzed by Saricks and Kvitek (1994), on the other hand, was between $\$ 4,200$ and $\$ 4,900$, depending on the year considered. This factor of 10 difference in reporting threshold most likely accounts for the factor of 2 to 5 lower accident probabilities reported by Saricks and Kvitek.

In the NTRA, the state data of Harwood and Russell were adopted as the basis for accident probabilities. To more closely dovetail with the level of data provided by the HIGHWAY 3.3 model, the Harwood and Russell statistics were divided into two road categories - interstates and noninterstates (state highways) — and three population density categories - urban, suburban, and rural. The noninterstate category combines the two-lane, multilane undivided, multilane divided, and one-way street categories (Table 2.4). In this combined category, all statistics for all road classes are weighted by total truck-miles. Dividing of the detailed Harwood and Russell road category statistics does not markedly reduce the precision of the statistical data because the only noninterstate road class that varies considerably from the average is the multilane undivided category, which only accounts for $5 \%$ of rural truck travel and $18.5 \%$ of urban truck travel. The accident rates for suburban areas are taken as the average of rural and urban areas. The suburban category was added to provide a smooth transition between urban and rural areas.

Table 2.4 Accident Rates for Interstate and Noninterstate Truck Transportation Used in the NTRA

\begin{tabular}{|lccc|}
\hline Category & Population Density & Interstate & Noninterstate \\
\hline Rural & $0<d<326$ & 0.64 & 2.3 \\
Suburban & $326<d<3,326$ & 1.4 & 5.7 \\
Urban & $3,326<d<15,000$ & 2.2 & 9.1 \\
\hline
\end{tabular}

Source: Adapted from Harwood and Russell (1990). 
2.3.3.1.2 Release Probabilities. The release probability is the conditional probability that a release will occur following an accident. Release probability depends on the nature of the accident, the type of cargo involved, and the integrity of the containers. As highlighted in the last section, the exact definition of what constitutes an accident is clearly important in determining accident rate. The definition of accident has an equally important role in determining release probability because it defines the range of accidents considered. This factor is frequently overlooked.

The most widely referenced release probabilities are those of Harwood and Russell (1990), who extended their accident analysis to specify the probabilities of release given an accident. In this phase of their analysis, Harwood and Russell analyzed the FHWA database from 1981 to 1985 . The FHWA database provides information as to whether a truck is carrying hazardous materials and whether a hazardous material release occurred. On the basis of a careful analysis of these data, Harwood and Russell concluded that the probability of a release following an accident is approximately $15 \%$. The breakdown of release probability by cargo type from 1984 to 1985 is given in Table 2.5.

Table 2.5 Distribution of FHWA Accidents Involving Hazardous Materials by Cargo Type, 1984-1985

\begin{tabular}{|lccc|}
\hline Cargo Type & $\begin{array}{c}\text { No. of HAZMAT } \\
\text { Accidents }\end{array}$ & $\begin{array}{c}\text { No. of HAZMAT } \\
\text { Releases }\end{array}$ & $\begin{array}{c}\text { Release } \\
\text { Probability (\%) }\end{array}$ \\
\hline General freight & 741 & 61 & 8.2 \\
Gases in bulk & 259 & 21 & 8.1 \\
Solids in bulk & 40 & 12 & 30 \\
Liquids in bulk & 1,831 & 345 & 18.8 \\
Explosives & 70 & 7 & 10.0 \\
Empty & 220 & 10 & 4.5 \\
Other type & 529 & 62 & 11.7 \\
\hline
\end{tabular}

Source: Harwood and Russell (1990).

Harwood and Russell note that the release probabilities in Table 2.5 most likely represent an upper limit because of the high reporting thresholds of the FHWA accident data. Indeed, a comparison of the accident probabilities of the state data used by Harwood and Russell (1990) with those calculated by Saricks and Kvitek (1994) demonstrate that the accident rate drops by a factor of 3 to 5 when the reporting threshold is increased from the state levels, which ranges from $\$ 200$ to $\$ 500$, to the higher level required by FHWA ( $\$ 4,400$ in 1988). Therefore, the accident probabilities quoted by Harwood and Russell are potentially high by a factor of 3 or more when used with their state-derived accident probabilities. By considering (1) the overall distribution of truck-miles over the road types present in the state-level data considered by Harwood and Russell, and (2) the differences in the reported accident rates between Harwood and Russell and Saricks and Kvitek, we estimate that the release probabilities provided by Harwood and Russell should be lowered by a factor of 3.75 when used with the state accident-rate data. 
To check the validity of this hypothesis, we estimated the probability of a release occurring by using the overall commodity flow data for high-volume hazardous materials and estimating the number of accidents involving these commodities. Then, by using release frequency data from the HMIS database, we estimated the release probability by dividing the number of reported releases by the estimated number of accidents. Although this approach has a considerable degree of uncertainty, it provides a reasonable way to check our hypothesis. This general approach has two significant advantages over the Harwood and Russell method. First, it eliminates bias errors introduced through the choice of accident definition because the number of accidents is estimated from total commodity flow data and accident-rate statistics. Second, this method provides a larger statistical sample with which to look at specific container types. The principal shortcoming of our analysis arises from the overall uncertainty involved in both the commodity flow data and the reported HMIS release frequencies.

In the analysis of highway containers, we considered two general classes of materials: (1) liquefied gases shipped in standard MC 330 and MC 331 cargo tanks and (2) bulk liquids shipped in standard MC 306 and MC 312 cargo tanks. The analyses of release probabilities from each of these container types are discussed below.

Bulk Liquefied Gases. We estimated the release probability for bulk liquefied gases transported in MC 330 and MC 331 cargo tanks by using commodity flow and historical release data for LP gas and anhydrous ammonia, the two most commonly transported liquefied gases in cargo tanks. The results of our analysis are outlined in Table 2.6. Referring to our commodity flow analysis detailed in Section 4, we estimated that the total commodity flow for ammonia is approximately 857 million ton-miles (MTM) a year. Furthermore, analysis of en route/nonaccident and loading/unloading incidents in the HMIS database reveals that approximately $90 \%$ of highway commodity movements are in MC 330 and MC 331 cargo tanks, with most of the remaining being in cylinders and large portable tanks ( 1,000 gal) for agricultural use (commonly referred to as "nurse" tanks). We estimate that this latter category accounts for no more than $2 \%$ of the total commodity flow by ton-mile. Therefore, we assume that the total commodity flow in MC 330 and MC 331 cargo tanks is 840 MTM. In the 11-yr study period (1985-1995), the HMIS database lists 5 accidents that involved releases from MC 330 and MC 331 cargo tanks of a total of 16 ammonia releases related to highway accidents. Most of the remainder of this total are from the smaller nurse tanks.

To obtain the overall release probability, we first estimated the total vehicle-miles for transporting ammonia. The average size for MC 330 and MC 331 cargo tanks for ammonia transportation is approximately 6,000 gal. Allowing for 10\% outage, we arrived at an average shipment weight of 15 tons. By dividing 840 MTM by 15 tons, we estimated approximately 56 million truck-miles per year. Next, by applying the results of our routing analysis described in Section 4, we estimated that the accident rate for

5 CFR 49 Section 173 specifies the transportation of bulk TIH liquids in both MC 312 and DOT 312 cargo tanks. For clarity, we refer to these cargo tanks as MC 312 cargo tanks, although the specifications also apply to DOT 312 cargo tanks. 
Table 2.6 Release Probability Analysis for Liquefied Gases ${ }^{a}$

\begin{tabular}{|c|c|c|c|c|c|c|c|c|c|}
\hline $\begin{array}{c}\text { Primary } \\
\text { Container } \\
\text { Type }\end{array}$ & Material & $\begin{array}{c}\text { Annual } \\
\text { Commodity } \\
\text { Flow (MTM) }\end{array}$ & $\begin{array}{c}\text { Average } \\
\text { Cargo } \\
\text { Capacity } \\
\text { (gal) }\end{array}$ & $\begin{array}{c}\text { Average } \\
\text { Shipment } \\
\text { Weight } \\
\text { (tons) }\end{array}$ & $\begin{array}{l}\text { Annual } \\
\text { Truck- } \\
\text { Miles } \\
\left(\times 10^{6}\right)\end{array}$ & $\begin{array}{l}\text { Accident } \\
\text { Rate (per } \\
10^{6} \text { miles) }\end{array}$ & $\begin{array}{c}\text { No. of } \\
\text { Accidents } \\
\text { (11 yr) }\end{array}$ & $\begin{array}{c}\text { No. of } \\
\text { Releases } \\
\text { (11 yr) }\end{array}$ & $\begin{array}{c}\text { Release } \\
\text { Probability }\end{array}$ \\
\hline MC 331 & Ammonia & 840 & 6,000 & 15 & 56 & 0.9 & 550 & 8 & 0.014 \\
\hline MC 331 & LP gas & 1,500 & 6,000 & 10 & 150 & 1.9 & 3,200 & 83 & 0.026 \\
\hline
\end{tabular}

a Commodity flow is estimated from the 1977 CTS (DOC 1981) and the 1993 CFS (DOC 1996). Cargo capacity is the average from HMIS database records. Accident rate is estimated on the basis of Table 2.4, and the number of releases is from the HMIS database (1985-1995) and is adjusted for intrastate shippers and under-reporting.

transportation of ammonia was approximately $9 \times 10^{-7}$ accident $/$ mile. Therefore, approximately $\left(52 \times 10^{6} \mathrm{mile}\right) \times\left(9 \times 10^{-7}\right.$ accident $\left./ \mathrm{mile}\right) \times(11 \mathrm{yr})=510$ accidents have occurred in the 11-yr record considered in our HMIS database analysis. The release probability was estimated by multiplying the number of releases divided by the number of accidents. To account for both under-reporting and intrastate shipments in the HMIS database, we multiplied the number of releases by 1.5 . Thus, the release probability determined from ammonia transportation was estimated as approximately 0.014 , where the accident rate is defined in Table 2.4.

For LP gas, we estimated an overall commodity flow of approximately 1,500 MTM/yr. The average size for MC 330 and MC 331 cargo tanks for transportation of LP gases is also about 6,000 gal. If we assume an average filling density of $0.4 \mathrm{~kg} / \mathrm{m}^{3}$, the average shipment weight is approximately 10 tons, or approximately 150 million truck-miles/yr. By applying the results of our routing analysis described in Section 4, the accident rate for LP gas transportation is approximately $1.8 \times 10^{-6}$ accident $/ \mathrm{mile}$. This overall accident rate is significantly higher than that estimated for MC 330 and MC 331 ammonia transportation because of a lower percentage of rural interstate miles. Following our analysis for ammonia, the estimated number of accidents involving LP gas from 1985 to 1995 is about 3,000. The HMIS database reports 55 accident-related releases involving MC 330 and MC 331 cargo tanks. By applying our factor of 1.5 for HMIS under-reporting, we arrived at a release probability of 0.026 release/accident. Then, by averaging the results for ammonia and LP gases, weighted by number of releases, we obtained a release probability of 0.024 release/accident, which is more than three times less than that estimated by Harwood and Russell (Table 2.5).

Bulk Liquids. The release probability for bulk liquids was estimated in a similar manner as for bulk liquefied gases using commodity flow and historical release data for gasoline (including aviation fuel), distillate fuel oil and sulfuric acid. Gasoline and fuel oil were used in estimating release probabilities for MC 306 cargo tanks, whereas sulfuric acid was used in estimating the release probability for MC 312 cargo tanks. The results of our analysis for these materials are provided in Table 2.7. Estimated commodity flows for gasoline (STCC 29111), distillate fuel oil (STCC 29113), and sulfuric acid (STCC 28193) are 17,000, 6,600, and 2,700 MTM/yr, respectively. 
Table 2.7 Release Probability Analysis for Bulk Liquidsa

\begin{tabular}{|c|c|c|c|c|c|c|c|c|c|}
\hline $\begin{array}{c}\text { Primary } \\
\text { Container } \\
\text { Type }\end{array}$ & Commodity & $\begin{array}{c}\text { Annual } \\
\text { Commodity } \\
\text { Flow (MTM) }\end{array}$ & $\begin{array}{c}\text { Average } \\
\text { Cargo } \\
\text { Capacity } \\
\text { (gal) }\end{array}$ & $\begin{array}{c}\text { Average } \\
\text { Shipment } \\
\text { Weight } \\
\text { (tons) }\end{array}$ & $\begin{array}{l}\text { Annual } \\
\text { Truck- } \\
\text { Miles } \\
\left(\times 10^{6}\right)\end{array}$ & $\begin{array}{c}\text { Accident } \\
\text { Rate (per } \\
\left.10^{6} \mathrm{mi}\right)\end{array}$ & $\begin{array}{c}\text { No. of } \\
\text { Accidents }\end{array}$ & $\begin{array}{c}\text { No. of } \\
\text { Releases }\end{array}$ & $\begin{array}{c}\text { Release } \\
\text { Probability }\end{array}$ \\
\hline MC 306 & $\begin{array}{c}\text { Gasoline/ } \\
\text { aviation fuel }\end{array}$ & 17,000 & 8,500 & 25 & 690 & 2.5 & 19,000 & 1,125 & 0.06 \\
\hline MC 306 & Fuel oil & 6,600 & 7,000 & 21 & 310 & 3.0 & 11,000 & 720 & 0.07 \\
\hline MC 312 & Sulfuric acid & 2,700 & 4,000 & 28 & 96 & 1.3 & 1,400 & 53 & 0.04 \\
\hline
\end{tabular}

a Commodity flow is estimated from the 1977 CTS (DOC 1981) and the 1993 CFS (DOC 1996). Cargo capacity is the average from HMIS database records. Accident rate is estimated on the basis of Table 2.4, and the number of releases is from HMIS database (1985-1995) and is adjusted for intrastate shippers and under-reporting.

Commodity flow estimates for gasoline and fuel oil were calculated in a similar fashion as for LP gas (Section 4.3.2). The average size of MC 306 cargo tanks for gasoline and fuel oil transportation and MC 312 cargo tanks for sulfuric acid transportation were estimated from HMIS records. The accident rate for gasoline was estimated by assuming that $25 \%$ of gasoline transportation occurs in urban areas and $50 \%$ occurs on interstates, whereas the accident rate for fuel oil was estimated by assuming that only $15 \%$ of fuel oil transportation occurs in urban areas and $15 \%$ occurs on interstates. The fact that our estimated accident rates for gasoline and fuel oil are similar demonstrates that accident rates are not very sensitive in our assumptions concerning urban and interstate travel. The accident rate for sulfuric acid transportation is estimated from our routing analysis for fuming sulfuric acid (Section 4.3). The HMIS database reports 689 and 65 accidentrelated releases for gasoline and aviation fuel, respectively, from 1985 to 1995. During the same period, there were 480 accident-related releases of fuel oil from cargo tanks and 35 accident-related releases involving sulfuric acid (regular and fuming) from MC 312 cargo tanks. By applying our factor of 1.5 for HMIS under-reporting, we arrive at release probabilities of $0.06,0.07$, and 0.04 for transporting gasoline, fuel oil, and sulfuric acid, respectively. These release probabilities are also approximately three times less than those for bulk liquids in Table 2.5.

Summary of Release Probabilities for Highway Transportation. The release probabilities for a variety of bulk and package freight containers used in highway transportation are listed in Table 2.8. For standard MC 330, MC 331, MC 306, and MC 312 cargo tanks, the release probabilities in Table 2.8 are as calculated above in the commodity flow, HMIS incident analysis. For upgraded MC 331 cargo tanks used for chlorine and sulfur dioxide service, we reduced the release probability by a factor of 2.5 to account for the much more rigorous nature of these containers. As outlined in 49 CFR Section 178.337, the minimum shell thickness of MC 331 tanks is 0.187 in. However, when used for transporting chlorine and sulfur dioxide, the minimum shell thickness when standard steel is used is $0.625 \mathrm{in}$. The factor of 2.5 was estimated by considering the forces necessary for shell failure, together with the distributions of velocity changes for bulk containers for highway collision accidents as reported by Dennis et al. (1977). 
Table 2.8 Release Probabilities for Various Bulk and Package Freight Containers Used in Highway

Transportation $^{\mathrm{a}}$

\begin{tabular}{lcc|}
\hline \multicolumn{1}{|c}{ Container Type } & $\begin{array}{c}\text { Shell } \\
\text { Characteristics }\end{array}$ & $\begin{array}{c}\text { Release } \\
\text { Probability (\%) }\end{array}$ \\
\hline MC 331 & 0.187 S & 2.5 \\
MC 331 & 0.625 S or 0.300 SS & 1.0 \\
MC 306 & All & 6.5 \\
MC 312 & 0.25 S & 4.0 \\
MC 312 & 0.25 SS & 1.5 \\
Misc. package freight & All & 2.5 \\
Drums & All & 2.5 \\
Cylinders & All & 1.0 \\
a The accident frequencies used with these release probabilities are \\
based on the state-level statistics presented by Harwood and Russell \\
(1990) and listed in Table 2.4. & \\
b S = standard steel; SS $=$ stainless steel.
\end{tabular}

Similarly, the upgraded MC 312 cargo tanks authorized for shipment of TIH liquids (excluding HF) are given a lower release probability to account for the increased shell strength of these containers as required in the 1990 regulatory changes.

The release probabilities for drums and miscellaneous package freight containers are estimated from the general freight category listed in Table 2.5 as corrected for the revision in accident definition discussed previously. Because of the relative rarity of cylinder failures in traffic accidents (Appendix C), the release probability for cylinders was reduced by a factor of 2.5. This reduction accounts for the increased safety that transportation in cylinders affords over transportation in drums and other package freight containers. We believe that the true release probability for cylinders may be somewhat lower than is shown in Table 2.8. However, because the primary risk of transporting of materials considered in the NTRA is dominated by bulk transportation, it was beyond the scope of the current study to investigate this issue further.

For the TIH materials considered in the NTRA, the release probabilities in Table 2.8 were modified for large portable tanks used for transporting anhydrous ammonia for agricultural applications (nurse tanks). The HMIS database shows several accidentrelated and relatively few nonaccident incidents that involved transporting ammonia in nurse tanks. Two conclusions can be drawn: (1) trucks (usually pickup trucks) carrying these tanks are more likely to be involved in traffic accidents, and/or (2) the containers themselves are more likely to fail in accidents. On the basis of the review of comments in the HMIS database, which shows that for several of the accidents, drivers lost control of their vehicles due to difficulties associated with towing the tanks, the former conclusion appears to be more likely. However, the failure rate of these tanks could be marginally higher than MC 331 tank trucks. For simplicity, we accounted for both of these factors 
by setting the release probability for nurse tanks at $7.5 \%$, while using the accident rates used for all other highway freight.

In summary, the release probabilities for the six TIH chemicals and LP gas are given in Tables 2.9 and 2.10. Table 2.9 provides release probabilities for bulk freight, and Table 2.10 provides release probabilities for package freight.

Table 2.9 Release Probabilities for Bulk Highway Transportation of the Six NTRA TIH Chemicals and LP Gas ${ }^{a}$

\begin{tabular}{|lccc|}
\hline \multicolumn{1}{|c}{ Chemical } & $\begin{array}{c}\text { CFR 49 } \\
\text { Packaging } \\
\text { Requirements }\end{array}$ & $\begin{array}{c}\text { Tank Type/Shell } \\
\text { Thickness }^{\mathbf{b}}\end{array}$ & $\begin{array}{c}\text { Release } \\
\text { Probability } \\
\text { (\%) }\end{array}$ \\
\hline Ammonia & $173.314 / 315$ & MC 331 & 2.5 \\
Ammonia & $173.314 / 315$ & MC 331 (nurse tank) & $7.5^{c}$ \\
Chlorine & $173.314 / 315$ & MC 331 (0.625 S or 0.300 SS) & 1.0 \\
Sulfur dioxide & $173.314 / 315$ & MC 331 (0.625 S or 0.250 SS) & 1.0 \\
Hydrogen fluoride & 173.243 & MC 312 & 4.0 \\
Fuming sulfuric acid & 173.244 & MC 312 (0.25 SS) & 1.5 \\
Fuming nitric acid & 173.244 & MC 312 (0.25 SS) & 1.5 \\
LP gas & $173.314 / 315$ & MC 331 & 2.5 \\
\hline
\end{tabular}

a The accident frequencies used with these release probabilities are based on the state-level data presented by Harwood and Russell (1990) and listed in Table 2.4.

b $\mathrm{S}=$ standard steel; $\mathrm{SS}=$ stainless steel.

c Release probability accounts for increased accident rate; see discussion in text.

Table 2.10 Release Probabilities for Package Freight Highway Transportation of the Six NTRA TIH Chemicals ${ }^{a}$

\begin{tabular}{|c|c|c|c|}
\hline Chemical & $\begin{array}{c}\text { CFR } 49 \\
\text { Packaging } \\
\text { Requirements }\end{array}$ & $\begin{array}{c}\text { Package Freight } \\
\text { Type }\end{array}$ & $\begin{array}{c}\text { Release } \\
\text { Probability } \\
(\%)\end{array}$ \\
\hline Ammonia & 173.304 & Cylinders & 1.0 \\
\hline Chlorine & 173.304 & Cylinders & 1.0 \\
\hline Sulfur dioxide & 173.304 & Cylinders & 1.0 \\
\hline Hydrogen fluoride & 173.163 & Cylinders & 1.0 \\
\hline Fuming sulfuric acid & 173.227 & $\begin{array}{l}\text { Drums and misc. } \\
\text { package freight }\end{array}$ & 2.5 \\
\hline Fuming nitric acid & 173.227 & $\begin{array}{l}\text { Drums and misc. } \\
\text { package freight }\end{array}$ & 2.5 \\
\hline
\end{tabular}

a The accident frequencies used with these release probabilities are based on the state-level data presented by Harwood and Russell (1990) and listed in Table 2.4. 


\subsubsection{Rail Transportation}

For rail transportation, calculation of accident rates and release probabilities is more straightforward than that for highway transportation because accurate commodity flow data are available and accident data have been consolidated into a few major databases. Statistics compiled by the Federal Railroad Administration (FRA) show that the rail accident rate dropped by a factor of 3 from 14.8 to 4.6 accident/million train-miles, between 1978 and 1988. Since 1988, little change has occurred; the current accident rate remains at about 4.5 accident/million train-miles. When yard accidents are excluded, the rate decreases to 2.4 accident/million train-miles (Rhyne 1994).

Significant variations occur in accident rates along different classes of track. Track is delineated into six classes denoted as Class 1-6, with Class 6 having the most stringent track tolerances and maintenance schedules. Mainline track is generally Class 5 or 6 ; therefore, the accident rate of 2.4 accident/million train-miles is applicable. Class 1 has an accident rate almost 100 times greater than Classes 4, 5, and 6 (Nayak et al. 1983). In yards, track is often maintained to less stringent specifications. This fact, coupled with switching yard activities, leads to substantially higher accident rates on a mile-by-mile basis. Yard accidents, however, are usually less severe than mainline accidents, so the probability of a release in an accident is much lower for yard accidents than for mainline accidents, although the exact reduction in release probability has not been explored in the literature.

Because the severity of accidents varies for yard track and mainline track, the calculation of release probabilities is difficult. One method of calculating release probability is to estimate separately (1) the probability that a car is damaged, which generally is independent of car type; and (2) the probability that a damaged car experiences a release, which depends on car type. However, our analysis of the literature shows that the probability that a car is damaged has not been separated for yard and mainline accidents. Because few accident-related releases occur in yards, this category of accidents is often neglected.

Because of the uncertainties associated with performing individual calculations of the probability of cars being damaged and damaged cars releasing their contents, we did not attempt to separate these events in this study. Rather, we directly calculated the probability of a derailment-related release per railcar-mile traveled for different car types. First, we estimated the commodity flow in millions of car-miles for particular commodities from 1986 to 1995 and then used the HMIS database to determine the number of derailment-related releases that occurred over the same period. We derived separate probabilities for the Class 111 A nonpressure car, 112J340W and 105A300W pressure cars, and the $105 \mathrm{~A} 500 \mathrm{~W}$ pressure car.

Table 2.11 provides commodity flow estimates and the number of derailment-related releases for four commodities for pressurized and nonpressurized railcars. For Class 111A cars, we analyzed rail transportation of two hazardous materials shipped frequently by rail: sulfuric acid and phosphoric acid. The total commodity flow in 
Table 2.11 Commodity Flow Estimates and Derailment-Related Release Numbers for Four Commodities Used to Estimate Release Probabilities for Nonpressurized and Pressurized Railcars, 1986-1995

\begin{tabular}{|c|c|c|c|c|}
\hline Chemical & Car Type & $\begin{array}{l}\text { Commodity } \\
\text { flow }\left(10^{6} \text { car- }\right. \\
\text { miles })\end{array}$ & $\begin{array}{c}\text { Derailment- } \\
\text { Related } \\
\text { Releases } \\
\text { from HMIS }\end{array}$ & $\begin{array}{c}\text { Release } \\
\text { Probability } \\
\text { (per } 10^{6} \text { car- } \\
\text { miles) }\end{array}$ \\
\hline Sulfuric acid & $111 \mathrm{~A}$ & 380 & 52 & 0.13 \\
\hline Phosphoric acid & $111 \mathrm{~A}$ & 233 & 36 & 0.15 \\
\hline LP gas $^{a}$ & $\begin{array}{l}112 \mathrm{~J} 340 \mathrm{~W},{ }^{\mathrm{b}} \\
105 \mathrm{~J} 300 \mathrm{~W}\end{array}$ & 607 & 20 & 0.033 \\
\hline Ammonia & $\begin{array}{l}112 \mathrm{~S} 340 \mathrm{~W}, \mathrm{~b} \\
112 \mathrm{~J} 340 \mathrm{~W} \\
105 \mathrm{~A} 300 \mathrm{~W}\end{array}$ & 267 & 10 & 0.037 \\
\hline
\end{tabular}

car-miles, number of releases, and corresponding release probabilities are shown in the table. For Class 105 and 112 cars, we analyzed commodity flow and release data for LP gas and ammonia. While these commodities are transported both in Class 112 and 105 rail cars, Class 112 railcars account for the majority of transportation.

The AAR reports that the waybill data from which our commodity flow estimates originated account for approximately $80 \%$ of the total rail commodity flow. Therefore, the actual railcar mileage is probably about $25 \%$ higher than that reported by AAR and shown listed in Table 2.11. However, because the HMIS database is vulnerable to underreporting, the true number of rail-related releases is likely greater than that given in Table 2.11. These effects offset each other, so we did not attempt to modify the commodity flow or HMIS release data. The analysis results in a release probability of 0.13 release/million tank-car miles for Class 111A tank cars and 0.035 release/million miles for specification $112 \mathrm{~J} 340 \mathrm{~W}, 112 \mathrm{~S} 340 \mathrm{~W}, 105 \mathrm{~J} 300 \mathrm{~W}$, and $105 \mathrm{~A} 300 \mathrm{~W}$ tank cars. The available data did not allow differentiation of release probabilities based on cars insulation characteristics (i.e., 112J340W versus $112 \mathrm{~S} 340 \mathrm{~W}$ ). However, we believe that the release probabilities for the four pressure car types listed in Table 2.11 are similar, especially considering the relative agreement of release probabilities for anhydrous ammonia and LP gas.

Release probabilities are substantially lower for specification 105A500W tank cars, however. Historical accident records show that chlorine releases during derailments are rare compared with releases of other hazardous materials carried in Class 112 and 105 rail cars. No derailment-related chlorine releases are listed in the HMIS database from 1985 to 1995. For comparison, 10 derailment-related anhydrous ammonia releases are listed in HMIS over the same period. Considering the fact that commodity flow estimates for anhydrous ammonia and chlorine from AAR waybill records are 267 and 
233 million car-miles for 1986 to 1995 , the absence of chlorine releases suggests that the $105 \mathrm{~A} 500 \mathrm{~W}$ tank car is a considerably more robust transportation vehicle than the Class 112 and 105 railcars used for liquefied flammable gases. The 105A300W railcars for transporting ammonia and the $105 \mathrm{~J} 300 \mathrm{~W}$ rail cars used for LP gas service have also experienced relatively few releases, even though the number of $105 \mathrm{~A} 300 \mathrm{~W}$ and $112 J 340 \mathrm{~W}$ railcars in service is similar. Considering tank car failure rates from 1980 to 1986, Phillips and Role (1986) calculated that the frequency of chlorine car failures was half that of anhydrous ammonia car failures and one quarter that of liquefied flammable gas car failures. Chlorine and anhydrous ammonia releases over this time totaled 2 and 4, respectively, so statistical confidence in these results is not particularly high. As outlined in 49 CFR Section 173.314, the chlorine tank car is required to have thicker tank shells, insulation and thermal protection, a metal jacket, and increased head protection. These factors offer additional protection against puncture or rupture in fires. In the NTRA, we took the release probability of $105 \mathrm{~A} 500 \mathrm{~W}$ railcars used for chlorine service as one-third that of other Class 112 and 105 railcars, or 0.012 release/million rail-car-miles. This factor of additional protection afforded with the 105A500W car agrees with that used in other analyses (e.g., Barkan et al. 1991). Because of the robustness of this particular car and the infrequency of chlorine releases in the recent historical record, this factor may still be conservative.

Table 2.12 provides the railcar types and associated release probabilities for the six TIH chemicals considered in the NTRA.

Table 2.12 Railcar Types and Release Probabilities Used for Rail Transportation of the Six NTRA TIH Chemicals

\begin{tabular}{|lcc|}
\hline \multicolumn{1}{|c}{ Chemical } & Railcar Type & $\begin{array}{c}\text { Release } \\
\text { Probability (per } \\
\mathbf{1 0}^{\mathbf{6}} \text { car-miles) }\end{array}$ \\
\hline Ammonia & 112S340W, 112J340W, & 0.035 \\
Chlorine & $105 \mathrm{~A} 300 \mathrm{~W}$ & \\
Sulfur dioxide & $105 \mathrm{~A} 500 \mathrm{~W}$ & 0.012 \\
Hydrogen fluoride & $105 \mathrm{~A} 300 \mathrm{~W}$ & 0.035 \\
Fuming sulfuric acid & $112 \mathrm{~A} 300 \mathrm{~W}$ & 0.035 \\
Fuming nitric acid & $112 \mathrm{~A} 300 \mathrm{~W}$ & 0.035 \\
\hline
\end{tabular}

\subsubsection{En Route/Nonaccident Releases}

In the NTRA, we considered risk from two types of releases: those occurring in accidents and derailments and those occurring en route from origin to destination, but not during an accident or derailment. These release types are called accident-related and en route/nonaccident releases (Section 3.1.3). 
Release probabilities for en route/nonaccident incidents in this study are derived from incident reports in the HMIS database. Data provided in Appendix C detail the incident counts for accident-related releases, en route/nonaccident releases, and loading/unloading releases. From these data, it is clear that (1) there is a wide variation in the relative incident rates between different container types, and

(2) en route/nonaccident releases are substantially more common than accident-related releases for most container types. For this study, we used these HMIS statistics to calculate an approximate failure rate per shipment-mile. To estimate this factor, we determined the ratio of en route/nonaccident releases to accident-related releases and then scaled the en route/nonaccident incident rate according to the vehicular accident rate and release probability data discussed in Section 2.3.3.1. These factors, together with the calculated en route/nonaccident release probability on a per mile basis are listed in Table 2.13. The container types in this table are chosen to agree with container types used for the discharge fraction distributions in Section 3.3.2.

Table 2.13 Relative Number of En Route/Nonaccident Releases Compared with Accident-Related Releases for Various Container Types ${ }^{a}$

\begin{tabular}{|c|c|c|c|}
\hline Container Type ${ }^{b}$ & $\begin{array}{c}\left(\frac{\text { EnRoute/Nonaccident Releases }}{\text { Accident-Related Releases }}\right) \\
\text { in HMIS }\end{array}$ & $\begin{array}{c}\text { Vehicular } \\
\text { Accident Rate } \\
\text { (per } 10^{6} \text { miles) }\end{array}$ & $\begin{array}{l}\text { En Route/ } \\
\text { Nonaccident Release } \\
\text { Probability (per } 10^{6} \\
\text { vehicle-miles) }\end{array}$ \\
\hline Class $111 \mathrm{~A}$ tank cars & 25 & $N A^{c}$ & 3.5 \\
\hline Class 112 and 105 tank cars ${ }^{d}$ & 40 & NA & 1.4 \\
\hline MC 306 cargo tanks & 0.25 & 2.5 & 0.04 \\
\hline MC 307 cargo tanks & 2.5 & 1.5 & 0.2 \\
\hline \multicolumn{4}{|l|}{ MC 312 cargo tanks } \\
\hline $0.25 \mathrm{~S}$ & 3.5 & 0.2 & 1.3 \\
\hline $0.25 \mathrm{SS}$ & 3.5 & 0.07 & 1.3 \\
\hline \multicolumn{4}{|l|}{ MC 330/331 cargo tanks } \\
\hline $0.187 \mathrm{~S}$ & 0.5 & 0.02 & 1.7 \\
\hline $0.625 \mathrm{~S}, 0.300 \mathrm{SS}$ & 0.5 & 0.008 & 1.5 \\
\hline Small and medium drums & 25 & 1.5 & 1 \\
\hline Large drums & 7 & 1.5 & 0.3 \\
\hline Cylinders & 7 & 1.5 & 0.1 \\
\hline Miscellaneous package freight & 50 & 1.5 & 2 \\
\hline \multicolumn{4}{|c|}{ As determined from the HMIS database 1990-1995. } \\
\hline \multicolumn{4}{|c|}{ S = standard steel; SS = stainless steel. } \\
\hline \multicolumn{4}{|l|}{ NA = not applicable. } \\
\hline An en route/nonaccident relec & ability of 0.5 release $/ 10^{6}$ car-miles is & for the $105 \mathrm{~A} 500$ & car employed for chlorine \\
\hline
\end{tabular}

For highway transportation, this analysis involves considerable uncertainty because of the under-reporting problems associated with nonaccident-related releases in the HMIS database and the need to estimate an aggregate accident rate. For rail, the en route/nonaccident incident rate is scaled directly from the derailment-related release probabilities, thus reducing uncertainties introduced through accident rate estimation. On 
the basis of the uncertainties of the data sources, we estimate that the incident probabilities for en route/nonaccident incidents are valid to a factor of 2 for rail, 3 for highway bulk freight, and 4 for package freight. Also, the en route/nonaccident release probabilities listed in Table 2.13 and used in this study do not depend on highway type or on the location of the vehicle or rail car (i.e., urban or rural).

Finally, on the basis of HMIS statistics, the en route release probability for MC 306 cargo tanks is undoubtedly higher than that indicated by our analysis. We believe that a majority of small en route-type releases of gasoline - the primary material shipped in MC 306 cargo tanks - are unreported. This potential problem does not affect the NTRA study because MC 306 cargo tanks are not authorized for the materials evaluated in the risk assessment phase of this study. We suggest that in future application of these release probability statistics, the en route/nonaccident release probability for MC 307 cargo tanks be used as a surrogate for MC 306 cargo tanks.

\subsubsection{Protection Afforded by Sheltering}

The analysis methods used in this study are based on population exposure estimates for outdoor concentrations. This methodology is consistent with previous risk assessment studies and with regulatory permitting activities. However, it leads to a conservative estimate of actual exposure.

Two principal reactions reduce exposure: evacuation and sheltering. For scenarios characteristic of transportation incidents, sheltering is the more prevalent avenue for exposure reduction because once a release has occurred, there is rarely time to organize and execute an evacuation. For transportation-related incidents that involve TIH materials, evacuations are most often conducted when a release has not occurred, but there is a strong possibility for a large release. Prominent examples of evacuations of this variety are the Mississauga rail accident near Toronto in 1988 and the Pittsburgh rail accident in April 1987.

The degree of protection afforded by sheltering depends primarily on the building ventilation rate and secondarily on the passage time of the vapor cloud. The former is a measure of the exchange between the indoor and outdoor air for a building and is usually measured in air exchanges per hour (APH). Table 2.14 shows typical ranges of building ventilation rates for various commercial and residential structures under normal operating conditions. Ventilation rates for commercial buildings average from 1 to $6 \mathrm{APH}$, whereas ventilation rates for residential structures range from 0.2 to $2 \mathrm{APH}$ (with windows and doors closed), depending on construction and season. In an emergency, building ventilation rates, especially for commercial buildings, can usually be reduced substantially by deactivating the ventilation system. For residential structures, air exchange rates are most often governed by building leakage; therefore, additional measures do not dramatically reduce outdoor air infiltration.

6 APH can also refer to the air exchanges within a building without respect to whether indoor or outdoor air is being exchanged. Throughout our discussion, APH refers to air exchange with only outdoor air. 
Table 2.14 Outdoor Air Exchange Rates for Various Building Types

\begin{tabular}{|lc|}
\hline \multicolumn{1}{c}{ Building Type } & APH \\
\hline Office building & $1-3$ \\
School & $4-6$ \\
Hospital & $2-4$ \\
Restaurant & $5-10$ \\
Bars and cocktail lounge & $10-20$ \\
Theaters and auditorium & $2-5$ \\
Retail store & $1-3$ \\
Hotel/motel and apartment building & $0.5-2$ \\
Single-family home, tightly constructed & $0.2-1$ \\
Single-family home, loosely constructed & $1-2$ \\
\hline
\end{tabular}

Sources: Values adapted from BOCA (1993) and ASHRAE (1997).

The time it takes for the vapor cloud to pass also affects the degree of protection offered by sheltering. A number of factors affect the passage time, including release duration, wind speed, distance from the source, and atmospheric stability. Of these factors, release duration and wind speed are the most important. In general, liquefied gases exhibit shorter duration releases in comparison with liquids, and greater protection is afforded through sheltering. However, for short-duration releases (under $15 \mathrm{~min}$ ), the protective effects of sheltering are reduced as the downwind distance from the source increases because streamwise spreading of the cloud increases passage time. This effect is particularly important during the day when atmospheric turbulence is more vigorous.

Given the time history of the outdoor concentration, the indoor concentration is represented by using the convolution integral

$$
C_{\text {in }}(t)=\int_{0}^{\infty} C_{\text {out }}(\tau)\left\{1-\exp \left[A_{c}(t-\tau)\right]\right\} d \tau,
$$

where

$$
\begin{aligned}
C_{o u t} \text { and } C_{i n} & =\text { outdoor and indoor concentrations, respectively, } \\
t & =\text { time, and } \\
A_{c} & =\text { building ventilation rate. }
\end{aligned}
$$


For a constant outdoor concentration of $C_{\text {out }}$ between $t=0$ and $t=T$, Equation (2.1) reduces to:

$$
\begin{array}{lc}
C_{\text {in }}(t)=C_{\text {out }}\left(1-\exp \left[A_{c} t\right]\right) & 0 \leq t \leq T \\
C_{\text {in }}(t)=C_{\text {out }} \exp \left[A_{c}(t-T)\right] & t>T .
\end{array}
$$

Figures 2.5 and 2.6 show the effects of sheltering for two release scenarios. Figure 2.5 exemplifies a large release of a liquefied gas such as ammonia or chlorine where the release amounts are high and the release duration is short. Figure 2.6, on the other hand, exemplifies a large release of a liquid such as fuming nitric acid. Here, the release rate is considerably lower than that for a liquefied gas, but the release duration is much longer. Each figure shows the history of release rate and the outdoor and indoor concentration at near and far downwind locations. Indoor concentrations are shown for building ventilation rates of $0.25,1$ and $4 \mathrm{APH}$. The meteorological conditions considered here are typical of a summer day in late afternoon with a windspeed of $4 \mathrm{~m} / \mathrm{s}$ ( $\sim 8 \mathrm{mph})$.

For the scenario considered in Figure 2.5, the peak and average indoor concentrations are substantially reduced from their respective outdoor values at both downwind distances. The 15-min average concentrations at $500 \mathrm{~m}$ are reduced by factors of 17, 5, and 2 for building ventilation rates of $0.25,1$, and $4 \mathrm{APH}$, respectively, whereas at $10 \mathrm{~km}$, the 15-min average concentrations are reduced by factors of 15, 4, and 1.5 for these same building ventilation rates, respectively. However, the indoor exposure duration is considerably longer, especially for building ventilation rates less than $1 \mathrm{APH}$. For this reason, it is often suggested that people remain indoors while the vapor cloud passes outside and then evacuate outdoors once the cloud has passed. Although this advice is usually sound, it can be difficult to implement in emergency situations. For longer duration releases (Figure 2.6), sheltering is less effective unless the building is very airtight. Although peak concentrations are still reduced substantially, 15- or 30-min average concentrations are reduced by a factor of 2 or less from outdoor values for ventilation rates above $1 \mathrm{APH}$. In a real emergency situation, the actual release duration may be limited due to mitigation strategies, thus increasing the protective effects of sheltering.

To further quantify the effect of sheltering for TIH transportation-related incidents, we calculated the average reduction of casualties due to sheltering for various scenarios. We used concentration time histories predicted by the CASRAM dispersion module and the relationship given in Equation (2.1). These results are shown in Table 2.15. Both liquefied gas and liquid release scenarios were considered. The release scenarios were similar to the case studies presented in Figures 2.5 and 2.6, except that liquid evaporative releases were terminated after $1 \mathrm{~h}$ to account for anticipated release mitigation measures. For each release scenario, hazard area reduction factors were provided for three building 

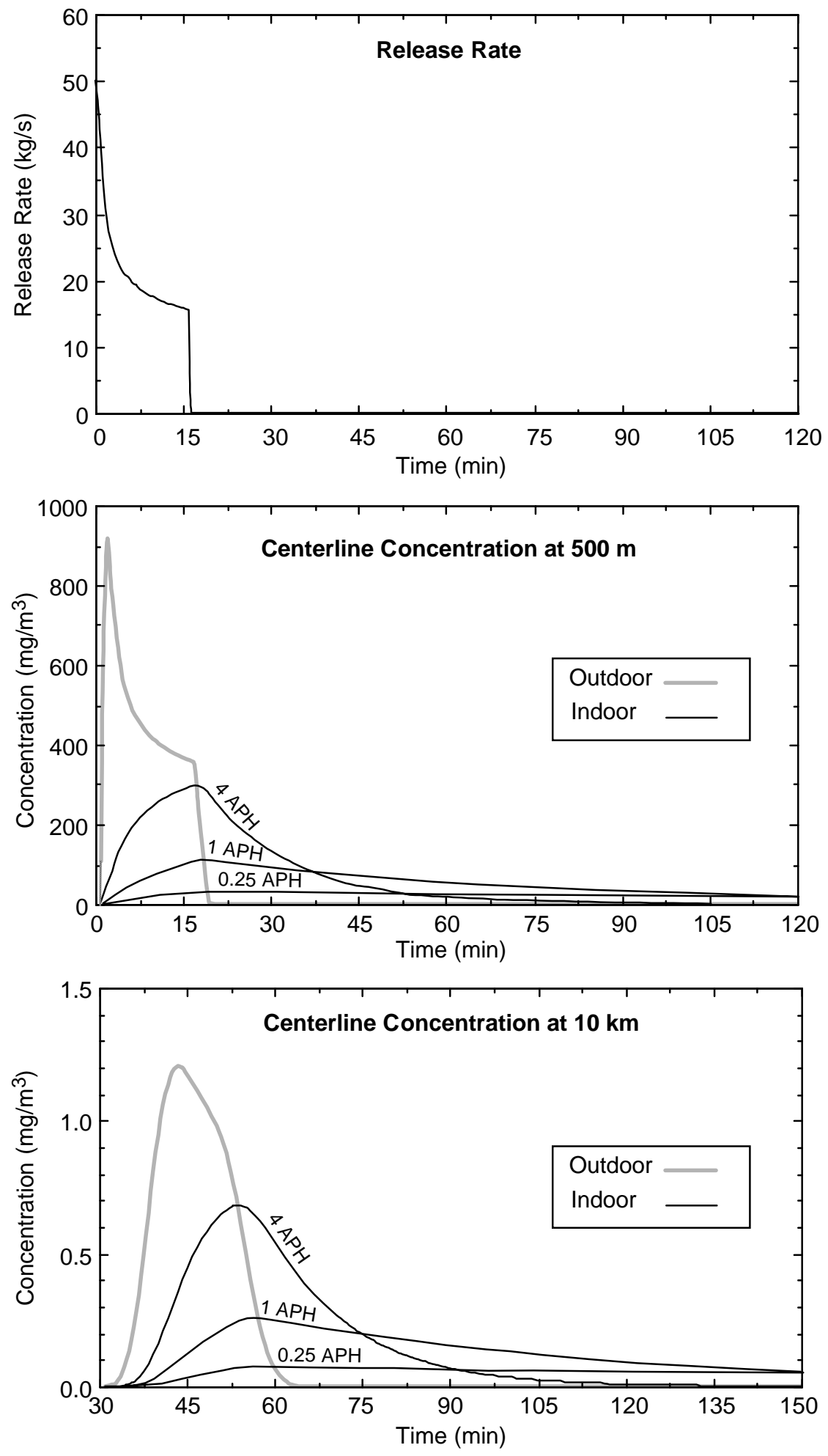

Figure 2.5 Effects of Sheltering for Outdoor and Indoor Release Scenarios for a Large Release of Liquefied Gas 

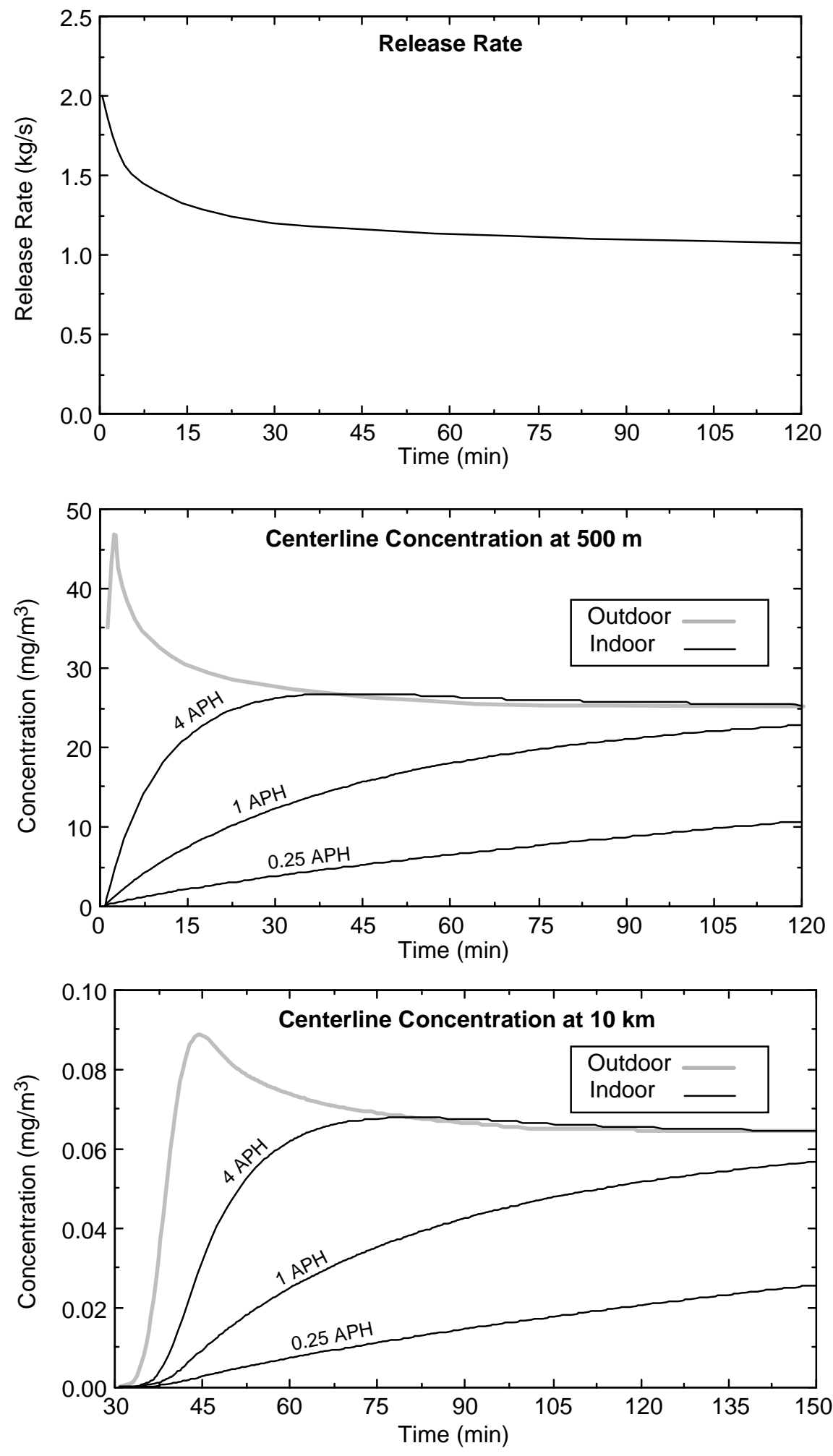

Figure 2.6 Effect of Sheltering for Outdoor and Indoor Release Scenarios for a Large Release of a Liquid 
Table 2.15 Average Reduction in Casualties in Transportation-Related Incidents for Three Building Ventilation Rates ${ }^{a}$

\begin{tabular}{|c|c|c|c|c|c|c|c|}
\hline \multirow{2}{*}{$\begin{array}{c}\text { Material } \\
\text { Class }\end{array}$} & \multirow{2}{*}{$\begin{array}{c}\text { Relative } \\
\text { Hazard }\end{array}$} & \multicolumn{2}{|c|}{$0.25 \mathrm{APH}^{\mathrm{b}}$} & \multicolumn{2}{|c|}{$1 \mathrm{APH}$} & \multicolumn{2}{|c|}{$4 \mathrm{APH}$} \\
\hline & & Day & Night & Day & Night & Day & Night \\
\hline \multirow[t]{3}{*}{ Liquefied gas } & High & 6.3 & 83 & 2.6 & 9.1 & 1.5 & 1.9 \\
\hline & Med. & 15 & 29 & 4.4 & 6.7 & 1.9 & 2.4 \\
\hline & Low & 17 & 22 & 5.0 & 5.6 & 2.0 & 2.2 \\
\hline \multirow[t]{3}{*}{ Liquid } & High & 3.7 & 8.3 & 1.7 & 2.4 & 1.2 & 1.4 \\
\hline & Med. & 5.6 & 7.1 & 2.1 & 2.2 & 1.3 & 1.4 \\
\hline & Low & 6.3 & 6.5 & 2.1 & 2.1 & 1.4 & 1.4 \\
\hline
\end{tabular}

a Data are provided separately for liquefied gases and liquids, day and night, and for different relative hazards involved. See text and Table 2.16 for further explanation.

b $\mathrm{APH}=$ air exchanges per hour.

ventilation rates and for day and night. In addition, hazard area reduction factors were provided for three different "relative hazard" values.

The relative hazard value is a measure of the ratio of the release rate to the health end point (threshold concentration). This parameter, together with meteorology, governs the size of the hazard zone in an incident. In Table 2.15, the high relative hazard category applies to situations that involve a large release and a low-threshold concentration. ERPG-2 exposures for large chlorine or fuming nitric acid releases in the NTRA analysis are examples of high-hazard releases. The medium relative hazard category applies to situations that involve a small release and a low-threshold concentration or a large release and a high-threshold concentration. Examples of medium relative hazard incidents include ERPG-2 exposures for small chlorine or fuming nitric acid releases and $\mathrm{LC}_{50}$ exposures from large chlorine or fuming nitric acid releases. Because ammonia is considerably less toxic than chlorine or nitric acid, the medium relative hazard category also applies to ERPG-2 exposures for large ammonia releases. The low relative hazard category applies to situations that involve a small release coupled with a high-threshold concentration. Examples of low-relative hazard incidents are $\mathrm{LC}_{50}$ exposures for small chlorine or fuming nitric acid releases. Table 2.16 lists the relative hazard category applicable for ERPG-2 and LC 50 exposures for both large and small releases for the six TIH NTRA chemicals. As an example application of these categories, the protective effects of sheltering on ERPG-2 exposures and fatalities ( $\mathrm{LC}_{50}$ exposures) for large chlorine releases are provided by the reduction factors for high and medium relative hazards for liquefied gases in Table 2.15. 
Table 2.16 Relationship of Relative Hazard Category to Release Type and Threshold Concentration ${ }^{a}$

\begin{tabular}{|c|c|c|c|c|c|}
\hline \multirow{2}{*}{$\begin{array}{c}\text { Material } \\
\text { Class }\end{array}$} & \multirow[b]{2}{*}{ Chemical } & \multicolumn{2}{|c|}{ Large Release } & \multicolumn{2}{|c|}{ Small Release } \\
\hline & & ERPG-2 & $\mathbf{L C}_{50}$ & ERPG-2 & $\mathbf{L C}_{50}$ \\
\hline \multirow[t]{4}{*}{ Liquefied gas } & Chlorine & High & Med. & Med. & Low \\
\hline & Ammonia & Med. & Low & Low & Very low \\
\hline & Sulfur dioxide & High & Med. & Med. & Low \\
\hline & Hydrogen fluoride ${ }^{b}$ & High & Med. & Med. & Low \\
\hline \multirow[t]{2}{*}{ Liquid } & Fuming nitric acid & High & Med. & Med. & Low \\
\hline & Fuming sulfuric acid & High & Med. & Med. & Low \\
\hline
\end{tabular}

a Large and small releases are taken to be on the order of 10,000 and $100 \mathrm{~kg}$, respectively.

b Volatile liquid at temperatures less than $20^{\circ} \mathrm{C}$.

Sheltering is most effective for large nighttime liquefied gas releases. For residential structures with building ventilation rates of about $0.25-1 \mathrm{APH}$, the factors of reduction for ERPG-2 exposures and fatalities for liquefied gas releases range from 10 to 80 and from 7 to 30, respectively. For daytime incidents, the reduction factors are still significant but considerably less than those for nighttime because of the increased dispersive effects of the daytime atmosphere. An interesting consequence is that the protective effects of sheltering decrease during night as the relative hazard decreases, whereas the protective effects of sheltering increase during day as the relative hazard decreases. Another important observation from Table 2.15 is that the protective effects of sheltering are substantially less for liquids, especially for high building ventilation rates. This behavior is a direct consequence of the longer release duration for liquids.

In Section 5.1.4, we discuss how these results are applied to account for the mitigative effects of sheltering in comparing risks that result from transporting TIH materials to risks that result from transporting flammable materials and explosives.

\subsection{Flammable Materials}

In this section, we outline the methodology used to calculate the national risk from transporting flammable materials and identify those materials that pose the greatest transportation-related risk to the public. These materials are LP gas, and gasoline. In Section 2.4.1, we extend the CASRAM analysis for TIH materials to treat thermal radiation hazards associated with highway transportation of LP gas. In Section 2.4.2, we discuss the analysis for gasoline. The analysis differs from other materials considered in the NTRA because we adopted a statistical approach that directly used historical fatality and injury data. Such an approach is preferable for gasoline because the risk is driven by frequently occurring incidents that can be easily characterized from historical data. 


\subsubsection{LP Gases}

The principal hazards from liquefied flammable gases in transportation-related incidents are fireballs and flash fires. Fireballs occur when a vapor cloud ignites shortly after release (when the vapor cloud contains high concentrations of aerosolized liquid and vapor). Flash fires occur when the cloud ignites after it has dispersed some, but while flammable vapors are still above the lower flammability limit. In our analysis, we identified the probabilities of these events and calculated fatality and injury hazard zones for thermal radiation impacts that arose from each of these consequences. In situations where the vapor cloud is confined, blast and flying debris could pose a significant threat to human health. However, the historical evidence shows that impacts from thermal radiation are significantly higher, especially for releases associated with highway transportation. Therefore, only thermal radiation effects are included. Section 2.4.1 considers the ignition probabilities and the likelihood that ignition will result in either a fireball or a flash fire. The consequence analysis is briefly discussed in Section 2.4.2.

\subsubsection{Ignition and Consequence Probabilities}

To assess risk associated with transportation-related LP gas releases, we must know the probability of ignition and the probability that ignition will result in a fireball or flash fire. These probabilities can be estimated with a fair degree of precision from historical data. For highway releases of LP gas, ignition is generally caused by one of three sources: (1) sparks generated in the accident; (2) the engine, electrical, or exhaust system of the vehicles involved in the accident; or (3) a passing vehicle. The probability of ignition depends on the size of the release, the severity of the accident, and the availability of external ignition sources. The nature of the ensuing explosion or fire strongly depends on the time elapsed from the release to ignition. For instance, the immediate ignition following a catastrophic rupture of an LP gas tank truck will most likely result in a fireball, whereas ignition after a plume has formed will usually result in a flash fire.

Croce (1982) analyzed historical data from highway accidents involving 50 LP gas releases in a 10-yr period. Only 12 of these releases involved ignition of the LP gas, leading to an ignition probability of $24 \%$. On the basis of comments from more recent HMIS database records, our analysis yielded a slightly higher ignition probability $34 \%$; however, considering the low numbers of incidents involved, these ignition probabilities are not statistically different. We found that the ignition probability strongly depends on release amounts, as shown in Table 2.17. From these data, we are also roughly estimated the probability of near-instantaneous, ignition which would likely lead to the generation of a fireball for larger releases. In such cases, near-instantaneous ignition appears to occur in about $19 \%$ of all releases, or about $36 \%$ of cases where ignition occurs. For medium releases, the HMIS comments do not refer to explosions or fireballs. Because the fires were usually small, however, these subtleties may not have been reported; therefore, we cannot speculate on the occurrence probability of instantaneous ignition. 
Table 2.17 Ignition Probabilities for Small (less than $5 \mathrm{gal}$ ), Medium (5-100 gal), and Large (greater than 100 gal) Highway LP Gas Releases ${ }^{a}$

\begin{tabular}{lcccccc|} 
& & \multicolumn{2}{c}{ Fire } & & \multicolumn{2}{c|}{ Explosion and Fire } \\
\cline { 3 - 4 } \cline { 5 - 6 } Spill Size & Total & No. & $\%$ & & No. & $\%$ \\
\cline { 6 - 7 } Small & 6 & 0 & 0 & & 0 & 0 \\
Medium & 11 & 2 & 18 & & 0 & 0 \\
Large & 21 & 11 & 52 & & 4 & 19 \\
Total & 38 & 13 & 34 & & 4 & 11 \\
\hline
\end{tabular}

a As determined from HMIS database incident records from 1985 to 1995 . Only those records that included comments are included in this table.

On the basis of the results given in Table 2.17, the ignition probability for small, medium and large LP gas releases is $0 \%, 18 \%$, and $52 \%$, respectively. For large releases, approximately $36 \%$ of ignitions (19\% of large releases) are instantaneous.

\subsubsection{Consequence Analysis}

The CASRAM methodology for hazard zone analysis as applied to the transportation of LP gas is shown in Figure 2.7. The model structure and execution are very similar to those for TIH materials (Figure 2.2). The differences lie in the consequence analysis. For each release, after the release amount and meteorology have been determined, we first estimated if an instantaneous ignition occurs. The probability of instantaneous ignition is taken as $18 \%$ for medium and large releases. Although the descriptions in the HMIS database do not indicate that medium-release cases (i.e., 5-100 gal) produce fireballs or explosions, most of those cases probably do involve ignition shortly after release because the vapor cloud concentrations quickly fall below the lower flammability limit. If an instantaneous release occurs, a fireball hazard zone analysis is conducted. If an instantaneous release does not occur, the vapor cloud model is initiated. The vapor cloud model consists of an integral dispersion model used to calculate the time history of LP gas concentration and the size of the flammable portion of the vapor cloud together with a statistical ignition probability algorithm. If ignition does not occur before the peak cloud concentration falls below the lower flammability limit, no consequences occur. If ignition occurs, a vapor cloud hazard zone analysis is performed. Appendix A contains details of the consequence models and human health impacts.

\subsubsection{Gasoline}

In the NTRA, we used a statistical approach that directly utilizes historical fatality and injury data, rather than our comprehensive risk assessment model to estimate fatality and injury distributions for transporting gasoline. For gasoline, this approach is preferable because a reliable distribution of consequences on a per incident-basis can be 


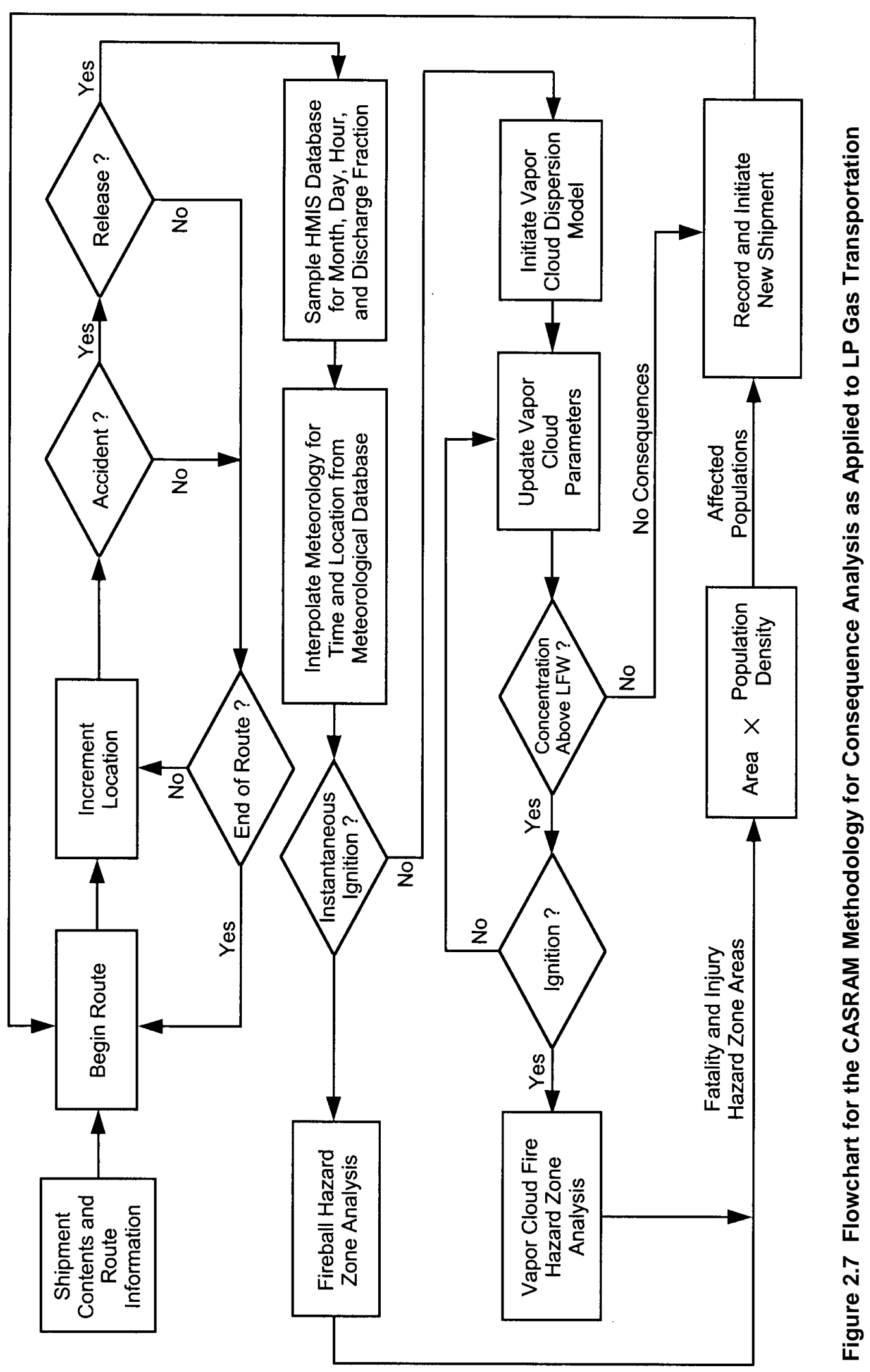


constructed directly from historical data, therefore eliminating potential biases introduced through incident modeling.

Development of a reliable distribution that adequately captures risk from gasoline is possible because of the high-probability/low-consequence nature of gasoline incidents. For instance, the HMIS database lists 481 incidents from 1985 to 1995 that involved the release of gasoline in a traffic accident. In 51 incidents, the driver or a member of the general public was killed as a direct result of the gasoline release. More than $70 \%$ of the fatalities involved only the death of the driver, and only 3 incidents involved more than 3 fatalities. The incidents surveyed show that while fatal gasoline incidents occur frequently with respect to other hazardous materials, their consequences on a perincident basis are relatively low. Another important element is that worst-case gasoline incidents, which comprise the tail of the consequence distribution, do not dramatically affect the long-term injury and fatality rates. For example, a worst-case incident for gasoline could involve 50 fatalities; however, the average number of fatalities over a 10 -yr period is on the order of 100 people, so a single incident that involves 50 fatalities increases the fatalities for that period by $50 \%$. Although that $50 \%$ increase is not trivial, it does not significantly alter the long-term fatality rate (i.e., average fatalities per 10-yr period). For example, contrast the situation with gasoline with that of chlorine. The number of fatalities that result from transporting chlorine in any 10 -yr period generally is very low, but a single worst-case incident can involve more than 5,000 fatalities. As a result, these worst-case chlorine incidents have a large impact on the average fatality statistics for chlorine. Therefore, worst-case incidents, which comprise the tail of the consequence distribution, become very important, requiring a more sophisticated risk assessment methodology based on detailed incident modeling.

The first step involved in developing fatality distributions for gasoline was estimation of fatal-accident frequency. Analysis of the fatal gasoline incidents in the 11-yr record of the HMIS database discussed in Section 3 showed that one fatal incident is reported to HMIS approximately every 78 days. Approximately $70 \%$ of those incidents involved only the death of the driver. We found that the fatality distribution for the remaining $30 \%$ of incidents was well represented by a pair of exponential distributions. The first distribution accounts for less severe incidents involving the gasoline truck and only one or two other vehicles. From an examination of HMIS incident data, we estimated that the mean of this fatality distribution was 1.5. The second distribution accounts for more severe incidents involving several vehicles or other extenuating circumstances such as a collision with a bus or passenger train, or an accident within a tunnel. Here, direct examination of HMIS database incidents is less helpful because few accidents of this type have occurred. To approximate events falling into this category, we set the mean of this second exponential fatality distribution as 5 . Of the $30 \%$ of fatal gasoline accidents where persons other than the driver are killed, we estimate that $90 \%$ fall into the "less severe" accident category and $10 \%$ fall into the "more severe" category. As a result, the substantial uncertainty in the exponential fatality distribution accounting for more severe accidents is not critical because the overall fatality distribution is overwhelmingly dominated by the $70 \%$ of incidents involving only the death of the driver as well as the additional $27 \%$ of incidents that fall into the less severe category. Injuries from 
transporting gasoline are treated in a similar manner. Here also, we estimate that only the driver is injured about $70 \%$ of the time. Likewise, injuries for the remaining $30 \%$ of incidents are also broken into the less and more severe categories and represented by using exponential distributions developed from gasoline-incident injury statistics in the HMIS database. Table 2.18 gives the frequencies and distribution parameters for our modeled gasoline consequence distributions.

Table 2.18 Incident Frequencies and Distribution Parameters for Modeled Fatality and Injury Consequence Distributions for Highway Transportation of Gasoline

\begin{tabular}{|lccccc|}
\hline & \multicolumn{2}{c}{ Fatalities } & & \multicolumn{2}{c|}{ Injuries } \\
\cline { 2 - 3 } \cline { 5 - 6 } Category & $\begin{array}{c}\text { Incident } \\
\text { Frequency } \\
\text { (per year) }\end{array}$ & $\begin{array}{c}\text { Mean Number } \\
\text { per Incident }\end{array}$ & & $\begin{array}{c}\text { Incident } \\
\text { Frequency } \\
\text { (per year) }\end{array}$ & $\begin{array}{c}\text { Mean Number } \\
\text { per Incident }\end{array}$ \\
\hline Driver only & 5.7 & & & 7.3 & 1 \\
Other/less severe & 2.2 & 1 & & 2.8 & 1.8 \\
Other/more severe & 0.24 & 1.5 & & 0.31 & 20 \\
\hline
\end{tabular}

In the NTRA, the frequencies of fatality and injury accidents are 1 every 45 days and 1 every 35 days, respectively. These incident frequencies are raised by $50 \%$ over the actual incident frequencies in HMIS to account for intrastate shipments that were not included in the HMIS database over the 11-yr period considered in the analysis as well as under-reporting. Table 2.18 gives incident frequencies and distribution parameters.

In extending this analysis to generate injury and fatality distributions in 10-yr period similar to those for other materials considered in the NTRA, we used a Monte Carlo analysis that randomly samples the model fatality and injury distributions summarized in Table 2.18. Event frequencies are randomly selected on the basis of incident frequencies (Table 2.18). For each event, a fatality and injury estimate is selected by using random sampling from the corresponding model distribution. To validate this general approach, we compared our fatality and injury distributions on a per-incident basis with corresponding data from the HMIS database in Table 2.19. Comparisons between our predicted cumulative probability and statistics taken from the HMIS database are made for $1,2,3,5,10,20$, and 50 persons/incident. The substantial agreement between the modeled and actual distributions demonstrates that the approach outlined here captures the actual fatality and injury distributions on a per-incident basis extremely well. However, a degree of uncertainty is present in the event frequencies, which have been necessarily corrected from HMIS database estimates. 
Table 2.19 Comparison of Predicted and Observed Fatality and Injury Distributions for Gasoline Transportation on a Per-Incident Basis

\begin{tabular}{|cccccc|}
\hline & \multicolumn{2}{c}{ Fatalities } & & \multicolumn{2}{c|}{ Injuries } \\
\cline { 2 - 3 } \cline { 5 - 6 } $\begin{array}{c}\text { Persons per } \\
\text { Incident }\end{array}$ & $\begin{array}{c}\text { Cumulative } \\
\text { Probability }\end{array}$ & $\begin{array}{c}\text { Cumulative } \\
\text { Probability }\end{array}$ & & $\begin{array}{c}\text { Cumulative } \\
\text { Predicted } \\
\text { Probability }\end{array}$ & $\begin{array}{c}\text { Cumulative } \\
\text { Probability }\end{array}$ \\
\hline 1 & 81 & 80 & 82 & 81 \\
2 & 89 & 89 & 89 & 90 \\
3 & 93.3 & 94 & 92.9 & 94 \\
5 & 97.2 & 98 & & 95.8 & 97 \\
10 & 99.49 & 100 & & 97.8 & 97 \\
20 & 99.956 & 100 & 98.7 & 98.7 \\
50 & 99.9999 & 100 & 99.60 & 100 \\
\hline
\end{tabular}

\subsection{Explosive Materials}

A wide variety of hazards arise from the detonation of explosives during an accident or ensuing fire that influence transportation risk. For clarity in the following discussion, we delineate these effects into (1) blast overpressure effects and (2) thermal effects due to an explosion generated fireball. Blast overpressure effects are further categorized into direct effects, secondary effects, and tertiary effects. Direct effects are those in which the blast-induced pressure variations damage human tissue leading to injury or death. Organs that contain substantial volumes of air (e.g., lungs, ears) are the most susceptible to this type of injury. Secondary effects are those due to blast-generated debris or missiles. Here, perforation of human tissue or blunt trauma are the principal hazards. Closely related are tertiary effects in which the body becomes a missile and impacts a fixed object. Secondary and tertiary effects are the principal blast overpressure hazards because the overpressure necessary for direct injury or death is substantially higher than that necessary for fragmentation of buildings or propulsion of large objects, including people.

Thermal effects due to explosion-generated fireballs are analogous to those from LP gas transportation (Section 2.4 and Appendix A), although some differences in the overall analysis are necessary to account for the high temperatures of fireballs that emanate from Class 1 explosives.

As for TIH materials and LP gas, we separated the general risk assessment problem into two components: estimation of event probability, which in this case is detonation, and assessment of consequences when a detonation occurs. In the following discussion and in Appendix A, we outline a simple methodology for treating each of these components in the most realistic manner possible. 


\subsubsection{Event Probabilities and Consequence Analysis}

\subsubsection{Fire-Initiated Explosions}

An accident that results in a fire is the primary mechanism that leads to an explosion. In an analysis of accident reports filed by commercial carriers, Dennis et al. (1977) estimated that the probability of a fire in a truck accident $[\mathrm{P}(\mathrm{F} \mid \mathrm{A})]$ is approximately $1.6 \%$. As Dennis et al. note, various factors influence the fire such as fuel tank involvement, amount of fuel or combustible material available, the type of accident or collision (e.g., collision with a tanker truck), the degree of involvement of the truck, and the availability of fire-fighting equipment. Because it is not practical to independently include all of these factors due to a lack of statistical information, we combined them and defined a probability that a fire will lead directly to an explosion. We refer to this as the probability of explosion given that a fire occurs $\mathrm{P}(\mathrm{E} \mid \mathrm{F})$. For Division 1.1, 1.2, 1.3, and 1.4 explosives, this probability is taken as the probability that the fire will engulf the cargo. On the basis of an analysis of limited data, Clarke et al. (1976) suggest that about $40 \%$ of fires involve cargo. Therefore, for these materials, $\mathrm{P}(\mathrm{E} \mid \mathrm{F})=0.4$. For Division 1.5 explosives, for which ammonium nitrate fuel oil mixture (ANFO) is our modeled explosive, the probability of an explosion in a fire is considerably less because a variety of other conditions need to be met. Most likely, the fire will need to burn for a considerable time (greater than $30 \mathrm{~min}$ ). For Division 1.5 materials, we set $\mathrm{P}(\mathrm{E} \mid \mathrm{F})$ as $5 \%$ because this percentage is slightly less than the probability that a truck-accident fire will exceed 30 min as estimated by Dennis et al.

If a fire-initiated explosion occurs, we also need to estimate the amount of explosive material that contributes to explosion. For most explosives, except those of Division 1.1, the amount of material that actually detonates is almost always less than the full load due to two important factors. The first is the nature of the material itself. Materials with a significant blast hazard that do not also have a mass explosion hazard are, by definition, not going to suffer explosions that simultaneously detonate the entire load. The second factor, which is especially important for Division 1.5 materials, is that a significant quantity of the material must burn to generate enough heat to detonate a portion of the remaining quantity. To address this question statistically, we assign probabilities of various percentages of the load detonating for each division. These percentages are designated to be compatible with the explosives division definitions given in CFR 49 173.50. Note that Division 1.3, 1.4, and 1.6 materials are not treated in the NTRA due to low commodity flow or low hazard. Parameters for these materials are listed in Table 2.20 for completeness only. 
Table 2.20 Probabilistic Data Used in Estimating the Detonation Frequency for Explosives in the NTRA

\begin{tabular}{|c|c|c|c|c|c|c|c|c|c|}
\hline \multirow[b]{2}{*}{ Division } & \multirow{2}{*}{$\begin{array}{c}P(F \mid A) \\
(\%)\end{array}$} & \multirow{2}{*}{$\begin{array}{c}P(E \mid F) \\
(\%)\end{array}$} & \multirow{2}{*}{$\begin{array}{c}P(E \mid A)^{a} \\
(\%)\end{array}$} & \multicolumn{6}{|c|}{ Load Consumed in Explosion (\%) } \\
\hline & & & & 100 & 80 & 60 & 40 & 20 & $<10$ \\
\hline 1.1 & 1.6 & 40 & 0.64 & 50 & 25 & 25 & $-b$ & - & - \\
\hline 1.2 & 1.6 & 40 & 0.64 & - & - & - & 20 & 30 & 50 \\
\hline $1.3^{\mathrm{C}}$ & 1.6 & 40 & 0.64 & - & - & & & 50 & 50 \\
\hline $1.4^{\mathrm{d}}$ & 1.6 & 40 & 0.64 & - & - & - & - & - & 100 \\
\hline 1.5 & 1.6 & 5 & 0.08 & - & 30 & 30 & 20 & 20 & - \\
\hline $1.6^{c}$ & 1.6 & 0 & 0 & - & - & - & - & - & - \\
\hline
\end{tabular}

a $P(E \mid A)=P(F \mid A) \times P(E \mid F)$.

b A hyphen denotes not applicable.

c Division 1.3 are 1.6 materials are not treated in the NTRA due to low commodity flow.

d Division 1.4 materials are not treated in the NTRA due to low risk of appreciable explosions.

\subsubsection{Crush- and Impact-Initiated Explosions}

Impact-initiated explosions related to highway accidents are rare. However, under extraordinary circumstances, Division 1.1 materials could detonate due to crush and impact forces in an accident. Obviously, such an accident would have to be extremely violent. The Dennis et al. (1977) analysis is useful in estimating the probability of such an explosion. For example, Dennis et al. estimate that the probability that velocity change will be at least 25 and $50 \mathrm{mph}$ for a 25 -ton truck is about $1.3 \%$ and $0.2 \%$, respectively. Further, Harwood and Russell (1990) report that the probability of an accident due to a collision with a train is only $0.5 \%$. Clearly, events that would lead to the impact- or crush-initiated detonation of the shipment are very rare but nevertheless significant. For this study, we set the probability of an impact- or crush-initiated explosion at $0.25 \%$, or 1 per 400 accidents. In such an event, the entire load is assumed to detonate instantaneously. This assumption is probably somewhat conservative, given the packing requirement for such materials. At this rate, however, the number of crushinitiated explosions of Division 1.1 materials is substantially less than those caused by fire.

\subsubsection{Consequence Analysis}

Figure 2.8 is a flowchart that shows the CASRAM methodology for hazard zone analysis as applied to explosives transportation. The model structure and execution are very similar to that for TIH materials and LP gas (Figures 2.2 and 2.7), although significant differences lie in both the "event tree" phase of the analysis as well as the consequence analysis. For all but Division 1.1 explosives, an external fire must ignite in the accident to promote an explosion. 


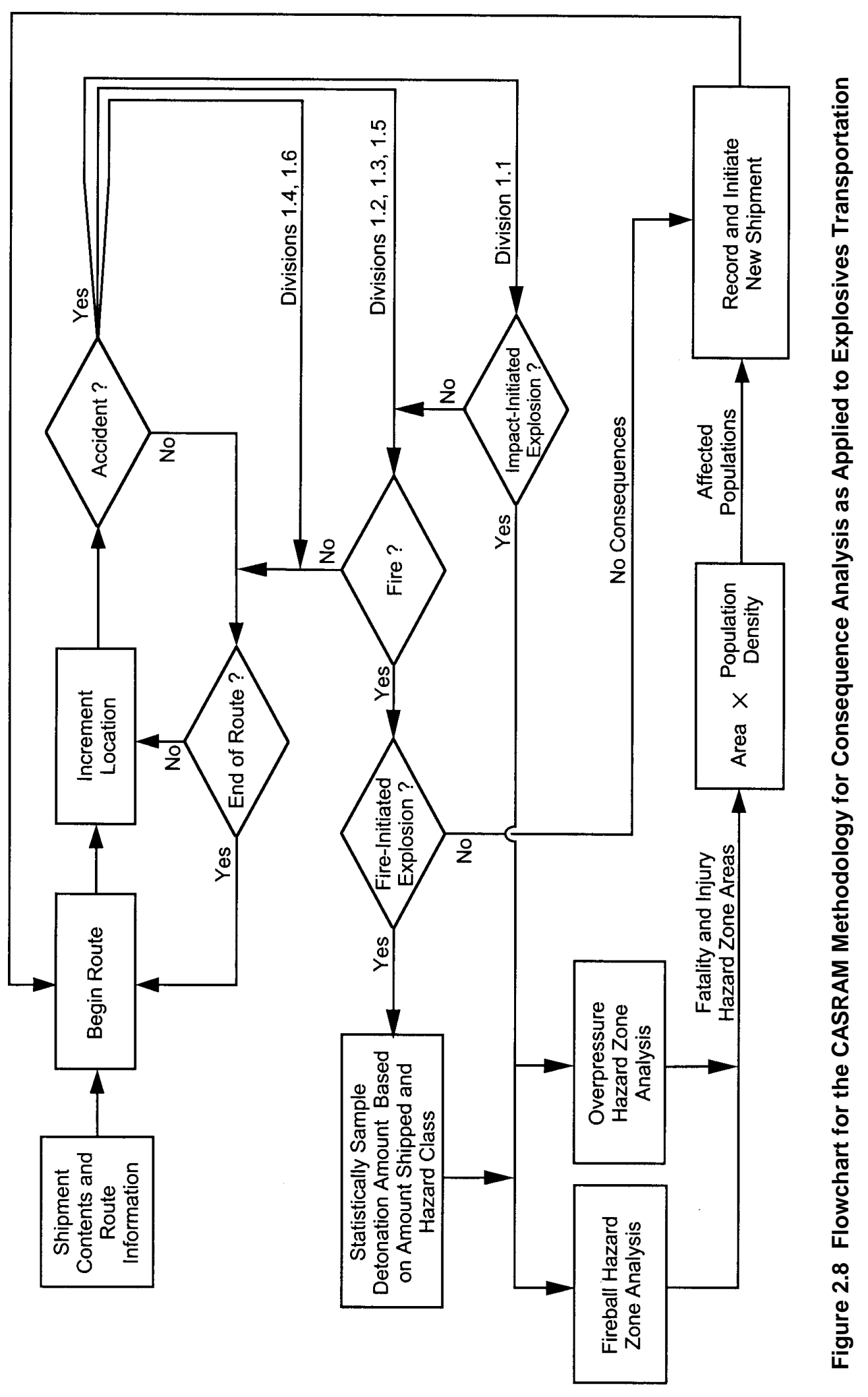


As noted, the hazards associated with explosives include (1) direct blast overpressure effects, (2) secondary overpressure effects such as impact from blast-generated debris, (3) whole-body displacement (i.e., tertiary blast effects), and (4) thermal effects due to an explosion-generated fireball. Each of these effects is considered in the NTRA analysis. Secondary and tertiary overpressure effects are grouped into the treatment of direct blast overpressure effects through their intrinsic relationship to the blast overpressure. Details of the consequence models and human health impacts considered for explosives are contained in Appendix A.

\subsection{Assumptions and Limitations}

1. The purpose of this study is to assess the risk that results from transporting selected hazardous materials and to define the nature of that risk. This information has clear implications concerning the effectiveness of current regulations as well as highlighting areas where the regulations may not be adequate. To provide the necessary baseline for addressing these questions, container specifications used in this study are taken directly from 49 CFR 172.101 and associated subsections. While this publication provides an accurate picture of transportation for many of the materials considered (e.g., ammonia, chlorine, and LP gas), it represents the minimum acceptable packaging. The true nature of the container population for some $\mathrm{TIH}$ materials may be significantly more robust than the regulations require.

2. The information developed within this report is aimed at identifying the risks associated with the transportation of hazardous materials. This study does not address the acceptability of risk or offer specific recommendations pertaining to regulations, except for highway transportation of HF. Risk acceptability and regulatory oversight are policy issues that can be addressed in future applications of the results or methodology developed in this study.

3. The accident rates and release probabilities used in this study are consistent with available historical data when averaged on a national basis; however, they do not account for certain local factors that can influence the risk, including variations in accident rates along the same type of highway or railway. Consideration of accident rate variations on a detailed level (e.g., state-by-state or even mile-by-mile) was not possible because of the broad scope of the current study. Such factors can be important when comparing one route against another but are less important when considering large numbers of routes taken together as is done in this study. For rail, the fact that train speeds in urban areas are typically lower than in rural areas may lead to a lower release probability in a derailment than is used in this study. However, the increased number of grade crossings in urban areas might increase the derailment rate, so the cumulative effect of these factors is difficult to estimate.

4. The commodity flow data for highway transportation used in this study are less reliable than those used for rail transportation. Since highway commodity flow data for chlorine, ammonia, LP gas, and explosives are derived from the 1977 CTS and 1993 CFS, the uncertainties involved for these materials are probably within a factor 
of 2 for ton-miles. Likewise, this study uses highway HF tonnage data reported by CMA, and total sulfur dioxide tonnage data reported by the Census Bureau

(Section 4.3.2). These tonnage data are probably accurate to better than $50 \%$; however, the ton-mile data, which more closely correlate with risk, are uncertain to within a factor of 2. Highway commodity flow data for fuming sulfuric acid and fuming nitric acid are derived from total sulfuric and nitric acid commodity flow data from the 1977 CTS and 1993 CFS. The percentage of fuming acid with respect to regular acid commodity flow is inferred by considering HMIS database incidents. This method provides an approximate commodity flow estimate, so commodity flow estimates on a ton-mile basis for these materials are uncertain to a factor of 3 . Errors in commodity flow estimates cause proportional errors in the total numbers of estimates for injuries and fatalities for their respective materials, but have no effect on normalized risk estimates (fatalities or injuries per million ton-miles).

5. In selecting the routes for analysis, we tried to consider the variations in shipment size, population density, and climatology characteristics in transporting the commodity considered. However, available shipment size and routing information for some materials were better than that for other materials. In particular, uncertainties in the routing information for highway transportation of $\mathrm{HF}, \mathrm{SO}_{2}$, fuming sulfuric acid, fuming nitric acid, and Class 1 explosives were high relative to the other materials. However, as shown in Section 5.2.7, uncertainties introduced through routing are limited to $50 \%$ or less. For rail, the uncertainties are much lower because the routes could be estimated with precision by using the AAR Waybill sample. The reduction of routes from all available in the Waybill sample to the 16-30 used in this study for each material introduces uncertainties of $20 \%$ or less, comparable with the uncertainties in rail commodity flow.

6. Fuming sulfuric acid or oleum is a mixture of sulfuric acid and $\mathrm{SO}_{3}$ that is classified according to the percentage by weight of excess $\mathrm{SO}_{3}$ (known as free $\mathrm{SO}_{3}$ ). The evolution of $\mathrm{SO}_{3}$ from oleum spills depends greatly on the percentage of free $\mathrm{SO}_{3}$ in the liquid, which is typically between $20 \%$ and $65 \%$. Oleum with $30 \%$ or greater free $\mathrm{SO}_{3}$ is considered a $\mathrm{TIH}$, whereas oleum with less than $30 \%$ free $\mathrm{SO}_{3}$ is not a $\mathrm{TIH}$. The analysis of oleum is complicated by the fact that the free percentage of $\mathrm{SO}_{3}$ cannot be determined from commodity flow data. In fact, oleum that is considered a TIH cannot be separated from non-TIH oleum on the basis of UN number or STCC codes. For this study, we assume one-third of oleum is shipped with $65 \%$ free $\mathrm{SO}_{3}$ and two-thirds is shipped with $30 \%$ free $\mathrm{SO}_{3}$. Separate consideration of $20 \%$ free $\mathrm{SO}_{3}$ oleum transportation would have slightly raised fatality and injury estimates in our analysis. Fatality and injury impacts from oleum with $20 \%$ free $\mathrm{SO}_{3}$ are $50 \%$ to $60 \%$ of those resulting from oleum spills with $30 \%$ free $\mathrm{SO}_{3}$, but the containers authorized for oleums with less than $30 \%$ free $\mathrm{SO}_{3}$ are significantly less robust, which would have led to more releases. 
$\Delta$ 


\section{Section 3 Review and Analysis of HMIS Incident Records}

The HMIS database catalogues transportation-related incidents that involve a release of hazardous materials. Because this database is composed of data from actual hazardous materials incidents, it is an invaluable tool in statistical analyses of hazardous material transportation incidents and is well suited for risk analysis studies such as the NTRA.

In this section, we provide a detailed review and analysis of the HMIS database and develop specific statistical data used in the risk assessment study detailed later in this report. This section begins with an overview of the HMIS database, which describes reporting requirements and provides database incident counts according to time, transportation phase (accident, en route/nonaccident or loading/unloading), and transportation mode (highway, rail, air, etc.), as well as occurrences of fire, explosion and water immersion. Section 3.2 provides a thorough breakdown of statistics concerning fatalities, injuries, and persons evacuated. We then outline the analysis of container discharge fraction distributions as categorized by container type and transportation phase in Section 3.3 and then describe temporal incident distributions in Section 3.4. Our discussion concludes with a list of suggestions for improving the quality and functionality of the HMIS database in Section 3.5.

\subsection{The HMIS Database}

\subsubsection{Reporting Requirements}

The HMIS was established in 1971 to fulfill the requirements of the Hazardous Materials Control Act of 1970. General reporting requirements apply to air, rail, water, and highway transportation and are outlined in 49 CFR 171.15 and 171.16. The requirements in $\S 171.15$ mandate that if any of the conditions listed below exist as a direct result of a hazardous materials incident occurring during transportation, the carrier must notify DOT and, in certain circumstances, other regulatory agencies at the earliest opportunity. These conditions include:

- A person being killed,

- A person receiving injuries that require hospitalization,

- Property damage in excess of $\$ 50,000$,

- An evacuation of the general public that lasts 1 or more hours, 
- Closing of one or more major transportation arteries or facilities for 1 or more hours, and

- Interruption of the operational flight pattern or routine of an aircraft.

Furthermore, $\S 171.16$ requires carriers to submit a completed written copy of DOT Form 5800.1 within 30 days for any incident that occurs as a result of transportation activities that either meets the requirements of $\S 171.15$ or involves any unintentional release of hazardous material. In addition to the above mandatory reporting requirements, a carrier can voluntarily report any hazardous material shipment-related problems.

For each incident cataloged in the HMIS database, information pertaining directly to the hazardous material release includes: (1) name of chemical shipped, (2) container type and capacity, (3) number of containers shipped, (4) number of containers that fail, and (5) the amount of material released. Multiple chemicals released during the same incident are recorded in the database as separate records. The database also contains information concerning the occurrence of fire, explosion, water immersion, environmental damage, as well as the numbers of deaths, major and minor injuries and number of persons evacuated. The death and injury statistics pertain only to the consequence of the hazardous material release and not to trauma caused by the incident.

In January 1985, RSPA established a rigorous quality assurance program for the incoming written reports (DOT Form 5800.1), which are subsequently included in the HMIS database. For this reason, HMIS incident records catalogued after 1985 are of higher quality than earlier data and are preferred for most analyses. Furthermore, beginning on January 1, 1990, additional information was added to Form DOT 5800.1. As a result, entries after 1990 are more descriptive than previous entries. The most valuable addition in this regard is the phase field, which describes the transportation phase in which the incident occurred. The transportation phases listed in HMIS are en route from the origin to the destination, loading or unloading, and temporary storage. Data previous to 1990 do not explicitly identify the transportation phase of the incidents; however, they do indicate whether a release was due to an accident or derailment. In addition to the previously noted improvements, the quality and reliability of individual reports have steadily improved over the past 10 years. A higher percentage of recent records contain written remarks, which are particularly valuable in establishing the credibility of individual records and providing supplemental information.

\subsubsection{Overview of Database Incidents}

The HMIS database contains information on 104,338 hazardous materials incidents that occurred from 1985 to 1995 . Of the 104,338 records, fewer than 100 are inconsistent in terms of report number in comparing the HAZMAT and HAZCON databases within the HMIS. Therefore, for our analysis, almost all of the records are complete. Figure 3.1 shows the number of records per year. The number of incidents reported has steadily increased over the 11-yr period. Although the frequency of hazardous materials incidents 
might be increasing slowly with time, the large increases in reported incidents shown in Figure 3.1 are the result of better and more consistent reporting of the incidents that do occur. As we see later, most of this increase is due to an increase in reporting loading and unloading incidents.

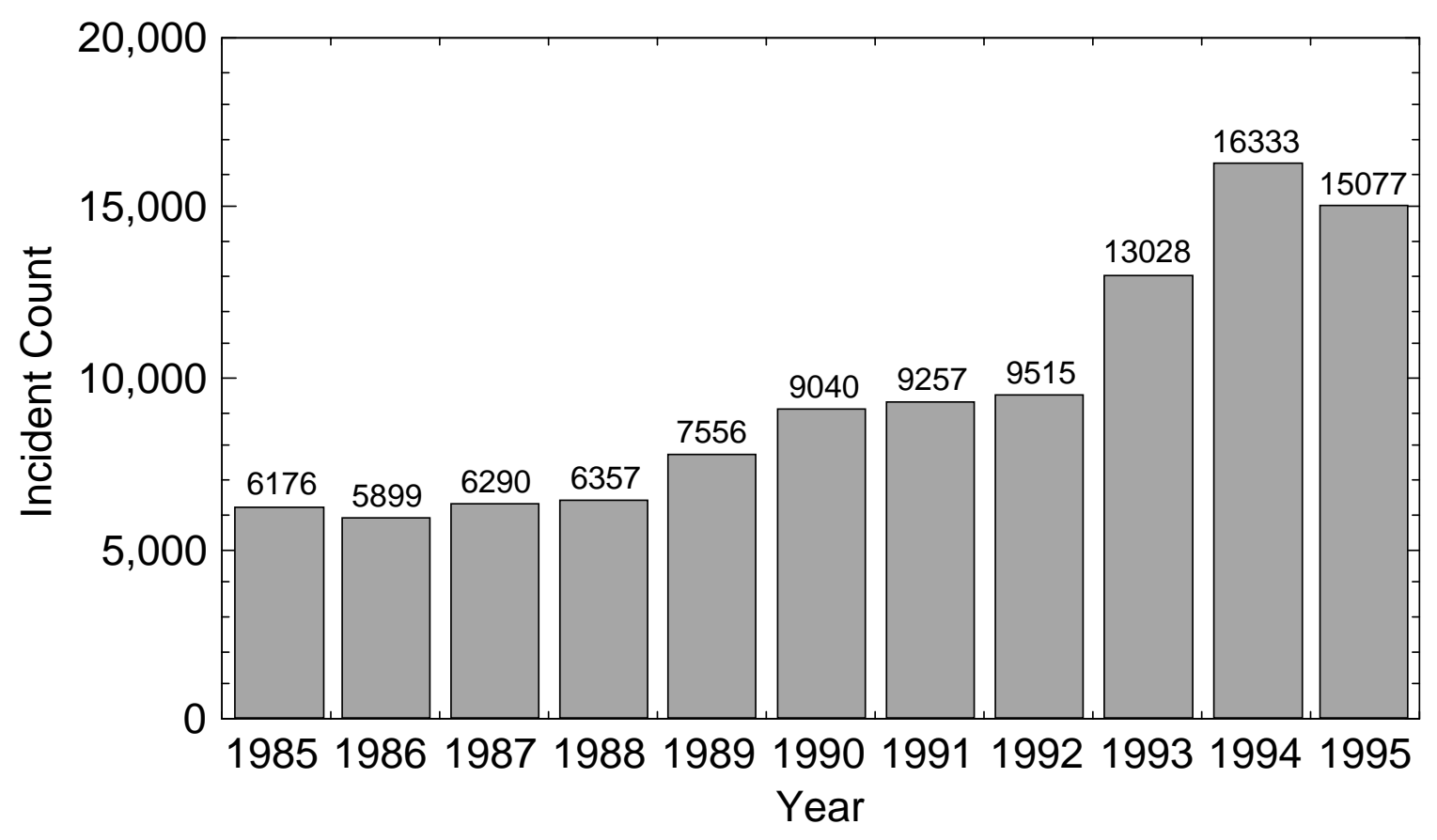

Figure 3.1 Incidents Reported in the HMIS Database, 1985-1995

Table 3.1 provides a breakdown of HMIS-reported incidents by year and transportation mode. For the 11-yr period, the total percentage of air; highway; and railrelated incidents is $4.1 \%, 83.2 \%$, and $11.9 \%$, respectively, with less than $1 \%$ of incidents associated with other transportation modes. We believe that the absence of "other" mode reports after 1990 is due to better reporting. Over the 11-yr period, reported incidents for air and highway modes increased about $800 \%$ and $250 \%$, respectively, while those for rail increased only about $30 \%$, and water-related incidents decreased slightly. Because the average air and highway shipment amounts are considerably smaller than rail and water shipment amounts, the large relative increase in air and highway incident reporting can be attributed to the increased reporting of minor incidents, in particular those that occur during loading and unloading. 
Table 3.1 Yearly and Total Numbers of Incidents Recorded in the HMIS Database for Various Transportation Modes

\begin{tabular}{|ccccccc|}
\hline Year & Air & Highway & Rail & Water & $\begin{array}{c}\text { Freight } \\
\text { Forwarder }\end{array}$ & Other \\
\hline 1985 & 119 & 4,818 & 926 & 9 & 298 & 6 \\
1986 & 122 & 4,684 & 919 & 7 & 155 & 12 \\
1987 & 165 & 5,018 & 963 & 15 & 118 & 1 \\
1988 & 174 & 4,708 & 1,029 & 16 & 66 & 1 \\
1989 & 191 & 6,157 & 1,264 & 11 & 130 & 2 \\
1990 & 300 & 7,388 & 1,343 & 7 & 0 & 0 \\
1991 & 306 & 7,697 & 1,185 & 12 & 0 & 0 \\
1992 & 430 & 7,893 & 1,159 & 6 & 0 & 0 \\
1993 & 618 & 10,577 & 1,078 & 8 & 0 & 0 \\
1994 & 943 & 14,173 & 1,190 & 6 & 0 & 0 \\
1995 & 840 & 13,000 & 1,223 & 12 & 0 & 0 \\
Total & 4,208 & 86,113 & 12,279 & 109 & 767 & 22 \\
\hline
\end{tabular}

a The freight forwarding mode was eliminated in 1990.

\subsubsection{Highway and Rail Incident Counts by Transportation Phase}

As discussed in Section 3.1.1, the transportation phase was included in the reports starting in 1990. This additional information allows hazardous material incidents to be segregated according to whether they occur en route or during loading and unloading. Table 3.2 shows the number of incidents in the HMIS database according to whether they occur (1) during an accident (i.e., during a vehicular mishap or a train derailment), (2) en route, but not during an accident (e.g., due to a cargo shift or valve failure), or (3) during loading or unloading of the material. These three categories form the basis for much of the statistical data presented throughout the rest of this section.

Table 3.2 Incident Counts Recorded in the HMIS Database for Accident, En Route/Nonaccident, and Loading/Unloading Releases for Highway and Rail Transportation, 1990-1995

\begin{tabular}{|c|c|c|c|c|c|c|}
\hline \multirow[b]{2}{*}{ Year } & \multicolumn{3}{|c|}{ Highway } & \multicolumn{3}{|c|}{ Rail } \\
\hline & $\begin{array}{c}\text { Total } \\
\text { Accidents }\end{array}$ & $\begin{array}{c}\text { En Route/ } \\
\text { Nonaccident }\end{array}$ & $\begin{array}{l}\text { Loading/ } \\
\text { Unloading }\end{array}$ & $\begin{array}{c}\text { Total } \\
\text { Accidents }\end{array}$ & $\begin{array}{c}\text { En Route/ } \\
\text { Nonaccident }\end{array}$ & $\begin{array}{l}\text { Loading/ } \\
\text { Unloading }\end{array}$ \\
\hline 1990 & 267 & 923 & 5,877 & 102 & 1,159 & 33 \\
\hline 1991 & 265 & 961 & 6,126 & 72 & 1,024 & 38 \\
\hline 1992 & 265 & 941 & 6,354 & 47 & 1,016 & 40 \\
\hline 1993 & 213 & 1,011 & 8,804 & 72 & 939 & 28 \\
\hline 1994 & 284 & 1,307 & 11,725 & 66 & 1,010 & 46 \\
\hline 1995 & 286 & 1,140 & 10,721 & 100 & 997 & 68 \\
\hline Total & 1,580 & 6,283 & 49,607 & 459 & 6,145 & 253 \\
\hline
\end{tabular}


For highway transportation, $85 \%$ of the incidents in the HMIS database occur during loading and unloading. In addition, the number of reported loading/unloading incidents has increased steadily during the past 6 years. This change accounts for approximately $80 \%$ of the total increase in incident reports in the HMIS database from 1990 to 1995. Releases occurring during vehicular accidents and derailments, as well as en route but not associated with an accident, have increased only slightly over the same time.

The distribution of rail incidents by transportation phase differs considerably from that for highway incidents. As demonstrated in Table 3.2, rail incidents are dominated by en route/nonaccident releases. Over recent years, releases occurring during accidents and while en route have tended to decrease. During this same period, the overall rail volume of hazardous materials has increased substantially. Possible reasons for the lower incident numbers include a gradual upgrading of the tank car fleet due to more stringent tank-car design criteria as well as more careful procedures for handling hazardous materials. During this same 6 yr period, the reported loading and unloading incidents has increased substantially, although such incidents represent a fairly small fraction of total rail releases.

\subsubsection{Fire, Explosion, and Waterway Entry Incidents}

The HMIS database records occurrences of fire, explosion and waterway entry of hazardous materials. Tables 3.3 and 3.4 provide the number of fire, explosion and waterway entry incidents for highway and rail, respectively, for 1990 to 1995 . Note that

Table 3.3 Number of Fire, Explosion, and Water Immersion Incidents Recorded in the HMIS Database for Highway Transportation, 1990-1995a

\begin{tabular}{|lccc|}
\hline Consequence & $\begin{array}{c}\text { Total } \\
\text { Accidents }\end{array}$ & $\begin{array}{c}\text { En Route/ } \\
\text { Nonaccident }\end{array}$ & $\begin{array}{c}\text { Loading/ } \\
\text { Unloading }\end{array}$ \\
\hline Fire & $179(11.3 \%)$ & $29(0.46 \%)$ & $75(0.15 \%)$ \\
Explosion & $53(3.4 \%)$ & $15(0.24 \%)$ & $30(0.06 \%)$ \\
Waterway entry & $125(7.9 \%)$ & $4(0.06 \%)$ & $120(0.24 \%)$ \\
\hline
\end{tabular}

a Percentage of total for each entry is provided in parentheses.

Table 3.4 Number of Fire, Explosion, and Water Immersion Incidents Recorded in the HMIS Database for Rail Transportation, 1990-1995a

\begin{tabular}{|lccc|}
\hline Consequence & $\begin{array}{c}\text { Total } \\
\text { Accidents }\end{array}$ & $\begin{array}{c}\text { En Route/ } \\
\text { Nonaccident }\end{array}$ & $\begin{array}{c}\text { Loading/ } \\
\text { Unloading }\end{array}$ \\
\hline Fire & $48(10.4 \%)$ & $17(0.28 \%)$ & $2(0.79 \%)$ \\
Explosion & $10(2.2 \%)$ & $3(0.05 \%)$ & $1(0.40 \%)$ \\
Waterway entry & $30(6.5 \%)$ & $6(0.10 \%)$ & $3(1.19 \%)$ \\
\hline
\end{tabular}

a Percentage of total for each entry is provided in parentheses. 
the incidence statistics are provided separately for accidents, en route/nonaccident, and loading/unloading releases. Also provided are the percentages of fire, explosion, and waterway entry incidents that occur for each transportation phase.

In considering these statistics, especially for accidents, note that they are specifically for accidents where a hazardous material release occurred. Thus, they are a subset of all transportation accidents and most likely reflect accidents that are more severe. In addition, the statistics for highway are somewhat skewed by incidents involving gasoline (UN 1203). For instance, highway accidents involving the release of gasoline (316) are $20 \%$ of the total recorded in the HMIS database for the period in question. Of these, 79 involved fire, 32 involved an explosion, and 44 involved a waterway entry.

\subsection{Fatalities, Injuries, and Evacuations}

Records cataloged in the HMIS database include the number of fatalities, major and minor injuries, and evacuations associated with the incident. Fatality and injury statistics in the HMIS pertain only to those related to the effects of the hazardous material, not to physical trauma involved with the accident. This consideration is important because only about $10 \%$ of all fatalities and $5 \%$ of all injuries that occur in highway accidents that involve vehicles transporting hazardous materials are the direct result of a hazardous material release (Harwood and Russell 1990). For rail accidents involving hazardous material shipments, the percentage of overall injuries and fatalities attributable to the hazardous material itself is probably much greater, however. An additional consideration is that the fatality and injury counts provided in the HMIS database are primarily those that occur at the accident scene and sometimes do not include additional injuries due to vapor inhalation or other effects in the surrounding area (especially for data prior to 1990). Therefore, the fatality and injury statistics obtained from HMIS can substantially underestimate the true number of fatalities and injuries from such incidents, especially those from TIH materials where a vapor cloud can travel a considerable distance from the accident scene. An example database record that illustrates this general problem with the HMIS database is discussed in Section 3.5.

In addition, there does not seem to be a clear distinction between major and minor injuries. Through examination of the remarks files, we found that major injuries include everything from being briefly treated and released from a local hospital to disfiguring burns and other injuries requiring long hospital stays. Minor injuries are not often mentioned in the remarks files; however, when mentioned, they seem to include everything from minor burns and other injuries requiring little or no medical attention to vapor inhalation and other injuries requiring overnight hospital stays. Where feasible in the following discussions, we have distinguished between major and minor injuries. However, the above comments should be kept in mind in interpreting these statistical results.

The remainder of this section is organized as follows. Section 3.2.1 provides an overview of fatalities, injuries, and evacuations by year for highway and rail.

Section 3.2.2 examines the distribution of these consequences by transportation phase. 
Sections 3.2.3 and 3.2.4 consider the distribution of fatalities, injuries, and evacuations by hazard class and chemical, respectively, and Section 3.2.5 breaks down these statistics by container type.

\subsubsection{Fatalities, Injuries, and Evacuations by Year}

Table 3.5 gives the HMIS fatality, injury, and evacuation records for 1985 to 1995 (evacuations were not recorded until 1990) for rail and highway incidents. For rail and highway accidents, 120 deaths, 373 major injuries, and 3,634 minor injuries are listed. For all shipping modes, the corresponding numbers of affected persons are 120, 392, and 4,018 , respectively, indicating that rail and highway were responsible for all fatalities, $95 \%$ of the major injuries, and $88 \%$ of the minor injuries.

A listing of all incidents that involved fatalities or major injuries is given in Appendix E. This list includes the name and hazard class of the commodity involved, the transportation phase, the container type, the release amount, and the container capacity.

Table 3.5 Number of Fatalities, Major Injuries, Minor Injuries, and Persons Evacuated as Reported in the HMIS Database for Rail and Highway Incidents, 1985-1995

\begin{tabular}{|c|c|c|c|c|c|c|c|c|}
\hline \multirow[b]{2}{*}{ Year } & \multicolumn{4}{|c|}{ Rail } & \multicolumn{4}{|c|}{ Highway } \\
\hline & Fatalities & $\begin{array}{c}\text { Major } \\
\text { Injuries }\end{array}$ & $\begin{array}{c}\text { Minor } \\
\text { Injuries }\end{array}$ & $\begin{array}{l}\text { No. of Persons } \\
\text { Evacuated }\end{array}$ & Fatalities & $\begin{array}{l}\text { Major } \\
\text { Injuries }\end{array}$ & $\begin{array}{l}\text { Minor } \\
\text { Injuries }\end{array}$ & $\begin{array}{l}\text { No. of Persons } \\
\text { Evacuated }\end{array}$ \\
\hline 1985 & 0 & 9 & 44 & $-a$ & 8 & 10 & 185 & - \\
\hline 1986 & 1 & 6 & 53 & - & 16 & 45 & 184 & - \\
\hline 1987 & 0 & 0 & 25 & - & 10 & 18 & 225 & - \\
\hline 1988 & 0 & 9 & 26 & - & 14 & 24 & 91 & - \\
\hline 1989 & 0 & 5 & 31 & - & 8 & 28 & 190 & - \\
\hline 1990 & 0 & 11 & 62 & 6,229 & 8 & 30 & 280 & 5,752 \\
\hline 1991 & 0 & 8 & 68 & 6,849 & 10 & 17 & 314 & 3,571 \\
\hline 1992 & 0 & 13 & 102 & 23,640 & 16 & 32 & 415 & 4,777 \\
\hline 1993 & 0 & 2 & 58 & 5,854 & 12 & 25 & 473 & 11,556 \\
\hline 1994 & 0 & 12 & 83 & 10,015 & 11 & 42 & 383 & 7,984 \\
\hline 1995 & 0 & 8 & 63 & 6,146 & 6 & 19 & 279 & 5,780 \\
\hline Total & 1 & 83 & 615 & 61,273 & 119 & 290 & 3,019 & 39,758 \\
\hline
\end{tabular}

a A hyphen denotes not available.

\subsubsection{Fatalities, Injuries, and Evacuations by Transportation Phase}

Table 3.6 gives a breakdown of fatality, injury, and evacuation statistics for the three transportation phases. For rail transportation, en route/nonaccident releases were responsible for most major and minor injuries, whereas derailments were responsible for most evacuations. (No deaths associated with rail transportation of hazardous materials occurred during the period). For highway transportation, vehicular accidents were 
Table 3.6 Percentage of Fatalities, Major Injuries, Minor Injuries, and Persons Evacuated for Rail and Highway Incidents Occurring in Accidents, En Route/Nonaccident Events, and Loading/Unloading Events as Determined from the HMIS Database, 1990-1995

\begin{tabular}{|c|c|c|c|c|c|c|}
\hline \multirow[b]{2}{*}{ Consequence } & \multicolumn{3}{|c|}{ Rail (\%) } & \multicolumn{3}{|c|}{ Highway (\%) } \\
\hline & Accident & $\begin{array}{c}\text { En Route/ } \\
\text { Nonaccident }\end{array}$ & $\begin{array}{l}\text { Loading/ } \\
\text { Unloading }\end{array}$ & Accident & $\begin{array}{c}\text { En Route/ } \\
\text { Nonaccident }\end{array}$ & $\begin{array}{l}\text { Loading/ } \\
\text { Unloading }\end{array}$ \\
\hline Fatalities & 0 & 0 & 0 & 95.2 & 0 & 4.8 \\
\hline Major injuries & 9.6 & 73.1 & 17.3 & 28.3 & 11.8 & 59.9 \\
\hline Minor injuries & 23.4 & 67.6 & 9.0 & 9.5 & 23.1 & 67.3 \\
\hline Evacuations & 70.8 & 27.5 & 1.7 & 51.1 & 16.8 & 32.1 \\
\hline
\end{tabular}

responsible for the majority of fatalities and a large percentage of evacuations, and loading/unloading incidents were responsible for most major and minor injuries.

\subsubsection{Fatalities, Injuries, and Evacuations by Hazard Class}

Table 3.7 lists the fatalities, major injuries, minor injuries, and numbers of persons evacuated for various hazard classes, and Table 3.8 provides a list of the top four hazard classes in terms of fatality, injury, and evacuation consequences. Hazard Class 3 (Flammable Combustible Liquid) is responsible for most fatalities, with the majority due to highway transportation of gasoline. Flammable compressed gases comprise the next group of fatalities with $16 \%$. The breakdown is substantially different for injuries, however; corrosive materials and poisonous materials and gases account for about onehalf of the injuries, with flammable materials accounting for most of the remainder. Concerning evacuation statistics, Hazard Class 3 (Flammable Combustible Liquid) is the leading contributor. However, almost one-half of all persons evacuated as a result of Hazard Class 3 incidents (and 20\% of all persons evacuated in Tables 3.7 and 3.8) are due to one incident that involved a benzene release that resulted from a rail accident near Duluth, Minnesota, in June 1992. Although benzene is a Hazard Class 3 material, it was the potential toxic effects of the benzene vapor cloud rather than the flammability of the material that led to the large evacuation.

Explosives (Hazard Class 1) are responsible for only one fatality, one injury, and under $1 \%$ of all persons evacuated. It is evident that on a national scale, the total risk due to the transportation of explosives is low compared with the total risk due to the transportation of flammable and poisonous materials. However, the total commodity flow for explosives is also very low, so its risk on a relative basis is not necessarily low. (The relative risk for explosives is explored further in the risk assessment portion of the study.) 
Table 3.7 Number of Fatalities, Major Injuries, Minor Injuries, and Persons Evacuated as Reported in the HMIS Database by Hazard Class of the Material, 1985-1995

\begin{tabular}{|clcccc|}
$\begin{array}{c}\text { Class/ } \\
\text { Division }\end{array}$ & \multicolumn{1}{c}{ Hazard Class } & Fatalities & $\begin{array}{c}\text { Major } \\
\text { Injuries }\end{array}$ & $\begin{array}{c}\text { Minor } \\
\text { Injuries }\end{array}$ & $\begin{array}{c}\text { No. of Persons } \\
\text { Evacuated }\end{array}$ \\
\hline 1.1 & Explosive Mass Hazard & 0 & 0 & 0 & 10 \\
1.3 & Explosives Class B & 1 & 0 & 0 & 756 \\
1.4 & Explosive No Blast Hazard & 0 & 0 & 1 & 0 \\
2.1 & Flammable Compressed Gas & 18 & 51 & 73 & 11,136 \\
2.2 & Nonflammable Compressed Gas & 0 & 8 & 180 & 4,264 \\
2.3 & Poisonous Gas & 1 & 27 & 253 & 6,646 \\
3 & Flammable and Combustible Liquids & 94 & 107 & 1,118 & 44,946 \\
4.1 & Flammable Solids & 0 & 3 & 26 & 584 \\
4.2 & Spontaneously Combustible & 0 & 0 & 3 & 72 \\
4.3 & Dangerous when Wet Material & 0 & 1 & 6 & 415 \\
5.1 & Oxidizer & 1 & 11 & 159 & 5,231 \\
5.2 & Organic Peroxide & 0 & 0 & 11 & 98 \\
6.1 & Poisonous Materials & 0 & 19 & 400 & 7,483 \\
6.2 & Infectious Substance & 0 & 0 & 2 & 0 \\
7 & Radioactive Material & 0 & 0 & 4 & 41 \\
8 & Corrosive Material & 3 & 157 & 1,580 & 20,332 \\
9 & Miscellaneous Hazardous Material & 2 & 9 & 198 & 488 \\
\hline
\end{tabular}

a The number of persons evacuated was not recorded prior to 1990 .

Table 3.8 Top Three Hazard Classes in Terms of Fatalities, Major Injuries, Minor Injuries, and Persons Evacuated as Determined from the HMIS Database, 1985-1995a

\begin{tabular}{|c|c|c|c|c|c|c|c|c|}
\hline \multirow[b]{2}{*}{ Rank } & \multicolumn{2}{|l|}{ Fatalities } & \multicolumn{2}{|c|}{ Major Injuries } & \multicolumn{2}{|l|}{ Minor Injuries } & \multicolumn{2}{|c|}{$\begin{array}{l}\text { No. of Persons } \\
\text { Evacuated }\end{array}$} \\
\hline & Hazard Class & $\%$ & Hazard Class & $\%$ & Hazard Class & $\%$ & Hazard Class & $\%$ \\
\hline 1 & $\begin{array}{l}\text { Flammable } \\
\text { combustible liquid }\end{array}$ & 77 & Corrosive material & 40 & Corrosive material & 39 & $\begin{array}{l}\text { Flammable } \\
\text { combustible liquid }\end{array}$ & 44 \\
\hline 2 & $\begin{array}{l}\text { Flammable } \\
\text { compressed gas }\end{array}$ & 16 & $\begin{array}{l}\text { Flammable } \\
\text { combustible liquid }\end{array}$ & 27 & $\begin{array}{l}\text { Flammable } \\
\text { combustible liquid }\end{array}$ & 28 & Corrosive material & 20 \\
\hline 3 & Corrosive material & 3 & $\begin{array}{l}\text { Flammable } \\
\text { compressed gas }\end{array}$ & 13 & Poisonous material & 10 & $\begin{array}{l}\text { Flammable } \\
\text { compressed gas }\end{array}$ & 11 \\
\hline
\end{tabular}

a The percentage of the respective consequences for each hazard class is also provided.

\subsubsection{Fatalities, Injuries, and Evacuations by Chemical Type}

Tables 3.9-3.12 list the top 10 materials responsible for fatalities, major injuries, minor injuries, and evacuations, respectively, and provides the percentage of the respective consequences due to each material. The top 6 materials in terms of fatalities are flammable substances with other materials individually responsible for very few 
Table 3.9 Top 10 Materials Responsible for Fatalities as Determined from the HMIS Database, 1985-1995a

\begin{tabular}{|clcc|}
\hline Rank & \multicolumn{1}{c}{ Chemical } & Fatalities & $\begin{array}{c}\text { Percentage } \\
\text { of Total }\end{array}$ \\
\hline 1 & Gasoline & 76 & 63.3 \\
2 & LP gas & 16 & 13.3 \\
3 & Petroleum crude oil & 4 & 3.3 \\
4 & Aviation fuel & 3 & 2.5 \\
5 & Ethyl hexanol & 3 & 2.5 \\
6 & Fuel oil & 2 & 1.7 \\
7 & Paint & 2 & 1.7 \\
8 & Anhydrous ammonia & 1 & 0.8 \\
9 & Toluene & 1 & 0.8 \\
10 & Hydrochloric acid & 1 & 0.8 \\
\hline
\end{tabular}

a The percentage of total fatalities for each material is also provided. Only specific materials and not generic groups (such as flammable gases n.o.s.) are listed.

Table 3.11 Top 10 Materials Responsible for Minor Injuries as Determined from the HMIS Database, 1985-1995a

\begin{tabular}{|clcc|}
\hline Rank & \multicolumn{1}{c}{ Chemical } & $\begin{array}{c}\text { Minor } \\
\text { Injuries }\end{array}$ & $\begin{array}{c}\text { Percentage } \\
\text { of Total }\end{array}$ \\
\hline 1 & Sulfuric acid & 239 & 5.9 \\
2 & Hydrochloric acid & 222 & 5.5 \\
3 & Anhydrous ammonia & 145 & 3.6 \\
4 & Sodium hydroxide & 143 & 3.6 \\
5 & Pyridine & 108 & 2.7 \\
6 & Gasoline & 102 & 2.5 \\
7 & Sulfur dioxide & 86 & 2.1 \\
8 & Formaldehyde & 84 & 2.1 \\
9 & Nitric acid & 58 & 1.4 \\
10 & Chlorine & 58 & 1.4 \\
\hline
\end{tabular}

a The percentage of total numbers of minor injuries for each material is also provided. Only specific materials and not generic groups (such as flammable gases n.o.s.) are listed.
Table 3.10 Top 10 Materials Responsible for Major Injuries as Determined from the HMIS Database, 1985-1995a

\begin{tabular}{|clcc|}
\hline Rank & Chemical & $\begin{array}{c}\text { Major } \\
\text { Injuries }\end{array}$ & $\begin{array}{c}\text { Percentage } \\
\text { of Total }\end{array}$ \\
\hline 1 & Sulfuric acid & 56 & 14.3 \\
2 & LP gas & 50 & 12.8 \\
3 & Gasoline & 42 & 10.7 \\
4 & Sodium hydroxide & 20 & 5.1 \\
5 & Anhydrous ammonia & 13 & 3.3 \\
6 & Hydrochloric acid & 11 & 2.8 \\
7 & Chlorine & 9 & 2.3 \\
8 & Nitric acid & 7 & 1.8 \\
9 & Hypochlorite solution & 5 & 1.3 \\
10 & Hydrogen peroxide & 5 & 1.3 \\
\hline
\end{tabular}

a The percentage of total numbers of major injuries for each material is also provided. Only specific materials and not generic groups (such as flammable gases n.o.s.) are listed.

Table 3.12 Top 10 Materials Responsible for Persons Evacuated as Determined from the HMIS Database, 1985-1995a

\begin{tabular}{|clcc|}
\hline Rank & \multicolumn{1}{c}{ Chemical } & $\begin{array}{c}\text { Persons } \\
\text { Evacuated }\end{array}$ & $\begin{array}{c}\text { Percentage } \\
\text { of Total }\end{array}$ \\
\hline & & & \\
1 & Benzene & 20,000 & 19.5 \\
2 & Hydrochloric acid & 6,884 & 6.7 \\
3 & LP gas & 7,970 & 7.8 \\
4 & Anhydrous ammonia & 4,479 & 4.4 \\
5 & Gasoline & 4,060 & 4.0 \\
6 & Chloroprene inhibited & 3,200 & 3.1 \\
7 & Potassium nitrate & 3,000 & 2.9 \\
8 & Hexane & 2,523 & 2.5 \\
9 & Chlorine & 2,204 & 2.2 \\
10 & Carbamate pesticide & 2,044 & 2.0 \\
\hline
\end{tabular}

a The percentage of total numbers of persons evacuated for each material is also provided. Only specific materials and not generic groups (such as flammable gases n.o.s.) are listed.

fatalities. Gasoline is particularly noteworthy. In the 11-yr record considered here, gasoline was responsible for 76 fatalities, 42 major injuries, and 102 minor injuries. In percentage terms, this is $63 \%$ of all fatalities, $11 \%$ of major injuries, and $3 \%$ of minor injuries. LP gas was responsible for 16 fatalities, 8 of which occurred during a single incident in December 1988 (Appendix E). Sulfuric acid is responsible for $14 \%$ of major injuries and $6 \%$ of minor injuries, making it the leading contributor in terms of injuries. LP gas and gasoline are responsible for $13 \%$ and $11 \%$ of all major injuries, respectively. 
Many of the remaining top 10 materials in terms of major injuries are corrosive or poisonous materials that are TIH hazards. The top 10 chemicals (in terms of minor injuries) primarily consist of corrosives; gasoline, pyridine, and formaldehyde are the only flammable substances. However, no one particular chemical is responsible for a large percentage of minor injuries.

For persons evacuated, benzene is responsible for nearly $20 \%$ of all evacuations from 1990 to 1995 . However, all evacuations from benzene are due to a single incident. In addition, 5,000 of the 6,884 persons evacuated for hydrochloric acid arose from one incident involving a release from drums in a traffic accident. The presence of a large evacuation for this material is somewhat puzzling because hydrochloric acid is not a TIH material (although anhydrous hydrochloric acid is a TIH material). Unless incorrectly reported in the HMIS database (an unlikely event), this incident might have involved a misapplication of the Emergency Response Guidebook. TIH materials and flammable materials were responsible for most of the remaining evacuations.

\subsubsection{Fatalities, Injuries, and Evacuations by Container Type}

Appendix D provides a further breakdown of fatality and injury statistics by container type. Table 3.13 lists the top 10 container types involved with fatalities and major injuries. For fatalities, the top three container types involved are those routinely involved in transporting gasoline, while numbers 4,6 , and 7 in Table 3.13 are involved in transporting LP gas. Considering that most fatalities are due to releases that occur as a result of traffic accidents, the high number of fatalities for MC 306 containers represents both the wide use of this container in transporting gasoline as well as its susceptibility to failure in a major traffic accident (i.e., those involving rollovers or direct impacts on the container). Concerning major injuries, the top two containers, $111 \mathrm{AW}$ and MC 312, are the primary rail and highway containers for sulfuric acid, respectively. The next three containers in the list are primarily used for gasoline, LP gas, sodium hydroxide, and other corrosive materials. For releases involving 111AW rail cars, most major injuries occurred as a result of en route/nonderailment events, whereby a worker was overcome with fumes from a leaking tank car, usually in a railyard. Except for MC 306 cargo tanks, more than one-half of the major injuries involving highway containers (e.g., MC 312, tank trailer n.o.s.) were due to loading/unloading incidents where the material either spilled on a worker or vapors overcame workers after a spill. For MC 306 containers, traffic accidents (most of which involved gasoline) were responsible for most major injuries. 
Table 3.13 Top 10 Container Types Involved with Fatalities and Major Injuries as Determined from the HMIS Database, 1985-1995

\begin{tabular}{|llclc|}
\hline & Container Type & Fatalities & Container Type & Major Injuries \\
\hline 1 & MC 306 & 41 & 111 AW & 41 \\
2 & Tank trailer n.o.s. & 32 & MC 312 & 37 \\
3 & Tank truck n.o.s. & 26 & Tank trailer n.o.s. & 37 \\
4 & MC 330 & 8 & Tank truck n.o.s. & 31 \\
5 & MC 307 & 5 & MC 307 & 30 \\
6 & MC 331 & 3 & MC 331 & 30 \\
7 & 105AW & 1 & MC 306 & 26 \\
8 & 21C & 1 & Tank car n.o.s. & 18 \\
9 & 37A & 1 & Metal drum n.o.s. & 10 \\
10 & Cylinder n.o.s. & 1 & 105AW & 8 \\
\hline
\end{tabular}

\subsection{Development of Discharge Fraction Distributions}

\subsubsection{Overview of Available Container Information}

Hazardous materials are shipped in various containers that depend on the nature of the material and the quantity shipped or offered for transport. The Code of Federal Regulations, Title 49, Part 172.101, together with Part 173, provides precise details on determining the acceptability of a given container for a specific hazardous material offered for transportation. In addition, Parts 173, 178, 179, and 180 provide guidance on construction and testing of rail cars, cargo tanks, and package freight containers. The acceptability of a particular container is determined by performance tests as well as the ability of the container to withstand pressure or corrosion. Performance tests include drop, leak, hydrostatic pressure, and vibration tests. For example, one type of container may leak when dropped from a height exceeding $5 \mathrm{ft}$, whereas a second type of container will not leak unless it is dropped from a height exceeding $25 \mathrm{ft}$. Consequently, the second container type receives a higher rating and is specified for use when shipping more dangerous substances.

One of the most valuable aspects of the HMIS database is that it catalogues container information in the accident records from which release data can be categorized. The containers listed in the database fall into two major groups - bulk containers and package freight containers. Bulk containers generally have capacities above 100 gal and are shipped as either a physical part of a vehicle or as portable units in small numbers. Bulk container classifications listed in the HMIS database include various types of rail tank cars (e.g., 111A, 112J, 105A) as well as highway cargo tanks (e.g., MC 306, MC 307, MC 331 tanks) and large portable tanks (e.g., 3AX cylinders, 56 and 57 tanks). Package freight containers range in size from a few ounces to approximately 100 gal and can be shipped singly or in large numbers. Package freight containers in the HMIS database fall into several categories, including drums, pressurized cylinders, cans, pails jerricans, kegs/barrels, jars, jugs, bottles, and carboys. 
Appendix C lists the frequency of specific container occurrences in the HMIS database from 1990 to 1995 for containers for which at least one incident occurred. The container types are segregated into rail cars, cargo and portable tanks, drums, cylinders, miscellaneous package freight, inside containers, and miscellaneous other containers (such as those used for bulk solids and radioactive materials). The incident numbers are provided for total occurrences, incidents where a release was reported, loading/unloading incidents, en route/nonaccident incidents, and accident incidents. All incident numbers except those in the second column from the left, which provides the total number of incidents, exclude incidents where the release amount was either given as zero or was not reported. Such non-release incidents involve those where the reporting criteria were triggered even though a release did not occur (i.e., an evacuation was ordered, highway was closed, etc.) as well as those where the release amount was either not reported or reported incorrectly. As discussed in Section 3.5, many of these non-release incidents for bulk containers (especially those for en route/nonaccident releases) are reported incorrectly. However, there is no way of assessing the release amount in these cases. For our purposes, non-release incidents are of little use in analyzing container-related statistics. Note that loading/unloading incidents, en route/nonaccident incidents, and accident-related incidents will not necessarily add to the number of incidents where a release was reported since the flags that segregate en route from loading/unloading incidents in the accidents were occasionally missing in the database records.

\subsubsection{Discharge Fraction Statistics}

One of the most important statistical measures that can be derived from the HMIS database concerns the amount of material released in hazardous material incidents. This information can be used in a variety of ways in risk assessment studies. For instance, using HMIS database observations, one may calculate (1) the average percentage of failed containers, (2) the amount of material released per container, (3) the amount of material released per shipment, and (4) the fraction of the total container capacity that is released. Each of these statistics, of course, varies considerably with container type and to some degree with material shipped.

In our preliminary analysis of the HMIS database, several of the options listed above were explored. This initial study led to the conclusion that the fraction of the container capacity released was the most robust statistic in terms of both collapsing data from a wide variety of containers and ease of use in subsequent risk assessment studies. This fraction of the total container capacity that is released is defined here as the discharge fraction. In constructing distributions for discharge fraction for various container types, we inferred the amount shipped by multiplying the number of containers by the container capacity. Since the amount of material actually shipped is not currently provided in the HMIS database, the container capacity provides the best estimate for the shipment amount. The implications of this assumption are discussed below. As an example of a discharge fraction calculation, consider a vehicular accident involving the shipment of four, 10-gal drums of acetone where 1.6 gal are released. Here, we would designate the discharge fraction as $1.6 /(4 \times 10)=0.04$. As is discussed later, this incident would be grouped with all other incidents involving drums with capacities under 20 gal in 
constructing the discharge fraction distributions for accident-related releases. As discussed later, the discharge fraction for package freight containers involved in en route/nonaccident releases and loading and unloading mishaps is calculated based on the capacity of a single container. Considering the above example, the discharge fraction would be $1.6 / 10=0.16$ if the release occurred while en route but not during an accident or during loading or unloading of the drums.

Implicit in the discharge fraction estimates discussed above is that all containers are full when shipped. This puts a nonconservative bias in the discharge fraction distributions, since not all containers are full when shipped. This is especially a problem for rail cars and cargo tanks, which are often classified as empty but contain a small amount of material (residue) that can be released in an incident. As discussed in Section 3.5, the absence of data concerning the actual shipment amount is one of the more problematic omissions in the HMIS database. In spite of this concern, the HMIS database is the best catalogue of historical release data, and discharge fraction distributions generated from the HMIS database (as defined above) provide the most realistic representation of release amounts for use in transportation risk assessment applications.

The next two sections discuss discharge fraction statistics for bulk and package freight containers, respectively. This is followed by a general discussion of the results. For each container, discharge fraction distributions are provided for three transportation-related phases in which hazardous material incidents can occur. These involve releases during (1) vehicular accidents and train derailments,

(2) en route/nonaccident events (e.g., a cargo shifts, relief valve failure, etc.), and

(3) incidents during loading or unloading of the material. For accident and derailment incidents, data from 1985 to 1995 were used. For en route/nonaccident and loading/unloading incidents, only data from 1990 to 1995 were used since before this time, en route/nonaccident and loading/unloading incidents could not be distinguished.

\subsubsection{Bulk Container Discharge Fraction Statistics}

The discharge fraction statistics for bulk containers are shown in Figures 3.2 and 3.3. Figure 3.2 shows discharge fraction distributions for containers that are used for nonpressurized and low-pressure materials, and Figure 3.3 shows discharge fraction distributions for containers that are specified for high-pressure materials. As discussed above, discharge fraction distributions are provided for the three transportation-related phases in which accidents can occur. Discharge fraction statistics for bulk package freight were developed for a specific container type (e.g., Class 111A tank cars, MC 306 tanks) when sufficient statistical data were available (i.e., at least 25 incidents). Discharge fractions for other container types for which insufficient data currently exist can be estimated using a surrogate for a similar container type for which data do exist. For example, the surrogate discharge fraction distribution for Class 103 tank cars is the discharge fraction distribution for Class 111A tank cars, and the surrogate discharge fraction distribution for MC 338 cargo tank is the discharge fraction distribution for a MC 330/331 cargo tank. In addition to specific container types, discharge fraction 

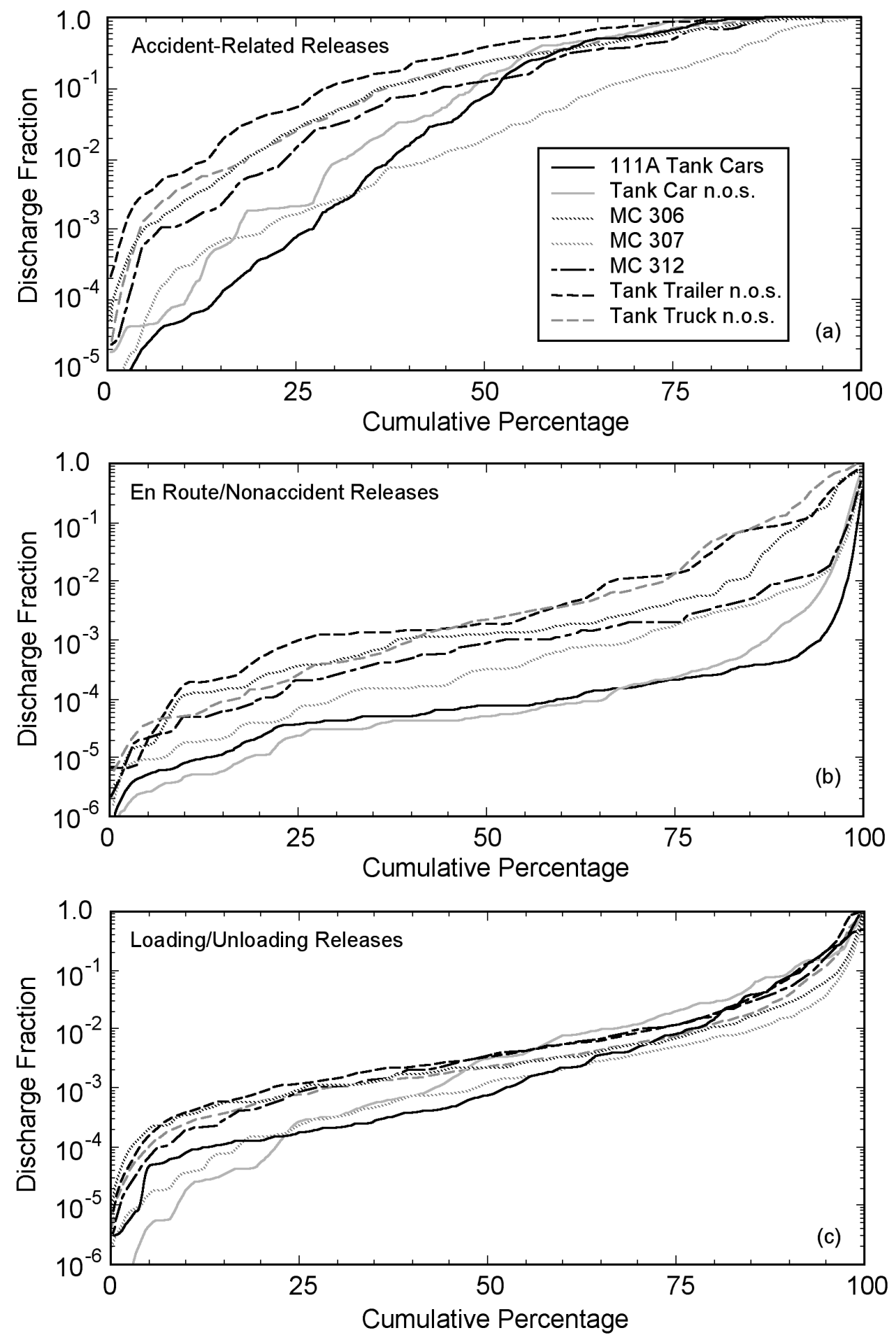

Figure 3.2 Discharge Fraction Cumulative Probability for Bulk Nonpressure and Low-Pressure Containers as Derived from the HMIS Database for (a) Accident-Related Releases, (b) En Route/Nonaccident Releases, and (c) Loading/Unloading Releases (The discharge fraction is given as the fraction of container capacity released.) 

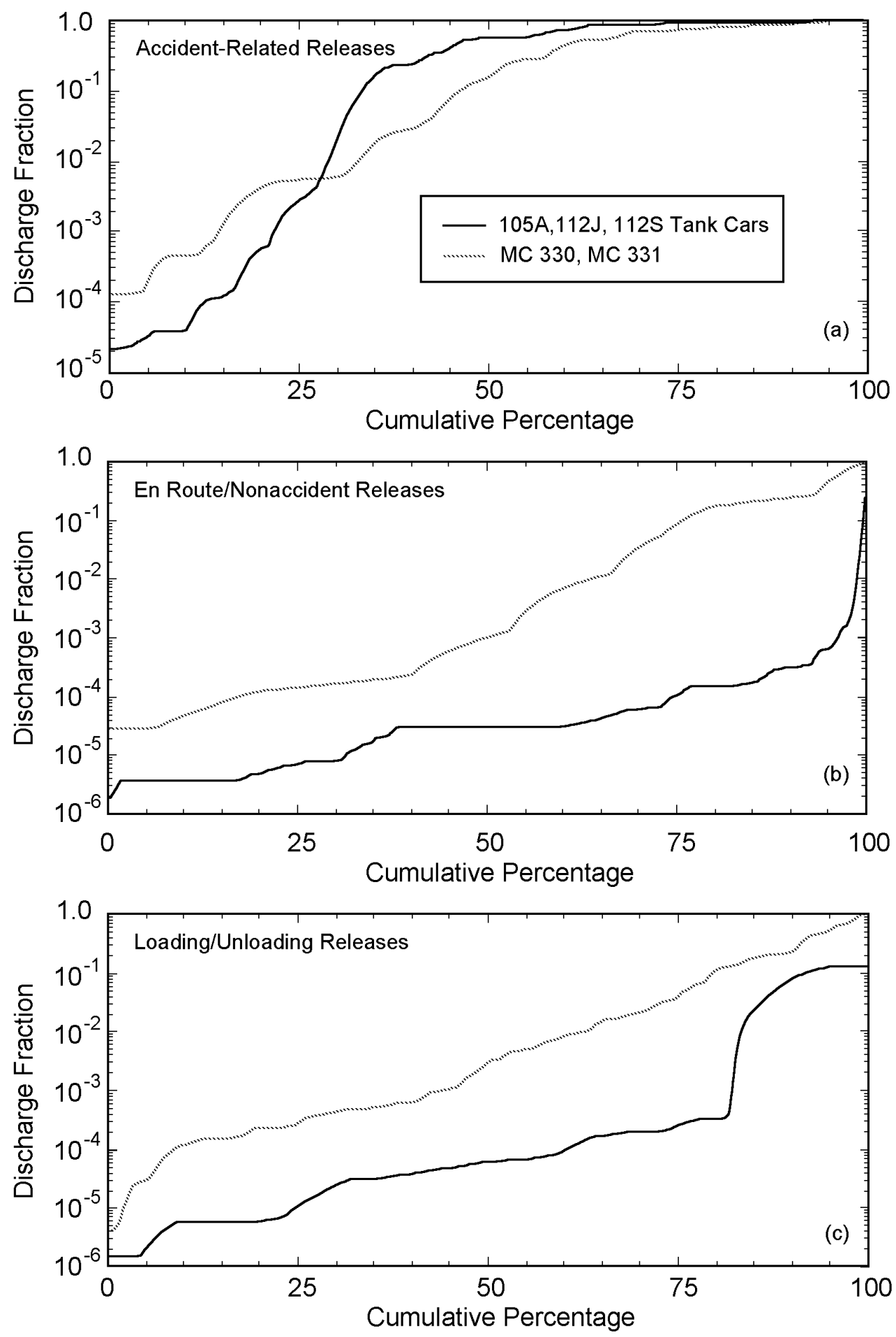

Figure 3.3 Discharge Fraction Cumulative Probability for Bulk Pressurized Containers as Derived from the HMIS Database for (a) Accident-Related Releases, (b) En Route/Nonaccident Releases, and (c) Loading/Unloading Releases (The discharge fraction is given as the fraction of container capacity that was released.) 
distributions are provided for several generic classes of bulk containers for cases in which the exact container type is unknown. These generic container categories are taken directly from the HMIS database.

The discharge fraction distributions are provided in terms of cumulative probability. In reading these distributions, the cumulative probability shown on the abscissa provides the percentage of incidents for the particular container type and transportation phase where the discharge amount normalized by the container capacity (i.e., discharge fraction) is below the amount shown on the ordinate. For instance, in considering the discharge fraction distribution for Class 111A tank cars for accident-related releases (Figure $3.2 \mathrm{a}$ ), we see that the $25^{\mathrm{th}}, 50^{\mathrm{th}}$, and $75^{\text {th }}$ percentiles correspond to discharge fractions of $0.009,0.08$, and 0.7 . Thus, $25 \%, 50 \%$, and $75 \%$ of all respective incidents had release amounts less than $0.9 \%, 8 \%$, and $70 \%$ of the tank car capacity.

The distributions for the Class 112 and 105 rail cars should be discussed. In constructing these distributions, some incidents where the generic container type "TANK CAR" was listed were used. The incidents used were ones involving anhydrous ammonia and LP gas, which are specified for transportation only in Class 105 or Class 112 tank cars. In addition, several incidents involving refrigerated gases, especially carbon dioxide, were omitted from the data. This is because in several accidents where these materials were involved, personnel at the accident site chose to vent the car to the atmosphere to facilitate clean-up activities. Additionally, refrigerated gases are more vulnerable to en route/nonaccident releases due to relief valve settings. The inclusion of these data would have biased the discharge fractions considerably. This observation also holds true for en route/nonaccident incidents involving MC 338 cargo tanks since on several occasions involving the transportation of liquid hydrogen, the entire cargo was vented in transit.

\subsubsection{Package Freight Discharge Fraction Statistics}

The discharge fraction statistics for the three phases of transportation for package freight containers as well as portable tanks are shown in Figure 3.4. Due to the large numbers of container types, discharge fraction statistics were grouped into several categories: (1) portable tanks (including metal drums with capacities greater than 100 gal), (2) metal drums with capacities less than 100 gal but greater than 20 gal, (3) metal drums with capacities less than 20 gal, (4) nonmetal drums, (5) metal cylinders, and (6) miscellaneous containers. Category 6 contains data from cans, bottles, pails, jerricans, carboys, and kegs/barrels. The discharge fraction distributions for accidentrelated releases are given in terms of the amount released as a fraction of the total container capacity (i.e., capacity of all containers combined). In contrast, the discharge fraction distributions for en route/nonaccident and loading/unloading releases are given as the fraction of the capacity of an individual container in the shipment that is released in the incident. Through trial and error, it was found that this was the most reliable method of scaling discharge fraction statistics over a variety of shipment sizes, since en route/nonaccident releases and loading/ unloading releases frequently involve damage to a single container. One drawback of this release fraction normalization for three of the 

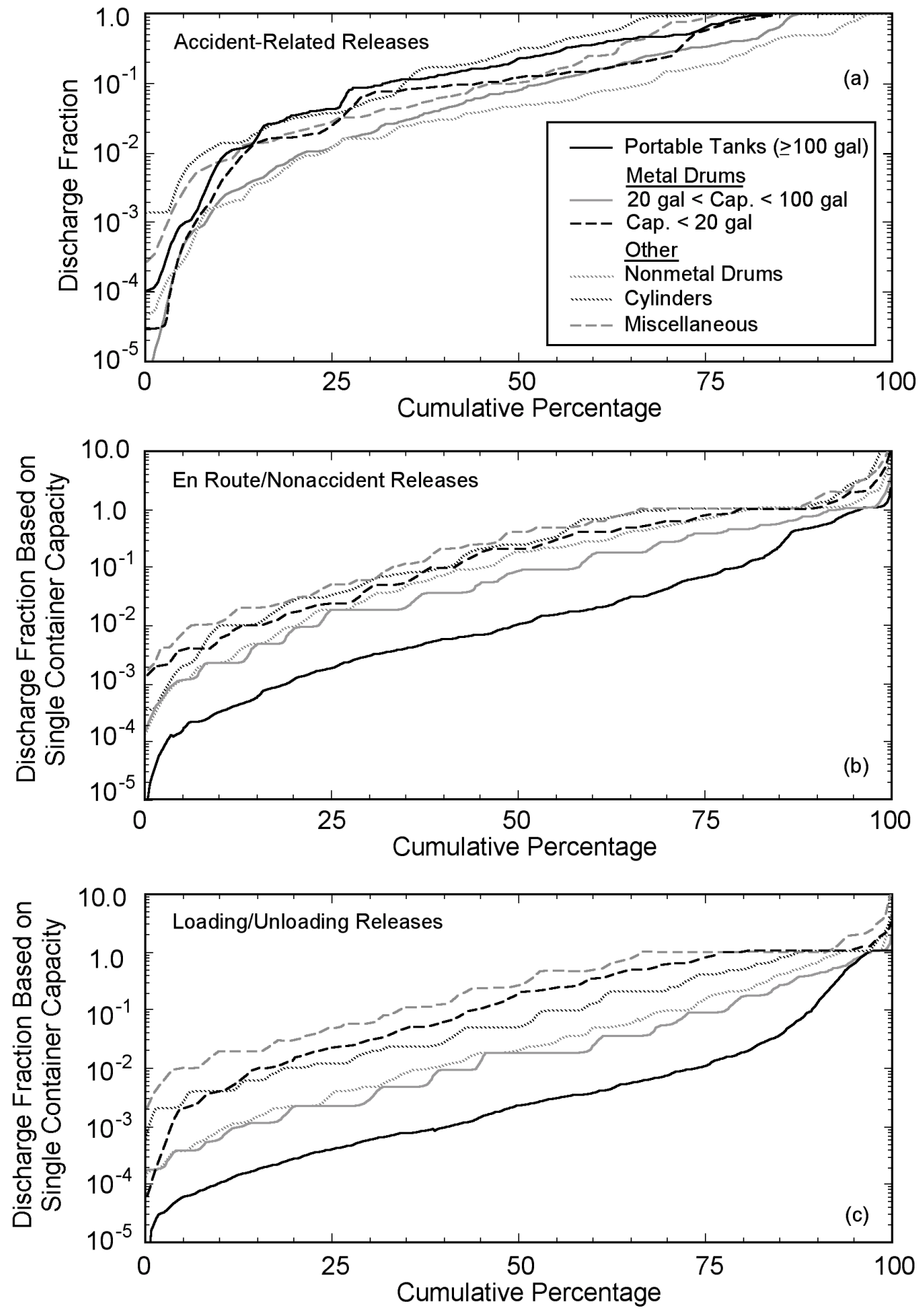

Figure 3.4 Discharge Fraction Cumulative Probability for Package Freight Containers (including portable tanks) as Derived from the HMIS Database for (a) Accident-Related Releases, (b) En Route/Nonaccident Releases, and (c) Loading/Unloading Releases (In 3.4a the discharge fraction is given as the fraction of total capacity of all containers that was releases. In $3.4 \mathrm{~b}$ and $3.4 \mathrm{c}$, the discharge fraction is given as the fraction of the single container released.) 
container categories is that the distributions do not properly represent shipments that contain only a few containers. The affected container categories are drums with capacities under 20 gal, cylinders, and miscellaneous package freight. To correct this problem, correction factors were formulated for the discharge fraction statistics for these container classes for en route/nonaccident and loading/unloading incidents where only one or two containers are involved in the shipment. These correction factors are provided in Table 3.14. Note that corrections are not necessary for cylinder discharge fraction distributions for loading/unloading incidents. As an example of the application of these correction factors, consider a shipment consisting of 1 drum under 20 gal. The release fractions for en route/nonaccident and loading/unloading incidents as read from Figure 3.4 would need to be multiplied by 0.4 and 0.6 , respectively, to provide the best representation for that shipment.

Table 3.14 Suggested Correction Factors for Use with En Route/Nonaccident and Loading/Unloading Incidents Involving Shipments of One or Two Containers $^{a}$

\begin{tabular}{|lcccc|}
\hline & \multicolumn{1}{c}{$\begin{array}{c}\text { En Route/ } \\
\text { Nonaccident }\end{array}$} & $\begin{array}{c}\text { Loading/ } \\
\text { Unloading }\end{array}$ \\
\cline { 2 - 5 } & \multicolumn{4}{c}{ No. of Containers } \\
\cline { 2 - 5 } Container Type & 1 & 2 & 1 & 2 \\
\hline Drums <20 gal & 0.4 & 0.6 & 0.6 & 0.7 \\
Cylinders & 0.5 & 0.8 & $-\mathrm{b}$ & - \\
Miscellaneous & 0.4 & 0.8 & 0.6 & - \\
\hline
\end{tabular}

a Correction factors are only necessary for three categories of package freight containers.

b A hyphen denotes not applicable.

In application of the package freight discharge fraction statistics presented here for en route/nonaccident and loading/unloading incidents, the release amount should be limited by the shipment size. This is because for releases that are above the $95^{\text {th }}$ percentile for cylinders and miscellaneous package freight containers, the release amount as estimated by the discharge fraction distributions can be several times the single-container capacity and therefore can potentially exceed the shipment amount. As an example, the release amount corresponding to the $99^{\text {th }}$ percentile of the en route/nonaccident cylinder discharge fraction is approximately 13 times the capacity of a single container. If, however, only five containers are involved in the shipment being considered, the release amount should be limited to five times the single container capacity. 


\subsubsection{Discussion}

The skewed characteristic of the discharge fraction distributions leads to fairly low mean discharge fractions for most incidents, indicating that the mean is a poor statistic for representing the general character of the distribution (as opposed to a Gaussian distribution where the mean is a reasonably descriptive statistic). In some cases, the low mean values for the discharge fraction distributions are contrary to what one might expect from a given class of containers. For instance, it is well known that a ruptured cylinder will readily release its contents, leading to a discharge fraction close to 1 . However, the low discharge fraction values for cylinders are due to the fact that many cylinder-related incidents involve small releases from a leaky valve. Additionally, a low discharge fraction value for package freight containers involved in accidents can result from the failure of a single container among a shipment of many containers.

The factors that affect the amount of material released in an accident may be loosely segregated by accident severity and container quality. In applying the discharge fraction distributions provided in Figures 3.2-3.4, one must be aware of the large variations among packaging quality and internal release mitigation measures such as nested containers and/or overpacks to absorb potential releases. In particular, many incidents used to construct the discharge fraction distributions concern releases of chemicals presenting a low level of hazard (e.g. paint, stain, oil, gasoline, acetylene). Package quality for these materials is generally less robust than that used for shipping materials representing greater risks to human health and the environment. For example, paintrelated materials and bromine can both be shipped in 55-gal drums. However, paint is generally shipped in standard unprotected 55-gal drums whereas bromine is usually shipped surrounded by thick absorbent over-packing in drums of superior construction quality (i.e., thicker gauge steel drums with all welded seams). If we consider release statistics for accidents of similar severity, release amounts for bromine, if packed as noted above, will generally be smaller than those for paint.

Ideally, separate consideration of low- and high-hazard materials within our discharge fraction distributions would be desirable. However, such specific breakdowns are not currently practical within the limitations of the HMIS database. For many container types, the vast majority of accidents in the database involve low-hazard materials, the inclusion of which is often necessary to ensure an adequate statistical sample of releases. For container types that are used for both TIH and non-TIH materials, the use of many non-TIH incidents in generating the discharge fraction distribution may lead to a degree of conservatism when the statistics are applied to TIH chemicals or other highly hazardous materials. This may especially be true for package freight containers.

\subsection{Analysis of Temporal Incident Distributions}

The HMIS database provides valuable insights into the temporal distributions of hazardous-material incidents. In particular, time of day and season are important due to large diurnal and seasonal differences in meteorology as well as diurnal changes in local population density. The temporal data presented here are currently used in CASRAM 
and are used in the transportation risk assessments discussed in this report. In applying these distributions, we imply that shipment of the individual chemicals detailed in this report follow the temporal distributions of all hazardous material shipments.

The temporal distributions are broken into two categories: (1) hour of day, and (2) month of year. Furthermore, these distributions are broken into three phases of hazardous material transportation: accident-related incidents, en route/nonaccident incidents, and loading and unloading incidents. Temporal distributions for highway and rail incidents are given in Figures 3.5-3.6 and 3.7-3.8, respectively.

Considering release statistics for highway transportation, releases initiated by vehicular accidents are most frequent during morning hours. This general distribution with hour of day agrees well with data for fatal truck accidents as cataloged by Massie (1991) and Sullivan and Massie (1992), although the peak hours for hazardous materials incidents are a few hours earlier. En route/nonaccident releases are more strongly concentrated during the midday hours when traffic volume is highest. Loading/unloading accidents also peak during the morning hours and are at a minimum during nighttime hours when work volume is lowest. Considering monthly highway release statistics, the frequency of accident-related incidents shows little variation. These incidents are slightly more frequent during August and September and are slightly less frequent in November and February. Both en route/nonaccident incidents and loading/unloading incidents have a stronger monthly dependence with maximums during mid summer and minimums during mid winter.

Considering releases resulting from rail transportation, accident-related incidents are slightly more frequent during the midday hours. Considerable hour-to-hour variations, which result from the low number of total rail incidents involving hazardous materials, may mask trends that would become apparent with a larger statistical sample.

En route/nonaccident releases and loading/unloading releases have strong peaks during midday hours. While a midday peak in the loading/unloading incidents is simply explained by considering work volume, the strong midday peak in the en route/nonaccident releases seem at first to be contrary to intuition, since it should follow rail traffic volume, which is approximately uniform with hour of day. However, a large percentage of en route/nonaccident releases are discovered in railyards, where the worker population is highest in midday hours. Many leaks in this category probably originate randomly in time, but are noticed only during midday hours. Looking at the monthly temporal distributions for rail releases, accident-related incidents appear to be most frequent in the spring (April, May, and June) and least frequent in February and August. Due to the small statistical sample, these trends may simply be a statistical aberation. En route/nonaccident releases are most frequent in summer and least frequent in winter. No clear monthly trend is evident in the loading/unloading incidents except for the strong maximums in April and August. However, these are probably also statistical aberrations due to the small statistical sample of loading/unloading incidents. 

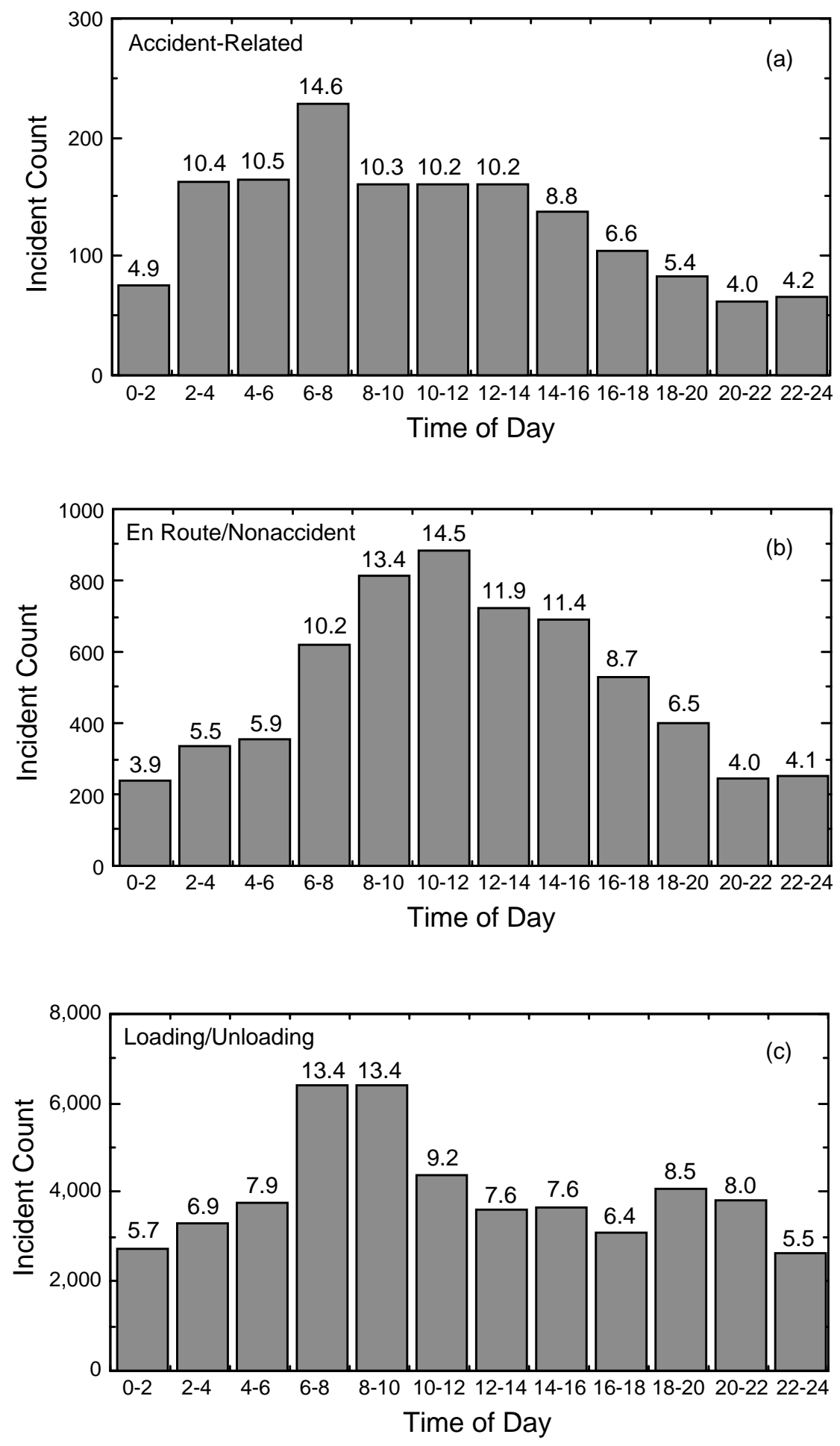

Figure 3.5 Hourly Distribution of Highway-Transportation-Related Hazardous Material Releases Occurring during (a) Vehicle Accidents, (b) En Route/Nonaccident Incidents, and (c) Loading/Unloading Incidents 

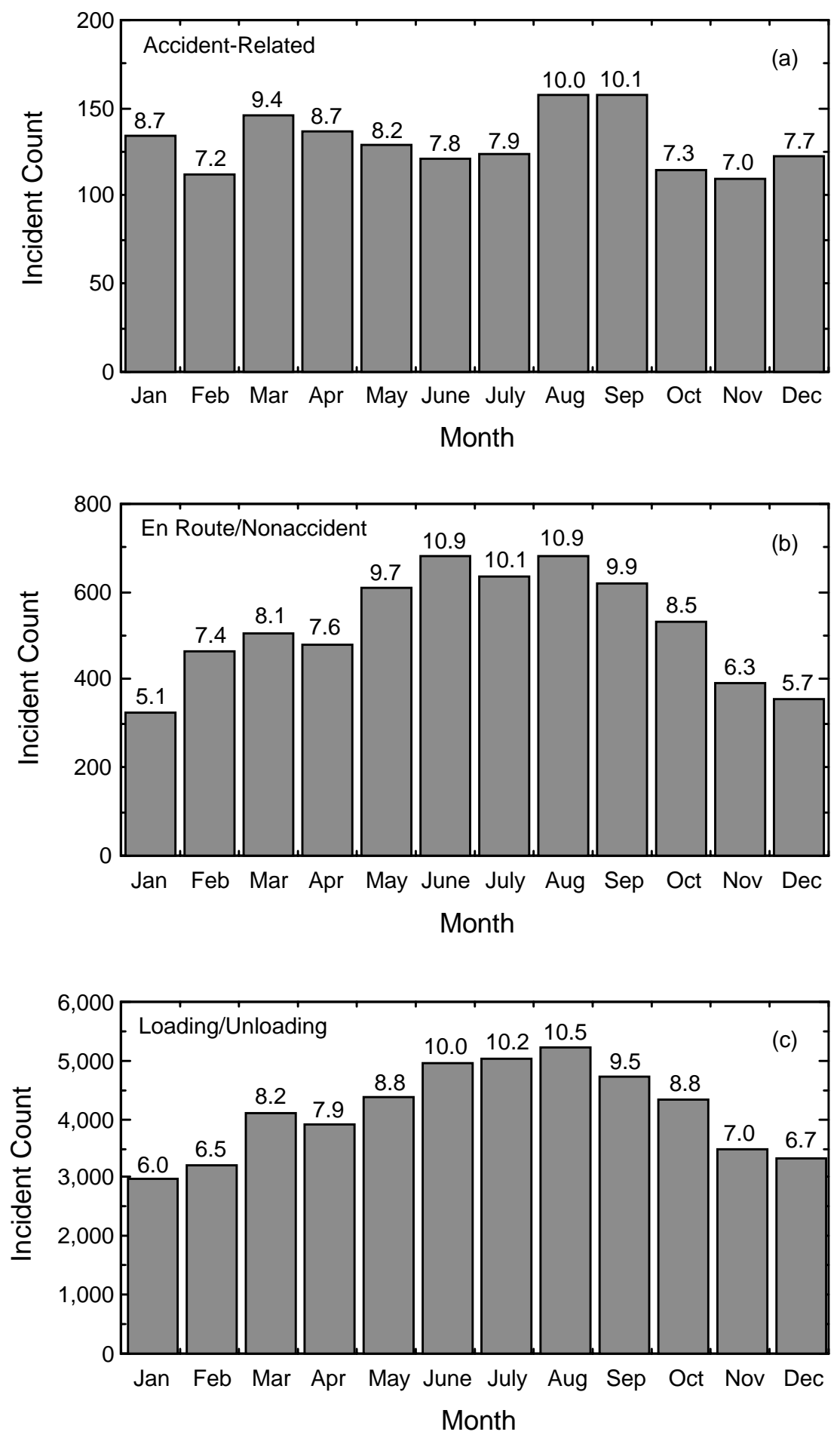

Figure 3.6 Monthly Distribution of Highway-TransportationRelated Hazardous Material Releases Occurring during (a) Vehicle Accidents, (b) En Route/Nonaccident Incidents, and (c) Loading/Unloading Incidents 

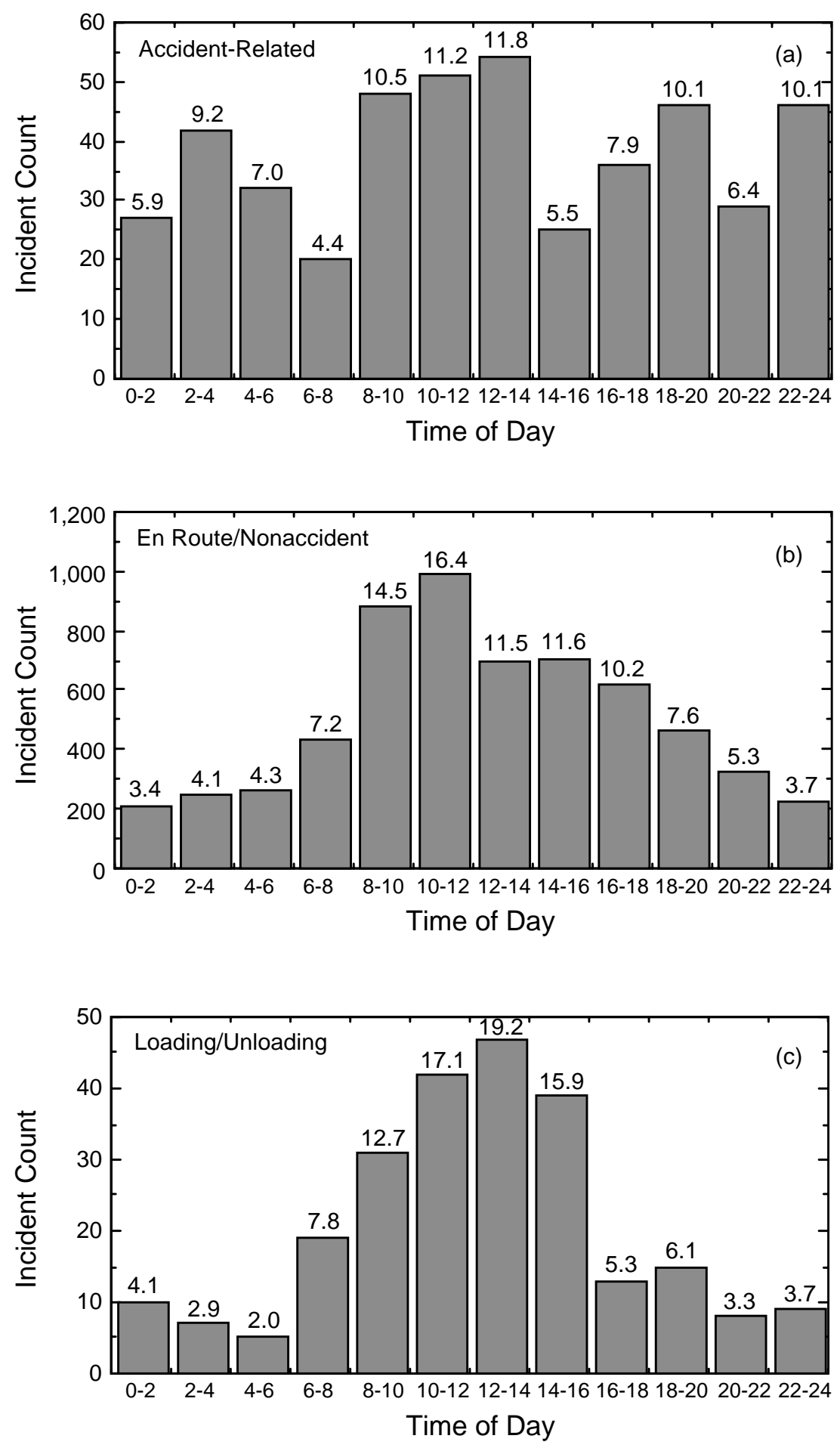

Figure 3.7 Hourly Distribution of Rail-Transportation-Related Hazardous Material Releases Occurring during (a) Train Derailments, (b) En Route/Nonaccident Incidents, and (c) Loading/Unloading Incidents 

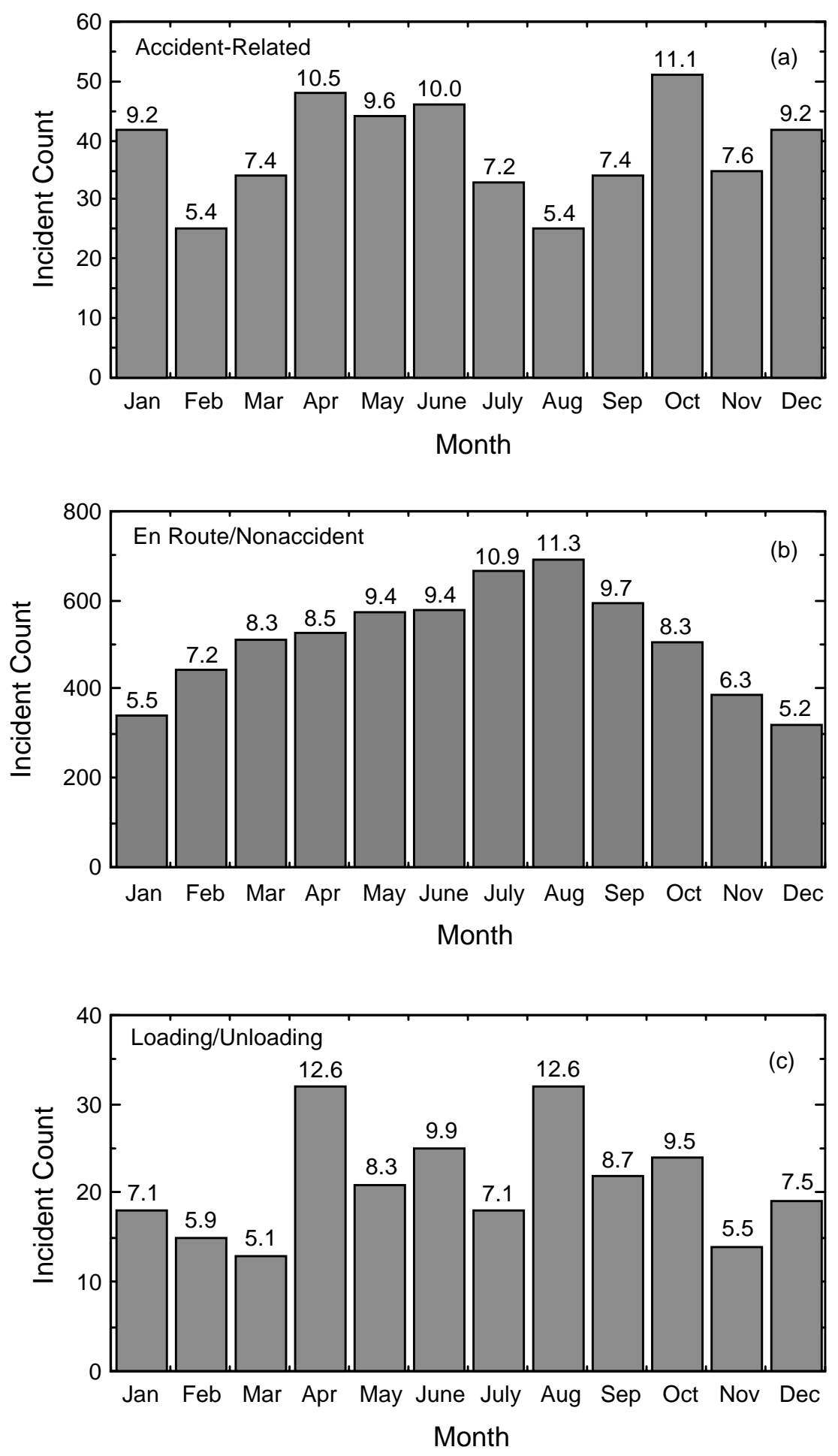

Figure 3.8 Monthly Distribution of Rail-Transportation-Related Hazardous Material Releases Occurring during (a) Train Derailments, (b) En Route/Nonaccident Incidents, and (c) Loading/Unloading Incidents 


\subsection{Suggestions for Improvements to the HMIS Database}

As previously stated, the usefulness of the HMIS database in risk-assessment studies has increased in recent years due to the inclusion of additional data fields and the increased quality of individual records. Several items, however, would further increase the usefulness of the HMIS database for the transportation risk assessment community. These are listed below:

1. An additional entry that would substantially improve discharge fraction statistics, such as those developed in our analysis, is the amount of material contained in the shipment. Currently, this information must be inferred from the container capacity and the number of containers shipped. This data field would pose little additional burden to the parties responsible for reporting the incident.

2. The usefulness of the database as a general catalogue of transportation-related hazardous material incident statistics would be greatly enhanced by including reports from carriers who solely conduct intrastate business. It is believed that only a small fraction of intrastate-shipment incidents are currently included in the HMIS database. This leads to an overall underrepresentation of incidents. Although this is a considerable problem, DOT RSPA has taken steps to correct it. As discussed in the Federal Register September 22, 1997, voluntary reporting of intrastate shippers was authorized beginning in April 1997. Mandatory reporting of incidents became effective October 1998.

3. More stringent reporting requirements coupled with a better quality control program should be implemented to correct two deficiencies in carrier reports. The first of these involves leaking containers for which the released quantity is not provided or is listed as zero. As an example, in examining liquefied gas incidents involving rail cars, we discovered many instances (in fact, a substantial majority of en route/nonaccident releases) where a zero release amount was reported even though the remarks contained in the record indicated a release occurred. Some of these incidents involved minor injuries to personnel and at least one (see below) was a major incident involving a large evacuation and at least 70 injuries to the general public. The second deficiency involves the reporting of fatality and injury statistics. Here, carriers should be required to (1) include all injuries reported at local hospitals, and (2) update information if the situation warrants. This will provide a more realistic count of the actual fatality and injury consequences involved with hazardous materials transportation. Furthermore, a more clear designation should be drawn between major and minor injuries since these categories seem to either overlap or are being misapplied.

An example illustrating the issues noted above is an en route/nonaccident release of HF from a Class 112 tank car that occurred on February 4, 1985, in Elkhart, Indiana. The HMIS database record provided by DOT (report number 85020296A) indicates that the release amount was zero and there were no injuries. However, a hydrogen fluoride study listed the release amount for this incident as 6,400 lb, making it the 
worst transportation-related release of HF in the past 20 years (EPA 1993). Indeed, a check of the remarks file (i.e., the HAZRMK file) for the incident in the HMIS database showed that 100 people were treated and released at local hospitals following the incident (this information is not listed in the HAZMAT record, though). Another interesting aspect of this incident is that EPA (1993) reports that 1,500 persons were evacuated and that 71 offsite personnel and 4 emergency responders were injured (although not seriously) and cites the HMIS database as the source for this information. This may be an error on their part, since they analyzed several databases in the course of the study (for instance, the Emergency Response Notification System database could also have provided this information); however, it raises questions as to why the database record was incomplete for a major incident such as this or, why information that was previously included in the database record may have been deleted. In considering this incident, it must be kept in mind that HMIS database reporting and quality control have improved substantially since 1985. In particular, documentation of more recent incidents such as the June 1992 benzene release near Duluth, Minnesota, is substantially better.

4. For cases involving releases from bulk containers (large metal cylinders, cargo tanks, and rail cars) that are cracked, punctured, or ruptured as a result of an accident or derailment, cataloguing the approximate size and geometry of the resulting hole would be very helpful to future investigators. For rail cars, information on container failure including hole size and hole geometry is collected by RPI (Railroad Progress Institute) and AAR. However, no information concerning hole size and geometry exists for bulk highway containers. The HMIS database could serve as a consolidated database for these critical failure statistics.

5. An additional release statistic that would be particularly valuable in certain dispersion studies is the approximate release duration, for this is a primary factor in determining the rate of emissions to the atmosphere. For some types of releases, such as leaky drums and other package freight, release duration may not be definable. However, for other release types, especially those from bulk containers, release duration may be easily determined by onsite personnel and subsequently included in the HMIS incident record.

6. A separate database containing digitized photographs of accident scenes and failed containers would be beneficial in constructing accident scenarios and evaluating container damage. This extension of the HMIS database could be similar to the current HAZRMK database except that photographs of the accident scene would be keyed by report number instead of text remarks. Photographs detailing container damage and any release-related environmental and property damage would be especially beneficial. Due to advances in computer storage, such a database is now a realistic extension of the HMIS database framework and could be easily assembled, maintained, and stored. Photographs could be referred to in the remarks record of HMIS, providing more complete descriptions of events and incident consequences. Since accidents and derailments are a small percentage of the total number of 
incidents, the photographic database would be fairly manageable in size. The database could be distributed online or on CD-ROM. 


\section{Section 4 \\ Commodity Flow and Shipment Analysis}

In this section, we present an analysis of national commodity flow and shipment information conducted as part of the NTRA. In particular, we detail the methodology used to generate representative shipments that reflect the national transportation of specific hazardous materials analyzed in the NTRA. These chemicals, identified in Section 2, are ammonia, chlorine, $\mathrm{SO}_{2}$, $\mathrm{HF}$, fuming sulfuric acid, fuming nitric acid, LP gas, and explosives. The overall goal of the commodity flow phase of the NTRA is to reduce the national transportation of specific commodities to a reasonable number of representative highway and rail shipments that accurately reflects the national distributions of geography, population density, shipment containers, and shipment sizes characteristic of the transportation of that commodity. CASRAM is used to model these representative shipments. In this manner, we determine the national risk as a result of inhalation toxicity from TIH materials, thermal radiation from LP gas, and blast overpressure and thermal radiation effects from explosives.

In Section 4.1, we outline the two primary sources of publicly available commodity flow information used in the NTRA: (1) the Surface Transportation Board (STB) Waybill Sample and (2) the CFS (formerly the Commodity Transportation Survey) conducted as part of the Economic Census. In Section 4.2, we outline the analysis of the Waybill Sample and other data to construct representative rail shipments, and in Section 4.3, we outline the use of various diverse sources to construct representative highway shipments. These sources include the 1977 CTS, the 1993 CFS, the HMIS database, and other government and industry sources.

\subsection{Primary Commodity Flow Databases}

\subsubsection{Surface Transportation Board Waybill Sample}

\subsubsection{Background on the Waybill Sample}

In 1946, the Interstate Commerce Commission (ICC) initiated a national waybill collection program. The ICC required all Class I railroads to submit copies of at least $1 \%$ of all termination waybills for rail shipments. The initial purpose of the Waybill Sample was to gather detailed information on rail traffic flow, railroad revenue, and rate structures for use in guiding regulatory policy with respect to rate proceedings. Because of the success of this system, the Waybill Sample was extended in 1964 to include additional commodity information, specifically the standard seven-digit STCC (Standard Transportation Commodity Code), which created the opportunity to use the Waybill Sample for other analyses. In the past 30 years, more specific routing data have been added to the Waybill Sample, including detailed origin, destination, and routing information. In addition, information pertaining to the rail equipment, as cataloged from the Universal Machine Equipment Register, has been added to individual waybill 
records. The result of this gradual evolution is that the Waybill Sample has become an invaluable source of information for a wide variety of commodity flow and economic analyses, especially because other economic and transportation databases and studies, such as the CFS, have been conducted on a sporadic basis or discontinued altogether in recent years.

\subsubsection{Waybill Sampling Rates}

In 1946, the ICC's original sampling method involved collecting all waybills ending with 1 or 01 . This particular sampling method was chosen for its simplicity as well as its low cost to the reporting railroads; however, this method had some drawbacks. For example, from 1946 to 1980 , the true sampling rates were closer to $0.8 \%$ rather than to $1 \%$, thus failing to meet the original criteria of the ICC. A more troubling problem is that this sampling method led to substantial bias, particularly with respect to multiple-car shipments, which were chronically under-reported.

A more modern method of sampling initiated in 1976 involves the machine-readable input (MRI) reporting system. Under this sampling method, a series of four random samples is selected from five strata categorized by the number of carloads listed on the waybill. The sampling strata are provided in Table 4.1 along with sampling rates and the corresponding expansion factor. The expansion factor is the inverse of the sampling rate and, in essence, the number of actual shipments a sample waybill represents. Since full implementation of the MRI system in the early 1980s, the sampling rates have averaged approximately $2.8 \%$.

Table 4.1 Sampling Strata in the MRI Format

\begin{tabular}{|ccc|}
\hline $\begin{array}{c}\text { No. of Cars } \\
\text { Listed on Waybill }\end{array}$ & $\begin{array}{c}\text { Percent } \\
\text { Sampled }\end{array}$ & $\begin{array}{c}\text { Expansion } \\
\text { Factor }\end{array}$ \\
\hline $1-2$ & 2.5 & 40 \\
$3-15$ & 8.3 & 12 \\
$16-60$ & 25.0 & 4 \\
$61-100$ & 33.0 & 3 \\
More than 100 & 50.0 & 2 \\
\hline
\end{tabular}

Source: AAR (1996).
A valuable addition to the Waybill Sample included in the data in this study is an "exact expansion factor" calculated from the ratio of the strata sample size to the corresponding population size. The exact expansion factor allows us to extrapolate waybill samples to estimate the overall population of rail traffic of a specific commodity with a high degree of precision. The use of expansion factors in estimating actual rail volume is illustrated in Section 4.2.1.

\subsubsection{Data Used in the NTRA}

Currently, the AAR (under contract with the STB) collects and archives the Waybill Sample. In 1995, the Waybill Sample contained more than 500,000 waybills, including 39,000 for hazardous material shipments. The Waybill Sample is archived by the STB in a 973-byte record format and is distributed in either a 570- or 274-byte format. Data distributed in the 274-byte format are public-use files and are available from the Bureau 
of Transportation Statistics (BTS). The 570-byte format is not distributed to the general public because of the potential for extracting proprietary information on specific railroads and/or their customers. Because the 570-byte format data contain the 49 series STCC, which allow specific hazardous materials to be identified, and more detailed routing data not included in the 274-byte public-use files, we obtained access to 10 years of the 570-byte format data for use in this study through an agreement between Argonne National Laboratory and AAR.

\subsubsection{Commodity Transportation Survey and Commodity Flow Surveys}

The CFS is generated from the 5-yr economic census and provides information on the national movement of various commodities. The data are organized into several categories, including a three-digit STCC (five digits in 1977), mode of transportation, amount of material shipped, and shipment mileage. Prior to 1993, the last CFS (or CTS) was conducted in 1977. Commodity flow information in the 1977 CTS was broken down into more detailed commodity categories as specified by the five-digit STCC as opposed to the less-specific three-digit STCC available in the 1993 CTS. In 1983, the CFS was conducted but was not published because of problems with the survey sample, apparently associated with the sampling procedure, and in 1987, no survey was conducted due to inadequate funding.

In 1993, the CFS covered all manufacturers, mining companies, wholesale operations, and mail-order catalog houses. The survey included 200,000 establishments that randomly sampled their individual outgoing shipments for a two-week period during each of four calendar quarters. The survey participants reported various shipment attributes, including the STCC commodity code, transportation mode, origin, destination, and monetary value. The 1977 CTS included only manufacturers, encompassing approximately 20,000 establishments. The survey participants in 1977 reported items similar in nature to those reported in 1993; however, the 1977 CTS did not include shipments from regional storage facilities, whereas the 1993 CFS included such shipments.

Both the 1977 CTS and 1993 CFS provide commodity flow information in ton-miles. In addition, statistics are further broken down by average shipment distance and average shipment size. Shipment distances reported in the 1993 CFS were calculated at Oak Ridge National Laboratory (ORNL) by the Center for Transportation Analysis, which used the $\mathrm{O} / \mathrm{D}$ zip codes provided in the survey samples. (The routing models used in generating the CFS are an earlier version of that used in conjunction with the CASRAM risk assessment model in this study.) In contrast, the shipment distances reported in the 1977 CTS were simple straight-line distances between the origin and destination, and therefore under-represented the actual travel distances by up to $30 \%$. For this reason, distance-related statistics (such as ton-miles) as reported in the 1977 CTS are somewhat biased toward smaller shipment distances. 


\subsection{Representative Shipments for Rail Transportation}

Representative shipments for rail transportation were developed by performing a statistical analysis of shipment frequency, routing (i.e., origin, destination, and passthrough states), and lading weight data provided in the STB Waybill Sample. These data were supplemented by listings of authorized car types in 49 CFR 173 and by car types found in the HMIS incident records. Section 4.2.1 outlines the analysis of O/D data in the Waybill Sample. Section 4.2.2 discusses the designation of other shipment attributes and lists the representative rail routes. Finally, Section 4.2.3 discusses the route generating code INTERLINE 5.0 and its application in this study by using origin, destination, and pass-through states provided by the Waybill Sample.

\subsubsection{Analysis of Origin and Destination Data from Waybill Samples}

Representative shipments for rail transportation were generated by performing a statistical analysis of origin, destination, and routing data provided in the STB Waybill Sample. In the 570-byte format Waybill Sample, O/D information is provided in terms of the state, Business Economic Area code, and Federal Information Processing Standard (FIPS) code. Because the FIPS code is essentially an indicator of the country, it divides the United States into approximately 3,200 zones and thus provides the greatest resolution for assessing origin and destination. Since origin and destination were treated as end points in this analysis, the FIPS code pairs, regardless of order or direction of shipment, were combined.

For each chemical, the first step in generating representative routes was to sort the 10-yr Waybill Sample record for the particular chemical by FIPS code pairs (i.e., $\mathrm{O} / \mathrm{D}$ pairs) and then combine identical pairs. In this sorting process, the total carmiles represented by the Waybill Sample was calculated by using the shipping distance and the exact expansion factor (previously discussed in Section 4.1.1) provided in the Waybill Sample. For example, for a waybill for a single chlorine tank car transported 1,500 miles with an exact expansion factor of 39, the tank-car-miles would be computed as follows:

No. of cars $\times$ distance $\times$ exact expansion factor $=$ total tank-car-miles
$1 \times 1,500 \times$
39
$=58,500$.

The FIPS code pairs were then combined and sorted according to total tank-car-miles.

To illustrate this process in more detail, we consider this analysis as applied to chlorine (STCC 28128). The 10-yr Waybill Sample analyzed for this study included 10,811 waybill samples for chlorine ladings. Of this total, 9,980 had valid $\mathrm{O} / \mathrm{D}$ information and therefore could be included in the shipment analysis. (In the remaining waybills, either origin or destination FIPS codes were missing.) These 9,980 useful records contained 1,048 different FIPS code pairs. The top 10 FIPS code pairs in terms of total tank-car-miles are listed in Table 4.2. Shown in this table are the number of waybills in the 10-yr Waybill Sample for the particular FIPS code pair, 
Table 4.2 Top 10 FIPS Code Pairs for Origin and Destination for Chlorine in the STB Waybill Sample, 1986-1995 (tank-car-miles)

\begin{tabular}{|cccccc|}
\hline FIPS Code & $\begin{array}{c}\text { No. of } \\
\text { Waybill } \\
\text { End Points }\end{array}$ & $\begin{array}{c}\text { Average } \\
\text { Distance per } \\
\text { Waybill }\end{array}$ & $\begin{array}{c}\text { Total Tank- } \\
\text { Car-Miles } \\
\text { Represented }\end{array}$ & $\begin{array}{c}\text { Cumulative } \\
\text { Fraction of } \\
\text { Totala }\end{array}$ \\
\hline 48409 & 53053 & 62 & 3,053 & $5,884,665$ & 0.034 \\
01129 & 22019 & 256 & 630 & $4,850,152$ & 0.062 \\
22019 & 29510 & 123 & 795 & $3,670,666$ & 0.084 \\
06037 & 53053 & 74 & 1,349 & $3,579,564$ & 0.105 \\
10003 & 36063 & 178 & 452 & $2,998,559$ & 0.122 \\
01129 & 22005 & 198 & 483 & $2,922,059$ & 0.139 \\
48201 & 53053 & 25 & 2,840 & $2,610,582$ & 0.154 \\
22033 & 53073 & 21 & 3,127 & $2,393,194$ & 0.168 \\
17163 & 22019 & 76 & 929 & $2,365,610$ & 0.182 \\
06013 & 22047 & 32 & 2,236 & $2,326,807$ & 0.195 \\
\hline
\end{tabular}

a The cumulative percentage with respect to total tank-car-miles.

average distance traveled according to the waybill, and the total tank-car-miles represented by the waybills corresponding to the FIPS code pair. These 10 FIPS code pairs accounted for almost $20 \%$ of the total tank-car-miles for chlorine $\left(2.2 \times 10^{8}\right)$ as represented by the entire Waybill Sample.

Ordering by total tank-car-miles provides a much different ordering of the FIPS code pairs than ordering by the number of waybills (i.e., frequency of shipment). For instance, the most frequently used shipment route is between Ascension and Iberville Counties in Louisiana (FIPS codes 22005 and 22047), but this route accounts for only $0.5 \%$ of the total tank-car-miles for chlorine because its average distance is about 50 miles. This particular FIPS code pair ranks $49^{\text {th }}$ in terms of total tank-car-miles. In fact, only three of the FIPS code pairs given in Table 4.2 appear in the top 10 FIPS code pairs when ordered by frequency of shipment. In considering risk due to en route releases (both accident and nonaccident), total tank-car-miles, not frequency of shipment, is the governing factor.

The routes with the greatest number of total tank-car-miles were chosen for detailed analysis. Between 16 and 30 routes for each of the six chemicals considered were specifically analyzed by using the CASRAM model to develop the national risk profiles discussed in Section 5. As discussed in Section 4.2.2, the shipment frequencies of these representative routes were adjusted so that the total tank-car-miles, as determined from all waybills for the respective chemical, remained the same. For $\mathrm{SO}_{2}, \mathrm{HF}$, fuming sulfuric acid, and fuming nitric acid, the routes chosen for analysis account for between $76 \%$ and $93 \%$ of the total rail commodity flow for those materials. For ammonia and chlorine, the total percentage of actual rail commodity flow represented by the 30 routes chosen for analysis is $52 \%$ and $41 \%$, respectively. For these two materials, we use 30 rail routes to adequately characterize the distributions of population density and regional climatology that govern the rail transportation risk. Although the risk could be slightly 
better resolved by considering the routes generated from all FIPS code pairs, the additional resolution would not lead to a meaningful increase in the precision of the risk assessment results because of other uncertainties in the analysis, such as accident rates and tank car failure probabilities. The sensitivity of risk to routing is further discussed in Section 5.2.7.

Because different FIPS code pairs often result in nearly identical routes due to either the origin or the destination is in the adjacent county, FIPS code pairs were combined if their respective end points were each within a threshold distance of each other. In combining the FIPS code pairs, great circle distances between the end points (i.e., the $\mathrm{O} / \mathrm{D}$ counties) were calculated on the basis of latitude and longitude of each county obtained from the Bureau of the Census. If respective end points of any two (or more) FIPS code pairs were within $60 \mathrm{~km}$ of each other, the statistics for the FIPS code pair (namely frequency of shipment and total tank-car-miles) with the fewest total tank-carmiles were added to those of the FIPS code pair with the greatest total tank-car-miles. As a net result of this combining process, the 1,048 original FIPS code pairs were reduced to 652 FIPS code pairs, and the top 30 accounted for approximately $40 \%$ of the total tankcar-miles for chlorine. In considering ammonia, 1,483 FIPS code pairs existed in the 10,284 Waybill Samples for this study. After combining the FIPS code pairs, this number was reduced to 846 , and the top 30 FIPS code pairs accounted for more than $52 \%$ of the total tank-car-miles and were analyzed in the risk assessment.

\subsubsection{Formulation of Representative Rail Shipments}

The representative rail routes for ammonia, chlorine, $\mathrm{SO}_{2}, \mathrm{HF}$, fuming sulfuric acid, and fuming nitric acid are listed in Tables 4.3 to 4.8. The cities that serve as the shipment end points were selected randomly within the county denoted by the FIPS code. For many counties, only one or two cities could be used because the O/D city provided to the INTERLINE 5.0 model must coincide with a node point in the model rail network. The tank car types were determined from 49 CFR 173, which provides a list of the authorized tank car types for each material. Where more than one tank car type was authorized, the relative percentage of the different tank car types was selected via container data in the HMIS database for the particular chemical under consideration. The lading weight in Tables 4.3 to 4.8 was determined directly from the waybill samples. For the six NTRA $\mathrm{TIH}$ chemicals, the lading weights tended to cluster around values corresponding to standard tank car sizes. The percentage of single car lading weights in six weight ranges for the six chemicals considered in this study are given in Table 4.9. The respective percentages shown in this table are reflected in the lading weights provided in Tables 4.3-4.8. In general, the single-car lading weights showed little correlation with origin and destination. However, when a trend was apparent in the Waybill Sample, it was reflected in the lading weights selected for the representative shipments. The final quantity in Tables $4.3-4.8$ is shipment distance. 
Table 4.3 Thirty Representative Rail Routes Used to Model Risk due to Rail Transportation of Anhydrous Ammonia

\begin{tabular}{|c|c|c|c|c|}
\hline \multicolumn{2}{|c|}{ Route End Points } & \multirow{2}{*}{$\begin{array}{c}\begin{array}{c}\text { Tank Car } \\
\text { Type }\end{array} \\
\text { 112S340W }\end{array}$} & \multirow{2}{*}{ 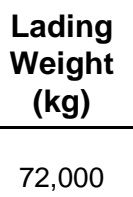 } & \multirow{2}{*}{$\begin{array}{c}\begin{array}{c}\text { Route } \\
\text { Length } \\
\text { (mi) }\end{array} \\
820\end{array}$} \\
\hline Plant City, FL & Gonzales, LA & & & \\
\hline Savannah, GA & Chocowinity, NC & $112 S 340 \mathrm{~W}$ & 73,000 & 444 \\
\hline Bartow, FL & Georgetown, LA & $105 \mathrm{~A} 300 \mathrm{~W}$ & 72,000 & 1,025 \\
\hline Bartow, FL & Monroe, LA & $112 \mathrm{~S} 340 \mathrm{~W}$ & 74,000 & 1,082 \\
\hline Woodward, OK & Provo, UT & $112 S 340 \mathrm{~W}$ & 71,000 & 1,065 \\
\hline Jasper, FL & Savannah, GA & 112J340W & 73,000 & 360 \\
\hline Enid, OK & Rock Springs, WY & 112J340W & 72,000 & 1,341 \\
\hline Carthage, MO & Enid, OK & 105A300W & 72,000 & 265 \\
\hline Bisbee, AZ & Enid, OK & 112J340W & 73,000 & 1,100 \\
\hline Plant City, FL & Pascagoula, MS & $112 S 340 \mathrm{~W}$ & 74,000 & 653 \\
\hline Beatrice, Gage, NE & Cheyenne, WY & 112J340W & 71,000 & 629 \\
\hline Bagdad, FL & Harvey, LA & $112 S 340 \mathrm{~W}$ & 68,000 & 279 \\
\hline Savannah, GA & Hopewell, VA & 112J340W & 71,000 & 504 \\
\hline Hastings, NE & Enid, OK & 105A300W & 72,000 & 685 \\
\hline Santa Ana, CA & Woodland, CA & $112 S 340 \mathrm{~W}$ & 73,000 & 771 \\
\hline Gonzales, LA & Yazoo City, MS & 112J340W & 73,000 & 243 \\
\hline Bisbee, AZ & Woodward, OK & 105A300W & 72,000 & 1,001 \\
\hline Woodward, OK & Plainview, TX & $112 S 340 \mathrm{~W}$ & 73,000 & 242 \\
\hline Bainbridge, GA & Harvey, LA & $112 \mathrm{~S} 340 \mathrm{~W}$ & 72,000 & 511 \\
\hline Soda Springs, ID & Enid, OK & 112J340W & 71,000 & 1,736 \\
\hline El Centro, CA & Woodward, OK & $112 \mathrm{~S} 340 \mathrm{~W}$ & 72,000 & 1,343 \\
\hline Beatrice, NE & Wallace, NE & 112J340W & 74,000 & 586 \\
\hline Wallace, NE & Enid, OK & 105A300W & 71,000 & 1,211 \\
\hline Lawrence, KS & Hastings, NE & $112 \mathrm{~S} 340 \mathrm{~W}$ & 72,000 & 347 \\
\hline Gonzales, LA & Abilene, TX & $112 \mathrm{~S} 340 \mathrm{~W}$ & 55,000 & 716 \\
\hline El Centro, CA & Stockton, CA & 105A300W & 73,000 & 577 \\
\hline Council Bluffs, IA & Rock Springs, WY & $112 \mathrm{~S} 340 \mathrm{~W}$ & 71,000 & 810 \\
\hline Gonzales, LA & Port Lavaca, TX & 112J340W & 72,000 & 770 \\
\hline Pascagoula, MS & Richland, WA & $112 \mathrm{~S} 340 \mathrm{~W}$ & 72,000 & 2,923 \\
\hline Bisbee, AZ & Pascagoula, MS & $112 \mathrm{~S} 340 \mathrm{~W}$ & 68,000 & 1,625 \\
\hline
\end{tabular}

Also calculated for this study are an estimated number of rail cars shipped per year based on the waybill data and the modeled number of rail cars shipped per year. These data are not provided in the tables because for some materials they may be proprietary due to the small number of manufacturers and end users. The estimated number of rail cars shipped per year is the annual number of cars shipped along the given route as estimated from the Waybill Sample. Besides accounting for the exact expansion factor previously discussed, the estimated number of shipments includes two adjustments to the actual shipment frequency. The first adjustment is a multiplier to account for the number of waybill samples for which incomplete O/D information exists. The second adjustment is a multiplier of 1.25 to account for the estimated underrepresentation of shipments in the AAR Waybill Sample because the sample accounts for only $80 \%$ of total commodity movements (Phillips and Role 1986). The modeled number of shipments per year reflects the necessary expansion of the estimated number of shipments for that particular route so 
Table 4.4 Thirty Representative Rail Routes Used to Model Risk due to Rail Transportation of Chlorine

\begin{tabular}{|c|c|c|c|c|}
\hline \multicolumn{2}{|c|}{ Route End Points } & \multirow{2}{*}{$\begin{array}{c}\begin{array}{c}\text { Tank Car } \\
\text { Type }\end{array} \\
\text { 105A500W }\end{array}$} & \multirow{2}{*}{ 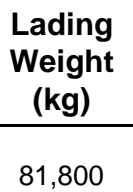 } & \multirow{2}{*}{$\begin{array}{c}\begin{array}{c}\text { Route } \\
\text { Length } \\
\text { (mi) }\end{array} \\
777\end{array}$} \\
\hline Lake Charles, LA & Ellisville, MO & & & \\
\hline Robstown, TX & Tacoma, WA & 105A500W & 81,800 & 2,969 \\
\hline Townsend, DE & Lockport, NY & 105A500W & 78,000 & 461 \\
\hline Mobile, AL & Lake Charles, LA & 105A500W & 81,800 & 403 \\
\hline Mobile, AL & Gonzales, LA & 105A500W & 81,800 & 207 \\
\hline Glendale, CA & Tacoma, WA & 105A500W & 81,800 & 1,818 \\
\hline Gonzales, LA & Boutte, LA & 105A500W & 81,800 & 72 \\
\hline Houston, TX & Tacoma, WA & 105A500W & 51,000 & 2,833 \\
\hline Baton Rouge, LA & Bellingham, WA & 105A500W & 81,800 & 2,846 \\
\hline Pittsburg, CA & Plaquemine, LA & 105A500W & 81,800 & 2,337 \\
\hline Glendale, CA & Kelso, WA & 105A500W & 77,000 & 1,243 \\
\hline Pittsburg, CA & Kelso, WA & 105A500W & 81,800 & 770 \\
\hline Lake Charles, LA & Lockport, NY & 105A500W & 81,800 & 1,724 \\
\hline Elko, NV & Kelso, WA & 105A500W & 78,000 & 859 \\
\hline Lockport, NY & Charleston, SC & 105A500W & 81,800 & 1,000 \\
\hline Portland, OR & Ogden, UT & 105A500W & 81,800 & 1,030 \\
\hline Jersey City, NJ & Lockport, NY & 105A500W & 81,800 & 505 \\
\hline Robstown, TX & Kelso, WA & 105A500W & 81,800 & 2,991 \\
\hline Lake Charles, LA & Houston, TX & 105A500W & 81,800 & 153 \\
\hline Houston, TX & Robstown, TX & 105A500W & 81,800 & 242 \\
\hline Lewiston, ID & Tacoma, WA & 105A500W & 50,000 & 519 \\
\hline Lockport, NY & Marshfield, WI & 105A500W & 81,800 & 843 \\
\hline Elko, NV & Tacoma, WA & 105A500W & 81,800 & 1,311 \\
\hline Boutte, LA & Robstown, TX & 105A500W & 78,000 & 614 \\
\hline Gonzales, LA & Kelso, WA & $105 \mathrm{~A} 500 \mathrm{~W}$ & 81,800 & 2,989 \\
\hline Dearborn, MI & Portland, OR & 105A500W & 81,800 & 2,553 \\
\hline Relay, MD & Moundsville, WV & 105A500W & 81,800 & 478 \\
\hline Lake Charles, LA & Waverly, TN & 105A500W & 81,800 & 712 \\
\hline Plaquemine, LA & Houston, TX & 105A500W & 76,000 & 283 \\
\hline Lake Charles, LA & Robstown, TX & 105A500W & 81,800 & 452 \\
\hline
\end{tabular}

that the total number of tank-car-miles for the particular chemical will be reflected by the 16 to 30 representative rail shipments. For instance, for ammonia, the 30 routes selected for detailed analysis accounted for 52\% of the actual total tank-car-miles from 1986 to 1995. Therefore, we multiply the estimated annual tank car shipment frequency for each shipment by the expansion factor $1 / 0.52=1.92$ so that the total tank-car-miles for the 30 representative shipments equals the total tank-car-miles for all ammonia rail shipments. Corresponding data for the remaining TIH materials are summarized in Table 4.10.

One last note concerns fuming sulfuric acid. The percentage of free $\mathrm{SO}_{3}$ could not be determined from the seven-digit STCC codes used to analyze rail commodity flow data. For both rail and highway, one-third of fuming sulfuric acid shipments for each route 
Table 4.5 Twenty-six Representative Rail Routes Used to Model Risk due to Rail Transportation of Sulfur Dioxide

\begin{tabular}{|c|c|c|c|c|}
\hline \multicolumn{2}{|c|}{ Route End Points } & \multirow{2}{*}{$\begin{array}{c}\begin{array}{c}\text { Tank Car } \\
\text { Type }\end{array} \\
\text { 105A300W }\end{array}$} & \multirow{2}{*}{$\begin{array}{c}\begin{array}{c}\text { Lading } \\
\text { Weight } \\
\text { (kg) }\end{array} \\
81,800\end{array}$} & \multirow{2}{*}{$\begin{array}{c}\begin{array}{c}\text { Route } \\
\text { Length } \\
\text { (mi) }\end{array} \\
860\end{array}$} \\
\hline Baton Rouge, LA & Chester, SC & & & \\
\hline Glendale, CA & Houston, TX & 105A300W & 81,800 & 1,654 \\
\hline Pittsburg, CA & Houston, TX & 105A300W & 45,500 & 2,056 \\
\hline Cicero, IL & Baton Rouge, LA & 105A300W & 81,800 & 923 \\
\hline Mobile, AL & Chester, SC & 105A300W & 82,000 & 581 \\
\hline Cicero, IL & Houston, TX & 105A300W & 49,000 & 1,124 \\
\hline Augusta, GA & Montclair, NJ & 105A300W & 81,800 & 794 \\
\hline Mobile, AL & Norfolk, VA & 105A300W & 81,800 & 1,034 \\
\hline Fresno, CA & Houston, TX & 105A300W & 48,800 & 1,883 \\
\hline Glendale, CA & Spokane, WA & 105A300W & 81,800 & 1,677 \\
\hline Mobile, AL & Kelso, WA & 105A300W & 52,000 & 3,029 \\
\hline Salt Lake City, UT & Renton, WA & 105A300W & 81,800 & 1,087 \\
\hline Albia, IA & Spokane, WA & 105A300W & 81,800 & 1,832 \\
\hline Mobile, AL & Callahan, FL & 105A300W & 81,800 & 465 \\
\hline Mobile, AL & Houston, TX & 105A300W & 82,000 & 514 \\
\hline Waterloo, IA & Houston, TX & 105A300W & 45,500 & 1,264 \\
\hline Cicero, IL & Salt Lake City, UT & 105A300W & 81,800 & 1,650 \\
\hline Mobile, AL & Augusta, GA & 105A300W & 79,000 & 529 \\
\hline Stockton, CA & Ocoee, TN & 105A300W & 81,800 & 3,143 \\
\hline Clinton, IA & Cicero, IL & 105A300W & 81,800 & 223 \\
\hline Muscatine, IA & Ocoee, TN & 105A300W & 45,500 & 967 \\
\hline Houston, TX & Bellingham, WA & 105A300W & 81,800 & 2,712 \\
\hline Mobile, AL & South River, NJ & $105 \mathrm{~A} 300 \mathrm{~W}$ & 81,800 & 1,319 \\
\hline Paducah, KY & Ocoee, TN & 105A300W & 52,000 & 494 \\
\hline Portland, OR & Houston, TX & $105 \mathrm{~A} 300 \mathrm{~W}$ & 81,800 & 2,699 \\
\hline Mobile, AL & Chadbourn, NC & 105A300W & 81,800 & 764 \\
\hline
\end{tabular}

contains $65 \%$ free $\mathrm{SO}_{3}$ and two-thirds contains $30 \%$ free $\mathrm{SO}_{3}$. Additional details are provided in Section 2.6.

\subsubsection{Calculation of Rail Routes by Using INTERLINE 5.0}

As discussed in Section 2.2, the ORNL INTERLINE 5.0 model (Johnson et al. 1993b) was used to generate the representative rail routes from origin and destination information provided by the Waybill Sample. INTERLINE is based on a sophisticated network representation of the U.S. rail system that is composed of over 13,000 nodes connected by over 15,000 links. All rail lines in the United States, except industrial rail spurs, are included in the INTERLINE network. By using the origin and destination supplied by the user, together with starting and ending railroads, INTERLINE determines a set of nodes and links that represent an optimized route between the end points under the constraints set by the user. For routes generated for the NTRA, careful attention was paid to states that the route passed through because this information was available from the Waybill Sample. For the same O/D pair, INTERLINE 5.0 can generate several 
Table 4.6 Twenty Representative Rail Routes Used to Model Risk due to Rail Transportation of Hydrogen Fluoride

\begin{tabular}{|c|c|c|c|c|}
\hline \multicolumn{2}{|c|}{ Route End Points } & $\begin{array}{c}\text { Tank Car } \\
\text { Type }\end{array}$ & $\begin{array}{c}\text { Lading } \\
\text { Weight } \\
\text { (kg) }\end{array}$ & $\begin{array}{c}\text { Route } \\
\text { Length } \\
\text { (mi) }\end{array}$ \\
\hline Louisville, KY & Harlingen, TX & $112 \mathrm{~A} 300 \mathrm{~W}$ & 76,000 & 1,395 \\
\hline Salem, NJ & Houston, TX & $112 \mathrm{~A} 300 \mathrm{~W}$ & 80,000 & 1,871 \\
\hline Salem, NJ & Harlingen, TX & $112 \mathrm{~A} 300 \mathrm{~W}$ & 80,000 & 2,171 \\
\hline Louisville, KY & Houston, TX & $112 \mathrm{~A} 300 \mathrm{~W}$ & 37,000 & 1,345 \\
\hline Gonzales, LA & Chester, PA & $112 \mathrm{~A} 300 \mathrm{~W}$ & 96,000 & 1,842 \\
\hline Wichita, KS & Gonzales, LA & $112 \mathrm{~A} 300 \mathrm{~W}$ & 76,000 & 1,043 \\
\hline Muskegon, MI & Harlingen, TX & $112 \mathrm{~A} 300 \mathrm{~W}$ & 80,000 & 1,619 \\
\hline Pittsburg, CA & Houston, TX & $112 \mathrm{~A} 300 \mathrm{~W}$ & 70,000 & 2,056 \\
\hline Belleville, IL & Harlingen, TX & $112 \mathrm{~A} 300 \mathrm{~W}$ & 76,000 & 1,218 \\
\hline Pittsburg, CA & Harlingen, TX & $112 \mathrm{~A} 300 \mathrm{~W}$ & 80,000 & 2,295 \\
\hline Wichita, KS & El Paso, TX & $112 \mathrm{~A} 300 \mathrm{~W}$ & 80,000 & 1,137 \\
\hline Wichita, KS & Harlingen, TX & $112 \mathrm{~A} 300 \mathrm{~W}$ & 37,000 & 1,054 \\
\hline Metropolis, IL & Gonzales, LA & $112 \mathrm{~A} 300 \mathrm{~W}$ & 96,000 & 600 \\
\hline Muskegon, MI & Houston, TX & $112 \mathrm{~A} 300 \mathrm{~W}$ & 63,000 & 1,247 \\
\hline Glendale, CA & Gonzales, LA & $112 \mathrm{~A} 300 \mathrm{~W}$ & 70,000 & 2,158 \\
\hline Houston, TX & Robstown, TX & $112 \mathrm{~A} 300 \mathrm{~W}$ & 76,000 & 242 \\
\hline Alameda, CA & Calvery City, KY & $112 \mathrm{~A} 300 \mathrm{~W}$ & 86,000 & 2,589 \\
\hline Wichita, KS & Laredo, TX & $112 \mathrm{~A} 300 \mathrm{~W}$ & 77,000 & 946 \\
\hline Decatur, AL & Gonzales, LA & $112 \mathrm{~A} 300 \mathrm{~W}$ & 72,000 & 565 \\
\hline Danville, IL & Houston, TX & $112 \mathrm{~A} 300 \mathrm{~W}$ & 76,000 & 1,015 \\
\hline
\end{tabular}

Table 4.7 Seventeen Representative Rail Routes Used to Model Risk due to Rail Transportation of Fuming Sulfuric Acid

\begin{tabular}{|c|c|c|c|c|}
\hline \multicolumn{2}{|c|}{ Route End Points } & $\begin{array}{c}\text { Tank Car } \\
\text { Type }\end{array}$ & $\begin{array}{c}\text { Lading } \\
\text { Weight } \\
(\mathbf{k g})\end{array}$ & $\begin{array}{c}\text { Route } \\
\text { Length } \\
\text { (mi) }\end{array}$ \\
\hline Ashland, KY & Butler, PA & $112 \mathrm{~A} 300 \mathrm{~W}$ & 82,000 & 514 \\
\hline Augusta, GA & Ocoee, TN & $112 \mathrm{~A} 300 \mathrm{~W}$ & 83,000 & 281 \\
\hline Lafayette, IN & Cincinnati, $\mathrm{OH}$ & $112 \mathrm{~A} 300 \mathrm{~W}$ & 82,000 & 295 \\
\hline Ocoee, TN & Hopewell, VA & $112 \mathrm{~A} 300 \mathrm{~W}$ & 83,000 & 707 \\
\hline Batesville, AR & Gonzales, LA & $112 \mathrm{~A} 300 \mathrm{~W}$ & 86,000 & 537 \\
\hline Buffalo, NY & Tulsa, OK & $112 \mathrm{~A} 300 \mathrm{~W}$ & 82,000 & 1,118 \\
\hline South River, NJ & Lockport, NY & $112 \mathrm{~A} 300 \mathrm{~W}$ & 83,000 & 506 \\
\hline Ashland, $\mathrm{KY}$ & Collierville, TN & $112 \mathrm{~A} 300 \mathrm{~W}$ & 82,000 & 672 \\
\hline Shreveport, LA & Alexandria, LA & $112 \mathrm{~A} 300 \mathrm{~W}$ & 65,000 & 125 \\
\hline Baton Rouge, LA & Natchez, MS & $112 \mathrm{~A} 300 \mathrm{~W}$ & 86,000 & 187 \\
\hline Cicero, IL & Butler, PA & $112 \mathrm{~A} 300 \mathrm{~W}$ & 83,000 & 542 \\
\hline Mobile, AL & Baton Rouge, LA & $112 \mathrm{~A} 300 \mathrm{~W}$ & 78,000 & 352 \\
\hline Cincinnati, $\mathrm{OH}$ & Uniontown, PA & $112 \mathrm{~A} 300 \mathrm{~W}$ & 86,000 & 434 \\
\hline Cicero, IL & Edwardsville, IL & $112 \mathrm{~A} 300 \mathrm{~W}$ & 82,000 & 358 \\
\hline Lafayette, IN & Buffalo, NY & $112 \mathrm{~A} 300 \mathrm{~W}$ & 83,000 & 491 \\
\hline Mobile, AL & Ocoee, TN & $112 \mathrm{~A} 300 \mathrm{~W}$ & 83,000 & 472 \\
\hline Dallas, TX & Houston, TX & $112 \mathrm{~A} 300 \mathrm{~W}$ & 81,000 & 318 \\
\hline
\end{tabular}


Table 4.8 Sixteen Representative Rail Routes Used to Model Risk due to Rail Transportation of Fuming Nitric Acid

\begin{tabular}{|llccc|}
\hline \multicolumn{2}{|c}{ Route End Points } & Tank Car & $\begin{array}{c}\text { Lading } \\
\text { Weight } \\
\text { (kg) }\end{array}$ & $\begin{array}{c}\text { Route } \\
\text { Length } \\
\text { (mi) }\end{array}$ \\
\hline El Dorado, AR & Salt Lake City, UT & 112A300W & 87,000 & 1,739 \\
El Dorado, AR & St. Louis, MO & $112 \mathrm{A300W}$ & 109,000 & 539 \\
El Dorado, AR & Lafayette, IN & $112 \mathrm{~A} 300 \mathrm{~W}$ & 87,000 & 780 \\
Houston, TX & Moundsville, WV & $112 \mathrm{~A} 300 \mathrm{~W}$ & 87,000 & 1,418 \\
Fresno, CA & Louisiana, MO & $112 \mathrm{~A} 300 \mathrm{~W}$ & 87,000 & 2,133 \\
Lafayette, IN & Woodbury, NJ & $112 \mathrm{~A} 300 \mathrm{~W}$ & 109,000 & 822 \\
Wilmington, NC & South River, NJ & $112 \mathrm{~A} 300 \mathrm{~W}$ & 87,000 & 691 \\
El Dorado, AR & Salem, NJ & $112 \mathrm{A300W}$ & 87,000 & 1,488 \\
Blytheville, AR & Claremore, OK & $112 \mathrm{~A} 300 \mathrm{~W}$ & 55,000 & 455 \\
Glendale, CA & Richland, WA & $112 \mathrm{~A} 300 \mathrm{~W}$ & 87,000 & 1,202 \\
Glendale, CA & Cicero, IL & $112 \mathrm{~A} 300 \mathrm{~W}$ & 87,000 & 2,249 \\
El Dorado, AR & Pittsburg, CA & $112 \mathrm{~A} 300 \mathrm{~W}$ & 87,000 & 2,217 \\
Barstow, CA & Cicero, IL & $112 \mathrm{~A} 300 \mathrm{~W}$ & 87,000 & 2,103 \\
La Salle, IL & Woodbury, NJ & $112 \mathrm{~A} 300 \mathrm{~W}$ & 55,000 & 965 \\
Louisiana, MO & Provo, UT & $112 \mathrm{~A} 300 \mathrm{~W}$ & 87,000 & 1,454 \\
Lafayette, IN & Radford, VA & $112 \mathrm{~A} 300 \mathrm{~W}$ & 87,000 & 551 \\
\hline
\end{tabular}

Table 4.9 Percentage of Single-Car Lading Weights Occurring in Six Weight Ranges for the NTRA TIH Chemicals

\begin{tabular}{|lcccccc|}
\hline & \multicolumn{7}{c|}{ Tank Car Lading Weight $(\mathbf{k g} \times \mathbf{1 , 0 0 0})$} \\
\cline { 2 - 7 } \multicolumn{1}{c}{ Chemical } & $\mathbf{0 - 2 0}$ & $\mathbf{2 0 - 4 0}$ & $\mathbf{4 0 - 6 0}$ & $\mathbf{6 0 - 8 0}$ & $\mathbf{8 0 - 1 0 0}$ & $\mathbf{> 1 0 0}$ \\
\hline Ammonia & 0.1 & 0.9 & 0.1 & 98.4 & 0.4 & 0.1 \\
Chlorine & 0.2 & 0.4 & 4.3 & 1.5 & 93.5 & 0.1 \\
Sulfur dioxide & 0 & 0.3 & 22.3 & 7.1 & 70.2 & 0 \\
Hydrogen fluoride & 0.2 & 4.3 & 2.3 & 69.2 & 23.4 & 0.5 \\
Sulfuric acid & 0.2 & 0.4 & 0.5 & 13.4 & 85.3 & 0.2 \\
Nitric acid & 1.6 & 0 & 6.3 & 3.2 & 80.0 & 9.0 \\
\hline
\end{tabular}

Table 4.10 Summary of Routing Information Used for Rail TIH Shipments

\begin{tabular}{|lccc|}
\hline \multicolumn{1}{|c}{ Chemical } & $\begin{array}{c}\text { No. of } \\
\text { Routes }\end{array}$ & $\begin{array}{c}\text { Percent of Actual } \\
\text { Commodity Flow } \\
\text { Represented }\end{array}$ & $\begin{array}{c}\text { Expansion } \\
\text { Factor }\end{array}$ \\
\hline Anhydrous ammonia & 30 & 52 & 1.92 \\
Chlorine & 30 & 41 & 2.43 \\
Sulfur dioxide & 26 & 76 & 1.31 \\
Hydrogen fluoride & 20 & 85 & 1.18 \\
Fuming sulfuric acid & 17 & 85 & 1.18 \\
Fuming nitric acid & 16 & 93 & 1.08 \\
\hline
\end{tabular}


different routes depending on the choice of origin and termination railroads. For each $\mathrm{O} / \mathrm{D}$ pair, we evaluated several routes and selected those that most closely matched the pass-through states and total route miles listed in the Waybill Sample. For more than $80 \%$ of the routes considered in this study, a very good match of pass-through states and total miles between the waybill data and the modeled route was obtained.

An example of a route generated by using INTERLINE 5.0 is provided in Table 4.11. The listing is in the form of route nodes that serve as segment end points with the node locations denoted by latitude and longitude. The designation of latitude and longitude is an option provided by a post-processor to the standard INTERLINE model, which is used for geographic information system applications. Population density information for the route segment between each node pair is given in segment mileage in each of 12 population density categories. These categories, denoted as ranges of persons per square mile $(d)$, are $d=0 ; 0<d \leq 5 ; 5<d \leq 22.7 ; 22.7<d \leq 59.7 ; 59.7<d \leq 139$; $139<d \leq 326 ; 326<d \leq 821 ; 821<d \leq 1,861 ; 1,861<d \leq 3,326 ; 3,326<d \leq 5,815$; $5,815<d \leq 9,995$; and $d>9995$. All population density information in INTERLINE 5.0 and HIGHWAY 3.3 (the companion model to INTERLINE 5.0 for highway transportation) are derived from the 1990 census.

Table 4.11 Example of a Rail Route Generated by INTERLINE 5.0 as Postprocessed to Provide Latitude and Longitude for Each Node ${ }^{a}$

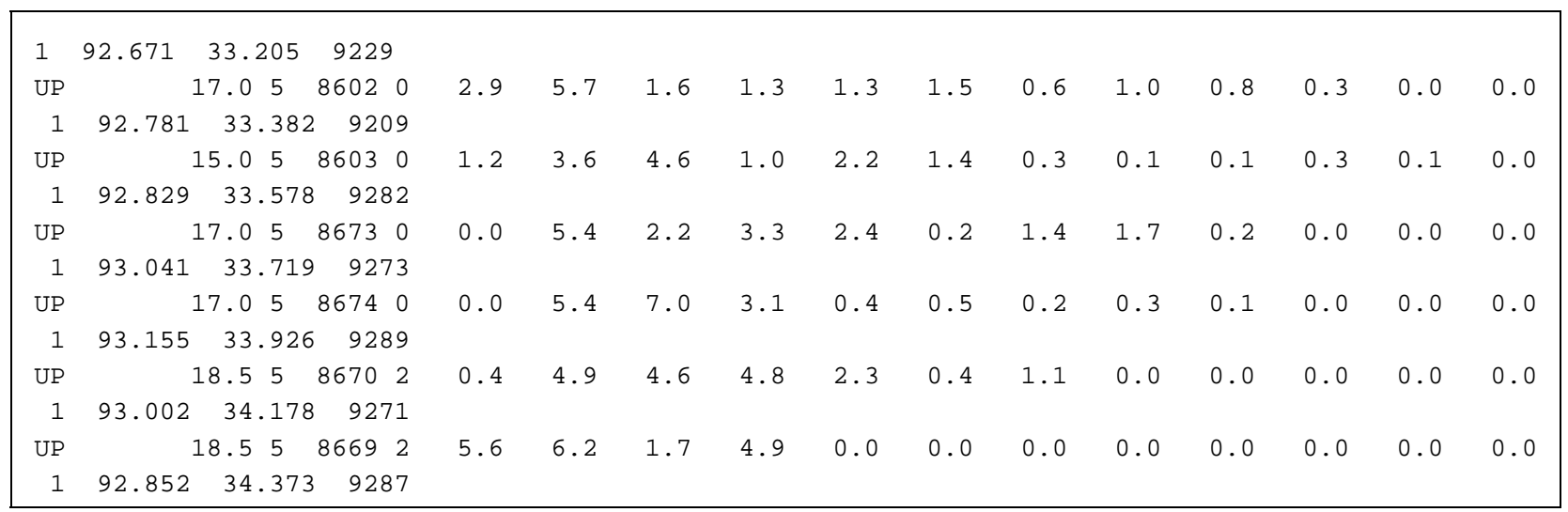

a This example provides the first six legs of the rail route between Eldorado, Arkansas, and Salt Lake City, Utah, used to model Shipment 1 for fuming nitric acid.

\subsection{Representative Shipments for Highway Transportation}

Representative shipments for highway transportation were formulated from various sources, including the 1977 CTS and 1993 CFS, the HMIS database, and other government and industry data. Due to the lack of a structured transportation data collection mechanism such as the Waybill Sample for rail transportation, greater uncertainty exists in the routing and commodity flow information for highway transportation. However, the available information is sufficient to ascertain the general commodity flow and routing characteristics of the chemicals considered in this study. 
The primary source of routing information for highway transportation used in this study was the 1977 CTS as analyzed by Maio and Liu (1988). This study, as well as our application of the study results, is discussed in Section 4.3.1. The formulation of representative shipments is discussed in Section 4.3.2. Here, the 1977 CTS, the 1993 CFS, and industry data were used to ascertain the overall commodity flow for the respective chemicals. The national commodity flow was then distributed among 10 to 33 routes for each chemical as determined by the study of Maio and Liu (1988), the HMIS database, or other data. Finally, in Section 4.3.3 we briefly discuss the routegenerating code HIGHWAY 3.3 and its application by using the shipment end point data provided by the analyses discussed in Sections 4.3.1 and 4.3.2.

\subsubsection{Analysis of Origin and Destination Data from the 1977 CTS}

The primary information used to determine commodity flow and routing information for ammonia, chlorine, fuming nitric acid, fuming sulfuric acid, and LP gas originated from the 1977 CTS. The most detailed study of the 1977 CTS for hazardous materials transportation was performed by Maio and Liu (1988), who conducted an exhaustive analysis of the 1977 CTS and the 1977 and 1983 Truck Inventory and Use Survey to quantify the amount of hazardous material and petroleum products transported by truck and to characterize the vehicle fleet involved in the transport. Although their report was published in 1988, the analysis contained therein remains the best available source for highway routing information because the 1977 CTS data used in the study are the most recent data available that provide both $\mathrm{O} / \mathrm{D}$ data and commodity-flow data on a national basis. Maio and Liu (1988) separately considered three distinct sources of truck traffic: transportation from U.S. domestic production from manufacturing plants, transportation of foreign imports from ports of entry into the United States, and transportation from regional storage facilities through which material from both U.S. manufacturing plants and foreign imports are routed. Since the 1977 CTS only contained survey information from manufacturers, detailed origin and destination data were available only for transportation from U.S. production facilities.

The 1977 CTS listed O/D information in terms of Bureau of Economic Activity (BEA) zones and provided these data for commodities broken down at the five-digit STCC level. Therefore, detailed O/D statistics were available for widely shipped individual chemicals, such as chlorine, ammonia, and nitric acid. (Routing data were also available in the 1993 CFS; however, the 1993 CFS routing data were only broken down by three-digit STCC. All TIH chemicals considered in this study fall under the same three-digit STCC; namely, STCC 281, industrial organic, and inorganic chemicals.) Analysis of the O/D information allowed Maio and Liu to identify the major commodity corridors for several materials, including chlorine, ammonia, nitric acid, and cyclic intermediates of benzene. In this analysis, they used the ORNL highway model (an earlier version of that used in our analysis) to assign the minimum-time routes for each $\mathrm{O} / \mathrm{D}$ pair. They presented their data in the form of highway corridor maps that contained both the route and the total commodity flow along the route. Because the maps were generated by using BEA information, they are only suggestive of actual routes but are an excellent representation of the overall commodity flow and are adequate for our risk 
assessment analysis. For the NTRA, we obtained O/D information directly from the commodity corridors maps presented by Maio and Liu because direct analysis of the 1977 CTS data would have provided little additional benefit. The shipment end points, as determined directly from the corridor maps, are precise within the limit imposed by the BEA designations in the original 1977 CTS data.

While the transportation of petroleum products in terms of ton-miles is dominated by transportation from regional storage facilities, the transportation of hazardous chemical products is dominated by shipments from U.S. production facilities. Indeed, Maio and Liu found that transportation from U.S. production facilities accounts for approximately $90 \%$ of hazardous chemical products transported in the United States. To supplement O/D information provided by analysis of the Maio and Liu data, we used O/D information from the HMIS database and, where warranted, industry sources. This additional information is intended to represent commodity flows from regional storage facilities to end users. Generation of representative shipments from the various data sources is described on a per-chemical basis in Section 4.3.2.

\subsubsection{Formulation of Representative Highway Shipments}

Representative highway shipments for ammonia, chlorine, $\mathrm{SO}_{2}, \mathrm{HF}$, fuming sulfuric acid, fuming nitric acid, LP gas, and explosives are given in Tables 4.12-4.19. For each shipment, origin, destination, and distance are provided. For all materials except explosives, the container type, container capacity, and number of containers shipped are also provided. The specific containers used for each shipment were assigned on the basis of our analysis of the 49 CFR 173 and incidents appearing in the HMIS database. CFR 49173 provided guidance on the containers authorized for the particular commodity, whereas the HMIS database records allowed us to estimate the distribution of containers used in actual shipments. The total shipment amount in kilograms is the product of the container capacity, the number of containers shipped, and the density of the material. For explosives, the hazard class, name of material, and total shipment amount are provided because container types do not enter into our analysis. The annual shipment frequency is provided in the last column. Designation of annual shipment frequency is discussed below.

For each chemical considered in this study, the specific routes and shipment frequencies were determined from a variety of sources. The goal of this phase of the analysis was to properly represent the total commodity for highway transportation of the various chemicals in terms of both total tons shipped and ton-miles when the statistical data were available. Since the available data are different for each chemical considered in the analysis, the commodity flow analysis leading to the annual shipment frequencies are discussed for each chemical separately. 
Table 4.12 Twenty-two Representative Highway Shipments Used to Model Risk due to Highway Transportation of Ammonia Determined by Using the 1977 CTS and the HMIS Database

\begin{tabular}{|c|c|c|c|c|c|c|c|}
\hline \multicolumn{2}{|c|}{ Route End Points } & \multirow{2}{*}{$\begin{array}{c}\begin{array}{c}\text { Route } \\
\text { Length } \\
\text { (mi) }\end{array} \\
246\end{array}$} & \multirow{2}{*}{$\begin{array}{c}\begin{array}{c}\text { Container } \\
\text { Type }\end{array} \\
\text { MC } 331\end{array}$} & \multirow{2}{*}{$\begin{array}{c}\begin{array}{c}\text { Container } \\
\text { Capacity } \\
\text { (gal) }\end{array} \\
10,000\end{array}$} & \multirow{2}{*}{$\begin{array}{c}\begin{array}{c}\text { No. of } \\
\text { Containers }\end{array} \\
1\end{array}$} & \multirow{2}{*}{$\begin{array}{c}\begin{array}{c}\text { Total } \\
\text { Shipment } \\
\text { Amount } \\
\text { (kg) }\end{array} \\
25,799\end{array}$} & \multirow{2}{*}{$\begin{array}{c}\begin{array}{c}\text { Annual } \\
\text { Shipment } \\
\text { Frequency }\end{array} \\
19,772\end{array}$} \\
\hline Dallas, TX & Houston, TX & & & & & & \\
\hline Odessa, TX & Fort Worth, TX & 322 & MC 331 & 11,000 & 1 & 28,379 & 10,785 \\
\hline Baton Rouge, LA & Joliet, IL & 884 & MC 331 & 8,000 & 1 & 20,639 & 3,707 \\
\hline Houston, TX & Galveston, TX & 46 & MC 331 & 11,000 & 1 & 28,379 & 44,937 \\
\hline El Paso, TX & Houston, TX & 741 & MC 331 & 8,000 & 1 & 20,639 & 3,707 \\
\hline Kansas City, MO & Baltimore, MD & 1,057 & MC 331 & 7,000 & 1 & 18,060 & 2,825 \\
\hline San Antonio, TX & Houston, TX & 195 & MC 331 & 10,000 & 1 & 25,799 & 9,886 \\
\hline Detroit, MI & Dayton, $\mathrm{OH}$ & 218 & MC 331 & 4,000 & 1 & 10,320 & 19,772 \\
\hline San Antonio, TX & Fort Worth, TX & 255 & MC 331 & 8,000 & 1 & 20,639 & 6,179 \\
\hline San Antonio, TX & Corpus Christi, TX & 140 & MC 331 & 7,500 & 1 & 19,349 & 10,545 \\
\hline Dallas, TX & Oklahoma City, OK & 207 & MC 331 & 8,000 & 1 & 20,639 & 4,943 \\
\hline Gary, IN & Cincinnati, $\mathrm{OH}$ & 259 & MC 330 & 6,500 & 1 & 16,770 & 4,563 \\
\hline Amarillo, TX & Oklahoma City, OK & 256 & MC 330 & 4,000 & 1 & 10,320 & 7,415 \\
\hline Oklahoma City, OK & Kansas City, MO & 345 & MC 330 & 8,000 & 1 & 20,639 & 2,472 \\
\hline Beaumont, TX & Baton Rouge, LA & 184 & MC 330 & 5,000 & 1 & 12,900 & 5,932 \\
\hline Cincinnati, $\mathrm{OH}$ & Erie, PA & 344 & $4 \mathrm{~A}$ & 19 & 30 & 1,471 & 17,344 \\
\hline North Platte, NE & O'Neill, NE & 229 & TANK PRT & 1,000 & 1 & 2,580 & 39,545 \\
\hline Chicago, IL & Cleveland, TN & 343 & $4 \mathrm{~A}$ & 19 & 30 & 1,471 & 17,344 \\
\hline Tacoma, WA & Spokane, WA & 292 & $3 A$ & 19 & 30 & 1,471 & 17,344 \\
\hline Springfield, IL & Mattoon, IL & 86 & TANK PRT & 1,000 & 1 & 2,580 & 39,545 \\
\hline Dubuque, IA & Cedar Rapids, IA & 74 & TANK PRT & 1,000 & 1 & 2,580 & 39,545 \\
\hline Albert Lea, MN & Rochester, MN & 62 & TANK PRT & 1,000 & 1 & 2,580 & 39,545 \\
\hline
\end{tabular}

\subsubsection{Ammonia}

The basis for the total highway commodity flow data for anhydrous ammonia is the 1977 CTS and 1993 CFS. The 1977 CTS reported that 2.8 million tons of ammonia were transported by highway in 1977 over 476 million ton-miles. Since the 1993 CFS does not provide specific data for ammonia, the 1977 CTS results for ammonia were scaled to 1993 using the commodity flow data for STCC 281 (industrial organic and inorganic chemicals). A comparison of the 1977 CTS and 1993 CFS ton and ton-mile statistics is presented in Table 4.20 with scaling factors for private and for-hire truck transportation.

Table 4.21 illustrates the use of the scaling factors discussed in Table 4.19 to estimate 1993 commodity flow for ammonia from 1977 CTS data. Due to the large differences in the commodity flow volume increases between private and for-hire truck transportation, these categories were separated in the scaling of commodity flow data. The large increases in ton traffic for private truck transportation is due not only to the overall increase in chemical transportation but also the incorporation of shipments from regional distribution facilities in the 1993 CFS. The effect is that many small distance shipments are included in the sample. 
Table 4.13 Twenty Representative Highway Shipments Used to Model Risk due to Highway Transportation of Chlorine Determined by Using the 1977 CTS and the HMIS Database

\begin{tabular}{|c|c|c|c|c|c|c|c|}
\hline \multicolumn{2}{|c|}{ Route End Points } & \multirow{2}{*}{$\begin{array}{c}\begin{array}{c}\text { Route } \\
\text { Length } \\
\text { (mi) }\end{array} \\
73\end{array}$} & \multirow{2}{*}{$\begin{array}{c}\begin{array}{c}\text { Container } \\
\text { Type }\end{array} \\
\text { MC } 331\end{array}$} & \multirow{2}{*}{$\begin{array}{c}\begin{array}{c}\text { Container } \\
\text { Capacity } \\
\text { (gal) }\end{array} \\
4,000\end{array}$} & \multirow{2}{*}{$\begin{array}{c}\begin{array}{c}\text { No. of } \\
\text { Containers }\end{array} \\
1\end{array}$} & \multirow{2}{*}{$\begin{array}{c}\begin{array}{c}\text { Total } \\
\text { Shipment } \\
\text { Amount } \\
\text { (kg) }\end{array} \\
21,327\end{array}$} & \multirow{2}{*}{$\begin{array}{c}\begin{array}{c}\text { Annual } \\
\text { Shipment } \\
\text { Frequency }\end{array} \\
27,024\end{array}$} \\
\hline New Orleans, LA & Baton Rouge, LA & & & & & & \\
\hline Pomona, CA & Houston, TX & 1,518 & MC 331 & 4,000 & 1 & 21,327 & 772 \\
\hline Lake Charles, LA & New Orleans, LA & 201 & MC 331 & 4,000 & 1 & 21,327 & 5,791 \\
\hline Houston, TX & Hastings, NE & 600 & MC 331 & 6,000 & 1 & 31,991 & 1,287 \\
\hline Tallahassee, FL & Detroit, MI & 1,027 & MC 331 & 4,000 & 1 & 21,327 & 772 \\
\hline New Orleans, LA & Detroit, MI & 1,091 & 3AA & 2,000 & 1 & 10,664 & 1,081 \\
\hline Miami, FL & Cleveland, $\mathrm{OH}$ & 1,258 & $3 A$ & 19 & 30 & 3,036 & 2,709 \\
\hline Tacoma, WA & Boise, ID & 511 & $106 \mathrm{AX}$ & 250 & 8 & 10,553 & 2,059 \\
\hline Nashville, TN & Detroit, MI & 558 & $3 A$ & 19 & 40 & 4,055 & 3,251 \\
\hline Oakland, CA & Pomona, CA & 414 & $106 \mathrm{AX}$ & 250 & 4 & 5,276 & 2,059 \\
\hline Pecos, TX & Fort Worth, TX & 396 & $3 \mathrm{~A}$ & 19 & 30 & 3,036 & 5,418 \\
\hline Shreveport, LA & Jackson, MS & 219 & MC 331 & 4,000 & 1 & 21,327 & 1,158 \\
\hline Memphis, TN & Baton Rouge, LA & 372 & $3 A$ & 19 & 50 & 5,064 & 2,276 \\
\hline Amarillo, TX & Oklahoma City, OK & 259 & $106 A X$ & 250 & 12 & 15,828 & 2,059 \\
\hline Tacoma, WA & Spokane, WA & 295 & MC 331 & 4,000 & 1 & 21,327 & 540 \\
\hline Lake Charles, LA & Monroe, LA & 192 & $106 \mathrm{AX}$ & 250 & 12 & 15,991 & 1,029 \\
\hline Atlanta, GA & Columbia, SC & 232 & $106 A X$ & 250 & 8 & 10,664 & 1,081 \\
\hline Memphis, TN & Nashville, TN & 215 & $3 A$ & 19 & 30 & 3,036 & 3,793 \\
\hline Tacoma, WA & Portland, OR & 138 & 3AA & 2,000 & 1 & 10,664 & 1,544 \\
\hline Riverton, NJ & Syracuse, NY & 242 & $3 A$ & 19 & 15 & 1,518 & 5,418 \\
\hline
\end{tabular}

Table 4.14 Fifteen Representative Highway Shipments Used to Model Risk due to Highway Transportation of Sulfur Dioxide Determined by Using the 1977 CTS and the HMIS Database

\begin{tabular}{|c|c|c|c|c|c|c|c|}
\hline \multicolumn{2}{|c|}{ Route End Points } & \multirow{2}{*}{$\begin{array}{c}\begin{array}{c}\text { Route } \\
\text { Length } \\
\text { (mi) }\end{array} \\
791\end{array}$} & \multirow{2}{*}{$\begin{array}{c}\begin{array}{c}\text { Container } \\
\text { Type }\end{array} \\
\text { MC } 331\end{array}$} & \multirow{2}{*}{$\begin{array}{c}\begin{array}{c}\text { Container } \\
\text { Capacity } \\
\text { (gal) }\end{array} \\
5,000\end{array}$} & \multirow{2}{*}{$\begin{array}{c}\begin{array}{c}\text { No. of } \\
\text { Containers }\end{array} \\
1\end{array}$} & \multirow{2}{*}{$\begin{array}{c}\begin{array}{c}\text { Total } \\
\text { Shipment } \\
\text { Amount } \\
\text { (kg) }\end{array} \\
27,131\end{array}$} & \multirow{2}{*}{$\begin{array}{c}\begin{array}{c}\text { Annual } \\
\text { Shipment } \\
\text { Frequency }\end{array} \\
125\end{array}$} \\
\hline Hammond, IN & Albany, NY & & & & & & \\
\hline Hammond, IN & Kansas City, MO & 507 & MC 331 & 5,000 & 1 & 27,131 & 165 \\
\hline Baton Rouge, LA & Red Level, FL & 599 & MC 331 & 5,000 & 1 & 27,131 & 78 \\
\hline Baton Rouge, LA & Houston, TX & 282 & MC 331 & 5,000 & 1 & 27,131 & 156 \\
\hline Kent, WA & Port Angeles, WA & 124 & MC 331 & 5,000 & 1 & 27,131 & 225 \\
\hline Columbia, SC & Alexandria, VA & 449 & MC 331 & 5,000 & 1 & 27,131 & 175 \\
\hline Carson, CA & Oakland, CA & 383 & MC 331 & 5,000 & 1 & 27,131 & 78 \\
\hline Baton Rouge, LA & Montgomery, AL & 370 & MC 331 & 5,000 & 1 & 27,131 & 85 \\
\hline Newark, NJ & Baltimore, MD & 185 & MC 331 & 5,000 & 1 & 27,131 & 175 \\
\hline El Dorado, AR & Baton Rouge, LA & 290 & MC 331 & 5,000 & 1 & 27,131 & 85 \\
\hline Dallas, TX & Houston, TX & 247 & MC 331 & 5,000 & 1 & 27,131 & 85 \\
\hline Dallas, TX & South Bend, IN & 1,029 & $3 A$ & 19 & 30 & 3,093 & 200 \\
\hline Houston, TX & Morrisville, PA & 1,554 & $3 A$ & 30 & 16 & 2,605 & 200 \\
\hline San Diego, CA & Santa Rosa, CA & 558 & $3 A$ & 19 & 5 & 1,031 & 250 \\
\hline Glassboro, NJ & Binghamton, NY & 201 & $3 A$ & 19 & 10 & 3,093 & 375 \\
\hline
\end{tabular}


Table 4.15 Twelve Representative Highway Shipments Used to Model Risk due to Highway Transportation of Anhydrous Hydrogen Fluoride Determined by Using the Data Provided by EPA (1993) and the HMIS Database

\begin{tabular}{|c|c|c|c|c|c|c|c|}
\hline \multicolumn{2}{|c|}{ Route End Points } & \multirow{2}{*}{$\begin{array}{c}\begin{array}{c}\text { Route } \\
\text { Length } \\
\text { (mi) }\end{array} \\
2,510\end{array}$} & \multirow{2}{*}{$\begin{array}{c}\begin{array}{c}\text { Container } \\
\text { Type }\end{array} \\
\text { MC } 312\end{array}$} & \multirow{2}{*}{$\begin{array}{c}\begin{array}{c}\text { Container } \\
\text { Capacity } \\
\text { (gal) }\end{array} \\
5,000\end{array}$} & \multirow{2}{*}{$\begin{array}{c}\begin{array}{c}\text { No. of } \\
\text { Containers }\end{array} \\
1\end{array}$} & \multirow{2}{*}{$\begin{array}{c}\begin{array}{c}\text { Total } \\
\text { Shipment } \\
\text { Amount } \\
\text { (kg) }\end{array} \\
18,750\end{array}$} & \multirow{2}{*}{$\begin{array}{c}\begin{array}{c}\text { Annual } \\
\text { Shipment } \\
\text { Frequency }\end{array} \\
75\end{array}$} \\
\hline New Philadelphia, $\mathrm{OH}$ & Union City, CA & & & & & & \\
\hline Torrance, CA & Deepwater, NJ & 2,546 & MC 312 & 5,000 & 1 & 18,750 & 75 \\
\hline Texas City, TX & Chalmette, LA & 280 & MC 312 & 5,000 & 1 & 18,750 & 480 \\
\hline Laporte, TX & Wichita, KS & 617 & MC 312 & 5,000 & 1 & 18,750 & 225 \\
\hline Torrance, CA & Riverside, CA & 64 & MC 312 & 5,000 & 1 & 18,750 & 325 \\
\hline Laporte, TX & Pittsburg, CA & 1,933 & MC 312 & 5,000 & 1 & 18,750 & 100 \\
\hline Akron, $\mathrm{OH}$ & Cleveland, $\mathrm{OH}$ & 35 & MC 312 & 5,000 & 1 & 18,750 & 250 \\
\hline Geismar, LA & Joliet, IL & 905 & MC 312 & 5,000 & 1 & 18,750 & 75 \\
\hline Geismar, LA & Houston, TX & 282 & MC 312 & 5,000 & 1 & 18,750 & 375 \\
\hline Valencia, CA & El Dorado, AR & 1,744 & $5 \mathrm{C}$ & 30 & 10 & 1,123 & 125 \\
\hline Akron, $\mathrm{OH}$ & Cleveland, $\mathrm{OH}$ & 35 & $4 \mathrm{~A}$ & 19 & 15 & 1,067 & 450 \\
\hline Torrance, CA & Wilmington, CA & 7 & $4 \mathrm{~A}$ & 19 & 15 & 1,067 & 350 \\
\hline
\end{tabular}

Table 4.16 Seventeen Representative Highway Shipments Used to Model Risk due to Highway Transportation of Fuming Sulfuric Acid Determined by Using the 1977 CTS and the HMIS Database

\begin{tabular}{|c|c|c|c|c|c|c|c|}
\hline \multicolumn{2}{|c|}{ Route End Points } & \multirow{2}{*}{$\begin{array}{c}\begin{array}{c}\text { Route } \\
\text { Length } \\
\text { (mi) }\end{array} \\
259\end{array}$} & \multirow{2}{*}{$\begin{array}{c}\begin{array}{c}\text { Container } \\
\text { Type }\end{array} \\
\text { MC } 312\end{array}$} & \multirow{2}{*}{$\begin{array}{c}\begin{array}{c}\text { Container } \\
\text { Capacity } \\
\text { (gal) }\end{array} \\
6,000\end{array}$} & \multirow{2}{*}{$\begin{array}{c}\begin{array}{c}\text { No. of } \\
\text { Containers }\end{array} \\
1\end{array}$} & \multirow{2}{*}{$\begin{array}{c}\begin{array}{c}\text { Total } \\
\text { Shipment } \\
\text { Amount } \\
(\mathbf{k g})\end{array} \\
43,365\end{array}$} & \multirow{2}{*}{$\begin{array}{c}\begin{array}{c}\text { Annual } \\
\text { Shipment } \\
\text { Frequency }\end{array} \\
3,960\end{array}$} \\
\hline Joliet, IL & St. Louis, MO & & & & & & \\
\hline Lancaster, PA & Oregon, $\mathrm{OH}$ & 455 & MC 312 & 6,000 & 1 & 43,365 & 1,485 \\
\hline Baton Rouge, LA & New York, NY & 1,365 & MC 312 & 5,000 & 1 & 36,137 & 594 \\
\hline Camden, NJ & Cleveland, $\mathrm{OH}$ & 439 & MC 312 & 4,000 & 1 & 28,910 & 2,227 \\
\hline Baton Rouge, LA & Nashville, TN & 583 & MC 312 & 4,000 & 1 & 28,910 & 1,485 \\
\hline San Antonio, TX & Gretna, LA & 540 & MC 312 & 4,000 & 1 & 28,910 & 1,485 \\
\hline Mobile, AL & Atlanta, GA & 326 & MC 312 & 4,000 & 1 & 28,910 & 2,227 \\
\hline Chicago Heights, IL & Toledo, $\mathrm{OH}$ & 213 & MC 312 & 4,000 & 1 & 28,910 & 2,970 \\
\hline Baton Rouge, LA & Gretna, LA & 84 & MC 312 & 6,000 & 1 & 43,365 & 4,950 \\
\hline Carson, CA & Martinez, CA & 393 & MC 312 & 4,000 & 1 & 28,910 & 1,485 \\
\hline New York, NY & Buffalo, NY & 379 & MC 312 & 4,000 & 1 & 28,910 & 1,485 \\
\hline Linden, NJ & Chemolite, MN & 1,263 & $5 \mathrm{C}$ & 55 & 10 & 3,975 & 2,160 \\
\hline Claymont, DE & Norristown, PA & 31 & MC 312 & 4,000 & 1 & 28,910 & 7,425 \\
\hline Chicago, IL & Gary, IN & 31 & MC 312 & 4,000 & 1 & 28,910 & 5,940 \\
\hline Long Beach, CA & Los Angeles, CA & 23 & MC 312 & 4,000 & 1 & 28,910 & 2,970 \\
\hline Texarkana, AR & Jasper, TX & 192 & $5 \mathrm{C}$ & 55 & 10 & 3,975 & 2,160 \\
\hline Springfield, NJ & Baltimore, MD & 180 & $5 \mathrm{C}$ & 55 & 5 & 1,988 & 540 \\
\hline
\end{tabular}


Table 4.17 Seventeen Representative Highway Shipments Used to Model Risk due to Highway Transportation of Fuming Nitric Acid Determined by Using the 1977 CTS and the HMIS Database

\begin{tabular}{|c|c|c|c|c|c|c|c|}
\hline \multicolumn{2}{|c|}{ Route End Points } & \multirow{2}{*}{$\begin{array}{c}\begin{array}{c}\text { Route } \\
\text { Length } \\
\text { (mi) }\end{array} \\
295\end{array}$} & \multirow{2}{*}{$\begin{array}{c}\begin{array}{c}\text { Container } \\
\text { Type }\end{array} \\
\text { MC } 312\end{array}$} & \multirow{2}{*}{$\begin{array}{c}\begin{array}{c}\text { Container } \\
\text { Capacity } \\
\text { (gal) }\end{array} \\
5,000\end{array}$} & \multirow{2}{*}{$\begin{array}{c}\begin{array}{c}\text { No. of } \\
\text { Containers }\end{array} \\
1\end{array}$} & \multirow{2}{*}{$\begin{array}{c}\begin{array}{c}\text { Total } \\
\text { Shipment } \\
\text { Amount } \\
\text { (kg) }\end{array} \\
28,437\end{array}$} & \multirow{2}{*}{$\begin{array}{c}\begin{array}{c}\text { Annual } \\
\text { Shipment } \\
\text { Frequency }\end{array} \\
784\end{array}$} \\
\hline El Dorado, AR & Meridian, MS & & & & & & \\
\hline El Dorado, AR & Pensacola, FL & 451 & MC 312 & 4,000 & 1 & 22,749 & 752 \\
\hline Lake Charles, LA & El Dorado, AR & 247 & MC 312 & 5,000 & 1 & 28,437 & 522 \\
\hline Lubbock, TX & Jackson, MS & 741 & MC 312 & 5,000 & 1 & 28,437 & 457 \\
\hline El Dorado, AR & Valencia, CA & 1,744 & $5 \mathrm{C}$ & 55 & 10 & 3,128 & 100 \\
\hline Houston, TX & Lake Charles, LA & 143 & MC 312 & 5,000 & 1 & 28,437 & 522 \\
\hline Dallas, TX & Houston, TX & 247 & MC 312 & 4,000 & 1 & 22,749 & 380 \\
\hline El Dorado, AR & Jackson, MS & 209 & MC 312 & 4,000 & 1 & 22,749 & 271 \\
\hline New York, NY & Camden, NJ & 105 & MC 312 & 4,000 & 1 & 22,749 & 175 \\
\hline New York, NY & Buffalo, NY & 379 & $5 \mathrm{C}$ & 55 & 15 & 4,692 & 75 \\
\hline Joliet, IL & St. Louis, MO & 259 & $5 \mathrm{C}$ & 55 & 10 & 3,128 & 175 \\
\hline San Antonio, TX & Houston, TX & 204 & $5 \mathrm{C}$ & 55 & 10 & 3,128 & 225 \\
\hline Mobile, AL & Atlanta, GA & 326 & MC 312 & 4,000 & 1 & 22,749 & 135 \\
\hline Buffalo, NY & Toledo, $\mathrm{OH}$ & 315 & BOT GLS & 1 & 100 & 569 & 175 \\
\hline Camden, NJ & Cleveland, $\mathrm{OH}$ & 441 & $5 \mathrm{C}$ & 55 & 10 & 3,128 & 150 \\
\hline Baton Rouge, LA & Nashville, TN & 583 & $5 \mathrm{C}$ & 55 & 5 & 1,564 & 175 \\
\hline El Paso, TX & San Antonio, TX & 567 & $5 \mathrm{C}$ & 55 & 5 & 1,564 & 225 \\
\hline
\end{tabular}

The overall commodity flow for ammonia estimated for 1993 was 4,676,000 tons of material transported over 857 million ton-miles. The annual frequencies for the representative shipments appearing in Table 4.12 were set so that the 22 representative shipments accounted for 857 million ton-miles. The total tons transported for the 22 shipments in Table 4.12 is $4,477,000$, or about $5 \%$ less than that estimated in Table 4.21. We attempted to match the ton-mile estimate because ton-miles, rather than the total tons shipped, is the parameter that influences en route transportation risk.

Most of the routes in Table 4.12 were obtained from the 1977 CTS as discussed in Section 4.3.1. However, several additional routes were added to account for rural transportation of ammonia, primarily for agricultural use. Routes for these shipments, numbers 10,19, 20, and 21 as read from the top of the Table 4.12, were developed in part using HMIS database records. The containers for the shipments were specified as portable tanks (TANK PRT in HMIS). These are commonly referred to as nurse tanks and are often seen in rural farm areas, especially in the central United States. These shipments are given high shipment frequencies to reflect the overall national transportation of ammonia in this manner. The overall risk from shipments of this type, however, is small compared to other ammonia transportation due to the fairly low shipment amounts involved and the low population densities characteristic of the rural areas where such shipments occur. 
Table 4.18 Thirty-three Representative Highway Shipments Used to Model Risk due to Highway Transportation of LP Gases Determined by Using the 1977 CTS and the HMIS Database

\begin{tabular}{|c|c|c|c|c|c|c|c|}
\hline \multicolumn{2}{|c|}{ Route End Points } & \multirow{2}{*}{$\begin{array}{c}\begin{array}{c}\text { Route } \\
\text { Length } \\
\text { (mi) }\end{array} \\
1,352\end{array}$} & \multirow{2}{*}{$\begin{array}{c}\begin{array}{c}\text { Container } \\
\text { Type }\end{array} \\
\text { MC } 331\end{array}$} & \multirow{2}{*}{$\begin{array}{c}\begin{array}{c}\text { Container } \\
\text { Capacity } \\
\text { (gal) }\end{array} \\
8,000\end{array}$} & \multirow{2}{*}{$\begin{array}{c}\begin{array}{c}\text { No. of } \\
\text { Containers }\end{array} \\
1\end{array}$} & \multirow{2}{*}{$\begin{array}{c}\begin{array}{c}\text { Total } \\
\text { Shipment } \\
\text { Amount } \\
\text { (kg) }\end{array} \\
10,906\end{array}$} & \multirow{2}{*}{$\begin{array}{c}\begin{array}{c}\text { Annual } \\
\text { Shipment } \\
\text { Frequency }\end{array} \\
5,849\end{array}$} \\
\hline Norman, OK & Santa Ana, CA & & & & & & \\
\hline Charleston, IL & Springfield, IL & 92 & MC 331 & 2,400 & 1 & 3,280 & 259,950 \\
\hline Detroit, MI & New Orleans, LA & 72 & MC 331 & 10,000 & 1 & 13,694 & 62,388 \\
\hline St. Louis, MO & Oklahoma City, OK & 511 & MC 331 & 11,000 & 1 & 15,006 & 7,090 \\
\hline Rochester, MN & Albert Lea, MN & 62 & MC 331 & 2,400 & 1 & 3,280 & 259,950 \\
\hline Dallas, TX & Houston, TX & 246 & MC 331 & 11,000 & 1 & 15,006 & 14,179 \\
\hline Buffalo, NY & Erie, PA & 94 & MC 331 & 7,500 & 1 & 10,250 & 51,990 \\
\hline Philadelphia, PA & Pittsburgh, PA & 312 & MC 331 & 11,000 & 1 & 15,006 & 10,634 \\
\hline Baton Rouge, LA & Orlando, FL & 700 & MC 331 & 8,000 & 1 & 10,906 & 5,849 \\
\hline Oakland, CA & Pomona, CA & 414 & MC 331 & 10,000 & 1 & 13,694 & 7,799 \\
\hline Corpus Christi, TX & Fort Worth, TX & 407 & MC 331 & 8,000 & 1 & 10,906 & 9,748 \\
\hline New York, NY & Philadelphia, PA & 95 & MC 331 & 8,000 & 1 & 10,906 & 38,993 \\
\hline O'Neill, NE & Bassett, NE & 47 & MC 331 & 2,400 & 1 & 3,280 & 259,950 \\
\hline Chicago, IL & Baton Rouge, LA & 859 & MC 331 & 11,000 & 1 & 15,006 & 9,925 \\
\hline Springfield, NJ & Baltimore, MD & 180 & MC 331 & 8,000 & 1 & 10,906 & 19,496 \\
\hline San Antonio, TX & Austin TX & 88 & MC 331 & 10,000 & 1 & 13,694 & 31,194 \\
\hline Johnstown, PA & Indianapolis, IN & 427 & MC 331 & 10,000 & 1 & 13,694 & 6,239 \\
\hline Monticello, IA & Dubuque, IA & 39 & MC 331 & 2,400 & 1 & 3,280 & 259,950 \\
\hline Tyler, TX & Corsicana, TX & 73 & MC 331 & 8,000 & 1 & 10,906 & 38,993 \\
\hline Houston, TX & Port Arthur, TX & 94 & MC 331 & 10,000 & 1 & 13,694 & 23,396 \\
\hline Poughkeepsie, NY & Peekskill, NY & 33 & MC 331 & 2,400 & 1 & 3,280 & 259,950 \\
\hline St. Louis, MO & Joliet, IL & 258 & MC 331 & 8,000 & 1 & 10,906 & 9,748 \\
\hline Jackson, MS & Baton Rouge, LA & 169 & MC 331 & 11,000 & 1 & 15,006 & 10,634 \\
\hline La Junta, CO & Fowler, CO & 30 & MC 331 & 2,400 & 1 & 3,280 & 259,950 \\
\hline Shreveport, LA & Jackson, MS & 219 & MC 331 & 10,000 & 1 & 13,694 & 7,799 \\
\hline San Antonio, TX & Houston, TX & 204 & MC 331 & 8,000 & 1 & 10,906 & 9,748 \\
\hline Lake Charles, LA & New Orleans, LA & 201 & MC 331 & 11,000 & 1 & 15,006 & 7,090 \\
\hline Seattle, WA & Portland, OR & 177 & MC 331 & 8,000 & 1 & 10,906 & 9,748 \\
\hline Chicago, IL & East Chicago, IN & 31 & MC 331 & 8,000 & 1 & 10,906 & 48,741 \\
\hline Chicago, IL & Indianapolis, IN & 154 & MC 331 & 10,000 & 1 & 13,694 & 7,799 \\
\hline Junction City, AR & Ruston, LA & 19 & MC 331 & 2,400 & 1 & 3,280 & 259,950 \\
\hline Syracruse, NY & Buffalo, NY & 143 & MC 331 & 8,000 & 1 & 10,906 & 9,748 \\
\hline Los Angeles, CA & Long Beach, CA & 23 & MC 331 & 11,000 & 1 & 15,006 & 42,537 \\
\hline
\end{tabular}

\subsubsection{Chlorine}

The basis for the total highway commodity flow data for chlorine is the 1977 CTS and 1993 CFS. The 1977 CTS reported that 736,000 tons of chlorine were transported by highway in 1977 over 132 million ton-miles. The 1977 CTS commodity flow statistics for chlorine were scaled to 1993 using the scaling factors for private and for-hire truck transportation given previously in Table 4.20. The 1993 estimated commodity flow data are shown in Table 4.22. The annual frequencies for the shipments shown in Table 4.13 are specified so that the total ton-mile estimate is matched. Consequently, the total tons 
Table 4.19 Twenty-eight Representative Highway Shipments Used to Model Risk due to Highway Transportation of Explosives Determined by Using the 1977 CTS and the 1993 CTS

\begin{tabular}{|c|c|c|c|c|c|c|}
\hline \multicolumn{2}{|c|}{ Route End Points } & \multirow{2}{*}{$\begin{array}{c}\begin{array}{c}\text { Route } \\
\text { Length } \\
\text { (mi) }\end{array} \\
1,518\end{array}$} & \multirow{2}{*}{$\begin{array}{c}\begin{array}{c}\text { Hazard } \\
\text { Class }\end{array} \\
1.5\end{array}$} & \multirow{2}{*}{$\begin{array}{c}\begin{array}{c}\text { Explosive } \\
\text { Material }\end{array} \\
\text { ANFO }\end{array}$} & \multirow{2}{*}{$\begin{array}{c}\begin{array}{c}\text { Shipment } \\
\text { Amount } \\
\text { (kg) }\end{array} \\
25,000\end{array}$} & \multirow{2}{*}{$\begin{array}{c}\begin{array}{c}\text { Annual } \\
\text { Shipment } \\
\text { Frequency }\end{array} \\
2,420\end{array}$} \\
\hline Pomona, CA & Houston, TX & & & & & \\
\hline Linden, NJ & Chemolite, MN & 1,263 & 1.5 & ANFO & 10,000 & 6,051 \\
\hline Detroit, MI & New Orleans, LA & 1,091 & 1.5 & ANFO & 20,000 & 3,026 \\
\hline Lubbock, TX & Jackson, MS & 741 & 1.5 & ANFO & 10,000 & 7,564 \\
\hline Hope, AR & Valencia, CA & 1,774 & 1.5 & ANFO & 25,000 & 1,210 \\
\hline Oakland, CA & Tooele, UT & 759 & 1.2 & Ammunition $^{\mathrm{a}}$ & 20,000 & 3,026 \\
\hline Columbia, SC & Alexandria, VA & 449 & 1.5 & ANFO & 15,000 & 4,034 \\
\hline Anniston, $\mathrm{AL}$ & Aberdeen, MD & 773 & 1.2 & Ammunition $^{a}$ & 20,000 & 1,513 \\
\hline Fort Worth, TX & Pecos, TX & 396 & 1.5 & ANFO & 5,000 & 9,077 \\
\hline Atlanta, GA & Columbia, SC & 232 & 1.1 & Dynamite & 25,000 & 3,026 \\
\hline Oklahoma City, OK & St. Louis, MO & 511 & 1.1 & Dynamite & 15,000 & 2,017 \\
\hline Denver, CO & Alamosa, $\mathrm{CO}$ & 236 & 1.5 & ANFO & 30,000 & 2,017 \\
\hline Durham, NC & Waycross, GA & 449 & 1.5 & ANFO & 2,000 & 15,128 \\
\hline Erie, PA & Birmingham, AL & 379 & 1.5 & ANFO & 25,000 & 1,210 \\
\hline Jacksonville, FL & Charleston, SC & 250 & 1.5 & ANFO & 15,000 & 3,026 \\
\hline Buffalo, NY & Toledo, $\mathrm{OH}$ & 315 & 1.5 & ANFO & 10,000 & 3,026 \\
\hline Joliet, IL & St. Louis, MO & 259 & 1.5 & ANFO & 20,000 & 1,815 \\
\hline Lander, WY & Boise, ID & 555 & 1.1 & Dynamite & 15,000 & 1,009 \\
\hline Columbia, SC & Dover, DE & 547 & 1.5 & ANFO & 10,000 & 1,513 \\
\hline Savannah, GA & Jackson, MS & 236 & 1.5 & ANFO & 25,000 & 1,210 \\
\hline Atlanta, GA & Columbia, SC & 232 & 1.5 & ANFO & 5,000 & 6,051 \\
\hline Camden, NJ & Cleveland, $\mathrm{OH}$ & 441 & 1.5 & ANFO & 15,000 & 1,009 \\
\hline New York, NY & Buffalo, NY & 379 & 1.1 & Dynamite & 15,000 & 1,009 \\
\hline Newark, NJ & Baltimore, MD & 185 & 1.5 & ANFO & 15,000 & 2,017 \\
\hline Chicago, IL & Indianapolis, IN & 154 & 1.5 & ANFO & 15,000 & 2,017 \\
\hline Joliet, IL & St. Louis, MO & 259 & 1.1 & Dynamite & 5,000 & 3,026 \\
\hline Shreveport, LA & Jackson, MS & 219 & 1.1 & Dynamite & 15,000 & 1,009 \\
\hline Houston, TX & Little Rock, AR & 773 & 1.1 & Dynamite & 5,000 & 756 \\
\hline Texarkana, AR & Jasper, TX & 192 & 1.1 & Dynamite & 15,000 & 1,009 \\
\hline Springfield, NJ & Baltimore, MD & 180 & 1.5 & ANFO & 15,000 & 1,009 \\
\hline
\end{tabular}

a Greater than $30 \mathrm{~mm}$.

transported for the shipments in Table 4.13 is 108,000, about $34 \%$ less than that provided in Table 4.20. To make the total tons more closely match the estimated value, considerable changes would have been necessary in the weightings of the various shipments, which would have taken them out of agreement with the 1977 CTS commodity flows. The route end points for chlorine were determined from the 1977 CTS.

\subsubsection{Sulfur Dioxide}

The basis for the highway commodity flow data used for $\mathrm{SO}_{2}$ are annual surveys of industrial gas production and consumption conducted by the U.S. Census Bureau. These 
Table 4.20 Commodity Flow Data in Tons (thousands) and Ton-Miles (millions) for Industrial Inorganic and Organic Chemicals (STCC 281) from the 1977 CTS and 1993 CFS with Scaling Factors Derived from the Data

\begin{tabular}{|c|c|c|c|c|c|c|}
\hline \multirow[b]{2}{*}{$\begin{array}{c}\text { Transportation } \\
\text { Type }\end{array}$} & \multicolumn{2}{|c|}{1977 CTS $^{a}$} & \multicolumn{2}{|c|}{1993 CFS $^{b}$} & \multicolumn{2}{|c|}{ Scaling Factors } \\
\hline & $\begin{array}{c}\text { Tons } \\
\left(\times 10^{3}\right)\end{array}$ & $\begin{array}{c}\text { Ton-Miles } \\
\left(\times 10^{6}\right)\end{array}$ & $\begin{array}{c}\text { Tons } \\
\left(\times 10^{3}\right)\end{array}$ & $\begin{array}{c}\text { Ton-Miles } \\
\left(\times 10^{6}\right)\end{array}$ & Tons & Ton-Miles \\
\hline For-hire truck & 49,037 & 8,863 & 63,569 & 16,305 & 1.30 & 1.84 \\
\hline Private truck & 28,001 & 5,389 & 94,751 & 9,073 & 3.38 & 1.68 \\
\hline Total & 77,038 & 14,252 & 158,320 & 25,378 & 2.06 & 1.78 \\
\hline
\end{tabular}

a DOC (1981).

b DOC (1996).

Table 4.21 Commodity Flow Data in Tons (thousands) and Ton-Miles (millions) for Anhydrous Ammonia (STCC 28198) from the 1977 CTS with Estimated Values for 1993 Calculated by Using the Scaling Factors in Table 4.20

\begin{tabular}{|c|c|c|c|c|c|c|}
\hline \multirow[b]{2}{*}{$\begin{array}{c}\text { Transportation } \\
\text { Type }\end{array}$} & \multicolumn{2}{|c|}{1977 CTS $^{a}$} & \multicolumn{2}{|c|}{ Scaling Factors } & \multicolumn{2}{|c|}{1993 Estimate } \\
\hline & $\begin{array}{c}\text { Tons } \\
\left(\times 10^{3}\right)\end{array}$ & $\begin{array}{c}\text { Ton-Miles } \\
\left(\times 10^{6}\right)\end{array}$ & Tons & $\begin{array}{l}\text { Ton- } \\
\text { Miles }\end{array}$ & $\begin{array}{c}\text { Tons } \\
\left(\times 10^{3}\right)\end{array}$ & $\begin{array}{c}\text { Ton-Miles } \\
\left(\times 10^{6}\right)\end{array}$ \\
\hline For-hire truck & 2,297 & 402 & 1.30 & 1.84 & 2,978 & 740 \\
\hline Private truck & 502 & 70 & 3.38 & 1.68 & 1,699 & 118 \\
\hline Total & & & & & 4,676 & 857 \\
\hline
\end{tabular}

a DOC (1981).

Table 4.22 Commodity Flow Data in Tons (thousands) and Ton-Miles (millions) for Chlorine (STCC 28128) from the 1977 CTS with Estimated Values for 1993 Calculated by Using the Scaling Factors in Table 4.20

\begin{tabular}{|c|c|c|c|c|c|c|}
\hline \multirow[b]{2}{*}{$\begin{array}{c}\text { Transportation } \\
\text { Type }\end{array}$} & \multicolumn{2}{|c|}{1977 CTS $^{a}$} & \multicolumn{2}{|c|}{ Scaling Factors } & \multicolumn{2}{|c|}{1993 Estimate } \\
\hline & $\begin{array}{c}\text { Tons } \\
\left(\times 10^{3}\right)\end{array}$ & $\begin{array}{c}\text { Ton-Miles } \\
\left(\times 10^{6}\right)\end{array}$ & Tons & $\begin{array}{l}\text { Ton- } \\
\text { Miles }\end{array}$ & $\begin{array}{c}\text { Tons } \\
\left(\times 10^{3}\right)\end{array}$ & $\begin{array}{c}\text { Ton-Miles } \\
\left(\times 10^{6}\right)\end{array}$ \\
\hline For-hire truck & 407 & 97 & 1.30 & 1.84 & 529 & 178 \\
\hline Private truck & 329 & 35 & 3.38 & 1.68 & 1,112 & 59 \\
\hline Total & & & & & 1,641 & 237 \\
\hline
\end{tabular}

a DOC (1981). 
statistics provide total number of shipments and shipping volume, including interplant transfers and imports, for selected materials. Many TIH materials are included in these census statistics. The primary drawback of these data is that they do not delineate between rail and highway transportation. Since transportation of most of the TIH chemicals considered in this report is dominated by rail, the small but significant uncertainty in total rail transportation causes large uncertainties in highway transportation. Another problem with the Census Bureau quarterly and annual reports is that data for several chemicals (e.g., HF) are withheld to avoid disclosing figures for individual companies. Nevertheless, for chemicals not specifically included in the 1977 CTS, this provides the best available means for estimating the total highway commodity flow.

The commodity flow data for $\mathrm{SO}_{2}$ in Table 4.23 shows the Census Bureau statistics for 1991 to 1995. Included are total shipments from production facilities within the United States and total imports. The rail data are taken from the Waybill Sample previously discussed. The waybill ton statistics were calculated using expansion factors within each waybill sample and have been multiplied by 1.25 to account for underreporting of waybill numbers. The estimated highway tonnage of 45,517 ton/yr is the difference between the Census Bureau tonnage and that estimated from the Waybill Sample.

Table 4.23 Commodity Flow Data for Sulfur Dioxide in Tons Shippeda

\begin{tabular}{|lccc|}
\hline Year & $\begin{array}{c}\text { Total } \\
\text { Commodity } \\
\text { Flow (tons) }\end{array}$ & $\begin{array}{c}\text { Rail } \\
\text { (tons) }\end{array}$ & $\begin{array}{c}\text { Highway } \\
\text { Estimate } \\
\text { (tons) }\end{array}$ \\
\hline 1991 & 287,696 & 247,096 & 40,600 \\
1992 & 325,148 & 209,371 & 115,777 \\
1993 & 312,680 & 287,844 & 24,836 \\
1994 & 299,339 & 264,269 & 35,070 \\
1995 & 295,315 & 284,011 & 11,304 \\
Average & 304,036 & 258,518 & 45,517 \\
\hline
\end{tabular}

a Rail data were derived from the Waybill Sample and represent the total estimated tonnage. The estimated highway tonnage is the difference between the tonnage reported by the Census Bureau and that reported in the railroad Waybill Sample.

b U.S. Bureau of the Census (1996).
Route end points for $\mathrm{SO}_{2}$ were obtained from the routing information for STCC 281 in the 1977 CTS with $\mathrm{O} / \mathrm{D}$ data in the HMIS database.

\subsubsection{Hydrogen Fluoride}

The basis for HF highway commodity flow data is information presented in an EPA study (EPA 1993). In the report, total highway and rail tonnage of $\mathrm{HF}$ for 10 years is provided. The data originated from Chemical Manufacturers Association as reported to an HF panel in Washington, D.C. Although the 10-yr period is not specified, we assume it is 1982 to 1991 because the panel

convened in March 1992. Broken down in annual amounts, the data indicate that 250,000 and 32,500 tons of HF were shipped annually by rail and highway, respectively, between 1982 and 1991. On the basis of the increase in total highway tonnage of all industrial organic and inorganic chemicals between 1977 and 1993 given in Table 4.20, we increased this HF tonnage estimate by $30 \%$ to 42,000 tons to be compatible with the 1993 CFS data used as the baseline for highway commodity flow of the other materials considered in the NTRA. 
The shipment end points for HF were determined from both HMIS database records and information contained in EPA (1993). Although the EPA report did not provide specific data concerning HF shipments, it did list major producers and users, allowing for a rough estimate of representative routing. Due to a lack of more detailed routing information, the number of representative shipments for HF is smaller as compared with other hazardous materials considered in this report.

\subsubsection{Fuming Sulfuric Acid}

The total highway commodity flow data for fuming sulfuric acid are based on the 1977 CTS and 1993 CFS together with the HMIS database. The 1977 CTS reported that $13,838,000$ tons of sulfuric acid were transported by highway in 1977 over 1,502 million ton-miles. The 1977 CTS commodity flow statistics for sulfuric acid were scaled to 1993 factors using the scaling factors for private and for-hire truck transportation previously shown in Table 4.20. The 1993 estimated commodity flow data for sulfuric acid is shown in Table 4.24. To obtain the percentage of sulfuric acid shipments that are fuming sulfuric acid, we analyzed incidents in the HMIS database from 1985 to 1995 that were reported for sulfuric acid (UN 1830) and fuming sulfuric acid (UN 1831). The percentage of fuming sulfuric acid shipments on a tonnage basis was then taken as the total volume of fuming sulfuric acid shipments with respect to regular sulfuric acid shipments for incidents appearing in HMIS. Through this method, we ascertained that approximately $4 \%$ of sulfuric acid shipments are fuming sulfuric acid. Because the vast majority of incidents appearing in HMIS occur during loading and unloading, we made no attempt to account for the fact that the containers currently authorized for transportation of fuming sulfuric acid with $30 \%$ or greater free $\mathrm{SO}_{3}$ are significantly more robust than those authorized for regular sulfuric acid. In fact, it is likely that the containers used for most of the sample period are actually the same for both regular and fuming sulfuric acid because the regulations mandating more robust MC 312 cargo tanks for TIH liquid transportation were not in place until 1991 and included significant

Table 4.24 Commodity Flow Data in Tons (thousands) and Ton-Miles (millions) for Sulfuric Acid (STCC 28193) from the 1977 CTS with Estimated Values for $1993^{\mathrm{a}}$

\begin{tabular}{|c|c|c|c|c|c|c|}
\hline \multirow[b]{2}{*}{$\begin{array}{c}\text { Transportation } \\
\text { Type }\end{array}$} & \multicolumn{2}{|c|}{1977 CTS $^{b}$} & \multicolumn{2}{|c|}{1993 Estimate } & \multicolumn{2}{|c|}{1993 Fuming } \\
\hline & $\begin{array}{c}\text { Tons } \\
\left(\times 10^{3}\right)\end{array}$ & $\begin{array}{c}\text { Ton- } \\
\text { Miles } \\
\left(\times 10^{6}\right)\end{array}$ & $\begin{array}{c}\text { Tons } \\
\left(\times 10^{3}\right)\end{array}$ & $\begin{array}{c}\text { Ton- } \\
\text { Miles } \\
\left(\times 10^{6}\right)\end{array}$ & $\begin{array}{c}\text { Tons } \\
\left(\times 10^{3}\right)\end{array}$ & $\begin{array}{c}\text { Ton- } \\
\text { Miles } \\
\left(\times 10^{6}\right)\end{array}$ \\
\hline For-hire truck & 10,739 & 1,108 & 13,921 & 2,038 & 556 & _c \\
\hline Private truck & 3,099 & 394 & 10,487 & 663 & 410 & - \\
\hline Total & & & 24,408 & 2,702 & 976 & - \\
\hline
\end{tabular}

a The tonnage values for fuming sulfuric acid are taken as $4 \%$ of total sulfuric acid tonnage.

b DOC (1981).

c A hyphen denotes not available. 
grandfather provisions. Because this method did not allow for the estimation of tonmiles, the annual frequencies for the shipments appearing in Table 4.16 were specified to match total tonnage. As discussed in Section 2.6, two-thirds of fuming sulfuric acid shipments for each route is taken as having $30 \%$ free $\mathrm{SO}_{3}$, and one-third is taken as having $65 \%$ free $\mathrm{SO}_{3}$.

Maio and Liu (1988) reported that the lack of concentration of sulfuric acid shipment along specific corridors precluded the generation of commodity flow maps for sulfuric acid. For this reason, we routed fuming sulfuric acid along the primary commodity flow corridors for all STCC 281 chemicals since sulfuric acid is the most widely transported chemical in STCC 281. We also applied shipment end point data gathered from the HMIS database to establish general weights for specific routes.

\subsubsection{Fuming Nitric Acid}

The total highway commodity flow data for fuming nitric acid are based on the 1977 CTS and 1993 CFS together with the HMIS database. The commodity flow analysis for fuming nitric acid is very similar to that for fuming sulfuric acid. The 1977 CTS reported that 794,000 tons of nitric acid were transported by highway in 1977 over 151 million ton-miles. The 1977 CTS commodity flow statistics for nitric acid were scaled to 1993 values using scaling factors for private and for-hire truck transportation previously discussed. The 1993 estimated commodity flow data for nitric acid is shown in Table 4.25. To obtain the percentage of nitric acid shipments that are fuming nitric acid, we analyzed incidents in the HMIS database from 1985 to 1995 that were reported for nitric acid (UN 2031) and fuming nitric acid (UN 2032) in a manner similar to that done for fuming sulfuric acid. Through this method, we determined that approximately $11 \%$ of nitric acid shipments are fuming nitric acid. Because this method does not allow the estimation of ton-miles, the annual frequencies for the shipments appearing in Table 4.17 are specified so that only total tonnage is matched.

Table 4.25 Commodity Flow Data in Tons (thousands) and Ton-Miles (millions) for Nitric Acid (STCC 28192) from the 1977 CTS with Estimated Values for $1993^{a}$

\begin{tabular}{|c|c|c|c|c|c|c|}
\hline \multirow[b]{2}{*}{$\begin{array}{c}\text { Transportation } \\
\text { Type }\end{array}$} & \multicolumn{2}{|c|}{1977 CTS $^{b}$} & \multicolumn{2}{|c|}{1993 Estimate } & \multicolumn{2}{|c|}{1993 Fuming } \\
\hline & $\begin{array}{c}\text { Tons } \\
\left(\times 10^{3}\right)\end{array}$ & $\begin{array}{c}\text { Ton- } \\
\text { Miles } \\
\left(\times 10^{6}\right)\end{array}$ & $\begin{array}{c}\text { Tons } \\
\left(\times 10^{3}\right)\end{array}$ & $\begin{array}{c}\text { Ton- } \\
\text { Miles } \\
\left(\times 10^{6}\right)\end{array}$ & $\begin{array}{c}\text { Tons } \\
\left(\times 10^{3}\right)\end{array}$ & $\begin{array}{c}\text { Ton- } \\
\text { Miles } \\
\left(\times 10^{6}\right)\end{array}$ \\
\hline For-hire truck & 772 & 149 & 1,001 & 274 & 110 & -c \\
\hline Private truck & 22 & 2 & 74 & 3 & 8 & - \\
\hline Total & & & 1,075 & 277 & 118 & - \\
\hline
\end{tabular}

a Tonnage values for fuming nitric acid are taken as $11 \%$ of total nitric acid tonnage.

b DOC (1981).

c A hyphen denotes not available. 
The route end points for fuming nitric acid were determined from the 1977 CTS nitric acid commodity flow as reported by Maio and Liu (1988). Weights for specific routes were adjusted to more closely match the geographical distributions of shipment end points for fuming nitric acid reported in the HMIS database.

\subsubsection{Liquefied Petroleum Gas and Combustible Liquids}

The total highway commodity flow data for LP gas (STCC 29121) are based on the 1977 CTS and 1993 CFS. The 1977 CTS reported that 4.9 million tons of LP gas were transported by highway in 1977 over 498 million ton-miles. Because the 1993 CFS does not provide specific data for LP gas, the 1977 CTS results for LP gas were scaled to 1993 using the commodity flow data for STCC 291, products of petroleum refining. A comparison of the 1977 CTS and 1993 CFS ton and ton-mile statistics for STCC 291 is presented in Table 4.26 with scaling factors for private and for-hire truck transportation.

Table 4.26 Commodity Flow Data in Tons (thousands) and Ton-Miles (millions) for Products of Petroleum Refining (STCC 291) from the 1977 CTS and 1993 CFS with the Scaling Factors Derived from the Data

\begin{tabular}{|c|c|c|c|c|c|c|}
\hline \multirow[b]{2}{*}{$\begin{array}{c}\text { Transportation } \\
\text { Type }\end{array}$} & \multicolumn{2}{|c|}{1977 CTS $^{a}$} & \multicolumn{2}{|c|}{1993 CFS $^{b}$} & \multicolumn{2}{|c|}{ Scaling Factors } \\
\hline & $\begin{array}{c}\text { Tons } \\
\left(\times 10^{3}\right)\end{array}$ & $\begin{array}{c}\text { Ton- } \\
\text { Miles } \\
\left(\times 10^{6}\right)\end{array}$ & $\begin{array}{c}\text { Tons } \\
\left(\times 10^{3}\right)\end{array}$ & $\begin{array}{c}\text { Ton- } \\
\text { Miles } \\
\left(\times 10^{6}\right)\end{array}$ & Tons & $\begin{array}{l}\text { Ton- } \\
\text { Miles }\end{array}$ \\
\hline For-hire truck & 54,506 & 8,221 & 312,080 & 21,607 & 5.73 & 2.63 \\
\hline Private truck & 54,861 & 6,506 & 535,487 & 21,206 & 9.76 & 3.26 \\
\hline Total & 109,367 & 14,727 & 847,567 & 42,813 & 7.75 & 2.91 \\
\hline
\end{tabular}

a DOC (1981).

b DOC (1996).

The relative increase in ton-miles between 1977 and 1993 is about 50\% larger for STCC 291 than for STCC 281 (industrial organic and inorganic chemicals) shown previously in Table 4.20. The increase in tons is even more dramatic. The factor of 7.75 increase in tons for STCC 291 is almost 4 times that for STCC 281. The larger increases in both tons and ton-miles for products of petroleum refining results from the fact that commodity flow for petroleum products is dominated by transportation from regional storage facilities, whereas commodity flow for chemical products is dominated by transportation from manufacturing facilities. Maio and Liu (1988) reported that transportation from regional storage facilities accounted for $60 \%$ of petroleum-products commodity flow but only $10 \%$ of chemical-products commodity flow on a ton-mile basis. Since the 1993 CFS included transportation from regional storage facilities and the 1977 CTS did not, the relative increases for petroleum products between the 1977 CTS and 1993 CFS are considerably higher. Because of the large increases in commodity flow estimates for petroleum products, the commodity flow estimates (especially tons) for LP gas and other petroleum products are considerably more uncertain than those for 
chemical products. Additional uncertainty exists due to reporting problems inherent in petroleum product shipments in the 1993 CFS (Amah-Tagoe 1998).

The use of the scaling factors in Table 4.26 to estimate 1993 commodity flow for LP gas from 1977 CTS data is done in a similar fashion as for ammonia and chlorine. The 1977 commodity flow estimates for LP gas and the estimated 1993 values are provided in Table 4.27. Here, we also show the commodity flow estimates for gasoline and fuel oil, which are used in Section 2 to estimate release probabilities for MC 306 and MC 307 cargo tanks.

Table 4.27 Commodity Flow Data in Tons (thousands) and Ton-Miles (millions) for LP Gas, Gasoline, and Fuel Oil from the 1977 CTS with Estimated Values for 1993 Calculated by Using the Scaling Factors in Table 4.26

\begin{tabular}{|c|c|c|c|c|c|c|}
\hline \multirow[b]{2}{*}{ Commodity } & \multicolumn{2}{|c|}{1977 For-Hire Truck ${ }^{a}$} & \multicolumn{2}{|c|}{$\begin{array}{c}1977 \text { Private } \\
\text { Truck }^{\mathrm{a}}\end{array}$} & \multicolumn{2}{|c|}{1993 Estimate } \\
\hline & $\begin{array}{c}\text { Tons } \\
\left(\times 10^{3}\right)\end{array}$ & $\begin{array}{c}\text { Ton- } \\
\text { Miles } \\
\left(\times 10^{6}\right)\end{array}$ & $\begin{array}{c}\text { Tons } \\
\left(\times 10^{3}\right)\end{array}$ & $\begin{array}{c}\text { Ton- } \\
\text { Miles } \\
\left(\times 10^{6}\right)\end{array}$ & $\begin{array}{c}\text { Tons } \\
\left(\times 10^{3}\right)\end{array}$ & $\begin{array}{c}\text { Ton- } \\
\text { Miles } \\
\left(\times 10^{6}\right)\end{array}$ \\
\hline LP gas & 2,035 & 223 & 2,878 & 275 & 39,743 & 1,482 \\
\hline Gasoline & 17,153 & 2,992 & 23,441 & 2,866 & 327,014 & 17,205 \\
\hline Fuel oil & 9,595 & 1,342 & 10,096 & 949 & 153,482 & 6,620 \\
\hline
\end{tabular}

a DOC (1981).

The estimated commodity flow for LP gas for 1993 was 39,743,000 tons of material transported over 1,482 million ton-miles. The annual frequencies for the shipments appearing in Table 4.18 were specified so that the total ton-mile estimate was matched. Most routes appearing in Table 4.18 were obtained from the 1977 CTS as discussed in Section 4.3.1. However, a few additional routes were added to account for the rural transportation of LP gas by bobtail trucks.

\subsubsection{Explosives}

The total highway commodity flow data for explosives are based on the 1977 CTS and 1993 CFS. The primary commodity category encompassing explosives as defined by the five-digit STCC code is 28921, namely, explosives excluding ammunition.

Ammunition, which accounts for a small fraction of total explosives commodity flow, is covered by the three-digit STCC codes 192 and 196.

The 1977 CTS reported that 801,000 tons of explosives (excluding ammunition) were transported by highway in 1977 over 326 million ton-miles. Since the 1993 CFS does not provide specific data for STCC 28921, the 1977 CTS results for explosives were scaled to 1993 using the commodity flow data for STCC 289, miscellaneous chemical products. A comparison of the 1977 CTS and 1993 CFS ton and ton-mile statistics for STCC 289 
is presented in Table 4.28 with scaling factors for private and for-hire truck transportation. Estimated explosives commodity flow for 1993 as determined from the 1977 CTS using the scaling factors in Table 4.28 is shown in Table 4.29, and a summary of all 1993 commodity flow data for explosives is given in Table 4.30.

Table 4.28 Commodity Flow Data in Tons (thousands) and Ton-Miles (millions) for Miscellaneous Chemical Products (STCC 289) from the 1977 CTS and 1993 CFS with the Scaling Factors Derived from the Data

\begin{tabular}{|c|c|c|c|c|c|c|}
\hline \multirow[b]{2}{*}{$\begin{array}{c}\text { Transportation } \\
\text { Type }\end{array}$} & \multicolumn{2}{|c|}{1977 CTS $^{a}$} & \multicolumn{2}{|c|}{1993 CFS $^{b}$} & \multicolumn{2}{|c|}{ Scaling Factors } \\
\hline & $\begin{array}{c}\text { Tons } \\
\left(\times 10^{3}\right)\end{array}$ & $\begin{array}{c}\text { Ton- } \\
\text { Miles } \\
\left(\times 10^{6}\right)\end{array}$ & $\begin{array}{c}\text { Tons } \\
\left(\times 10^{3}\right)\end{array}$ & $\begin{array}{c}\text { Ton- } \\
\text { Miles } \\
\left(\times 10^{6}\right)\end{array}$ & Tons & $\begin{array}{l}\text { Ton- } \\
\text { Miles }\end{array}$ \\
\hline For-hire truck & 9,880 & 3,557 & 17,161 & 7,987 & 1.74 & 2.25 \\
\hline Private truck & 6,648 & 1,398 & 9,927 & 1,711 & 1.49 & 1.22 \\
\hline Total & 16,528 & 4,955 & 17,161 & 7,987 & 1.04 & 1.61 \\
\hline
\end{tabular}

a DOC (1981).

b DOC (1996).

Table 4.29 Commodity Flow Data in Tons (thousands) and Ton-Miles (millions) for Explosives (STCC 28921) from the 1977 CTS with Estimated Values for 1993 by Using the Scaling Factors in Table 4.28

\begin{tabular}{|c|c|c|c|c|c|c|}
\hline \multirow[b]{2}{*}{$\begin{array}{c}\text { Transportation } \\
\text { Type }\end{array}$} & \multicolumn{2}{|c|}{1977 CTS $^{a}$} & \multicolumn{2}{|c|}{ Scaling Factors } & \multicolumn{2}{|c|}{1993 Estimate } \\
\hline & $\begin{array}{c}\text { Tons } \\
\left(\times 10^{3}\right)\end{array}$ & $\begin{array}{c}\text { Ton- } \\
\text { Miles } \\
\left(\times 10^{6}\right)\end{array}$ & Tons & $\begin{array}{l}\text { Ton- } \\
\text { Miles }\end{array}$ & $\begin{array}{c}\text { Tons } \\
\left(\times 10^{3}\right)\end{array}$ & $\begin{array}{c}\text { Ton- } \\
\text { Miles } \\
\left(\times 10^{6}\right)\end{array}$ \\
\hline For-hire truck & 357 & 254 & 1.74 & 2.25 & 621 & 571 \\
\hline Private truck & 415 & 65 & 1.49 & 1.22 & 618 & 79 \\
\hline Total & & & & & 1,240 & 651 \\
\hline
\end{tabular}

a DOC (1981).

Table 4.30 Summary of the 1993 Commodity Flow Data for Explosives

\begin{tabular}{|cccc|}
\hline STCC & Commodity & $\begin{array}{c}\text { Tons } \\
\left(\times \mathbf{1 0}^{3}\right)\end{array}$ & $\begin{array}{c}\text { Ton- } \\
\text { Miles } \\
\left(\times \mathbf{1 0}^{\mathbf{6}}\right)\end{array}$ \\
\hline STCC 28921 & Explosives & 1,240 & 651 \\
STCC 192 & Ammunition $>30 \mathrm{~mm}$ & 111 & 56 \\
STCC $196^{\mathrm{a}}$ & Ammunition $<30 \mathrm{~mm}$ & 108 & 91 \\
& All explosives & 1,459 & 798 \\
\hline
\end{tabular}

a DOC (1996). 
The representative shipments and shipment frequencies in Table 4.19 were selected based on regional commodity flow estimates in 1977 CTS. Two additional representative shipments were added to account for transportation of ammunition $>30 \mathrm{~mm}$ primarily between suppliers and military installations. Except for ammunition, the explosives used to model the remainder of the shipments were trinitrotoluene (TNT) and ANFO. TNT was used to model Division 1.1 materials, whereas ANFO was used to model Division 1.5 materials. Based on incident reports in HMIS, about two-thirds of total explosives shipments are Division 1.5 materials, and about 10\% are Division 1.1 materials. Most of the remainder are Division 1.4 materials. Division 1.4 materials have a very low risk of appreciable explosions and are therefore not modeled in detail in the NTRA. Division 1.3 and 1.6 materials are not considered due to their very low commodity flows.

\subsubsection{Calculation of Highway Routes by Using HIGHWAY 3.3}

As discussed in Section 2.2, the ORNL HIGHWAY 3.3 model (Johnson et al. 1993b) was used to generate the representative highway routes from the shipment end points discussed above. The structure of HIGHWAY 3.3 is very similar to its rail counterpart INTERLINE 5.0 (Section 4.2.3). HIGHWAY 3.3 uses a computerized atlas of more than 250,000 miles of roadways in the United States. This road network is represented by more than 13,000 nodes (intersections) connected by more than 20,000 highway segments. All interstates, U.S. highways, and many secondary highways are included in the network. Using the origin and destination supplied by the user, the model determines a set of nodes and links that represents an optimized route between the end points. The routes are optimized using several user-defined weighting criteria such as specific node or link avoidance, tollway weighting, and hazardous material (HM-181) constraints with a default criteria of minimum time.

An example of a route generated using HIGHWAY 3.3 is shown in Table 4.31 and is very similar (in appearance) to routes provided by INTERLINE 5.0. The listing is in the form of route nodes that serve as segment end points. The node locations are denoted by latitude and longitude, which are provided by a post processor to the standard HIGHWAY 3.3 model. Population density information for each route segment is listed between the respective node end points. The population density data, which is from the 1990 census, is provided in terms of mileage within the segment for each of 12 population density categories in the same format as in the INTERLINE model discussed previously. 
Table 4.31 Highway Route Generated by HIGHWAY 3.3 as Postprocessed to Provide Latitude and Longitude

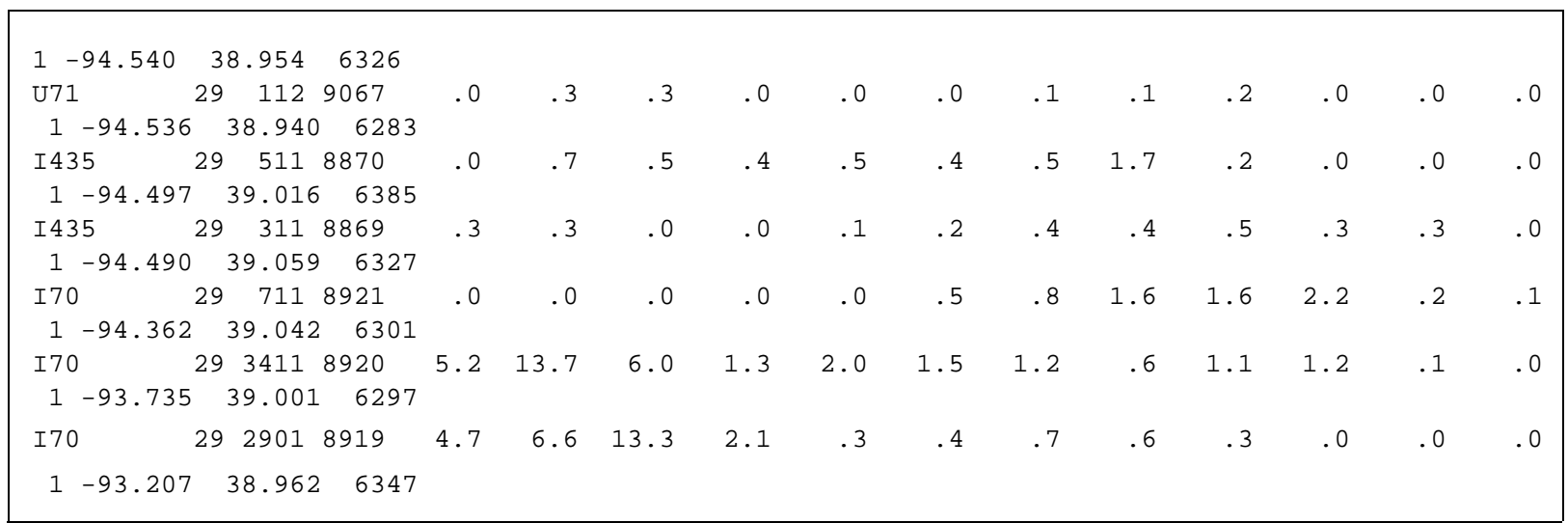

a This particular example provides the first six legs of the rail route between Hammond, Indiana, and Albany, New York, used to model Shipment 1 for sulfur dioxide. 
$\Delta$ 


\section{Section 5 \\ Risk Assessment Results}

On the basis of the analysis set forth in previous sections, we calculated the injury and fatality probabilities for six TIH chemicals, LP gas, gasoline, and explosive materials. The results of this analysis are discussed in this section. In Section 5.1, we introduce important statistical concepts and key definitions necessary for interpreting and understanding the risk assessment results presented in the remainder of the section. In Section 5.2, risk profiles for six TIH materials are presented. Here, we provide results separately for both highway and rail incidents and for accident-related and en route/ nonaccident releases. (Recall that accident-related releases refer to releases that occur in traffic accidents and train derailments, whereas en route/nonaccident releases refer to releases that occur as a result of a cargo shift, valve failure, corrosion-induced container failure, and other events.) Results are presented for two consequence levels related to injuries and fatalities. For each type of release and consequence level, results are presented in two forms. The first form consists of probability tables, which list the probability of certain numbers of persons being affected, and the second form consists of figures showing cumulative probability versus persons affected. Sections 5.3 and 5.4 provide the NTRA results for flammable and explosive materials in a similar manner as for TIH materials. In these sections, we examine risk associated with highway transportation of LP gas, gasoline, and explosives. For each of these materials, risk assessment results are shown for injuries and fatalities in both tabular and graphical form. Finally, in Section 5.5, we offer comparisons of the risk distributions and average risk between TIH materials, flammable materials, and explosives.

\subsection{Presentation of Risk Assessment Results}

The NTRA risk assessment results for TIH materials, flammable materials, and explosives are presented in terms of cumulative probability versus persons affected per 10-yr period. In addition, annual statistics and other risk measures are provided to compare and contrast risk associated with different chemicals and transportation modes. To facilitate a fuller understanding of the information presented in the remainder of this report, we provide a few definitions and explanations beginning in Section 5.1.1, which emphasizes the significance of the choice of averaging time. We then discuss the graphical presentation of the results in Section 5.1.2 and define the key consequence levels and risk measures in Section 5.1.3. Finally, in Section 5.1.4, we discuss the treatment of mitigating effects that reduce TIH-related risk.

\subsubsection{Risk Assessment Averaging Time}

In this report, we refer to the time period used in the presentation of the risk assessment results as the averaging time. Averaging time is a fundamental parameter in the risk assessment since the probability of a certain event occurring increases as the averaging time increases. Note that averaging time is different from the overall time 
period analyzed for the statistical sample of accidents. We refer to this latter time as the sample time. For this study, the sample time is on the order of millions of years.

Increasing the sample time adds resolution and precision to the results. That is, it will not change the probability of an event occurring but will allow a more accurate calculation of that probability. A large sample time is required to fully resolve the low-probability tail of the consequence distribution, especially for individual TIH chemicals for which only a few incidents might occur over a 10-yr period.

To illustrate how results are affected by the choice of averaging time, consider the hypothetical distribution of accidents and consequences for a 40 -yr period given in Table 5.1. Table 5.2 provides the risk distributions for 1-, 5-, and 10-yr averaging times, which illustrates how averaging time affects the risk probabilities. Table 5.3 further highlights these differences by extending the concept to shorter averaging times. Clearly, as the averaging time increases, the probability that a given number of people will be affected increases accordingly. Although our study is based on the simulation of more than 1 million 10-yr periods, not just the four considered above, the effect of averaging time is qualitatively similar for materials in this study.

Table 5.1 Hypothetical Distribution of Incidents and Consequences

\begin{tabular}{|c|c|c|c|c|c|c|c|c|c|c|c|}
\hline $\mathbf{Y r}$ & Incidents & Persons & $\mathrm{Yr}$ & Incidents & Persons & $\mathrm{Yr}$ & Incidents & Persons & $\mathrm{Yr}$ & Incidents & Persons \\
\hline 1 & 0 & 0 & 11 & 1 & 5 & 21 & 9 & 37 & 31 & 0 & 0 \\
\hline 2 & 1 & 5 & 12 & 1 & 1 & 22 & 0 & 0 & 32 & 1 & 4 \\
\hline 3 & 0 & 0 & 13 & 3 & 27 & 23 & 0 & 0 & 33 & 1 & 1 \\
\hline 4 & 0 & 0 & 14 & 0 & 0 & 24 & 0 & 0 & 34 & 1 & 1 \\
\hline 5 & 3 & 6 & 15 & 0 & 0 & 25 & 0 & 0 & 35 & 1 & 6 \\
\hline 6 & 0 & 0 & 16 & 0 & 0 & 26 & 0 & 0 & 36 & 1 & 1 \\
\hline 7 & 0 & 0 & 17 & 0 & 0 & 27 & 0 & 0 & 37 & 0 & 0 \\
\hline 8 & 0 & 0 & 18 & 0 & 0 & 28 & 0 & 0 & 38 & 0 & 0 \\
\hline 9 & 2 & 14 & 19 & 0 & 0 & 29 & 6 & 1 & 39 & 0 & 0 \\
\hline 10 & 1 & 1 & 20 & 0 & 0 & 30 & 0 & 0 & 40 & 0 & 0 \\
\hline
\end{tabular}

This example illustrates that averaging time is an integral component of the overall risk analysis; it is as necessary to consider averaging time as it is to consider commodity flow, shipping mode, routing, container robustness, or toxicity. In fact, averaging time and commodity flow are intrinsically related since the number of events considered in the averaging window is linearly proportional to each factor. In terms of the consequence distributions, averaging time cannot be removed from the results, and thus an arbitrary choice is required.

For presentation of the risk assessment results, we used a 10-yr period. In addition, several risk measures such as average injuries and fatalities are also given in annual terms (i.e., for a 1-yr period) to allow a more convenient comparison of hazardous materials transportation risk with current and historical incident statistics. 
Table 5.2 Cumulative Probability for Incidents Shown in Table 5.1 for 1-, 5-, and 10-yr Averaging Times

\begin{tabular}{|lccc|}
\hline & \multicolumn{4}{c|}{ Cumulative Probability (yr) } \\
\cline { 2 - 4 } $\begin{array}{c}\text { Consequence } \\
\text { Level }\end{array}$ & $\mathbf{1}$ & $\mathbf{5}$ & $\mathbf{1 0}$ \\
\hline 30 or more persons & 1 in $40=0.025$ & 2 in $8=0.25$ & 2 in $4=0.50$ \\
20 or more persons & 2 in $40=0.05$ & 2 in $8=0.25$ & 3 in $4=0.75$ \\
10 or more persons & 3 in $40=0.075$ & 5 in $8=0.625$ & 4 in $4=1$ \\
5 or more persons & 7 in $40=0.175$ & 5 in $8=0.625$ & 4 in $4=1$ \\
4 or more persons & 8 in $40=0.2$ & 5 in $8=0.625$ & 4 in $4=1$ \\
3 or more persons & 8 in $40=0.2$ & 5 in $8=0.625$ & 4 in $4=1$ \\
2 or more persons & 8 in $40=0.2$ & 5 in $8=0.625$ & 4 in $4=1$ \\
1 or more persons & 14 in $40=0.35$ & 7 in $8=0.875$ & 4 in $4=1$ \\
\hline
\end{tabular}

Table 5.3 Effect of Averaging Time on Cumulative Probability

\begin{tabular}{|lcc|}
\hline $\begin{array}{c}\text { Averaging } \\
\text { Time }\end{array}$ & $\begin{array}{c}\text { 1 or More } \\
\text { Persons }\end{array}$ & $\begin{array}{c}\text { 30 or More } \\
\text { Persons }\end{array}$ \\
\hline 1 day & 0.002 & $7 \times 10^{-5}$ \\
1 month & 0.067 & 0.002 \\
1 year & 0.35 & 0.025 \\
5 year & 0.875 & 0.25 \\
10 year & 1 & 0.50 \\
\hline
\end{tabular}

\subsubsection{Graphical Risk Profiles}

Figure 5.1 shows cumulative probability curves typical of those for a transportation-related risk illustrating some of the important factors that influence the shape of these curves and therefore the nature of the risk distributions. In this figure, probability is plotted with respect to persons affected over a 10 -yr period.

The ordinate of the figure (i.e., probability) is represented in two ways. On the left side, probability is represented as odds of occurrence. For example a probability of 1 in 10 indicates a $10 \%$ probability of occurrence over a 10 -yr period. On the right side, the probability is given in decimal form. For instance, a probability of 0.1 indicates that for a 10 -yr period, the probability of $N$ persons being affected is $10 \%$, where $N$ is the number of affected persons as indicated on the abscissa. The two curves reflect distributions driven by high-probability/low-consequence events and low-probability/highconsequence events. In describing probability and consequences, recall that we use the terms low and high only in a relative sense. For example, low-consequence incidents on average affect fewer people than do high-consequence incidents. Similarly, lowprobability incidents occur less often on average than do high-probability incidents, even though neither may be highly probable in an absolute sense.

Factors that contribute to a low probability, which will move the probability curves in Figure 5.1 downward, include low annual commodity flow (expressed as ton-miles), low accident rates, and high container robustness. Factors that contribute to high consequences, which will move the probability curves in Figure 5.1 to the right, include large shipment sizes, high volatility, high toxicity, and high population density. 


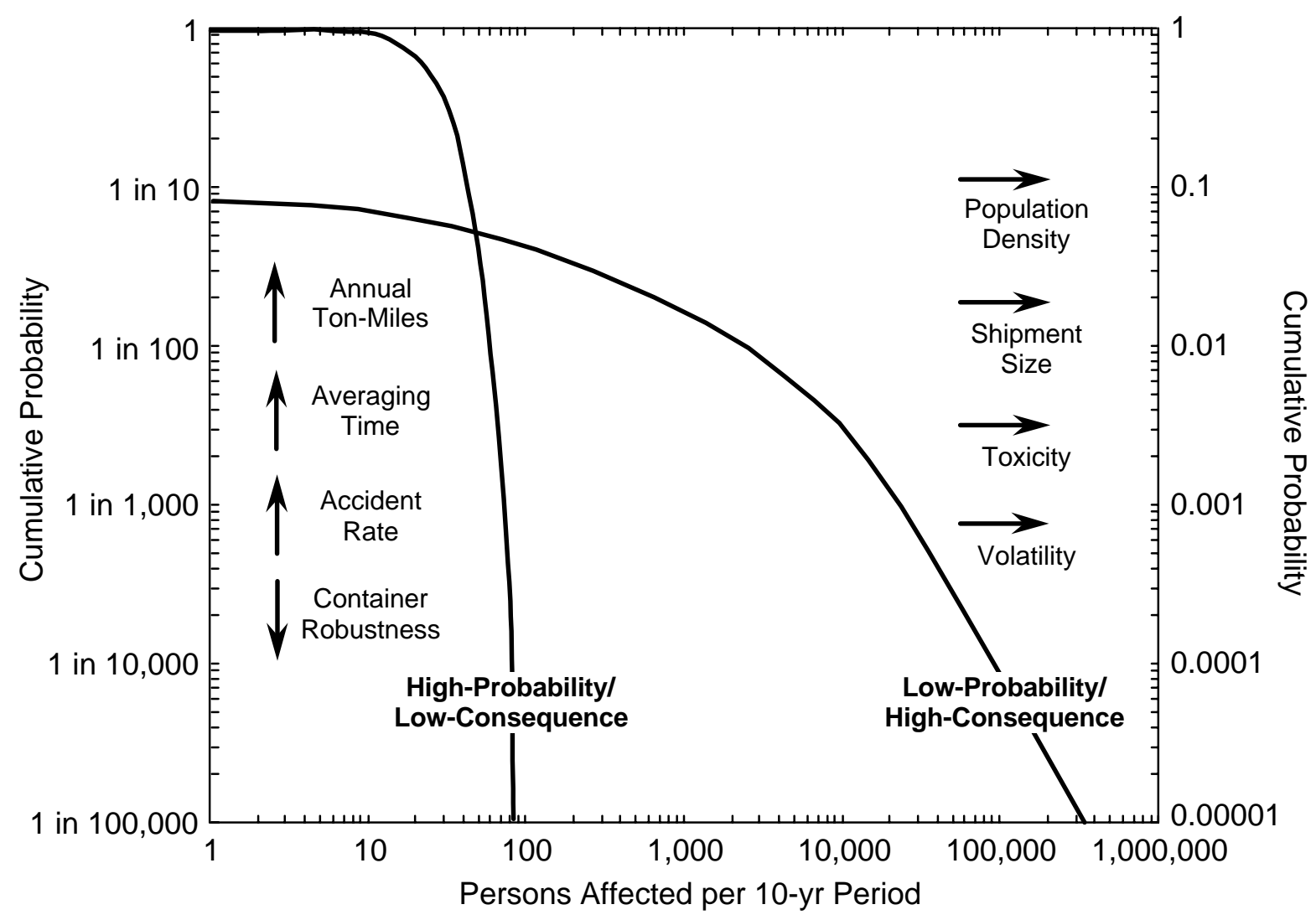

Figure 5.1 Cumulative Probability Curves Characteristic of Transportation-Related Risk (Factors that influence the shape of these curves are also shown. The arrows indicate how increasing each of these quantities will affect the resulting probability curve.)

This graphical representation has some important differences from standard $F-N$ curves commonly used in single-shipment or fixed facility risk assessments to convey societal risk. $F-N$ curves plot cumulative frequency $(F)$ versus the number of injuries or fatalities $(N)$, thus providing the consequence probability associated with discrete events. Because the NTRA considers all incidents in various categories (such as highway accidents) occurring in the United States over a fixed period, a standard $F-N$ representation does not provide an adequate means of communicating risk since a large number of incidents can occur within our averaging time (10 years for this study), each of which will contribute to the total consequences for that time. This is a very important distinction since the consequences calculated in the NTRA analysis and presented in this section can involve impacts from several separate events rather than from a single event. This type of presentation was selected for this study since it reflects the total risk on a national basis for a given time rather than the probability of certain discrete events. 


\subsubsection{Consequence Levels and Risk Measures}

In this section, we define some of the consequence levels and risk measures. Although the definitions for the risk measures are applicable for ERPG-2 exposures, fatal exposures, injuries, and fatalities, we speak in terms of exposures to simplify the discussion.

\subsubsection{ERPG-2 Exposures}

The term ERPG-2 exposures expresses the number of persons potentially exposed to concentration levels exceeding the ERPG-2 health criteria (or equivalent) as calculated from outdoor chemical concentrations and population density. The number of ERPG-2 exposures does not consider potential exposure reduction due to the protective effects of sheltering or possible evacuation of the persons out of the area of danger. Therefore, the number of ERPG-2 exposures represents a conservative estimate of the actual number of injuries. To account for these mitigative effects and thus provide a more realistic comparison of TIH injury risk with that due to LP gas, gasoline, and explosives, the number of injuries is taken as one tenth of the number of ERPG-2 exposures (see Section 5.1.4 for a more detailed discussion).

\subsubsection{Fatal Exposures}

The term fatal exposures expresses the number of persons potentially exposed to lethal concentrations as calculated from $\mathrm{LC}_{50}$ thresholds (Section 2.3.2.4). Like ERPG-2 exposures, fatal exposures are calculated directly from outdoor chemical concentrations and population density and do not include potential exposure reductions due to the protective effects of sheltering or possible evacuation. As a result, the number of fatal exposures is a conservative estimate for the number of fatalities. To account for these mitigative effects and provide a more realistic comparison of TIH fatality risk with that due to LP gas, gasoline, and explosives, the number of fatalities is taken as one-seventh of the number of fatal exposures (see Section 5.1.4 for a more detailed discussion).

\subsubsection{Average Number of Incidents}

This term denotes the average number of incidents that occur every 10 years or every year, depending on the table. This number is linearly proportional to total commodity and to averaging time flow as long as the shipment distribution remains fixed.

\subsubsection{Average Number of Exposures}

This term denotes the average number of exposures that occur every $10 \mathrm{yr}$ or every year, depending on the table. Since this is an average of the entire risk distribution, it can be strongly influenced by low-probability/high-consequence events, especially for TIH materials. Like the average number of incidents, the average number of exposures is linearly proportional to total commodity flow and averaging time. 


\subsubsection{Median Number of Exposures}

The median number of exposures is by definition the $50^{\text {th }}$ percentile value for the risk distribution for our 10 -yr period. Therefore, there is a $50 \%$ probability that the number of exposures in any 10-yr period in our analysis is below the median value and $50 \%$ probability that the number of exposures in any 10-yr period is above the median value. Although the median value is not necessarily the most likely value (which is the mode of the distribution), it does provide a number characteristic of what one would expect to see in any given 10-yr period. An important consequence of this is that for materials rarely involved in accidents (e.g., certain TIH materials and explosives), a majority of 10-yr periods have no incidents and therefore no exposures. This directly translates to median exposure values of zero even though the average number of exposures may be quite high. The effect of total commodity flow and averaging time on the median is somewhat more complicated than for the other risk measures. The median value will tend to approach the average value as total commodity flow and averaging time increase. However, until the total commodity flow and averaging time have exceeded a certain level, the median value will be zero due to the infrequency of incidents.

\subsubsection{Average Number of Exposures per Million Ton-Miles}

The average number of exposures per million ton-miles is a measure of risk in which averaging time and commodity flow have been factored out. This measure is of particular importance since it reflects the normalized risk associated with transportation of that particular material. As such, it is very useful in comparing and contrasting the relative risk associated with different chemicals or transportation modes such as chlorine ammonia, highway versus rail, or package freight versus bulk freight. From a regulatory perspective, the average number of exposures per million ton-miles, which we shall refer to as the normalized risk, is valuable in highlighting where regulations might be too burdensome or need strengthening.

\subsubsection{Average Number of Exposures per Incident}

The average number of exposures per incident reflects the general danger of the material in a transportation-related release. All influences relating to event probability including averaging time, commodity flow, accident rate, and container robustness are factored out of this risk measure. The average number of exposures per incident is influenced by average shipment size, volatility, toxicity, and population density. Since this risk measure is an average of all incidents, it can be strongly affected by low-probability/high-consequence events, especially for TIH materials.

\subsubsection{Treatment of Mitigating Effects That Reduce TIH-Related Risk}

For TIH materials, the consequence analysis used in this study does not account for mitigating factors that may reduce risk. The most significant factor in this regard is that most people are normally indoors and are thus partially protected from outdoor concentrations of toxic materials. This effect, denoted as passive sheltering, impacts 
severe accidents more profoundly than less severe accidents and therefore has a substantial influence on the risk assessment results. As discussed in Section 2, the general approach taken in this report, namely the exclusion of mitigating factors from the risk assessment, is consistent with almost all related studies. For example, mitigating factors are excluded in analyzing air pollution impacts from stationary sources for the purpose of issuing air-quality permits and also in determining Protective Action Distances for the Emergency Response Guidebook (Brown et al. 2000).

However, in comparing TIH transportation risk with the risk associated with the transportation of flammable materials (including gasoline) and explosives, the neglect of mitigating factors in $\mathrm{TIH}$ incidents does not allow a fair and accurate comparison of the relative risks involved with the transportation of these materials. To provide a fairer comparison, we include the effects of sheltering in converting ERPG-2 exposures and fatal exposures to injuries and fatalities by using the exposure reduction factors calculated in Section 2.3.4. In applying these results, we note that for TIH materials, approximately $75 \%$ to $80 \%$ of the risk of ERPG-2 and fatal exposure results from nighttime incidents. Furthermore, the vast majority of this risk arises from large liquefied gas releases. Therefore, using the results previously given in Table 2.6 as general guidance and assuming that most people will be at home and indoors, we set the numbers of injuries and fatalities occurring as a result of TIH transportation as one-tenth of the ERPG-2 exposures and one-seventh of the fatal exposures, respectively. These factors are summarized in Table 5.4.

Table 5.4 Reduction Factors for Relating ERPG-2 Exposures to Injuries and Fatal Exposures to Fatalities ${ }^{a}$

\begin{tabular}{|lc|}
\hline $\begin{array}{c}\text { Consequence } \\
\text { Level }\end{array}$ & $\begin{array}{c}\text { Reduction Factor Used to } \\
\text { Account for Sheltering }\end{array}$ \\
\hline ERPG-2 exposures & 10 \\
Fatal exposures & 7 \\
\hline
\end{tabular}

a Unless otherwise noted, these factors are incorporated into the discussion of results contained in Sections 5.5 and 6. The results presented in Section 5.2 do not include these sheltering reduction factors.
In discussing the TIH risk assessment results in Section 5.2, we do not include the effects of sheltering (i.e., the exposure reduction factors are not used). Therefore, the results in Section 5.2 represent a conservative upper bound on possible exposures and fatalities resulting from $\mathrm{TIH}$ transportation. In Sections 5.5 and 6, the sheltering reduction factors in Table 5.4 are used when comparing $\mathrm{TIH}$ transportation risk to risk arising from transportation of other materials.

\subsection{Toxic-by-Inhalation Materials}

This section provides consequence distributions for the TIH materials analyzed in the NTRA. Individual results are provided for highway and rail transportation and for two classes of releases: those that occur (1) during a traffic accident or a train derailment or (2) while en route from the origin to the destination, but not during an accident or derailment. For each class of release, results are presented for two consequence levels ERPG-2 exposures and fatal exposures. 
In Section 5.2.1, we present results for highway transportation for accident-related incidents, and in Section 5.2.2, we provide results for en route/nonaccident incidents. We then present results for rail transportation for accident-related incidents in Section 5.2.3 and for en route/nonaccident incidents in Section 5.2.4. The average results from these four incident types are summarized in Section 5.2.5. In Section 5.2.6, we consider TIH risk assessment results with respect to chemical and total TIH risk, and in Section 5.2.7, we discuss the sensitivity of the results to routing. Finally, in Section 5.2.8, we discuss the reduction of risk as a result of recent regulatory changes.

Mitigating factors such as evacuations and sheltering are not included in the results presented in Section 5.2. To compare the risk resulting from transporting TIH materials to the risk from transporting flammable materials and explosives, the effects of sheltering are included (Section 5.1.4).

\subsubsection{Accident-Related Highway Releases}

Table 5.5 provides the probability of exposure to ERPG-2 concentrations for accident-related highway releases of ammonia, chlorine, $\mathrm{SO}_{2}, \mathrm{HF}$, fuming sulfuric acid, and fuming nitric acid over a 10 -yr period. The population exposure probabilities listed in the table are cumulative and are interpreted as follows. Consider, for example, chlorine. Here, the probability of exposing one person (0.66) means that there is a $66 \%$ chance that one person will be exposed to chlorine concentrations above the ERPG-2 threshold as a result of highway accidents involving chlorine transportation during a 10 -yr period. 7 Similarly, there is a $52 \%, 32 \%$, and $13 \%$ chance that 10,100 , and 1,000 people, respectively, will be affected in a similar manner. Note that each of these consequence levels (except 1 affected person) may involve contributions from more than one incident in the 10-yr period.

Figure 5.2 provides a graphical presentation of these same results. Here, probability is plotted with respect to persons exposed to the ERPG-2 concentrations over a 10-yr period. The ordinate (i.e., probability) is represented in two ways. On the left, the probability is represented as odds of occurrence. For example, a probability of 1 in 10 indicates a $10 \%$ probability of occurrence. On the right, the probability is given in decimal form. For instance, a probability of 0.1 indicates that for any 10 -yr period, the probability of $N$ persons being exposed to concentrations exceeding the ERPG-2 concentration is $10 \%$, where $N$ is the number persons as denoted on the abscissa.

Average statistics and other risk measures for ERPG-2 exposures resulting from highway-accident-related releases are shown in the lower portion of Table 5.5 and in Table 5.6. First, we discuss the risk measures listed in Table 5.5. These include the average number of ERPG-2 exposures during $10 \mathrm{yr}$ and the median number of people exposed over a 10 -yr period.

7 The probabilities represented in Table 5.2, Figure 5.1, and the remainder of this section are cumulative. Therefore, the cumulative probability of one person being exposed includes all instances where one or more people are exposed. 
Table 5.5 Probability of Population Exposure to Airborne Concentrations Exceeding ERPG-2 Thresholds Resulting from Accident-Related Highway Releases over a 10-yr Period for the Six NTRA TIH Chemicalsa

\begin{tabular}{|c|c|c|c|c|c|c|}
\hline $\begin{array}{l}\text { Transportation } \\
\text { Consequence } \\
\text { Incident Type: }\end{array}$ & $\begin{array}{l}\text { ode: Highn } \\
\text { vel: } \text { ERPG } \\
\text { Traffic }\end{array}$ & $\begin{array}{l}\text { Iay } \\
\text {-2 Exposur } \\
\text { Accident }\end{array}$ & & & & \\
\hline $\begin{array}{l}\text { Persons } \\
\text { Exposed }\end{array}$ & Ammonia & Chlorine & $\begin{array}{l}\text { Sulfur } \\
\text { Dioxide }\end{array}$ & $\begin{array}{c}\text { Hydrogen } \\
\text { Fluoride }\end{array}$ & $\begin{array}{c}\text { Fuming } \\
\text { Sulfuric Acid }\end{array}$ & $\begin{array}{c}\text { Fuming } \\
\text { Nitric Acid }\end{array}$ \\
\hline 1 & $>0.995$ & 0.66 & 0.083 & 0.22 & 0.50 & 0.18 \\
\hline 2 & $>0.995$ & 0.63 & 0.077 & 0.21 & 0.46 & 0.16 \\
\hline 5 & 0.99 & 0.57 & 0.066 & 0.18 & 0.39 & 0.13 \\
\hline 10 & 0.98 & 0.52 & 0.058 & 0.16 & 0.33 & 0.11 \\
\hline 20 & 0.93 & 0.46 & 0.049 & 0.14 & 0.27 & 0.084 \\
\hline 50 & 0.77 & 0.38 & 0.038 & 0.11 & 0.19 & 0.057 \\
\hline 100 & 0.58 & 0.32 & 0.030 & 0.083 & 0.13 & 0.040 \\
\hline 200 & 0.38 & 0.25 & 0.023 & 0.062 & 0.083 & 0.026 \\
\hline 500 & 0.18 & 0.18 & 0.015 & 0.037 & 0.041 & 0.013 \\
\hline 1,000 & 0.084 & 0.13 & 0.010 & 0.023 & 0.022 & 0.0068 \\
\hline 2,000 & 0.027 & 0.081 & 0.0063 & 0.013 & 0.011 & 0.0026 \\
\hline 5,000 & 0.0029 & 0.036 & 0.0025 & 0.0043 & 0.0036 & $3.9 \times 10^{-4}$ \\
\hline 10,000 & $1.5 \times 10^{-4}$ & 0.014 & 0.00095 & 0.0014 & 0.0013 & $4.2 \times 10^{-5}$ \\
\hline 20,000 & $2.6 \times 10^{-6}$ & 0.0033 & 0.00032 & $2.1 \times 10^{-4}$ & $3.8 \times 10^{-4}$ & $1.0 \times 10^{-6}$ \\
\hline 50,000 & $<10^{-6}$ & $1.7 \times 10^{-4}$ & $6.6 \times 10^{-5}$ & $3.5 \times 10^{-6}$ & $4.7 \times 10^{-5}$ & $<10^{-6}$ \\
\hline 100,000 & $<10^{-6}$ & $3.0 \times 10^{-6}$ & $8.9 \times 10^{-6}$ & $<10^{-6}$ & $4.9 \times 10^{-6}$ & $<10^{-6}$ \\
\hline 200,000 & $<10^{-6}$ & $<10^{-6}$ & $<10^{-6}$ & $<10^{-6}$ & $<10^{-6}$ & $<10^{-6}$ \\
\hline \multicolumn{7}{|c|}{ Ten-year exposure statistics } \\
\hline Median & 133 & 14 & 0 & 0 & 1 & 0 \\
\hline Average & 351 & 679 & 57 & 108 & 120 & 28 \\
\hline
\end{tabular}

a Mitigative measures such as sheltering or evacuation are not included in these results.

As discussed in Section 5.1.3, the median number of exposures represents the $50^{\text {th }}$ percentile value for all 10-yr periods. By definition, the median value is such that half of 10 -yr periods have exposures less than the median value and half of 10 -yr periods have exposures greater than the median value. Although the median value is not necessarily the most likely value, it does provide a number characteristic of what one would expect to see in any given 10-yr period. However, due to the fact that highway-accident-related releases of $\mathrm{SO}_{2}, \mathrm{HF}$, and fuming nitric acid occur infrequently, over a 10 -yr period can pass without a single release. Therefore, a majority of 10-yr periods have no highwayaccident-related exposures due to transportation of these chemicals and consequently have median exposure values of zero. The number of average exposures, on the other hand, is a numeric average of exposures for all 10-yr periods considered in the analysis (more than 1 million). As such, the average is strongly influenced by low-probability/ high-consequence events. As an example of how these statistics represent risk, consider a 
Transportation Mode: Highway

Consequence Level: ERPG-2 Exposures

Incident Type: Traffic Accident

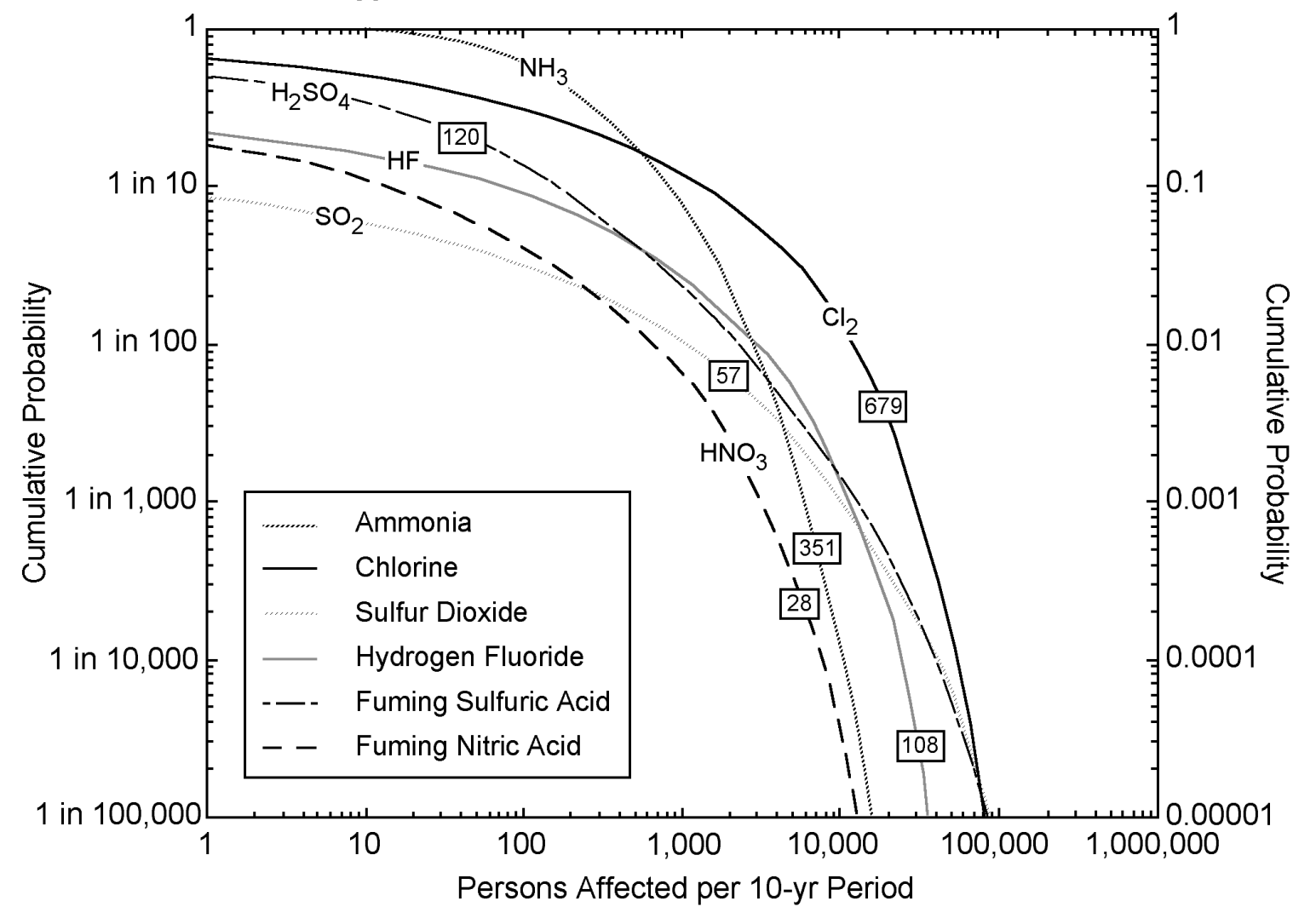

Figure 5.2 Probability of ERPG-2 Exposure for Accident-Related Highway Releases over a 10-yr Period for the Six NTRA TIH Chemicals (Means of the exposure distributions are shown in the boxes superimposed on the curves. Mitigative measures such as sheltering or evacuation are not included in these results.)

hypothetical chemical for which there is a single release every $100 \mathrm{yr}$, which leads to 1,000 exposures. For this chemical, the median exposures for any $10 \mathrm{yr}$ period is zero (because 9 of 10 10-yr periods have no releases). However, the number of average exposures for a 10 -yr period is 100 .

The above example as well as the results in Table 5.5 illustrate the fact that the skewed consequence distributions for TIH materials often cause averages to exceed median values by a large factor. This effect is clearly evident in the results for chlorine, where the average number of people exposed to ERPG-2 chlorine concentrations is more than 650, whereas the median is only 14 . Another important effect of the distribution skewness is that the probability of exceeding the long-term average ERPG-2 exposures is low for any given 10-year period. For instance, the probability that ERPG-2 chlorine exposures will exceed the long-term average of such exposures during any 10-yr period 
Table 5.6 Risk Measures and Annual Population Exposure Statistics for ERPG-2 Exposures Resulting from Accident-Related Highway Releases for the Six NTRA TIH Chemicals ${ }^{a}$

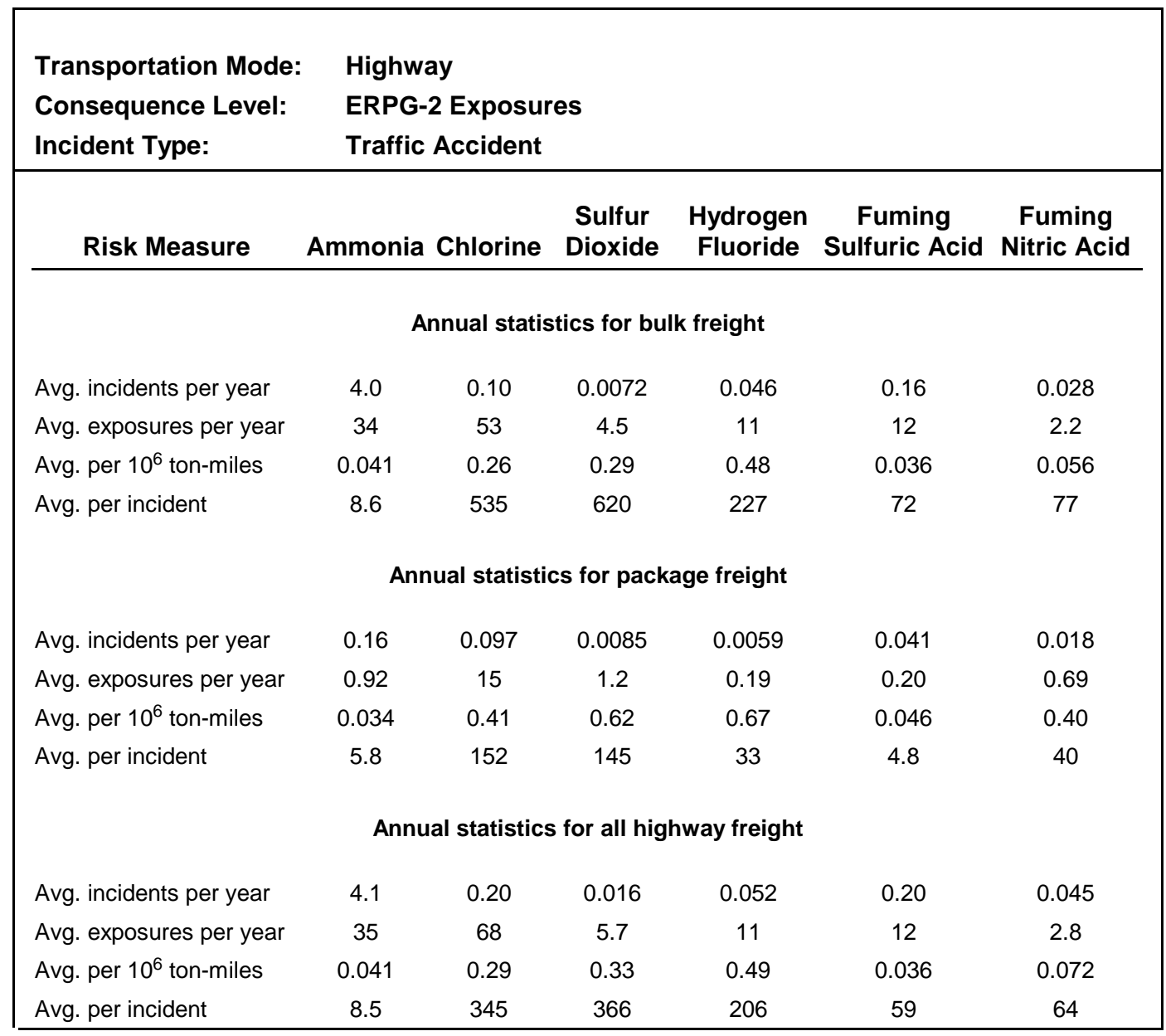

a Mitigative measures such as sheltering or evacuation are not included in these results.

(i.e., 707 exposures, see Table 5.6) is less than $18 \%$ as demonstrated in Figure 5.2. For this reason, it is important to consider the character of the underlying distribution when interpreting the average results for individual TIH materials and comparing these results to historical data.

Table 5.6 provides annual exposure statistics as well as other risk measures. These results are separated by package freight, bulk freight (highway only), and package and bulk freight combined. The risk measures in Table 5.6 include average number of incidents per year, average number of people exposed per year, average number of people exposed per million ton-miles, and average number of people exposed per incident. The first two risk measures are straightforward and do not require further explanation. The latter two risk measures require further discussion. 
The average number of people exposed per million ton-miles and the average number of people exposed per incident measure risk on a relative basis without respect to averaging time or commodity flow. As discussed in Section 1, we refer to average exposures per million ton-miles as the normalized risk. For accident-related highway incidents, $\mathrm{HF}, \mathrm{SO}_{2}$, and chlorine have the highest normalized risk whereas ammonia and fuming sulfuric acid have the lowest. The low normalized risk for ammonia is a direct result of the low toxicity of ammonia relative to the other TIH chemicals, and the low normalized risk for fuming sulfuric acid results from the low volatility of most fuming sulfuric acid in transportation ( $30 \%$ free $\left.\mathrm{SO}_{3}\right)$. The high normalized risk for chlorine and $\mathrm{SO}_{2}$ result from the high toxicity of these materials. The high normalized risk for HF, on the other hand, is due to the less robust nature of the MC 312 cargo tank authorized for HF transportation. The most toxic material (as denoted by the ERPG-2 equivalent), fuming nitric acid, has a lower relative risk than that of chlorine or $\mathrm{SO}_{2}$ because it is much less volatile, as reflected in the vapor pressure. The final risk measure is the average number of persons exposed per incident. This measure largely factors out the container robustness and therefore directly depends on volatility and toxicity of the material as well as shipping amounts and population density.

The risk measures given in Table 5.6 are convenient for comparing and contrasting exposure risk associated with various chemicals and transportation modes. For example, a comparison of risk shows that the average exposure risk from bulk transportation is significantly higher than that of package freight transportation. However, when normalized by commodity flow (i.e., average per ton-mile), the risks from package freight transportation are generally the same as or higher than those for bulk transportation. The risk measures also provide useful insights into the nature of the underlying risk for each chemical. The exposure probabilities of chlorine and ammonia (Figure 5.2) indicate that the probability for ERPG-2 exposures of less than 500 persons is much higher for ammonia than for chlorine because for highway-accident-related incidents, there are about 25 ammonia releases for every chlorine release. However, because individual chlorine releases have much greater impacts as evidenced from the average persons exposed per incident, the probability for exposure of greater than 1,000 persons in a 10-yr period is higher for chlorine than it is for ammonia. By comparing the chlorine and $\mathrm{SO}_{2}$ results, we see that the exposure probability for $\mathrm{SO}_{2}$ is about 8 to 10 times lower than that for chlorine. Because the consequence potential on a per incident basis is similar for the two chemicals, the lower exposure probabilities for $\mathrm{SO}_{2}$ result from fewer incidents which, in turn, result from a lower commodity flow.

Tables 5.7 and 5.8 and Figure 5.3 provide the fatal exposure probabilities for accident-related highway releases for the six NTRA TIH chemicals. Recall from Section 2 that fatal exposures are calculated by multiplying the population exposed to $\mathrm{LC}_{50}$ concentrations by a factor of 1.1. This factor accounts for persons exposed to concentrations greater than the $\mathrm{LC}_{50}$ that are not killed due to other intangible factors (e.g., good physical health, high tolerance) as well as persons exposed to concentrations less than the $\mathrm{LC}_{50}$ that are killed as a result of other intangible factors (e.g., poor physical health, low tolerance). As noted previously, the ERPG-2 and fatal exposure distributions presented here do not account for exposure reduction measures such as 
Table 5.7 Probability of Population Exposure to Airborne Concentrations Exceeding Fatal Thresholds Resulting from Accident-Related Highway Releases over a 10-yr Period for the Six NTRA TIH Chemicalsa

\begin{tabular}{|c|c|c|c|c|c|c|}
\hline $\begin{array}{l}\text { Transportation } \\
\text { Consequence L } \\
\text { Incident Type: }\end{array}$ & $\begin{array}{l}\text { ode: } \text { Highw } \\
\text { el: } \text { Fatal E } \\
\text { Traffic }\end{array}$ & $\begin{array}{l}\text { ay } \\
\text { Exposures } \\
\text { Accident }\end{array}$ & & & & \\
\hline $\begin{array}{l}\text { Persons } \\
\text { Exposed }\end{array}$ & Ammonia & Chlorine & $\begin{array}{l}\text { Sulfur } \\
\text { Dioxide }\end{array}$ & $\begin{array}{l}\text { Hydrogen } \\
\text { Fluoride }\end{array}$ & $\begin{array}{l}\text { Fuming } \\
\text { Sulfuric Acid }\end{array}$ & $\begin{array}{c}\text { Fuming } \\
\text { Nitric Acid }\end{array}$ \\
\hline 1 & 0.68 & 0.27 & 0.0063 & 0.080 & 0.068 & 0.026 \\
\hline 2 & 0.53 & 0.22 & 0.0042 & 0.062 & 0.043 & 0.017 \\
\hline 5 & 0.29 & 0.15 & 0.0022 & 0.038 & 0.020 & 0.0080 \\
\hline 10 & 0.15 & 0.11 & 0.0012 & 0.024 & 0.010 & 0.0042 \\
\hline 20 & 0.071 & 0.071 & $7.2 \times 10^{-4}$ & 0.013 & 0.0045 & 0.0020 \\
\hline 50 & 0.021 & 0.039 & $3.0 \times 10^{-4}$ & 0.0058 & 0.0012 & $5.4 \times 10^{-4}$ \\
\hline 100 & 0.0084 & 0.023 & $1.3 \times 10^{-4}$ & 0.0029 & $3.4 \times 10^{-4}$ & $1.7 \times 10^{-4}$ \\
\hline 200 & 0.0025 & 0.013 & $4.1 \times 10^{-4}$ & 0.0011 & $9.1 \times 10^{-4}$ & $3.1 \times 10^{-5}$ \\
\hline 500 & 0.00016 & 0.0049 & $5.1 \times 10^{-6}$ & $2.0 \times 10^{-4}$ & $1.5 \times 10^{-5}$ & $2.0 \times 10^{-6}$ \\
\hline 1,000 & $<10^{-6}$ & 0.0019 & $<10^{-6}$ & $2.3 \times 10^{-5}$ & $<10^{-6}$ & $<10^{-6}$ \\
\hline 2,000 & $<10^{-6}$ & $4.9 \times 10^{-4}$ & $<10^{-6}$ & $1.5 \times 10^{-6}$ & $<10^{-6}$ & $<10^{-6}$ \\
\hline 5,000 & $<10^{-6}$ & $6.9 \times 10^{-5}$ & $<10^{-6}$ & $<10^{-6}$ & $<10^{-6}$ & $<10^{-6}$ \\
\hline 10,000 & $<10^{-6}$ & $1.5 \times 10^{-5}$ & $<10^{-6}$ & $<10^{-6}$ & $<10^{-6}$ & $<10^{-6}$ \\
\hline 20,000 & $<10^{-6}$ & $1.0 \times 10^{-6}$ & $<10^{-6}$ & $<10^{-6}$ & $<10^{-6}$ & $<10^{-6}$ \\
\hline 50,000 & $<10^{-6}$ & $<10^{-6}$ & $<10^{-6}$ & $<10^{-6}$ & $<10^{-6}$ & $<10^{-6}$ \\
\hline \multicolumn{7}{|c|}{ Ten-year exposure statistics } \\
\hline Median & 3 & 0 & 0 & 0 & 0 & 0 \\
\hline Average & 7.6 & 13 & 0.088 & 1.6 & 0.61 & 0.25 \\
\hline
\end{tabular}

a Mitigative measures such as sheltering or evacuation are not included in these results. 
Table 5.8 Risk Measures and Annual Population Exposure Statistics for Fatal Exposures Resulting from Accident-Related Highway Releases for the Six NTRA TIH Chemicals ${ }^{a}$

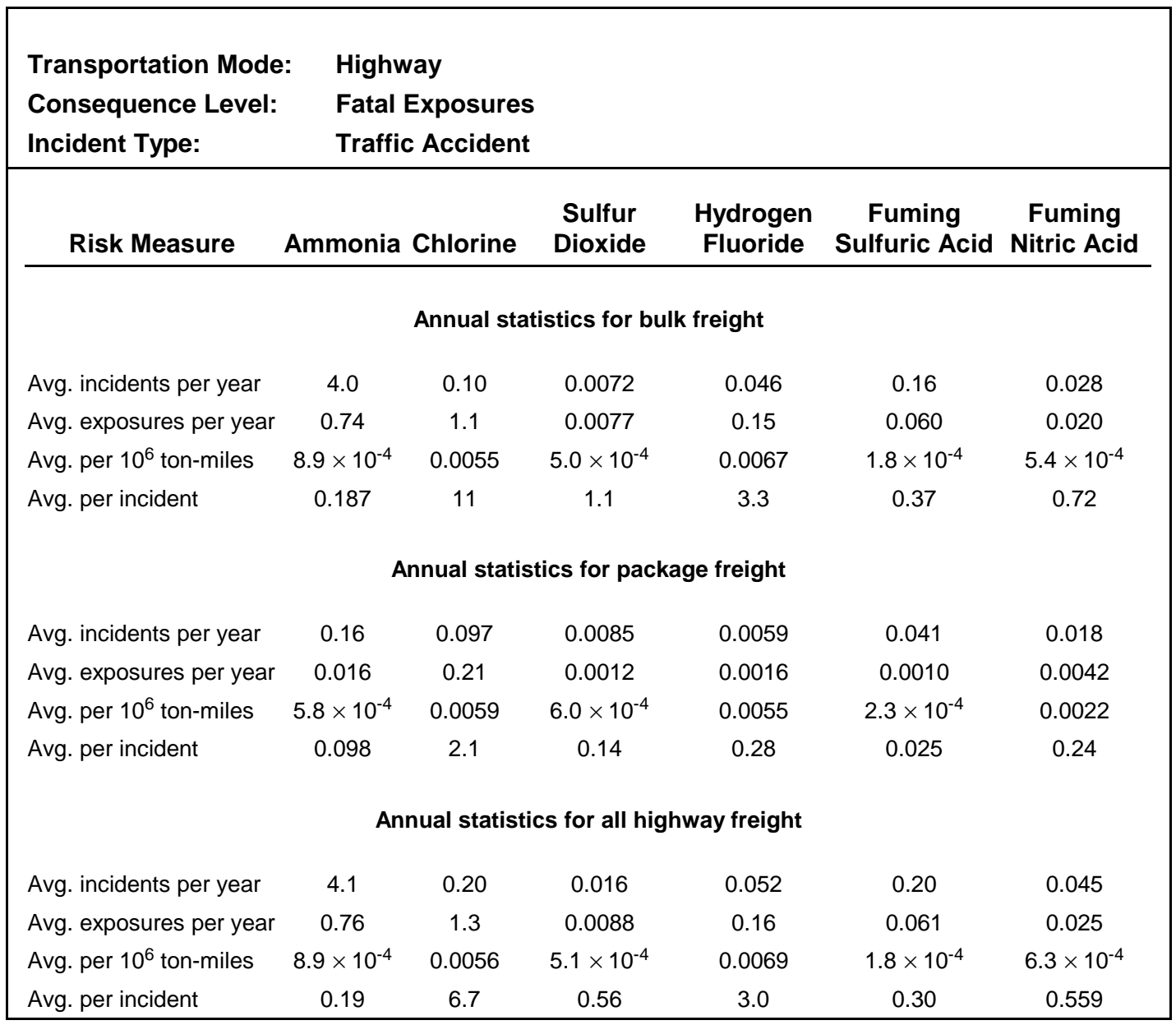

a Mitigative measures such as sheltering or evacuation are not included in these results. 


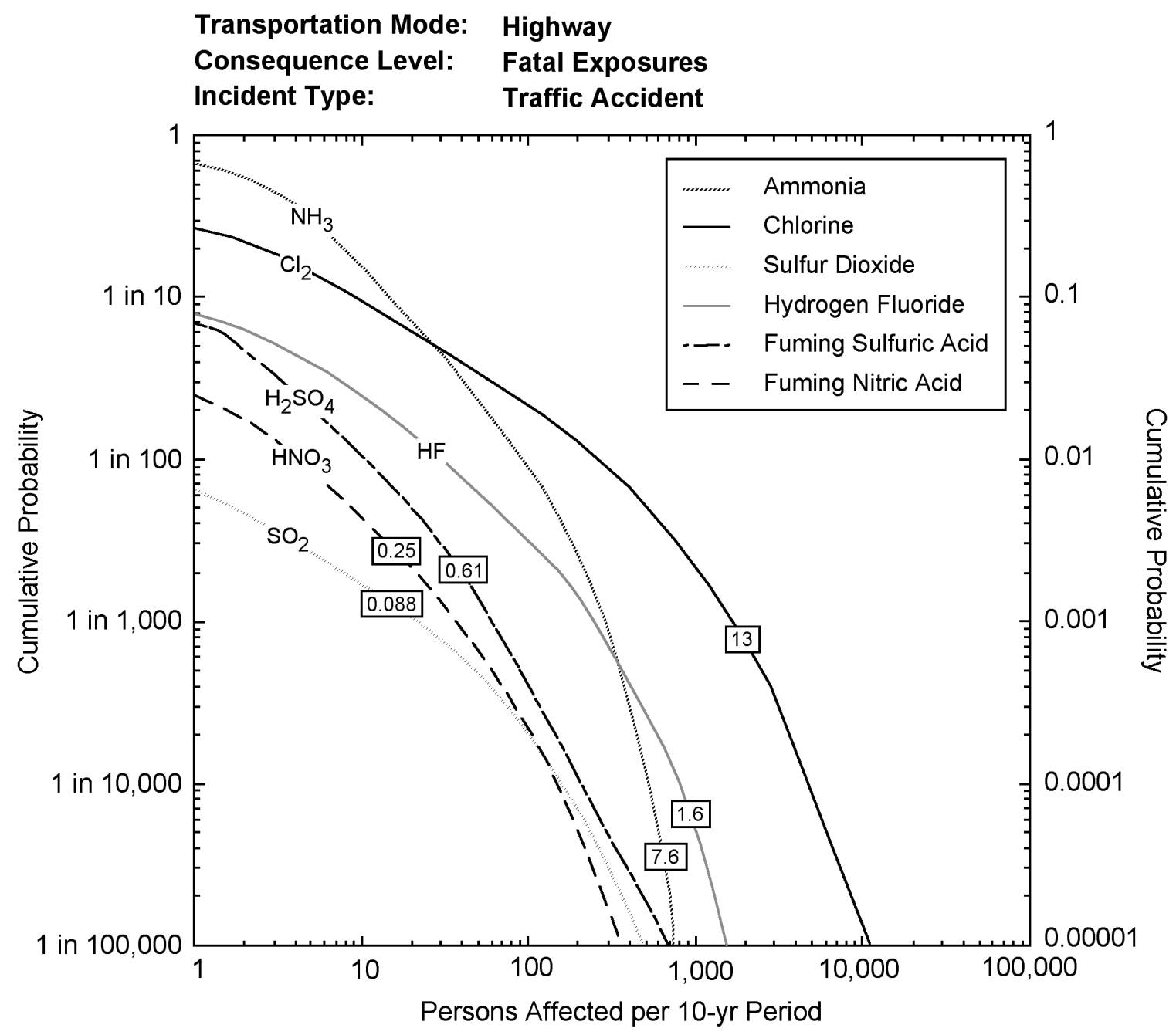

Figure 5.3 Probability of Fatal Exposure Resulting from Accident-Related Highway Releases over a 10-yr Period for the Six NTRA TIH Chemicals (Means of the exposure distributions are shown in the boxes superimposed on the curves. Mitigative measures such as sheltering or evacuation are not included in these results.) 
escape or sheltering. Therefore, these results do not directly translate to injuries or fatalities, but rather indicate the population levels at risk of exposure.

Clearly, the probabilities associated with fatal exposures are very low compared with those associated with ERPG-2 exposures. For most chemicals, the average number of fatal exposures is two orders of magnitude below the average number of ERPG-2 exposures. However, the probabilities associated with a large number of fatal exposures occurring in a 10-yr period are still very significant. Of the six TIH materials considered in this study, chlorine has the highest risk of fatal exposures for highway-accident-related releases, although individual incidents involving fatal exposures are more likely to be caused by ammonia. While ammonia incidents are considerably more frequent than chlorine incidents, the average number of fatal exposures per incident for ammonia is much lower than the average number of fatal exposures per chlorine incident.

Further discussions concerning ERPG-2 exposure and fatal exposure statistics including comparisons between the various transportation modes are contained in Sections 5.2.5 and 5.2.6.

\subsubsection{En Route/Nonaccident Highway Incidents}

Tables 5.9 and 5.10 and Figure 5.4 provide the probability of exposure to ERPG-2 concentrations for en route/nonaccident highway releases for the six NTRA TIH chemicals, and Tables 5.11 and 5.12 and Figure 5.5 provide corresponding fatal exposure probabilities. The format of these tables and figures is identical to the format used in the presentation of highway-accident-related results. Namely, Tables 5.9 and 5.11 and Figures 5.4 and 5.5 present exposure distributions and risk measures (average and median) for a 10 -yr period, and Tables 5.10 and 5.12 present exposure averages and other risk measures for a 1-yr period for package freight, bulk freight, and bulk and package freight combined. In general, exposure probabilities for en route/nonaccident highway releases are lower than those for accident-related highway releases. For all materials except ammonia and HF, however, the ERPG-2 exposure probability associated with a small number of people (fewer than five) is higher for en route/nonaccident incidents than for accident-related incidents. This results from the large number of en route/nonaccident highway incidents compared with accident-related highway incidents. However, the average number of people exposed per incident is much less for en route/nonaccident incidents than for accident-related incidents. As a consequence, the frequency of major en route/nonaccident incidents (i.e., those that affect large numbers of people) is substantially lower than the frequency of major accident-related incidents. Therefore, the overall risk from ERPG-2 and fatal exposures is lower for highway en route/nonaccident releases than for that of accident related releases.

For fuming sulfuric acid and fuming nitric acid, package freight poses a significantly greater risk from en route/nonaccident releases than from bulk freight due to the higher frequency of en route/nonaccident releases for package freight containers as compared with bulk freight containers. This higher frequency of package freight leakage is also 
Table 5.9 Probability of Population Exposure to Airborne Concentrations Exceeding ERPG-2 Thresholds Resulting from En Route/Nonaccident Highway Releases over a 10-yr Period for the Six NTRA TIH Chemicalsa

\begin{tabular}{|c|c|c|c|c|c|c|}
\hline \multicolumn{2}{|c|}{$\begin{array}{l}\text { Transportation Mode: } \\
\text { Consequence Level: } \\
\text { Incident Type: }\end{array}$} & \multicolumn{5}{|c|}{$\begin{array}{l}\text { Highway } \\
\text { ERPG-2 Exposures } \\
\text { En Route/Nonaccident Releases }\end{array}$} \\
\hline $\begin{array}{l}\text { Persons } \\
\text { Exposed }\end{array}$ & Ammonia & Chlorine & $\begin{array}{l}\text { Sulfur } \\
\text { Dioxide }\end{array}$ & $\begin{array}{l}\text { Hydrogen } \\
\text { Fluoride }\end{array}$ & $\begin{array}{c}\text { Fuming } \\
\text { Sulfuric Acid }\end{array}$ & $\begin{array}{l}\text { Fuming } \\
\text { Nitric Acid }\end{array}$ \\
\hline 1 & 0.65 & 0.93 & 0.13 & 0.16 & 0.71 & 0.56 \\
\hline 2 & 0.53 & 0.89 & 0.11 & 0.13 & 0.59 & 0.46 \\
\hline 5 & 0.37 & 0.78 & 0.077 & 0.082 & 0.38 & 0.33 \\
\hline 10 & 0.26 & 0.66 & 0.056 & 0.054 & 0.24 & 0.23 \\
\hline 20 & 0.16 & 0.51 & 0.039 & 0.037 & 0.14 & 0.15 \\
\hline 50 & 0.075 & 0.34 & 0.022 & 0.019 & 0.061 & 0.070 \\
\hline 100 & 0.040 & 0.23 & 0.014 & 0.011 & 0.031 & 0.036 \\
\hline 200 & 0.021 & 0.15 & 0.0090 & 0.0058 & 0.016 & 0.018 \\
\hline 500 & 0.0069 & 0.080 & 0.0044 & 0.0026 & 0.0055 & 0.0057 \\
\hline 1,000 & 0.0026 & 0.048 & 0.0023 & 0.0013 & 0.0027 & 0.0021 \\
\hline 2,000 & $4.9 \times 10^{-4}$ & 0.027 & $9.9 \times 10^{-4}$ & $4.7 \times 10^{-4}$ & 0.0011 & $4.9 \times 10^{-4}$ \\
\hline 5,000 & $4.7 \times 10^{-5}$ & 0.0088 & $2.1 \times 10^{-4}$ & $1.1 \times 10^{-4}$ & $2.5 \times 10^{-4}$ & $2.3 \times 10^{-5}$ \\
\hline 10,000 & $<10^{-6}$ & 0.0030 & $6.0 \times 10^{-5}$ & $2.3 \times 10^{-5}$ & $1.3 \times 10^{-4}$ & $1.2 \times 10^{-6}$ \\
\hline 20,000 & $<10^{-6}$ & $4.3 \times 10^{-4}$ & $5.0 \times 10^{-6}$ & $<10^{-6}$ & $3.2 \times 10^{-5}$ & $<10^{-6}$ \\
\hline 50,000 & $<10^{-6}$ & $6.0 \times 10^{-6}$ & $<10^{-6}$ & $<10^{-6}$ & $<10^{-6}$ & $<10^{-6}$ \\
\hline 100,000 & $<10^{-6}$ & $<10^{-6}$ & $<10^{-6}$ & $<10^{-6}$ & $<10^{-6}$ & $<10^{-6}$ \\
\hline 200,000 & $<10^{-6}$ & $<10^{-6}$ & $<10^{-6}$ & $<10^{-6}$ & $<10^{-6}$ & $<10^{-6}$ \\
\hline \multicolumn{7}{|c|}{ Ten-year exposure statistics } \\
\hline Median & 3 & 22 & 0 & 0 & 3 & 1 \\
\hline Average & 23 & 243 & 12 & 7.7 & 24 & 20 \\
\hline
\end{tabular}

a Mitigative measures such as sheltering or evacuation are not included in these results. 
Table 5.10 Risk Measures and Annual Population Exposure Statistics for ERPG-2 Exposures Resulting from En Route/Nonaccident Highway Releases for the Six NTRA TIH Chemicalsa

\begin{tabular}{|c|c|c|c|c|c|c|}
\hline $\begin{array}{l}\text { Transportation Mode: } \\
\text { Consequence Level: } \\
\text { Incident Type: }\end{array}$ & $\begin{array}{l}\text { Highw } \\
\text { ERPG- } \\
\text { En Rol }\end{array}$ & $\begin{array}{l}\text { lay } \\
-2 \text { Exposur } \\
\text { ute/Nonacc }\end{array}$ & $\begin{array}{l}\text { es } \\
\text { cident Rel }\end{array}$ & ases & & \\
\hline Risk Measure & Ammonia & Chlorine & $\begin{array}{l}\text { Sulfur } \\
\text { Dioxide }\end{array}$ & $\begin{array}{l}\text { Hydrogen } \\
\text { Fluoride }\end{array}$ & $\begin{array}{l}\text { Fuming } \\
\text { Sulfuric Acid }\end{array}$ & $\begin{array}{c}\text { Fuming } \\
\text { Nitric Acid }\end{array}$ \\
\hline \multicolumn{7}{|c|}{ Annual statistics for bulk freight } \\
\hline Avg. incidents per year & 1.0 & 0.38 & 0.0042 & 0.21 & 0.76 & 0.090 \\
\hline Avg. exposures per year & 2.1 & 18 & 0.32 & 0.64 & 1.8 & 0.29 \\
\hline Avg. per $10^{6}$ ton-miles & 0.0025 & 0.090 & 0.021 & 0.029 & 0.0055 & 0.0077 \\
\hline Avg. per incident & 1.9 & 48 & 77 & 2.9 & 2.4 & 3.2 \\
\hline \multicolumn{7}{|c|}{ Annual statistics for package freight } \\
\hline Avg. incidents per year & 1.9 & 1.1 & 0.080 & 0.062 & 1.6 & 0.72 \\
\hline Avg. exposures per year & 0.28 & 6.5 & 0.85 & 0.15 & 0.61 & 1.7 \\
\hline Avg. per $10^{6}$ ton-miles & 0.010 & 0.18 & 0.43 & 0.53 & 0.15 & 1.0 \\
\hline Avg. per incident & 0.15 & 5.7 & 11 & 2.4 & 0.37 & 2.3 \\
\hline \multicolumn{7}{|c|}{ Annual statistics for all highway freight } \\
\hline Avg. incidents per year & 2.9 & 1.5 & 0.084 & 0.28 & 2.4 & 0.81 \\
\hline Avg. exposures per year & 2.3 & 24 & 1.2 & 0.77 & 2.4 & 2.0 \\
\hline Avg. per $10^{6}$ ton-mile & 0.0027 & 0.10 & 0.067 & 0.035 & 0.0072 & 0.051 \\
\hline Avg. per incident & 0.79 & 16 & 14 & 2.8 & 1.0 & 2.5 \\
\hline
\end{tabular}

a Mitigative measures such as sheltering or evacuation are not included in these results. 


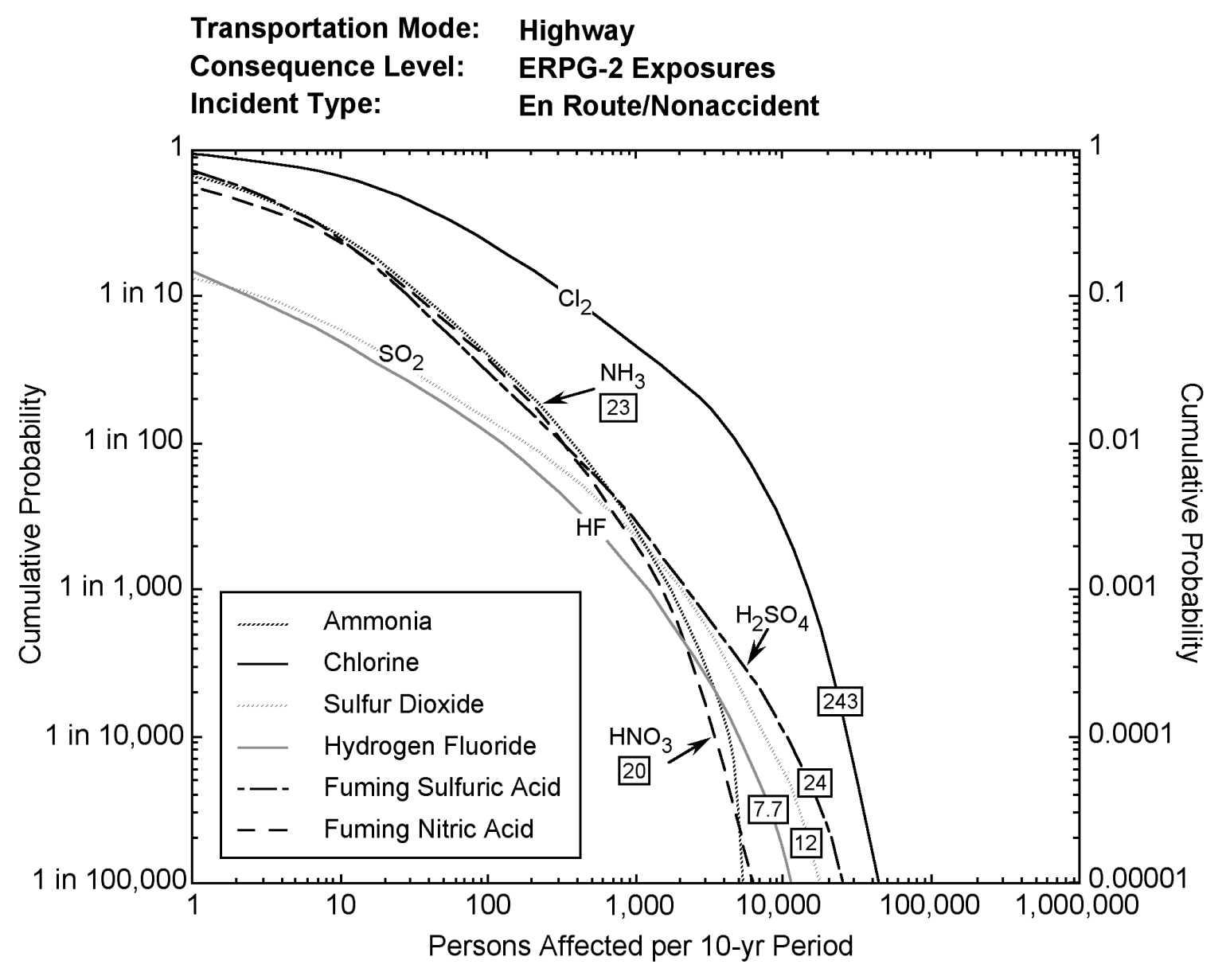

Figure 5.4 Probability of ERPG-2 Exposure for En Route/Nonaccident Highway Releases over a 10-yr Period for the Six NTRA TIH Chemicals (Means of the exposure distributions are shown in the boxes superimposed on the curves. Mitigative measures such as sheltering or evacuation are not included in these results.) 
Table 5.11 Probability of Population Exposure to Airborne Concentrations Exceeding Fatal Thresholds Resulting from En Route/Nonaccident Highway Releases over a 10-yr Period for the Six NTRA TIH Chemicalsa

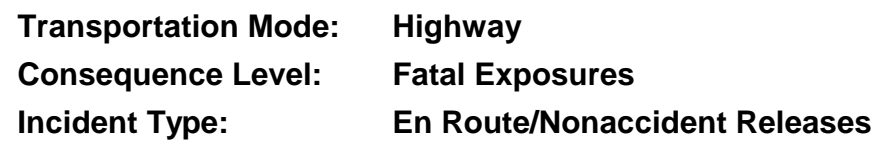

\begin{tabular}{|c|c|c|c|c|c|c|}
\hline $\begin{array}{l}\text { Persons } \\
\text { Exposed }\end{array}$ & Ammonia & Chlorine & $\begin{array}{l}\text { Sulfur } \\
\text { Dioxide }\end{array}$ & $\begin{array}{l}\text { Hydrogen } \\
\text { Fluoride }\end{array}$ & $\begin{array}{c}\text { Fuming } \\
\text { Sulfuric Acid }\end{array}$ & $\begin{array}{c}\text { Fuming } \\
\text { Nitric Acid }\end{array}$ \\
\hline 1 & 0.058 & 0.17 & $9.0 \times 10^{-4}$ & 0.0090 & 0.011 & 0.0135 \\
\hline 2 & 0.031 & 0.12 & $4.8 \times 10^{-4}$ & 0.0056 & 0.0055 & 0.0061 \\
\hline 5 & 0.012 & 0.064 & $1.7 \times 10^{-4}$ & 0.0026 & 0.0023 & 0.0018 \\
\hline 10 & 0.0056 & 0.039 & $7.9 \times 10^{-5}$ & 0.0013 & 0.0012 & $4.8 \times 10^{-4}$ \\
\hline 20 & 0.0022 & 0.022 & $2.5 \times 10^{-5}$ & $6.1 \times 10^{-4}$ & $5.1 \times 10^{-4}$ & $1.2 \times 10^{-4}$ \\
\hline 50 & $4.7 \times 10^{-4}$ & 0.010 & $5.0 \times 10^{-6}$ & $2.6 \times 10^{-4}$ & $1.4 \times 10^{-4}$ & $1.9 \times 10^{-5}$ \\
\hline 100 & $7.8 \times 10^{-5}$ & 0.0056 & $<10^{-6}$ & $7.3 \times 10^{-5}$ & $6.8 \times 10^{-5}$ & $4.2 \times 10^{-6}$ \\
\hline 200 & $1.8 \times 10^{-5}$ & 0.0031 & $<10^{-6}$ & $5.0 \times 10^{-6}$ & $8.2 \times 10^{-6}$ & $<10^{-6}$ \\
\hline 500 & $2.5 \times 10^{-6}$ & $9.6 \times 10^{-4}$ & $<10^{-6}$ & $<10^{-6}$ & $<10^{-6}$ & $<10^{-6}$ \\
\hline 1,000 & $<10^{-6}$ & $3.5 \times 10^{-4}$ & $<10^{-6}$ & $<10^{-6}$ & $<10^{-6}$ & $<10^{-6}$ \\
\hline 2,000 & $<10^{-6}$ & $5.1 \times 10^{-5}$ & $<10^{-6}$ & $<10^{-6}$ & $<10^{-6}$ & $<10^{-6}$ \\
\hline 5,000 & $<10^{-6}$ & $<10^{-6}$ & $<10^{-6}$ & $<10^{-6}$ & $<10^{-6}$ & $<10^{-6}$ \\
\hline 10,000 & $<10^{-6}$ & $<10^{-6}$ & $<10^{-6}$ & $<10^{-6}$ & $<10^{-6}$ & $<10^{-6}$ \\
\hline \multicolumn{7}{|c|}{ Ten-year exposure statistics } \\
\hline Median & 0 & 0 & 0 & 0 & 0 & 0 \\
\hline Average & 0.45 & 3.4 & 0.0095 & 0.099 & 0.12 & 0.12 \\
\hline
\end{tabular}

a Mitigative measures such as sheltering or evacuation are not included in these results. 
Table 5.12 Risk Measures and Annual Population Exposure Statistics for Fatal Exposures Resulting from En Route/Nonaccident Highway Releases for the Six NTRA TIH Chemicals ${ }^{a}$

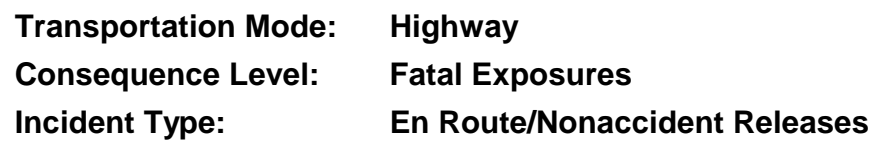

Transportation Mode: Highway

Consequence Level: $\quad$ Fatal Exposures

Incident Type:

En Route/Nonaccident Releases

\begin{tabular}{|c|c|c|c|c|c|c|}
\hline Risk Measure & Ammonia & Chlorine & $\begin{array}{c}\text { Sulfur } \\
\text { Dioxide }\end{array}$ & $\begin{array}{c}\text { Hydrogen } \\
\text { Fluoride }\end{array}$ & $\begin{array}{l}\text { Fuming } \\
\text { Sulfuric Acid }\end{array}$ & $\begin{array}{l}\text { Fuming } \\
\text { Nitric Acid }\end{array}$ \\
\hline \multicolumn{7}{|c|}{ Annual statistics for bulk freight } \\
\hline Avg. incidents per year & 1.0 & 0.38 & 0.0042 & 0.21 & 0.76 & 0.090 \\
\hline Avg. exposures per year & 0.041 & 0.27 & $4.1 \times 10^{-4}$ & 0.0082 & 0.0092 & 0.0022 \\
\hline Avg. per $10^{6}$ ton-miles & $4.9 \times 10^{-5}$ & 0.0013 & $2.6 \times 10^{-5}$ & $3.7 \times 10^{-4}$ & $2.8 \times 10^{-5}$ & $5.8 \times 10^{-5}$ \\
\hline Avg. per incident & 0.039 & 0.71 & 0.098 & 0.038 & 0.012 & 0.024 \\
\hline \multicolumn{7}{|c|}{ Annual statistics for package freight } \\
\hline Avg. incidents per year & 1.9 & 1.1 & 0.080 & 0.062 & 1.6 & 0.70 \\
\hline Avg. exposures per year & 0.0047 & 0.066 & $5.4 \times 10^{-4}$ & 0.0016 & 0.0023 & 0.010 \\
\hline Avg. per $10^{6}$ ton-miles & $1.7 \times 10^{-4}$ & 0.0018 & $2.7 \times 10^{-4}$ & 0.0055 & $5.5 \times 10^{-4}$ & 0.0058 \\
\hline Avg. per incident & 0.0024 & 0.058 & 0.0068 & 0.026 & 0.0014 & 0.014 \\
\hline \multicolumn{7}{|c|}{ Annual statistics for all highway freight } \\
\hline Avg. incidents per year & 2.9 & 1.5 & 0.084 & 0.28 & 2.4 & 0.79 \\
\hline Avg. exposures per year & 0.045 & 0.34 & $9.5 \times 10^{-4}$ & 0.0099 & 0.012 & 0.012 \\
\hline Avg. per $10^{6}$ ton-miles & $5.3 \times 10^{-5}$ & 0.0014 & $5.4 \times 10^{-5}$ & $4.4 \times 10^{-4}$ & $3.4 \times 10^{-5}$ & $3.0 \times 10^{-4}$ \\
\hline Avg. per incident & 0.015 & 0.23 & 0.011 & 0.036 & 0.0048 & 0.015 \\
\hline
\end{tabular}

a Mitigative measures such as sheltering or evacuation are not included in these results. 


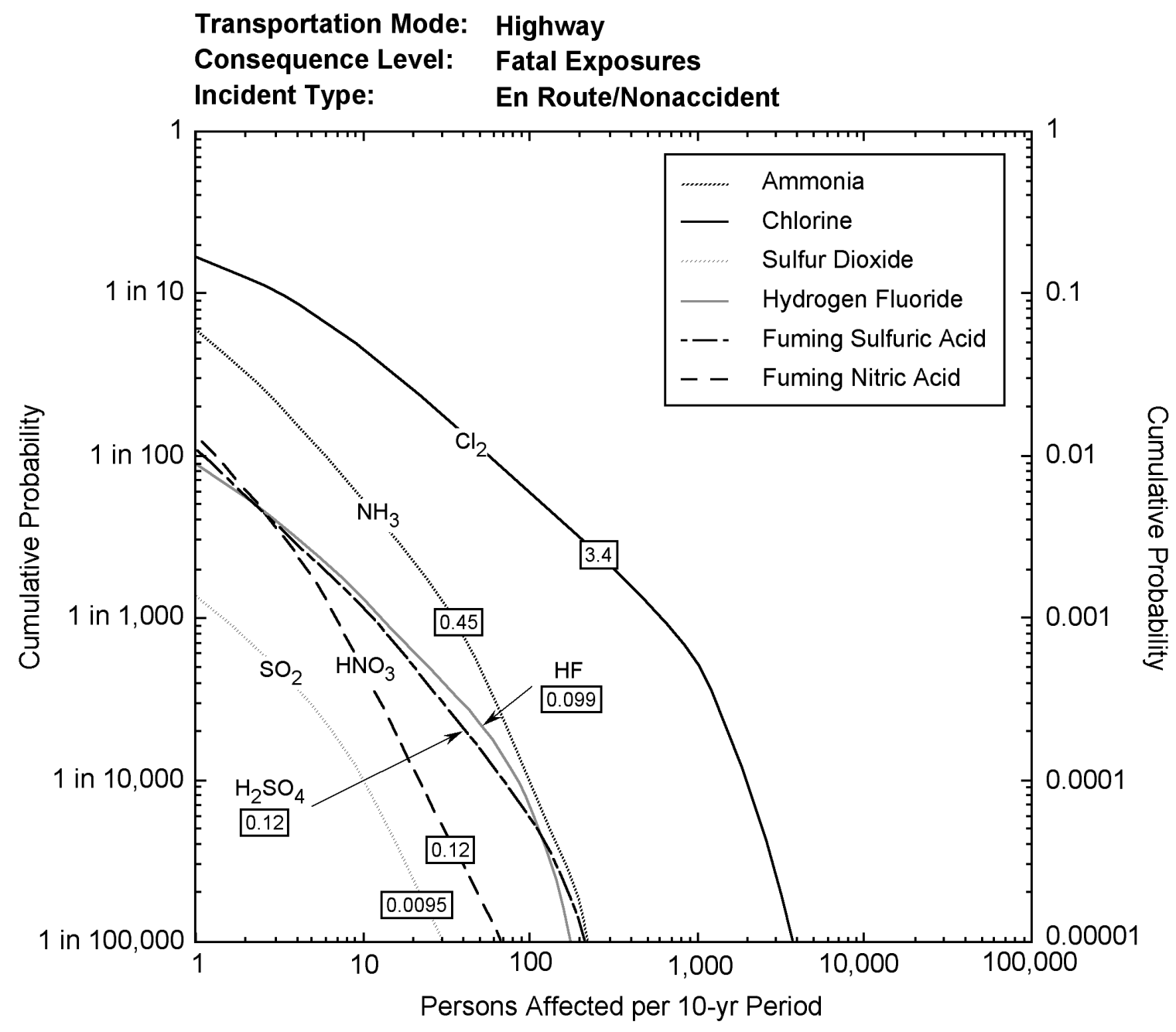

Figure 5.5 Probability of Fatal Exposure Resulting from En Route/Nonaccident Highway Releases over a 10-yr Period for the Six NTRA TIH Chemicals (Means of the exposure distributions are shown in the boxes superimposed on the curves. Mitigative measures such as sheltering or evacuation are not included in these results.) 
reflected in the average ERPG-2 and fatal exposure statistics on a per-ton-mile basis. Here, the average number of exposures per ton mile is considerably higher for package freight even though the number of persons exposed per incident is generally less than that for bulk freight incidents.

\subsubsection{Accident-Related Rail Releases}

Table 5.13 and Figure 5.6 provide the probability of exposure to ERPG-2 concentrations for accident-related rail releases for the six NTRA TIH chemicals. The format of Table 5.13 and Figure 5.6 is the same as that used in highway risk assessment results, except that Table 5.13 contains both the 10 -yr probabilities and risk measures with the 1-yr risk measures in the lower portion of the table.

In general, ERPG-2 exposure probabilities for accident-related rail releases are significantly higher than those for accident-related highway releases, except for fuming sulfuric acid and fuming nitric acid. As discussed further in Section 5.2.5, the higher overall risk associated with rail transportation is a direct result of the larger commodity flows associated with rail transportation. Another contributing factor leading to high ERPG-2 exposure estimates for ammonia, chlorine, and $\mathrm{SO}_{2}$ is that consequences from accident-related rail incidents on a per-incident basis are substantially more severe than for accident-related highway incidents.

Table 5.14 and Figure 5.7 provide fatal exposure probabilities for accident-related rail releases for the six TIH chemicals in the NTRA analysis. The format used is identical to the ERPG-2 exposure probabilities given in Table 5.13 and Figure 5.6. The same trends observed when contrasting ERPG-2 exposure and fatal exposure levels for accidentrelated highway incidents are also observed for accident-related rail incidents. The probability of large exposures is especially high for chlorine and ammonia. As a result, ERPG-2 exposures and fatal exposures for ammonia and chlorine rail transportation exceed those of the other chemicals considered in the NTRA by a large margin. This fact is not unexpected, however, because the rail commodity flow for these two chemicals exceeds that of the other four TIH chemicals considered in the NTRA by a factor of 20 or more (Appendix B). When considering the fatal exposures and ERPG-2 exposures on a per-ton-mile basis, the greatest risk comes from chlorine and HF because of their toxicity (also from $\mathrm{SO}_{2}$ when considering ERPG-2 exposures). The lowest risk is associated with the transportation of fuming acids because they are less volatile. These trends are discussed in detail Section 5.2.5.

\subsubsection{En Route/Nonaccident Rail Incidents}

Table 5.15 and Figure 5.8 provide the probability of exposure to ERPG-2 concentrations resulting from en route/nonaccident rail releases for the six NTRA TIH chemicals, and Table 5.16 and Figure 5.9 provide corresponding fatal exposure probabilities. The nature of the differences in the exposure probabilities between accident-related and en route/nonaccident incidents for rail transportation is very similar 
Table 5.13 Probability of Population Exposure to Airborne Concentrations Exceeding ERPG-2 Thresholds Resulting from Accident-Related Rail Releases over a 10-yr Period for the Six NTRA TIH Chemicals ${ }^{a}$

\begin{tabular}{|c|c|c|c|c|c|c|}
\hline $\begin{array}{l}\text { Transportation Mode } \\
\text { Consequence Level: } \\
\text { Incident Type: }\end{array}$ & $\begin{array}{l}\text { Rail } \\
\text { ERPG- } \\
\text { Derailn }\end{array}$ & $\begin{array}{l}2 \text { Exposur } \\
\text { nent }\end{array}$ & & & & \\
\hline $\begin{array}{l}\text { Persons } \\
\text { Exposed }\end{array}$ & Ammonia & Chlorine & $\begin{array}{c}\text { Sulfur } \\
\text { Dioxide }\end{array}$ & $\begin{array}{c}\text { Hydrogen } \\
\text { Fluoride }\end{array}$ & $\begin{array}{c}\text { Fuming } \\
\text { Sulfuric Acid }\end{array}$ & $\begin{array}{l}\text { Fuming } \\
\text { Nitric Acid }\end{array}$ \\
\hline 1 & 0.99 & 0.83 & 0.38 & 0.39 & 0.13 & 0.086 \\
\hline 2 & 0.98 & 0.82 & 0.36 & 0.36 & 0.11 & 0.075 \\
\hline 5 & 0.97 & 0.79 & 0.33 & 0.31 & 0.091 & 0.059 \\
\hline 10 & 0.94 & 0.76 & 0.30 & 0.27 & 0.073 & 0.048 \\
\hline 20 & 0.90 & 0.72 & 0.27 & 0.23 & 0.055 & 0.037 \\
\hline 50 & 0.80 & 0.64 & 0.22 & 0.17 & 0.036 & 0.025 \\
\hline 100 & 0.68 & 0.58 & 0.19 & 0.13 & 0.024 & 0.018 \\
\hline 200 & 0.53 & 0.51 & 0.15 & 0.094 & 0.016 & 0.012 \\
\hline 500 & 0.33 & 0.40 & 0.11 & 0.057 & 0.0076 & 0.0065 \\
\hline 1,000 & 0.20 & 0.32 & 0.082 & 0.036 & 0.0041 & 0.0037 \\
\hline 2,000 & 0.10 & 0.24 & 0.059 & 0.021 & 0.0020 & 0.0019 \\
\hline 5,000 & 0.023 & 0.15 & 0.034 & 0.0071 & $7.3 \times 10^{-4}$ & $4.8 \times 10^{-4}$ \\
\hline 10,000 & 0.0036 & 0.093 & 0.019 & 0.0022 & $2.5 \times 10^{-4}$ & $1.2 \times 10^{-4}$ \\
\hline 20,000 & $1.2 \times 10^{-4}$ & 0.045 & 0.0079 & $4.8 \times 10^{-4}$ & $6.0 \times 10^{-5}$ & $2.3 \times 10^{-5}$ \\
\hline 50,000 & $8.0 \times 10^{-6}$ & 0.0088 & 0.0013 & $3.8 \times 10^{-5}$ & $1.0 \times 10^{-6}$ & $2.1 \times 10^{-6}$ \\
\hline 100,000 & $<10^{-6}$ & $9.9 \times 10^{-4}$ & $1.2 \times 10^{-4}$ & $<10^{-6}$ & $<10^{-6}$ & $<10^{-6}$ \\
\hline 200,000 & $<10^{-6}$ & $2.2 \times 10^{-5}$ & $1.0 \times 10^{-6}$ & $<10^{-6}$ & $<10^{-6}$ & $<10^{-6}$ \\
\hline 500,000 & $<10^{-6}$ & $<10^{-6}$ & $<10^{-6}$ & $<10^{-6}$ & $<10^{-6}$ & $<10^{-6}$ \\
\hline \multicolumn{7}{|c|}{ Ten-year exposure statistics } \\
\hline Median & 228 & 210 & 0 & 0 & 0 & 0 \\
\hline Average & 753 & 3,370 & 704 & 174 & 23 & 17 \\
\hline \multicolumn{7}{|c|}{ Annual exposure statistics } \\
\hline Avg. incidents per year & 1.2 & 0.31 & 0.085 & 0.097 & 0.040 & 0.023 \\
\hline Avg. exposures per year & 75 & 337 & 70 & 17 & 2.3 & 1.7 \\
\hline Avg. per $10^{6}$ ton-miles & 0.029 & 0.15 & 0.35 & 0.077 & 0.022 & 0.024 \\
\hline Avg. per incident & 65 & 1,072 & 836 & 181 & 57 & 74 \\
\hline
\end{tabular}

a Mitigative measures such as sheltering or evacuation are not included in these results. 


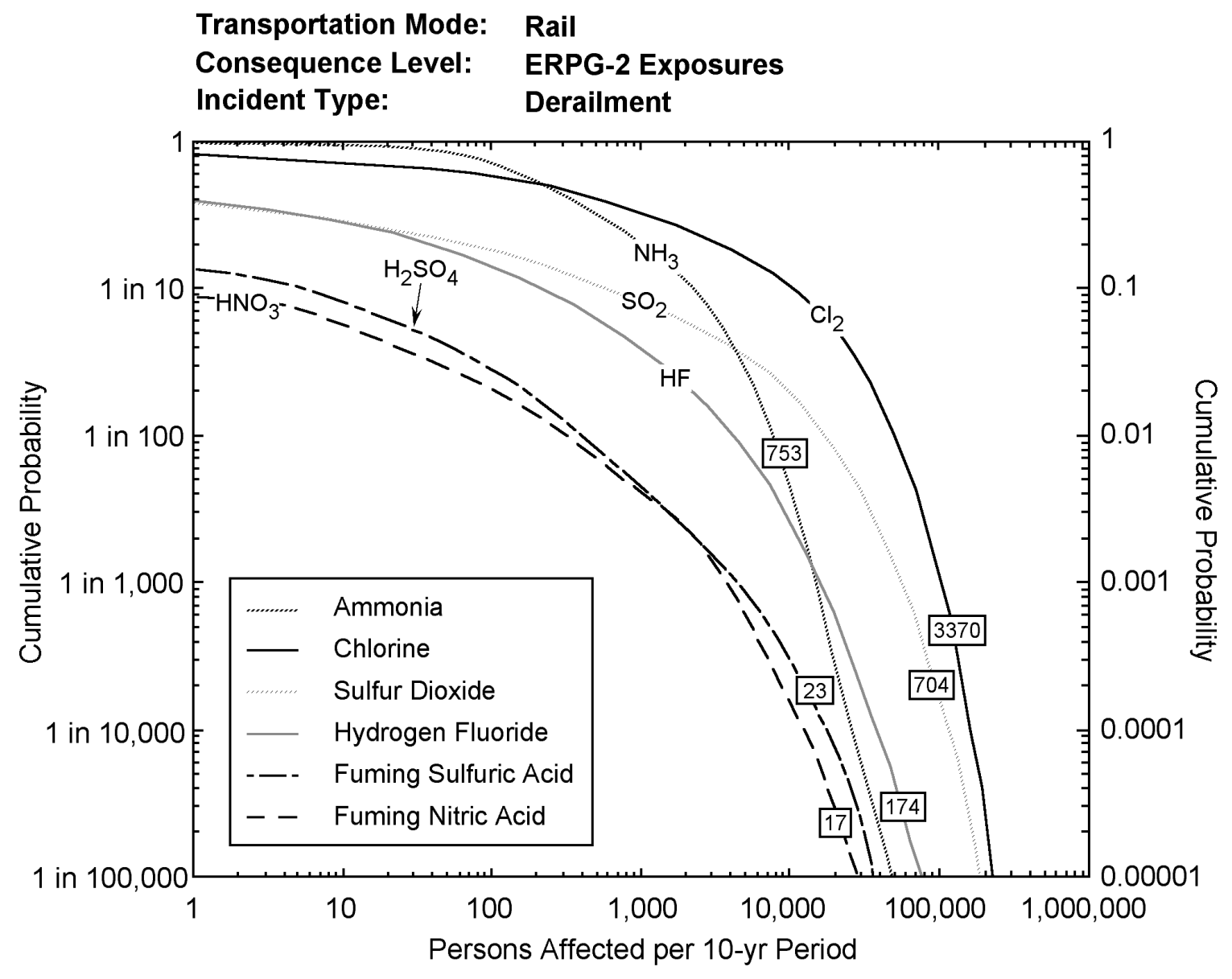

Figure 5.6 Probability of ERPG-2 Exposure Resulting from Accident-Related Rail Releases over a 10-yr Period for the Six NTRA TIH Chemicals (Means of the exposure distributions are shown in the boxes superimposed on the curves. Mitigative measures such as sheltering or evacuation are not included in these results.)

to that between accident-related and en route/nonaccident incidents for highway transportation. Although average exposure probabilities are substantially lower for en route/nonaccident releases, the large number of such releases, especially for liquefied gases, causes the probabilities associated with small numbers of ERPG-2 exposures resulting from en route/nonaccident releases to substantially exceed the probabilities of similar exposures resulting from accident-related releases. The statistics shown in Table 5.15 indicate that the average number of ERPG-2 exposures resulting from en route/nonaccident rail releases is a factor of 2 to 7 less than the average number of ERPG-2 exposures resulting from accident-related rail releases. However, on a per-incident basis, the average number of ERPG-2 exposures resulting from en route/nonaccident rail releases is a factor of 50 to 250 less than that for accidentrelated rail releases. Trends observed in the fatal exposures distributions closely follow the trends observed in the ERPG-2 exposure distributions. 
Table 5.14 Probability of Population Exposure to Airborne Concentrations Exceeding Fatal Thresholds Resulting from Accident-Related Rail Releases over a 10-yr Period for the Six NTRA TIH Chemicals ${ }^{a}$

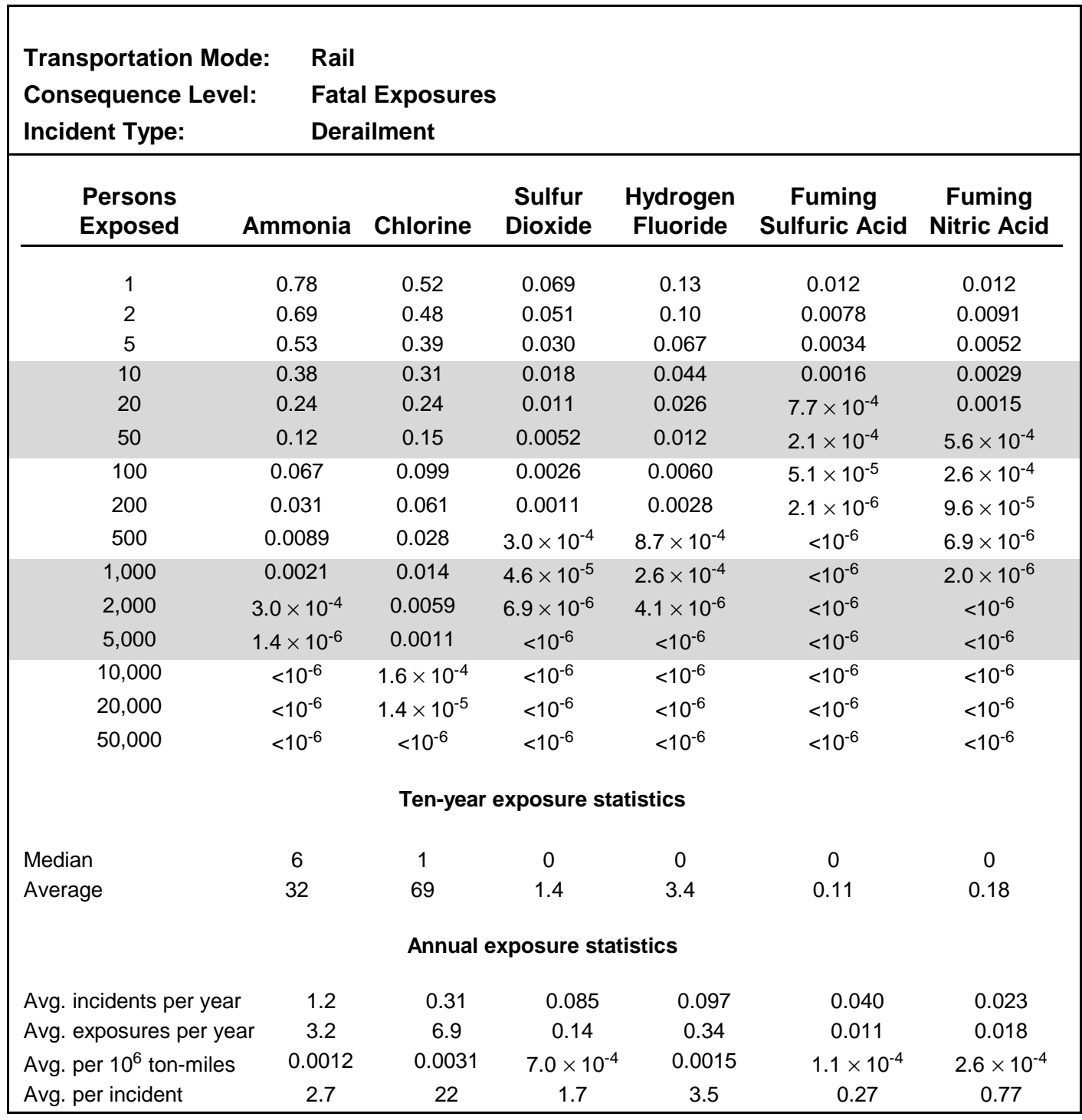

a Mitigative measures such as sheltering or evacuation are not included in these results. 


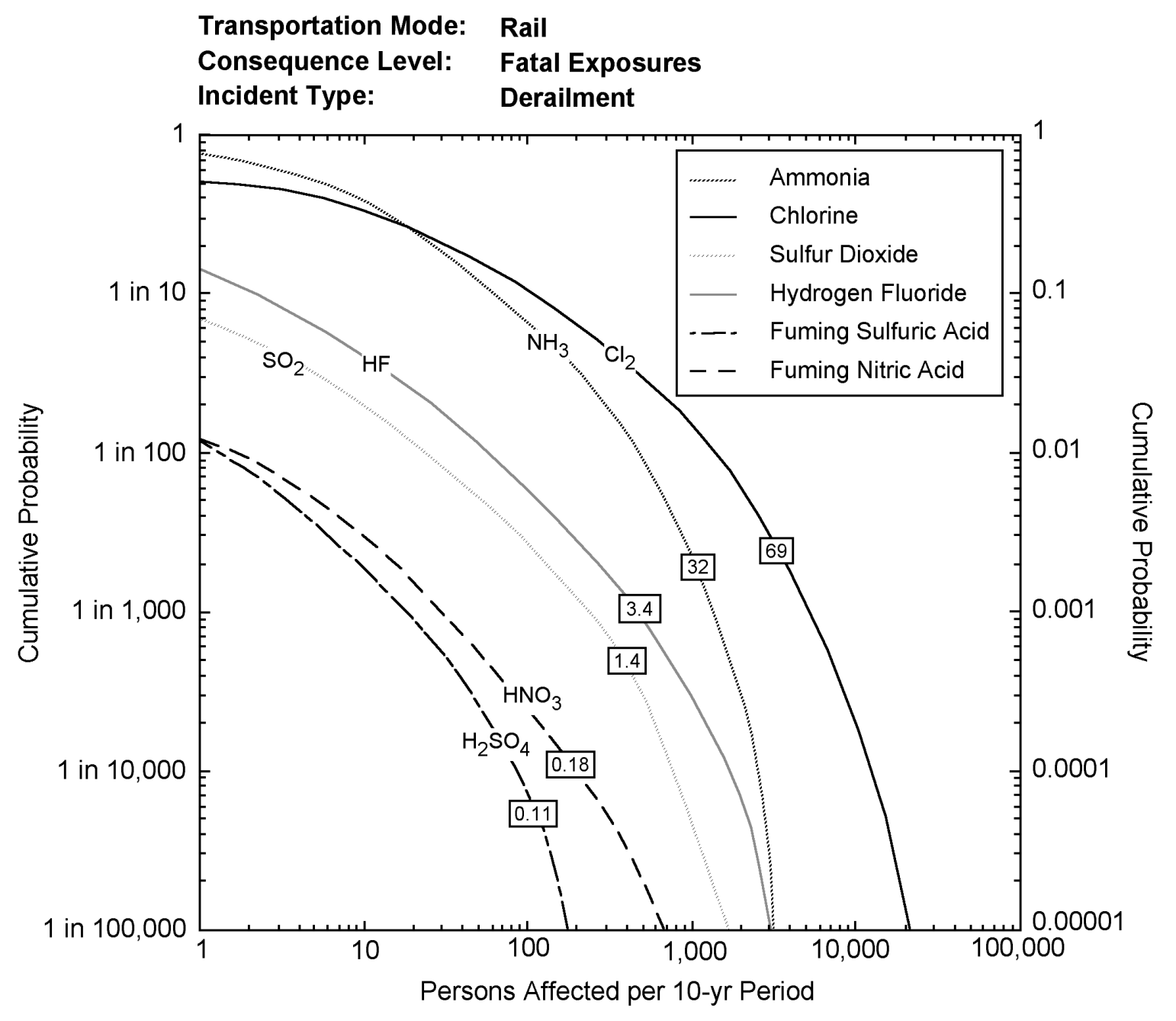

Figure 5.7 Probability of Fatal Exposure Resulting from Accident-Related Rail Releases over a 10 -yr Period for the Six NTRA TIH Chemicals (Means of the exposure distributions are shown in the boxes superimposed on the curves. Mitigative measures such as sheltering or evacuation are not included in these results.) 
Table 5.15 Probability of Population Exposure to Airborne Concentrations Exceeding ERPG-2 Thresholds Resulting from En Route/Nonaccident Rail Releases over a 10-yr Period for the Six NTRA TIH Chemicals ${ }^{a}$

\begin{tabular}{|c|c|c|c|c|c|c|}
\hline $\begin{array}{l}\text { Transportation Mode } \\
\text { Consequence Level: } \\
\text { Incident Type: }\end{array}$ & $\begin{array}{l}\text { Rail } \\
\text { ERPG } \\
\text { En Ro }\end{array}$ & $\begin{array}{l}-2 \text { Exposur } \\
\text { ute/Nonac }\end{array}$ & ident Rele & ises & & \\
\hline $\begin{array}{l}\text { Persons } \\
\text { Exposed }\end{array}$ & Ammonia & Chlorine & $\begin{array}{l}\text { Sulfur } \\
\text { Dioxide }\end{array}$ & $\begin{array}{l}\text { Hydrogen } \\
\text { Fluoride }\end{array}$ & $\begin{array}{c}\text { Fuming } \\
\text { Sulfuric Acid }\end{array}$ & $\begin{array}{c}\text { Fuming } \\
\text { Nitric Acid }\end{array}$ \\
\hline 1 & $>0.995$ & $>0.995$ & 0.83 & 0.72 & 0.17 & 0.34 \\
\hline 2 & 0.99 & $>0.995$ & 0.74 & 0.60 & 0.12 & 0.25 \\
\hline 5 & 0.96 & 0.99 & 0.55 & 0.40 & 0.078 & 0.14 \\
\hline 10 & 0.86 & 0.94 & 0.41 & 0.28 & 0.054 & 0.088 \\
\hline 20 & 0.66 & 0.82 & 0.29 & 0.19 & 0.035 & 0.053 \\
\hline 50 & 0.39 & 0.59 & 0.18 & 0.11 & 0.019 & 0.027 \\
\hline 100 & 0.22 & 0.42 & 0.12 & 0.064 & 0.012 & 0.015 \\
\hline 200 & 0.12 & 0.29 & 0.079 & 0.037 & 0.0060 & 0.0079 \\
\hline 500 & 0.041 & 0.16 & 0.044 & 0.015 & 0.0029 & 0.0035 \\
\hline 1,000 & 0.013 & 0.10 & 0.028 & 0.0072 & 0.0014 & 0.0017 \\
\hline 2,000 & 0.0072 & 0.059 & 0.016 & 0.0032 & $7.4 \times 10^{-4}$ & $5.6 \times 10^{-4}$ \\
\hline 5,000 & 0.0012 & 0.023 & 0.0058 & $7.9 \times 10^{-4}$ & $3.2 \times 10^{-4}$ & $1.3 \times 10^{-5}$ \\
\hline 10,000 & $3.9 \times 10^{-6}$ & 0.0086 & 0.0024 & $2.2 \times 10^{-4}$ & $1.4 \times 10^{-4}$ & $<10^{-6}$ \\
\hline 20,000 & $<10^{-6}$ & 0.0031 & $5.7 \times 10^{-4}$ & $<10^{-6}$ & $5.5 \times 10^{-6}$ & $<10^{-6}$ \\
\hline 50,000 & $<10^{-6}$ & $6.4 \times 10^{-4}$ & $1.0 \times 10^{-6}$ & $<10^{-6}$ & $<10^{-6}$ & $<10^{-6}$ \\
\hline 100,000 & $<10^{-6}$ & $1.6 \times 10^{-4}$ & $<10^{-6}$ & $<10^{-6}$ & $<10^{-6}$ & $<10^{-6}$ \\
\hline 200,000 & $<10^{-6}$ & $<10^{-6}$ & $<10^{-6}$ & $<10^{-6}$ & $<10^{-6}$ & $<10^{-6}$ \\
\hline \multicolumn{7}{|c|}{ Ten-year exposure statistics } \\
\hline Median & 35 & 72 & 6 & 4 & 0 & 0 \\
\hline Average & 112 & 594 & 153 & 45 & 13 & 10 \\
\hline \multicolumn{7}{|c|}{ Annual exposure statistics } \\
\hline Avg. incidents per year & 47 & 13 & 3.4 & 3.9 & 1.6 & 0.93 \\
\hline Avg. exposures per year & 11 & 59 & 15 & 4.5 & 1.3 & 1.0 \\
\hline Avg. per $10^{6}$ ton-miles & 0.0043 & 0.027 & 0.076 & 0.020 & 0.013 & 0.016 \\
\hline Avg. per incident & 0.24 & 4.7 & 4.5 & 1.2 & 0.80 & 1.1 \\
\hline
\end{tabular}

a Mitigative measures such as sheltering or evacuation are not included in these results. 


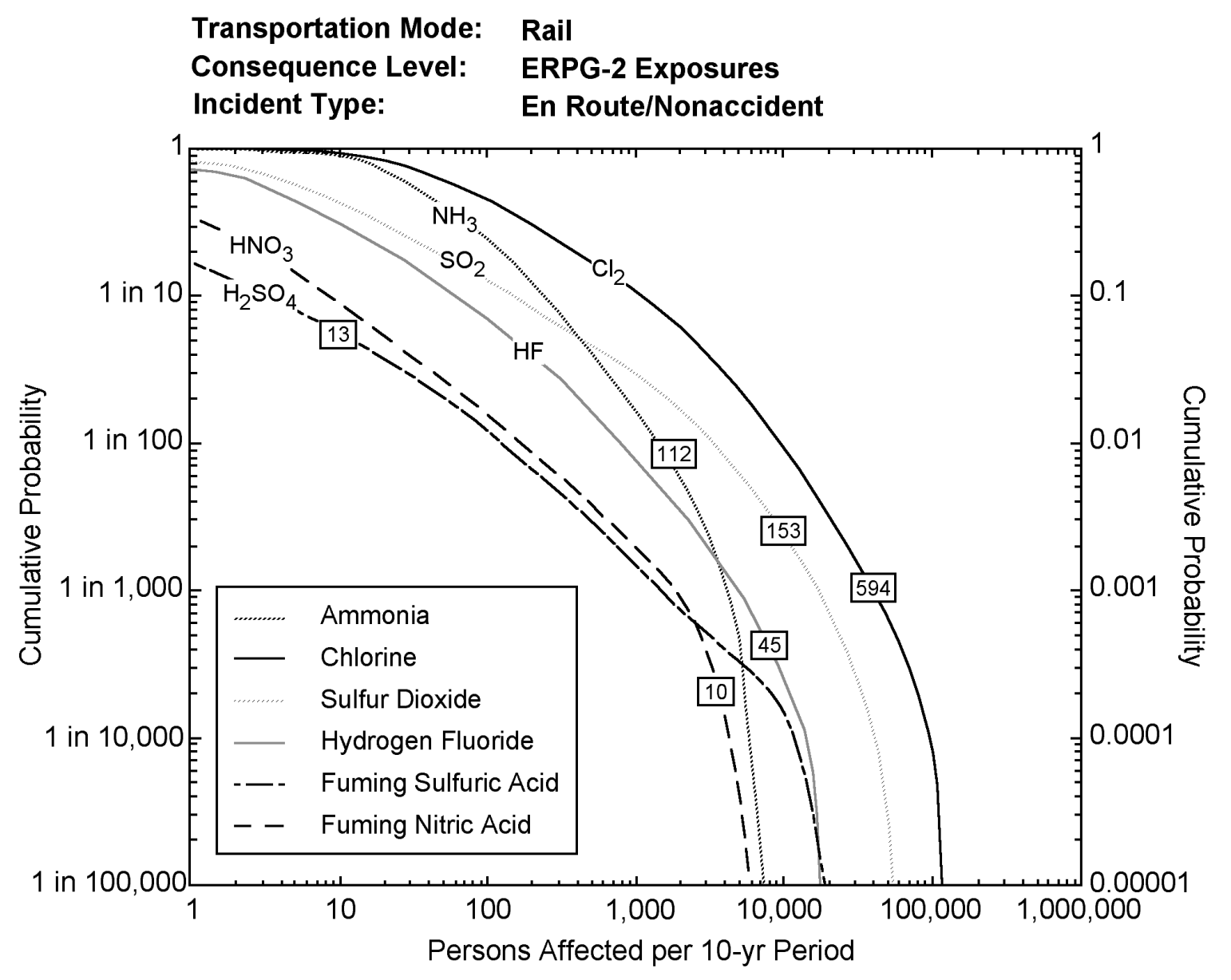

Figure 5.8 Probability of ERPG-2 Exposure Resulting from En Route/Nonaccident Rail Releases over a 10-yr Period for the Six NTRA TIH Chemicals (Means of the exposure distributions are shown in the boxes superimposed on the curves. Mitigative measures such as sheltering or evacuation are not included in these results.) 
Table 5.16 Probability of Population Exposure to Airborne Concentrations Exceeding Fatal Thresholds Resulting from En Route/Nonaccident Rail Releases over a 10-yr Period for the Six NTRA TIH Chemicals ${ }^{a}$

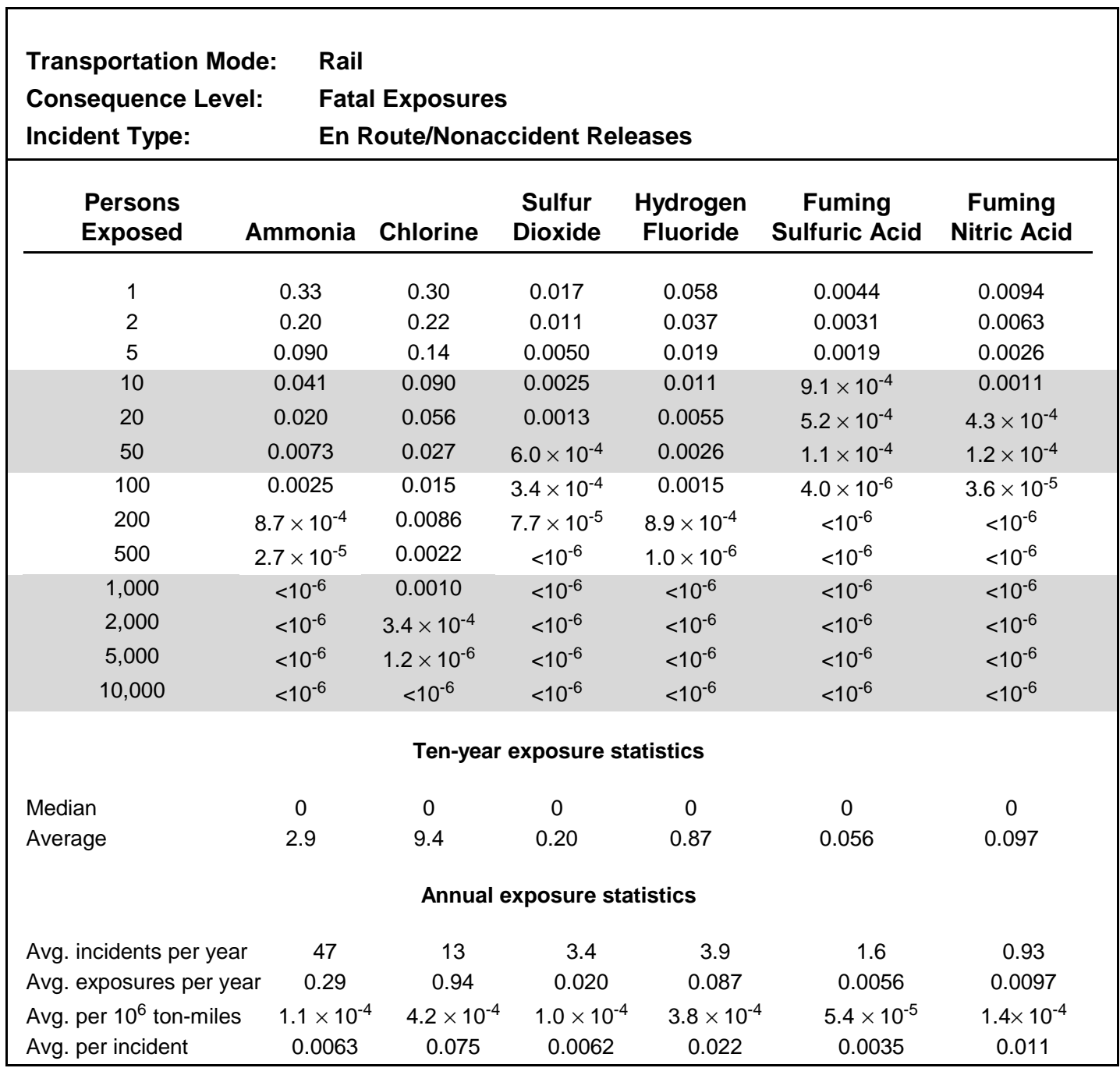

a Mitigative measures such as sheltering or evacuation are not included in these results. 


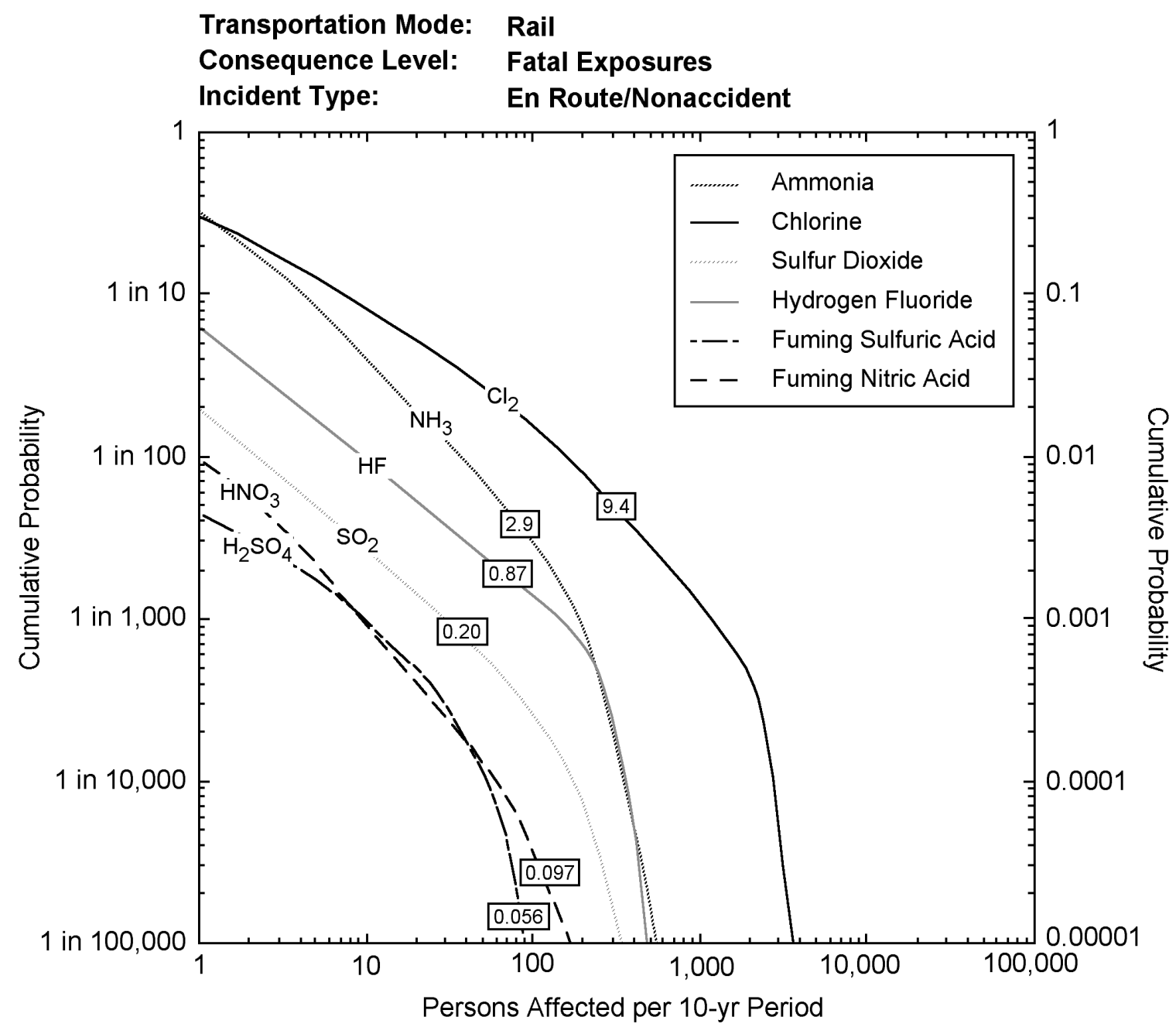

Figure 5.9 Probability of Fatal Exposure Resulting from En Route/Nonaccident Rail Releases over a 10-yr Period for the Six NTRA TIH Chemicals (Means of the exposure distributions are shown in the boxes superimposed on the curves. Mitigative measures such as sheltering or evacuation are not included in these results.) 


\subsubsection{Risk Distributions with Respect to Incident Type}

The results presented in Sections 5.2.1 to 5.2.4 provide an excellent overview of TIH transportation risk with respect to incident type. Here, we summarize these results to clarify the differences in risk between the four incident types and to draw general conclusions regarding the risk profiles of highway and rail transportation.

Tables 5.17 and 5.18 provide summary statistics for ERPG-2 exposures and fatal exposures, respectively, for the four release types considered in the TIH analysis: accident-related highway releases, en route/nonaccident highway releases, accidentrelated rail releases, and en route/nonaccident rail releases. In these tables, both 10-yr and 1-yr statistics are provided with per-ton-mile and per-incident averages. These results clearly indicate that total TIH transportation risk as measured by long-term average ERPG-2 exposure and fatal exposure numbers is much higher for rail than for highway. Since commodity flow for rail on a ton-mile basis is 4 times higher than it is for highway, this result is no surprise. Indeed, on a per-ton-mile basis, highway transportation poses slightly more risk than rail for $\mathrm{TIH}$ transportation as a whole, and for HF, fuming sulfuric acid, and fuming nitric acid, the normalized risk associated with highway transportation is more than a factor of 2 higher than for rail transportation (Tables 5.6 and 5.14). Another important observation is that en route/nonaccident releases account for only $20 \%$ and $16 \%$ of the estimated ERPG-2 exposures for highway and rail, respectively, even though such releases are far more common, especially for rail. For fatal exposures, contributions from en route/nonaccident incidents are even lower.

Although the overall risk is highest for accident-related rail releases, such releases are much more infrequent than other types of releases. Their domination in overall TIH transportation risk comes from the fact that such releases are, on average, three to five times more severe than highway-accident-related incidents and up to two orders of magnitude more severe than en route/nonaccident releases on a per-incident basis. En route/nonaccident rail releases are the least severe release type on a per-incident basis. However, because these releases are more than nine times more frequent than en route/nonaccident highway releases, their total risk exceeds that of en route/nonaccident highway releases.

\subsubsection{Risk Distributions with Respect to Chemical and Total TIH Risk}

The results presented in Sections 5.2.1 to 5.2.4 and summarized in Section 5.2.5 outline the risk associated with the four incident types considered in this report for TIH materials: accident-related highway releases, en route/nonaccident highway releases, accident-related rail releases, and en route/nonaccident rail releases. In this section, we take a different look at these results by combining consequence statistics for the various incident types and presenting consequence distributions on the basis of the chemical. 
Table 5.17 Average ERPG-2 Exposure Statistics for Four NTRA Incident Types for 10- and 1-yr Periods ${ }^{a}$

\begin{tabular}{|c|c|c|c|c|}
\hline \multirow[b]{2}{*}{ Risk Measure } & \multicolumn{2}{|c|}{ Highway } & \multicolumn{2}{|c|}{ Rail } \\
\hline & $\begin{array}{l}\text { Accident- } \\
\text { Related }\end{array}$ & $\begin{array}{c}\text { En Route/ } \\
\text { Nonaccident }\end{array}$ & $\begin{array}{c}\text { Accident- } \\
\text { Related }\end{array}$ & $\begin{array}{l}\text { En Route/ } \\
\text { Nonaccident }\end{array}$ \\
\hline \multicolumn{5}{|c|}{ Ten-year exposure statistics } \\
\hline Median & 428 & 72 & 1440 & 249 \\
\hline Average & 1,346 & 329 & 5029 & 927 \\
\hline \multicolumn{5}{|c|}{ Annual exposure statistics } \\
\hline Avg. incidents per year & 4.6 & 8.0 & 1.8 & 70 \\
\hline Avg. exposures per year & 135 & 33 & 503 & 93 \\
\hline Avg. exp. per $10^{6}$ ton-miles & 0.089 & 0.022 & 0.093 & 0.017 \\
\hline Avg. exp. per incident & 29 & 4.1 & 280 & 1.3 \\
\hline
\end{tabular}

a Mitigative measures such as sheltering or evacuation are not included in these results.

Table 5.18 Average Fatal Exposure Statistics for Four NTRA Incident Types for 10- and 1-yr Periods ${ }^{a}$

\begin{tabular}{|c|c|c|c|c|}
\hline \multirow[b]{2}{*}{ Risk Measure } & \multicolumn{2}{|c|}{ Highway } & \multicolumn{2}{|c|}{ Rail } \\
\hline & $\begin{array}{l}\text { Accident- } \\
\text { Related }\end{array}$ & $\begin{array}{c}\text { En Route/ } \\
\text { Nonaccident }\end{array}$ & $\begin{array}{c}\text { Accident- } \\
\text { Related }\end{array}$ & $\begin{array}{c}\text { En Route/ } \\
\text { Nonaccident }\end{array}$ \\
\hline \multicolumn{5}{|c|}{ Ten-year exposure statistics } \\
\hline Median & 5 & 0 & 16 & 1 \\
\hline Average & 23 & 4.2 & 93 & 12 \\
\hline \multicolumn{5}{|c|}{ Annual exposure statistics } \\
\hline Avg. incidents per year & 4.6 & 8.0 & 1.8 & 70 \\
\hline Avg. exposures per year & 2.3 & 0.42 & 9.3 & 1.2 \\
\hline Avg. exp. per $10^{6}$ ton-miles & 0.0015 & $2.8 \times 10^{-4}$ & 0.0017 & $2.2 \times 10^{-4}$ \\
\hline Avg. exp. per incident & 0.51 & 0.053 & 5.8 & 0.019 \\
\hline
\end{tabular}

a Mitigative measures such as sheltering or evacuation are not included in these results. 
Table 5.19 and Figure 5.10 provide the probability of exposure to ERPG-2 concentrations resulting from all four release types for the six TIH chemicals considered in this study. It is clearly evident that the greatest transportation-related TIH risk arises from chlorine, with ammonia and $\mathrm{SO}_{2}$ following a distant second and third, respectively. Of the six chemicals considered, the least risk comes from fuming nitric acid.

Table 5.20 and Figure 5.11 provide the probability of fatal exposure resulting from all four release types for the six TIH chemicals considered in our analysis. The same general trends noted with the ERPG-2 exposures hold true for fatal exposures, except for $\mathrm{SO}_{2}$, which accounts for a much lower percentage of overall TIH-related fatal exposures than of overall TIH-related ERPG-2 exposures. The difference in injury and fatality risk for $\mathrm{SO}_{2}$ relative to the other NTRA TIH chemicals results from the much higher ratio of $\mathrm{LC}_{50}$ concentration to ERPG-2 concentration for $\mathrm{SO}_{2}$. For ammonia, chlorine, HF, fuming nitric acid, and fuming sulfuric acid, this ratio ranges from approximately 50 to 100 , whereas for $\mathrm{SO}_{2}$ this ratio is greater than 800 .

By combining statistical results for the six NTRA TIH chemicals, we can develop a distribution for total TIH transportation risk. As discussed in Section 2.3.1, five of the six chemicals - ammonia, chlorine, $\mathrm{SO}_{2}$, fuming nitric acid, and fuming sulfuric acid account for $75 \%$ of the total number of incidents reported to the HMIS database for the 10-yr period (1985-1995). Furthermore, these five chemicals account for the only fatality and more than $75 \%$ of the injuries resulting from the transportation of $\mathrm{TIH}$, as reported in the HMIS for this period. If injuries from loading/unloading incidents are not considered, the percentage of TIH-related injuries caused by these five TIH chemicals increases to about $90 \%$. In addition, these five chemicals, together with HF, account for more than $95 \%$ of the total commodity flow for all $\mathrm{TIH}$ materials for rail transportation as determined from the analysis of the Waybill Sample (Appendix B). For highway transportation, the percentage of total TIH commodity flow represented by these chemicals exceeds $90 \%$ and may exceed $95 \%$. Therefore, we estimate that the six NTRA $\mathrm{TIH}$ chemicals account for at least $90 \%$ of the total $\mathrm{TIH}$ transportation risk, excluding loading and unloading incidents.

Table 5.21 shows the probabilities of ERPG-2 exposures for all six TIH chemicals combined, and Figure 5.10 shows the six chemicals individually. These probabilities are calculated by combining the results presented in Table 5.18 and adjusting to account for the remaining the TIH chemicals. Table 5.22 and Figure 5.11 provide a similar presentation of results for fatal exposures. The consolidation of all $\mathrm{TIH}$ chemicals into a single distribution results in a less skewed distribution. As discussed earlier, this is a natural result of the inclusion of more incidents in the consequence distribution. For ERPG-2 exposures, it is clearly evident that $\mathrm{SO}_{2}$ and chlorine dominate the tail of the consequence distribution (i.e., for more than 10,000 affected persons). For fatal exposures, chlorine alone dominates the tail of the consequence distribution.

As discussed, these consequence estimates are conservative because they do not account for mitigating circumstances, such as evacuations and sheltering or release 
Table 5.19 Probability of Population Exposure to Airborne Concentrations Exceeding ERPG-2 Thresholds Resulting from Accident-Related and En Route/ Nonaccident Releases for Highway and Rail over a 10-yr Period for the Six NTRA TIH Chemicalsa

\begin{tabular}{|c|c|c|c|c|c|c|}
\hline $\begin{array}{l}\text { Transportation Mode: } \\
\text { Consequence Level: } \\
\text { Incident Type: }\end{array}$ & \multicolumn{6}{|c|}{$\begin{array}{l}\text { Highway and Rail } \\
\text { ERPG-2 Exposures } \\
\text { Accident-related and En Route/Nonaccident Releases }\end{array}$} \\
\hline $\begin{array}{l}\text { Persons } \\
\text { Exposed }\end{array}$ & Ammonia & Chlorine & $\begin{array}{c}\text { Sulfur } \\
\text { Dioxide }\end{array}$ & $\begin{array}{c}\text { Hydrogen } \\
\text { Fluoride }\end{array}$ & $\begin{array}{c}\text { Fuming } \\
\text { Sulfuric Acid }\end{array}$ & $\begin{array}{c}\text { Fuming } \\
\text { Nitric Acid }\end{array}$ \\
\hline 1 & $>0.995$ & $>0.995$ & 0.93 & 0.91 & 0.92 & 0.82 \\
\hline 2 & $>0.995$ & $>0.995$ & 0.88 & 0.85 & 0.86 & 0.73 \\
\hline 5 & $>0.995$ & $>0.995$ & 0.76 & 0.73 & 0.74 & 0.57 \\
\hline 10 & $>0.995$ & $>0.995$ & 0.66 & 0.62 & 0.61 & 0.44 \\
\hline 20 & $>0.995$ & $>0.995$ & 0.55 & 0.51 & 0.47 & 0.31 \\
\hline 50 & $>0.995$ & 0.97 & 0.42 & 0.37 & 0.30 & 0.18 \\
\hline 100 & 0.97 & 0.92 & 0.33 & 0.27 & 0.20 & 0.11 \\
\hline 200 & 0.88 & 0.84 & 0.26 & 0.20 & 0.13 & 0.066 \\
\hline 500 & 0.61 & 0.68 & 0.17 & 0.11 & 0.059 & 0.030 \\
\hline 1,000 & 0.37 & 0.54 & 0.12 & 0.070 & 0.030 & 0.015 \\
\hline 2,000 & 0.17 & 0.41 & 0.082 & 0.039 & 0.015 & 0.0059 \\
\hline 5,000 & 0.035 & 0.24 & 0.043 & 0.013 & 0.0053 & $9.9 \times 10^{-4}$ \\
\hline 10,000 & 0.0045 & 0.13 & 0.023 & 0.0040 & 0.0020 & $1.8 \times 10^{-4}$ \\
\hline 20,000 & $1.5 \times 10^{-4}$ & 0.058 & 0.0089 & $6.9 \times 10^{-4}$ & $5.0 \times 10^{-4}$ & $2.6 \times 10^{-5}$ \\
\hline 50,000 & $1.1 \times 10^{-5}$ & 0.011 & 0.0014 & $3.3 \times 10^{-5}$ & $2.2 \times 10^{-5}$ & $1.1 \times 10^{-6}$ \\
\hline 100,000 & $<10^{-6}$ & 0.0012 & $1.4 \times 10^{-4}$ & $<10^{-6}$ & $2.0 \times 10^{-6}$ & $<10^{-6}$ \\
\hline 200,000 & $<10^{-6}$ & $1.7 \times 10^{-5}$ & $2.0 \times 10^{-6}$ & $<10^{-6}$ & $<10^{-6}$ & $<10^{-6}$ \\
\hline 500,000 & $<10^{-6}$ & $<10^{-6}$ & $<10^{-6}$ & $<10^{-6}$ & $<10^{-6}$ & $<10^{-6}$ \\
\hline \multicolumn{7}{|c|}{ Ten-year exposure statistics } \\
\hline Median & 675 & 1,255 & 28 & 22 & 17 & 8 \\
\hline Average & 1,238 & 4,882 & 924 & 334 & 179 & 77 \\
\hline \multicolumn{7}{|c|}{ Annual exposure statistics } \\
\hline Avg. incidents per year & 55 & 15 & 3.6 & 4.3 & 4.2 & 1.8 \\
\hline Avg. exposures per year & 124 & 488 & 92 & 33 & 18 & 7.7 \\
\hline Avg. per $10^{6}$ ton-miles & 0.036 & 0.19 & 0.43 & 0.13 & 0.041 & 0.072 \\
\hline Avg. per incident & 2.2 & 33 & 26 & 7.7 & 4.2 & 4.3 \\
\hline
\end{tabular}

a Mitigative measures such as sheltering or evacuation are not included in these results. 


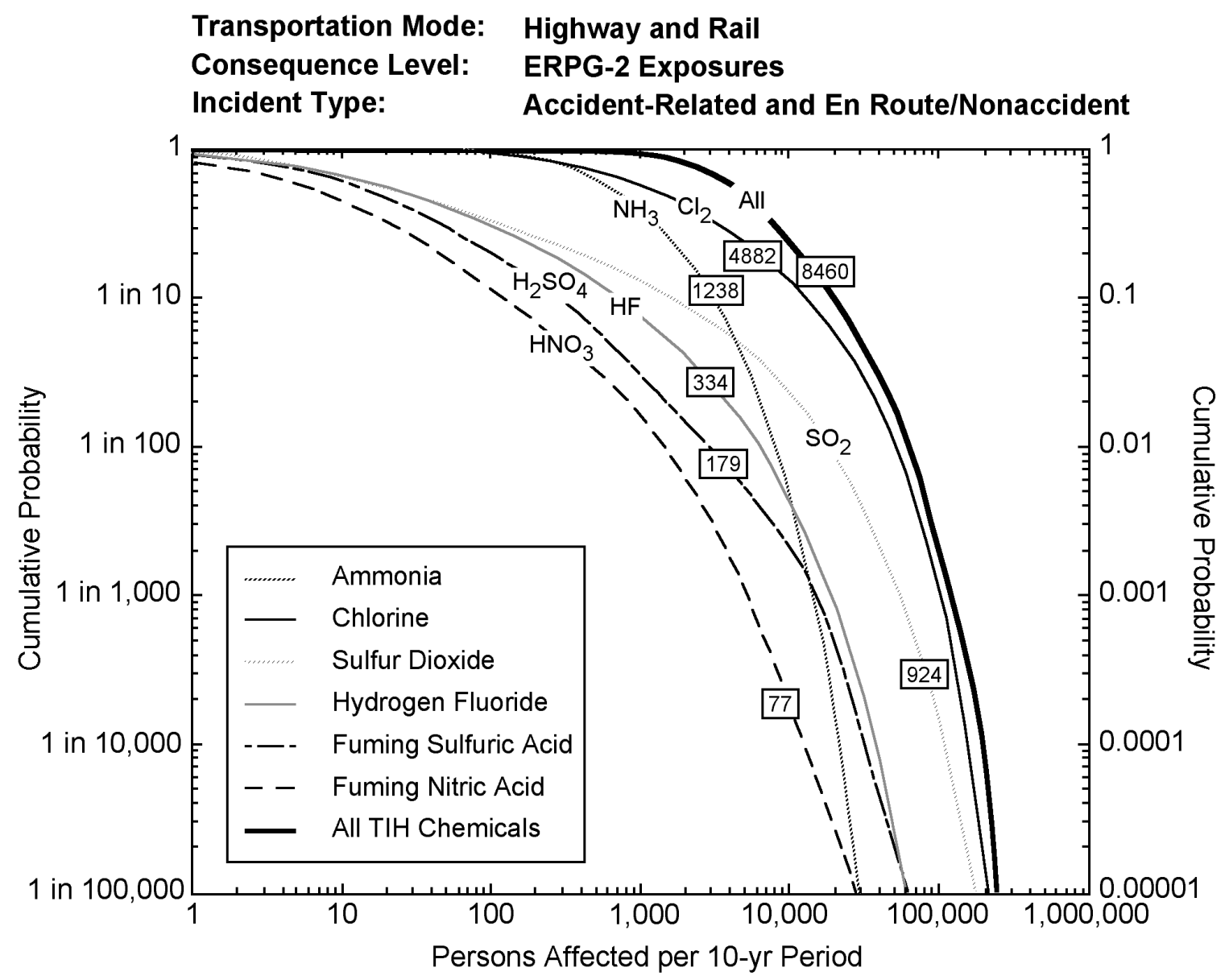

Figure 5.10 Probability of Population Exposure to ERPG-2 Concentrations Resulting from Accident-Related and En Route/Nonaccident Releases for Highway and Rail Transportation over a 10-yr Period for the Six NTRA TIH Chemicals (The total ERPG-2 exposure distribution for transportation of all TIH chemicals is also shown. Means of the exposure distributions are shown in the boxes superimposed on the curves. Mitigative measures such as sheltering or evacuation are not included in these results.) 
Table 5.20 Probability of Population Exposure to Airborne Concentrations Exceeding Fatal Thresholds Resulting from Accident-Related and En Route/ Nonaccident Releases for Highway and Rail over a 10-yr Period for the Six NTRA TIH Chemicalsa

\begin{tabular}{|c|c|c|c|c|c|c|}
\hline $\begin{array}{l}\text { Transportation Mode: } \\
\text { Consequence Level: } \\
\text { Incident Type: }\end{array}$ & \multicolumn{6}{|c|}{$\begin{array}{l}\text { Highway and Rail } \\
\text { Fatal Exposures } \\
\text { Accident-related and En Route/Nonaccident Releases }\end{array}$} \\
\hline $\begin{array}{l}\text { Persons } \\
\text { Exposed }\end{array}$ & Ammonia & Chlorine & $\begin{array}{l}\text { Sulfur } \\
\text { Dioxide }\end{array}$ & $\begin{array}{l}\text { Hydrogen } \\
\text { Fluoride }\end{array}$ & $\begin{array}{l}\text { Fuming } \\
\text { Sulfuric Acid }\end{array}$ & $\begin{array}{c}\text { Fuming Nitric } \\
\text { Acid }\end{array}$ \\
\hline 1 & 0.98 & 0.85 & 0.095 & 0.27 & 0.10 & 0.068 \\
\hline 2 & 0.95 & 0.78 & 0.068 & 0.21 & 0.062 & 0.041 \\
\hline 5 & 0.83 & 0.64 & 0.038 & 0.13 & 0.028 & 0.018 \\
\hline 10 & 0.63 & 0.51 & 0.023 & 0.082 & 0.014 & 0.0087 \\
\hline 20 & 0.40 & 0.38 & 0.013 & 0.047 & 0.0065 & 0.0040 \\
\hline 50 & 0.18 & 0.23 & 0.0062 & 0.021 & 0.0018 & 0.0014 \\
\hline 100 & 0.086 & 0.15 & 0.0031 & 0.011 & $5.1 \times 10^{-4}$ & $4.7 \times 10^{-4}$ \\
\hline 200 & 0.038 & 0.089 & 0.0012 & 0.0049 & $1.4 \times 10^{-4}$ & $1.3 \times 10^{-4}$ \\
\hline 500 & 0.0096 & 0.038 & 0.00030 & 0.0011 & $2.6 \times 10^{-5}$ & $3.1 \times 10^{-5}$ \\
\hline 1,000 & 0.0023 & 0.018 & $4.8 \times 10^{-5}$ & $3.1 \times 10^{-4}$ & $<10^{-6}$ & $2.0 \times 10^{-6}$ \\
\hline 2,000 & $3.3 \times 10^{-5}$ & 0.0070 & $5.0 \times 10^{-6}$ & $4.6 \times 10^{-5}$ & $<10^{-6}$ & $<10^{-6}$ \\
\hline 5,000 & $<10^{-6}$ & 0.0012 & $<10^{-6}$ & $<10^{-6}$ & $<10^{-6}$ & $<10^{-6}$ \\
\hline 10,000 & $<10^{-6}$ & $1.7 \times 10^{-4}$ & $<10^{-6}$ & $<10^{-6}$ & $<10^{-6}$ & $<10^{-6}$ \\
\hline 20,000 & $<10^{-6}$ & $7.9 \times 10^{-6}$ & $<10^{-6}$ & $<10^{-6}$ & $<10^{-6}$ & $<10^{-6}$ \\
\hline 50,000 & $<10^{-6}$ & $<10^{-6}$ & $<10^{-6}$ & $<10^{-6}$ & $<10^{-6}$ & $<10^{-6}$ \\
\hline \multicolumn{7}{|c|}{ Ten-year exposure statistics } \\
\hline Median & 15 & 11 & 0 & 0 & 0 & 0 \\
\hline Average & 43 & 95 & 1.7 & 6.0 & 0.91 & 0.64 \\
\hline \multicolumn{7}{|c|}{ Annual exposure statistics } \\
\hline Avg. incidents per year & 55 & 15 & 3.6 & 4.3 & 4.2 & 1.8 \\
\hline Avg. exposures per year & 4.3 & 9.5 & 0.17 & 0.60 & 0.091 & 0.064 \\
\hline Avg. per $10^{6}$ ton-miles & 0.0012 & 0.0038 & $7.9 \times 10^{-5}$ & 0.0024 & $2.1 \times 10^{-4}$ & $6.0 \times 10^{-4}$ \\
\hline Avg. per incident & 0.077 & 0.63 & 0.047 & 0.14 & 0.021 & 0.035 \\
\hline
\end{tabular}

a Mitigative measures such as sheltering or evacuation are not included in these results. 
Transportation Mode: Highway and Rail

Consequence Level: Fatal Exposures

Incident Type: $\quad$ Accident-Related and En Route/Nonaccident

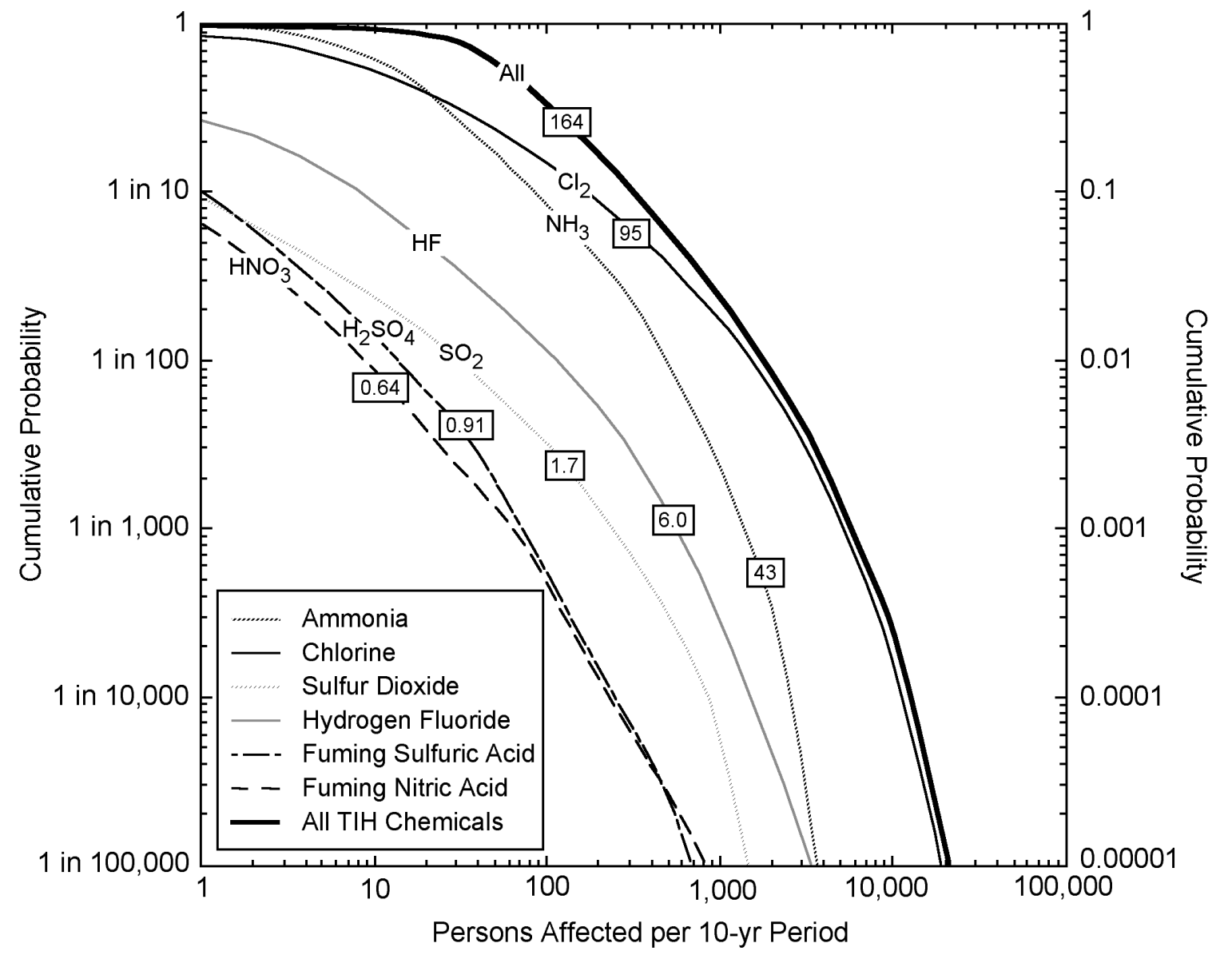

Figure 5.11 Probability of Fatal Exposure Resulting from Accident-Related and En Route/Nonaccident Releases for Highway and Rail Transportation over a 10-yr Period for the Six NTRA TIH Chemicals (The total fatal exposure distribution for transportation of all TIH chemicals is also shown. Means of the exposure distributions are shown in the boxes superimposed on the curves. Mitigative measures such as sheltering or evacuation are not included in these results.) 
Table 5.21 Probability of ERPG-2 Exposure Resulting from All Highway and Rail TIH Transportation (excluding loading/unloading incidents) over a 10-yr Period $^{\mathrm{a}}$

\begin{tabular}{|c|c|c|c|}
\hline $\begin{array}{c}\text { ERPG-2 } \\
\text { Exposures }\end{array}$ & Probability & $\begin{array}{c}\text { ERPG-2 } \\
\text { Exposures }\end{array}$ & Probability \\
\hline 500 & 0.99 & 15,000 & 0.14 \\
\hline 750 & 0.99 & 20,000 & 0.090 \\
\hline 1,000 & 0.97 & 30,000 & 0.045 \\
\hline 1,250 & 0.94 & 50,000 & 0.015 \\
\hline 1,500 & 0.91 & 75,000 & 0.0046 \\
\hline 2,000 & 0.83 & 100,000 & 0.0016 \\
\hline 3,000 & 0.69 & 125,000 & $6.2 \times 10^{-4}$ \\
\hline 5,000 & 0.48 & 150,000 & $3.6 \times 10^{-4}$ \\
\hline 7,500 & 0.32 & 200,000 & $3.9 \times 10^{-5}$ \\
\hline 10,000 & 0.23 & 300,000 & $1.2 \times 10^{-6}$ \\
\hline 12,500 & 0.18 & 500,000 & $<10^{-6}$ \\
\hline \multicolumn{4}{|c|}{ Ten-year exposure statistics } \\
\hline Median & & & 4,748 \\
\hline Average & & & 8,460 \\
\hline \multicolumn{4}{|c|}{ Annual exposure statistics } \\
\hline \multicolumn{3}{|c|}{ Average incidents per year } & 93 \\
\hline \multicolumn{3}{|c|}{ Average ERPG-2 exposures per year } & 846 \\
\hline \multicolumn{3}{|c|}{ Average ERPG- 2 exposures per $10^{6}$ ton-miles } & 0.11 \\
\hline
\end{tabular}

a Mitigative measures such as sheltering or evacuation are not included in these results.

containment. Discussions of these results in Sections 5.5 and 6 incorporate the effects of sheltering.

\subsubsection{Sensitivity of Results to Routing}

The use of a limited number of representative routes to model the national transportation of particular commodities introduces uncertainty into the resulting risk distributions beyond the uncertainties introduced through commodity flow estimates or physical modeling of the release scenarios. To investigate the potential uncertainties involved with the routing analysis, we conducted a sensitivity analysis. Because of the differences in information available, the issues associated with highway and rail routing differ substantially. Therefore, we consider their sensitivities to routing separately.

\subsubsection{Highway Transportation}

For highway transportation, O/D pairs were developed from various sources as outlined in Section 4.2. The routes between these pairs were then obtained by using the 
Table 5.22 Probability of Fatal Exposure Resulting from All Highway and Rail TIH Transportation (excluding loading/unloading incidents) over a 10-yr Period ${ }^{a}$

\begin{tabular}{|c|c|c|c|}
\hline Fatalities & Probability & Fatalities & Probability \\
\hline 5 & 0.98 & 1,250 & 0.017 \\
\hline 10 & 0.98 & 1,500 & 0.013 \\
\hline 25 & 0.84 & 2,000 & 0.0079 \\
\hline 50 & 0.59 & 3,000 & 0.0040 \\
\hline 75 & 0.43 & 5,000 & 0.0013 \\
\hline 100 & 0.34 & 7,500 & $5.1 \times 10^{-4}$ \\
\hline 150 & 0.23 & 10,000 & $2.3 \times 10^{-4}$ \\
\hline 200 & 0.17 & 12,500 & $9.9 \times 10^{-5}$ \\
\hline 300 & 0.11 & 15,000 & $4.2 \times 10^{-5}$ \\
\hline 500 & 0.059 & 20,000 & $1.2 \times 10^{-5}$ \\
\hline 750 & 0.035 & 30,000 & $1.5 \times 10^{-6}$ \\
\hline 1,000 & 0.023 & 50,000 & $<10^{-6}$ \\
\hline \multicolumn{4}{|c|}{ Ten-year exposure statistics } \\
\hline Median & & & 63 \\
\hline Average & & & 164 \\
\hline \multicolumn{4}{|c|}{ Annual exposure statistics } \\
\hline Average incide & oer year & & 93 \\
\hline Average fatal e & sures per year & & 16 \\
\hline Average fataliti & er $10^{6}$ ton-miles & & 0.0021 \\
\hline
\end{tabular}

a Mitigative measures such as sheltering or evacuation are not included in these results.

HIGHWAY 3.3 model. To investigate the sensitivity of the results to routing for highway transportation, we compared the ERPG-2 exposures calculated for accident-related releases in the NTRA study with ERPG-2 exposures calculated by using similar shipments whose transportation is modeled via a generic routing scheme. This generic routing scheme distributes accidents over the entire country on the basis of state incident counts in the HMIS database for 1985-1995 (Table 5.23). For example, 6.24\% of highway-transportation-related releases occurred in Illinois in that 10-yr period.

Therefore, the generic routing scheme places $6.24 \%$ of incidents in Illinois. The variation with population density is taken as a composite of all highway transportation routes considered in the NTRA study (Table 5.24). The generic routing assumes that $75 \%$ of all miles are on interstate highways, with the remaining $25 \%$ traveled on state highways.

For all materials, we modeled the transportation of both bulk and package freight over the generic routes. The shipment miles on the generic routes were specified to match the bulk and package freight ton-mile commodity flow values used in the NTRA study. For $\mathrm{SO}_{2}, \mathrm{HF}$, fuming sulfuric acid, and fuming nitric acid, one bulk shipment in a cargo tank 
Table 5.23 Geographical Distribution of Highway Incidents from the HMIS Database, 1985-1995

\begin{tabular}{|llllll|}
\hline \multicolumn{1}{|c}{ State/District } & $\%$ & State/District & $\%$ & State/District & $\%$ \\
\hline Alabama & 2.08 & Kentucky & 2.25 & North Dakota & 0.25 \\
Alaska & 0.14 & Louisiana & 3.60 & Ohio & 6.87 \\
Arizona & 1.70 & Massachusetts & 1.41 & Oklahoma & 1.46 \\
Arkansas & 2.88 & Maryland & 1.63 & Oregon & 1.37 \\
California & 5.20 & Maine & 0.32 & Pennsylvania & 7.33 \\
Colorado & 1.80 & Michigan & 2.06 & Rhode Island & 0.20 \\
Connecticut & 0.89 & Minnesota & 1.71 & South Carolina & 1.23 \\
District of Columbia & 0.05 & Mississippi & 1.40 & South Dakota & 0.20 \\
Delaware & 0.29 & Missouri & 2.83 & Tennessee & 3.60 \\
Florida & 2.28 & Montana & 0.37 & Texas & 7.86 \\
Georgia & 2.74 & Nebraska & 0.71 & Utah & 1.06 \\
Hawaii & 0.02 & Nevada & 0.54 & Vermont & 0.18 \\
Idaho & 0.52 & New Hampshire & 0.19 & Virginia & 1.97 \\
Illinois & 6.24 & New Jersey & 2.03 & Washington & 1.52 \\
Indiana & 2.81 & New Mexico & 1.63 & West Virginia & 1.22 \\
lowa & 1.43 & New York & 2.94 & Wisconsin & 1.52 \\
Kansas & 2.01 & North Carolina & 2.73 & Wyoming & 0.71 \\
\hline
\end{tabular}

Table 5.24 Percentage of Miles in Generic Routing by Population Density

\begin{tabular}{|cc|}
\hline $\begin{array}{c}\text { Population } \\
\text { Density }\end{array}$ & $\begin{array}{c}\text { Percentage of } \\
\text { Total Miles }\end{array}$ \\
\hline 0 & 9.19 \\
$0-5$ & 24.39 \\
$5-22.7$ & 17.49 \\
$22.7-59.7$ & 13.80 \\
$59.7-139$ & 10.43 \\
$139-326$ & 7.46 \\
$326-821$ & 6.02 \\
$821-1,861$ & 4.85 \\
$1,861-3,326$ & 3.01 \\
$3,326-5,815$ & 2.04 \\
$5,815-9,995$ & 0.94 \\
$>9,995$ & 0.38 \\
\hline
\end{tabular}

and one package freight shipment of 15 to 30 containers were modeled using the generic routing scheme. For ammonia and chlorine, additional bulk shipments were modeled for transporting ammonia in nurse tanks and chlorine in ton cylinders. For example, the shipments for chlorine in the generic routing scheme include 175 million ton-miles shipped in 4,000-gal MC 331 cargo tanks, 26 million ton-miles shipped in ton cylinders (12 per shipment), and 36 million ton-miles shipped in 19-gal cylinders (30 per shipment).

Table 5.25 presents the average annual ERPG-2 exposures from highway accident-related releases for the chemicalspecific routing used in the NTRA analysis as well as the generic routing. We can gauge the

sensitivity to routing by considering the differences between the two analyses. For all $\mathrm{TIH}$ materials, the differences between the two routing scenarios are less than $40 \%$ relative to the chemical-specific NTRA routing results. We believe that the chemicalspecific routing provides a more accurate representation of the total highway transportation risk for the materials considered. However, we can also recognize that the influence of the chemical-specific routing appears to be limited when considering the 
Table 5.25 Sensitivity of NTRA Results as Measured by Average Annual ERPG-2 Exposures from Highway Accident-Related Releases ${ }^{a}$

\begin{tabular}{|lccc|} 
& \multicolumn{3}{c}{ Route } \\
\cline { 2 - 3 } & & & \\
\cline { 2 - 3 } \multicolumn{1}{c}{ Chemical } & NTRA & Generic & $\begin{array}{c}\text { Difference } \\
\text { (\%) }\end{array}$ \\
\hline Ammonia & 35 & 48 & +37 \\
Chlorine & 68 & 87 & +28 \\
Sulfur dioxide & 5.7 & 4.0 & -30 \\
Hydrogen fluoride & 11 & 6.8 & -38 \\
Fuming sulfuric acid & 12 & 7.5 & -38 \\
Fuming nitric acid & 2.8 & 3.2 & +14 \\
\hline
\end{tabular}

a Sensitivity is gauged by comparing the chemical specific routing used in the NTRA analysis with a generic routing for all hazardous materials developed from analysis of HMIS database incidents.

national transportation of the different materials. The primary reason for this limited influence is that the chemical-specific routings account for transportation over many individual routes over wide geographical areas and through regions of varying population density. Variations of risk between single individual routes are much higher, but these variations decrease substantially when groups of routes were considered.

\subsubsection{Rail Transportation}

The issues associated with rail routing sensitivity in this study differ substantially from those for highway routing. First, the uncertainty for rail routings is much less than that for highway because Waybill Sample data were used. The O/D pairs generated through the analysis of the Waybill Sample are very reliable; however, two sources for uncertainty remain in the rail routing analysis. The first source is the routes generated from INTERLINE 5.0 from the O/D pairs derived from the Waybill Sample. For a given $\mathrm{O} / \mathrm{D}$ pair, several routes can be generated depending on the choice of origin and termination railroads in INTERLINE 5.0. In developing the routes used for the NTRA, we attempted to match the actual routes used with those from the pass-through states marked in the Waybill Sample. In addition, we also attempted to match the miles traveled on the route. For more than $80 \%$ of the routes considered, we obtained a very good match between the reported pass-through states and total miles and the modeled routes. While a significant level for uncertainty still remains for a few individual routes, this uncertainty has a very limited effect on per-chemical risk estimated by using the 16 to 30 routes taken together.

The second source of uncertainty arises because we did not consider all routes in the Waybill Sample. Rather, we looked at a limited number of routes and scaled the shipment frequency along these routes to match the total national commodity flow. For $\mathrm{SO}_{2}, \mathrm{HF}$, fuming sulfuric acid, and fuming nitric acid, the routes chosen for analysis 
account for between $76 \%$ and $93 \%$ of the actual rail commodity flow for those materials. Figure 5.12 illustrates how the risk estimates vary with respect to the number of routes considered for these materials. In these figures, the estimated annual risk as denoted by ERPG-2 exposures is plotted with respect to the number of routes chosen for analysis. The percentages of actual commodity flow represented by the routes on the abscissa are also provided. It is important to emphasize that the total commodity flow (in ton-miles) is the same regardless of the number of routes considered. Clearly, in each of these cases, the risk estimates are approaching a constant value, as the number of routes and percentage of total actual commodity flow represented are increased. Interestingly, except for fuming nitric acid, considering only five routes would provide a risk estimate within $20 \%$ of the final value calculated in the NTRA. However, for these materials, between $40 \%$ and $60 \%$ of total actual commodity flow is transported by the top five routes in terms of total commodity flow, so this result is not especially surprising. For there to be significant errors in the resulting risk estimates for these materials due to routing, the fraction of actual commodity flow not represented (between $7 \%$ and $24 \%$, depending on material) would have to occur in regions of very high population density relative to that of the large fraction of commodity flow represented. Because this is very unlikely, we estimate that the uncertainty of the resulting risk estimates due to routing for these materials is less than $15 \%$.

For ammonia and chlorine, the total percentages of actual rail commodity flow represented by the 30 routes chosen for analysis are $52 \%$ and $41 \%$, respectively.

Figure 5.13 shows the estimated annual risk for these two chemicals on the basis of ERPG-2 exposures with respect to the number of routes chosen for analysis. (Figure 5.12 did the same for the other four TIH materials.) For ammonia and chlorine, we can see the same approach to a steady risk estimate with increasing number of routes employed as was shown for the other four TIH materials, even though the actual commodity flow represented by the routes selected for analysis is substantially less than that for the other TIH materials. From this example, it is apparent that for ammonia and chlorine, about 20 routes cover a sufficiently large distribution of geography and commodity flow so that incorporation of additional routes does not significantly change the overall risk results. Even though individual routes that are not considered can vary widely in risk on a per-ton-mile basis, each route accounts for a very small fraction of the total commodity flow. From these observations, we conclude that the uncertainty of the resulting risk estimates is less than $20 \%$ for rail transportation of ammonia and chlorine.

\subsubsection{Reduction of Risk Resulting from 1990 Regulatory Changes}

In this section, we use the risk assessment results presented in Sections 5.2.1 to 5.2.4 to estimate the reduction of risk resulting from regulatory changes in 1990 concerning transportation of TIH liquids in MC 312 cargo tanks and tank cars. In 1990, the regulations concerning the design of MC 312 cargo tanks authorized for transportation of TIH liquids were modified so that the standard MC 312 cargo tank was replaced with a significantly more robust MC 312 cargo tank. As a result of these regulatory changes, MC 312 cargo tanks for TIH liquids were to be constructed of stainless steel with a minimum thickness of 0.25 in. In addition, an insulating jacket is also required for 

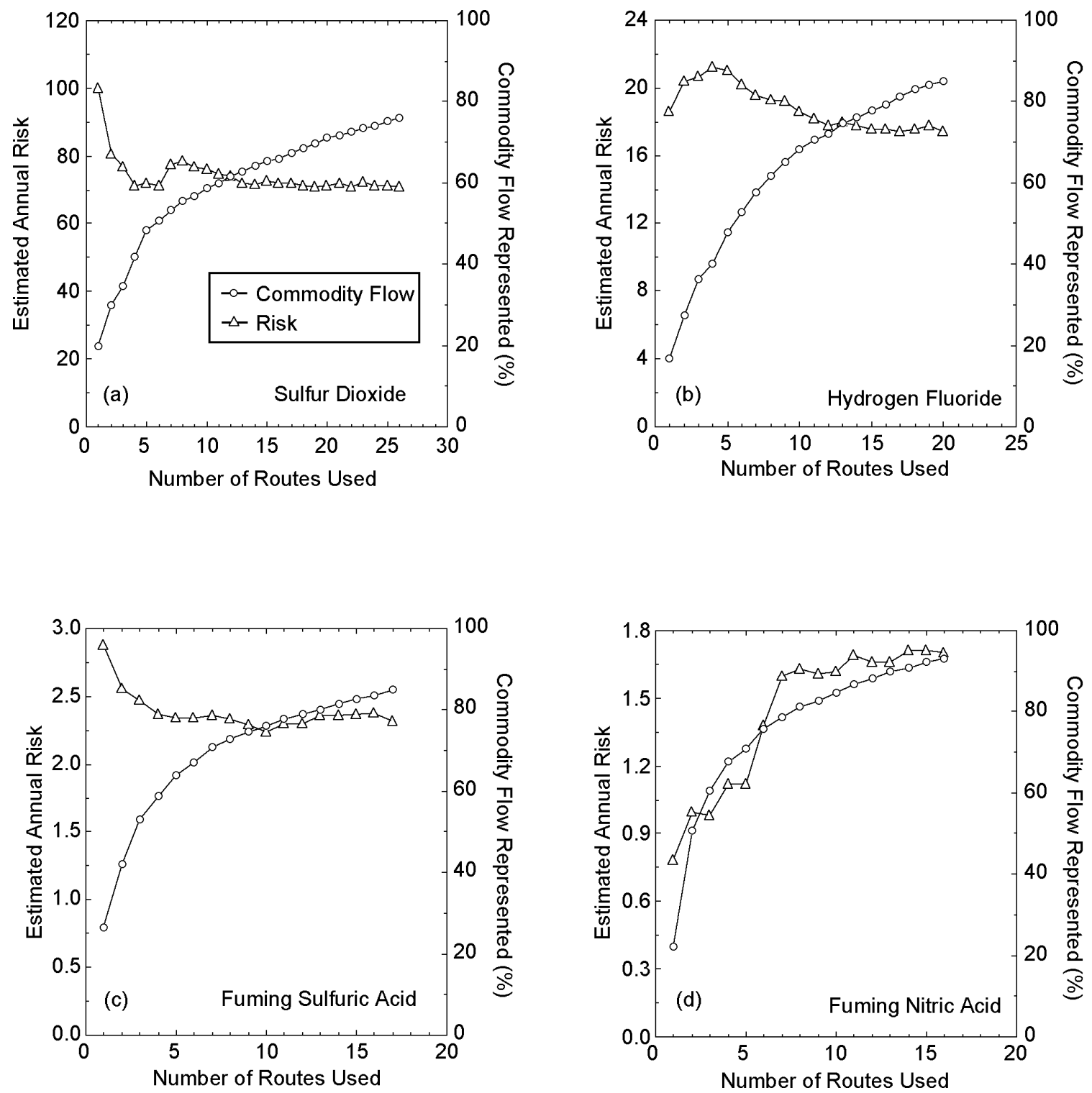

Figure 5.12 Annual Risk Denoted by ERPG-2 Exposures as a Function of the Number of Routes Used in the Risk Assessment (The percent actual commodity flow represented by the routes is also provided.) 

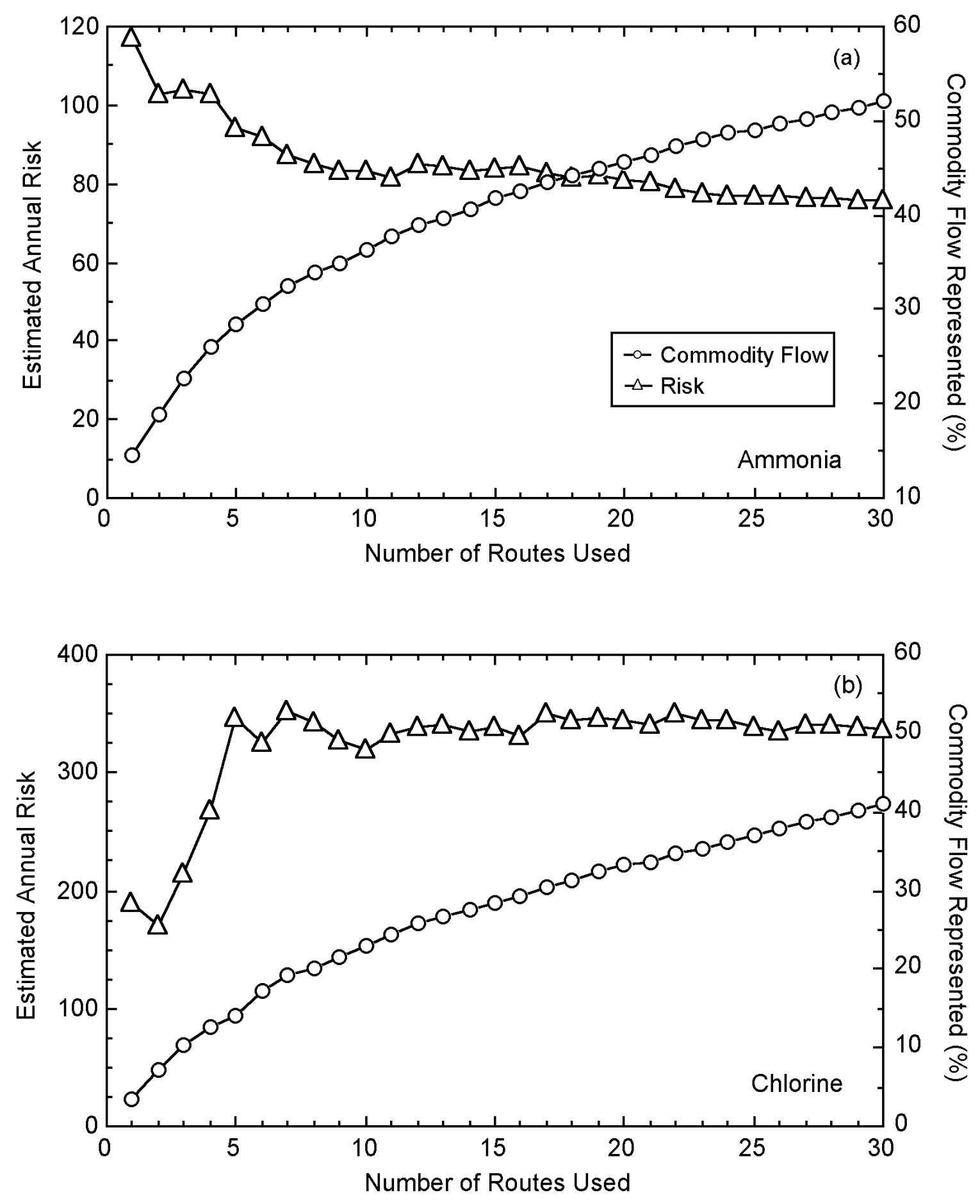

Figure 5.13 Annual Risk Denoted by ERPG-2 Exposures to Ammonia and Chlorine as a Function of the Number of Routes Used in the Risk Assessment (The percent actual commodity flow represented by the routes is also provided.) 
fuming sulfuric acid. In contrast, the standard MC 312 cargo tank authorized prior to 1990 was typically constructed of standard steel, 0.25 in. thick with no insulating jacket. As outlined in Section 2.3.3, the probability of release in a traffic accident is much less for the upgraded MC 312 cargo tank. The release probability for the standard MC 312 cargo tank is $4 \%$, whereas the release probability for the upgraded MC 312 tank as estimated for this study is $1.5 \%$.

Table 5.26 shows the reduction of annual risk, as measured by average ERPG-2 and fatal exposures per year, associated with highway accident-related releases as a result of the 1990 regulatory changes for MC 312 cargo tanks. Risk reduction estimates are shown for fuming sulfuric acid and fuming nitric acid, the two most frequently shipped TIH liquids in MC 312 cargo tanks. In this table, we also illustrate the potential reduction of risk if these regulations are extended to HF. Although HF meets the criteria for a TIH, standard MC 312 cargo tanks are still authorized for its transportation. Industry practice has been to ship HF in containers that exceed the design criteria for standard MC 312 tanks, and at least one major producer ships HF in tanks that substantially exceed the post-1990 TIH requirements. Therefore, ERPG-2 and fatal exposures for current operation are conservative. Nevertheless, codifying the more robust container within the regulations will further reduce the potential for a release.

Table 5.26 Reduction of Annual Risk Associated with Highway AccidentRelated Releases for Fuming Sulfuric Acid and Fuming Nitric Acid as a Result of 1990 Regulatory Changes for MC 312 Cargo Tanks ${ }^{a}$

\begin{tabular}{|lcccccc|}
\hline & \multicolumn{2}{c}{ ERPG-2 Exposures/yr } & & \multicolumn{2}{c|}{ Fatal Exposures/yr } \\
\cline { 2 - 3 } \cline { 5 - 6 } \multicolumn{1}{c}{ Chemical } & Pre-1990 & Post-1990 & & Pre-1990 & Post-1990 \\
\hline Fuming sulfuric acid & 32 & 12 & & 0.16 & 0.061 \\
$\begin{array}{l}\text { Fuming nitric acid } \\
\text { Hydrogen fluoride }\end{array}$ & 7.5 & 2.8 & & 0.067 & 0.025 \\
$\quad$ Current regulations & & 11 & & & 0.16 \\
$\quad$ TIH standard & & 3.9 & & & 0.060 \\
\hline
\end{tabular}

a Mitigative measures such as sheltering or evacuation are not included in these results.

A similar comparison for fuming sulfuric acid and fuming nitric acid shipped by rail is shown in Table 5.27. As a result of a 1990 regulation change, Class 111A tank cars were no longer authorized for these materials and other TIH liquids. This change also results in a considerable reduction in the probability of derailment-related releases. As outlined in Section 2, our analysis of historical release and commodity flow data shows that Class 111 A cars without insulation experience about 1 derailment-related release for every 7 million tank-car-miles, whereas Class 112 cars (300 psi rating) experience 1 derailment-related release for every 30 million tank-car-miles. This in turn translates to approximately a 75\% reduction in ERPG-2 exposure and fatal exposure risk for the shipment of these materials by rail. 
Table 5.27 Reduction of Annual Risk Associated with Derailment-Related Releases for Fuming Sulfuric Acid and Fuming Nitric Acid as a Result of 1990 Regulatory Changes ${ }^{a}$

\begin{tabular}{|lcclll|}
\hline & \multicolumn{2}{c}{$\begin{array}{c}\text { ERPG-2 } \\
\text { Exposures/yr }\end{array}$} & & \multicolumn{2}{c|}{$\begin{array}{c}\text { Fatal } \\
\text { Exposures/yr }\end{array}$} \\
\cline { 2 - 3 } \cline { 5 - 6 } \multicolumn{1}{c}{ Chemical } & Class 111 Class 112 & & Class 111 & Class 112 \\
\hline Fuming sulfuric acid & 9.9 & 2.3 & & 0.047 & 0.011 \\
Fuming nitric acid & 7.3 & 1.7 & & 0.077 & 0.018 \\
\hline
\end{tabular}

a Mitigative measures such as sheltering or evacuation are not included in these results.

\subsection{Flammable Materials}

In this section, we outline the NTRA results for flammable materials that contribute the greatest transportation-related risk to the public. These materials are LP gas and gasoline. We discuss the risk associated with highway transportation of these materials in Sections 5.3.1 and 5.3.2, respectively. Later, in Section 5.5, we compare the transportation risk associated with flammable materials with that associated with $\mathrm{TIH}$ materials and explosives. Recall from Sections 2 and 3 that historical evidence from the HMIS database demonstrates that a substantial majority of risk associated with transportation of flammable materials is due to highway transportation. For this reason, only highway transportation of LP gas and gasoline is considered in the NTRA.

\subsubsection{Highway Incidents Involving LP Gases}

The principal hazards from LP gas releases in transportation-related incidents are fireballs, which result from a near-instantaneous release and ignition, and flash fires, which result from the ignition of a vapor cloud after the cloud has dispersed to some extent. Blast overpressure and flying debris can also be significant hazards in certain situations; however, historical evidence has shown that impacts arising from thermal radiation are significantly higher for transportation-related releases. Therefore, only thermal-radiation effects are considered in this study. On the basis of the consequence analysis methods outlined in Section 2.4.1 and Appendix A, we calculated fatality and injury distributions for LP gas in the same manner as for TIH chemicals.

Tables 5.28 and 5.29 list the probabilities of injuries and fatalities, respectively, resulting from highway transportation of LP gases for a 10 -yr period. These consequence statistics are presented in the same format as those for TIH materials in Section 5.2. For example, the probability that 50 or more fatalities will occur in a 10-yr period as a result of LP gas transportation is about $30 \%$. Similarly, the probability that more than 200 such fatalities will occur in the same period is less than $0.5 \%$. Figure 5.14 provides the injury and fatality distributions in graphical form showing probability as a function of persons injured or killed. Similar to the probability distributions shown for TIH materials, 
Table 5.28 Probability of Injuries Resulting from Highway Transportation of LP Gas over a 10-yr Period

\begin{tabular}{|c|c|c|c|}
\hline Injuries & Probability & Injuries & Probability \\
\hline 1 & $>0.995$ & 175 & 0.33 \\
\hline 2 & 0.99 & 200 & 0.28 \\
\hline 5 & 0.99 & 225 & 0.23 \\
\hline 10 & 0.97 & 250 & 0.19 \\
\hline 20 & 0.92 & 300 & 0.13 \\
\hline 30 & 0.87 & 350 & 0.086 \\
\hline 40 & 0.82 & 400 & 0.058 \\
\hline 50 & 0.78 & 450 & 0.039 \\
\hline 60 & 0.73 & 500 & 0.026 \\
\hline 75 & 0.67 & 750 & 0.0028 \\
\hline 100 & 0.55 & 1,000 & 0.00024 \\
\hline 125 & 0.48 & 1,250 & $1.3 \times 10^{-5}$ \\
\hline 150 & 0.40 & 1,500 & $<10^{-6}$ \\
\hline \multicolumn{4}{|c|}{ Ten-year exposure statistics } \\
\hline \multirow{2}{*}{\multicolumn{3}{|c|}{$\begin{array}{l}\text { Median injuries } \\
\text { Average injuries }\end{array}$}} & 118 \\
\hline & & & 154 \\
\hline \multicolumn{4}{|c|}{ Annual exposure statistics } \\
\hline \multicolumn{3}{|c|}{ Average incidents per year } & 7.1 \\
\hline \multicolumn{3}{|c|}{ Average injuries per year } & 15 \\
\hline \multicolumn{3}{|c|}{ Average injuries per $10^{6}$ ton-miles } & 0.010 \\
\hline
\end{tabular}

probability is expressed in terms of odds of occurrence on the left scale (e.g., 1 in 10, 1 in 100) and decimal fraction (e.g., 0.1 is $10 \%, 0.5$ is $50 \%$ ) on the right scale.

The nature of the transportation risk associated with LP gas differs substantially from that associated with TIH materials. The differences are most apparent in comparing the probability curves in Figure 5.14 with those shown previously in conjunction with individual TIH materials as well as the total TIH risk distributions in Figures 5.10 and 5.11. (These are compared directly in Section 5.5.) For LP gas, the consequence probability decreases more quickly as the number of affected persons increases. Graphically, this behavior is directly reflected in a steeper probability curve and reflects the fact that the risk for LP gas transportation is driven by incidents that occur frequently rather than very infrequently. This overall characteristic of LP gas transportation risk can be quantified by the ratio of the average to the median numbers of injuries and fatalities.

For both fatalities and injuries, the ratio of average to median numbers of persons affected is about 1.3:1 for LP gas transportation. For individual TIH materials, this ratio ranges from about 2:1 to 10:1, and for all TIH materials and all release types taken together, this ratio is about 3:1 for fatalities and 2:1 for injuries. An important consequence of this behavior is that injuries and fatalities from LP gas transportation for any 10-yr period should not usually vary by more than a factor of 2 from the long-term 
Table 5.29 Probability of Fatalities Resulting from Highway Transportation of LP Gas over a 10-yr Period

\begin{tabular}{|c|c|c|c|}
\hline Fatalities & Probability & Fatalities & Probability \\
\hline 1 & 0.99 & 125 & 0.038 \\
\hline 2 & 0.98 & 150 & 0.019 \\
\hline 5 & 0.94 & 175 & 0.0093 \\
\hline 10 & 0.85 & 200 & 0.0046 \\
\hline 20 & 0.68 & 225 & 0.0022 \\
\hline 30 & 0.53 & 250 & 0.0010 \\
\hline 40 & 0.41 & 300 & 0.00020 \\
\hline 50 & 0.31 & 350 & $3.9 \times 10^{-5}$ \\
\hline 60 & 0.23 & 400 & $1.0 \times 10^{-6}$ \\
\hline 75 & 0.15 & 450 & $<10^{-6}$ \\
\hline 100 & 0.071 & 500 & $<10^{-6}$ \\
\hline \multicolumn{4}{|c|}{ Ten-year exposure statistics } \\
\hline Median fatalities & & & 33 \\
\hline Average fatalities & & & 42 \\
\hline \multicolumn{4}{|c|}{ Annual exposure statistics } \\
\hline Average incidents & per year & & 7.1 \\
\hline Average fatalities & er year & & 4.2 \\
\hline Average fatalities & er $10^{6}$ ton-miles & & 0.0028 \\
\hline
\end{tabular}

average. A more general discussion concerning the character of TIH, LP gas, and gasoline risk distributions is provided in Section 5.5.

In considering the normalized risk of LP gas transportation by highway, the average number of injuries per million ton-miles $(0.010)$ is considerably less than the injuries (taken as ERPG-2 exposures) associated with TIH transportation, namely, 0.12 injuries per million ton-miles. However, when TIH ERPG-2 exposures are adjusted to account for sheltering, we obtain 0.012 injuries per million ton-miles which is comparable to the normalized risk of injuries associated with LP gas transportation. For fatalities, the normalized risk of LP gas transportation is similar to that for TIH transportation when sheltering effects are not included. When TIH fatality statistics are adjusted to account for sheltering, however, the normalized fatality risk associated with LP gas transportation is about an order of magnitude above that for TIH transportation.

\subsubsection{Highway Incidents Involving Gasoline}

Tables 5.30 and 5.31 list the probabilities of injuries and fatalities, respectively, resulting from highway transportation of gasoline for a 10-yr period as calculated from the Monte Carlo analysis outlined in Section 2.4.2. These consequence statistics are presented in the same format as results presented earlier in this section. As an example, 


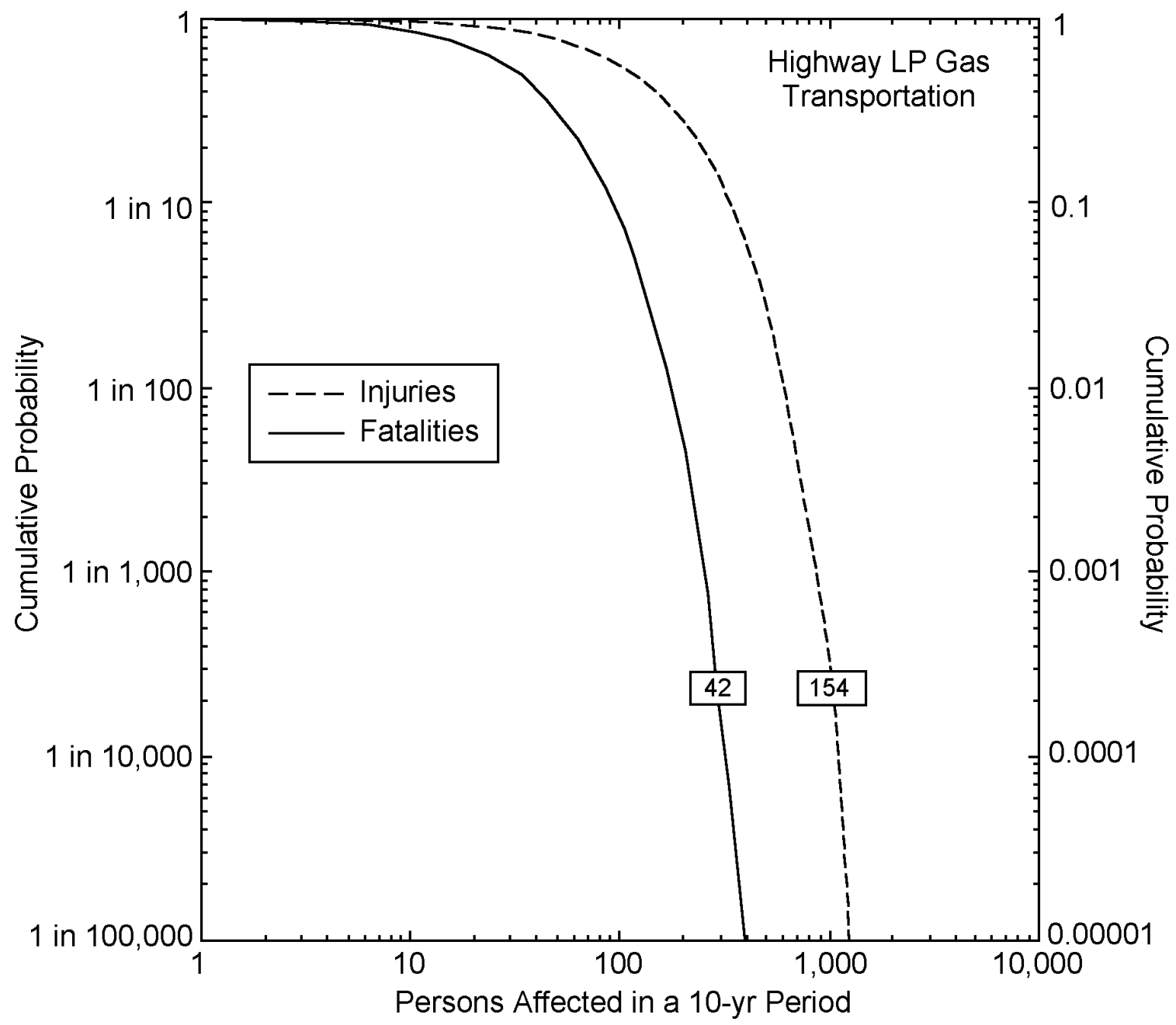

Figure 5.14 Probability of Injuries and Fatalities Resulting from Highway Transportation of LP Gases over a 10-yr Period (Means of the consequence distributions are shown in the boxes superimposed on the curves.)

there is a $64 \%$ probability that there will be over 100 fatalities due to highway gasoline transportation during any 10 -yr period. However, the probability of over 200 fatalities during the same period is very small, only 0.000067 , or about 1 in 15,000 . Figure 5.15 provides the injury and fatality distributions in graphical form showing the probability as a function of number of persons affected per 10 -yr period. The probability distributions are shown in the same manner as for TIH materials and LP gas, with the probability expressed in terms of odds of occurrence on the left scale (e.g., 1 in 10, 1 in 100) and decimal fraction (i.e., 0.1 is $10 \%, 0.5$ is $50 \%$, etc.) on the right scale. 
Table 5.30 Probability of Injuries Resulting from Highway Transportation of Gasoline over a 10-yr Period

\begin{tabular}{|c|c|c|c|}
\hline Injuries & Probability & Injuries & Probability \\
\hline 100 & $>0.995$ & 200 & 0.48 \\
\hline 110 & 0.99 & 225 & 0.31 \\
\hline 120 & 0.98 & 250 & 0.19 \\
\hline 130 & 0.95 & 275 & 0.11 \\
\hline 140 & 0.90 & 300 & 0.058 \\
\hline 150 & 0.84 & 350 & 0.014 \\
\hline 160 & 0.77 & 400 & 0.0028 \\
\hline 170 & 0.70 & 500 & $7.4 \times 10^{-5}$ \\
\hline 180 & 0.63 & 600 & $<10^{-6}$ \\
\hline 190 & 0.55 & 700 & $<10^{-6}$ \\
\hline \multicolumn{4}{|c|}{ Ten-year exposure statistics } \\
\hline Median injuries & & & 197 \\
\hline Average injuries & & & 205 \\
\hline \multicolumn{4}{|c|}{ Annual exposure statistics } \\
\hline Average injuries & year & & 21 \\
\hline Average injuries & $10^{6}$ ton-miles & & 0.00120 \\
\hline
\end{tabular}

Table 5.31 Probability of Fatalities Resulting from Highway Transportation of Gasoline over a 10-yr Period

\begin{tabular}{|cc|cc|}
\hline Fatalities & Probability & Fatalities & Probability \\
\hline 60 & $>0.995$ & 140 & 0.049 \\
70 & 0.99 & 150 & 0.019 \\
80 & 0.95 & 160 & 0.0070 \\
90 & 0.83 & 170 & 0.0024 \\
100 & 0.64 & 180 & 0.00077 \\
110 & 0.41 & 190 & 0.00024 \\
120 & 0.23 & 200 & $6.7 \times 10^{-5}$ \\
130 & 0.11 & 220 & $<10^{-6}$ \\
\hline \multicolumn{4}{c}{ Ten-year exposure statistics } \\
Avedian fatalities & Annual exposure statistics & 106 \\
Average fatalities & & 108 \\
Average fatalities per $10^{6}$ ton-miles & 11 \\
\hline
\end{tabular}




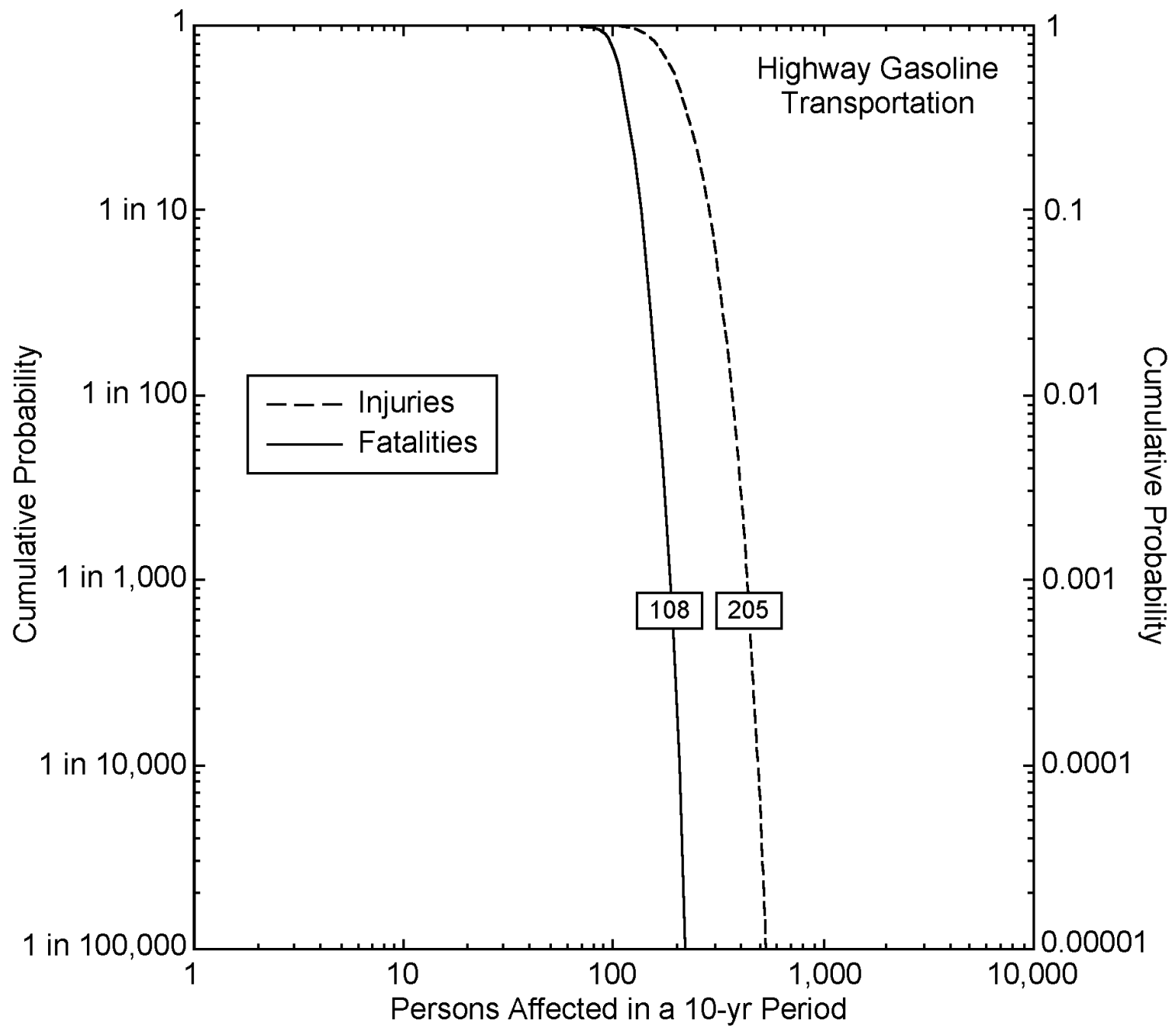

Figure 5.15 Probability of Injuries and Fatalities Resulting from Highway Transportation of Gasoline over a 10-yr Period (Means of the consequence distributions are shown in the boxes superimposed on the curves.)

The fatality and injury distributions for gasoline are markedly different from those of LP gas and TIH materials. The most obvious difference is the extremely sharp reduction in consequence probability over a very small range of injuries or fatalities. The immediate consequence of this behavior is that median and average values for injuries or fatalities resulting from highway gasoline transportation differ by only a few percent. In addition, the probability that the number of fatalities or injuries during any 10 -yr period will be substantially different from the long-term average (say $50 \%$ ) is very small, as long as no significant changes occur in commodity flow or regulations. Differences in the character of injury and fatality distributions between gasoline and the other materials considered in the NTRA are further explored in Section 5.5. 
For gasoline transportation by highway, the normalized injury risk per million tonmiles $(0.0012)$ is considerably less than the normalized injury risk associated with TIH transportation (0.012, taken as ERPG-2 exposures and including sheltering effects) and that associated with LP gas transportation (0.010). For fatalities, however, the normalized risk from highway gasoline transportation ( 0.00064 fatalities per million tonmiles) is less than the LP gas normalized risk (0.0028), but it is substantially greater than the TIH fatality risk $(0.00028)$ when sheltering effects are included.

\subsection{Explosive Materials}

In this section, we present the NTRA results for transportation of explosives. Since $99 \%$ of commodity flow for explosives is due to highway transportation, only highway transportation of explosives in considered in the NTRA. First, we discuss the risk associated with highway transportation of explosives in this section, and then we compare the transportation risk associated with explosive materials with that associated with TIH materials and flammable materials in Section 5.5.

In Section 2.5 and Appendix A, the consequence analysis for explosives was discussed. Recall that there are two principal hazards associated with explosives incidents. The first is blast overpressure, which can generate missiles and collapse buildings. Blast overpressure can also cause direct injury to human tissue, but the thresholds for injury and fatality are high enough that persons are much more likely to be injured or killed due to secondary effects. The second hazard is due to thermal radiation from the blast itself. In calculating injury and fatality distributions, both blast overpressure and thermal radiation were considered in the analysis.

Tables 5.32 and 5.33 list the probabilities of injuries and fatalities, respectively, resulting from highway transportation of explosives for a 10-yr period. These consequence statistics are presented in the same format as the risk assessment results for $\mathrm{TIH}$ and flammable materials given in Sections 5.2 and 5.3. For example, the probability that 10 or more fatalities will occur in a $10-y r$ period as a result of explosives transportation is about $12 \%$. Similarly, the probability that more than 100 such fatalities will occur in the same period is less than $0.5 \%$. Figure 5.16 shows the injury and fatality distributions in graphical form showing the probability as a function of persons injured or killed. Like the probability distributions for TIH and flammable materials, the probability is expressed in terms of odds of occurrence on the left scale (i.e., 1 in 10, 1 in 100 ) and decimal fraction (i.e., 0.1 is $10 \%, 0.5$ is $50 \%$ ) on the right scale.

The results for explosives are somewhat different in character than those for TIH materials, LP gas, and gasoline. On a per-incident basis, the fatality hazard associated with explosives is significantly higher than that for LP gas and is similar to that for a TIH material. The difference in the risk profiles between explosives and TIH materials, however, lies in the fact that consequence distributions for explosive materials do not exhibit the considerable tail typical of that for a TIH material. As an example, the average number of persons killed per explosives incident is comparable to highway-accident-related releases of HF (without the effects of active or passive 
Table 5.32 Probability of Injuries Resulting from Highway Transportation of Explosives over a 10-yr Period

\begin{tabular}{|c|c|c|c|}
\hline Injuries & Probability & Injuries & Probability \\
\hline 1 & 0.36 & 175 & 0.015 \\
\hline 2 & 0.32 & 200 & 0.012 \\
\hline 5 & 0.27 & 225 & 0.0089 \\
\hline 10 & 0.22 & 250 & 0.0069 \\
\hline 20 & 0.16 & 275 & 0.0055 \\
\hline 30 & 0.12 & 300 & 0.0042 \\
\hline 40 & 0.099 & 350 & 0.0026 \\
\hline 50 & 0.081 & 400 & 0.0016 \\
\hline 60 & 0.068 & 450 & 0.0010 \\
\hline 75 & 0.053 & 500 & 0.00064 \\
\hline 100 & 0.037 & 750 & $2.8 \times 10^{-5}$ \\
\hline 125 & 0.027 & 1,000 & $2.0 \times 10^{-6}$ \\
\hline 150 & 0.020 & 1,250 & $<10^{-6}$ \\
\hline \multicolumn{4}{|c|}{ Ten-year exposure statistics } \\
\hline Median injuries & & & 0 \\
\hline Average injuries & & & 14 \\
\hline \multicolumn{4}{|c|}{ Annual exposure statistics } \\
\hline Average incident & per year & & 0.11 \\
\hline Average injuries & r year & & 1.4 \\
\hline Average injuries & $r 10^{6}$ ton-miles & & 0.0018 \\
\hline
\end{tabular}

mitigation). However, a worst-case explosives event is substantially less hazardous than a worst-case TIH event. Comparing injury and fatality statistics, explosives share the trait of LP gas and gasoline in that the average injuries are only a factor 2 to 3 higher than the average fatalities. For TIH materials, on the other hand, the average injuries are typically a factor 25 to 100 higher than the average fatalities.

The other substantial difference between explosives and the other classes of materials considered in the NTRA is related to the frequency of events. Explosives-related transportation incidents are very rare in comparison to transportation incidents involving $\mathrm{TIH}$ materials and flammable materials. In our analysis, the average number of detonations per 10 yr was about 1.1, or about one every 9 yr. LP gas, gasoline, and TIH incidents are much more frequent. The net result of this is that the average injuries and fatalities for explosives are much lower than those for LP gas, gasoline, and TIH materials. However, as we shall discuss in the next section, the normalized fatality and injury risk for explosives lies between that of TIH materials and LP gas and is, in fact, very similar to that of gasoline. 
Table 5.33 Probability of Fatalities Resulting from Highway Transportation of Explosives over a 10-yr Period

\begin{tabular}{|c|c|c|c|}
\hline Fatalities & Probability & Fatalities & Probability \\
\hline 1 & 0.29 & 125 & 0.0022 \\
\hline 2 & 0.25 & 150 & 0.0011 \\
\hline 5 & 0.18 & 175 & 0.00055 \\
\hline 10 & 0.12 & 200 & 0.00016 \\
\hline 20 & 0.070 & 225 & $7.0 \times 10^{-5}$ \\
\hline 30 & 0.045 & 250 & $2.9 \times 10^{-5}$ \\
\hline 40 & 0.031 & 275 & $1.5 \times 10^{-5}$ \\
\hline 50 & 0.022 & 300 & $6.0 \times 10^{-6}$ \\
\hline 60 & 0.016 & 325 & $3.0 \times 10^{-6}$ \\
\hline 75 & 0.0097 & 350 & $1.3 \times 10^{-6}$ \\
\hline 100 & 0.0045 & 400 & $<10^{-6}$ \\
\hline \multicolumn{4}{|c|}{ Ten-year exposure statistics } \\
\hline Median fatalities & & & 0 \\
\hline Average fatalities & & & 4.9 \\
\hline \multicolumn{4}{|c|}{ Annual exposure statistics } \\
\hline Average incidents & per year & & 0.11 \\
\hline Average fatalities & er year & & 0.49 \\
\hline Average fatalities & er $10^{6}$ ton-miles & & 0.00061 \\
\hline
\end{tabular}

\subsection{Comparison of Risk from Transportation of TIH Materials, Flammable Materials, and Explosives}

In this section, we compare the risks due to transportation of TIH materials, flammable materials, and explosives. We shall first discuss the 10-year consequence distributions in Section 5.5.1 and then discuss annual averages and normalized risk in Section 5.5.2.

In this section and in Section 6, we include the effects of sheltering for TIH materials through the use of the exposure reduction factors discussed in Section 5.1.4 and listed in Table 5.4. As discussed previously, results for TIH materials without sheltering are conservative since most people are indoors and thus partially protected from outdoor concentrations of toxic materials. The actual TIH injury and fatality risk as reflected by historical data are better represented by our analysis when sheltering effects are included. Furthermore, the inclusion of sheltering effects allows a more meaningful comparison of risk between TIH materials, flammable materials, and explosives. 


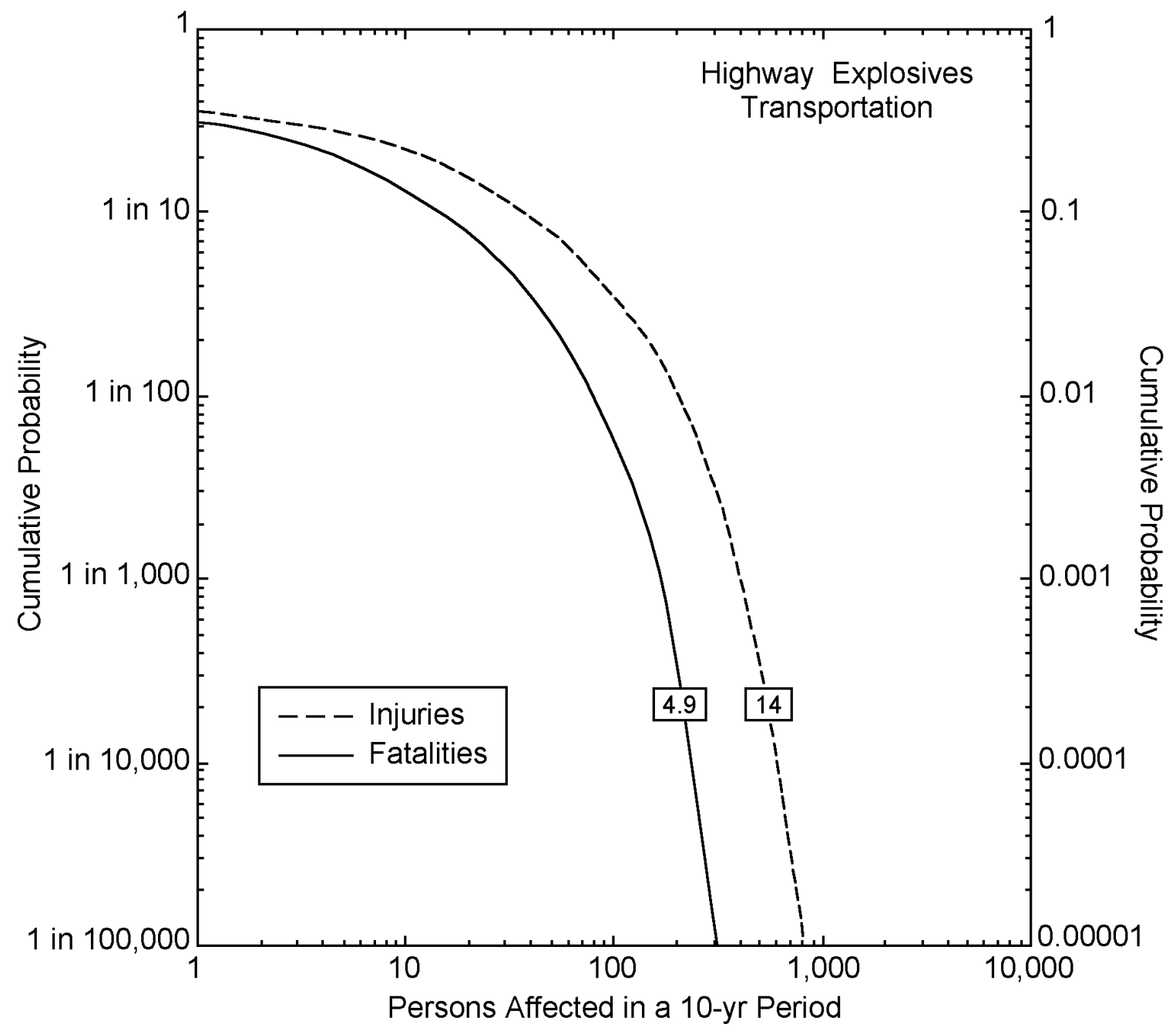

Figure 5.16 Probability of Injuries and Fatalities Resulting from Transportation of Explosives over a 10-yr Period (Means of the consequence distributions are shown in the boxes superimposed on the curves.)

\subsubsection{Comparison of 10-yr Fatality and Injury Distributions}

Figures 5.17 and 5.18 compare the 10 -yr injury and fatality distributions, respectively, for highway and rail transportation of all $\mathrm{TIH}$ materials, highway transportation of LP gas, highway transportation of gasoline, and highway transportation of explosives. In the figures, TIH injuries are taken as ERPG-2 exposures, and in each figure, TIH consequence distributions are shown for the baseline case without the effects of passive and active mitigation, and with the effects of sheltering included.

Differences between consequence distributions for the various commodity types are clearly evident in this comparison. As noted throughout this report, TIH consequence 


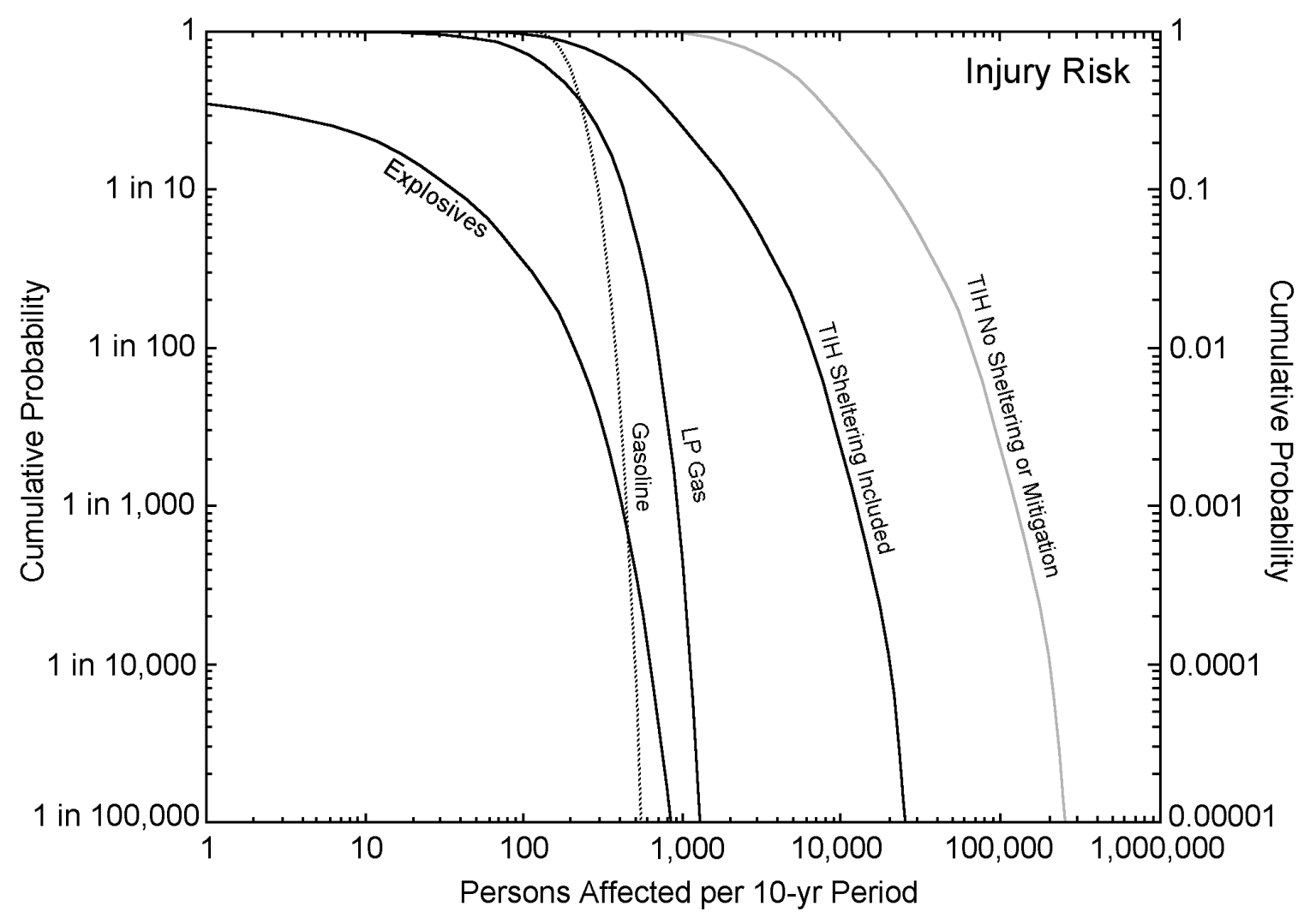

Figure 5.17 Comparison of Injury Probability Resulting from Transportation of TIH Materials, LP Gas, Gasoline, and Explosives over a 10-yr Period (For TIH materials, injuries are taken as ERPG-2 exposures. TIH results are shown both for the baseline case, which does not include measures such as sheltering or evacuation, and as adjusted for the effects of passive sheltering.)

distributions are strongly affected by low-probability/high-consequence events, especially for individual chemicals for which few incidents occur in a 10-yr period. In other words, a substantial fraction of the risk results from events whose probability of occurrence is extremely low. This creates highly skewed consequence distributions where the vast majority of 10-yr periods have low numbers of injuries and fatalities, and a very small percentage of 10-yr periods have high numbers of injuries and fatalities due to a single major incident. For distributions characteristic of transportation risk, the skewness of the distribution can be roughly gauged by the ratio of the average consequences to the median consequences. For highly skewed distributions whose risk is governed by rarely occurring events, this ratio is much greater than 1 . As discussed in Section 5.2.6, combining all TIH materials into a single distribution softens this character somewhat by incorporating many more incidents in the consequence distribution, including large numbers of low consequence events such as en route/nonaccident releases. However, the overall character of the distribution remains qualitatively similar. 


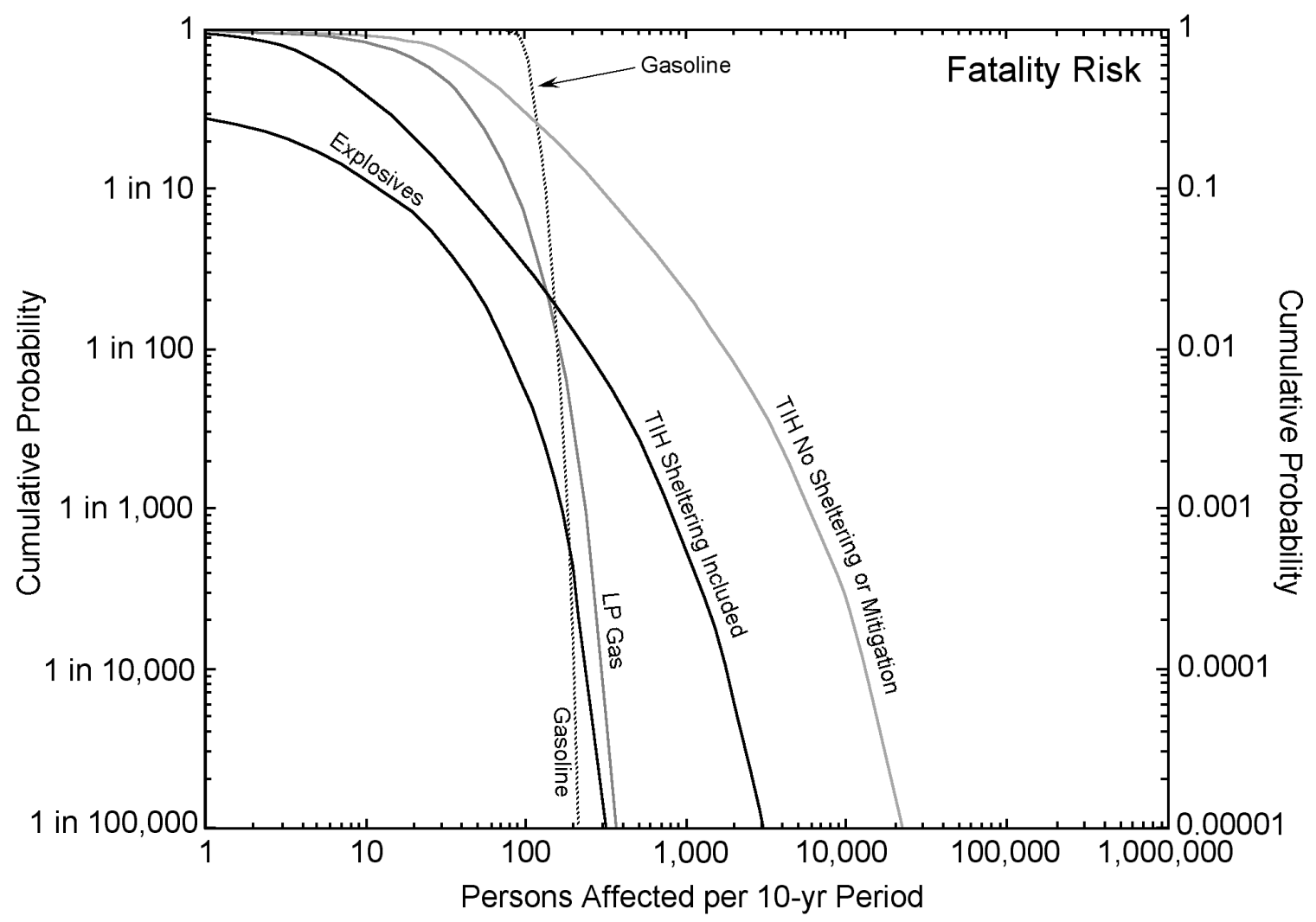

Figure 5.18 Comparison of Fatality Probability Resulting from Transportation of TIH Materials, LP Gas, Gasoline, and Explosives over a 10-yr Period (For TIH materials, injuries are taken as ERPG-2 exposures. TIH results are shown both for the baseline case, which does not include measures such as sheltering or evacuation, and as adjusted for the effects of passive sheltering.)

At the other end of the spectrum lies the risk associated with flammable liquids, exemplified in our analysis by gasoline. Fatality and injury distributions for gasoline are marked by an extremely sharp reduction in consequence probability over a small range of injuries and fatalities, indicating little variation in injuries and fatalities from one 10-yr period to the next. This character results directly from the high-probability/ low-consequence nature of flammable liquid risk. The risk is almost entirely driven by incidents that occur frequently, and the influence of worst-case-type accidents is very small in comparison to the high-probability/low-consequence accidents.

In the intermediate range between the low-probability/high-consequence $\mathrm{TIH}$ risk and the high-probability/low-consequence flammable liquid risk is risk associated with liquefied flammable gases and explosives. The consequence distributions of LP gas and explosives are qualitatively similar to each other, except that the number of injuries and fatalities due to explosives transportation are much lower due to the rarity of explosivesrelated transportation incidents. 
As previously noted, a quantitative assessment of the character of these distributions can be made in comparing average and median values for the consequence distributions. Median and average injuries and fatalities for TIH materials, LP gas, gasoline, and explosives together with their ratios are listed in Table 5.34. For all TIH materials taken together, the ratio of average-to-median numbers of persons affected is around 3:1 for fatalities and 2:1 for injuries. However, for individual TIH materials, this ratio is considerably higher as exemplified by the results for chlorine shown in Table 5.35 (3.9 and 8.8 for injuries and fatalities, respectively). For gasoline transportation, however, ratios of average-to-median fatalities and injuries are very close to 1 , indicating a distribution with little or no skewness. The probability that the number of gasolinerelated fatalities or injuries during any 10 -yr period will be substantially different from the long-term average (say $50 \%$ above or below) is very small barring changes in commodity flow or regulations. For LP gas, the ratio of average-to-median fatalities and injuries is about 1.3. For explosives, this ratio cannot be calculated for a 10 -yr period because most 10-yr periods have no explosives-related injuries or fatalities.

Table 5.34 Median and Average Injuries and Fatalities Resulting from Transportation of TIH Materials, LP Gas, Gasoline, and Explosives over a 10-yr Perioda

\begin{tabular}{|c|c|c|c|c|c|c|}
\hline \multirow[b]{2}{*}{ Material } & \multicolumn{3}{|c|}{ Injuries } & \multicolumn{3}{|c|}{ Fatalities } \\
\hline & $\begin{array}{l}\text { Median in } \\
10 \mathrm{yr}\end{array}$ & $\begin{array}{l}\text { Avg. in } \\
10 \mathrm{yr}\end{array}$ & Ratio & $\begin{array}{c}\text { Median in } \\
10 \mathrm{yr}\end{array}$ & $\begin{array}{l}\text { Avg. in } \\
10 \mathrm{yr}\end{array}$ & Ratio \\
\hline Chlorine & 125 & 488 & 3.9 & 1.6 & 14 & 8.8 \\
\hline All TIH materials & 475 & 846 & 1.8 & 9.0 & 23 & 2.6 \\
\hline LP gas & 118 & 154 & 1.30 & 33 & 42 & 1.27 \\
\hline Gasoline & 197 & 205 & 1.04 & 106 & 108 & 1.02 \\
\hline Explosives & 0 & 14 & $-b$ & 0 & 4.9 & - \\
\hline
\end{tabular}

a An individual TIH material, chlorine, is also provided for comparison. TIH injuries are taken as ERPG-2 exposures. Effects of sheltering are included for chlorine and TIH values.

b A hyphen denotes not applicable.

Table 5.35 Total Annual Risk and Normalized Risk Resulting from Transportation of TIH Materials (highway and rail), LP Gas (highway), Gasoline (highway), and Explosives (highway) ${ }^{a}$

\begin{tabular}{|c|c|c|c|c|}
\hline \multirow[b]{2}{*}{ Material } & \multicolumn{2}{|c|}{ Total Annual Risk } & \multicolumn{2}{|c|}{ Normalized Risk } \\
\hline & $\begin{array}{c}\text { Injuries } \\
\text { per yr }\end{array}$ & $\begin{array}{c}\text { Fatalities } \\
\text { per yr }\end{array}$ & $\begin{array}{l}\text { Injuries per } \\
10^{6} \text { ton-miles }\end{array}$ & $\begin{array}{l}\text { Fatalities per } \\
10^{6} \text { ton-miles }\end{array}$ \\
\hline All TIH materials & 85 & 2.3 & 0.011 & 0.00030 \\
\hline LP gas & 15 & 4.2 & 0.010 & 0.0028 \\
\hline Gasoline & 21 & 11 & 0.0012 & 0.00064 \\
\hline Explosives & 1.4 & 0.49 & 0.0018 & 0.00061 \\
\hline
\end{tabular}

a Effects of sheltering are included for $\mathrm{TIH}$ results. 


\subsubsection{Comparison of Total Annual and Normalized Injury and Fatality Risk}

Table 5.35 provides the annual injuries and fatalities for TIH materials, LP gas, gasoline, and explosives as estimated in the NTRA. For injuries, the transportation risk associated with TIH materials dominates the respective risk of both LP gas transportation and gasoline transportation. TIH-related injuries are a factor of 6 and 4 greater than LP gas and gasoline injuries, respectively. For fatalities, however, gasoline dominates both LP gas and TIH materials. Interestingly, the fatality risk from TIH materials is the lowest of all classes of materials except explosives by a considerable margin. Due to the low commodity flow of explosives, injures and fatalities associated with explosives transportation are very low compared to injures and fatalities associated with transportation of TIH materials, LP gas, and gasoline.

The normalized risk associated with TIH materials, LP gas, gasoline and explosives is also presented in Table 5.35. Recall that the normalized risk is measured in terms of consequences (injuries or fatalities) per million ton-miles and, therefore, is independent of total commodity flow for a particular material or class of materials. Considering injuries, gasoline transportation exhibits the lowest normalized risk with $\mathrm{TIH}$ transportation and highway LP gas transportation exhibiting considerably greater risk. For fatalities, the highest normalized risk by a large margin is associated with highway LP gas transportation. Gasoline and explosives transportation are second and third with a normalized fatality risk about a factor of 4 below LP gas. TIH materials present the lowest normalized fatality risk, that is, a factor of $\sim 2$ below gasoline and explosives, and a factor of $>10$ below LP gas. 


\section{Section 6 Summary and Conclusions}

The NTRA methodology developed and applied in this study quantifies risk due to the national transportation of select hazardous materials and reveals the nature of that risk. Although the quantitative results contain substantial uncertainties because of the imprecision in the commodity flow data and consequence modeling (e.g., effects of sheltering for TIH materials), relative comparisons of risk between materials, packagings, and transportation modes and operations can highlight areas of increased hazardous materials transportation risk. In addition, the quantitative results are very valuable in addressing what types of incidents lead to the greatest risk and also in comparing hazardous materials transportation risk to other risks encountered by the public. This study supports the premise that the overall societal risk due to hazardous materials transportation is low, especially in comparison with other types of transportation risks encountered by the public. However, the potential exists for very serious accidents with many injuries and fatalities, especially for TIH materials, although the probability of such events is very low. In addition, this study has shown areas of higher risk relative to other hazardous materials transportation risks. Identification of these areas can form the basis for more detailed studies to better characterize and determine acceptable levels of risk.

In the discussions that follow, averages on a per-year or per-10-year basis are said to measure total risk. Total risk can be used to relate the risk of hazardous materials transportation with other transportation- or nontransportation-related risks encountered by the public. Averages on a per-ton-mile basis are referred to as normalized risk. Normalized risk is essential for comparing and contrasting the relative risk associated with different chemicals or transportation modes, such as chlorine versus ammonia, highway versus rail, or package freight versus bulk freight. The key difference between these risk measures is that total risk varies with commodity flow and averaging time (per year, per 10 years), whereas normalized risk does not. Section 5.1.3 provides a more detailed discussion of risk measures.

In this section, we summarize the important conclusions of the NTRA study. In Section 6.1, we discuss the HMIS database. In Section 6.2, we discuss the important conclusions regarding TIH materials, and in Section 6.3, we discuss the important conclusions regarding flammable materials and explosives. Finally, in Section 6.4, we compare transportation risks associated with TIH materials, flammable materials, and explosives with each other and with other transportation-related injury and fatality risks.

\subsection{The HMIS Database}

Although the HMIS database appears to suffer from certain problems that are documented in the literature and discussed in this report, we found that the database contains a great deal of valuable information with which to quantify the risk associated 
with hazardous materials transportation. DOT has taken significant steps in the past 15 years to correct major deficiencies that existed for the system in the 1970s and 1980s. In addition, the HMIS database in risk assessment studies has become more useful in recent years because of the inclusion of additional data fields and the increasing quality of individual records. A remaining problem with the HMIS database is that it appears to suffer from under-reporting, in part because it did not include data from intrastate shippers until 1998. However, descriptive data obtained from the database concerning such items as fatality and injury rates, discharge fraction distributions, temporal incident distributions, and accident descriptions are valuable for risk assessment activities and are largely unaffected by under-reporting. Recent and future improvements in the database, such as the inclusion of data from intrastate shippers, will increase the usefulness of the HMIS.

The HMIS database could be improved in the following ways:

- Catalog the amount of material actually shipped. Currently, this information must be inferred from the container capacity and the number of containers.

- Reduce instances where the release amount is listed as zero even though a release obviously occurred. For example, numerous records concerning liquefied gas railcar incidents list a zero release amount even though descriptions in the remarks section of the record indicate otherwise. Some of these incidents involved minor injuries to personnel, and at least one was a major incident that resulted in a large-scale evacuation and injuries to the general public.

- Provide better guidance for separating major and minor injuries, including off-site injuries and fatalities.

- Include information on crack or hole size where applicable. For railcars, RPI and AAR collect information on container failure, including hole size and geometry. However, information on hole size and geometry does not currently exist for bulk highway containers.

- Include release duration where applicable. For some types of releases, such as leaky drums and other package freight, release duration may not be definable. However, for other release types, especially those from bulk containers, on-site personnel can easily determine release duration, which can then be included in the HMIS database.

- Include photographic data for major incidents in digitized format in a companion database keyed by incident number. Photographs detailing container damage and any release-related environmental and property damage would be especially beneficial to future investigators. 


\subsection{Toxic-by-Inhalation Materials}

\subsubsection{Risk by Chemical}

Figure 6.1 shows the distribution of total TIH transportation risk among the six TIH chemicals analyzed in this study. These six chemicals are ammonia, chlorine, $\mathrm{SO}_{2}$, hydrogen fluoride, fuming nitric acid, and fuming sulfuric acid. Clearly, chlorine and ammonia dominate the total TIH transportation risk. Chlorine accounts for 58\% and 59\% of total TIH injury and fatality risk, and ammonia accounts for $15 \%$ and $26 \%$ of total injury and fatality risk, respectively. The fact that chlorine and ammonia dominate the TIH transportation risk profile is not surprising because our commodity flow analysis indicates that chlorine and ammonia together account for $70 \%$ and $84 \%$ of the total $\mathrm{TIH}$ commodity flow for highway and rail, respectively. Our analysis of HMIS incident statistics and commodity flow data lead us to conclude that the six TIH chemicals considered in the NTRA account for at least $90 \%$ of the total TIH risk. Accordingly, we attribute $10 \%$ of total $\mathrm{TIH}$ transportation risk to other $\mathrm{TIH}$ materials.

The distribution of TIH risk with respect to chemicals shown in Figure 6.1 clearly demonstrates that liquefied gases (chlorine, ammonia, $\mathrm{SO}_{2}$, and $\mathrm{HF}$ ), not liquids (fuming sulfuric acid and fuming nitric acid), are responsible for more than $95 \%$ of the total TIHrelated fatality and injury risk. The contribution of liquefied gases to the total TIH risk for highway transportation is about $90 \%$, whereas the contribution of liquefied gases to $\mathrm{TIH}$ rail transportation risk exceeds $95 \%$. The dominance of liquefied gases in total TIH risk is due to the substantially greater commodity flow associated with liquefied gases (mainly chlorine and ammonia) coupled with the greater volatility of these materials. Greater commodity flows lead to higher numbers of incidents, and greater volatility leads to higher emission rates and thus increased impacts when incidents occur.

\subsubsection{Risk by Transportation Mode and Incident Type}

\subsubsection{Total Risk for Rail and Highway}

Figure 6.2 shows the distribution of total TIH risk for the four categories created by combining transportation mode (highway and rail) and release type (accident-related or en route/nonaccident). Rail transportation clearly accounts for the majority of total TIH risk, comprising $78 \%$ of the total TIH injury risk and $82 \%$ of the total TIH fatality risk. The fact that rail transportation is responsible for most of the total TIH transportation risk is expected because rail commodity flows exceed highway commodity flows by a factor of $\sim 4$. Although accident-related rail releases are infrequent relative to other release types, they alone are responsible for approximately two-thirds of the total TIH transportation risk. On a per-incident basis, accident-related rail releases are, on average, more than an order of magnitude more severe than accident-related highway releases, and up to two orders of magnitude more severe than en route/nonaccident highway and rail releases. 


\section{Total Fatality Risk}

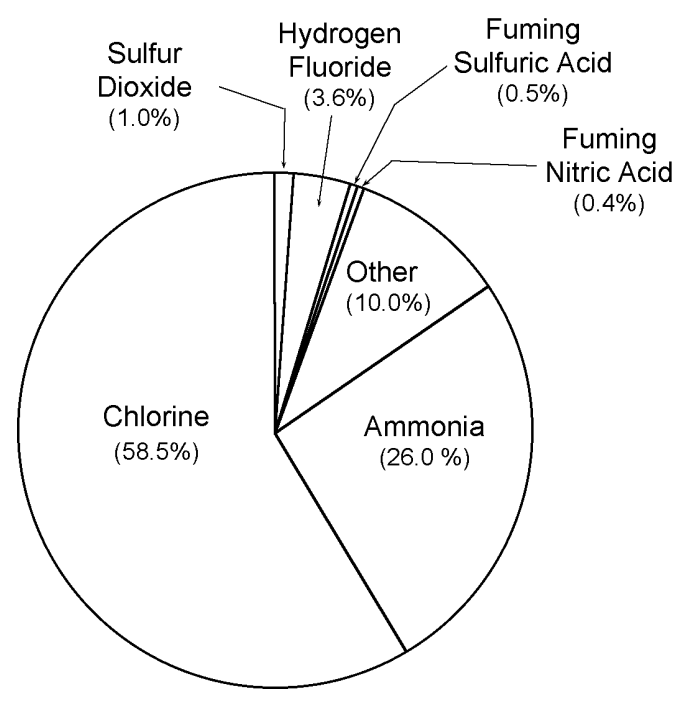

\section{Total Injury Risk}

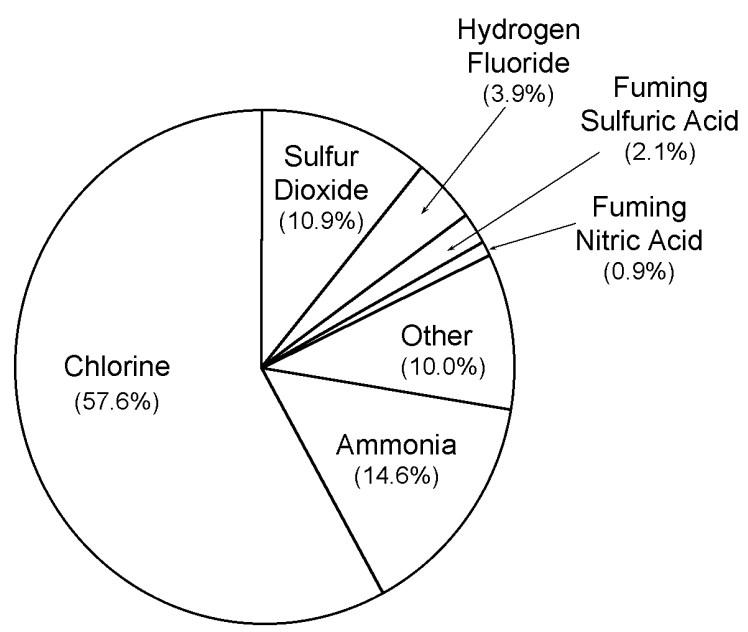

Figure 6.1 Distribution of Total TIH Fatality and Injury Risk by Chemical

Total Fatality Risk

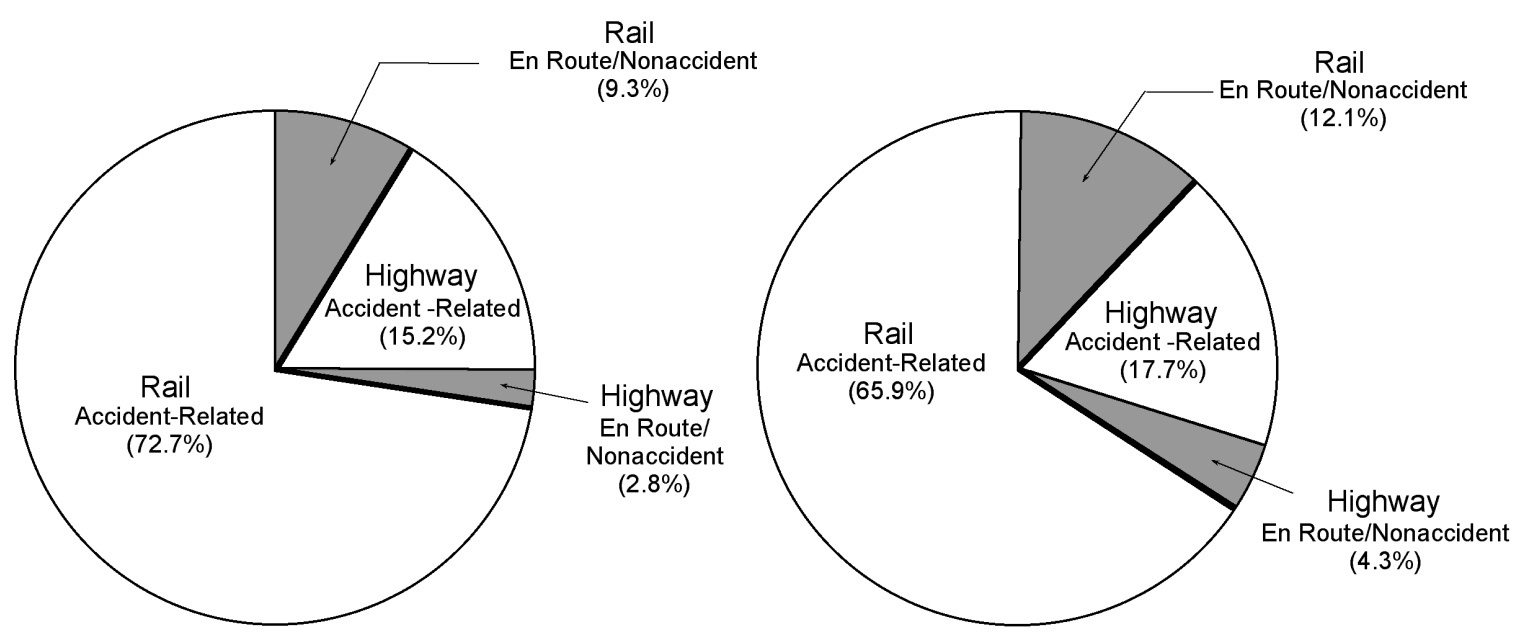

Figure 6.2 Distribution of Total TIH Fatality and Injury Risk by Transportation Mode and Release Type 
En route/nonaccident releases are considerably more common than accident-related releases, especially for rail and package freight shipments. For instance, en route/ nonaccident releases for Class 105 and 112 tank cars outnumber those for derailments by a factor of 40 . However, the consequences of en route/nonaccident releases on a perincident basis are very low relative to accident-related releases. This study suggests that en route/nonaccident releases account for only $20 \%$ and $16 \%$ of the estimated injury risk for highway and rail, respectively, and $16 \%$ and $11 \%$ of the estimated fatality risk for highway and rail, respectively.

\subsubsection{Normalized Risk for Rail and Highway}

On a per-ton-mile basis, or normalized risk, the risk posed by highway transportation is substantially higher than by rail than by highway, as shown in Figure 6.3. However, this risk varies considerably by chemical which, in turn, is due to the relative differences between the bulk containers used to ship the materials by highway and rail, the amount of highway transportation that is package freight, and the different routes used for highway and rail transportation. Our analysis indicates that highway transportation of chlorine, HF, and fuming nitric acid poses more than twice the normalized risk of rail transportation of the same commodities. For HF, the increased highway normalized risk calculated in this study results partly from the fact that we modeled HF transportation in standard MC 312 cargo tanks, which are not as robust as the MC 330 or MC 331 cargo tanks used for liquefied gases or the upgraded MC 312 cargo tanks used for other TIH liquids. Industry practice has generally been to ship HF in containers exceeding design criteria of standard MC 312 containers, and at least one major producer ships HF in tanks substantially exceeding the upgraded MC 312 cargo tanks as specified in the 1990 regulation changes. As a result, the high normalized risk of $\mathrm{HF}$ transportation relative to rail is overstated in Figure 6.3, but because we used the containers specified in the regulations as the baseline in our study, the degree to which the risks are overstated is difficult to gauge. While the increased normalized risk for highway transportation might be partially due to the differences in robustness between highway and rail bulk containers, a large portion of the increased highway risk results from package freight transportation (e.g., drums and cylinders), which makes up a fairly small portion of the total highway commodity flow but is highly susceptible to releases, especially of the en route/nonaccident variety.

\subsubsection{Risk from Package Freight and Bulk Freight}

Figure 6.4 provides charts that illustrate the distribution of total risk between package freight and bulk freight. For highway transportation, the total risk posed by package freight is less than that posed by bulk freight for all TIH materials considered in the analysis. For all TIH materials combined, about one-third of the total highway fatality and injury risk is due to package freight transportation. However, as shown in Figure 6.5, the normalized risk for package freight is substantially higher than it is for bulk freight for most materials. A considerable fraction of this increased risk for package freight results from en route/nonaccident releases, which are very common for package freight relative to bulk freight, especially for materials shipped in drums. The NTRA 


\section{Normalized Risk}

Highway and Rail
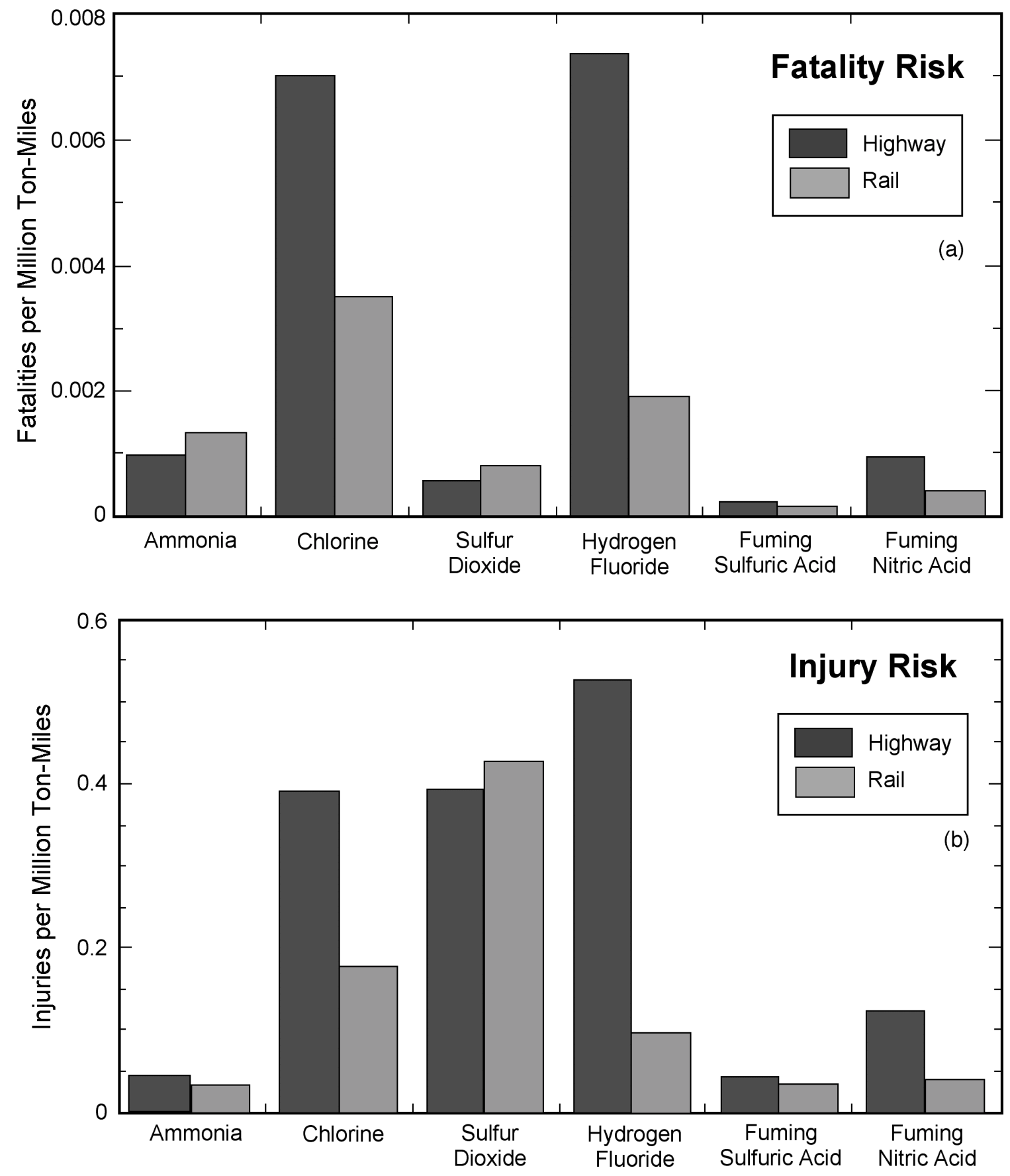

Figure 6.3 Normalized Risk of (a) Fatalities and (b) Injuries per Million Ton-Miles Associated with Highway and Rail Transportation for the Six NTRA TIH Chemicals (Mitigative measures such as sheltering or evacuation are not included in these results.) 


\section{Total Risk}

Bulk Freight (Highway Only)

Package Freight

Ammonia

Chlorine

Sulfur Dioxide

Hydrogen Fluoride

Fuming Sulfuric Acid

Fuming Nitric Acid

\section{All TIH Chemicals}

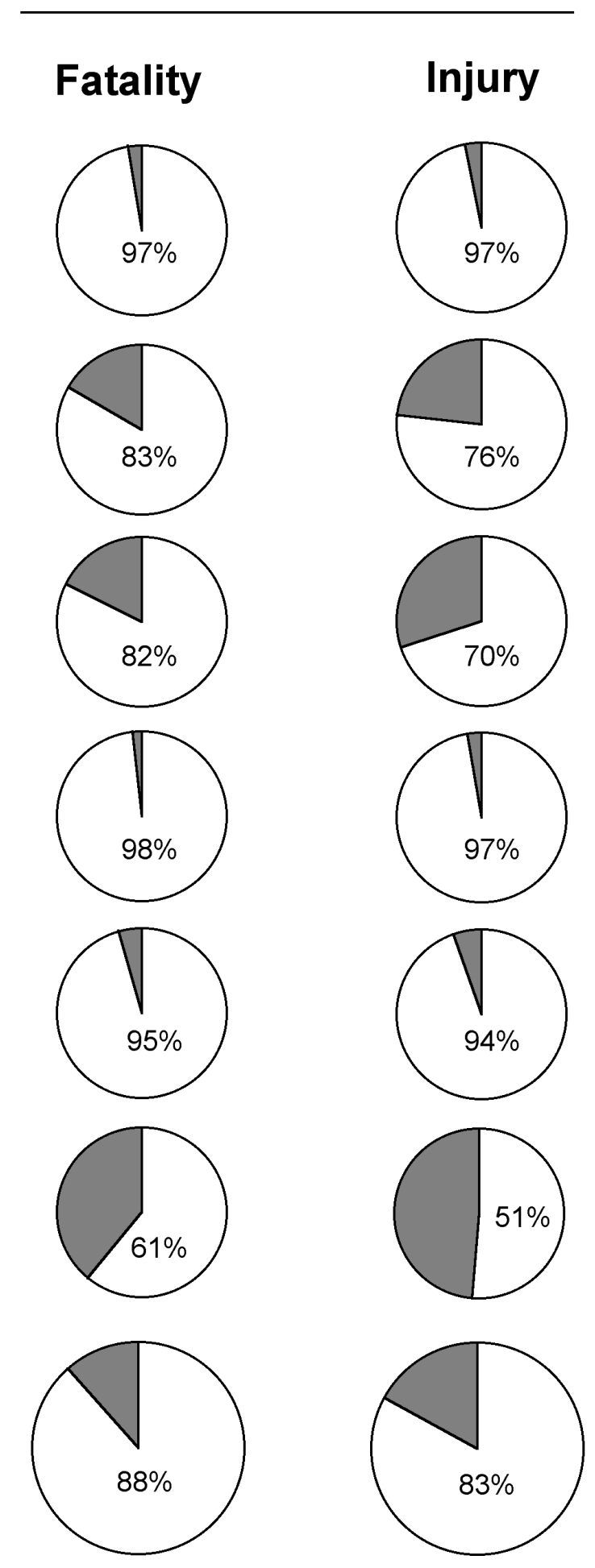

Injury

Figure 6.4 Distribution of Total TIH Fatality and Injury Risk between Bulk Freight and Package Freight for Highway Transportation for the Six NTRA TIH Chemicals 
Normalized Risk

Bulk Freight and Package Freight
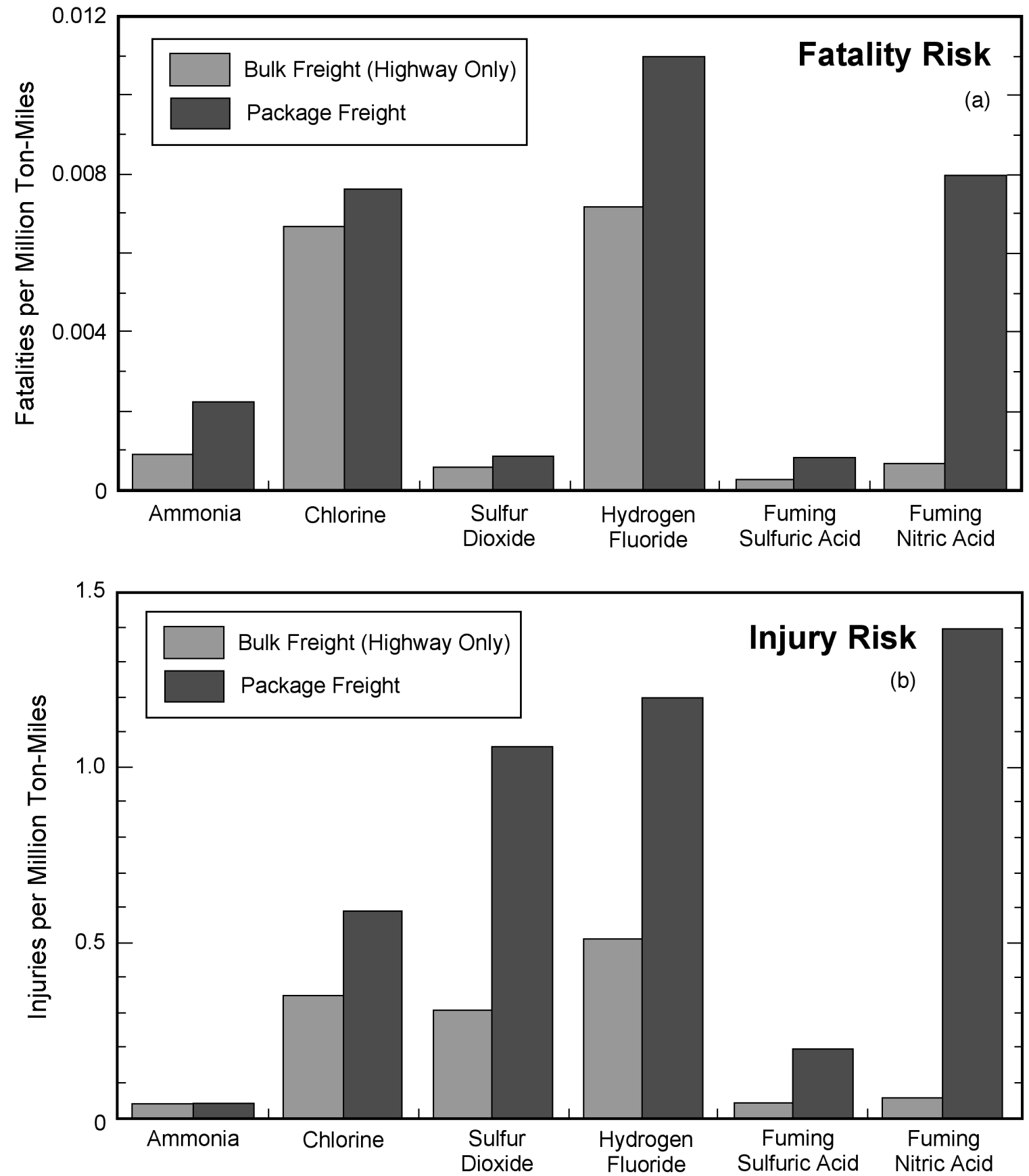

Figure 6.5 Normalized Risk of (a) Fatalities and (b) Injuries per Million Ton-Miles Associated with Bulk and Package Freight Highway Transportation for the Six NTRA TIH Chemicals (Mitigative measures such as sheltering or evacuation are not included in these results.) 
results are certainly less precise for package freight because of the lack of detailed shipment and commodity flow data. Nevertheless, the results of the study strongly suggest that normalized risk for package freight exceeds that for bulk freight for most of the TIH materials considered.

\subsubsection{Nature of TIH Transportation Risk}

Toxic-by-inhalation risk is largely driven by relatively unlikely events that have high consequences. We refer to this type of risk as high-consequence/low-probability risk. For individual chemicals for which few incidents occur in a given period (10 years for this study), the high-consequence/low-probability nature of transportation-related $\mathrm{TIH}$ incidents creates highly skewed consequence distributions where most 10-yr periods show no injuries and fatalities, and a very small percentage of 10 -yr periods indicate high numbers of injuries and fatalities due to a single major incident. As a result, the longterm average number of injuries and fatalities in any 10 -yr period is typically several times the median (the $50^{\text {th }}$ percentile value) for individual TIH chemicals.

The normalized risk varies by approximately an order of magnitude between individual routes for each material considered. This variation is primarily due to population density variations between the routes, and secondarily to climatological effects on temperature, wind speed, and atmospheric stability. In considering all shipments for individual TIH chemicals, the percentage of the risk resulting from transportation in urban areas (population densities greater than 3,300 person/mi ${ }^{2}$ ) is between one-third and two-thirds of total risk, depending on chemical and transportation mode. In general, rail risk is less concentrated in urban areas, and highway risk is more concentrated in urban areas. This relative difference between highway and rail results from the fact that accident rates for highway transportation are higher in urban areas, whereas the rail accident rates utilized in this study do not depend on population density. Less than $15 \%$ of the risk results from transportation in rural areas (population densities less than 350 person $/ \mathrm{mi}^{2}$ ). These general observations concerning urban and rural risk also extend to flammable materials and explosive materials.

\subsubsection{Effects of Sheltering}

Sheltering is often an effective means for protecting the public from TIH chemical exposure. The protection afforded by sheltering depends most strongly on the building ventilation rate and secondarily on the release duration and meteorology. Sheltering provides the greatest protection for short-duration liquefied gas releases and large releases that occur during the night. During such incidents, sheltering the population in relatively airtight buildings can reduce the number of people exposed to dangerous airborne chemical concentrations by more than two orders of magnitude over the potential that could be exposed if no sheltering occurs (i.e., everybody is outside). Considering the distribution of risk with respect to daytime and nighttime releases, liquefied gas and liquid releases, as well as population distributions within residential and commercial buildings, we estimate that the fact that many people are usually indoors reduces potential injuries and fatalities by approximately factors of 10 and 7 , 
respectively, over baseline estimates, which assume that everyone is exposed to outdoor concentrations. Well-planned emergency management procedures can potentially reduce TIH-related transportation risk further by advising all persons in the path of the plume to remain indoors, shut off building ventilation systems, and take steps to reduce infiltration into the building.

\subsubsection{Effects of the 1990 Regulatory Changes for TIH Liquids}

The regulatory changes in 1990 concerning transportation of TIH liquids in MC 312 cargo tanks and tank cars have the potential to dramatically reduce injury and fatality risk associated with the transportation of these materials. For highway transportation, the upgraded MC 312 cargo tank (0.25-in. stainless steel with an insulating jacket for fuming sulfuric acid) is projected to have an accident failure rate of less than half that of the regular MC 312 cargo tank (0.25-in. regular steel with no insulating jacket). Consequently, the reduction of risk for TIH liquid transportation as measured in this study is greater than $50 \%$. For rail, Class $111 \mathrm{~A}$ tank cars are no longer authorized for TIH liquids. Again, this change will result in a considerable reduction in the probability of derailment-related releases. Our analysis of historical release and commodity flow data show that Class 111A tank cars without insulation experience about 1 derailmentrelated release for every 7 million tank-car-miles, whereas Class 112 cars experience 1 derailment-related release for every 30 million tank-car-miles. Therefore, shipping in Class 112 tank cars rather than Class 111A tank cars translates to approximately a 75\% reduction in transportation risk for the shipment of TIH liquids by rail.

Hydrogen fluoride meets the criteria of a TIH material; however, standard MC 312 cargo tanks are authorized for the transportation of HF because it is classified as a corrosive (similar to regular sulfuric acid). Although industry practice has been to ship $\mathrm{HF}$ in containers exceeding design criteria of standard MC 312 containers, codifying the upgraded MC 312 cargo tank within the regulations will further reduce the potential for HF releases in bulk highway transportation.

\subsection{Flammable and Explosive Materials}

\subsubsection{Risk for Highway Transportation of Flammable Materials}

Historical evidence for the past two decades shows that the greatest transportation-related risk from flammable materials involves accident-related highway releases. This behavior can be traced to two significant causes. First, highway transportation is responsible for many more releases, especially for flammable liquids. Second, more persons are injured and killed on a per-incident basis because other vehicles are involved and ignition sources are nearby.

Because of its very high commodity flow, the total risk of fatalities and injuries resulting from gasoline transportation exceeds that of LP gas and all other flammable materials by a very large margin (Figure 6.6). Our analysis of the HMIS database indicates that gasoline transportation is responsible for an average of 11 fatalities and 

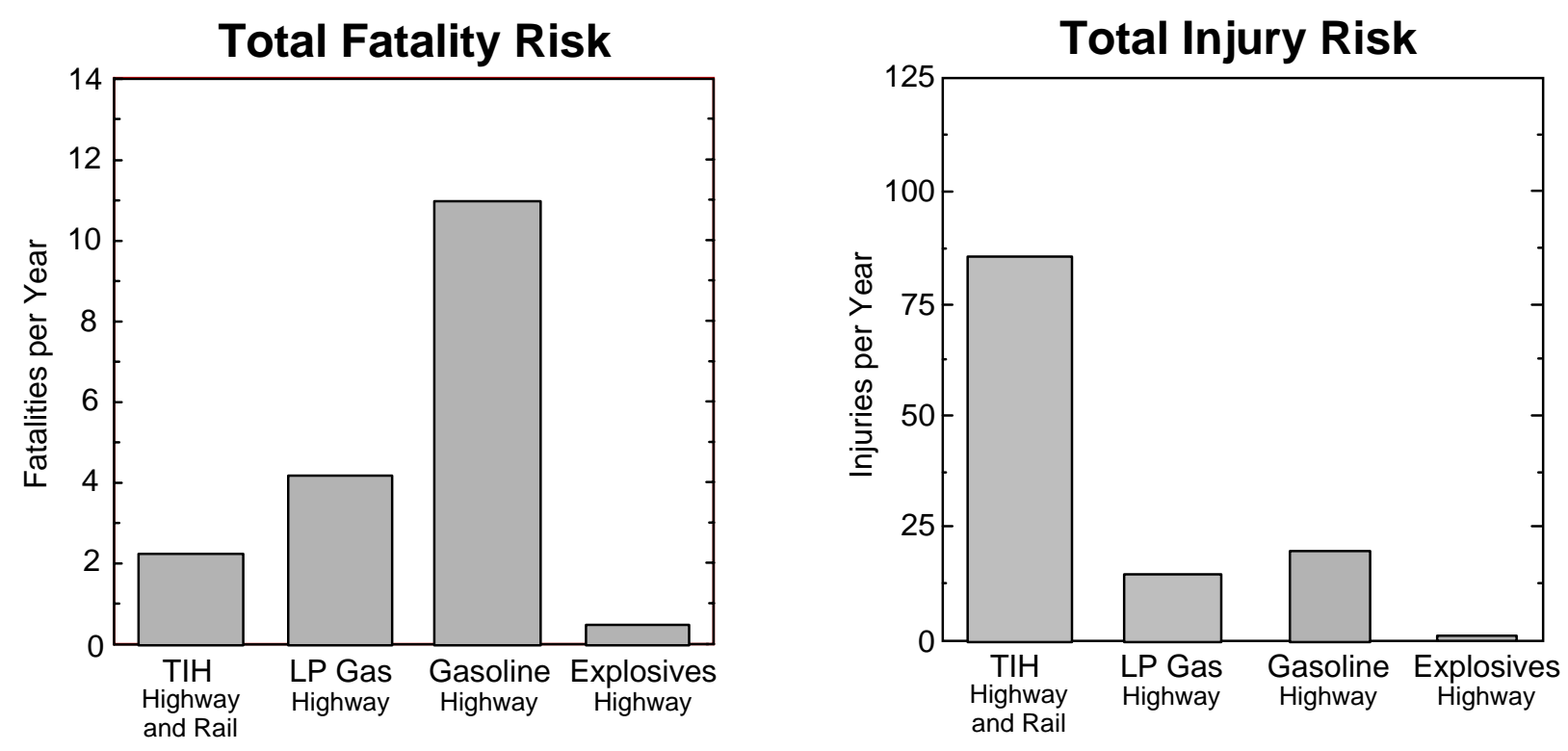

Figure 6.6 Annual Fatalities and Injuries as Estimated in the NTRA (Average results for TIH materials include exposure reductions due to sheltering.)

21 injuries per year. Our risk assessment results for LP gas transportation show that highway transportation of this material is responsible for about 4 fatalities and about 15 injuries per year on average. The LP gas transportation fatality and injury rates inferred from the HMIS database are about $40 \%$ of these values. However, considering the under-reporting within the HMIS database and the fact that some of the risk involves high-consequence/low-probability events not reflected in the 11-yr record of the HMIS database considered in this study (Section 6.3.3), these fatality and injury rates appear to be fairly consistent with the historical data.

Although gasoline has the highest total risk of all flammable materials, the normalized risk associated with LP gas is much higher. The normalized risk from LP gas transportation is a factor of 8 greater for injuries and a factor of 4 greater for fatalities than the normalized risk for gasoline transportation. This fact strongly suggests that liquefied flammable gases pose a much greater risk than flammable liquids on a pershipment basis.

\subsubsection{Risk for Highway Transportation of Explosive Materials}

Our analysis of HMIS database records from 1985 to 1995 showed that explosives were responsible for only one fatality, one injury, and less than $1 \%$ of all persons evacuated. Our risk assessment results for explosives support these observations, although the long-term average fatalities and injuries as calculated in the NTRA analysis are higher than those observed in the 11-yr record of the HMIS database. This difference is due to the longer sample time of the NTRA analysis, which accounts for highconsequence/low-probability explosives events. Both the historical record and the NTRA 
analysis demonstrate that, on a national scale, the total risk due to transportation of explosives is very low compared with the total risk due to TIH materials and flammable materials (see Figure 6.6).

Although the total risk due to explosives transportation is very low, the normalized risk for explosives transportation is significant (Figure 6.7). However, on a shipment-byshipment basis, the transportation risks of explosives and gasoline are significantly less than those of LP gas. The very low commodity flows for explosives leads to very few incidents and thus a very low total risk, as discussed previously.

\subsubsection{Nature of Transportation Risk for Flammables and Explosives}

Recall that TIH risk is driven by relatively unlikely events with high consequences. The risk of gasoline is just the opposite; namely, gasoline transportation risk is driven by frequent events that have low consequences. We refer to this type of risk as lowconsequence/high-probability. For gasoline, there will be 50 to 100 incidents involving fatalities in any 10 -yr period. Most of these incidents will involve only a few injuries or fatalities, and the maximum number of fatalities occurring in any one incident is very low compared with TIH consequence potentials. As a result, the probability that the number of fatalities or injuries during any 10 -yr period will be substantially different from the long term is small. This is also reflected in the fact that the long-term averages
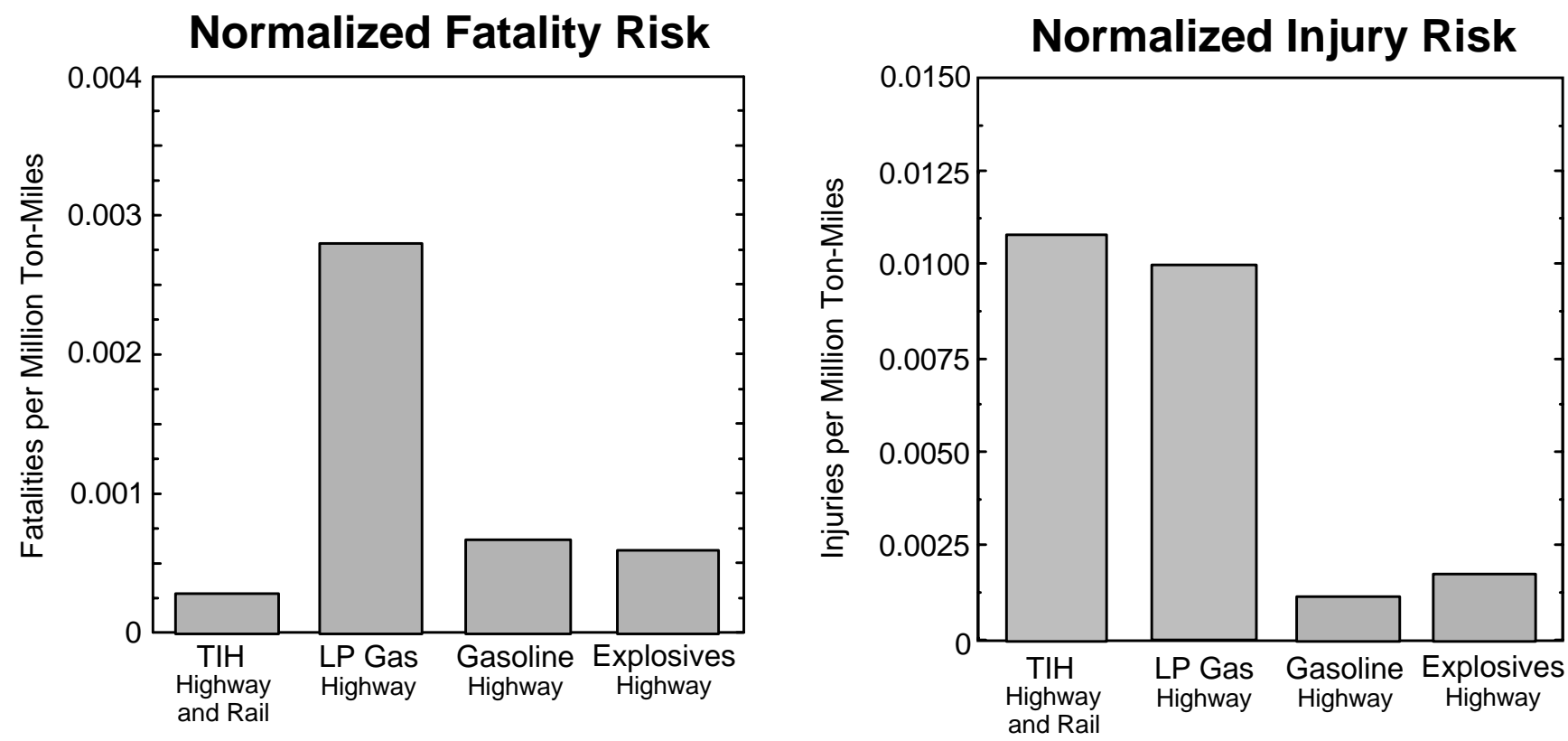

Figure 6.7 Fatalities and Injuries Normalized by Commodity Flow as Estimated in the NTRA (Results for TIH materials include exposure reductions due to sheltering.) 
for injuries or fatalities resulting from highway gasoline transportation differ from the corresponding medians by only a few percent.

The nature of risk for LP gas transportation, on the other hand, lies between that of gasoline and TIH materials. While about $50 \%$ of the risk results from low-consequence/high-probability events, infrequent, high-consequence events account for a substantial portion of the risk. For example, more than $30 \%$ of the total fatality risk results from incidents that involve more than 25 fatalities, and $5 \%$ of fatality risk results from incidents that involve more than 100 fatalities. However, the annual probability of an incident involving more than 25 and 100 fatalities is about $3 \%$ and $0.16 \%$, respectively (i.e., 1 incident every $30 \mathrm{yr}$ and 1 incident every $600 \mathrm{yr}$ ).

The nature of risk for explosives is very similar to that of LP gas in terms of consequence probability per incident. Because of the low commodity flow for explosives, however, incidents that involve explosives are rare. In any 10-yr period, the probability of having any explosives-related injuries or fatalities is only about $30 \%$. That is, one would not expect to see any explosives-related injuries or fatalities in any given 10 -yr period. Like LP gas, high-consequence/low-probability events account for a substantial portion of the risk, although not as much as for TIH materials. For example, slightly less than $50 \%$ of the fatality risk is due to incidents with 25 fatalities. However, the annual probability of such an event is less than $0.5 \%$ as estimated in this study.

\subsection{Comparisons of Risks}

\subsubsection{TIH Materials, Flammable Materials, and Explosives}

Figure 6.6 compares the total transportation risk for injuries and fatalities associated with TIH materials, LP gas, gasoline, and explosives. In terms of injuries, total transportation risk for TIH materials is considerably greater than for highway transportation of LP gas, gasoline, and explosives. Accounting for reductions due to sheltering, the long-term average injury rate for TIH transportation is 85 injuries per year. Corresponding injuries rates for gasoline and LP gas are 21 and 15 injuries per year, respectively. However, TIH materials have the lowest total fatality risk in comparison to gasoline and LP gas. The long-term average fatality rate resulting from $\mathrm{TIH}$ transportation is about 2.3 fatalities per year. Corresponding fatality rates resulting from LP gas and gasoline transportation are 4.2 and 11 fatalities per year, respectively. Because of the low commodity flow of explosives, injuries and fatalities associated with explosives transportation are lower than those due to TIH materials, LP gas, and gasoline transportation by a large margin.

Figure 6.7 compares the normalized transportation risk for injuries and fatalities associated with TIH materials, LP gas, gasoline, and explosives. The normalized injury risk for TIH transportation slightly exceeds that of LP gas and greatly exceeds that of gasoline and explosives. Accounting for reductions due to sheltering, the normalized injury rate for TIH transportation is 0.011 injuries per million ton-miles. Corresponding injury rates for LP gas, gasoline, and explosives are 0.010, 0.0012, and 0.0018 injuries 
per million ton-miles, respectively. Highway transportation of LP gas has the highest normalized fatality risk in comparison to TIH materials, gasoline, and explosives. On the other hand, TIH materials have the lowest normalized fatality risk of all the materials considered. The normalized transportation-related fatality rates resulting from transportation of TIH materials, LP gas, gasoline, and explosives are 0.00030, 0.0028, 0.00064 , and 0.00061 fatalities per million ton-miles, respectively.

\subsubsection{Comparison with Other Transportation-Related Risks}

Probably the most important conclusion from the results in this report is that the risks of hazardous materials transportation are low compared to other transportation-related risks. Table 6.1 shows a comparison of risks associated with the materials considered in this study against the total injuries and fatalities associated with motor vehicle accidents, large-truck accidents, and rail accidents (grade and nongrade crossing accidents). For example, persons are more than 18,000 times more likely to be injured and 2,300 times more likely to be killed by a motor vehicle accident than they are to be injured or killed due to transportation of the hazardous materials considered in this study. Of course, these comparisons do not reflect the fact that some of the risks listed in Table 6.1 are voluntary, whereas risks due to hazardous materials transportation are largely involuntary. For instance, people can choose not to drive, thereby greatly reducing their risks due to motor vehicle accidents. Although this precaution will shield them from some risks due to hazardous materials transportation, it certainly will not shield them from all those risks, especially $\mathrm{TIH}$ transportation risks.

A particularly interesting perspective on hazardous materials transportation risk is evident by looking at the injuries and fatalities from large-truck accidents (more than $10,000 \mathrm{lb}$ gross vehicle weight). Harwood and Russell (1989) estimated that $5 \%$ of all of truck accidents reported to the FHWA involved trucks carrying hazardous materials. By applying this percentage to the fatality and injury statistics for all large trucks, we can estimate the fatality and injury risks due to accidents involving trucks carrying hazardous materials as shown in Table 6.1. On the basis of this analysis, a person is 120 times more likely to be injured and 16 times more likely to be killed due to physical trauma in an accident involving a large truck carrying hazardous materials than due to the effects of the actual release of hazardous materials transported in that truck (as considered in this report). For rail, the probabilities of fatality and injury due to TIH releases (the only class of rail hazardous materials transportation considered in this study) are even lower relative to other varieties of risk from rail transportation. 
Table 6.1 Comparisons of Risks Calculated in This Study with Other Transportation-Related Risks in the United States

\begin{tabular}{|c|c|c|c|c|}
\hline \multirow[b]{2}{*}{ Risk Type } & \multicolumn{2}{|c|}{ 10-yr Period } & \multicolumn{2}{|c|}{ Annual } \\
\hline & Fatalities & Injuries & Fatalities & Injuries \\
\hline \multicolumn{5}{|l|}{ Risks primarily due to trauma } \\
\hline Motor vehicles, including large trucks ${ }^{a}$ & 416,160 & $22,500,000$ & 41,616 & $2,250,000$ \\
\hline Large trucks ${ }^{b}$ & 50,877 & $1,327,000$ & 5087 & 132,700 \\
\hline Large trucks carrying HAZMATC & 2,500 & 66,000 & 250 & 6,600 \\
\hline Rail accidents (grade crossing) ${ }^{d}$ & 5,439 & 16,905 & 544 & 1,691 \\
\hline Rail accidents (nongrade crossing) ${ }^{d}$ & 5,860 & 163,377 & 586 & 16,338 \\
\hline \multicolumn{5}{|l|}{ Risks due to hazardous materials releases only } \\
\hline Gasoline transportation ${ }^{\mathrm{e}}$ & 108 & 205 & 11 & 21 \\
\hline Highway LP gas transportation ${ }^{f}$ & 42 & 154 & 4.2 & 15 \\
\hline Explosives transportation ${ }^{f}$ & 4.9 & 14 & 0.49 & 1.4 \\
\hline TIH highway accidents ${ }^{f}$ & 3.8 & 149 & 0.38 & 15 \\
\hline TIH highway en route/nonaccidents ${ }^{f}$ & 0.70 & 36 & 0.07 & 3.6 \\
\hline TIH rail derailments ${ }^{f}$ & 16 & 559 & 1.6 & 56 \\
\hline TIH rail en route/nonaccidents ${ }^{\dagger}$ & 2.0 & 103 & 0.20 & 10 \\
\hline Total TIH materials transportation ${ }^{f}$ & 23 & 846 & 2.3 & 85 \\
\hline Total highway risk for HAZMAT releases ${ }^{g}$ & 160 & 558 & 16 & 56 \\
\hline Total rail risk for TIH material releases & 18 & 662 & 1.8 & 66 \\
\hline Total risk for HAZMAT releases considered in study 9 & 178 & 1,219 & 18 & 122 \\
\hline
\end{tabular}

a 1994-1998 from Injury Facts, 1996-1999, National Safety Council.

b 1989-1998, Federal Motor Carrier Safety Administration, MCSAFE Newsletter, May 2000.

c Taken as $5 \%$ of all large truck injuries and fatalities following Harwood and Russell (1989).

d 1989-1998 from Injury Facts, 1999, National Safety Council.

e Estimated from HMIS by means of statistical analysis developed in Section 2. A factor of 1.5 was applied to estimate total intrastate plus interstate fatalities and injuries and to account for under-reporting.

$f$ As calculated in the risk assessment phase of this study.

g TIH materials, gasoline, LP gas, and explosives. 
$\Delta$ 


\section{Section 7 References}

AICHE, 1995, Guidelines for Chemical Transportation Risk Analysis, American Institute of Chemical Engineers, Center for Chemical Process Safety, New York, N.Y.

AICHE, 1994, Guidelines for Evaluating the Characteristics of Vapor Cloud Explosions, Flash Fires and BLEVES, American Institute of Chemical Engineers, Center for Chemical Process Safety, New York, N.Y.

AIHA, 1999, The AIHA 1999 Emergency Response Planning Guidelines and Workplace Environmental Exposure Level Guidelines Handbook, American Industrial Hygiene Association, Fairfax, Va.

Amah-Tagoe, F., 1998, personal communication from Amah-Tagoe (Bureau of Transportation Statistics, Washington, D.C.) to D. Brown (Argonne National Laboratory, Argonne, Ill.).

ASHRAE, 1997, 1997 ASHRAE Handbook: Fundamentals, American Society of Heating, Refrigerating, and Air-Conditioning Engineers, Inc., Atlanta, Ga.

Association of American Railroads, 1996, User Guide for the 1985 Transportation Board Waybill Sample, Policy and Legislation and Economics Department, Washington, D.C.

Baker, W.E., et al., 1983, "Explosion Hazards and Evaluation," in Fundamental Studies in Engineering, p. 5, Elsevier, New York, N.Y.

Barad, M.L. (editor), 1958, Project Prairie Grass: A Field Program in Diffusion, Vols. 1 and 2, part of Geophysical Research Papers No. 59 series; also Report AFCRL-58-235, Air Force Cambridge Research Center, July.

Barkan, C.P.L., et al., 1991, "Benefit-Cost Evaluation Using Different Specification Tank Cars to Reduce the Risk of Transporting Environmentally Sensitive Chemicals," Transportation Research Record, 1313:33-43.

Blackmore, D.R., et al., 1982, "Dispersion and Combustion Behavior of Gas Clouds Resulting from Large Spillages of LNG and LPG onto the Sea," Trans. I. Mar. E., 94:29.

Brown, D.F., et al., 2000, Development of the Table of Initial Isolation and Protective Action Distances for the 2000 Emergency Response Guidebook, ANL/DIS-00-1, Argonne National Laboratory, Argonne, Ill. 
Brown, D.F., and W.E. Dunn, 1998, The Surface Energy Budget Meteorological Model (SEBMET) for Atmospheric Boundary Layer Parameterization, Department of Mechanical and Industrial Engineering, University of Illinois, Urbana, Ill.

Brown, D.F., 1997, "Development of an Improved Meteorological Preprocessor and Atmospheric Dispersion Model," Ph.D. thesis, Department of Mechanical and Industrial Engineering, University of Illinois, Urbana, Ill.

Building Officials and Code Administrators International, Inc., 1993, The BOCA National Mechanical Code/1993, Country Club Hills, Ill.

Calder, K.L., 1949, "Eddy Diffusion and Evaporation in Flow over Aerodynamically Smooth and Rough Surfaces: A Treatment Based on Laboratory Laws of Turbulent Flow with Special Reference to Conditions in the Lower Atmosphere," Quarterly Journal of Mechanical and Applied Math, 92:153-176.

Clarke, R.K., et al., 1976, Severities of Transportation Accidents, SLA-74-0001, Sandia National Laboratories, Albuquerque, N.M.

Croce, P.A, 1982, A Feasibility Study of a Sealed Safety Monitor for Trucks Carrying LNG and Other Hazardous Materials, DOE/EV/10502-1, completed by Arthur D. Little, for U.S. Department of Energy, Office of Operational Safety Programs.

Defense Threat Reduction Agency, 1999, HPAC User's Guide (Ver. 3.2), HPACUGUIDE-01-U-RACO, prepared by SAIC, Alexandria, Va.

Dennis, A.W., et al., 1977, Severities of Transportation Accidents Involving Large Packages, SAND 77-0001, Sandia National Laboratories, Albuquerque, N.M.

DOT et al., 1999, 2000 Emergency Response Guidebook, prepared by U.S. Department of Transportation, Transport Canada, and Secretariat of Transport and Communications of Mexico; J.J. Keller, Neenah, Wisc.

Draxler, R.R., 1976, "Determination of Atmospheric Diffusion Parameters," Atmospheric Environment, 10:99-105.

Dunn W.E., et al., 1996, Technical Documentation in Support of the 1996 Emergency Response Guidebook, UILU-ENG-97-4001, prepared by University of Illinois, Urbana, Ill., for Research and Special Projects Administration, Office of Hazardous Materials Technology, U.S. Department of Transportation.

Ermak, D.L., et al., 1987, Heavy Gas Dispersion Test Summary Report, UCID-21102, Lawrence Livermore National Laboratory, Livermore, Calif. 
Graf, V.D., and K. Archuleta, 1985, Truck Accidents by Classification, FHWA/CA/TE85, U.S. Department of Transportation, Federal Highway Administration, Washington, D.C.

Gryning, S.W., and E. Lyck, 1984, "Atmospheric Dispersion from Elevated Sources in an Urban Area: Comparison between Tracer Experiments and Model Calculations," Journal of Climate and Applied Meteorology, 23:651-660.

Gryning, S.E., et al., 1983, "Dispersion from a Continuous Ground-Level Source Investigated by a K Model," Quarterly Journal of the Royal Meteorological Society, 109, $355-364$.

Hanna, S.R., and J.C. Chang, 1992, "Boundary Layer Parameterizations for Applied Dispersion Modeling over Urban Areas,” Boundary Layer Meteorology, 58:229-259.

Harwood, D.W., and E.R. Russell, 1990, Present Practices of Highway Transportation of Hazardous Materials, FHWA/RD-89/013, U.S. Department of Transportation, Federal Highway Administration, Washington, D.C.

Hymes, J., 1983, The Physiological and Pathological Effects of Thermal Radiation, SRDR 275, U.K. Atomic Energy Authority.

Irwin, J.S., 1983, "Estimating Plume Dispersion - A Comparison of Several Sigma Schemes," Journal of Climate and Applied Meteorology, 22:92-114.

Jarrett, D.E., 1968, "Derivation of British Explosives Safety Distances," Annals of the New York Academy of Sciences, 152:18-35.

Johnson, D.M., et al., 1990, Large Scale Catastrophic Releases of Flammable Liquids, Commission of the European Communities Report.

Johnson, P.E., et al., 1993a, HIGHWAY 3.1-An Enhanced Highway Routing Model, ORNL/TM-12124, prepared by Oak Ridge National Laboratory, Oak Ridge, Tenn., for U.S. Department of Energy, Office of Environmental Restoration and Waste Management, Washington, D.C.

Johnson, P.E., et al., 1993b, INTERLINE 5.0-An Expanded Railroad Routing Model, ORNL/TM-12090, prepared by Oak Ridge National Laboratory, Oak Ridge, Tenn., for U.S. Department of Energy, Office of Environmental Restoration and Waste Management, Washington, D.C.

Jovanis, P.P., et al., 1989, "A Comparison of Accident Rates for Two Truck Configurations," Transportation Research Record, 1249:18-29.

Lees, F.P., 1980, Loss Prevention in the Process Industries: Hazard Identification, Assessment and Control, Butterworths, Boston, Mass. 
Massie, D.L., 1991, Trucks Involved in Fatal Accidents: Factbook 1987, UMTRI-91-6, University of Michigan Transportation Research Institute, Ann Arbor, Mich.

Maio, D.J., and T. Liu, 1988, Truck Transportation of Hazardous Materials: A National Overview, DOT-TSC-RSPA-87-8, U.S. Department of Transportation, Research and Special Programs Administration, Washington, D.C.

Moorhouse, J., and M.J. Pritchard, 1982, "Thermal Radiation from Large Pool Fires," Journal of Chemistry E Symposium Series, 71.

Nayak, P.R., et al., 1983, Event Probabilities and Impact Zones for Hazardous Materials Accidents on Railroads, DOT/FRA/ORD-83/20, Federal Railroad Administration, U.S. Department of Transportation, Washington, D.C.

Panofsky, H.A., et al., 1977, "The Characteristics of Turbulent Velocity Components in the Surface Layer under Convective Conditions," Boundary Layer Meteorology $11: 355-361$.

Perry, R.H., et al. (editors), 1984, Perry's Chemical Engineers Handbook, $6^{\text {th }}$ ed., McGraw-Hill, New York, N.Y.

Phillips, A.H., and H. Role, 1986, Analysis of Tank Cars Damaged in Accidents 1965 through 1986, RA-02-6-65, Association of American Railroads, Chicago, Ill.

Post, L., 1994, HGSystem 3.0 Technical Reference Manual, TNER.94.059, Shell Research Limited, Thornton Research Centre, Chester, England.

Raj, P.K., and C.K. Turner, 1993, Hazardous Materials Transportation in Tank Cars: Analysis of Risks Part 1, DOT/FRA/ORD-92/34, prepared by Technology \& Management Systems, Inc., Burlington, Mass., for the Federal Railroad Administration, Washington, D.C.

Rhyne, W.R., 1994, Hazardous Materials Transportation Risk Analysis, Van Norstrand Reinhold, New York, N.Y.

Roberts, A.F., 1982, "Thermal Radiation Hazards from Releases of LPG from Pressurized Storage," Fire Safety Journal, 4:197-212.

Roberts, O.F.T., 1923, "The Theoretical Scattering of Smoke in a Turbulent Atmosphere," pp. 640-654 in Proceedings of the Royal Society of London A, Vol. 104.

Saricks, C., and T. Kvitek, 1994, Longitudinal Review of State-Level Accident Statistics for Carriers of Interstate Freight, ANL/ESD/TM-68, Argonne National Laboratory, Argonne, Ill. 
Settles, J.E., 1968, "Deficiencies in the Testing and Classification of Dangerous Materials," Annals of the New York Academy of Sciences, 152:199-205.

Siegel, R., and J.R. Howell, 1992, Thermal Radiation Heat Transfer, 3d ed., Hemisphere Publishing, Washington, D.C.

Smith, R.N., and E.L. Wilmot, 1982, Truck Accident and Fatality Rates Calculated from California Highway Accident Statistics for 1980 and 1981, SAND82-7066, Sandia National Laboratories, Albuquerque, N.M.

Stephens, G.L., 1984, "A Review of the Parameterization of Radiation for Numerical Weather Prediction and Climate Models," Monthly Weather Review, 112:826-867.

Steward, F.R., 1964, "Linear Flame Heights for Various Fuels," Combustion and Flame 8:171-178.

Sullivan, K.P., and D.L. Massie, 1992, Trucks Involved in Fatal Accidents: Factbook 1989, UMTRI-92-19, University of Michigan Transportation Research Institute, Ann Arbor, Mich.

Taylor, G.I., 1921, “Diffusion by Continuous Movements," pp. 196-212 in Proceedings of the London Math Society, 20.

Ten Berge, W.F., et al., 1986, "Concentration-Time Mortality Response Relationship of Irritant and Systematically Acting Vapours and Gases," Journal of Hazardous Materials, 13:301-309.

U.S. Bureau of the Census, 1996, URL: http://www.census.gov/ftp/pub/industry/ ma28a95.txt accessed December 12, 1997.

U.S. Department of Commerce, 1996, 1992 Census of Transportation Communication and Utilities: 1993 Commodity Flow Survey, TC92-CF-52, U.S. Bureau of the Census, Washington, D.C.

U.S. Department of Commerce, 1981, 1977 Census of Transportation - Commodity Transportation Survey, Summary, U.S. Bureau of the Census, Washington, D.C.

U.S. Environmental Protection Agency, 1999, ALOHA User's Manual, prepared by Chemical Emergency Preparedness and Prevention Office and National Oceanic and Atmospheric Administration, Hazardous Materials Response Division, available at http://www.epa.gov/ceppo/cameo/pubs/.

U.S. Environmental Protection Agency, 1993, Hydrogen Fluoride Study: Report to Congress, EPA550-R-93-001, Chemical Emergency Preparedness and Prevention Office, Washington, D.C. 
van Ulden, A.P., 1978, "Simple Estimates for Vertical Diffusion from Sources near the Ground," Atmospheric Environment, 12:2125-2129. 


\section{Appendix A Technical Basis for Consequence Assessments}

This appendix briefly describes the technical basis for the consequence assessment models used within Chemical Accident Statistical Risk Assessment Model (CASRAM), the risk assessment model at the core of the National Transportation Risk Assessment (NTRA) study. Section A.1 considers the treatment of toxic-by-inhalation (TIH) materials, and Sections A.2 and A.3 discuss the modeling of liquefied flammable gas releases and explosive materials, respectively. Each section provides an overview of the types of consequence models used and the assessment of health effects.

\section{A.1 TIH Materials}

The assessment of risk from airborne hazardous materials naturally breaks down into three components: (1) characterization of the release rate into the atmosphere for the materials involved, (2) estimation of dispersion downwind of the release location, and (3) translation of atmospheric concentrations of the materials involved into specific health effects. This section briefly reviews the physical models used for these purposes in CASRAM.

\section{A.1.1 Emission Rate Modeling}

The source component of CASRAM determines hazardous material release rates for the spill and/or vaporization scenarios important to transportation-related releases. Information on the shipment, location, and meteorology is used in the emission rate model to determine the amount of material spilled and the release rate. The discharge fraction is estimated by using statistical distributions generated from analysis of Hazardous Materials Information System (HMIS) database incidents, as discussed in Section 3.3. One or more physical models are then used to estimate chemical discharge rates and evaporation rates.

\section{A.1.1.1 Assumptions Used to Develop Accident Scenarios}

The accident scenarios were developed on the basis of the following assumptions:

- For accident-related releases from rail shipments (i.e., tank cars) that involved a container breach, the release rate of material from the container is regulated by the size of the hole, which is specified statistically according to hole size distributions presented by Raj and Turner (1993). Because comparable data are not available for highway transportation, the hole size distributions for highway bulk containers are set to those for tank car types with similar specifications (wall thickness, insulation). Total release amounts are limited to conform with discharge fraction distributions in the HMIS database by varying the location of the hole in the container. 
- For en route/nonaccident incidents and for package freight accident-related incidents, release amounts are determined directly from the HMIS database release fraction distributions. For these incidents, the release is assumed to occur uniformly during a 15-min period.

- Liquids released from the container that are not flashed or entrained with the flashed liquid form a pool on the ground, which expands and contracts in response to gravity-driven fluid flow and evaporation. Equilibrium pool depth is calculated by using a stochastic relationship based on the volume of material released so that average pool depth for larger releases is greater than that for small releases. For highway-related releases, $50 \%$ of spills are assumed to occur on paved surfaces. For rail releases, $25 \%$ of spills are assumed to occur on pavement or roadbed. All other spills are assumed to occur on natural surfaces characteristic of the accident locale. Ground temperature profiles to a depth of $1 \mathrm{~m}$ are provided in the preprocessed meteorological database.

- Except for fuming sulfuric acid, chemical transformation is not considered.

- The temperature of the material upon release is taken as a weighted average of the air temperature and $290 \mathrm{~K}$, with the exact weight depending on the container type.

\section{A.1.1.2 Physical Considerations}

A.1.1.2.1 Discharge from Tanks. In CASRAM, tanks that are punctured below the liquid line release their contents according to the Bernoulli equation (Perry et al. 1984); namely,

$$
Q=c_{0} A_{h} \rho_{l}\left[2 g \Delta h+2\left(\frac{P_{t}-P_{a}}{\rho_{l}}\right)\right]^{\frac{1}{2}},
$$

where

$$
\begin{aligned}
& Q=\text { liquid release rate }(\mathrm{kg} / \mathrm{s}), \\
& c_{0}=\text { discharge coefficient, } \\
& A_{h}=\text { hole area }\left(\mathrm{m}^{2}\right), \\
& \rho_{l}=\text { liquid density }\left(\mathrm{kg} / \mathrm{m}^{3}\right), \\
& g=\text { gravitational acceleration }\left(9.81 \mathrm{~m} / \mathrm{s}^{2}\right), \\
& \Delta h=\text { height of liquid above the hole }(\mathrm{m}),
\end{aligned}
$$




$$
\begin{aligned}
& P_{t}=\text { tank pressure }(\mathrm{Pa}), \text { and } \\
& P_{a}=\text { atmospheric pressure }(\mathrm{Pa}) .
\end{aligned}
$$

In CASRAM, $c_{0}$ is set to 0.6 for all releases.

Equation A.1 is used to calculate the discharge rates from all bulk containers in CASRAM, where $A_{h}$ is provided by the hole size distributions given by Raj and Turner (1993). As stated, liquids form a pool on the ground or pavement, which then expands and contracts. Liquefied gases, on the other hand, equilibrate to atmospheric pressure through flashing (explosive evaporation of a fraction of the released material). A fraction of the remaining material is aerosolized and entrained in the flashed vapor, and the remaining material falls to the ground and evaporates.

A.1.1.2.2 Pool Evaporation. The release rate of material from an evaporating pool is represented as follows:

$$
Q=A_{p} E_{c},
$$

where

$$
\begin{aligned}
& A_{p}=\text { pool area }\left(\mathrm{m}^{2}\right), \text { and } \\
& E_{c}=\text { evaporation rate from the pool }\left(\mathrm{kg} / \mathrm{m}^{2}\right) .
\end{aligned}
$$

Pool evaporation in CASRAM is determined by using a time-dependent, energy budget model that considers heat transfer to and from the pool via radiation, convection, conduction, and evaporation. Conductive heat flux from the ground is especially important and is often the dominant source of available energy, especially for very volatile liquids. Treating conduction correctly, especially the initial and boundary conditions, was a principal motivation in the development of the CASRAM evaporation model.

The energy budget of the pool is a balance between solar radiation $S$, incoming longwave radiation $L^{+}$, outgoing long-wave radiation $\varepsilon_{p} \sigma T_{p}^{4}$, convective heat transfer $H_{p}$, latent heat transfer of water vapor from plant material $\lambda E_{w p}$, conductive heat transfer to ground $G_{p}$, chemical evaporation rate $h_{f g} E_{c}$, and energy storage $m c_{p}\left(d T_{p} / d t\right)$ (subscript $p$ variables refer to pool-specific quantities). Therefore, the pool energy budget is

$$
Q_{p}^{*}=H_{p}+\lambda E_{w p}+G_{p}+h_{f g} E_{c}+m c_{p} \frac{d T_{p}}{d t}
$$


where

$$
\begin{aligned}
& m=\text { liquid mass of pool }\left(\mathrm{kg} / \mathrm{m}^{2}\right) \text {, and } \\
& c_{p}=\text { specific heat of liquid }(\mathrm{kJ} /[\mathrm{kg} \times \mathrm{K}]),
\end{aligned}
$$

and $Q_{p}^{*}$ is the net radiation given by

$$
Q_{p}^{*}=\left(1-\alpha_{p}\right) S+L^{+}+\varepsilon_{p} \sigma T_{p}^{4}
$$

The ground heat flux to the pool $G_{p}$ is given by Fourier's law as

$$
G_{p}=-k_{g}\left(\frac{d T}{d z}\right)_{z=0} .
$$

In Equations A.4 and A.5, $\varepsilon_{p}$ is the pool emissivity, $\alpha_{p}$ is the pool albedo, and $k_{g}$ is the ground or surface conductivity. The necessary transfer coefficients for evaporation are provided by a chemical property database and the preprocessed meteorological database discussed in Section 2.3.2.3 and in Brown et al. (2000). In particular, the meteorological quantities of interest include aerodynamic resistances based on stability and wind speed, air temperature, incoming solar and long-wave radiation, and the initial ground temperature profile.

A.1.1.2.3 Compressed Gas Releases. In CASRAM, compressed gas releases are modeled by using semi-empirical blowdown relationships based on compressible-flow theory. Releases are assumed to be isentropic rather than isenthalpic. The isentropic assumption is that heat transfer to the vessel is negligible, which is a reasonable approximation for most accidental releases. The isenthalpic approximation, on the other hand, requires sufficient heat transfer to maintain isothermal conditions (assuming $c_{p}$ is constant).

For compressed gas releases, the release rate is calculated on the basis of hole size, tank pressure, and gas density:

$$
Q=c_{0} A_{h}\left[P_{t} \rho_{g} \gamma\left(\frac{2}{\gamma+1}\right)^{\frac{\gamma+1}{\gamma-1}}\right]^{\frac{1}{2}},
$$

where $\gamma$ is the specific heat ratio $c_{p} / c_{v}$. As in the case of liquid releases, $c_{0}$ is set to 0.6 for all releases. 
Equation A.6 is applicable until the tank pressure drops below a critical value, given as

$$
P_{r}=\left(\frac{\gamma+1}{2}\right)^{\frac{\gamma}{\gamma-1}}
$$

where $P_{r}$ is ratio of the tank pressure to atmospheric pressure. After this criterion is reached, the discharge rate is given by

$$
Q=c_{o} A_{h}\left[P_{t} \rho_{g}\left(\frac{2 \gamma}{\gamma-1}\right)\left(P_{r}^{-\frac{2}{\gamma}}-P_{r}^{-\frac{\gamma+1}{\gamma}}\right)\right]^{\frac{1}{2}}
$$

Calculations are conducted iteratively by adjusting the tank pressure and density at each time step with the isentropic assumption.

A.1.1.2.4 Liquefied Gas Releases. Liquefied gas releases are treated by first calculating the liquid release rate from the container given by Equation A.1. As discussed previously, this material either flashes to vapor, is aerosolized and entrained with the vapor, or remains liquid and falls to the ground. This flash fraction $f$ is given by

$$
f=\frac{c_{p}\left(T_{t}-T_{b}\right)}{h_{f g}}
$$

where $T_{t}$ is the tank temperature and $T_{b}$ is the boiling point. This fraction of remaining material, which is aerosolized and entrained into the flashed vapor, is calculated by using empirical relationships based on the discharge kinetic energy of the two-phase mixture. Released material that does not flash to vapor or become entrained in the vapor clouds is deposited on the ground. Evaporation of the remaining material is then estimated by using the pool evaporation algorithms.

\section{A.1.2 Dispersion Modeling}

Like many other dispersion models, CASRAM separates the dispersion calculation into two components: vertical dispersion and horizontal dispersion. Vertical turbulent dispersion is treated with a Lagrangian-integral model parameterized in terms of mean plume height, average advection velocity, and a dimensionless travel time. These parameters are expressed as integral equations written in terms of plume travel time and atmospheric boundary layer parameters. Continuous releases are treated as plumes, and instantaneous releases are treated as puffs. Horizontal turbulent dispersion is represented via Gaussian relationships that are parameterized in terms of the Lagrangian time scale and lateral wind direction fluctuations. Plume calculations are straight-line in nature because CASRAM currently does not consider the effects of terrain. 
The concentration relationship for continuous plume releases from point sources is represented in terms of the crosswind-integrated concentration (CWIC), chemical mass release rate $Q$, and the traditional Gaussian expression for the horizontal plume spread. The ground-level concentration distribution is computed as follows:

$$
C(x, y, z=0)=\frac{Q \hat{C}_{y}(x, z=0)}{\sqrt{2 \pi} \sigma_{y}} \exp \left[-\left(\frac{y}{\sqrt{2} \sigma_{y}}\right)^{2}\right]
$$

where

$$
\begin{aligned}
& \hat{C}_{y}=\text { CWIC normalized by the release rate, } \\
& \sigma_{y}=\text { lateral plume spread (m), and } \\
& y=\text { lateral distance from the plume centerline }(\mathrm{m}) .
\end{aligned}
$$

For time-variant evaporative emissions, the release rate is the average over the exposure time corresponding with the toxicological value.

For releases with finite width $2 y_{o}$, corresponding to large pools releases or dense gas releases as they become passive, the following expression is used:

$$
C(x, y, z=0)=Q \hat{C}_{y}(x, z=0)\left(\operatorname{erf}\left[\frac{y_{o}-y}{\sqrt{2} \sigma_{y}}\right]+\operatorname{erf}\left[\frac{y_{o}+y}{\sqrt{2} \sigma_{y}}\right]\right) .
$$

Peak concentration averages resulting from instantaneous releases are calculated according to the relationship in Equation A.12:

$$
C(x, y, z=0)=\frac{M \hat{C}_{y}(x, z=0)}{\sqrt{2 \pi} \sigma_{y} T} \operatorname{erf}\left[\frac{\mathrm{UT}}{2 \sqrt{2} \sigma_{y}}\right] \exp \left[-\left(\frac{y}{\sqrt{2} \sigma_{y}}\right)^{2}\right],
$$

where

$$
\begin{aligned}
M & =\text { total release amount }(\mathrm{kg}), \\
T & =\text { averaging time }(\mathrm{s}), \text { and } \\
U & =10-\mathrm{m} \text { wind speed }(\mathrm{m} / \mathrm{s}) .
\end{aligned}
$$


The subsections below first present the methodology for determining vertical dispersion (i.e., for determining $C_{y}$ as a function of downwind distance). They then discuss the determination of $\sigma_{y}$, thus providing horizontal dispersion.

\section{A.1.2.1 Vertical Dispersion}

This discussion begins with a review of Van Ulden's (1978) surface-layer, similaritybased model because the approach used in CASRAM represents a natural extension of that model. The van Ulden approach is based on writing an exact solution of the advection-diffusion equation. When written in terms of the CWIC form and neglecting stream-wise diffusion, it reads as follows:

$$
U(z) \frac{\partial C_{y}}{\partial z}=\frac{\partial}{\partial z}\left[K_{z}(z) \frac{\partial C_{y}}{\partial z}\right],
$$

where $K_{z}$ is the vertical diffusivity for a scalar. Here, van Ulden advances a solution written in terms of the mean plume height $\bar{z}$, the average plume advection velocity $U_{p}$, and the power-law wind speed coefficient $m$ and diffusivity coefficient $n$. The coefficients $m$ and $n$ are defined as follows:

$$
U(z)=u_{o} z^{m}
$$

and

$$
K_{z}(z)=k_{o} z^{n}
$$

where $u_{o}$ and $k_{o}$ are constants representing the wind speed and diffusivity at $1 \mathrm{~m}$. From Roberts (1923), it is well known that the advection-diffusion equation subject to the above power-law relationships yields an exact solution (Calder 1949). The work of van Ulden (1978) extends this analysis by using the power-law coefficients to determine the concentration profile shape a priori (i.e., from the Roberts' analysis) and then formulates integral relationships for the mean plume height and average advection velocity in terms of the more physically correct similarity functions for wind speed and diffusivity. The van Ulden (1978) solution reads as follows:

$$
\hat{C}_{y}(x, z)=\frac{A}{\bar{z} \overline{U_{p}}} \exp \left[-\left(\frac{B z}{\bar{z}}\right)^{s}\right]
$$

where

$$
A=\frac{s \Gamma(2 / s)}{\Gamma(1 / s)^{2}}
$$


and

$$
B=\frac{\Gamma(2 / s)}{\Gamma(1 / s)}
$$

and $s$ is a shape parameter given by $1-m-n$. In Equations A.17 and A.18, $\Gamma$ represents the gamma function.

In applying this model, van Ulden (1978) parameterized the mean plume height and average advection velocity by using surface-layer similarity functions for wind speed and diffusivity. In a subsequent study, Gryning et al. (1983) extended this analysis by adding a sophisticated relationship to determine the shape parameter $s$ as a function of stability and downwind distance. The relationships for $s$ were determined through analysis of numerical solutions for the advection-diffusion equation for a wide range of conditions. In a detailed model-data comparison that used CWIC data from the Prairie Grass experiments (Barad 1958), Gryning and colleagues demonstrated the utility of the Lagrangian empirical model in representing the concentration profile as well as in estimating ground-level concentrations. This model provided an excellent description of dispersion in the surface layer. However, its application is limited to dispersion problems in which the plume is primarily confined to the surface layer. When the plume rises above the surface layer, the concentration profile given by Equation A.16, as well as the similarity relationships for $\bar{z}$ and $U_{p}$, become invalid. For problems of practical interest, this rather severe constraint on the use of Equation A.16 strongly limits the applicability of the model for problems of practical interest.

Brown (1997) modified the original van Ulden work to correct this limitation. In this revised formulation, the normalized ground-level concentration is expressed as

$$
\hat{C}_{y}(x, z=0)=\frac{A^{\prime}(\widetilde{s}) F\left(x, u_{*}, z_{i}, H_{s}\right)}{z_{u} \overline{U_{p}}},
$$

where $z_{u}$ is defined as

$$
U\left(z_{u}\right)=\overline{U_{p}},
$$

and

$$
A^{\prime}(\tilde{s})=\frac{1.6 \tilde{s} \Gamma(2 / \tilde{s})}{\Gamma(1 / \tilde{s})^{2}}
$$


Here, $A^{\prime}$ takes the same functional form as $A$ in van Ulden's model, except that it is multiplied by 1.6 to account for the ratio of $\bar{z}$ to $z_{u}$ and depends on a modified shape parameter denoted as $\tilde{s}$.

The main departure of this approach from the models of van Ulden and Gryning et al. is the boundary-layer function $F$. This function is added to treat dispersion within the greater atmospheric boundary layer (ABL) outside the surface layer. As previously noted, the van Ulden model was developed by using the quasi-exponential concentration profile. For surface-layer dispersion, this assumed form for the concentration profile adequately represents the concentration profiles observed in field studies, most notably the Prairie Grass experiments. However, once the plume is influenced by boundary-layer effects outside of the surface layer, the concentration profiles depart significantly from the exponential form. In unstable conditions, this departure is particularly pronounced because the plume centerline actually lifts off the ground, creating a maximum concentration aloft. In stable conditions, the opposite effect is observed: the concentration profile is flattened as a result of the rapid decrease in turbulent energy with height. The transition function $F$ allows us to adapt this methodology, which was originally developed to model surface-layer dispersion, to treat dispersion throughout the entire ABL.

Brown (1997) developed relationships for $z_{u}, \tilde{s}$, and $F$ by using a parametric analysis of a Langevin-equation Monte Carlo dispersion model validated with data from field and laboratory experiments. In applying the CASRAM vertical dispersion model, $\widetilde{s}$ is a function of meteorology and therefore does not vary with distance, and $F$ is represented as a function of travel time and meteorology. The heart of the calculation lies in $z_{u}$, which is calculated by using integral relationships represented as a function of travel time. Numerical integration of this relationship provides $z_{u}$ as a function of downwind distance, which, together with $\widetilde{s}$ and $F$, allows the evaluation of Equation A.19 and ultimately Equation A.10, A.11, or A.12.

\section{A.1.2.2 Horizontal Dispersion}

Under horizontal homogeneous conditions, the Gaussian model correctly represents lateral concentration distributions. In CASRAM, the lateral spread from nonbuoyant releases can be related to the standard deviation of the horizontal wind fluctuations and is determined by using relationships originally proposed by Draxler (1976). Here, $\sigma_{y}$ is given by

$$
\sigma_{y}=\sigma_{v} f_{y}\left(\frac{t}{T_{d}}\right),
$$

where

$$
\sigma_{v}=\text { standard deviation of transverse velocity }(\mathrm{m} / \mathrm{s}) \text {, }
$$




$$
\begin{aligned}
& t=\text { transit time (estimated by using wind speed at } 2 \mathrm{~m} \text { and distance) (s), } \\
& T_{d}=\text { dispersion time scale related to the Lagrangian time scale (s), and } \\
& f_{y}=\text { a nondimensional function of travel time. }
\end{aligned}
$$

The empirical form of $f_{y}$ is estimated through the evaluation of field data. Several forms of $f_{y}$ have been proposed (Irwin 1983; Gryning and Lyck 1984), but the empirical expression that provides the best overall fit with available field data is the form proposed by Draxler (1976). His function is given by

$$
f_{y}=\frac{1}{1+0.9 \sqrt{t / T_{d}}} .
$$

For surface releases, a $T_{d}$ of $300 \mathrm{~s}$ is used for unstable conditions and a maximum of $300 \mathrm{~s}$ or $0.001 t^{2} \mathrm{~s}$ is used for stable conditions. The appeal of Draxler's relation is that it is developed from diffusion data from many experiments and is consistent with Taylor's limit for both small $\left(\sigma_{y} \sim t\right)$ and large $\left(\sigma_{y} \sim t^{1 / 2}\right)$ travel times (Taylor 1921).

Equation A.22 requires the standard deviation of transverse velocity $\sigma_{v}$. In the absence of observational data, $\sigma_{v}$ is determined by using the interpolation equation of Panofsky et al. (1977)

$$
\sigma_{v}=u_{*}\left(12-0.5 \frac{z_{i}}{L}\right)^{1 / 3}
$$

during unstable conditions and the proportionality relation of Panofsky and Dutton (1984)

$$
\sigma_{v}=1.92 u_{*}
$$

during stable conditions.

In very stable conditions, Equation A.25 fails to adequately represent $\sigma_{v}$ because wind speed and friction velocity become very small. For instance, if the friction velocity is about $0.015 \mathrm{~m} / \mathrm{s}$, indicative of a wind speed of about $0.5 \mathrm{~m} / \mathrm{s}$ with $z_{0}=0.1 \mathrm{~m}$ on a clear night, Equation A. 25 predicts $\sigma_{v}=0.03 \mathrm{~m} / \mathrm{s}$. One kilometer from the source, this value of $\sigma_{v}$ yields $\sigma_{y}=36 \mathrm{~m}$ from Equation A.22. Considering the 2,000-s travel time, such a narrow plume width is not realistic when the meandering nature of stable boundary layer flows is considered. To overcome this problem, we assign a minimum value of $0.15 \mathrm{~m} / \mathrm{s}$ for $\sigma_{v}$ on the basis of observations presented by Hanna and Chang (1992). 


\section{A.1.3 Assessment of Health Effects for the NTRA TIH Chemicals}

In the NTRA, two health end points are used for TIH materials corresponding to injuries and fatalities. To calculate injury risk, we used the Emergency Response Planning Guideline - Level 2 (ERPG-2) or equivalent. To calculate fatality risk, we used the $\mathrm{LC}_{50}$ health criteria (Lethal Concentration for $50 \%$ of the population). The health criteria used for each of these end points are discussed below.

\section{A.1.3.1 Injury Thresholds}

Exposure to the ERPG-2 health criteria is the baseline for TIH injury in the NTRA. ERPG-2 concentrations are available for five of the six TIH materials considered (AIHA 1999). For the remaining chemical, fuming nitric acid, we estimate potential injuries by using a method based on the $\mathrm{LC}_{50}$ concentration. The 4-h $\mathrm{LC}_{50}$ value for fuming nitric acid is $67 \mathrm{ppm}$, which can be converted to a 1-h value via the probit-based relationship (see Equation A.30):

$$
L C_{50}\left(T_{1}\right)=L C_{50}\left(T_{0}\right)\left(\frac{T_{1}}{T_{0}}\right)^{1 / n},
$$

where $T_{1}$ is the actual exposure time, $T_{0}$ is the experimental exposure time, and $n$ is a constant. For many chemicals, $n$ centers around a value of 0.5 (ten Berge et al. 1986). By using this value, we obtain a $1-\mathrm{h} \mathrm{LC}_{50}$ of $134 \mathrm{ppm}$. By applying a methodology for relating ERPG-2 to $\mathrm{LC}_{50}$ concentrations outlined in Dunn et al. (1996), this value is divided by 100 to obtain the 1-h health criteria equivalent to an ERPG-2 value.

Threshold concentrations for injury employed for the six TIH chemicals considered in the NTRA are provided in Table A.1. The 15- and 30-min health criteria are calculated by multiplying the 1 -h protective action values by 1.4 and 2 , respectively, according to the probit relationship given in Equation A.26. We note that the 1-h ERPG-2 or equivalent values used in this study are greater than the Occupational Safety and Health Administration Permissible Exposure Limits (OSHA PELs) for ammonia, chlorine, HF, and fuming nitric acid by factors of 1.5 to 6 . For sulfur dioxide and fuming nitric acid, OSHA PEL is about twice the ERPG-2. ACGIH short-term exposure limits are less than the ERPG-2 or equivalent for all materials by factors of 2 to 10, depending on the material.

\section{A.1.3.2 Lethality Thresholds}

The NTRA uses the $\mathrm{LC}_{50}$ concentration as a basis for fatality estimates. We use $\mathrm{LC}_{50}$ values as opposed to ERPG-3 values because $\mathrm{LC}_{50}$ denotes the concentration at which death would be expected for a substantial fraction (i.e., 50\%) of the population. The ERPG-3, on the other hand, denotes the maximum airborne concentration below which almost all people could be exposed for $1 \mathrm{~h}$ without developing life-threatening 
Table A.1 Injury Threshold Concentrations (in parts per million [ppm], except fuming sulfuric acid) for the Six NTRA TIH Chemicals

\begin{tabular}{|lcccc|}
\hline \multicolumn{1}{c}{ Chemical } & $\mathbf{1 ~ h}$ & $\mathbf{3 0} \mathbf{~} \mathbf{~ i n}$ & $\mathbf{1 5} \mathbf{~} \mathbf{i n}$ & Basis \\
\hline Ammonia & 200 & 283 & 400 & ERPG-2 \\
Chlorine & 3 & 4.2 & 6 & ERPG-2 \\
Hydrogen fluoride & 20 & 28 & 40 & ERPG-2 \\
Sulfur dioxide & 3 & 4.2 & 6 & ERPG-2 \\
Fuming sulfuric acid & $10 \mathrm{mg} / \mathrm{m}^{3}$ & $14 \mathrm{mg} / \mathrm{m}^{3}$ & $20 \mathrm{mg} / \mathrm{m}^{3}$ & ERPG-2 \\
Fuming nitric acid & 1.3 & 1.8 & 2.6 & LC $_{50}$ \\
\hline
\end{tabular}

a Values are for $\mathrm{H}_{2} \mathrm{SO}_{4}$ concentration.

health effects. On average, ERPG-3 concentrations are about a factor of 10 lower than LC $_{50}$ concentrations, so the use of ERPG- 3 would tend to dramatically overstate the true fatality risk. The 15-min, 30-min, and 1-h $\mathrm{LC}_{50}$ concentrations for the NTRA TIH chemicals are provided in Table A.2.

The NTRA extends the $\mathrm{LC}_{50}$ exposure analysis to estimate the number of fatalities. One method to estimate fatalities is to determine the hazard zones bounded by several fatality-probability concentrations (i.e., $\mathrm{LC}_{10}, \mathrm{LC}_{50}, \mathrm{LC}_{90}$ ). The respective percentages of the exposed populations within each region are then summed to obtain the total number of fatalities. Because several hazard zone calculations are required, this procedure can be computationally expensive. However, the number of fatalities can also be estimated (neglecting the effects of sheltering) by multiplying the population exposed in the $\mathrm{LC}_{50}$ contour by a single numerical factor to account for persons within the $\mathrm{LC}_{50}$ contour who are not fatally injured, as well as for persons outside the $\mathrm{LC}_{50}$ contour who are fatally injured. A necessary simplifying assumption is that the population density is uniform for all areas affected by the vapor plume. For the NTRA, this assumption does not unduly limit the resolution of the analysis because available population data are usually of lower resolution than the hazard zone areas for fatal concentration exposure (i.e., $\sim 1$ mile versus $\sim 0.1$ mile). Within this framework, the total number of expected fatalities is expressed as

$$
F=d A\left(\mathrm{LC}_{50}\right) N
$$

where $d$ is the population density, $A\left(\mathrm{LC}_{50}\right)$ is the hazard area corresponding to the $\mathrm{LC}_{50}$ concentration, and $N$ is a numerical factor given by

$$
N=\int_{0}^{\infty} A^{*}\left(C^{*}\right) P\left(C^{*}\right) d C^{*},
$$


Table A.2 Lethality Threshold Concentrations (in ppm) for the Six NTRA TIH Chemicals ${ }^{a}$

\begin{tabular}{|lccc|}
\hline \multicolumn{1}{|c}{ Chemical } & $\mathbf{1} \mathbf{h}$ & $\mathbf{3 0} \mathbf{~} \mathbf{i n}$ & $\mathbf{1 5} \mathbf{~} \mathbf{i n}$ \\
\hline Ammonia & 7,338 & 10,346 & 14,676 \\
Chlorine & 293 & 414 & 586 \\
Hydrogen fluoride & 1,300 & 1,800 & 2,600 \\
Sulfur dioxide & 2,520 & 3,563 & 5,040 \\
Fuming sulfuric acid & 347 & 491 & 694 \\
Fuming nitric acid & 134 & 190 & 268 \\
\hline
\end{tabular}

a The basis for these values are $\mathrm{LC}_{50}$ concentrations.

where

$C^{*}=$ chemical concentration normalized by its respective $\mathrm{LC}_{50}$ value (i.e., $C^{*}=C / \mathrm{LC}_{50}$ ),

$A^{*}=$ hazard zone area for concentration $C^{*}$ normalized by the $\mathrm{LC}_{50}$ hazard zone area, and

$P\left(C^{*}\right)=$ fatality probability at concentration $C^{*}$.

Under these definitions, $A^{*}=1$ and $P=0.5$ at $C^{*}=1$.

To calculate the factor $\mathrm{N}$, the relationships $A^{*}\left(C^{*}\right)$ and $P\left(C^{*}\right)$ need to be known. The function $A^{*}\left(C^{*}\right)$ relates the rate of increase of hazard zone area with decreasing threshold concentration. Examples of this relationship for a large liquefied gas release (chlorine in this example) are shown in Figure A.1. Here, hazard zones are calculated with the CASRAM dispersion module. Although $A^{*}\left(C^{*}\right)$ exhibits a slight dependence on spill size, it is most strongly dependent on meteorology. Figure A.1 provides $A^{*}$ as a function of $C^{*}$ for three general meteorological categories: unstable, neutral, and stable conditions. This function is most efficiently represented in the form

$$
A^{*}=C^{* m},
$$

where $m$ is a constant. By using the results of several dispersion trials exemplified by the results shown in Figure A.1, we selected representative values for $m$ of $-0.75,-1.0$, and -1.2 for unstable, neutral, and stable conditions, respectively. Calculations using Equation A.29 with these values are shown in Figure A.1 for comparison.

The function $P\left(C^{*}\right)$ can be estimated by using the probit equation, which is typically written in the form

$$
\operatorname{Pr}=a_{1}+a_{2} \ln \left(C^{n} t\right) .
$$




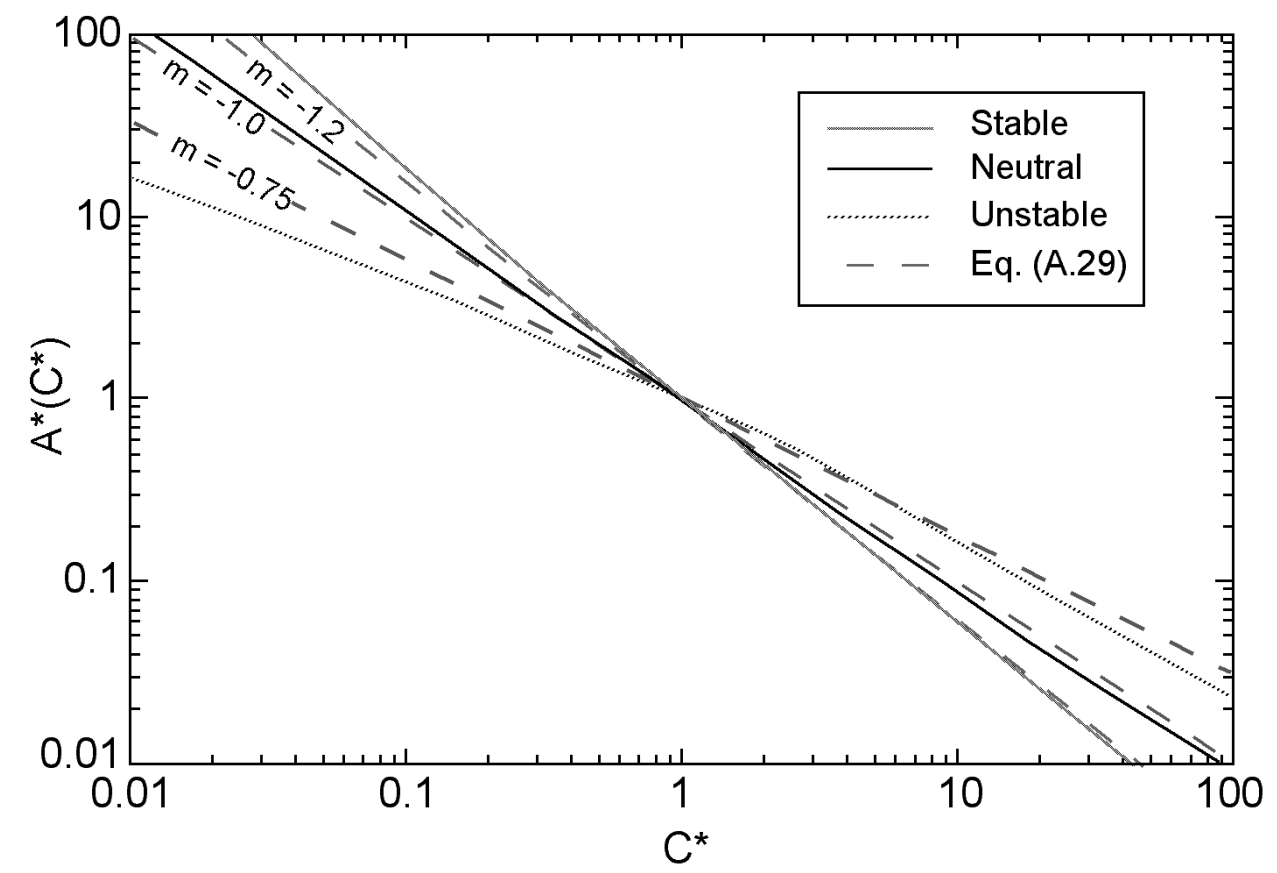

Figure A.1 Increase in Hazard Zone Size with Decreasing Threshold Concentration for Stable, Neutral, and Unstable Meteorological Conditions (Equation A.29 for $m=-0.75,-1.0$, and -1.2 is shown for comparison.)

where

$$
\operatorname{Pr} \quad=\text { probit, and }
$$

$a_{1}, a_{2}$, and $n=$ chemical-dependent constants.

The probability of fatality is related to the probit through the normal probability distribution where the probit has a mean value of 5 and a standard deviation of 1 . Hence, probit values corresponding to $\mathrm{LC}_{10}, \mathrm{LC}_{50}$, and $\mathrm{LC}_{90}$ are 3.72, 5.0, and 6.28, respectively. Expressing this relationship in terms of nondimensional concentration $C^{*}$, we obtain

$$
\operatorname{Pr}=5+n a_{2} \ln \left(C^{*}\right)
$$

Thus, the fatality probability can be expressed as

$$
N=\frac{1}{\sqrt{2 \pi}} \int_{-\infty}^{S} \exp \left(-t^{2}\right) d t
$$


where

$$
S=\frac{n a_{2} \ln \left(C^{*}\right)}{\sqrt{2}} .
$$

For a wide variety of chemicals such as chlorine, ammonia, and bromine, $a_{2} \cong 0.9$ and $n \cong 2$. By using these values, our numerical factor $N$ relating $\mathrm{LC}_{50}$ hazard zone size and population density to fatalities becomes $1.07,1.14$, and 1.20 for stable, neutral, and unstable meteorology (i.e., $m=-0.75,-1.0$, and -1.2 ), respectively. Because the variation with meteorology is relatively small, we set $N=1.1$ for all cases in the NTRA.

\section{A.2 Liquefied Flammable Gases}

The principal hazards from liquefied flammable gases in transportation-related incidents are fireballs and flash fires. Fireballs occur when a vapor cloud ignites shortly after release when the cloud contains high concentrations of aerosolized liquid and vapor. Flash fires occur when ignition occurs after the cloud has dispersed some, but while flammable vapors are still above the lower flammability limit. When the vapor cloud is confined, blast and flying debris might significantly threaten human health. As discussed in Section 2, however, the historical evidence shows that impacts arising from thermal radiation are significantly higher, especially for releases associated with highway transportation. Therefore, only thermal radiation effects are included in our analysis.

In Section A.2.1, we discuss the treatment of fireballs, outlining the modeling of thermal radiation and the assessment of health impacts. In Section A.2.2, we discuss flash fires in an analogous manner.

\section{A.2.1 Fireballs}

When a pressure vessel containing liquefied petroleum (LP) gas (in our case a MC 330 or MC 331 tank truck) explodes, a fraction of the LP gas flashes to vapor, entraining a considerable quantity of the remaining liquid in the process. If this vaporaerosol-air mixture is ignited before dispersing downwind, a fireball is the likely result. We discuss modeling of the radiation effects and then discuss the conversion of thermal radiation predictions to fatality and injury estimates.

\section{A.2.1.1 Modeling of Thermal Radiation}

The geometry of the fireball problem is illustrated in Figure A.2. A fireball of diameter $D_{f}$ forms and radiates to a receptor at a downwind distance $X$ from the fireball origin. Fireballs are usually modeled as spherical emitters, although significant departures from the spherical form often occur in practice (Roberts 1982). The centroid of the fireball is at a height $Z_{c}$ above ground. Because the fireball does not lift off the 


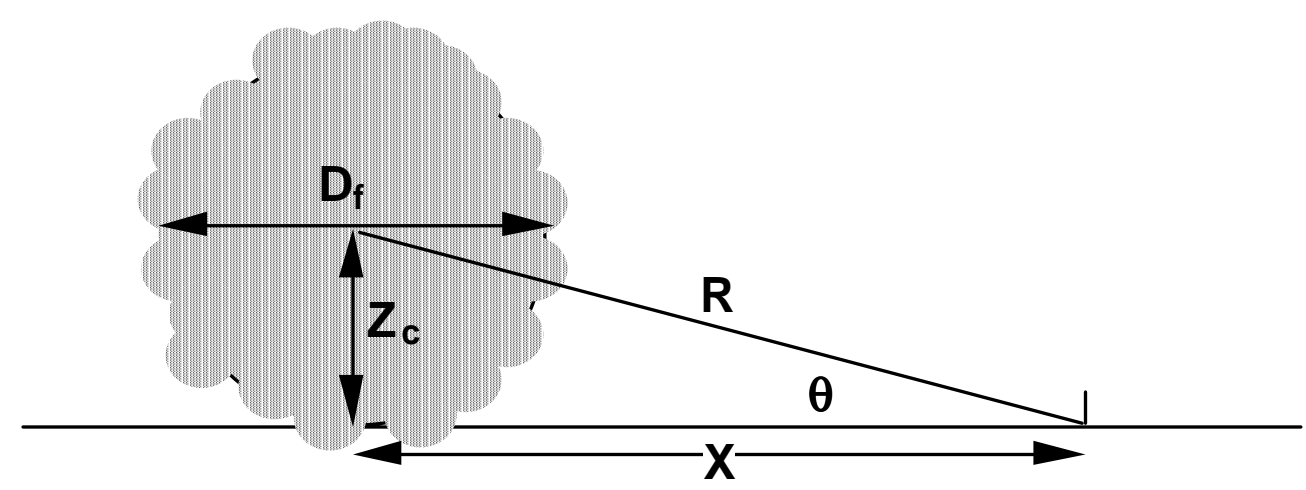

Figure A.2 Geometry for Calculating Radiative Effects from Fireballs

ground immediately, it is generally assumed that $Z_{c}=1 / 2 D_{f}$ such that the fireball is in contact with the ground.

Observations suggest that the maximum fireball diameter (in meters) is

$$
D_{f}=5.8 m^{1 / 3}
$$

where $m$ is the mass of the LP gas in kilograms. Roberts (1982) notes that this relationship can be theoretically obtained by assuming a stoichiometric mixture of propane (or similar hydrocarbon) and raising the temperature to the adiabatic flame temperature. The general agreement of the observational evidence to this simplified view of fireball combustion is fortuitous, however, because fireball combustion is not generally stoichiometric, and the radiative fluxes measured from hydrocarbon fireballs are usually lower than the adiabatic flame temperature would suggest.

The thermal radiation from a fireball received at a receptor is conveniently expressed as (AICHE 1994) as follows:

$$
q=\tau F E,
$$

where

$$
\begin{aligned}
& q= \text { radiation }\left(\mathrm{W} / \mathrm{m}^{2}\right), \\
& E= \text { emissive power of the fireball }\left(\mathrm{W} / \mathrm{m}^{2}\right), \text { and } \\
& F \text { and } \tau=\begin{array}{l}
\text { view factor and transmissivity, respectively, between the receptor and } \\
\text { the fireball. }
\end{array}
\end{aligned}
$$


The experimental results of Johnson et al. (1990) indicate that the surface emissive power for hydrocarbon releases in boiling liquid-expanding vapor explosions is 320 to $370 \mathrm{~kW} / \mathrm{m}^{2}$. Following recommendations by AICHE (1994), we use an emissive power of $350 \mathrm{~kW} / \mathrm{m}^{2}$.

The view factor from the fireball to receptor at distance $R$ from the fireball center and facing the fireball is (Siegel and Howell 1992)

$$
F=\left(\frac{D_{f}}{2 R}\right)^{2} \quad R>D / 2 .
$$

A person who is standing is most appropriately modeled as a vertical receptor at ground level. For $R>D_{f} / 2$, this view factor is approximately given by

$$
F=\left(\frac{D_{f}}{2 R}\right)^{2} \cos (\theta) \quad R>D / 2 .
$$

A more precise representation of the view factor based on the size of the receptor and accounting for the spherical nature of the source is quite cumbersome. Equation A.36 provides adequate results for typical fireball hazard calculations considering other uncertainties in the analysis.

Radiation emitted from the fireball is absorbed by water vapor, carbon dioxide, and, to a lesser extent, aerosols as it travels from the fireball surface to the receptor. To estimate this transmissivity with precision, a sophisticated radiation calculation is necessary, which requires the ambient partial pressures of water vapor and carbon dioxide and atmospheric aerosol properties. Because these parameters are often unavailable, several empirical expressions exist in the literature for calculating the transmissivity appearing in Equation A.34 (AICHE 1994). In this study, we use the expression of Moorhouse and Pritchard (1982):

$$
\tau=0.998^{x}
$$

Other relationships that use relative humidity are physically incorrect because transmissivity depends on water vapor partial pressure rather than on relative humidity (Stephens 1984).

\section{A.2.1.2 Assessment of Human Health Impacts}

The impact of thermal radiation on exposed persons depends on the intensity of the radiation and the exposure duration. Approximate injury and fatality levels are provided in Figure A.3. 


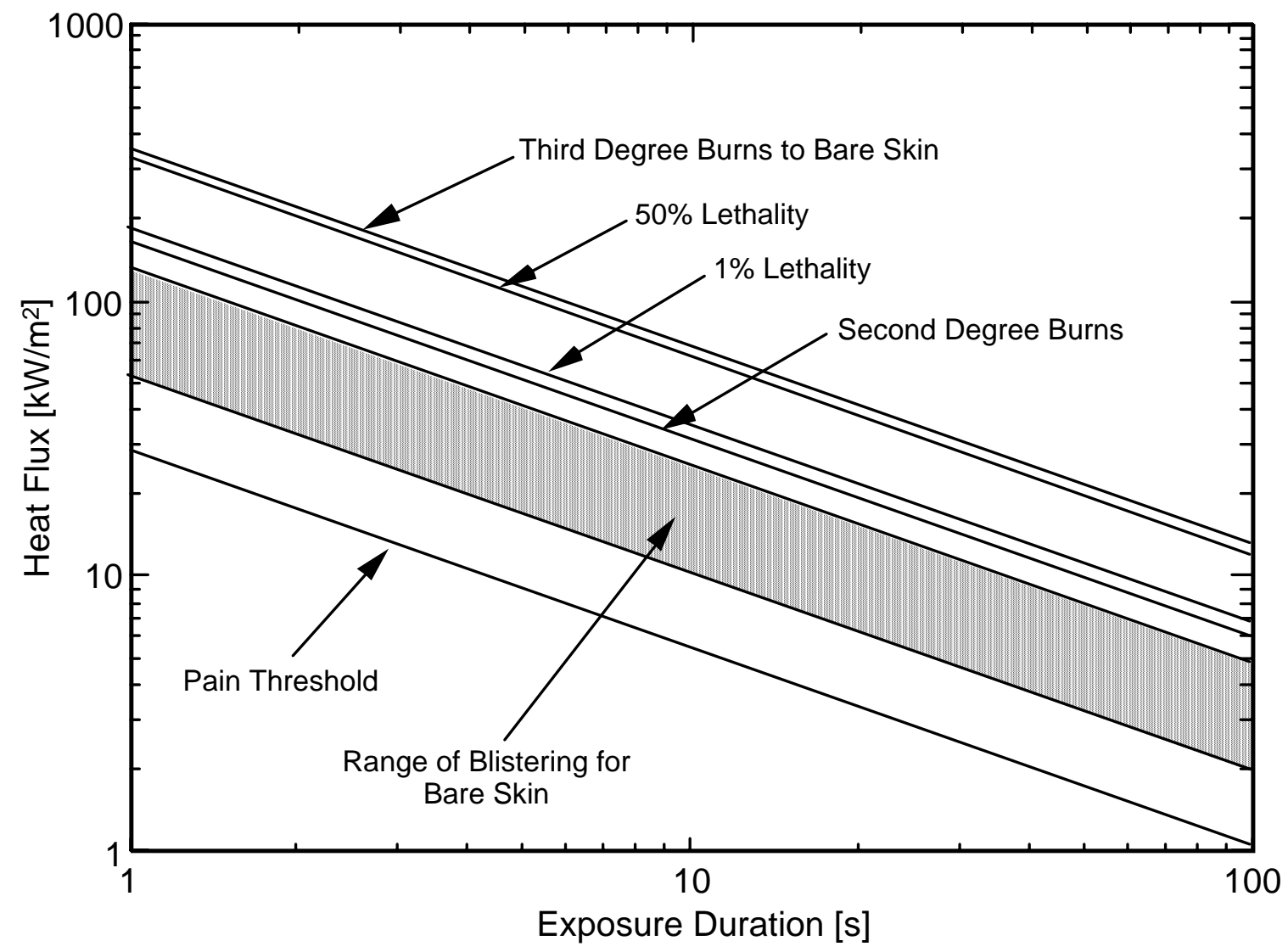

Figure A.3 Human Health Impacts from Thermal Radiation (Source: Adapted from AICHE [1994] and Hymes [1983])

For the NTRA, fatalities are calculated by directly multiplying the local population density by the hazard area bounded by the $50 \%$ lethality level of radiation for the time period corresponding to the fireball duration. Because some fatalities will occur outside the $50 \%$ lethality level and some persons outside the level will survive, the number of persons within the area bounded by the $50 \%$ lethality curve provides a reasonable estimate of fatalities. The $50 \%$ lethality curve is represented by the relationship

$$
q=325 t_{f}^{-0.7}
$$

where the fireball duration is given in terms of the fuel mass such that (Roberts 1982)

$$
t_{f}=0.45 m^{1 / 3} .
$$


In a similar manner, the injury zone for radiation effects is provided by the bounding curve:

$$
q=75 t_{f}^{-0.7}
$$

\section{A.2.2 Flash Fires}

If the flammable vapor/aerosol mix disperses downwind to a significant extent before igniting, a vapor cloud fire or flash fire will result. The area covered by this fire depends on many factors, including the amount of material released, meteorology, local terrain, and delay until ignition. To a large extent, the calculation of hazards due to flash fires is more complicated than those due to fireballs because both the dispersion of the mixture and the ignition time become important factors. The dispersion part of the problem is made especially complicated by the dense-gas nature of the vapor/aerosol mixture, causing the transport and dispersion (e.g., mixing) of the vapor cloud to become sensitive to local terrain variations. The hazard-zone phase of the analysis is further complicated by the fact that ignition can occur at any time along the path. Because the NTRA is statistical in nature, however, the treatment of site-specific parameters such as terrain and meteorology are not as critical as long as the overall methodology captures the correct statistical distribution of fire area and ignition probability. The methodology described in this section accomplishes this task in an efficient, straightforward manner while representing the key physical phenomena important to the vapor cloud fire problem.

\section{A.2.2.1 Vapor Cloud Dispersion and Ignition}

Because the dispersion of LP gas is strongly affected by dense gas effects when LP gas concentrations exceed flammable limits, standard passive release models such as that used in CASRAM are not applicable. Therefore, a simple dense-gas dispersion methodology is used in predicting hazard zone area. 8

The vapor/air mixture resulting from the LP gas release is modeled as a circular cloud characterized by uniform height and a Gaussian concentration profile such that,

$$
C=C_{o} \exp \left(\frac{r^{2}}{2 \sigma_{r}^{2}}\right)^{2},
$$

where

$$
C_{o}=\frac{M}{2 \pi \sigma_{r}^{2} H},
$$

8 A more sophisticated dense gas algorithm was added to CASRAM as part of the work for ERG 2000 (Brown et al. 2000). Therefore, subsequent studies will improve on the dispersion part of this analysis. 
$r$ is the radius from the center, $\sigma_{r}$ is the relative cloud size, and $H$ is the cloud height (in meters) given by

$$
H=3.0+0.75 U
$$

where $U$ is the wind speed (in meters per second). In this framework, the growth rate of the cloud is represented by

$$
\frac{d \sigma_{r}}{d t}=0.2 U
$$

where the initial radius is chosen such that the peak concentration is $25 \%$. Although the above model provides a fairly crude representation of dense gas dispersion, it does capture the general features of liquefied natural gas (LNG) dispersion observed in experimental studies of large LNG spills (Ermak et al. 1988).

At any given time while the plume is growing, the ignition probability is taken as the sum of independent source, area, and edge ignition probabilities. Assuming that the probabilities are small on a per-unit time basis, we represent the probabilities as

$$
P(\text { ignition })=P(\text { source })+P(\text { area })+P(\text { edge }),
$$

where

$$
\begin{aligned}
& P(\text { source })=a_{1}, \\
& P(\text { area })=a_{2} A,
\end{aligned}
$$

and where

$$
P(\text { edge })=a_{3} \frac{d A}{d t}
$$

$A=$ area of the cloud in which the LP gas concentration is above the lower flammability limit,

$p=$ probability of an ignition source being present within the plume per unit time, and

$a_{1}, a_{2}$, and $a_{3}=$ constants.

The source ignition term represents ignition sources such as the electrical and engine systems on the LP gas truck and any other immediate vehicles involved in the area. This 
term is represented by a constant probability with respect to time because it does not depend on source area. The area ignition term takes into account ignition sources whose probability of occurrence depend on the plume area. Sources in this class include passing vehicles and intermittent fixed sources within the plume. The last term represented in Equation A.44 accounts for ignition sources at the edge of the plume. Sources within this class include pilot lights within buildings or sheds and other fires or steady ignition sources away from the incident.

In the NTRA, we assume that approximately one-fourth of the fires ignite at the source, one-half of the fires are ignited within the plume area away from the source and away from the edge, and one-fourth of the fires are ignited at the edge as the plume edge passes over a fixed, steady ignition source. Considering the ignition probabilities previously outlined in Table 2.17 and the constraints above, the constants $a_{1}, a_{2}$, and $a_{3}$ in Equation A.44 become $0.002 \mathrm{~s}^{-1}, 3 \mathrm{e}-7 \mathrm{~s}^{-1} \mathrm{~m}^{-2}$, and $5 \mathrm{e}-6 \mathrm{~m}^{-2}$, respectively.

In calculating hazard area size and ignition probability, we stipulate that ignition cannot occur once the maximum cloud concentration decreases below the lower flammability limit. The properties of LP gas are assumed to be equivalent to those of propane, which has a lower flammability limit of $2 \%$ by volume.

\section{A.2.2.2 Assessment of Human Health Impacts}

The analysis previously outlined provides the geometry of the cloud at ignition. The use of this information for calculating human health effects from flash fires proceeds similarly as for the fireball calculation.

To estimate human health impacts, fires are modeled as radiating surfaces transmitting to receptors at various distances from the flame front. Calculating these effects is complicated by the fact that the flame is moving with respect to the receptor and that the flame propagation characteristics depend strongly on the cloud geometry and the location of the ignition source within the cloud. We define the geometry of the flame front and then outline how this information is used to calculate the radiation impacts in the region surrounding the fire.

A.2.2.2.1 Fire Geometry. In the NTRA, we approximate the flame as a cylinder of height $F_{h}$ and radius $r=0.6 R_{0}$ that burns for a fixed time

$$
t_{f}=\frac{R_{0}}{U_{f}} .
$$

Here, $R_{0}$ is the distance from the cloud center at which the LP concentration drops below the lower flammability limit, and $U_{f}$ is the flame speed, which is given by the following empirical relationship (AICHE 1994): 


$$
U_{f}=2.3 U .
$$

This flame description is a simplification of reality because the flame front evolves and moves considerably over the course of the vapor cloud fire. However, this general geometry is reasonably valid for problems where the ignition point is near the center of the plume, which is around $40 \%$ to $50 \%$ of the cases considered in our analysis.

Furthermore, it serves as a reasonable approximation for the scenarios whereby the flame initiates at the source or at the leading edge of the plume, since this methodology captures the general shape of the flame front and approximate burn time. These latter cases are particularly difficult to address more precisely because the flame area (as viewed at various points around the fire) varies considerably. Considering the nature of other simplifications used in the flash fire calculation, the use of a more sophisticated methodology for treating the radiation exposure would provide little additional precision for the model presented here.

The flame height $F_{h}$ is an important parameter to the flash fire radiation calculation because it governs the size of the radiating surface involved. Unfortunately, experimental data on flame height from flash fires are very scarce, and no experiments have been reported in which all important factors have been analyzed. As a consequence, flame height models are not well developed at this time. The model used for the NTRA is that developed by AICHE (1994) as a extension of the flame height model of Steward (1964). Here, the flame height after ignition is given as

$$
F_{h}=20 H\left(\frac{U_{f}^{2} \beta R_{s}^{2}}{g H(1-\beta)^{3}}\left(\frac{\rho_{f a}}{\rho_{a}}\right)^{2}\right),
$$

where

$$
\begin{aligned}
H & =\text { cloud depth }(\mathrm{m}), \\
U_{f} & =\text { flame speed }(\mathrm{m} / \mathrm{s}), \\
\rho_{f a} & =\text { air-fuel mixture density }\left(\mathrm{kg} / \mathrm{m}^{3}\right), \\
\rho_{a} & =\text { air density }(\mathrm{kg} / \mathrm{m}), \\
R_{S} & =\text { stoichiometric air-fuel mass ratio, and } \\
\beta & =\text { parameter denoting the inverse of the volumetric expansion. }
\end{aligned}
$$


The stoichiometric air-fuel mass ratio is given by

$$
R_{s}=\frac{\left(1-\phi_{s t}\right) M_{a}}{\phi_{s t} M_{f}},
$$

where $\phi_{s t}$ is the stoichiometric fuel volume ratio, and $M_{a}$ and $M_{f}$ are the air and fuel molecular weights, respectively. The inverse of the volumetric expansion $\beta$ is given by

$$
\begin{array}{cc}
\beta=\frac{\phi-\phi_{s t}}{\alpha\left(1-\phi_{s t}\right)}, & \phi>\phi_{s t} \\
\beta=0 & \phi \leq \phi_{s t},
\end{array}
$$

where $\phi$ is the fuel volume ratio of the cloud, and $\alpha$ is the constant pressure expansion ratio for stoichiometric combustion, which is around 8 for most hydrocarbon fuels.

The limits of applicability of Equation A.47 are not discussed in AICHE (1994). Our analysis showed that this method provides reasonable estimates for flame heights in many scenarios, but its application appears to be limited to problems where the fuel concentration is above the stoichiometric value ( $4 \%$ by volume for propane) and below around $15 \%$. For fuel concentrations below the stoichiometric value, the predicted flame height is zero because $\beta=0$. In these cases, we set the flame height to the cloud height. For higher fuel concentrations, unrealistically large flame heights can result, sometimes in excess of $150 \mathrm{~m}$ for releases considered in the NTRA analysis. In these cases, we limited the flame height to the diameter of the flammable portion of the cloud.

Fortunately, the hazard zone sizes are not very sensitive to flame height once the flame height is greater than $50 \mathrm{~m}$. Furthermore, since our initial concentration is set to $25 \%$ by volume, ignition at LP gas concentrations above $15 \%$ is very infrequent.

A.2.2.2.2 Hazard Zone Estimation. The thermal radiation from the fire received at a receptor was given in Equation A.34; namely,

$$
q=\tau F E
$$

In applying this relationship for flash-fire analysis, the emissive power of LP gas flames is $173 \mathrm{~kW} / \mathrm{m}^{2}$ on the basis of the experimental results of Blackmore et al. (1982) and recommendations of AICHE (1994). For the cylindrical geometry, the view factor as measured from the center of the cylinder is given by 


$$
F=\frac{1}{\pi X_{r}} \tan ^{-1}\left(\frac{H_{r}}{\left(X_{r}-1\right)^{1 / 2}}\right)+\frac{H_{r}}{\pi}\left(\frac{A-2 X_{r}}{X_{r} \sqrt{A B}} \tan ^{-1}\left(\left(\frac{A\left(X_{r}-1\right)}{B\left(X_{r}+1\right)}\right)^{1 / 2}\right)-\frac{1}{X_{r}} \tan ^{-1}\left(\frac{X_{r}-1}{X_{r}+1}\right)^{1 / 2}\right)
$$

where

$$
\begin{aligned}
& X_{r}=X / R_{O}, \\
& H_{r}=F_{h} / R_{O}, \\
& A=\left(1+H_{r}\right)^{2}+X_{r}^{2}, \text { and } \\
& B=\left(1-H_{r}\right)^{2}+X_{r}^{2} .
\end{aligned}
$$

The last parameter in Equation A.34, the transmissivity, is given by Equation A.37.

Similar to the analysis outlined for fireballs, fatalities are estimated by multiplying local population density by the hazard area bounded by the $50 \%$ lethality level of radiation given in Equation A.38 for the period corresponding to the fire duration. The injury zone for fire radiation effects is calculated in a similar fashion by using the radiation limits given in Equation A.40.

For some cases with low flame heights $(<5 \mathrm{~m})$, the fatality zone calculated in the above procedure was less than the fire area of the flammable portion of the vapor cloud prior to ignition. For these cases, we defined the fatality zone as the flammable vapor cloud area. The low number of fatalities for such areas is due to the approximations involved in the cylindrical fire assumption combined with the low emissive power of the flash fires, especially in comparison with those of fireballs. For most cases considered in this analysis, impacts due to the generation of a fireball exceeded those due to flash fires. Only when vapor cloud size was very large with concentrations near the lower flammability limit did impacts from flash fires exceed those of fireballs.

\section{A.3 Explosive Materials}

As discussed in Section 2.5, the hazards associated with explosives include direct blast overpressure effects, secondary overpressure effects such as impact from blast-generated debris, whole body displacement (i.e., tertiary blast effects), and thermal effects due to an explosion-generated fireball. Direct, secondary, and tertiary blast overpressure effects are wrapped together into a generalized treatment based on blast overpressure and are discussed in Section A.3.1. Thermal effects due to explosion-generated fireballs are discussed in Section A.3.2. 


\section{A.3.1 Blast Overpressure Effects}

\section{A.3.1.1 Calculation of Blast Parameters}

Given the mass of the explosive detonated, the calculation of explosion parameters such as blast overpressure and blast wave duration at various points away from the explosion center is very straightforward and uses simple scaling analyses. One of the most widely used methods for this purpose is Sachs scaling (Baker 1983; AICHE 1995). Here, a scaled pressure, defined as

$$
\bar{P}=\frac{P}{P_{o}}-1
$$

and a scaled impulse, defined as

$$
\bar{I}=\frac{I a_{o}}{E_{b}^{1 / 3} P_{o}^{1 / 3}},
$$

are represented as functions of a scaled distance defined as

$$
\bar{R}=\frac{R P_{o}^{1 / 3}}{E_{b}^{1 / 3}} .
$$

In these expressions, $P$ is the amplitude of the blast pressure wave, $P_{o}$ is atmospheric pressure, $I$ is the blast impulse (defined as integral of the pressure time history), $a_{o}$ is the speed of sound, $E_{b}$ is the blast energy, and $R$ is the distance from the blast center. The blast overpressure $\Delta P$, which is the difference between the peak pressure of the blast wave and atmospheric pressure, is then

$$
\Delta P=P-P_{o}=P_{o} \bar{P} .
$$

The blast energy in the above relationships is the mass of explosive detonated multiplied by the mass specific energy. For dynamite and ANFO, the mass specific energy is 4.52 and $6.42 \mathrm{MJ} / \mathrm{kg}$, respectively.

In practice, one first calculates the scaled distance at the point of interest and then obtains the scaled pressure and scaled impulse using curves generated from experimental observations. A curve relating $\bar{P}$ to $\bar{R}$ as determined from laboratory data for pentolite (50\% PETN, 50\% TNT) is shown in Figure A.4. For the NTRA analysis, we only consider blast overpressure. While blast impulse is a critical factor in assessing direct injuries or fatalities, it is less important in assessing the likelihood for flying debris, structural damage, or other blast effects that can lead to injury or death. Secondary and tertiary blast overpressure effects lead to the majority of injuries and fatalities. 


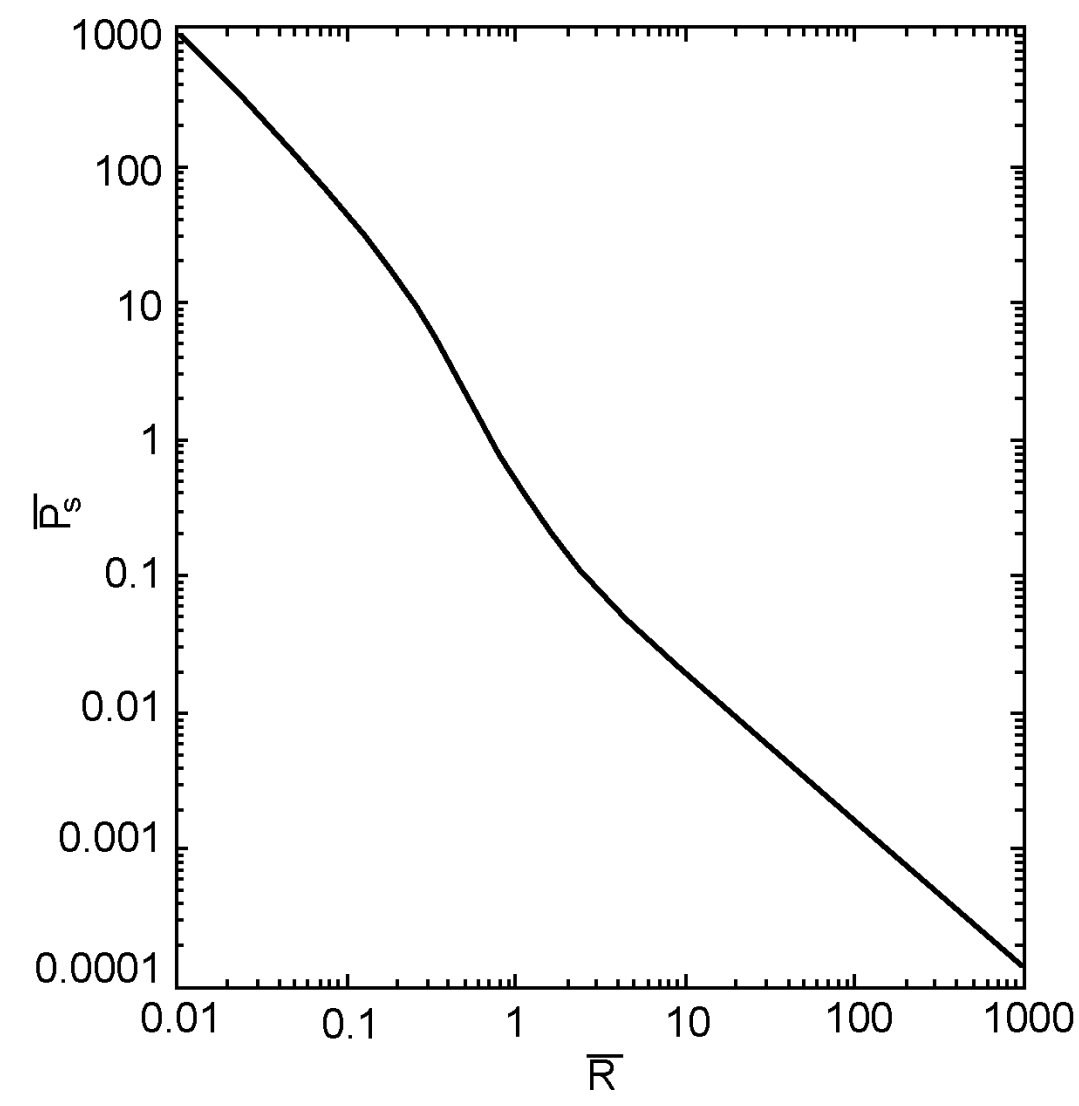

Figure A.4 Scaled Pressure as a Function of Scaled Distance for Pentolite (Source: Baker 1983)

\section{A.3.1.2 Assessment of Human Health Impacts as a Result of Blast Overpressure}

Estimating health impacts as a result of blast overpressure is difficult because of the variety of hazards from explosions. As noted, these hazards include direct blast overpressure effects on human tissue, and secondary and tertiary effects due to the explosion generated missiles as well as physical displacement of people themselves. Some of the effects of blast overpressure are given in Table A.3. The level of blast overpressure necessary to cause a significant level of damage on structures is much lower than that necessary to directly result in injuries or fatalities. For instance, it takes at least a 15-psi overpressure to injure tissue to the point where death can occur. ĐHowever, this is well above the limit required for complete destruction of buildings indicating that it is more

9 This is an absolute lower limit. Many references quote substantially higher overpressure values for $50 \%$ fatalities. The reason for these discrepancies is the influence of the duration of overpressure (as measured through the blast impulse previously discussed). 
Table A.3 Expected Damage and Injury for Various Levels of Blast Overpressure

\begin{tabular}{|lc|}
\hline \multicolumn{1}{|c|}{ Damage/Consequence } & Overpressure (psi) \\
\hline Breakage of small windows under strain & 0.1 \\
Some damage to house ceilings, 10\% window breakage & 0.3 \\
Limited minor structural damage & 0.4 \\
Windows usually shattered & $0.5-1.0$ \\
Partial demolition of houses & 1.0 \\
Lower limit for injuries due to flying debris & 1.0 \\
Nonreinforced concrete walls shatter & $1.0-2.0$ \\
Partial collapse of house walls and roofs & 2.0 \\
Lower limit for serious structural damage & 2.3 \\
Range for 1\%-99\% eardrum rupture & $2.4-12.2$ \\
50\% destruction of home brickwork & 2.5 \\
Wooden utility poles snapped & 5.0 \\
Complete destruction of houses & 7.0 \\
Loaded train cars overturned & 7.0 \\
Loaded train cars demolished & 9.0 \\
1\%-99\% fatalities due to direct blast effects & $15.5-29.0$ \\
\hline
\end{tabular}

Source: Adapted from Lees (1980).

likely for someone to be injured or killed due to flying debris, the collapse of buildings, or the trauma caused by impacting people into fixed objects than due to direct blast effects. Indeed, this has been observed in injury and fatality statistics for explosions. For example, the fatalities and injuries resulting from 81 accidents within the explosives or propellants industry were considered (Settles 1968). Although Settles estimates that detonating forces were present in at least 14 of the accidents, none of the fatalities was due to the effects of direct blast overpressure. Rather, fatalities were either caused by thermal effects or by debris, with one fatality being caused by tertiary overpressure effects.

The injury and lethality thresholds for blast overpressure used in the NTRA are listed in Table A.4. In establishing these thresholds, we attempted to included the influence of blast-generated debris as well as other secondary effects, while remaining consistent with the observations noted above. The $100 \%$ lethality threshold is set at a level at which we believe the combination of direct, secondary, and tertiary blast effects make survival very unlikely. As evidenced in Table A.3, this level is well beyond that necessary for complete destruction of houses, and is in the range where direct blast effects become important. The $50 \%$ lethality threshold is set at a level equivalent to that for complete destruction of houses. This level was chosen because of earthquake statistics, which indicate that approximately $50 \%$ of fatalities will occur in collapsed buildings (AICHE 1995). The injury threshold is set within the lower range for eardrum rupture and substantial building damage. 
Table A.4 Injury and Lethality Thresholds for Blast Overpressure Used in the NTRA

\begin{tabular}{|cc|}
\hline Effect & Threshold \\
\hline 100\% Lethality & 20 \\
$50 \%$ Lethality & 7 \\
Injury & 2.5 \\
\hline
\end{tabular}

\section{A.3.2 Thermal Effects}

The study by Settles (1968) illustrated the potential importance of thermal effects in assessment of injuries and fatalities in explosions. Therefore, thermal effects are considered in addition to blast overpressure effects. For explosives, we use a similar methodology as used for modeling fireballs generated by LP gas. However, the relationships used for propane fireballs do not directly apply for explosives because of the higher temperature of explosives detonations. Baker (1983) provides an excellent discussion on the scaling laws concerning fireball growth and duration. Baker's analysis results in the following scaling laws concerning the diameter and burn duration of fireballs:

$$
D_{f}\left(\frac{T_{f}}{E_{b}}\right)^{1 / 3}=A_{1},
$$

and

$$
\frac{t_{f} T^{10 / 3}}{E_{b}^{1 / 3}}=A_{2},
$$

where

$$
\begin{aligned}
& D_{f}, T_{f}, \text { and } t_{f}= \begin{array}{l}
\text { fireball diameter }(\mathrm{m}), \text { temperature }(\mathrm{K}), \text { and burn duration }(\mathrm{s}), \\
\text { respectively; }
\end{array} \\
& E_{b}= \text { total energy of the explosion }(\mathrm{mJ}) ; \text { and } \\
& A_{1} \text { and } A_{2}=\text { constants. }
\end{aligned}
$$

The most immediate consequence of these scaling arguments is that fireball diameter is inversely proportional to the cube root of the fireball temperature, whereas the burn duration is inversely proportional to the fireball temperature to the $10^{3}$. That is, for the same amount of energy, an increase in temperature from 1,600 to 4,000 K (the approximate temperature of a fireball generated by LP and high explosives, respectively) will decrease the fireball diameter by only $28 \%$ but will decrease the duration by more 
than $96 \%$. However, the emissive power of the fireball will increase an amount proportional to the temperature to the fourth power in accordance with Boltzmann's law. Scaling the diameter, burn duration, and emissive power relationships given in Section A.2.1 to an arbitrary fireball temperature $T_{f}$, we obtain

$$
\begin{aligned}
& D_{f}=18.73\left(\frac{E_{b}}{T_{f}}\right)^{1 / 3}, \\
& t_{f}=5.66 \times 10^{9} \frac{E_{b}^{1 / 3}}{T_{f}^{1 / 3}},
\end{aligned}
$$

and

$$
E=5.67 \times 10^{8} T_{f}^{4}
$$

For this study, we use an explosives temperature of 3,500 K. Published temperature values for explosive-generated fireballs range from less than 2,000 K (Jarrett 1968) to around $5,000 \mathrm{~K}$ (Baker 1983). The 3,500 K value chosen for this study is a compromise between these reported values. 
$\Delta$ 


\section{Appendix B Top 150 Hazardous Materials Transported by Rail, 1986-1995}

Table B.1 lists the top 150 most heavily shipped hazardous materials transported by rail from 1986 to 1995 in total ton-miles. Table B.1 was compiled by performing a detailed analysis of the Association of American Railroads (AAR) waybill records. For each material, the Standard Transportation Commodity Code (STCC), the number of waybill samples, the total number of cars shipped, and the total number of ton-miles are provided. Table B.1 is sorted in total ton-miles. Total number of cars shipped, and the total number of ton-miles were estimated by using mileage and lading weights provided in the actual waybill samples together with the exact expansion factor given in each sample (Section 4.2 discusses the Waybill Sample and the use of expansion factors). Because STCCs often change for individual materials, many materials given in the table have multiple STCCs because 10 years of data are included. Such materials are noted with an asterisk, and the most prevalent STCC is given. Materials designated by the U.S. Department of Transportation as toxic by inhalation (TIH) are listed in bold. The TIH materials in the top 150 hazardous materials shipped include ammonia, chlorine, ethylene oxide, hydrogen fluoride, sulfur dioxide, fuming sulfuric acid, ethylene oxide (with nitrate), hydrogen chloride, titanium tetrachloride, and fuming nitric acid.

Table B.1 Top 150 Most Heavily Shipped Hazardous Materials by Rail, 1986-1995, Determined from the AAR Waybill Samplea

\begin{tabular}{|c|c|c|c|c|c|}
\hline Rank & Commodity & STCC & $\begin{array}{l}\text { Waybill } \\
\text { Samples }\end{array}$ & $\begin{array}{c}\text { Total Cars } \\
\text { Shipped } \\
\left(\times 10^{3}\right)\end{array}$ & $\begin{array}{c}\text { Total Ton- } \\
\text { Miles } \\
\left(\times 10^{6}\right)\end{array}$ \\
\hline 1 & Molten sulfur & $4945770^{b}$ & 9,179 & 529.90 & 63,734 \\
\hline 2 & Sulfuric acid (solution) & 4930040 & 12,595 & 576.64 & 37,614 \\
\hline 3 & Sodium hydroxide & $4935240^{\mathrm{b}}$ & 17,130 & 714.09 & 35,335 \\
\hline 4 & LP gases & $4905752^{b}$ & 13,295 & 564.13 & 27,433 \\
\hline 5 & Phosphoric acid & $4930247^{b}$ & 5,977 & 316.37 & 22,092 \\
\hline 6 & Ammonia & $4904210^{b}$ & 10,284 & 450.22 & 21,012 \\
\hline 7 & Chlorine & $4920523^{b}$ & 10,761 & 445.71 & 20,613 \\
\hline 8 & Vinyl chloride & $4905792^{b}$ & 6,121 & 264.45 & 15,329 \\
\hline 9 & Methanol & $4909230^{b}$ & 4,234 & 174.80 & 14,130 \\
\hline 10 & Styrene monomer, inhibited & 4907265 & 2,937 & 120.70 & 13,839 \\
\hline 11 & Denatured alcohol & $4909151^{b}$ & 3,729 & 170.83 & 12,579 \\
\hline 12 & Ammonium nitrate & $4918311^{b}$ & 4,954 & 201.86 & 11,215 \\
\hline 13 & Propane & $4905781^{b}$ & 3,741 & 160.12 & 8,024 \\
\hline 14 & Elevated temperature liquid, n.o.s. ${ }^{c}$ & $4941196^{b}$ & 2,788 & 127.05 & 7,903 \\
\hline
\end{tabular}

Continued 
Table B.1 Top 150 Most Heavily Shipped Hazardous Materials by Rail, 1986-1995, Determined from the AAR Waybill Sample ${ }^{a}$ (Cont.)

\begin{tabular}{|c|c|c|c|c|c|}
\hline Rank & Commodity & STCC & $\begin{array}{l}\text { Waybill } \\
\text { Samples }\end{array}$ & $\begin{array}{c}\text { Total Cars } \\
\text { Shipped } \\
\left(\times 10^{3}\right)\end{array}$ & $\begin{array}{c}\text { Total Ton- } \\
\text { Miles } \\
\left(\times 10^{6}\right)\end{array}$ \\
\hline 15 & Butane & $4905706^{b}$ & 4,016 & 174.58 & 7,630 \\
\hline 16 & Organic acids or salts & 4966110 & 1,583 & 63.11 & 7,433 \\
\hline 17 & Hydrochloric acid, solution & 4930228 & 3,182 & 130.88 & 6,975 \\
\hline 18 & Butadiene, inhibited & $4905704^{b}$ & 2,159 & 89.76 & 6,449 \\
\hline 19 & Hexamethylenediamine, solid & 4935645 & 1,469 & 58.42 & 6,101 \\
\hline 20 & Carbon dioxide & 4904509 & 3,310 & 134.76 & 5,925 \\
\hline 21 & Sodium chlorate & $4918723^{b}$ & 1,313 & 55.78 & 5,386 \\
\hline 22 & Vinyl acetate, inhibited & 4907270 & 1,144 & 45.82 & 5,357 \\
\hline 23 & Acetic anhydride & $4931303^{b}$ & 1,271 & 51.25 & 5,244 \\
\hline 24 & Fuel oil & $4915111^{b}$ & 3,237 & 203.34 & 5,118 \\
\hline 25 & Hazardous substance, n.o.s. & $4960132^{b}$ & 1,520 & 62.25 & 5,068 \\
\hline 26 & Propylene & $4905782^{b}$ & 2,371 & 95.68 & 5,055 \\
\hline 27 & Methyl methacrylate monomer, inhibited & $4907255^{\mathrm{b}}$ & 1,124 & 45.34 & 4,817 \\
\hline 28 & Phenol, solid & 4921220 & 1,156 & 47.86 & 4,605 \\
\hline 29 & Phosphorus, white or yellow, dry & 4916141 & 832 & 33.78 & 4,055 \\
\hline 30 & Isobutane & $4905747^{b}$ & 2,436 & 100.46 & 3,686 \\
\hline 31 & Petroleum refining products & $4915259^{b}$ & 1,229 & 51.29 & 3,471 \\
\hline 32 & Propylene oxide & 4906620 & 1,273 & 50.99 & 3,340 \\
\hline 33 & Toluene & $4909305^{b}$ & 1,575 & 139.35 & 3,270 \\
\hline 34 & Toluene diisocyanate & 4921575 & 904 & 37.57 & 3,178 \\
\hline 35 & Ethylene oxide & 4906610 & 1,104 & 45.29 & 3,171 \\
\hline 36 & Petroleum crude oil & 4910165 & 1,628 & 96.68 & 2,771 \\
\hline 37 & Potassium hydroxide, solution & 4935230 & 855 & 34.20 & 2,667 \\
\hline 38 & Xylene & $4909350^{b}$ & 1,399 & 56.14 & 2,642 \\
\hline 39 & Combustible liquid, n.o.s. & 4915185 & 839 & 34.00 & 2,600 \\
\hline 40 & Acrylonitrile & 4906420 & 982 & 40.43 & 2,500 \\
\hline 41 & Butyl acrylate & 4912215 & 614 & 24.76 & 2,473 \\
\hline 42 & Formaldehyde solutions & $4913168^{b}$ & 1,140 & 47.17 & 2,399 \\
\hline 43 & Ethanol & $4909146^{b}$ & 594 & 25.17 & 2,306 \\
\hline 44 & Sulfuric acid, spent & 4930042 & 1,195 & 53.11 & 2,224 \\
\hline 45 & Naptha & $4910259^{b}$ & 946 & 61.16 & 2,159 \\
\hline 46 & Hydrogen peroxide, stabilized & 4918335 & 504 & 21.38 & 2,096 \\
\hline 47 & Methyl tert-butyl ether & 4908224 & 490 & 19.57 & 2,094 \\
\hline 48 & Acetone & 4908105 & 796 & 31.75 & 1,993 \\
\hline 49 & Corrosive liquids, n.o.s. & $4936540^{\mathrm{b}}$ & 1,054 & 42.91 & 1,988 \\
\hline 50 & Isopropanol & 4909205 & 647 & 26.20 & 1,972 \\
\hline 51 & Acetaldehyde & 4907210 & 680 & 26.96 & 1,927 \\
\hline 52 & Alcoholic beverage & $4910102^{b}$ & 723 & 29.66 & 1,874 \\
\hline 53 & Hydrogen fluoride & 4930024 & 571 & 22.87 & 1,829 \\
\hline 54 & Flammable liquids, n.o.s. & 4910185 & 830 & 34.32 & 1,684 \\
\hline 55 & Sulfur dioxide & $4920508^{b}$ & 543 & 21.86 & 1,648 \\
\hline 56 & Benzene & 4908110 & 742 & 44.96 & 1,622 \\
\hline 57 & Acrylic acid, inhibited & 4931405 & 504 & 20.12 & 1,521 \\
\hline
\end{tabular}

Continued 
Table B.1 Top 150 Most Heavily Shipped Hazardous Materials by Rail, 1986-1995, Determined from the AAR Waybill Sample ${ }^{a}$ (Cont.)

\begin{tabular}{|c|c|c|c|c|c|}
\hline Rank & Commodity Name & STCC Code & $\begin{array}{l}\text { Waybill } \\
\text { Samples }\end{array}$ & $\begin{array}{c}\text { Total Cars } \\
\text { Shipped } \\
\left(\times 10^{3}\right)\end{array}$ & $\begin{array}{c}\text { Total Ton- } \\
\text { Miles } \\
\left(\times 10^{6}\right)\end{array}$ \\
\hline 58 & Ferric chloride solution & $4932342^{b}$ & 522 & 21.34 & 1,507 \\
\hline 59 & Ethyl acrylate, inhibited & 4907215 & 338 & 13.70 & 1,444 \\
\hline 60 & Phenol, molten & 4921598 & 395 & 15.78 & 1,342 \\
\hline 61 & Butyl alcohol & $4909117^{b}$ & 539 & 21.34 & 1,320 \\
\hline 62 & Chemical or petroleum waste & 4910490 & 250 & 9.92 & 1,309 \\
\hline 63 & Copper conc. (lead sulfide, arsenic) & 4966325 & 304 & 16.11 & 1,289 \\
\hline 64 & Methyl ethyl ketone & 4909243 & 285 & 11.36 & 1,254 \\
\hline 65 & Maleic anhydride & $4941161^{b}$ & 378 & 15.01 & 1,202 \\
\hline 66 & Fuel oil additives & $4910535^{b}$ & 337 & 13.44 & 1,180 \\
\hline 67 & Cyclohexane & 4908132 & 805 & 34.29 & 1,172 \\
\hline 68 & Methyl chloride & 4905761 & 316 & 13.85 & 1,152 \\
\hline 69 & Fluorosilicic acid & 4930026 & 278 & 11.75 & 1,125 \\
\hline 70 & Argon, refrigerated liquid & 4904503 & 232 & 9.21 & 1,094 \\
\hline 71 & Vinylidene chloride, inhibited & 4907280 & 206 & 8.22 & 992 \\
\hline 72 & Industrial inorganic chemicals, n.o.s. & 4904290 & 317 & 12.91 & 987 \\
\hline 73 & Warheads, rocket & 4901240 & 231 & 13.37 & 975 \\
\hline 74 & Sodium hydrosulfide, solution & 4935268 & 260 & 10.77 & 955 \\
\hline 75 & Potassium nitrate & 4918737 & 311 & 12.32 & 912 \\
\hline 76 & Dichlorodifluoromethane & 4904516 & 275 & 11.01 & 903 \\
\hline 77 & 1,1,1-trichloroethylene & 4941176 & 170 & 6.73 & 867 \\
\hline 78 & Sodium cyanide, solid & 4923228 & 373 & 15.21 & 834 \\
\hline 79 & Naptha solvent & $4909279^{b}$ & 221 & 8.86 & 824 \\
\hline 80 & Sulfuric acid, fuming & 4930030 & 566 & 23.40 & 821 \\
\hline 81 & Octyl alcohol & 4913158 & 258 & 10.41 & 800 \\
\hline 82 & Ethylene oxide (with nitrate) & 4920353 & 270 & 11.08 & 795 \\
\hline 83 & Ethyl acetate & 4909160 & 272 & 10.91 & 782 \\
\hline 84 & Carbon disulfide & 4908125 & 297 & 12.23 & 779 \\
\hline 85 & Lead sulfide & $4963101^{b}$ & 240 & 12.48 & 744 \\
\hline 86 & Calcium carbide & 4916408 & 245 & 10.07 & 735 \\
\hline 87 & Glycol ethers & 4913194 & 212 & 8.40 & 726 \\
\hline 88 & Isoprene, inhibited & 4907230 & 190 & 7.54 & 710 \\
\hline 89 & Fuel, aviation, turbine engine & 4909215 & 789 & 77.29 & 690 \\
\hline 90 & Isobutylene & 4905748 & 348 & 13.81 & 687 \\
\hline 91 & Resin compound, liquid & 4910280 & 371 & 15.08 & 682 \\
\hline 92 & Gum or wood chemicals & 4910444 & 177 & 7.30 & 682 \\
\hline 93 & Hexanes & 4908183 & 285 & 11.63 & 680 \\
\hline 94 & Butyraldehyde & 4908119 & 199 & 7.90 & 672 \\
\hline 95 & Tetrahydrofuran & 4908290 & 168 & 7.15 & 661 \\
\hline 96 & Battery, wet, filled with acid & $4936556^{b}$ & 515 & 21.43 & 644 \\
\hline 97 & Butyl acetate & 4909128 & 223 & 8.86 & 640 \\
\hline 98 & Hydrogen chloride & $4904271^{b}$ & 211 & 9.21 & 637 \\
\hline 99 & Carbon tetrachloride & 4940320 & 217 & 8.67 & 601 \\
\hline 100 & Chlorodifluoromethane & 4904552 & 201 & 8.01 & 589 \\
\hline
\end{tabular}

Continued 
Table B.1 Top 150 Most Heavily Shipped Hazardous Materials by Rail, 1986-1995, Determined from the AAR Waybill Sample ${ }^{a}$ (Cont.)

\begin{tabular}{|c|c|c|c|c|c|}
\hline Rank & Commodity & STCC & $\begin{array}{l}\text { Waybill } \\
\text { Samples }\end{array}$ & $\begin{array}{c}\text { Total Cars } \\
\text { Shipped } \\
\left(\times 10^{3}\right)\end{array}$ & $\begin{array}{c}\text { Total Ton- } \\
\text { Miles } \\
\left(\times 10^{6}\right)\end{array}$ \\
\hline 101 & Waste sodium solution & 4935248 & 159 & 6.74 & 589 \\
\hline 102 & Ethanolamine & 4935665 & 158 & 6.29 & 585 \\
\hline 103 & White asbestos & $4945708^{b}$ & 356 & 15.47 & 573 \\
\hline 104 & Butene gas, liquefied & 4905707 & 396 & 17.51 & 567 \\
\hline 105 & Hydrogen peroxide solution & $4918776^{b}$ & 168 & 6.94 & 566 \\
\hline 106 & Nitric acid, fuming & $4918529^{b}$ & 190 & 7.60 & 546 \\
\hline 107 & Titanium tetrachloride & 4932385 & 53 & 2.11 & 534 \\
\hline 108 & Aniline & 4921410 & 228 & 9.63 & 506 \\
\hline 109 & Methylvaleraldehyde & 4908177 & 340 & 23.34 & 505 \\
\hline 110 & Sodium & 4916456 & 179 & 7.14 & 494 \\
\hline 111 & Chloroprene, inhibited & 4907223 & 167 & 7.72 & 489 \\
\hline 112 & Paints, stains, or varnish & $4910251^{b}$ & 597 & 24.87 & 477 \\
\hline 113 & Chlorobenzene & 4909153 & 158 & 6.38 & 477 \\
\hline 114 & Propyl alcohol & 4909267 & 156 & 6.20 & 464 \\
\hline 115 & Alcohol C13-C15 poly (1-6) ethoxylate & 4961384 & 136 & 5.43 & 461 \\
\hline 116 & Dichloromethane & 4941132 & 115 & 4.60 & 457 \\
\hline 117 & Diphenylmethane-4, 4-diisocyanate & 4925113 & 148 & 6.01 & 449 \\
\hline 118 & Sodium compounds n.o.s. & 4935273 & 155 & 6.43 & 446 \\
\hline 119 & 2-ethyl hexanol & 4915101 & 141 & 5.61 & 445 \\
\hline 120 & Chloroform & 4940310 & 104 & 4.20 & 437 \\
\hline 121 & Pentanes & 4908255 & 106 & 4.50 & 432 \\
\hline 122 & Propionaldehyde & 4908270 & 124 & 4.92 & 425 \\
\hline 123 & Pulp mill by-products & 4910320 & 275 & 11.70 & 419 \\
\hline 124 & Epichlorohydrin & 4907420 & 124 & 4.91 & 404 \\
\hline 125 & Ethylene dichloride & 4909166 & 74 & 2.94 & 397 \\
\hline 126 & Heptanes & 4909190 & 132 & 5.47 & 390 \\
\hline 127 & Creosote & 4963330 & 98 & 3.87 & 385 \\
\hline 128 & Projectiles (with bursting charge) & 4901271 & 67 & 4.60 & 385 \\
\hline 129 & Methyl acrylate (inhibited) & 4907245 & 87 & 3.52 & 370 \\
\hline 130 & Dichloropropene & 4909255 & 72 & 2.92 & 365 \\
\hline 131 & Tetrachloroethylene & 4940355 & 132 & 5.22 & 356 \\
\hline 132 & Methly chloroform & 4925182 & 67 & 2.68 & 351 \\
\hline 133 & Plastic material resins & 4910282 & 148 & 5.87 & 341 \\
\hline 134 & Sodium aluminate, solution & 4935260 & 146 & 5.86 & 341 \\
\hline 135 & Petroleum refinery waste & 4936539 & 112 & 4.63 & 328 \\
\hline 136 & Dimethylamine & 4905510 & 171 & 6.99 & 325 \\
\hline 137 & Napthelene & 4940360 & 160 & 6.37 & 315 \\
\hline 138 & Nitric acid & $4918528^{b}$ & 132 & 5.66 & 313 \\
\hline 139 & Caustic alkaline liquids, n.o.s. & 4935220 & 176 & 7.69 & 313 \\
\hline 140 & Weapon cartridges & 4903170 & 140 & 6.12 & 298 \\
\hline 141 & Coal tar distillate & 4910133 & 113 & 4.61 & 290 \\
\hline 142 & Bombs & 4901223 & 45 & 3.32 & 284 \\
\hline 143 & Fireworks & 4903520 & 203 & 9.20 & 281 \\
\hline
\end{tabular}

Continued 
Table B.1 150 Most Heavily Shipped Hazardous Materials by Rail, 1986-1995, Determined from the AAR Waybill Samplea (Cont.)

\begin{tabular}{|c|c|c|c|c|c|}
\hline Rank & Commodity & STCC & $\begin{array}{l}\text { Waybill } \\
\text { Samples }\end{array}$ & $\begin{array}{c}\text { Total Cars } \\
\text { Shipped } \\
\left(\times 10^{3}\right)\end{array}$ & $\begin{array}{c}\text { Total Ton- } \\
\text { Miles } \\
\left(\times 10^{6}\right)\end{array}$ \\
\hline 144 & Ferrosilicon & 4916301 & 69 & 2.93 & 279 \\
\hline 145 & Industrial inorganic acids n.o.s. & 4920125 & 221 & 8.82 & 276 \\
\hline 146 & Organic toxic liquids, n.o.s. & 4921475 & 184 & 7.72 & 272 \\
\hline 147 & Rocket motors & 4902530 & 70 & 3.35 & 251 \\
\hline 148 & Sodium cyanide solution & 4923227 & 130 & 5.18 & 247 \\
\hline 149 & Nitrochlorobenzene & 4921459 & 152 & 6.02 & 230 \\
\hline 150 & Detergents & 4915147 & 183 & 7.25 & 220 \\
\hline
\end{tabular}

a Rankings are in terms of total ton-miles. Total shipments and total ton-miles are estimated from waybill records by using exact expansion factors provided in the waybill samples. TIH materials are listed in bold.

b Multiple STCCs exist for the material. The most frequently occurring STCC is given, but shipment statistics include data from additional codes.

c n.o.s. $=$ not otherwise specified . 
$\Delta$ 


\section{Appendix C HMIS Incident Counts by Container Type}

Listed below are incident counts for all container types in the Hazardous Materials Information System (HMIS) database from 1990 to 1995. Incident counts are provided for all incidents (A); for incidents in which a nonzero release amount was reported (NZ); and for loading/unloading incidents (LUL), en route/nonaccident incidents (ENR), and accident-related incidents (ACC). Accident-related incidents include only those incidents involving a traffic accident or a train derailment.

\begin{tabular}{|c|c|c|c|c|c|c|c|c|c|c|c|}
\hline & $\mathbf{A}$ & $\mathbf{N Z}$ & LUL & ENR & $\mathrm{ACC}$ & & $\mathbf{A}$ & $\mathbf{N Z}$ & LUL & ENR & $\mathbf{A C C}$ \\
\hline Rail Cars & & & & & & MC331 & 116 & 89 & 46 & 8 & 28 \\
\hline 103AALW & 9 & 8 & 0 & 8 & 0 & MC338 & 29 & 22 & 2 & 16 & 4 \\
\hline $103 A W$ & 3 & 2 & 0 & 2 & 0 & TANK & 35 & 33 & 21 & 7 & 2 \\
\hline $103 W$ & 29 & 28 & 1 & 19 & 2 & TANK TRK & 3153 & 3059 & 2379 & 252 & 342 \\
\hline 104 & 1 & 1 & 0 & 1 & 0 & TANK TRL & 528 & 506 & 365 & 58 & 70 \\
\hline 105 & 48 & 23 & 0 & 21 & 1 & TANK PRT & 729 & 703 & 424 & 209 & 27 \\
\hline $105 \mathrm{~A}$ & 7 & 5 & 0 & 5 & 0 & & & & & & \\
\hline $105 \mathrm{AW}$ & 169 & 97 & 13 & 78 & 2 & $\underline{\text { Drums }}$ & & & & & \\
\hline $106 \mathrm{~A}$ & 1 & 1 & 1 & 0 & 0 & $\overline{1 \mathrm{~A} 1}$ & 673 & 661 & 470 & 143 & 3 \\
\hline $106 \mathrm{AX}$ & 3 & 2 & 0 & 2 & 0 & $1 \mathrm{~A} 2$ & 225 & 225 & 134 & 70 & 1 \\
\hline 109AALW & 2 & 2 & 0 & 2 & 0 & $1 \mathrm{G}$ & 17 & 17 & 14 & 3 & 0 \\
\hline $110 \mathrm{AW}$ & 1 & 1 & 0 & 1 & 0 & $1 \mathrm{H} 1$ & 352 & 349 & 253 & 74 & 5 \\
\hline $111 \mathrm{~A}$ & 43 & 23 & 1 & 19 & 2 & $1 \mathrm{H} 2$ & 126 & 126 & 98 & 26 & 0 \\
\hline 111AALW & 145 & 123 & 4 & 107 & 6 & $17 \mathrm{C}$ & 135 & 132 & 91 & 26 & 1 \\
\hline $111 \mathrm{AW}$ & 4388 & 3728 & 92 & 3353 & 132 & $17 \mathrm{E}$ & 2112 & 2087 & 1433 & 499 & 14 \\
\hline $112 \mathrm{AW}$ & 7 & 5 & 0 & 2 & 1 & $17 \mathrm{E} / 17 \mathrm{H}$ & 26 & 26 & 15 & 10 & 1 \\
\hline $112 \mathrm{~J}$ & 4 & 0 & 0 & 0 & 0 & $17 \mathrm{~F}$ & 2 & 2 & 0 & 2 & 0 \\
\hline $112 \mathrm{JW}$ & 432 & 175 & 1 & 164 & 5 & $17 \mathrm{H}$ & 573 & 567 & 291 & 224 & 11 \\
\hline $112 \mathrm{~S}$ & 1 & 1 & 0 & 0 & 0 & 34 & 1214 & 1202 & 915 & 223 & 10 \\
\hline $112 \mathrm{SW}$ & 222 & 97 & 2 & 91 & 0 & 35 & 77 & 76 & 61 & 13 & 0 \\
\hline $112 \mathrm{~T}$ & 14 & 8 & 1 & 6 & 0 & $37 A$ & 303 & 299 & 256 & 28 & 2 \\
\hline $112 \mathrm{TW}$ & 6 & 3 & 0 & 3 & 0 & $37 \mathrm{~B}$ & 107 & 106 & 87 & 13 & 0 \\
\hline $113 \mathrm{CW}$ & 4 & 2 & 0 & 2 & 0 & $37 \mathrm{C}$ & 494 & 493 & 423 & 55 & 2 \\
\hline $113 \mathrm{DW}$ & 2 & 1 & 0 & 1 & 0 & $37 D$ & 1 & 1 & 1 & 0 & 0 \\
\hline $114 \mathrm{AW}$ & 3 & 3 & 0 & 2 & 0 & $37 \mathrm{M}$ & 17 & 17 & 13 & 2 & 1 \\
\hline $114 \mathrm{JW}$ & 6 & 3 & 0 & 3 & 0 & $37 P$ & 9 & 9 & 8 & 1 & 0 \\
\hline $114 \mathrm{~T}$ & 1 & 0 & 0 & 0 & 0 & 5 & 1 & 1 & 1 & 0 & 0 \\
\hline $115 \mathrm{AW}$ & 6 & 6 & 0 & 5 & 1 & $5 \mathrm{~A}$ & 2 & 2 & 1 & 1 & 0 \\
\hline HOPPER R & 73 & 65 & 7 & 28 & 29 & $5 B$ & 9 & 9 & 5 & 3 & 0 \\
\hline TANK CAR & 599 & 379 & 45 & 274 & 20 & $5 \mathrm{C}$ & 8 & 8 & 6 & 2 & 0 \\
\hline & & & & & & $5 \mathrm{M}$ & 3 & 3 & 2 & 1 & 0 \\
\hline Cargo and I & table T & nks & & & & $5 \mathrm{P}$ & 1 & 0 & 0 & 0 & 0 \\
\hline 26 & 2 & 2 & 2 & 0 & 0 & $6 \mathrm{~B}$ & 3 & 2 & 1 & 1 & 0 \\
\hline 50 & 1 & 1 & 1 & 0 & 0 & $6 \mathrm{D}$ & 4 & 3 & 2 & 1 & 0 \\
\hline 51 & 4 & 4 & 4 & 0 & 0 & $6 \mathrm{~J}$ & 1 & 1 & 1 & 0 & 0 \\
\hline 52 & 1 & 1 & 0 & 1 & 0 & DRUM & 561 & 536 & 351 & 124 & 5 \\
\hline 56 & 7 & 7 & 1 & 5 & 1 & DRUM FBR & 412 & 400 & 307 & 62 & 5 \\
\hline 57 & 228 & 222 & 140 & 61 & 10 & DRUM MTL & 4392 & 4300 & 3211 & 781 & 43 \\
\hline 60 & 4 & 4 & 3 & 1 & 0 & DRUM PLS & 1748 & 1698 & 1331 & 271 & 9 \\
\hline IM101 & 64 & 59 & 3 & 46 & 0 & DRUM RBR & 4 & 4 & 2 & 2 & 0 \\
\hline IM102 & 4 & 4 & 0 & 3 & 0 & & & & & & \\
\hline MC301 & 6 & 6 & 4 & 1 & 1 & Cylinders & & & & & \\
\hline $\mathrm{MC} 302$ & 2 & 2 & 2 & 0 & 0 & $\overline{3}$ & 5 & 5 & 2 & 2 & 0 \\
\hline $\mathrm{MC} 303$ & 9 & 8 & 6 & 2 & 0 & $3 \mathrm{~A}$ & 29 & 26 & 21 & 3 & 0 \\
\hline MC 304 & 21 & 21 & 15 & 3 & 2 & $3 A 1$ & 66 & 65 & 58 & 3 & 0 \\
\hline MC305 & 19 & 19 & 16 & 0 & 2 & $3 A 2$ & 31 & 30 & 29 & 1 & 0 \\
\hline MC306 & 2750 & 2714 & 2247 & 88 & 349 & $3 A A$ & 25 & 16 & 12 & 2 & 0 \\
\hline MC307 & 2433 & 2363 & 1814 & 343 & 141 & $3 A A X$ & 3 & 3 & 1 & 2 & 0 \\
\hline MC 310 & 1 & 1 & 1 & 0 & 0 & 3AL & 12 & 9 & 8 & 0 & 0 \\
\hline MC311 & 25 & 24 & 18 & 5 & 0 & 39 & 25 & 23 & 23 & 0 & 0 \\
\hline MC 312 & 847 & 820 & 569 & 179 & 51 & $3 E$ & 2 & 2 & 1 & 1 & 0 \\
\hline MC 330 & . & 80 & . & 7 & - & & & & & & \\
\hline
\end{tabular}




\begin{tabular}{lrrrrr}
\multicolumn{1}{c}{ Cylinders (Cont.) } & A & NZ & LUL & ENR & ACC \\
\cline { 1 - 4 } 4 & 1 & 0 & 0 & 0 & 0 \\
40 & 1 & 1 & 1 & 0 & 0 \\
$4 \mathrm{~A}$ & 3 & 3 & 1 & 2 & 0 \\
$4 \mathrm{~B}$ & 8 & 6 & 6 & 0 & 0 \\
4BA & 6 & 5 & 2 & 1 & 0 \\
4BW & 20 & 16 & 12 & 0 & 0 \\
$4 \mathrm{E}$ & 3 & 2 & 1 & 0 & 0 \\
$4 \mathrm{~L}$ & 13 & 8 & 1 & 4 & 3 \\
8 & 5 & 5 & 0 & 2 & 2 \\
9 & 1 & 1 & 1 & 0 & 0 \\
CYL & 139 & 108 & 82 & 13 & 2 \\
CYL MTL & 339 & 251 & 214 & 18 & 1
\end{tabular}

Miscellaneous Package Freight

$\begin{array}{lrrrrr}\text { 1OB } & 2 & 2 & 2 & 0 & 0 \\ \text { 11B } & 1 & 1 & 1 & 0 & 0 \\ \text { 12A } & 4 & 4 & 4 & 0 & 0 \\ \text { 12B } & 22 & 22 & 22 & 0 & 0 \\ \text { 12C } & 3 & 1 & 1 & 0 & 0 \\ \text { 12P } & 5 & 4 & 4 & 0 & 0 \\ \text { 1A } & 10 & 10 & 8 & 2 & 0 \\ \text { 1H } & 5 & 5 & 5 & 0 & 0 \\ \text { 1M } & 2 & 2 & 0 & 2 & 0 \\ \text { 21C } & 23 & 21 & 15 & 3 & 2 \\ \text { 21P } & 4 & 4 & 3 & 0 & 0 \\ \text { 22B } & 1 & 1 & 1 & 0 & 0 \\ \text { 31 } & 1 & 1 & 0 & 1 & 0 \\ \text { 32A } & 1 & 1 & 1 & 0 & 0 \\ \text { 32B } & 1 & 1 & 1 & 0 & 0 \\ \text { 33A } & 4 & 4 & 4 & 0 & 0 \\ \text { 34B } & 2 & 2 & 1 & 1 & 0 \\ \text { 3H1 } & 71 & 71 & 68 & 2 & 0 \\ \text { 3H2 } & 11 & 11 & 11 & 0 & 0 \\ \text { 4G } & 12 & 12 & 7 & 2 & 3 \\ \text { BARREL W } & 1 & 1 & 0 & 1 & 0 \\ \text { BOTL } & 292 & 279 & 224 & 33 & 1 \\ \text { BOTL GLS } & 2428 & 2399 & 2131 & 112 & 0 \\ \text { BOTL PLS } & 8017 & 7876 & 6986 & 405 & 10 \\ \text { BOX } & 29 & 24 & 18 & 4 & 0 \\ \text { BOX FBR } & 210 & 185 & 140 & 22 & 5 \\ \text { BOX MTL } & 3 & 1 & 1 & 0 & 0 \\ \text { BOX WOOD } & 5 & 4 & 3 & 1 & 0 \\ \text { CAN } & 511 & 492 & 384 & 66 & 1 \\ \text { CAN AERO } & 232 & 222 & 195 & 9 & 0 \\ \text { CAN ALUM } & 142 & 139 & 121 & 10 & 0 \\ \text { CAN FBR } & 4 & 4 & 2 & 0 & 0 \\ \text { CAN MTL } & 3927 & 3860 & 3442 & 196 & 0 \\ \text { CARBOY } & 2 & 1 & 1 & 0 & 0 \\ \text { CARBOY G } & 5 & 5 & 4 & 1 & 0 \\ \text { CARBOY P } & 8 & 7 & 2 & 5 & 0 \\ \text { CARTON P } & 1 & 1 & 1 & 0 & 0 \\ \text { JAR } & 20 & 18 & 0 & 0 \\ \text { JAR GLS } & 806 & 726 & 41 & 0 \\ \text { BAR } & & & & & \end{array}$

$\begin{array}{lrrrrr} & \text { A } & \text { NZ } & \text { LUL } & \text { ENR } & \text { ACC } \\ \text { JAR PLS } & 250 & 242 & 227 & 6 & 1 \\ \text { JUG } & 107 & 96 & 79 & 13 & 1 \\ \text { JUG GLS } & 194 & 192 & 169 & 10 & 0 \\ \text { JUG PLS } & 3984 & 3922 & 3517 & 185 & 7 \\ \text { KEG MTL } & 1 & 1 & 1 & 0 & 0 \\ \text { PAIL } & 303 & 288 & 212 & 62 & 2 \\ \text { PAIL MTL } & 2175 & 2144 & 1834 & 214 & 2 \\ \text { PAIL PLS } & 1818 & 1780 & 1433 & 243 & 7 \\ \text { PALLET } & 1 & 1 & 0 & 0 & 1 \\ \text { TUBE } & 37 & 36 & 31 & 3 & 0 \\ \text { TUBE FBR } & 11 & 11 & 9 & 0 & 0 \\ \text { TUBE GLS } & 5 & 4 & 3 & 1 & 0\end{array}$

Inside Containers

\begin{tabular}{lrrrrr}
\hline $2 \mathrm{~A}$ & 6 & 6 & 4 & 2 & 0 \\
$2 \mathrm{C}$ & 3 & 3 & 2 & 1 & 0 \\
$2 \mathrm{E}$ & 1337 & 1323 & 1240 & 39 & 1 \\
$2 \mathrm{~F}$ & 2 & 1 & 1 & 0 & 0 \\
$2 \mathrm{M}$ & 1 & 1 & 1 & 0 & 0 \\
$2 \mathrm{~N}$ & 1 & 1 & 1 & 0 & 0 \\
$2 \mathrm{P}$ & 21 & 21 & 19 & 0 & 0 \\
$2 \mathrm{Q}$ & 5 & 5 & 4 & 1 & 0 \\
$2 \mathrm{R}$ & 2 & 2 & 2 & 0 & 0 \\
$2 \mathrm{~T}$ & 2 & 2 & 1 & 1 & 0 \\
$2 \mathrm{U}$ & 293 & 290 & 266 & 9 & 0 \\
$5 \mathrm{H} 2$ & 2 & 1 & 0 & 1 & 0 \\
5H3 & 3 & 3 & 3 & 0 & 0 \\
$5 \mathrm{H} 4$ & 10 & 10 & 9 & 0 & 0 \\
5M2 & 47 & 47 & 44 & 1 & 0 \\
6HA1 & 10 & 10 & 5 & 4 & 0 \\
$6 \mathrm{HA} 2$ & 3 & 3 & 3 & 0 & 0 \\
$6 \mathrm{HG1}$ & 4 & 4 & 4 & 0 & 0 \\
6HG2 & 47 & 47 & 46 & 1 & 0 \\
BAG CLTH & 24 & 24 & 13 & 9 & 0 \\
BAG PLS & 388 & 374 & 289 & 53 & 5 \\
BAG PPR & 1061 & 1028 & 865 & 94 & 9 \\
LINR PLS & 226 & 219 & 127 & 64 & 5
\end{tabular}

Miscellaneous Other

\begin{tabular}{lrrrrr}
\multicolumn{1}{l}{ M4C } & 4 & 4 & 3 & 0 & 0 \\
$44 \mathrm{D}$ & 8 & 8 & 7 & 1 & 0 \\
$44 \mathrm{P}$ & 9 & 9 & 9 & 0 & 0 \\
7A & 13 & 2 & 0 & 1 & 1 \\
BATTERY & 41 & 38 & 20 & 10 & 2 \\
BIN PORT & 34 & 30 & 16 & 11 & 1 \\
CONT & 2070 & 1885 & 1443 & 269 & 27 \\
CONT GLS & 312 & 305 & 245 & 32 & 0 \\
CONT PLS & 3248 & 3160 & 2752 & 201 & 7 \\
CONT STY & 9 & 8 & 8 & 0 & 0 \\
HOPPER T & 117 & 106 & 33 & 42 & 22 \\
TYPE A & 3 & 0 & 0 & 0 & 0 \\
TYPE B & 2 & 0 & 0 & 0 & 0
\end{tabular}




\section{Appendix D HMIS Fatalities, Injuries, and Evacuations by Container Type}

Listed below are fatalities (Fat.), major injuries ( Maj. inj.), minor injuries (Min. inj.), and evacuations (Evac.) associated with the various container types listed in the Hazardous Materials Information System (HMIS) database and Appendix C from 1985 to 1995 .

\begin{tabular}{|c|c|c|c|c|c|c|c|c|c|}
\hline \multicolumn{10}{|l|}{ Rail Cars } \\
\hline 103AALW & 0 & 0 & 1 & 0 & $5 \mathrm{P}$ & 0 & 0 & 2 & 0 \\
\hline $103 \mathrm{AW}$ & 0 & 1 & 0 & 0 & $6 \mathrm{~B}$ & 0 & 0 & 0 & 2 \\
\hline $103 \mathrm{~W}$ & 0 & 0 & 1 & 0 & $6 \mathrm{D}$ & 0 & 0 & 1 & 0 \\
\hline 105 & 0 & 0 & 7 & 2020 & $6 \mathrm{~J}$ & 0 & 1 & 4 & 1 \\
\hline $105 \mathrm{AW}$ & 1 & 8 & 20 & 183 & DRUM & 0 & 5 & 46 & 384 \\
\hline $106 \mathrm{AW}$ & 0 & 0 & 1 & 0 & DRUM FBR & 0 & 5 & 21 & 23 \\
\hline $106 \mathrm{AX}$ & 0 & 0 & 15 & 225 & DRUM MTL & 0 & 10 & 256 & 4867 \\
\hline 109AALW & 0 & 0 & 1 & 0 & DRUM PLS & 0 & 5 & 128 & 578 \\
\hline $111 \mathrm{~A}$ & 0 & 1 & 7 & 500 & & & & & \\
\hline 111AALW & 0 & 4 & 10 & 850 & \multicolumn{5}{|l|}{ Cylinders } \\
\hline $111 \mathrm{AW}$ & 0 & 41 & 343 & 35756 & $\overrightarrow{3}$ & 0 & 0 & 9 & 0 \\
\hline $112 \mathrm{AW}$ & 0 & 1 & 4 & 435 & $3 \mathrm{~A}$ & 0 & 0 & 23 & 864 \\
\hline $112 \mathrm{JW}$ & 0 & 5 & 19 & 2854 & $3 \mathrm{~A} 2$ & 0 & 0 & 16 & 60 \\
\hline $112 \mathrm{~S}$ & 0 & 0 & 1 & 20 & $3 A 480 X$ & 0 & 0 & 1 & 0 \\
\hline $112 \mathrm{SW}$ & 0 & 2 & 19 & 426 & $3 A A$ & 0 & 4 & 16 & 119 \\
\hline $112 \mathrm{~T}$ & 0 & 0 & 0 & 150 & ЗАAX & 0 & 0 & 2 & 0 \\
\hline TANK CAR & 0 & 18 & 109 & 13159 & $3 \mathrm{AL}$ & 0 & 1 & 1 & 20 \\
\hline \multirow[t]{2}{*}{ HOPPER R } & \multirow[t]{2}{*}{0} & \multirow[b]{3}{*}{ aks } & \multirow[t]{3}{*}{1} & \multirow[t]{3}{*}{1091} & $4 \mathrm{BA}$ & 0 & 0 & 1 & 35 \\
\hline & & & & & $4 \mathrm{BW}$ & 0 & 5 & 9 & 0 \\
\hline \multicolumn{2}{|c|}{ Cargo and Portable Tanks } & & & & $4 \mathrm{G}$ & 0 & 0 & 0 & 2000 \\
\hline 56 & 0 & 1 & 4 & 100 & $4 \mathrm{~L}$ & 0 & 0 & 2 & 0 \\
\hline 57 & 0 & 0 & 11 & 55 & CYL & 1 & 3 & 40 & 225 \\
\hline IM101 & 0 & 0 & 54 & 1010 & CYL MTL & 0 & 2 & 56 & 258 \\
\hline MC301 & 0 & 0 & 1 & 0 & & & & & \\
\hline $\mathrm{MC} 304$ & 0 & 1 & 0 & 5 & \multicolumn{5}{|c|}{ Miscellaneous Package Freight } \\
\hline MC306 & 41 & 26 & 68 & 3719 & $12 \mathrm{~B}$ & 0 & 0 & 5 & 0 \\
\hline MC 307 & 5 & 30 & 285 & 2086 & $12 \mathrm{C}$ & 0 & 0 & 1 & 0 \\
\hline MC 310 & 0 & 1 & 1 & 0 & $1 \mathrm{~A}$ & 0 & 0 & 8 & 10 \\
\hline MC311 & 0 & 0 & 24 & 0 & $21 \mathrm{C}$ & 1 & 0 & 1 & 0 \\
\hline MC 312 & 1 & 37 & 207 & 1467 & $34 B$ & 0 & 0 & 1 & 30 \\
\hline MC 330 & 8 & 6 & 8 & 231 & BOTL & 0 & 0 & 29 & 29 \\
\hline MC331 & 3 & 30 & 120 & 2295 & BOTL GLS & 0 & 5 & 150 & 693 \\
\hline MC338 & 0 & 3 & 0 & 527 & BOTL PLS & 0 & 2 & 122 & 325 \\
\hline TANK & 0 & 0 & 6 & 126 & $\mathrm{BOX}$ & 0 & 0 & 1 & 0 \\
\hline TANK PRT & 0 & 2 & 61 & 406 & BOX FBR & 0 & 0 & 4 & 151 \\
\hline TANK TRK & 26 & 31 & 155 & 4947 & CAN & 0 & 0 & 8 & 90 \\
\hline \multirow[t]{2}{*}{ TANK TRL } & \multirow[t]{2}{*}{32} & \multirow[t]{2}{*}{37} & \multirow[t]{2}{*}{126} & \multirow[t]{2}{*}{988} & CAN AERO & 0 & 0 & 2 & 3 \\
\hline & & & & & CAN ALUM & 0 & 0 & 1 & 16 \\
\hline Drums & & & & & CAN MTL & 0 & 0 & 49 & 734 \\
\hline $1 \mathrm{~A} 1$ & 0 & 2 & 22 & 125 & CARBOY G & 0 & 0 & 1 & 0 \\
\hline $1 \mathrm{~A} 2$ & 0 & 0 & 3 & 26 & CARTON P & 0 & 0 & 1 & 0 \\
\hline $1 \mathrm{H} 1$ & 0 & 0 & 9 & 46 & JAR & 0 & 0 & 1 & 0 \\
\hline $1 \mathrm{H} 2$ & 0 & 0 & 1 & 2 & JAR GLS & 0 & 0 & 36 & 161 \\
\hline $17 \mathrm{C}$ & 0 & 0 & 10 & 1095 & JAR PLS & 0 & 0 & 2 & 0 \\
\hline $17 \mathrm{E}$ & 0 & 4 & 149 & 249 & JUG & 0 & 0 & 4 & 21 \\
\hline $17 \mathrm{H}$ & 0 & 0 & 20 & 14 & JUG GLS & 0 & 0 & 26 & 22 \\
\hline 34 & 0 & 8 & 46 & 5890 & JUG PLS & 0 & 2 & 45 & 129 \\
\hline 35 & 0 & 0 & 5 & 0 & PAIL & 0 & 0 & 26 & 71 \\
\hline $37 \mathrm{~A}$ & 1 & 0 & 11 & 1 & PAIL MTL & 0 & 3 & 32 & 226 \\
\hline $37 \mathrm{~B}$ & 0 & 0 & $\begin{array}{r}1 \\
2\end{array}$ & 13 & PAIL PLS & 0 & 2 & 45 & 134 \\
\hline $37 \mathrm{C}$ & 0 & 1 & 2 & 0 & PALLET & 0 & 0 & 1 & 0 \\
\hline $37 \mathrm{M}$ & 0 & 0 & 12 & 250 & & & & & \\
\hline 5 & 0 & 0 & 1 & 0 & Inside Cont: & & & & \\
\hline $5 \mathrm{~A}$ & 0 & 0 & 1 & 0 & $2 \mathrm{E}$ & 0 & 1 & 4 & 114 \\
\hline $5 B$ & 0 & 0 & 1 & 5 & $2 \mathrm{SL}$ & 0 & 0 & 1 & $\begin{array}{r}1+1 \\
0\end{array}$ \\
\hline $5 \mathrm{C}$ & 0 & 4 & 0 & 0 & $2 \mathrm{U}$ & 0 & 0 & 2 & 0 \\
\hline $5 \mathrm{M}$ & 0 & 0 & 2 & 0 & $5 \mathrm{H} 2$ & 0 & 1 & 0 & 0 \\
\hline
\end{tabular}


$\Delta$

$\begin{array}{lcccr} & \text { Fat. } & \text { Maj. inj. } & \text { Min. inj. } & \text { Evac. } \\ \text { BAG PLS } & 0 & 0 & 20 & 26 \\ \text { BAG PPR } & 0 & 0 & 40 & 339 \\ \text { LINR PLS } & 0 & 1 & 52 & 40\end{array}$

Miscellaneous Other

$7 \mathrm{~A}$

BATTERY

BIN PORT

CONT

CONT GLS

CONT PLS

CONT STY

HOPPER T

0
0
0
0
0
0
0
0

$\begin{array}{rrr}0 & 0 & 2 \\ 1 & 7 & 0 \\ 0 & 3 & 16 \\ 7 & 137 & 1718 \\ 0 & 42 & 541 \\ 2 & 100 & 539 \\ 0 & 1 & 0 \\ 0 & 1 & 0\end{array}$




\section{Appendix E HMIS Fatality and Major Injury Incidents}

Listed below are all incidents in the Hazardous Materials Information System database from 1985 to 1995 that report fatalities and/or major injuries. Incidents with fatalities are given first, followed by incidents with major injuries. All incidents for both fatalities and major injuries are given in chronological order. From left to right, the table columns list (1) number of fatalities or major injuries, (2) year, (3) month, (4) chemical shipping name, (5) hazard class, (6) letter code indicating the transportation phase, (7) container type, (8) release quantity, (9) units of release quantity, (10) container capacity, and (11) units of container capacity. Field 6 in the tables, the transportation phase, is denoted by three letters, A, E, and L. The letter A indicates that the release occurred during a traffic accident or train derailment. The letter $\mathrm{E}$ indicates that the release occurred while en route from the origin to the destination, but not during a traffic accident or derailment. The letter L indicates that the release occurred during loading or unloading of the commodity. A blank value for any item means that information was missing from the incident record.

\section{Fatality Incidents}

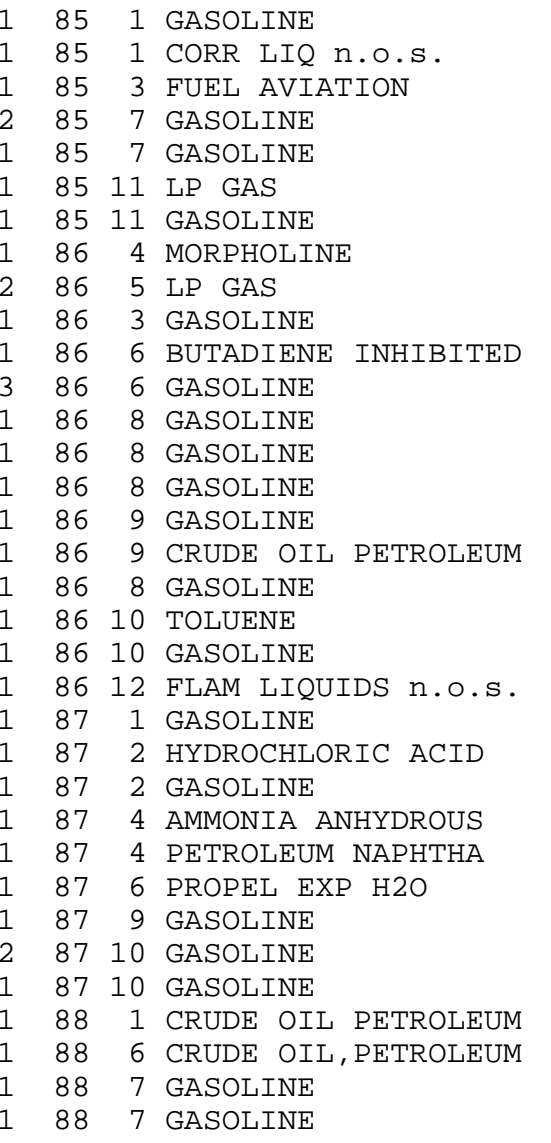




\section{Fatality Incidents (Cont.)}

$\begin{array}{rrrl}1 & 88 & 8 & \text { GASOLINE } \\ 1 & 88 & 12 & \text { GASOLINE } \\ 8 & 88 & 12 & \text { LP GAS } \\ 1 & 89 & 2 & \text { HYDROGEN PEROX }>52 \text { \% } \\ 1 & 89 & 7 & \text { FUEL AVIATION } \\ 2 & 89 & 9 & \text { GASOLINE } \\ 4 & 89 & 12 & \text { GASOLINE } \\ 1 & 90 & 2 & \text { GASOLINE } \\ 1 & 90 & 3 & \text { PAINT } \\ 3 & 90 & 6 & \text { COMBUSTIBLE LIQUID NOS } \\ 1 & 90 & 8 & \text { GASOLINE } \\ 1 & 90 & 11 & \text { GASOLINE } \\ 1 & 91 & 1 & \text { GASOLINE } \\ 5 & 91 & 5 & \text { GASOLINE } \\ 1 & 90 & 1 & \text { GASOLINE } \\ 1 & 91 & 9 & \text { FUEL OIL } \\ 1 & 91 & 8 & \text { FUEL OIL } \\ 2 & 91 & 10 & \text { GASOLINE } \\ 3 & 92 & 1 & \text { PETROLEUM GASES LIQ } \\ 2 & 92 & 2 & \text { GASOLINE } \\ 1 & 92 & 3 & \text { GASOLINE } \\ 1 & 92 & 4 & \text { GASOLINE } \\ 1 & 92 & 5 & \text { SODIUM HYDROXIDE SLN } \\ 1 & 92 & 7 & \text { GASOLINE } \\ 1 & 92 & 9 & \text { PETROLEUM CRUDE OIL } \\ 1 & 92 & 10 & \text { FUEL AVIATION } \\ 1 & 92 & 10 & \text { GASOLINE } \\ 3 & 92 & 10 & \text { GASOLINE } \\ 1 & 92 & 11 & \text { GASOLINE } \\ 1 & 93 & 2 & \text { GASOLINE } \\ 1 & 93 & 3 & \text { GASOLINE } \\ 6 & 93 & 3 & \text { GASOLINE } \\ 3 & 93 & 5 & \text { GASOLINE } \\ 1 & 93 & 5 & \text { ASPHALT } \\ 1 & 94 & 3 & \text { GASOLINE } \\ 1 & 94 & 5 & \text { GASOLINE } \\ 1 & 94 & 5 & \text { GASOLINE } \\ 1 & 94 & 5 & \text { GASOLINE } \\ 1 & 94 & 6 & \text { ELEVATED TEMP MATERIAL } \\ 1 & 94 & 8 & \text { ACETYLENE DISSOLVED } \\ 1 & 94 & 9 & \text { GASOLINE } \\ 1 & 94 & 6 & \text { GASOLINE } \\ 1 & 94 & 10 & \text { GASOLINE } \\ 1 & 94 & 11 & \text { GASOLINE } \\ 1 & 94 & 8 & \text { GASOLINE } \\ 1 & 95 & 2 & \text { PETROLEUM GASES LIQ } \\ 1 & 95 & 3 & \text { PAINT RELATED MATERIAL } \\ 1 & 95 & 3 & \text { GASOLINE } \\ 1 & 95 & 4 & \text { GASOLINE } \\ 1 & 95 & 9 & \text { PETROLEUM GASES LIQ } \\ 1 & 95 & 12 & \text { GASOLINE } \\ & & & \\ 1 & \end{array}$

$\begin{array}{lll}3 & \text { A } & \text { TANK TRK } \\ 3 & \text { A } & \text { MC306 } \\ 2 & \text { A } & \text { MC330 } \\ 5 & \text { A } & \text { TANK TRL } \\ 2 & \text { A } & \text { TANK TRL } \\ 3 & \text { A } & \text { TANK TRK } \\ 3 & \text { A } & \text { MC306 } \\ 3 & \text { A } & \text { MC306 } \\ 3 & \text { A } & 37 A \\ 2 & \text { A } & \text { MC307 } \\ 3 & \text { A } & \text { MC307 } \\ 3 & \text { A } & \text { MC306 } \\ 3 & \text { A } & \text { TANK TRK } \\ 3 & \text { A } & \text { MC306 } \\ 3 & \text { L } & \text { TANK TRK } \\ 2 & \text { A } & \text { TANK TRK } \\ 2 & \text { A } & \text { TANK TRK } \\ 3 & \text { A } & \text { TANK TRK } \\ 2 & \text { A } & \text { TANK TRK } \\ 3 & \text { A } & \text { TANK TRK } \\ 3 & \text { A } & \text { MC306 } \\ 3 & \text { A } & \text { TANK TRK } \\ 8 & \text { A } & \text { TANK TRK } \\ 3 & \text { A } & \text { MC306 } \\ 3 & \text { A } & \text { MC306 } \\ 3 & \text { A } & \text { TANK TRL } \\ 3 & \text { A } & \text { MC306 } \\ 3 & \text { A } & \text { TANK TRL } \\ 3 & \text { A } & \text { MC306 } \\ 3 & \text { A } & \text { TANK TRL } \\ 3 & \text { A } & \text { TANK TRL } \\ 3 & \text { A } & \text { TANK TRL } \\ 3 & \text { A } & \text { TANK TRK } \\ 3 & \text { L } & \text { TANK TRL } \\ 3 & \text { A } & \text { MC306 } \\ 3 & \text { A } & \text { TANK TRK } \\ 3 & \text { A } & \text { TANK TRK } \\ 3 & \text { A } & \text { MC306 } \\ 9 & \text { A } & \text { TANK TRK } \\ 2 & \text { A } & \text { CYL } \\ 3 & \text { A } & \text { TANK TRK } \\ 3 & \text { A } & \text { MC306 } \\ 3 & \text { A } & \text { MC306 } \\ 3 & \text { A } & \text { TANK TRK } \\ 3 & \text { A } & \text { MC306 } \\ 2 & \text { A } & \text { MC331 } \\ 3 & \text { A } & \text { MC306 } \\ 3 & \text { A } & \text { MC306 } \\ 3 & \text { A } & \text { MC306 } \\ 2 & \text { L } & \text { MC331 } \\ 3 & \text { A } & \text { TANK TRK } \\ & & \end{array}$

\begin{tabular}{|c|c|c|c|}
\hline 7999.00 & GAL & 0 . & \\
\hline 8804.00 & GAL & 9400. & GAL \\
\hline 1255.18 & $\mathrm{CFT}$ & 1397. & CFT \\
\hline 5642.50 & GAL & 0 . & \\
\hline 7499.00 & GAL & 9000 . & GAL \\
\hline 8400.00 & GAL & 8400 . & GAL \\
\hline 300.00 & GAL & 0 . & \\
\hline 589.00 & GAL & 0 . & \\
\hline 85.00 & GAL & 5 . & GAL \\
\hline 6982.00 & GAL & 8200 . & GAL \\
\hline 5000.00 & GAL & 12000 . & GAL \\
\hline 9000.00 & GAL & 9500 . & GAL \\
\hline 4200.00 & GAL & 4200 . & GAL \\
\hline 1880.00 & GAL & 3050 . & GAL \\
\hline 0.00 & & 8000 . & GAL \\
\hline 250.00 & GAL & 0 . & \\
\hline 7500.00 & GAL & 0 . & \\
\hline 8000.00 & GAL & 8000 . & GAL \\
\hline 6.68 & $\mathrm{CFT}$ & 0 . & \\
\hline 4413.00 & GAL & 8700 . & GAL \\
\hline 8500.00 & GAL & 9000 . & GAL \\
\hline 4285.00 & GAL & 9000 . & GAL \\
\hline 4000.00 & GAL & 0 . & \\
\hline 9000.00 & GAL & 9400 . & GAL \\
\hline 756.00 & GAL & 8500 . & GAL \\
\hline 1000.00 & GAL & 0 . & \\
\hline 8800.00 & GAL & 9500 . & GAL \\
\hline 5500.00 & GAL & 6000 . & GAL \\
\hline 8802.00 & GAL & 9400 . & GAL \\
\hline 8800.00 & GAL & 8800 . & GAL \\
\hline 500.00 & GAL & 8800 . & GAL \\
\hline 8500.00 & GAL & 8500 . & GAL \\
\hline 8500.00 & GAL & 0 . & \\
\hline 0.00 & & 6500 . & GAL \\
\hline 8000.00 & GAL & 9200 . & GAL \\
\hline 4733.00 & GAL & 0 . & \\
\hline 0.00 & & 0 . & \\
\hline 7197.00 & GAL & 7197. & GAL \\
\hline 5600.00 & GAL & 6500 . & GAL \\
\hline 350.00 & GAL & 350 . & GAL \\
\hline 100.00 & GAL & 7549 . & GAL \\
\hline 8900.00 & GAL & 9200 . & GAL \\
\hline 38.00 & GAL & 0 . & \\
\hline 6200.00 & GAL & 0 . & \\
\hline 8500.00 & GAL & 9200 . & GAL \\
\hline 1109.54 & $\mathrm{CFT}$ & 1337. & $\mathrm{CFT}$ \\
\hline 7000.00 & GAL & 7700 . & GAL \\
\hline 9000.00 & GAL & 0 . & \\
\hline 8500.00 & GAL & 0 . & \\
\hline 490.00 & GAL & 3000 . & GAL \\
\hline 8798.00 & GAL & 0 & \\
\hline
\end{tabular}

$7999.00 \mathrm{GAL}$ $8400.00 \mathrm{GAI}$ $1300.00 \mathrm{GAL}$ $8589.00 \mathrm{GAL}$ $6982.00 \mathrm{GAI}$ $5000.00 \mathrm{GAL}$ $9000.00 \mathrm{GAL}$ $4200.00 \mathrm{GAL}$ $1880.00 \mathrm{GAI}$ $250.00 \mathrm{GAL}$ $7500.00 \mathrm{GAL}$ $8000.00 \mathrm{GAL}$ $6.68 \mathrm{CFT}$ $4413.00 \mathrm{GAI}$ $8500.00 \mathrm{GAL}$ $4285.00 \mathrm{GAL}$ $9000.00 \mathrm{GAI}$ $756.00 \mathrm{GAI}$ $1000.00 \mathrm{GAL}$ $8800.00 \mathrm{GAL}$ $5500.00 \mathrm{GAL}$ $8802.00 \mathrm{GAL}$ $8800.00 \mathrm{GAL}$ $500.00 \mathrm{GAL}$ $8500.00 \mathrm{GAL}$ $8500.00 \mathrm{GAI}$ $8000.00 \mathrm{GAL}$ $4733.00 \mathrm{GAL}$ $7197.00 \mathrm{GAL}$ $5600.00 \mathrm{GAL}$ $350.00 \mathrm{GAI}$ $38.00 \mathrm{GAL}$ $6200.00 \mathrm{GAL}$ $1109.54 \mathrm{CFT}$ $7000.00 \mathrm{GAL}$ $9000.00 \mathrm{GAL}$ $490.00 \mathrm{GAL}$
$8798.00 \mathrm{GAI}$ 0 .

\section{Major Injury Incidents}

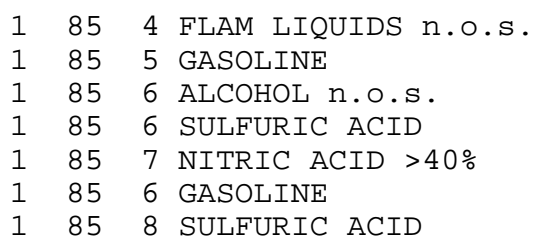

\begin{tabular}{|c|c|c|}
\hline 3 & $\mathrm{~L}$ & MC304 \\
\hline & A & TANK TRL \\
\hline & & CONT \\
\hline & & MC312 \\
\hline & L & MC312 \\
\hline & A & TANK TRL \\
\hline & & TANK CAR \\
\hline
\end{tabular}

$$
\begin{array}{r}
0.00 \\
8000.00 \mathrm{GAL} \\
0.00 \\
0.50 \mathrm{GAL} \\
15.00 \mathrm{GAL} \\
8500.00 \mathrm{GAL} \\
0.25 \mathrm{GAL}
\end{array}
$$

0 .

0 .

0 .

5175. GAL 0 .

8500 . GAL

0 . 


\section{Major Injury Incidents (Cont.)}

\begin{tabular}{|c|c|c|c|c|c|c|c|c|c|}
\hline 85 & 8 & METHYL ETHYL KETONE & 3 & $\mathrm{~L}$ & MC307 & 358.00 & GAL & 6500. & GAL \\
\hline 85 & 8 & SULFURIC ACID & 8 & & 34 & 3.00 & GAL & 15. & GAL \\
\hline 85 & 9 & SULFURIC ACID & 8 & $\mathrm{~L}$ & MC312 & 200.00 & GAL & 4972 . & GAL \\
\hline 85 & 9 & SULFURIC ACID & 8 & $\mathrm{~A}$ & $111 \mathrm{AW}$ & 13500.00 & GAL & 13500 . & GAL \\
\hline 85 & 11 & PHOSPHORUS OXYCHLORIDE & 8 & & DRUM PLS & 30.00 & GAL & 55. & GAL \\
\hline 85 & 11 & CHLORPICRIN LIQUID & 6 & & $105 \mathrm{AW}$ & 0.00 & & 25070 . & GAL \\
\hline 86 & 1 & FLUORINE & 2 & & 3AA & 0.00 & & 0 . & \\
\hline 86 & 1 & CORR SOLID n.o.s. & 8 & & DRUM FBR & 0.12 & GAL & 20 . & GAL \\
\hline 86 & 2 & ALLYL CHLOROCARBONATE & 3 & & DRUM MTL & 10.00 & GAL & 55. & GAL \\
\hline 86 & 2 & SULFURIC ACID & 8 & & 103AW & 1.00 & GAL & 13692 . & GAL \\
\hline 86 & 2 & PHOSPHORUS PENTASULFID & 4 & & 56 & 930.00 & LBS & 6600 . & LBS \\
\hline 86 & 2 & PARAFORMALDEHYDE & 9 & & BAG PPR & 2.00 & LBS & 50 . & LBS \\
\hline 86 & 4 & BUTYL ISOCYANATE & 3 & & DRUM MTL & 0.25 & GAL & 55. & GAL \\
\hline 86 & 4 & COMP CLEANING LIQ & 8 & & PAIL MTL & 1.50 & GAL & 5 . & GAL \\
\hline 86 & 4 & PAINT RELATED MATERIAL & 3 & & DRUM MTL & 0.12 & GAL & 55 . & GAL \\
\hline 86 & 4 & MORPHOLINE & 3 & & MC307 & 2000.00 & GAL & 5800 . & GAL \\
\hline 86 & 5 & LP GAS & 2 & A & TANK TRL & 11250.00 & GAL & 0 . & \\
\hline 86 & 5 & RESIN SOLUTION & 3 & & DRUM & 50.00 & GAL & 55. & GAL \\
\hline 86 & 5 & SULFURIC ACID & 8 & & $111 \mathrm{AW}$ & 0.00 & & 0 . & \\
\hline 86 & 5 & METHYL ETHYL KETONE & 3 & & $37 \mathrm{C}$ & 0.50 & GAL & 5 . & GAL \\
\hline 86 & 5 & GASOLINE & 3 & A & TANK TRL & 6000.00 & GAL & 0 . & \\
\hline 86 & 6 & NITRIC ACID & 8 & & MC307 & 1500.00 & GAL & 0 . & \\
\hline 86 & 4 & DIMETHYL CHLOROTHIOPHO & 8 & & TANK CAR & 0.00 & & 0 . & \\
\hline 86 & 6 & POISONOUS LIQ NOS B & 6 & & PAIL MTL & 0.03 & GAL & 5 . & GAL \\
\hline 86 & 6 & CORR LIQ n.o.s. & 8 & & BOTL GLS & 0.12 & GAL & 0 . & GAL \\
\hline 86 & 6 & HYDROCHLORIC ACID & 8 & $\mathrm{~L}$ & MC312 & 80.00 & GAL & 4700 . & GAL \\
\hline 86 & 7 & NITRIC ACID FUMING & 5 & & $5 \mathrm{C}$ & 55.00 & GAL & 55. & GAL \\
\hline 86 & 7 & INSECTICIDE LIQ & 3 & & CONT PLS & 0.50 & GAL & 1 . & GAL \\
\hline 86 & 7 & LP GAS & 2 & & MC331 & 1.00 & GAL & 1620 . & GAL \\
\hline 86 & 8 & SULFURIC ACID & 8 & $\mathrm{~L}$ & MC312 & 40.00 & GAL & 5500 . & GAL \\
\hline 86 & 6 & SODIUM HYDROXIDE LIQ & 8 & & DRUM MTL & 0.04 & GAL & 55. & GAL \\
\hline 86 & 8 & GASOLINE & 3 & $\mathrm{~L}$ & TANK TRL & 2.00 & GAL & 11400 . & GAL \\
\hline 86 & 9 & GASOLINE & 3 & A & MC306 & 8499.00 & GAL & 0 & \\
\hline 86 & 9 & SODIUM HYDROXIDE LQ & 8 & $\mathrm{~L}$ & TANK TRK & 0.00 & & 0 . & \\
\hline 86 & 8 & FLUOBORIC ACID & 8 & & 34 & 2.00 & GAL & 15. & GAL \\
\hline 86 & 10 & DICHLORO/METHY CHLO & 92 & & DRUM MTL & 55.00 & GAL & 55. & GAL \\
\hline 86 & 9 & CORR LIQ n.O.s. & 8 & & PAIL MTL & 6.00 & GAL & 5 . & GAL \\
\hline 86 & 10 & GASOLINE & 3 & A & MC307 & 7980.00 & GAL & 0 . & \\
\hline 86 & 11 & POISONOUS LIQ NOS B & 6 & & DRUM FBR & 1.25 & GAL & 30 . & GAL \\
\hline 86 & 11 & SULFURIC ACID & 8 & $\mathrm{~L}$ & MC312 & 30.00 & GAL & 0 . & \\
\hline 86 & 12 & SULFURIC ACID & 8 & A & MC312 & 3000.00 & GAL & 0 . & \\
\hline 86 & 11 & POTASS HYDROXIDE LQ & 8 & $\mathrm{~L}$ & TANK TRL & 1.00 & GAL & 0 . & \\
\hline 86 & 12 & VINYL ACETATE & 3 & A & TANK CAR & 14450.00 & GAL & 24088 . & GAL \\
\hline 86 & 3 & CHLORINE & 2 & & TANK PRT & 1000.00 & LBS & 2000 . & LBS \\
\hline 87 & 1 & FERRIC CHLORIDE SLN & 8 & & MC307 & 2650.00 & GAL & 4120 . & GAL \\
\hline 87 & 1 & SULFURIC ACID & 8 & $\mathrm{~L}$ & TANK TRL & 75.00 & GAL & 0 . & \\
\hline 87 & 2 & LP GAS & 2 & & MC330 & 5.00 & GAL & 2000 . & GAL \\
\hline 87 & 2 & CORR LIQ n.O.s. & 8 & & TANK TRL & 169.00 & GAL & 0 . & \\
\hline 87 & 6 & HYPOCHLORITE SLN & 8 & & DRUM & 40.00 & GAL & 55. & GAL \\
\hline 87 & 8 & SULFURIC ACID & 8 & & BOTL GLS & 0.25 & GAL & 0 . & GAL \\
\hline 87 & 6 & SULFURIC ACID & 8 & & MC312 & 10.00 & GAL & 0 . & \\
\hline 87 & 7 & SULFURIC ACID & 8 & $\mathrm{~L}$ & MC312 & 12.00 & GAL & 5000 . & GAL \\
\hline 87 & 10 & SODIUM HYDROXIDE LQ & 8 & & JAR PLS & 0.11 & GAL & 1 . & GAL \\
\hline 87 & 10 & SULFURIC ACID & 8 & $\mathrm{~L}$ & MC312 & 3.00 & GAL & 0 . & \\
\hline 87 & 10 & GASOLINE & 3 & A & MC306 & 8000.00 & GAL & 0 . & \\
\hline 87 & 11 & CRUDE OIL PETROLEUM & 3 & & TANK TRK & 2730.00 & GAL & 4620 . & GAL \\
\hline 87 & 12 & CYCLOHEXYLAMINE & 3 & $\mathrm{~L}$ & TANK TRL & 10.00 & GAL & 0 . & \\
\hline 88 & 3 & ACETIC ACID GLACIAL & 8 & & 111AALW & 2.00 & GAL & 0 . & \\
\hline 88 & 2 & SODIUM HYDROXIDE LQ & 8 & & $111 \mathrm{AW}$ & 0.00 & & 11008 & GAL \\
\hline 88 & 5 & FLAM LIQUIDS n.o.s. & 3 & & TANK TRL & 12000.00 & GAL & 14800 & GAL \\
\hline 88 & 4 & SULFUR DIOXIDE & 2 & & $105 \mathrm{AW}$ & 0.13 & $\mathrm{CFT}$ & 2313. & $\mathrm{CFT}$ \\
\hline 88 & 5 & ACETONITRILE & 3 & & 4BW & 0.25 & GAL & 150. & GAL \\
\hline
\end{tabular}




\section{Major Injury Incidents (Cont.)}

\begin{tabular}{|c|c|c|c|c|c|c|c|c|c|}
\hline 88 & 6 & GASOLINE & 3 & A & MC306 & 8850.00 & GAL & 8850 . & GAL \\
\hline 88 & 6 & NITRIC ACID > $>40 \%$ & 5 & & BOTL GLS & 2.00 & GAL & 1. & GAL \\
\hline 88 & 5 & GASOLINE & 3 & A & MC306 & 300.00 & GAL & 2350 . & GAL \\
\hline 88 & 7 & BENZOYL CHLORIDE & 8 & & DRUM PLS & 45.00 & GAL & 55. & GAL \\
\hline 88 & 7 & GASOLINE & 3 & & MC306 & 0.00 & & 9400 . & GAL \\
\hline 88 & 7 & HYPOCHLORITE SOL & 8 & & MC312 & 600.00 & GAL & 3000 . & GAL \\
\hline 88 & 7 & GASOLINE & 3 & $\mathrm{~L}$ & MC306 & 0.00 & & 0 . & \\
\hline 88 & 7 & SULFURIC ACID & 8 & & 111AW & 1.00 & GAL & 0 . & \\
\hline 88 & 8 & FERRIC CHLORIDE SLN & 8 & & MC312 & 5.00 & GAL & 5000 . & GAL \\
\hline 88 & 8 & SODIUM HYDROXID DRY & 8 & $\mathrm{~L}$ & MC307 & 30.00 & GAL & 6700. & GAL \\
\hline 88 & 8 & ETHYLENE & 2 & $\mathrm{~L}$ & MC338 & 0.00 & & 1444 . & $\mathrm{CFT}$ \\
\hline 88 & 8 & LP GAS & 2 & $\mathrm{~L}$ & MC331 & 2.67 & $\mathrm{CFT}$ & 3000 . & GAL \\
\hline 88 & 9 & PHENOL & 6 & & $111 \mathrm{AW}$ & 0.12 & GAL & 20764 . & GAL \\
\hline 88 & 10 & PHOSPHORUS TRICL2 & 8 & & $111 \mathrm{AW}$ & 0.00 & & 13617 . & GAL \\
\hline 88 & 10 & CHLORINE & 2 & & $105 \mathrm{AW}$ & 0.00 & & 17365 . & GAL \\
\hline 88 & 10 & COAL TAR DYE LIQ & 8 & & 34 & 0.12 & GAL & 30 . & GAL \\
\hline 88 & 11 & METHYL BROMIDE LIQ & 6 & A & 4BW & 187.50 & GAL & 188. & GAL \\
\hline 88 & 12 & LP GAS & 2 & A & MC330 & 1255.18 & $\mathrm{CFT}$ & 1397. & $\mathrm{CFT}$ \\
\hline 89 & 2 & AMMONIA ANHYDROUS & 2 & A & $112 \mathrm{JW}$ & 19807.75 & GAL & 19808 & GAL \\
\hline 89 & 2 & SODIUM HYDROXIDE LQ & 8 & & TANK CAR & 100.00 & GAL & 10000 & GAL \\
\hline 89 & 3 & SULFURIC ACID & 8 & $\mathrm{~L}$ & MC312 & 759.00 & GAL & 5412 . & GAL \\
\hline 89 & 4 & GASOLINE & 3 & A & TANK TRL & 8420.00 & GAL & 8420 . & GAL \\
\hline 89 & 4 & TOLUENE DIISOCYANATE & 6 & $\mathrm{~L}$ & MC307 & 0.25 & GAL & 6704. & GAL \\
\hline 89 & 4 & BROMINE & 8 & & CONT & 0.12 & GAL & 2 . & GAL \\
\hline 89 & 5 & SODIUM HYDROXID DRY & 8 & & CYL & 50.00 & LBS & 50 . & LBS \\
\hline 89 & 5 & SULFUR MOLTEN & 9 & $\mathrm{~L}$ & TANK TRL & 50.00 & GAL & 7273. & GAL \\
\hline 89 & 2 & LIQUEFIED PETROLEUM & 2 & & MC331 & 0.67 & $\mathrm{CFT}$ & 2500 . & GAL \\
\hline 89 & 6 & ORGANOP HOSP HORUS & 6 & & LINR PLS & 0.00 & & 55. & GAL \\
\hline 89 & 6 & SULFURIC ACID & 8 & & $111 \mathrm{AW}$ & 1.00 & GAL & 0 . & \\
\hline 89 & 6 & HYDROCHLORIC ACID & 8 & & 34 & 110.00 & GAL & 55 . & GAL \\
\hline 89 & 6 & AMMONIUM HYDROXIDE & 8 & & JUG PLS & 0.50 & GAL & 1 . & GAL \\
\hline 89 & 7 & FLAMMABLE LIQUID NOS & 3 & $\mathrm{~L}$ & MC307 & 20.00 & GAL & 7300 . & GAL \\
\hline 89 & 8 & METHYL ETHYL KETONE & 3 & & PAIL PLS & 5.00 & GAL & 5 & GAL \\
\hline 89 & 8 & SULFURIC ACID & 8 & & 34 & 1.00 & GAL & 13. & GAL \\
\hline 89 & 8 & CORROSIVE LIQUID NOS & 8 & & TANK TRL & 0.00 & GAL & 0 . & \\
\hline 89 & 9 & GASOLINE & 3 & A & MC306 & 9000.00 & GAL & 9000 . & GAL \\
\hline 89 & 10 & HYDRAZINE ANHYDROUS & 3 & & DRUM MTL & 50.00 & GAL & 55 . & GAL \\
\hline 89 & 10 & LIQUEFIED PETROLEUM & 2 & $\mathrm{~L}$ & MC331 & 10.00 & GAL & 11200 . & GAL \\
\hline 89 & 10 & POISONOUS LIQUID $\mathrm{N}$. & 6 & $\mathrm{~L}$ & MC307 & 0.25 & GAL & 6700. & GAL \\
\hline 89 & 10 & AMMONIA ANHYDROUS & 2 & $\mathrm{~L}$ & TANK TRL & 0.62 & GAL & 9200 . & GAL \\
\hline 89 & 11 & BORON TRIFLUORIDE & 2 & & $3 \mathrm{AA}$ & 7.50 & GAL & 8 . & GAL \\
\hline 89 & 11 & SODIUM ALUMINATE SLN & 8 & $\mathrm{~L}$ & TANK TRK & 100.00 & GAL & 0 . & \\
\hline 89 & 11 & SULFURIC ACID & 8 & & TANK CAR & 0.00 & & 13600 . & GAL \\
\hline 89 & 11 & PAINT & 8 & & PAIL PLS & 3.00 & GAL & 5 . & GAL \\
\hline 89 & 11 & SULFURIC ACID & 8 & & BOTL PLS & 0.25 & GAL & 0 . & GAL \\
\hline 89 & 12 & LIQUEFIED PETROLEUM & 2 & $\mathrm{~L}$ & TANK TRK & 401.04 & $\mathrm{CFT}$ & 0 . & \\
\hline 89 & 4 & PHOSPHORIC ACID & 8 & & $111 \mathrm{AW}$ & 15.00 & GAL & 14800 & GAL \\
\hline 90 & 1 & GASOLINE & 3 & A & TANK TRK & 9001.00 & GAL & 9001 . & GAL \\
\hline 90 & 1 & HYDROCHLORIC ACID & 8 & A & MC312 & 3241.00 & GAL & 5000 . & GAL \\
\hline 90 & 2 & CORROSIVE LIQUID NOS & 8 & $\mathrm{~L}$ & DRUM MTL & 1.00 & GAL & 55. & GAL \\
\hline 89 & 9 & AMMONIA ANHYDROUS & 2 & L & MC331 & 1.25 & GAL & 8500 . & GAL \\
\hline 90 & 3 & SULFURIC ACID & 8 & $\mathrm{E}$ & 111AW & 10.00 & GAL & 11444 & GAL \\
\hline 90 & 3 & PETROLEUM NAPHTHA & 3 & $\mathrm{E}$ & $111 \mathrm{AW}$ & 0.25 & GAL & 26705 . & GAL \\
\hline 89 & 8 & GASOLINE & 3 & $\mathrm{~L}$ & MC306 & 0.00 & & 9000 . & GAL \\
\hline 89 & 12 & ACRYLIC ACID & 8 & A & TANK TRK & 1000.00 & GAL & 0 . & \\
\hline 90 & 3 & LIQUEFIED PETROLEUM & 2 & $\mathrm{~L}$ & MC331 & 1.60 & $\mathrm{CFT}$ & 2600 . & GAL \\
\hline 90 & 4 & SODIUM HYDROXIDE LIQ & 8 & $\mathrm{~L}$ & MC307 & 20.00 & GAL & 5000 . & GAL \\
\hline 90 & 4 & FLAMMABLE LIQUID NOS & 3 & $\mathrm{~L}$ & DRUM MTL & 10.00 & GAL & 55 . & GAL \\
\hline 90 & 5 & SULFURIC ACID & 8 & $\mathrm{~L}$ & TANK TRK & 2.00 & GAL & 0 . & \\
\hline 90 & 4 & ACETONE & 3 & $\mathrm{~L}$ & BOTL PLS & 0.01 & GAL & 1 . & GAL \\
\hline 90 & 5 & HYDROCHLORIC ACID & 8 & $\mathrm{~L}$ & DRUM PLS & 0.01 & GAL & 5 . & GAL \\
\hline 90 & 4 & COMPOUND CLEANING LIQ & 8 & $\mathrm{~L}$ & $17 \mathrm{E}$ & 55.00 & GAL & 55 . & GAL \\
\hline
\end{tabular}




\section{Major Injury Incidents (Cont.)}

\begin{tabular}{|c|c|c|c|c|c|c|c|c|c|c|}
\hline 1 & 90 & 5 & HYDROCHLORIC ACID & 8 & $\mathrm{~L}$ & 34 & 45.00 & GAL & 62. & GAL \\
\hline L & 90 & 5 & SODIUM HYDROXIDE LIQ & 8 & $\mathrm{~L}$ & MC307 & 0.00 & & 5840 . & GAL \\
\hline . & 90 & 5 & SULFUR DIOXIDE & 2 & $\mathrm{~L}$ & MC331 & 0.00 & & 4200 . & GAL \\
\hline & 90 & 5 & TOLUENE DIISOCYANATE & 6 & $\mathrm{~L}$ & MC307 & 0.25 & GAL & 6520 . & GAL \\
\hline & 90 & 6 & CRUDE OIL PETROLEUM & 2 & $\mathrm{E}$ & TANK TRK & 1.00 & GAL & 0 . & \\
\hline & 90 & 5 & SODIUM HYDROXIDE DRY & 8 & $\mathrm{E}$ & TANK CAR & 0.00 & & 68300 . & LBS \\
\hline & 90 & 6 & AMMONIA ANHYDROUS & 2 & $\mathrm{~L}$ & MC331 & 4375.00 & GAL & 10400 . & GAL \\
\hline & 90 & 7 & SULFURIC ACID & 8 & $\mathrm{E}$ & $111 \mathrm{~A}$ & 0.00 & & 13635. & GAL \\
\hline & 90 & 7 & ACETIC ANHYDRIDE & 8 & $\mathrm{~L}$ & TANK TRK & 20.00 & GAL & 0 . & \\
\hline & 90 & 7 & SULFUR DIOXIDE & 2 & $\mathrm{E}$ & MC330 & 0.07 & $\mathrm{CFT}$ & 5000 . & GAL \\
\hline & 90 & 8 & SULFURIC ACID SPENT & 8 & $\mathrm{E}$ & 111AW & 0.25 & GAL & 13557 . & GAL \\
\hline & 90 & 7 & HYDROGEN PEROXIDE & 5 & $\mathrm{~L}$ & MC310 & 300.00 & GAL & 5000 . & GAL \\
\hline & 90 & 8 & COMBUSTIBLE LIQUID NOS & 2 & $\mathrm{~L}$ & DRUM MTL & 5.00 & GAL & 50 . & GAL \\
\hline & 90 & 8 & HYDROGEN PEROXIDE & 5 & $\mathrm{~L}$ & BOTL PLS & 2.00 & GAL & 4 . & GAL \\
\hline & 90 & 9 & CHLORINE & 2 & $\mathrm{~L}$ & TANK CAR & 25.00 & GAL & 0 . & \\
\hline & 90 & 8 & SODIUM HYDROXIDE LIQ & 8 & $\mathrm{~L}$ & TANK TRK & 5.00 & GAL & 0 . & \\
\hline & 90 & 9 & SULFUR MOLTEN & 9 & $\mathrm{~L}$ & TANK TRK & 60.00 & GAL & 3500 . & GAL \\
\hline 1 & 90 & 9 & SULFUR MOLTEN & 9 & $\mathrm{~L}$ & TANK TRK & 8.00 & LBS & 31200 . & LBS \\
\hline 2 & 90 & 8 & FLAMMABLE LIQUID NOS & 3 & $\mathrm{E}$ & 111AW & 1.00 & GAL & 21064 . & GAL \\
\hline 1 & 90 & 10 & ALKALINE LIQUID NOS & 8 & $\mathrm{~L}$ & $17 \mathrm{E}$ & 50.00 & GAL & 55. & GAL \\
\hline 2 & 90 & 9 & TOLUENE & 3 & $\mathrm{~L}$ & TANK TRK & 200.00 & GAL & 0 . & \\
\hline 1 & 90 & 9 & PHOSPHORIC ACID & 8 & A & 111AW & 100.00 & GAL & 12514 . & GAL \\
\hline 1 & 90 & 10 & METHYL ETHYL KETONE & 3 & $\mathrm{E}$ & $17 \mathrm{E}$ & 25.00 & GAL & 55. & GAL \\
\hline 1 & 90 & 11 & COMPOUND CLEANING LIQ & 3 & $\mathrm{~L}$ & CONT & 0.00 & & 0 . & GAL \\
\hline 1 & 90 & 11 & GASOLINE & 3 & $\mathrm{~L}$ & TANK TRK & 1.00 & GAL & 0 . & \\
\hline 1 & 90 & 11 & POTASSIUM HYDROXIDE & 8 & & TANK TRK & 1500.00 & GAL & 0 . & \\
\hline 1 & 91 & 2 & SULFURIC ACID & 8 & $\mathrm{~L}$ & MC312 & 52.00 & GAL & 7700 . & GAL \\
\hline 1 & 91 & 3 & SODIUM AZIDE & 6 & $\mathrm{~L}$ & DRUM FBR & 22.05 & LBS & 110. & LBS \\
\hline 1 & 91 & 2 & SULFURIC ACID & 8 & $\mathrm{~L}$ & MC312 & 1000.00 & GAL & 5400 . & GAL \\
\hline 1 & 91 & 2 & SULFURIC ACID & 8 & $\mathrm{~L}$ & $111 \mathrm{AW}$ & 1200.00 & GAL & 13971. & GAL \\
\hline 1 & 91 & 4 & AMMONIA ANHYDROUS & 2 & $\mathrm{~L}$ & MC331 & 0.03 & $\mathrm{CFT}$ & 1404 . & CFT \\
\hline 1 & 91 & 6 & BENZALDEHYDE & 2 & $\mathrm{E}$ & DRUM MTL & 30.00 & GAL & 55. & GAL \\
\hline$\perp$ & 91 & 6 & NITRATING ACID MIX & 8 & $\mathrm{E}$ & $111 \mathrm{AW}$ & 0.12 & GAL & 14659 . & GAL \\
\hline 2 & 91 & 6 & PETROLEUM GASES LIQ & 2 & & TANK TRK & 0.00 & & 0 . & \\
\hline 1 & 91 & 7 & HYDROGEN PEROXIDE & 5 & $\mathrm{E}$ & 111AALW & 2.00 & GAL & 20531 . & GAL \\
\hline 1 & 91 & 7 & SULFURIC ACID & 8 & $\mathrm{E}$ & $111 \mathrm{AW}$ & 1.00 & GAL & 13648 . & GAL \\
\hline 1 & 91 & 7 & BATTERY WET ACID & 8 & & BATTERY & 0.50 & GAL & 0 . & \\
\hline 1 & 91 & 7 & SULFURIC ACID & 8 & $\mathrm{~L}$ & MC312 & 243.00 & GAL & 5798. & GAL \\
\hline 1 & 91 & 7 & SODIUM HYDROXIDE SLN & 8 & $\mathrm{~L}$ & MC307 & 5.00 & GAL & 7500 . & GAL \\
\hline 1 & 91 & 8 & FLAMMABLE LIQUIDS NOS & 3 & $\mathrm{E}$ & $111 \mathrm{AW}$ & 0.00 & & 20615 . & GAL \\
\hline 1 & 91 & 8 & SULFURIC ACID & 8 & $\mathrm{~L}$ & MC312 & 50.00 & GAL & 6300 . & GAL \\
\hline 1 & 91 & 8 & SULFURIC ACID & 8 & $\mathrm{E}$ & MC312 & 10.00 & GAL & 3600 . & GAL \\
\hline 1 & 91 & 8 & SULFURIC ACID & 8 & L & MC312 & 550.00 & GAL & 5000 . & GAL \\
\hline 1 & 91 & 8 & SULFURIC ACID & 8 & $\mathrm{~L}$ & MC312 & 0.50 & GAL & 8750 . & GAL \\
\hline 1 & 91 & 8 & TETRAHYDROFURAN & 3 & $\mathrm{E}$ & BOTL GLS & 0.38 & GAL & 0 . & GAL \\
\hline 1 & 91 & 8 & HYDROCHLORIC ACID SLN & 8 & $\mathrm{E}$ & TANK CAR & 0.00 & & 22500 . & GAL \\
\hline 1 & 91 & 8 & PETROLEUM GASES LIQ & 2 & A & TANK TRK & 2000.00 & GAL & 2500 . & GAL \\
\hline 1 & 91 & 9 & AMMONIA ANHYDROUS & 2 & $\mathrm{E}$ & TANK CAR & 0.13 & CFT & 4495 . & CFT \\
\hline 1 & 91 & 10 & SULFURIC ACID & 8 & $\mathrm{~L}$ & TANK CAR & 6094.00 & GAL & 0 . & \\
\hline 1 & 91 & 10 & NITROGEN REFRIGERATED & 2 & $\mathrm{~L}$ & TANK TRK & 0.00 & & 0 . & \\
\hline 1 & 91 & 11 & ACRYLIC ACID INHIB & 8 & $\mathrm{~L}$ & MC307 & 11.00 & GAL & 7119. & GAL \\
\hline$\perp$ & 92 & 1 & AMMONIA SOLUTIONS & 8 & $\mathrm{~L}$ & MC307 & 1.50 & GAL & 6500 . & GAL \\
\hline 1 & 92 & 2 & BUTYLACRYLATE & 3 & $\mathrm{~L}$ & TANK TRK & 0.00 & & 0 . & \\
\hline 3 & 92 & 1 & CORROSIVE LIQUIDS NOS & 8 & $\mathrm{E}$ & MC312 & 4952.00 & GAL & 5500 . & GAL \\
\hline 2 & 92 & 2 & CORROSIVE LIQUIDS NOS & 8 & $\mathrm{~L}$ & MC307 & 2792.00 & GAL & 6500 . & GAL \\
\hline$\perp$ & 92 & 2 & CORROSIVE LIQUIDS NOS & 8 & $\mathrm{~L}$ & MC307 & 5.00 & GAL & 7000 . & GAL \\
\hline$\perp$ & 92 & 2 & ACRYLIC ACID INHIBITE & 8 & $\mathrm{~L}$ & MC307 & 10.00 & GAL & 7106. & GAL \\
\hline$\perp$ & 92 & 3 & SULFURIC ACID & 8 & $\mathrm{E}$ & 111AW & 3000.00 & GAL & 13677 . & GAL \\
\hline$\perp$ & 92 & 4 & PETROLEUM GASES LIQUE & 2 & A & MC331 & 1600.00 & GAL & 2400 . & GAL \\
\hline 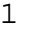 & 92 & 4 & TOLUENE DIISOCYANATE & 6 & $\mathrm{~L}$ & DRUM MTL & 90.00 & GAL & 90 & GAL \\
\hline 2 & 92 & 4 & HYDROGEN REFRIGERATED & 2 & $\mathrm{E}$ & MC338 & 513.33 & CFT & 2005 . & CFT \\
\hline 1 & 92 & 4 & TOLUENE & 3 & $\mathrm{~L}$ & $111 \mathrm{AW}$ & 100.00 & GAL & 26674 . & GAL \\
\hline
\end{tabular}




\section{Major Injury Incidents (Cont.)}

\begin{tabular}{|c|c|c|c|c|c|c|}
\hline 1 & 92 & 5 & SULFURIC ACID & 8 & $\mathrm{E}$ & TANK CAR \\
\hline 1 & 92 & 5 & SULFURIC ACID & 8 & $\mathrm{E}$ & 111AW \\
\hline 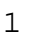 & 92 & 5 & SODIUM HYDROSULFIDE & 8 & $E$ & TANK TRK \\
\hline & 92 & 5 & NITROGEN COMPRESSED & 2 & $\mathrm{~L}$ & TANK TRL \\
\hline & 92 & 6 & DIMETHYLAMINE SLN & 3 & $\mathrm{~L}$ & MC307 \\
\hline & 92 & 6 & AMMONIA ANHYDROUS & 2 & $\mathrm{~L}$ & MC331 \\
\hline & 92 & 6 & CHLORINE & 2 & $\mathrm{~L}$ & $105 \mathrm{AW}$ \\
\hline & 92 & 7 & COAL TAR DISTILLATES & 3 & $\mathrm{E}$ & $111 \mathrm{AW}$ \\
\hline & 92 & 7 & SULFURIC ACID FUMING & 8 & $\mathrm{~L}$ & MC312 \\
\hline & 92 & 8 & GASOLINE & 3 & A & TANK TRL \\
\hline & 92 & 7 & AMMONIA ANHYDROUS & 2 & A & TANK CAR \\
\hline & 92 & 8 & HYDROGEN PEROXIDE $>60$ & 5 & $\mathrm{E}$ & 111AALW \\
\hline & 92 & 8 & HYDROCHLORIC ACID SLN & 8 & $\mathrm{~L}$ & 111AW \\
\hline & 92 & 8 & ASPHALT CUT BACK & 2 & $\mathrm{~L}$ & TANK TRL \\
\hline & 92 & 7 & PYRIDINE & 3 & $\mathrm{~L}$ & CONT GLS \\
\hline 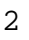 & 92 & 8 & HYDROCHLORIC ACID SLN & 8 & $\mathrm{~L}$ & MC312 \\
\hline & 92 & 8 & HAZ SUBSTANCE NOS & 9 & $\mathrm{~L}$ & MC307 \\
\hline & 92 & 9 & ACRYLIC ACID INHIB & 8 & $\mathrm{~L}$ & DRUM PLS \\
\hline 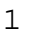 & 92 & 8 & POTASSIUM HYDROXIDE & 8 & $\mathrm{E}$ & $111 \mathrm{AW}$ \\
\hline | & 92 & 9 & COMPOUND CLEANING LIQ & 8 & $\mathrm{~L}$ & TANK PRT \\
\hline & 92 & 8 & SODIUM HYDROXIDE SLN & 8 & $\mathrm{~L}$ & MC307 \\
\hline & 92 & 10 & GASOLINE & 3 & A & TANK TRL \\
\hline & 92 & 9 & NAPHTHA PETROLEUM & 3 & A & TANK TRL \\
\hline & 92 & 10 & CORROSIVE LIQUIDS NOS & 8 & $\mathrm{~L}$ & 34 \\
\hline & 92 & 10 & SODIUM ALUMINATE SLN & 8 & $\mathrm{~L}$ & MC307 \\
\hline & 91 & 10 & HYDROCHLORIC ACID SLN & 8 & $\mathrm{~L}$ & MC312 \\
\hline & 92 & 10 & SULFURIC ACID & 8 & $\mathrm{E}$ & $111 \mathrm{AW}$ \\
\hline & 92 & 12 & FLAMMABLE LIQUIDS NOS & 3 & $\mathrm{~L}$ & MC307 \\
\hline & 93 & 3 & UNLEADED GASOLINE & 3 & A & MC306 \\
\hline & 93 & 2 & GASOLINE & 3 & A & TANK TRL \\
\hline & 93 & 3 & FERROUS CHLORIDE SLN & 8 & $\mathrm{~L}$ & TANK TRL \\
\hline & 93 & 3 & AMMONIA SOLUTIONS & 8 & $\mathrm{~L}$ & JUG PLS \\
\hline & 93 & 3 & GASOLINE & 3 & A & TANK TRL \\
\hline & 93 & 3 & AMMONIUM HYDROXIDE & 8 & $\mathrm{~L}$ & BOTL PLS \\
\hline & 93 & 5 & METHYLAMINE ANHYDROUS & 2 & $\mathrm{~L}$ & CYL \\
\hline & 93 & 5 & GASOLINE & 3 & A & MC306 \\
\hline 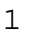 & 93 & 5 & PETROLEUM CRUDE OIL & 3 & A & MC306 \\
\hline & 93 & 6 & SULFURIC ACID & 8 & $\mathrm{E}$ & $111 \mathrm{AW}$ \\
\hline & 93 & 8 & FORMALDEHYDE SOLUTION & 3 & $\mathrm{~L}$ & $12 \mathrm{~A}$ \\
\hline & 93 & 7 & CHLORINE & 2 & & CYL MTL \\
\hline 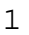 & 93 & 7 & CARBAMATE PESTICIDES & 3 & $\mathrm{~L}$ & $2 \mathrm{E}$ \\
\hline 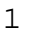 & 93 & 7 & CARBON DIOXIDE & 2 & $\mathrm{E}$ & $3 \mathrm{AA}$ \\
\hline 1 & 93 & 9 & SODIUM HYDROXIDE SLN & 8 & $\mathrm{~L}$ & JUG PLS \\
\hline 1 & 93 & 8 & RESIN SOLUTION & 3 & $\mathrm{~L}$ & MC307 \\
\hline 1 & 93 & 8 & SULFURIC ACID & 8 & $\mathrm{E}$ & $111 \mathrm{AW}$ \\
\hline 1 & 93 & 3 & GASOLINE & 3 & A & MC306 \\
\hline 1 & 93 & 10 & SULFURIC ACID & 8 & $\mathrm{~L}$ & BOTL GLS \\
\hline 1 & 93 & 12 & SULFUR MOLTEN & 4 & $\mathrm{~L}$ & TANK TRL \\
\hline 1 & 93 & 12 & SULFURIC ACID SPENT & 8 & $\mathrm{~L}$ & MC312 \\
\hline 7 & 93 & 12 & PETROLEUM GASES LIQ & 2 & $\mathrm{~L}$ & MC331 \\
\hline 2 & 94 & 2 & PETROLEUM GASES LIQ & 2 & A & $112 \mathrm{JW}$ \\
\hline 1 & 94 & 3 & OXYGEN COMPRESSED & 2 & & 3AL \\
\hline 1 & 94 & 4 & PETROLEUM GASES LIQ & 2 & & CONT \\
\hline 2 & 94 & 4 & SULFURIC ACID FUMING & 8 & $\mathrm{E}$ & MC312 \\
\hline 1 & 94 & 5 & SULFURIC ACID & 8 & $\mathrm{E}$ & $111 \mathrm{AW}$ \\
\hline 1 & 94 & 5 & SULFURIC ACID & 8 & $\mathrm{E}$ & $111 \mathrm{AW}$ \\
\hline 4 & 94 & 5 & GASOLINE & 3 & A & MC306 \\
\hline 1 & 94 & 6 & HYPOCHLORITE SLN & 8 & $\mathrm{~L}$ & TANK TRK \\
\hline 1 & 94 & 5 & AMMONIA ANHYDROUS & 2 & $\mathrm{E}$ & $112 \mathrm{SW}$ \\
\hline 1 & 94 & 6 & ETHYL ACRYLATE INHIB & 3 & $\mathrm{~L}$ & $1 \mathrm{~A} 1$ \\
\hline 1 & 94 & 7 & PAINT & 3 & L & $17 \mathrm{E}$ \\
\hline & 94 & 6 & FLAMMABLE LIQUIDS NOS & 3 & $\mathrm{~L}$ & PAIL MTL \\
\hline
\end{tabular}

$$
\begin{aligned}
& 0.00 \text { 207300. GAL } \\
& \text { 5.00 GAL 13655. GAL } \\
& 300.00 \mathrm{GAL} \quad 6500 \text {. GAL } \\
& 125.00 \mathrm{GAL} \quad 1408 \text {. GAL } \\
& 70.00 \mathrm{GAL} \quad 7000 \text {. GAL } \\
& 240.62 \text { CFT 1390. CFT } \\
& 0.12 \text { GAL 22500. GAL } \\
& \text { 5.00 GAL 25687. GAL } \\
& 2000.00 \text { GAL 6550. GAL } \\
& 2075.00 \mathrm{GAL} \quad 8490 \text {. GAL } \\
& 19966.25 \text { GAL 33938. GAL } \\
& \text { 2.00 GAL 20447. GAL } \\
& \text { 3.00 GAL 20609. GAL } \\
& 50.00 \mathrm{GAL} \quad 8000 \text {. GAL } \\
& 1.00 \mathrm{GAL} \text { 1. GAL } \\
& 1500.00 \mathrm{GAL} \text { 5351. GAL } \\
& 0.50 \mathrm{GAL} \quad 7000 \text {. GAL } \\
& 10.00 \mathrm{GAL} \text { 55. GAL } \\
& \text { 2.00 GAL 16319. GAL } \\
& 5.00 \mathrm{GAL} \text { 610. GAL } \\
& \text { 10.00 GAL 8000. GAL } \\
& 5500.00 \text { GAL 6000. GAL } \\
& 11200.00 \mathrm{GAL} \quad 11200 \text {. GAL } \\
& 1.00 \mathrm{GAL} \text { 55. GAL } \\
& 0.50 \mathrm{GAL} \quad 7000 \text {. GAL } \\
& 400.00 \mathrm{GAL} \quad 5000 \text {. GAL } \\
& 0.25 \mathrm{GAL} \text { 13566. GAL } \\
& 50.00 \mathrm{GAL} \text { 2125. GAL } \\
& 8700.00 \mathrm{GAL} \quad 10000 \text {. GAL } \\
& 8800.00 \mathrm{GAL} \quad 8800 \text {. GAL } \\
& 55.00 \mathrm{GAL} \\
& 0.50 \mathrm{GAL} \\
& 8500.00 \mathrm{GAL} \\
& 0.08 \mathrm{GAL} \\
& 0.00 \\
& 8800.00 \mathrm{GAL} \\
& 7050.00 \mathrm{GAL} \\
& 0.50 \mathrm{GAL} \\
& 0.12 \mathrm{GAL} \\
& 18.75 \mathrm{GAL} \\
& 0.75 \mathrm{GAL} \\
& 2.50 \mathrm{GAL} \\
& 0.05 \mathrm{GAL} \\
& 3.00 \mathrm{GAL} \\
& 0.67 \mathrm{GAL} \\
& 2300.00 \mathrm{GAL} \\
& 0.33 \mathrm{GAL} \\
& 0.00 \\
& \text { 3. } 00 \mathrm{GAL} \\
& 35.00 \mathrm{GAL} \\
& 17891.38 \mathrm{GAL} \\
& \text { 20.00 CFT } \\
& 100.00 \mathrm{GAL} \\
& \begin{array}{l}
0.00 \\
1.00 \mathrm{GAL}
\end{array} \\
& \text { 2.00 GAL } \\
& 7197.00 \mathrm{GAL} \\
& 5.00 \mathrm{GAL} \\
& 1227.50 \mathrm{GAL} \\
& 2.00 \mathrm{GAL} \\
& 55.00 \mathrm{GAL} \\
& 5.00 \mathrm{GAL} \\
& \text { 20. } \mathrm{CFT} \\
& 0 \text {. }
\end{aligned}
$$


Major Injury Incidents (Cont.)

\begin{tabular}{|c|c|c|c|c|c|c|}
\hline 1 & 4 & 6 & AMMONIUM SULFIDE SLN & 8 & $\mathrm{E}$ & TANK CAI \\
\hline 1 & 94 & 7 & FLUOROSILICIC ACID & 8 & $\mathrm{~L}$ & MC312 \\
\hline 1 & 4 & 6 & SODIUM HYDROXIDE SLN & & $\mathrm{L}$ & MC312 \\
\hline 1 & 4 & 7 & SODIUM HYDROXIDE SLN & & $\mathrm{L}$ & C 312 \\
\hline 1 & 4 & 7 & DIMETHYLAMINE ANHYDRO & & & $12 \mathrm{JW}$ \\
\hline 6 & 4 & 7 & PETROLEUM GASES LIQ & & A & MC331 \\
\hline 1 & 94 & 7 & HYPOCHLORITE SLN & & A & 34 \\
\hline 1 & 4 & 8 & CAUSTIC ALKALI LIQUID & & L & MC312 \\
\hline 1 & 4 & 8 & AMMONIA ANHYDROUS & & $\mathrm{L}$ & TANK TRI \\
\hline 1 & 4 & 8 & CHLORINE & 2 & & CYL \\
\hline 1 & 4 & 10 & AMMONIA ANHYDROUS & & $E$ & $112 \mathrm{SW}$ \\
\hline 1 & 4 & 9 & NITROCELLULOSE ALCOHOL & & $\mathrm{L}$ & $6 \mathrm{~J}$ \\
\hline 1 & 94 & 11 & SULFURIC ACID & 8 & $\mathrm{~L}$ & TANK TRK \\
\hline 1 & 4 & 11 & GASOLINE & 3 & $\mathrm{~L}$ & TANK \\
\hline 1 & 3 & 5 & FUEL OIL & & $\mathrm{L}$ & MC306 \\
\hline 1 & 4 & 11 & SULFURIC ACID & & $\mathrm{L}$ & L11AW \\
\hline 1 & 94 & 12 & SODIUM HYDROXIDE SLN & & $\mathrm{L}$ & MC307 \\
\hline 1 & 5 & 1 & SODIUM HYDROXIDE SLN & & $\mathrm{L}$ & MC307 \\
\hline 1 & 4 & 10 & HYDROFLUORIC ACID SLN & & A & CONT \\
\hline 1 & 95 & 1 & METHYL ACRYLATE INHIB & & E & $1 \mathrm{~A} 1$ \\
\hline 1 & 4 & 12 & GASOLINE & 3 & A & MC306 \\
\hline 2 & 94 & 12 & CHLORINE & & $\mathrm{E}$ & $105 \mathrm{AW}$ \\
\hline 1 & 95 & 2 & ENVIRON HAZ LIQ & 9 & $\mathrm{~L}$ & DRUM MT \\
\hline 1 & 95 & 1 & HYDROCHLORIC ACID SLN & & $\mathrm{L}$ & MC312 \\
\hline 1 & 94 & 12 & SULFURIC ACID & 8 & $\mathrm{~L}$ & CONT \\
\hline 1 & 94 & 12 & ACETIC ACID GLACIAL & 8 & $\mathrm{~L}$ & TANK \\
\hline 1 & 95 & 4 & FLAMMABLE LIQUIDS N.O & 3 & $\mathrm{E}$ & BOTL \\
\hline 1 & 95 & 4 & AMMONIA ANHYDROUS & 2 & $\mathrm{~L}$ & TANK \\
\hline 1 & 95 & 4 & ROPYLENE & 3 & & AW \\
\hline 2 & 95 & 5 & CARBAMATE PEST & 6 & & DRUM \\
\hline 1 & 95 & 6 & CORROSIVE SOLIDS NOS & 8 & $\mathrm{~L}$ & $5 \mathrm{H} 2$ \\
\hline 1 & 95 & 5 & GAS & 3 & $\mathrm{~L}$ & MC306 \\
\hline 2 & 95 & 7 & PA & 3 & $\mathrm{E}$ & BOTL PI \\
\hline 1 & 95 & 7 & SULFURIC ACID & 3 & $\mathrm{E}$ & $111 \mathrm{AW}$ \\
\hline 2 & 95 & 7 & DIMETHYLAMINE SLN & 3 & $\mathrm{E}$ & $111 \mathrm{AW}$ \\
\hline 1 & 95 & 8 & PETROLEUM GASES LIQ & 2 & $\mathrm{~L}$ & MC331 \\
\hline 1 & 95 & 8 & FLAM LIQ-ELEVATED TEMP & 3 & $\mathrm{~L}$ & TANK TR \\
\hline 1 & 95 & 7 & PHOSPHORUS TRICHLORIDE & 8 & $\mathrm{~L}$ & TANK $\mathrm{CP}$ \\
\hline 1 & 95 & 8 & METHYL MERCAPTAN & 2 & $\mathrm{E}$ & TANK $\mathrm{T}$ \\
\hline 2 & 95 & 8 & DICHLOROMETHANE & 6 & $\mathrm{E}$ & CONT \\
\hline 1 & 95 & 9 & VINYL ACETATE INHIB & & $\mathrm{E}$ & $111 \mathrm{AW}$ \\
\hline 2 & 95 & 11 & PETROLEUM GASES LIQ & 2 & & MC331 \\
\hline 1 & 95 & 11 & PETROLEUM GASES LIQ & 2 & A & TANK TH \\
\hline 1 & 95 & 10 & POTASSIUM HYDROXIDE & 8 & $\mathrm{~L}$ & MC307 \\
\hline 1 & 9 & 10 & CHLORODIFLUOROMETHANE & 2 & A & $112 \mathrm{AW}$ \\
\hline 1 & 95 & 11 & FORMIC ACID & & $E$ & MC307 \\
\hline & 95 & 12 & PETROLEUM GASES LIQ & 2 & $\mathrm{~L}$ & TANK \\
\hline
\end{tabular}

\begin{tabular}{|c|c|c|c|}
\hline 0.00 & & 20757 . & GAL \\
\hline 3.00 & GAL & 5000. & GAL \\
\hline 1.00 & GAL & 4500 . & GAL \\
\hline 40.00 & GAL & 5115. & GAL \\
\hline 0.00 & & 0 . & \\
\hline 9200.00 & GAL & 11500 & GAL \\
\hline 102.00 & GAL & 55. & GAL \\
\hline 10.00 & GAL & 8000 . & GAL \\
\hline 10.00 & GAL & 0 . & \\
\hline 25.00 & GAL & 250 . & GAL \\
\hline 0.00 & & 33645 . & GAL \\
\hline 1500.00 & GAL & 55. & GAL \\
\hline 0.06 & GAL & 0 . & \\
\hline 6.00 & GAL & 0 . & \\
\hline 0.00 & & 9200 . & GAL \\
\hline 500.00 & GAL & 23750 . & GAL \\
\hline 1.00 & GAL & 6500 . & GAL \\
\hline 1600.00 & GAL & 7000 . & GAL \\
\hline 363.00 & GAL & 0 . & \\
\hline 0.00 & & 55. & GAL \\
\hline 6000.00 & GAL & 0 . & \\
\hline 0.00 & & 17439 . & GAL \\
\hline 30.00 & GAL & 55. & GAL \\
\hline 70.00 & GAL & 5000 . & GAL \\
\hline 0.25 & GAL & 0 . & GAL \\
\hline 660.00 & GAL & 23250 . & GAL \\
\hline 0.28 & GAL & 0 . & GAL \\
\hline 0.12 & GAL & 5600 . & GAL \\
\hline 5.00 & GAL & 29963. & GAL \\
\hline 0.00 & & 15 . & GAL \\
\hline 0.00 & LBS & 52 . & LBS \\
\hline 0.00 & & 10300 . & GAL \\
\hline 0.04 & GAL & 0 . & GAL \\
\hline 15.00 & GAL & 13620 & GAL \\
\hline 0.00 & & 30542 . & GAL \\
\hline 267.36 & $\mathrm{CFT}$ & 401. & $\mathrm{CFT}$ \\
\hline 25.00 & GAL & 7000 . & GAL \\
\hline 20.00 & GAL & 0 . & \\
\hline 0.00 & & 24976 . & GAL \\
\hline 5.00 & GAL & 0 . & \\
\hline 1.00 & GAL & 26816 & GAL \\
\hline 5.00 & GAL & 2400 . & GAL \\
\hline 17.00 & GAL & 0 . & \\
\hline 0.50 & GAL & 7000 . & GAL \\
\hline 894.38 & GAL & 20934 & GAL \\
\hline 1.00 & GAL & 7000 & GAL \\
\hline 0.50 & GAL & & \\
\hline
\end{tabular}


$\Delta$ 